US Army Corps of Engineers ${ }_{\circledast}$ Engineer Research and Development Center

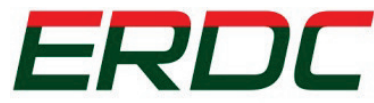

INNOVATIVE SOLUTIONS for a safer, better world

\title{
Vertical Ship Motion Study for Ambrose Entrance Channel, New York
}

Michael J. Briggs, Zeki Demirbilek, and Lihwa Lin

May 2014

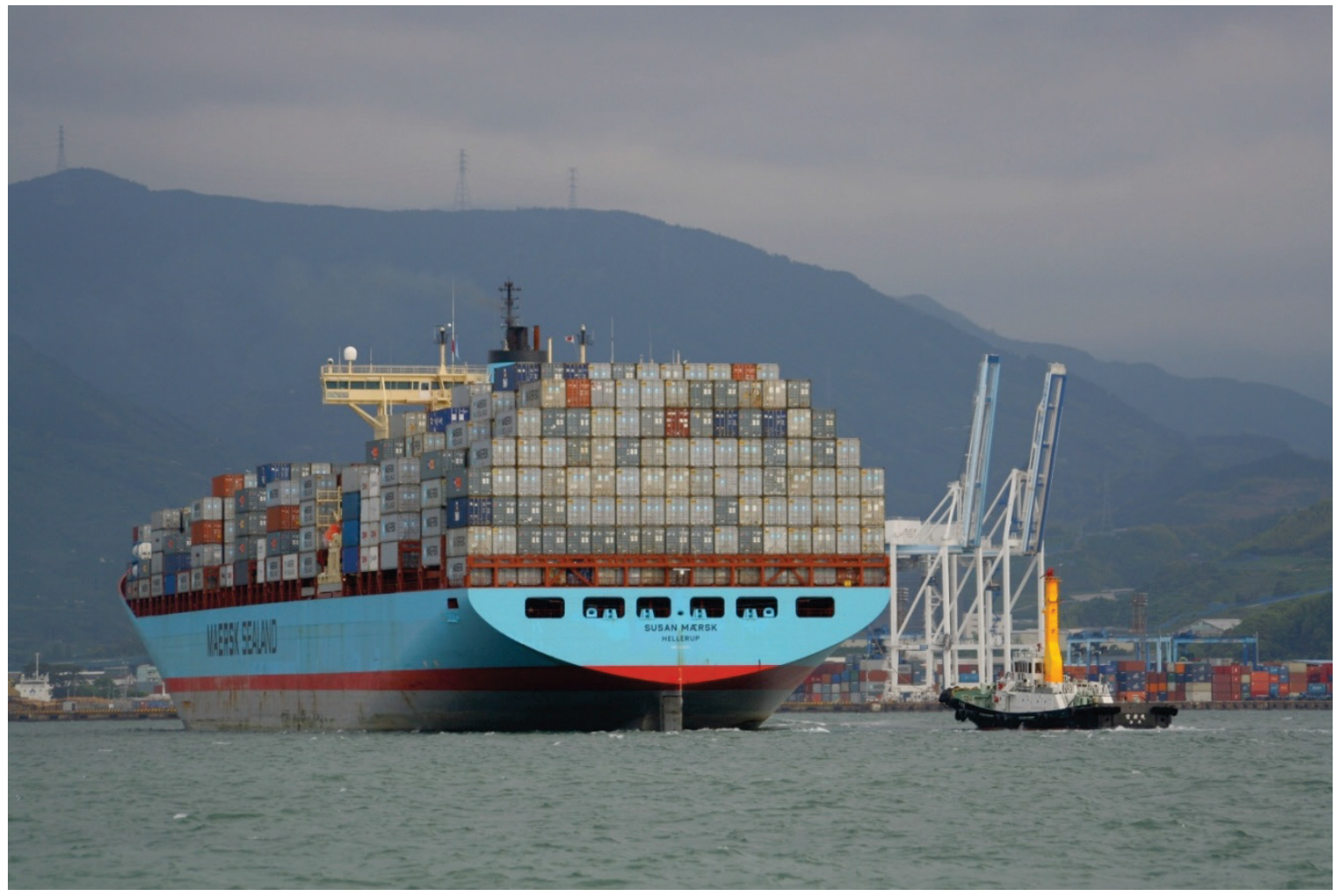


The US Army Engineer Research and Development Center (ERDC) solves the nation's toughest engineering and environmental challenges. ERDC develops innovative solutions in civil and military engineering, geospatial sciences, water resources, and environmental sciences for the Army, the Department of Defense, civilian agencies, and our nation's public good. Find out more at www.erdc.usace.army.mil.

To search for other technical reports published by ERDC, visit the ERDC online library at http://acwc.sdp.sirsi.net/client/default. 
May 2014

\section{Vertical Ship Motion Study for Ambrose Entrance Channel, New York}

Michael J. Briggs, Zeki Demirbilek, and Lihwa Lin

Coastal and Hydraulics Laboratory

US Army Engineer Research and Development Center

3909 Halls Ferry Road

Vicksburg, MS 39180-6199

Final report

Approved for public release; distribution is unlimited.

Prepared for Commander, US Army Engineer District, New York (CENAN-EN-H)

Under Unit 108976-NY \& NJ Harbor (50') NY\&NJ

Monitored by US Army Engineer Research and Development Center

3909 Halls Ferry Road, Vicksburg, MS 39180-6199 


\section{Abstract}

New York Harbor Pilots have expressed a concern to the New York District (NAN) about a mound that is approximately 1.5 miles seaward of the new limit of the Ambrose Channel. This mound is probably construction rubble that was placed there when the original Light Tower isolated and protected it somewhat from the main channel. The mound's diameter and depth are similar to the width and depth of the Ambrose Channel offshore reach. Now that the Light Tower is no longer marking this mound, the Pilots are concerned about whether a ship might experience larger or more dramatic ship motions due to possible amplification across the mound relative to similar transits in the offshore reach. The US Army Engineer Research and Development Center (ERDC), Coastal and Hydraulics Laboratory (CHL), used the numerical models STWAVE and CMS-Wave to evaluate possible amplification effects of a range of wave conditions. The Channel Analysis and Design Evaluation Tool (CADET) was used to predict vertical ship motions due to wave-induced heave, pitch, and roll. Ship squat estimates calculated with the PIANC and Ankudinov empirical formulas were compared with the Beck, Newman, Tuck (BNT) squat predictions used in CADET. The net underkeel clearance based on these vertical ship motion components was used in a risk-based method of evaluating transits over the mound compared to similar transits in the main channel. These results were used to select a minimum dredge depth over the mound to insure that inadvertent transits over the mound would not incur any significant differences in ship response and potential grounding relative to similar transits in the offshore reach of the Ambrose Channel.

DISCLAIMER: The contents of this report are not to be used for advertising, publication, or promotional purposes. Citation of trade names does not constitute an official endorsement or approval of the use of such commercial products. All product names and trademarks cited are the property of their respective owners. The findings of this report are not to be construed as an official Department of the Army position unless so designated by other authorized documents. 


\section{Contents}

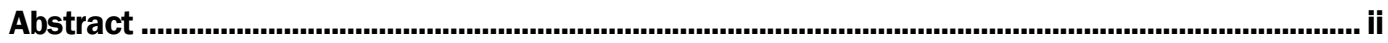

Figures and Tables..................................................................................................................vi

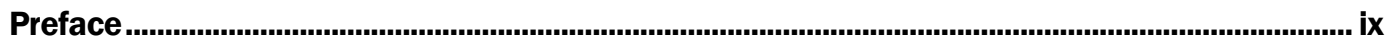

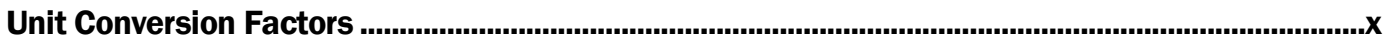

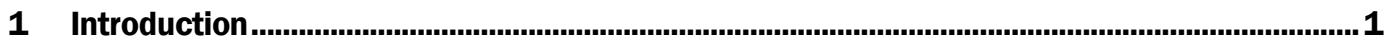

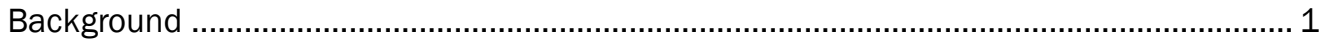

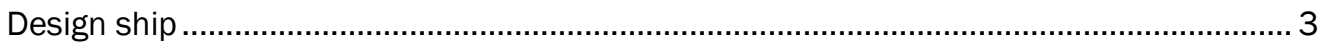

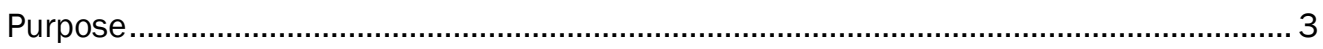

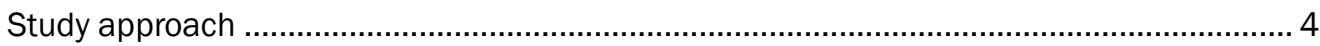

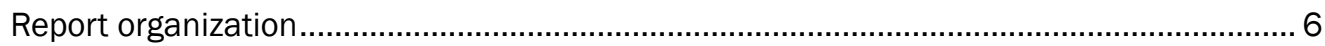

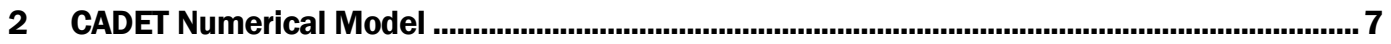

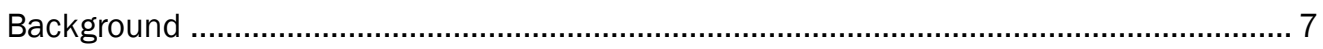

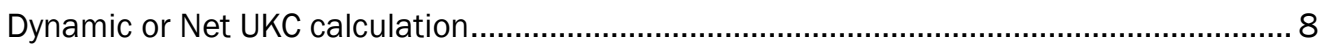

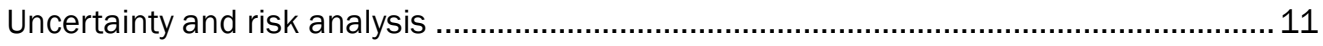

CADET organization ................................................................................................. 12

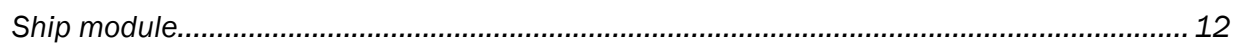

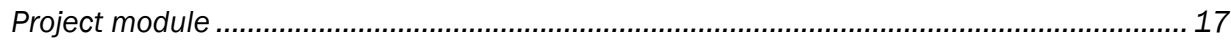

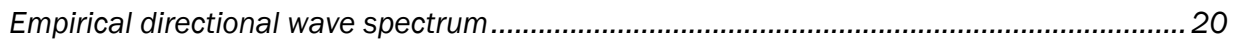

3 Numerical Wave Models .........................................................................................................23

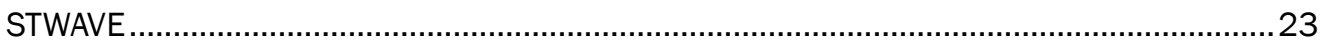

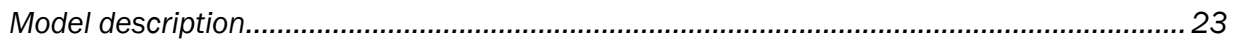

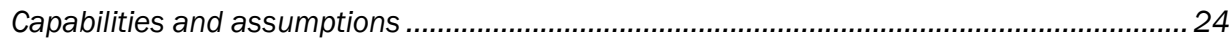

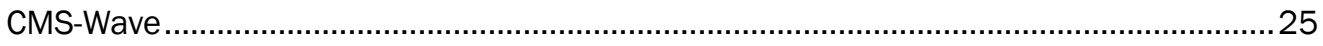

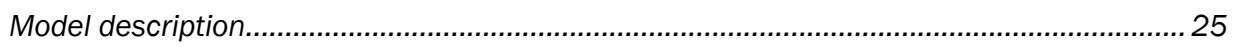

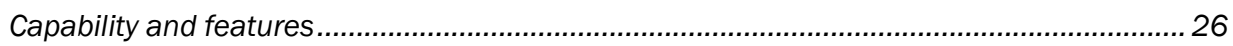

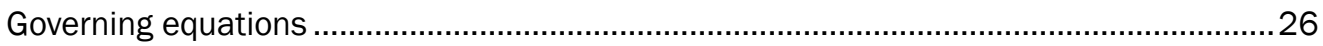

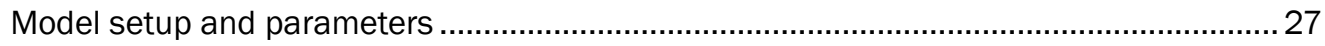

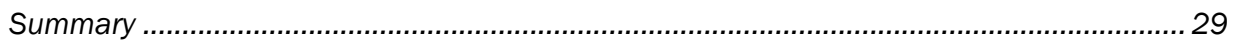

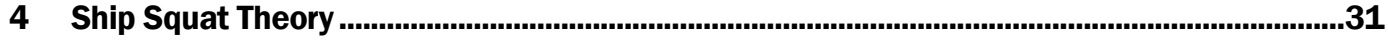

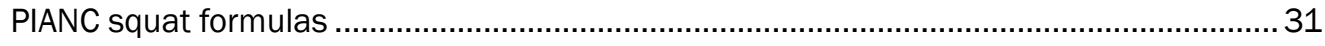

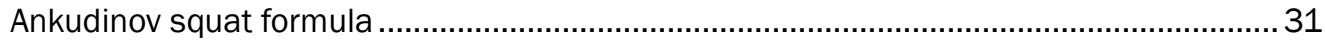

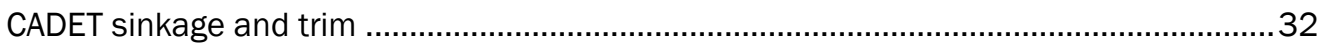

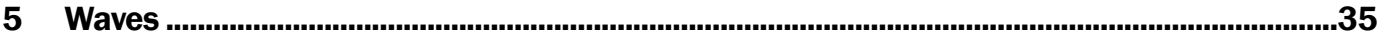

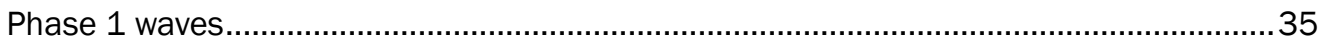

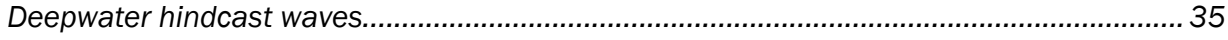




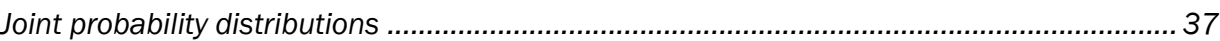

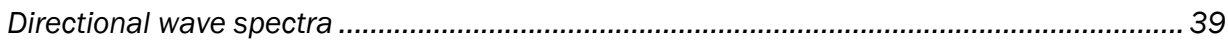

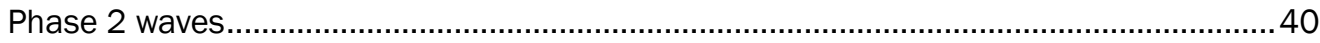

Preliminary STWAVE and CMS-Wave comparisons .............................................................. 40

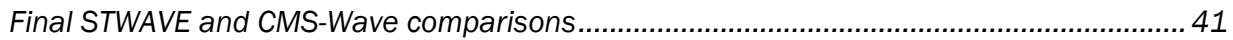

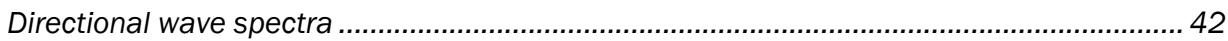

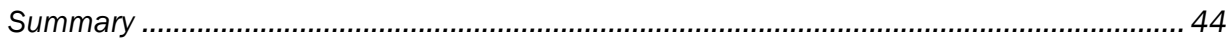

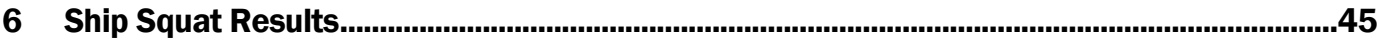

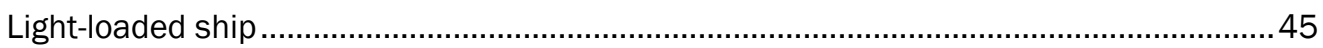

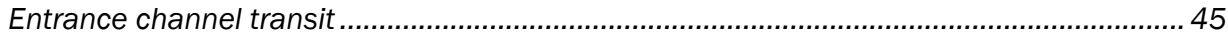

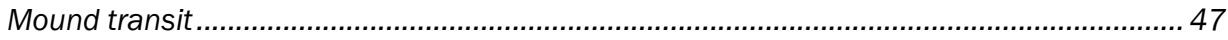

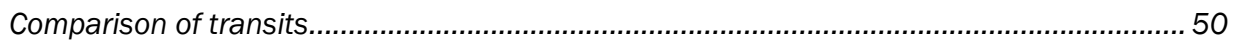

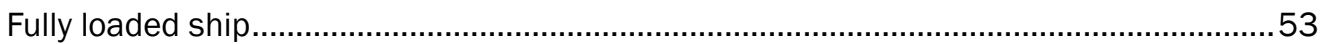

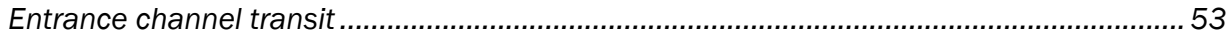

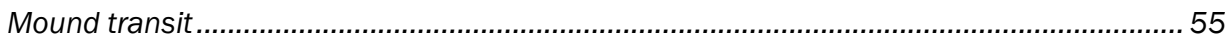

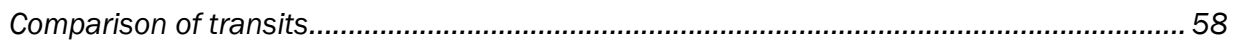

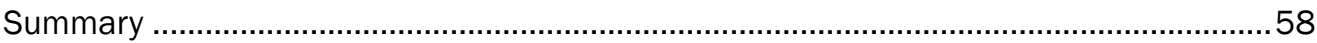

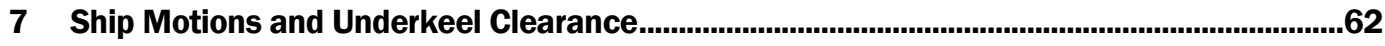

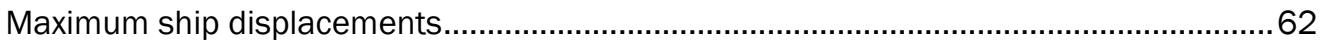

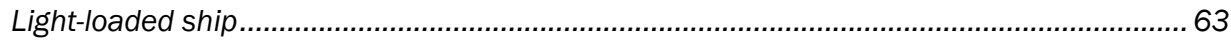

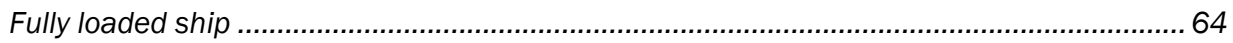

Phase 1 waves - fully loaded ship ........................................................................... 66

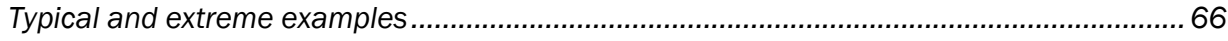

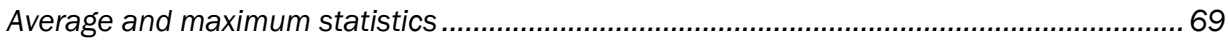

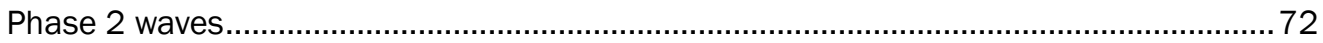

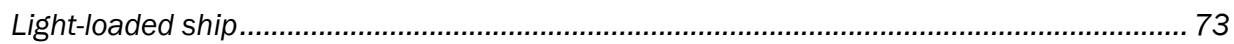

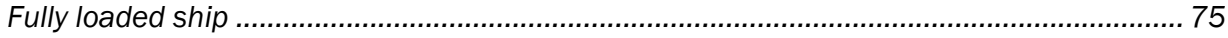

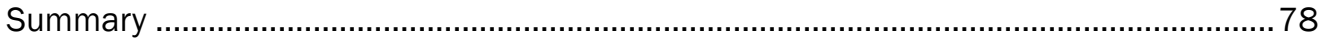

8 Summary and Conclusions ..................................................................................................82

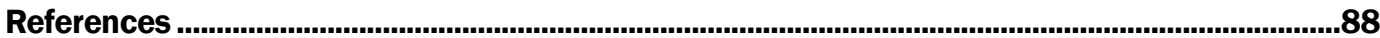

Appendix A: CMS-Wave Numerical Model Capabilities for Navigation Projects ..........................95

Appendix B: WIS126 $T_{p}$ vs. $H_{s}$ Percent Occurrence Tables for Each Direction Band in

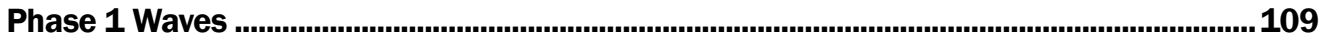

Appendix C: Phase 1 and Phase 2 Wave Climatology in the Ambrose Channel Reaches....... 117

Appendix D: Wave-induced Vertical Motion Allowances (ft) for Phase 1, Reach 1

Channel $(h=53 \mathrm{ft})$ and Reach 2 Mound $(h=55 \mathrm{ft})$, Fully loaded $(T=47.5 \mathrm{ft})$ Susan

Maersk.

Appendix E: Net UKC for Phase 1, Reach 1 Channel $(h=53 \mathrm{ft}$ ) and Reach 2 Mound (h $=55 \mathrm{ft})$, Fully loaded $(T=47.5 \mathrm{ft})$ Susan Maersk. 
Appendix F: Wave-induced Vertical Motion Allowances (ft) for Phase 2, Reach 1

Channel $(h=53 \mathrm{ft})$ and Reach 2 Mound $(h=55 \mathrm{ft})$, Lightly $(T=46.0 \mathrm{ft})$ and Fully loaded $(T=\mathbf{4 7 . 5} \mathrm{ft})$ Susan Maersk..

Appendix G: Net UKC for Phase 2, Reach 1 Channel $(h=53 \mathrm{ft}$ ) and Reach 2 Mound ( $h$ $=55 \mathrm{ft})$, Lightly $(T=46.0 \mathrm{ft})$ and Fully loaded $(T=47.5 \mathrm{ft})$ Susan Maersk ... 195

Report Documentation Page 


\section{Figures and Tables}

\section{Figures}

Figure 1. Project study area of Ambrose Channel, New York, showing offshore reach and mound (see "This is problematic" caption).

Figure 2. Susan Maersk design ship for Ambrose Channel. .................................................................. 4

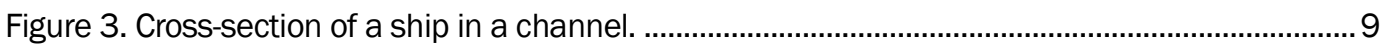

Figure 4. Wave transformation modeling domain for Ambrose Channel and mound (a)

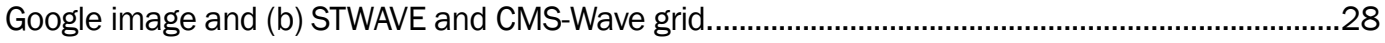

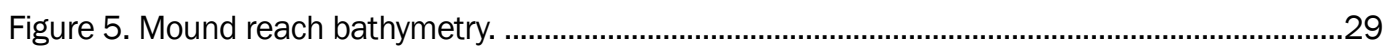

Figure 6. BNT channel geometry variables.................................................................................33

Figure 7. Locations of WIS126 WIS station and ALSN6 Ambrose Light Station in study area...............35

Figure 8. WIS126 percent occurrence histogram of wave direction, period, and height, 1980 to 1999

Figure 9. WIS126 wave roses for 1980 to 1999 (a) wave height and (b) peak wave period

Figure 10. Ship squat for light-loaded ( $T=46 \mathrm{ft}$ ) Susan Maersk containership during channel transit for Ankudinov, CADET, Barrass, Eryuzlu, Huuska, Römisch, and Yoshimura predictions (a) no tide $(h=53 \mathrm{ft}$ ) and (b) high tide $(h=58 \mathrm{ft})$.

Figure 11. Ship squat for light-loaded $(T=46 \mathrm{ft}$ ) Susan Maersk containership during mound transit for Ankudinov, CADET, Barrass, Eryuzlu, Huuska, Römisch, and Yoshimura predictions (a) no tide ( $h=55 \mathrm{ft}$ ) and (b) high tide ( $h=60 \mathrm{ft}$ ).

Figure 12. Ship squat differences for mound vs. channel transits with Susan Maersk containership ( $T=46.0 \mathrm{ft}$ ) (a) no tide predictions, (b) $+5 \mathrm{ft}$ tide advantage predictions.

Figure 13. Ship squat for fully loaded ( $T=47.5 \mathrm{ft}$ ) Susan Maersk containership during channel transit for Ankudinov, CADET, Barrass, Eryuzlu, Huuska, Römisch, and Yoshimura predictions (a) no tide ( $h=53 \mathrm{ft}$ ) and (b) high tide ( $h=58 \mathrm{ft})$.

Figure 14. Ship squat for fully loaded ( $T=47.5 \mathrm{ft}$ ) Susan Maersk containership during mound transit for Ankudinov, CADET, Barrass, Eryuzlu, Huuska, Römisch, and Yoshimura predictions (a) no tide $(h=55 \mathrm{ft}$ ) and $(\mathrm{b})$ high tide $(h=60 \mathrm{ft})$.

Figure 15. Ship squat differences for mound vs. channel transits with Susan Maersk containership ( $T=47.5 \mathrm{ft}$ ) (a) no tide predictions, (b) $+5 \mathrm{ft}$ tide advantage predictions.

Figure B1. WIS126 $T_{p}$ vs. $H_{s}$ percent occurrence table for direction band centered at $\theta_{p}$ $=67.5 \mathrm{deg}(\mathrm{a})$ percent and $(\mathrm{b})$ number of observations.

Figure B2. WIS126 $T_{p}$ vs. $H_{s}$ percent occurrence table for direction band centered at $\theta_{p}$ $=90 \mathrm{deg}(\mathrm{a})$ percent and (b) number of observations.

Figure B3. WIS126 $T_{p}$ vs. $H_{s}$ percent occurrence table for direction band centered at $\theta_{p}$ $=112.5 \mathrm{deg}(\mathrm{a})$ percent and (b) number of observations.

Figure B4. WIS126 $T_{p}$ vs. $H_{s}$ percent occurrence table for direction band centered at $\theta_{p}$ $=135 \mathrm{deg}$ (a) percent and (b) number of observations.

Figure B5. WIS126 $T_{p}$ vs. $H_{s}$ percent occurrence table for direction band centered at $\theta_{p}$ $=157.5 \mathrm{deg}$ (a) percent and (b) number of observations.

Figure B6. WIS126 $T_{p}$ vs. $H_{s}$ percent occurrence table for direction band centered at $\theta_{p}$ $=180 \mathrm{deg}(\mathrm{a})$ percent and $(\mathrm{b})$ number of observations. 
Figure B7. WIS126 $T_{p}$ vs. $H_{s}$ percent occurrence table for direction band centered at $\theta_{p}$ $=202.5 \mathrm{deg}(\mathrm{a})$ percent and $(\mathrm{b})$ number of observations.

\section{Tables}

Table 1. Susan Maersk containership parameters

Table 2. Input and derived parameters for Susan Maersk containership, CADET ship module.

Table 3. Ambrose Channel parameters. 18

Table 4. TMA spectral peakedness $y$ and directional spreading $n$ parameters. ...............................22

Table 5. Summary of half-plane and full-plane features .................................................................24

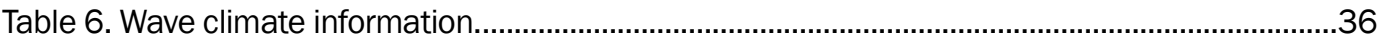

Table 7. Band limits on wave direction. ................................................................................................39

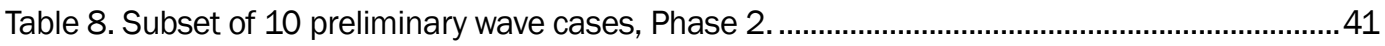

Table 9. Final set of 21 numerical model wave cases, Phase 2 ...........................................................42

Table 10. Wave cases in Phase 2. ......................................................................................................43

Table 11. Ship squat predictions for light-loaded Susan Maersk in Ambrose Channel. ....................47

Table 12. Ship squat predictions for light-loaded Susan Maersk during mound transit. ..................49

Table 13. Effect of tides on squat differences $\left(S_{D i f}\right)$ and ratios $\left(S_{R}\right)$ for mound and channel transits for light-loaded Susan Maersk containership........................................................................52

Table 14. Ship squat predictions for fully loaded Susan Maersk during channel transit. .................55

Table 15. Ship squat predictions for fully loaded Susan Maersk during mound transit...................57

Table 16. Effect of tides on squat differences $\left(S_{D i f}\right)$ and ratios $\left(S_{R}\right)$ for mound and channel transits for fully loaded Susan Maersk containership. .....................................................................60

Table 17. Maximum ship displacements $D_{M a x}$ for light-loaded ship...................................................63

Table 18. Maximum ship displacements $D_{\text {Max }}$ for fully loaded ship. .....................................................65

Table 19. Maximum vertical motion allowance $A_{\text {Max }}(\mathrm{ft})$, Phase 1, fully loaded ship........................67

Table 20. Net underkeel clearance $U K C_{\text {Net }}(\mathrm{ft})$, Phase 1, fully loaded ship.........................................69

Table 21. Vertical motion allowance statistics $A_{\text {Max }}$ (ft), Phase 1, fully loaded ship. ..........................70

Table 22. Net underkeel clearance $U K C_{\text {Net }}$ statistics (ft), Phase 1, fully loaded ship. ........................72

Table 23. Wave motion allowances $A_{\max }(\mathrm{ft})$, Phase 2, light-loaded ship, 12 kt inbound transits.

Table 24. Net underkeel clearance UKC $C_{\text {Net }}$ (ft), Phase 2, light-loaded ship, 12 kt inbound transits

Table 25. Wave motion allowances $A_{\text {Max }}$ (ft), Phase 2, fully loaded ship, 12 kt inbound transits.

Table 26. Net underkeel clearance $U K C_{\text {Net }}(\mathrm{ft})$, Phase 2, fully loaded ship, 12 kt inbound transits.

Table C1. Wave climatology in Ambrose Channel, Phase 1, Channel Reach 1...............................117

Table C2. Wave climatology in Ambrose Mound, Phase 1, Mound Reach 2. ................................ 123

Table C3. Wave climatology in Ambrose Channel, Phase 2, Channel Reach 1.............................. 129

Table C4. Wave climatology in Ambrose Mound, Phase 2, Mound Reach 2. ................................ 130 
Table D1. Wave-induced vertical motion allowances (ft), Phase 1, Channel Reach 1, $h=$ $53 \mathrm{ft}$, fully loaded Susan Maersk, inbound and outbound transits.

Table D2. Wave-induced vertical motion allowances (ft), Phase 1, Mound Reach 2, $h=55$

$\mathrm{ft}$, fully loaded Susan Maersk, inbound and outbound transits.

Table D3. Wave-induced vertical motion allowances (ft), Phase 1, Channel Reach 1, $h=$ $58 \mathrm{ft}$, fully loaded Susan Maersk, inbound and outbound transits.

Table D4. Wave-induced vertical motion allowances (ft), Phase 1, Mound Reach 2, $h=60$

$\mathrm{ft}$, fully loaded Susan Maersk, inbound and outbound transits.

Table E1. Net UKC (ft), Phase 1, Channel Reach 1, $h=53 \mathrm{ft}$, fully loaded Susan Maersk, inbound and outbound transits

Table E2. Net UKC (ft), Phase 1, Mound Reach 2, $h=55 \mathrm{ft}$, fully loaded Susan Maersk, inbound and outbound transits 166

Table E3. Net UKC (ft), Phase 1, Channel Reach 1, $h=58 \mathrm{ft}$, fully loaded Susan Maersk, inbound and outbound transits

Table E4. Net UKC (ft), Phase 1, Mound Reach 2, $h=60 \mathrm{ft}$, fully loaded Susan Maersk, inbound and outbound transits.

Table F1. Wave-induced vertical motion allowances (ft), Phase 2, Channel Reach 1, $h=$ $53 \mathrm{ft}$, light-loaded Susan Maersk, inbound and outbound transits.

Table F2. Wave-induced vertical motion allowances (ft), Phase 2, Mound Reach 2, $h=55$, 56, and $57 \mathrm{ft}$, light-loaded Susan Maersk, inbound and outbound transits.

Table F3. Wave-induced vertical motion allowances (ft), Phase 2, Channel Reach 1, $h=$ $53 \mathrm{ft}$, fully loaded Susan Maersk, inbound and outbound transits.

Table F4. Wave-induced vertical motion allowances (ft), Phase 2, Mound Reach 2, $h=55$, 56, and $57 \mathrm{ft}$, fully loaded Susan Maersk, inbound and outbound transits

Table G1. Net UKC (ft), Phase 2, Channel Reach 1, $h=53 \mathrm{ft}$, light-loaded Susan Maersk, inbound and outbound transits.

Table G2. Net UKC (ft), Phase 2, Mound Reach 2, $h=55,56$, and $57 \mathrm{ft}$, light-loaded Susan Maersk, inbound and outbound transits.

Table G3. Net UKC (ft), Phase 2, Channel Reach 1, $h=53 \mathrm{ft}$, fully loaded Susan Maersk, inbound and outbound transits

Table G4. Net UKC (ft), Phase 2, Mound Reach 2, $h=55,56$, and $57 \mathrm{ft}$, fully loaded

Susan Maersk, inbound and outbound transits. 200 


\section{Preface}

This report describes numerical modeling procedures and results of a vertical ship motion study for the Ambrose Channel, New York. The study was performed in support of the New York Pilots' request to investigate the possible effect of a "mound" located near the old Light Tower on wave amplification and ship response if a ship should inadvertently sail over it. The study was performed by the US Army Engineer Research and Development Center (ERDC), Coastal and Hydraulics Laboratory (CHL), for the US Army Engineer District, New York (NAN). The study was conducted during the period April 2010 through August 2011. Frank Santangelo, US Army Engineer District, New York, was the study manager and point of contact.

The investigation reported herein was conducted by Drs. Michael J. Briggs and Zeki Demirbilek of the Harbors, Entrances, and Structures Branch, CHL. The final report was written by Dr. Briggs with sections on the two wave models written by Drs. Lihwa Lin and Demirbilek. We gratefully acknowledge the support of Andrew Silver and Paul Kopp of the Naval Surface Warfare Center, Carderock Division, for discussion and review.

This study was performed under the general supervision of Dr. William Martin, Director, CHL. Direct supervision of this project was provided by Dr. Jackie Pettway, Chief, Harbors, Entrances, and Structures Branch. At the time of publication of this report, Dr. Jeffery P. Holland was Director of ERDC, and COL Jeffrey Eckstein, EN, was Commander and Executive Director. 


\section{Unit Conversion Factors}

\begin{tabular}{|c|c|c|}
\hline Multiply & By & To Obtain \\
\hline acres & $4,046.873$ & square meters \\
\hline cubic feet & 0.02831685 & cubic meters \\
\hline cubic inches & 1.6387064 E-05 & cubic meters \\
\hline cubic yards & 0.7645549 & cubic meters \\
\hline degrees (angle) & 0.01745329 & radians \\
\hline fathoms & 1.8288 & meters \\
\hline feet & 0.3048 & meters \\
\hline hectares & $1.0 \mathrm{E}+04$ & square meters \\
\hline inches & 0.0254 & meters \\
\hline knots & 0.5144444 & meters per second \\
\hline miles (nautical) & 1,852 & meters \\
\hline miles (US statute) & $1,609.347$ & meters \\
\hline miles per hour & 0.44704 & meters per second \\
\hline pounds (force) per square foot & 47.88026 & pascals \\
\hline pounds (force) per square inch & 6.894757 & kilopascals \\
\hline pounds (mass) & 0.45359237 & kilograms \\
\hline pounds (mass) per cubic foot & 16.01846 & kilograms per cubic meter \\
\hline pounds (mass) per cubic inch & $2.757990 \mathrm{E}+04$ & kilograms per cubic meter \\
\hline pounds (mass) per square foot & 4.882428 & kilograms per square meter \\
\hline pounds (mass) per square yard & 0.542492 & kilograms per square meter \\
\hline square feet & 0.09290304 & square meters \\
\hline square inches & $6.4516 \mathrm{E}-04$ & square meters \\
\hline square miles & $2.589998 \mathrm{E}+06$ & square meters \\
\hline square yards & 0.8361274 & square meters \\
\hline tons (force) & $8,896.443$ & newtons \\
\hline tons (force) per square foot & 95.76052 & kilopascals \\
\hline tons (long) per cubic yard & $1,328.939$ & kilograms per cubic meter \\
\hline tons $(2,000$ pounds, mass $)$ & 907.1847 & kilograms \\
\hline tons ( 2,000 pounds, mass) per square foot & $9,764.856$ & kilograms per square meter \\
\hline yards & 0.9144 & meters \\
\hline
\end{tabular}




\section{Introduction}

\section{Background}

New York Harbor Pilots have expressed a concern about a "high spot" mound that is about 1.5 miles seaward of the new limit of the Ambrose Channel (Figure 1). The end of the existing Ambrose Channel is at the "G1" and "R2" navigation markers. The existing Sea Buoy is just south of the mound, where the old Ambrose Light Tower was located. This mound is probably construction rubble (i.e., hard material) that was placed here when the Light Tower isolated and protected it somewhat from the main channel. The size is approximately 1,500 to $2,000 \mathrm{ft}$ in diameter with a depth of $53 \mathrm{ft}$ Mean Lower Low Water (MLLW). The mound's diameter and depth are similar to the width and depth of the Ambrose Channel offshore reach. Now that the Tower is no longer marking this mound, the pilots are concerned about whether a ship might experience larger or more dramatic ship motions due to possible amplification across the mound, relative to channel transits.

Figure 1. Project study area of Ambrose Channel, New York, showing offshore reach and mound (see "This is problematic" caption).

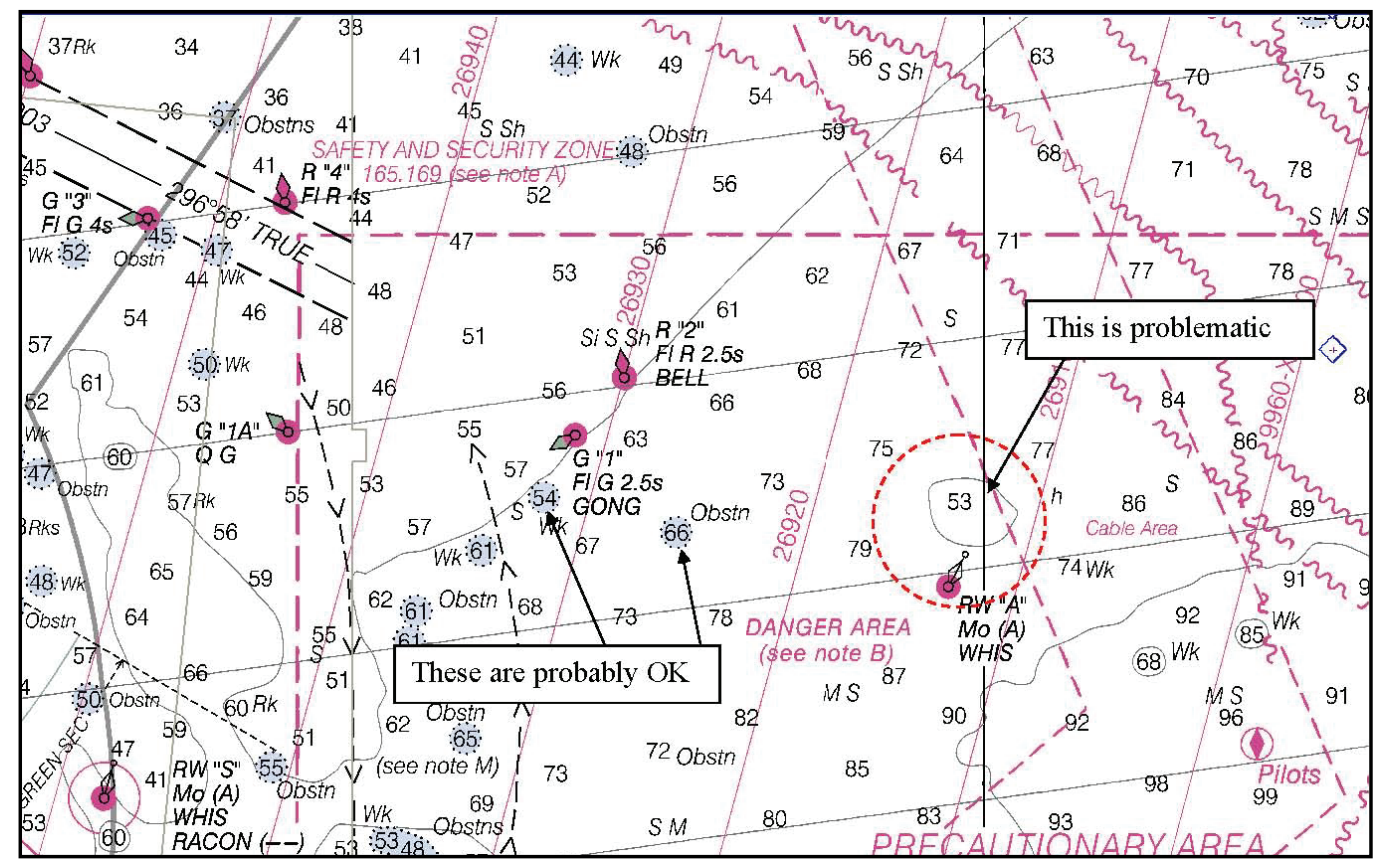

The static or gross underkeel clearance (UKC) is defined as the clearance under the ship after subtracting the draft from the depth that includes 
project depth and tides. The UKC must be adjusted to account for the effects of ship squat and wave-induced vertical ship motions. The resulting net UKC ( $\left.U K C_{N e t}\right)$ is considered a "safety factor" or "maneuvering margin" representing the adjusted clearance after subtracting squat and ship motions from the UKC. In a deterministic design, Corps guidelines recommend an $U K C_{\text {Net }}$ of $2 \mathrm{ft}$ for soft-bottom and $4 \mathrm{ft}$ for hard-bottom channels. However, in a risk-based or probabilistic design, it is possible to relax these requirements for $U K C_{N e t}$ as sufficient maneuverability clearance is included in the predicted ship motion allowances.

Port designers have historically relied on deterministic channel design approaches with large safety factors. Risk-based models are now recommended to define a useful lifetime with an acceptable level of risk of accidents or groundings. CADET (Channel Analysis and Design Evaluation Tool) is a program to aid in determining the 'optimum' dredge depth for the offshore portions of entrance channels that are exposed to waves. This 'optimum' dredge depth is defined as the depth that provides the maximum accessibility for the minimum amount of dredging and is determined by predicting ship UKC for different wave, ship, and channel combinations. A probabilistic risk analysis technique is used in CADET to evaluate the accessibility of a series of channel reaches for multiple vessel geometries, loading, and wave conditions.

Briggs et al. (2010, 2012, and 2013) performed a validation study with CADET for six ships during inbound and outbound transits in Ambrose Channel, NY. Comparisons between field measurements and CADET predictions agreed reasonably well in the three reaches. Additional validation comparisons between field and laboratory measurements and CADET predictions for the World Utility bulk carrier were performed for Barbers Pt, HI (Briggs et al. 2006, 2012, and 2013). The agreement between CADET predictions and field and laboratory measurements was reasonable.

The main concern is about amplification over the submerged mound due to refraction, diffraction, and shoaling of wind waves. Vincent and Briggs (1989) describe the effect of frequency and directional spreading of waves caused by a submerged elliptical shoal. They found amplification factors of over 2 for unbroken monochromatic and unidirectional waves for a laboratory model shoal. Their measured breaking wave heights usually were less than the incident wave heights. The shoal geometry tested in the laboratory had minor $X$ - and major $Y$ - axes normalized by the wavelength $L$ 
of $X / L=1.35$ and $Y / L=1.75$. The crest of the shoal was $h_{\text {mound }}=0.5 \mathrm{ft}$ below the mean water level in $h=1.5 \mathrm{ft}$ of water at laboratory scales. The normalized depth of the shoal was $h_{\text {mound }} / h=0.33$. In comparison, the Ambrose Channel mound is relatively deeper than the laboratory shoal with crest elevation of $h_{\text {mound }}=53 \mathrm{ft}$ in an approximate water depth $h=80 \mathrm{ft}$, or $h_{\text {mound }} / h=0.66$. For the mound size of 1,500 to $2,000 \mathrm{ft}$, a comparable wave period of $T=18$ to $22 \mathrm{sec}$ would be required to match the laboratory mound horizontal setup.

Since the laboratory experiment results do not match the Ambrose Channel mound very well in scaling and mound elliptical shape, it was necessary to examine the significance of wave amplification using two spectral (phase-averaged) wave models: STWAVE (Smith et al. 2001a) and CMS-Wave ( Lin and Demirbilek 2005; Demirbilek et al. 2007; Lin et al. 2006; Lin et al. 2008). Both of these models can provide locally generated wave estimates at the project site given incident wave conditions. These models are computationally efficient and can be used to model large areas since fine grid resolution is not necessary. However, this class of model has limitations for modeling wave diffraction, reflection, transmission, nonlinear waves, and bathymetric effects caused by submerged mounds, shoals, or navigation channels. For these reasons, two wave models were used because each has its own strengths and limitations.

\section{Design ship}

The Susan Maersk Post-Panamax containership (Figure 2) is the design ship for this study. It was completed in 1997 with a TEU (Twenty-feet Equivalent Units) capacity of 8,680 and a length overall, $L_{O A}$, of $1,138 \mathrm{ft}$. Typical ship speeds $V_{k}$ range from $8 \mathrm{kt}$ to $16 \mathrm{kt}$, with common ship speeds as fast as $15 \mathrm{kt}$ in this area. In addition to the fully loaded draft of $T=47.5 \mathrm{ft}$, a light-loaded draft of $T=46 \mathrm{ft}$ was also investigated in this study. This was necessary because a lighter ship (with less draft) will respond to waves differently than a fully loaded ship. Table 1 lists ship particulars for these two design drafts of the Susan Maersk.

\section{Purpose}

The New York District (NAN) has requested a study to evaluate the waves across this mound and determine if they will have a significant effect on ship response. If there is a significant effect, then how does this response compare to a similar transit through the Ambrose Channel offshore reach that is adjacent to the mound? 
Figure 2. Susan Maersk design ship for Ambrose Channel.

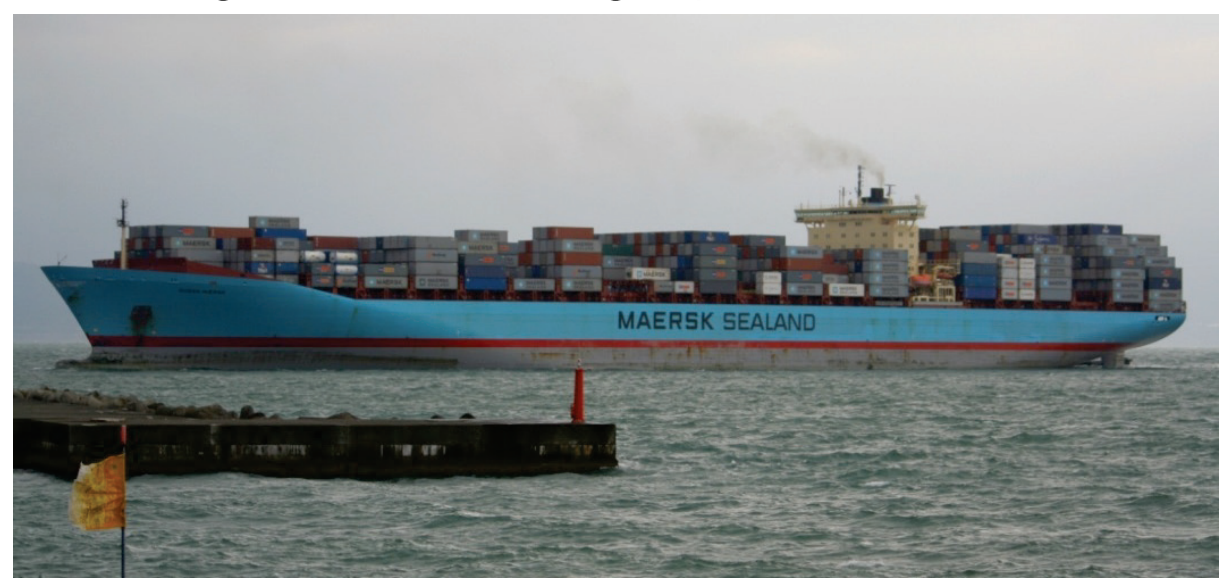

Table 1. Susan Maersk containership parameters.

\begin{tabular}{|l|l|l|l|l|}
\hline Description & Symbol & Units & Light-loaded & Fully loaded \\
\hline Length between perpendiculars & $L_{P P}$ & $\mathrm{ft}$ & 1087.9 & 1087.9 \\
\hline Beam & $B$ & $\mathrm{ft}$ & 140.4 & 140.4 \\
\hline Draft & $T$ & $\mathrm{ft}$ & 46.0 & 47.5 \\
\hline Block coefficient & $C_{B}$ & -- & 0.65 & 0.65 \\
\hline Longitudinal center of gravity & $L_{C G}$ & $\mathrm{ft}$ & 563.0 & 563.7 \\
\hline Vertical center of gravity (from keel) & $V_{C G}$ & $\mathrm{ft}$ & 62.8 & 62.2 \\
\hline Metacentric height & $G M$ & $\mathrm{ft}$ & 1.97 & 2.48 \\
\hline Roll damping factor, fractional percent & $\beta_{44}$ & --- & 0.04 & 0.08 \\
\hline Roll Gyradius & $k_{4}$ & $\mathrm{ft}$ & 57.6 & 57.6 \\
\hline Pitch Gyradius & $k_{6}$ & $\mathrm{ft}$ & 272.0 & 272.0 \\
\hline
\end{tabular}

Because the mound consists of hard material, it is proposed to dredge it to a minimum depth of $55 \mathrm{ft}$ so that there is an additional clearance of $+2 \mathrm{ft}$ relative to similar transits in the soft bottom of the Ambrose Channel. Additional dredging beyond a depth of $55 \mathrm{ft}$ will be recommended if the mound transits indicate a greater potential for groundings than the similar channel transits.

\section{Study approach}

The study described in this report was performed by the US Army Engineer Research and Development Center (ERDC), Coastal and Hydraulics Laboratory (CHL), in support of NAN planning and design for the Ambrose Channel. The CADET probabilistic model was used to predict vertical ship motions due to a range of wave conditions. Wave transformation was 
evaluated between the incident offshore site and the Ambrose Channel and over the mound using the STWAVE and CMS-Wave numerical models. Ship squat, ship motions, and $U K C_{\text {Net }}$ were compared between the channel and mound reaches. Significant differences were noted, and a dredge depth was recommended that would accommodate the $U K C_{N e t}$ requirements.

The first step was to define the offshore and mound reaches for the Ambrose Channel. The existing offshore reach has a width of 2,000 ft and a project depth of $53 \mathrm{ft}$. The mound reach was defined to have a similar width of 2,000 ft to match the existing diameter of the mound, but the depth will be $55 \mathrm{ft}$ as it was assumed that it would be dredged at least an additional $2 \mathrm{ft}$ to compensate for the hard-bottom guidelines within the Corps. The Ambrose Channel experiences a $5 \mathrm{ft}$ tidal increase; therefore, channel and mound depths included the effect of the $5 \mathrm{ft}$ tide. Depths ranged from 53 to $58 \mathrm{ft}$ in the channel and 55 to $60 \mathrm{ft}$ over the mound.

The study approach consisted of two phases. In Phase 1, relatively deepwater hindcast waves were used to examine vertical ship motions between the two reaches. For simplicity, it was assumed that the effect of wave transformation was negligible between locations and over the mound. Phase 1 consisted of the following tasks:

- Characterize incident wave climate in the Ambrose Channel area from WIS hindcast and National Oceanic and Atmospheric Administration (NOAA) buoy measurements.

- Simulate directional wave spectra based on the 20 yr hindcast wave dataset along offshore and mound channel reaches. These wave conditions are identical for both reaches.

- Predict ship squat using Ankudinov, Beck-Newman-Tuck (BNT), and five of the PIANC (The World Association for Waterborne Transport Infrastructure, formerly Permanent International Association of Navigation Congresses) empirical formulas (1997 and 2013).

- Predict wave-induced vertical ship motions for both the lightly and fully loaded Susan Maersk design ship in the channel and mound reaches using the CADET model.

- Compare squat, ship motions, and $U K C_{N e t}$ between channel and mound reaches. 
The results from the Phase 1 comparisons were used to select a limited wave dataset to investigate the effects of wave transformation using STWAVE and CMS-Wave in Phase 2. Phase 2 consisted of the following tasks:

- Select subset of wave conditions for wave transformation evaluation.

- Create STWAVE and CMS-Wave numerical models to evaluate transformation and potential for amplification of this reduced wave dataset.

- Create new wave dataset of directional wave spectra based on numerical model results.

- Re-run CADET with new dataset.

- Compare squat, ship motions, and $U K C_{\text {Net }}$ between channel and mound reaches for this reduced wave dataset. Investigate effect of increased water depths over the mound.

- Recommend optimum dredge depth for mound based on comparisons between the channel and mound reaches.

\section{Report organization}

In this report, the CADET numerical model is briefly described in Chapter 2. A brief description of the STWAVE and CMS-Wave wave transformation models is presented in Chapter 3. Chapter 4 contains a description of the PIANC, Ankudinov, and CADET/BNT ship squat predictions. The characterization of the waves in the two phases for the CADET, STWAVE, and CMS-Wave numerical model simulations is described in Chapter 5 . Results from the ship squat calculations are presented and discussed in Chapter 6 . The vertical ship motions and corresponding $U K C_{N e t}$ are discussed and presented in Chapter 7. These results compare $U K C_{N e t}$ over the mound relative to similar transits though the channel. Based on these comparisons, an optimum dredge depth for the mound is recommended. Finally, a summary and conclusions is presented in Chapter 8. 


\section{CADET Numerical Model}

\section{Background}

CADET (Kopp and Silver 2005) was developed by the Naval Surface Warfare Center, Carderock Division (NSWCCD), under contract to ERDCCHL. CADET is an expansion of the technology developed to determine the depth of entrance channels to new homeports for Nimitz-class Aircraft Carriers (CVN 68). The technology used in CADET (Silver 1992; Silver and Dalzell 1997) was initially developed for the Environmental Monitoring and Guidance System (EMOGS). EMOGS provides operational guidance on the expected UKC of a vessel given real-time wave and water level measurements or observed conditions at a particular port. For each UKC prediction, it also calculates the uncertainty and risk of touching the channel bottom under those conditions. EMOGS evaluates clearance and risk for a single specified ship at one channel depth, using a single wave spectrum, for a transit in one direction at a specific date and time. Astronomical tide effects on the water level are included and take into account the duration of transit for a given ship speed and entrance channel configuration. Meteorological effects on water level due to barometric pressure are also included. EMOGS is installed at naval stations in the United States and has been in operation for over 20 yrs. During this time, no known incident of bottom touching or grounding has occurred, and the users have not complained that the results are too restrictive.

CADET differs from EMOGS in several respects. It is more of a design tool as it evaluates clearance and risk for a range of possible water depths. In addition, it evaluates the entrance channel depths for any channel crosssection. Annual local wave statistics are used to determine the accessibility of the transit channels, expressed in days per year. Astronomical and meteorological tide effects are not explicitly included since, for design purposes, a transit could occur in either direction at any time. Water level changes can be included by varying the project depth relative to ship draft. A tide calculator is a post-processor option that can be used to indicate additional days of accessibility due to hindcast of $20 \mathrm{yr}$ tidal cycles for a particular location. CADET also assumes an equal probability of a transit in either inbound or outbound directions at any time of day or night. 


\section{Dynamic or Net UKC calculation}

CADET calculates the dynamic or net UKC, $U K C_{N e t}$, of a specific ship, commercial or naval, at a specified channel location, and provides information to aid in determining the optimum dredge depth (Briggs et al. 2004 and 2012). This optimum depth is defined as the shallowest depth that allows the maximum days of access for any given year at that location. The accessibility of the channel is determined by calculating the vertical $U K C_{N e t}$ and the risk of the vessel touching the channel bottom under all wave conditions that are present. The general rule is that if the risk, $\alpha$, of the ship touching a flat channel bottom is less than 1 in 100 (i.e., $\alpha=0.01$ ) for each wave in a climatology during a given transit, then the channel is considered accessible for that depth. The Navy is comfortable with this level of risk and corresponding accessibility. The number of days per year the channel is accessible is dependent on the persistence of the local wave conditions obtained from the local wave climatology.

The $U K C_{N e t}$ of the vessel is influenced by five major parameters that include the following:

- Static draft and trim of the ship at rest

- Underway sinkage and trim or ship squat

- Wave-induced vertical motions

- Hydrologic factors of channel depth at (MLLW) project depth

- Change in water level due to the astronomical tides

Because CADET is primarily a channel-depth design tool, ephemeral parameters such as meteorological tides are not factored into the calculation. As mentioned previously, CADET does have a post-processing option for tidal effects. Otherwise, the user can input equivalent tides in the range of water depths used for the predictions. CADET does not explicitly include channel width or bank effects.

Figure 3 shows the major parameters considered when calculating the vertical underkeel clearance of the ship in a channel. The static or gross UKC $(U K C)$ is the difference between the nominal channel depth and the static at-rest draft of the vessel. Static trim must also be taken into account. As the ship travels at speed along the channel, the ship both sinks and trims (i.e., squat or midship sinkage and trim by the bow or stern) due to a pressure field between the hull of the vessel and the channel bottom. The 
Figure 3. Cross-section of a ship in a channel.

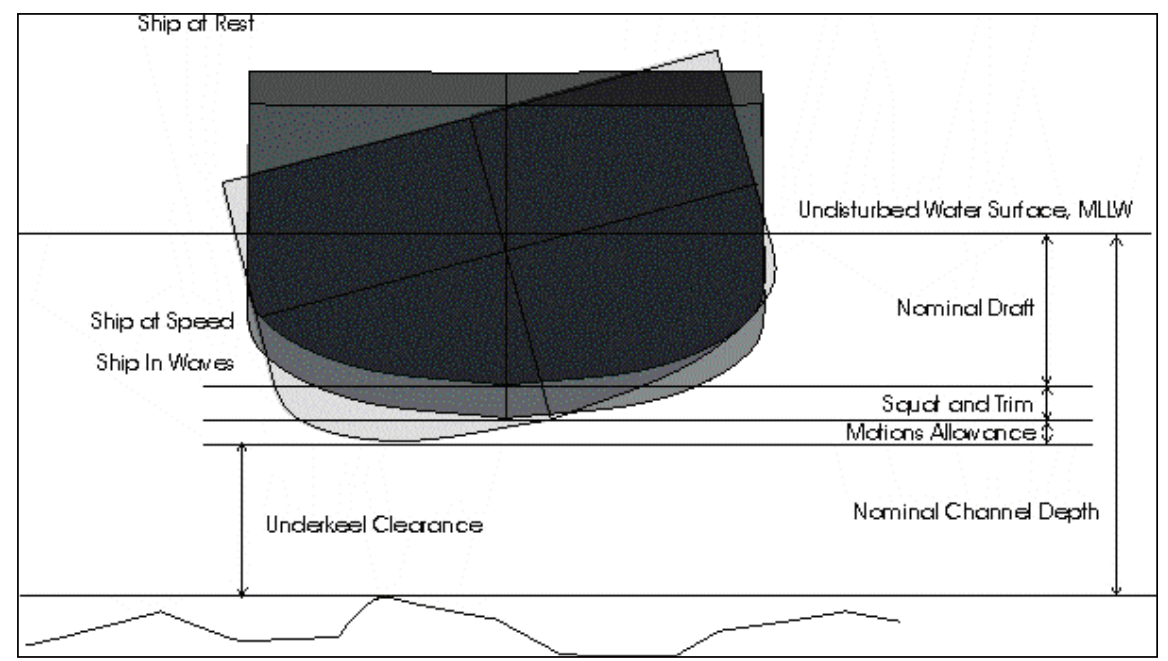

dynamic or net $U K C_{\text {Net }_{j}}$ at location $j$ (i.e., $j^{\text {th }}$ control point on a hull corresponding to the lowest points, usually at the bow, stern, rudder, and bilges) is given by

$$
U K C_{N_{j} t_{j}}=D_{c}+E_{t}-\left(T_{j}+S_{j}+A_{j}\right)
$$

where:

$D_{c}=$ nominal channel depth at MLLW

$E_{t}=$ water level due to tide relative to MLLW

$T_{j}=$ static draft

$S_{j}=\operatorname{ship}$ squat

$A_{j}=$ vertical motions allowance.

The vertical motion allowance, $A_{j}$, is determined from the vertical, waveinduced, rigid-body motion transfer functions of heave, pitch, and roll. The magnitude of the vertical displacement at a point on the ship is dependent upon the height and period of the waves in the channel, ship speed, relative ship heading to the waves, channel depth, and position of the point relative to the center of gravity. For the coupled heave, pitch, and roll motions, a complex-valued vertical displacement transfer function, $H_{j}(f, \theta)$, is calculated as

$$
H_{j}(f, \theta)=Z+X_{j} \Theta(f, \theta)+Y_{j} \Phi(f, \theta)
$$


where:

$j=$ corresponds to the $j^{\text {th }}$ control point location

$\mathrm{Z}=$ complex vertical heave motion transfer function

$X_{j}=$ longitudinal distance from the ship's center of gravity to the $j^{\text {th }}$ control point

$Y_{j}=$ transverse distance from the ship's center of gravity to the $j^{\text {th }}$ control point

$\Theta(f, \theta)=$ complex pitch transfer function

$\Phi(f, \theta)=$ complex roll transfer function.

These transfer functions are then used in the calculation of the RMS (root mean square) displacement, $\sigma_{j}$, given by

$$
\sigma_{j}=\sqrt{\sigma_{j}^{2}}=\sqrt{\sum_{f} \sum_{\theta} S(f, \theta)\left|H_{j}(f, \theta)\right|^{2} \Delta f \Delta \theta}
$$

where:

$\sigma_{j}=\mathrm{RMS}$ displacement at $j^{\text {th }}$ control point location, $\mathrm{ft}$

$S(f, \theta)=$ directional wave spectrum, $\mathrm{ft}^{2} / \mathrm{Hz} / \mathrm{deg}$

$\left|H_{j}(f, \theta)\right|^{2}=$ square of the modulus of the transfer function, known as the

Response Amplitude Operator (RAO)

$\Delta f=$ increment in frequency, $\mathrm{Hz}$

$\Delta \theta=$ increment in direction, deg.

Because of phase differences, $\sigma_{j}$ calculated from individual wave conditions may not provide the largest vertical excursion the ship can experience during a transit. Therefore, higher order extremal statistics (Ochi 1973) are used to define an expected extreme motion allowance, $A_{j}$, during a given transit as

$$
A_{j}=\sigma_{j} \sqrt{2 \ln \left[\frac{T_{d} \sigma_{v j}}{2 \pi \alpha \sigma_{j}}\right]}
$$

where:

$$
\begin{aligned}
T_{d}= & \text { exposure time in the channel (i.e., reach length/ship speed), } \\
& \text { sec }
\end{aligned}
$$




$$
\begin{aligned}
& \sigma_{v j}= \text { vertical velocity of the vertical motion (i.e., time derivative of } \\
& \sigma_{j} \text { ) at location } j, \mathrm{ft} / \mathrm{sec} \\
& \alpha= \text { risk parameter, normally taken to be } 0.01 \text { (i.e., } 1 / 100 \text { ) in } \\
& \text { CADET. If } \alpha=0.01 \text {, then the ship has a risk of } 1 \text { in } 100 \text { that the } \\
& \text { predicted motions allowance, } A_{j} \text {, will be exceeded for the given } \\
& \text { set of wave conditions. }
\end{aligned}
$$

\section{Uncertainty and risk analysis}

Each of the parameters in Equation 1 has inherent uncertainties. These uncertainties are quantified by their bias and variability. The shallow water motions calculation for Navy ships was based on a software program that was a hybrid of the Navy Standard Ship Motion Program (SMP). This hybrid was validated by both model tests and comparisons of predicted motions with full-scale measurements (Silver and Dalzell 1997). The motions of the commercial ships used in CADET were computed through the shallow-water version of SCORES which calculates ship motions due to waves (Kaplan 1996a, 1996b). As more experience using CADET is attained for commercial ships, the bias and variability could change. However, since a large component of the uncertainty and bias in the motions calculation comes from the uncertainty in the wave measurement, the difference in the uncertainty of the motions between commercial and Navy ships may be small.

The primary objective for calculating uncertainty is to provide a measure of risk of the vessel touching the various project depths being considered. Risk is defined as that proportion of all possible transits under statistically constant conditions in which the minimum channel clearance would be zero or negative. The risk model takes into account the uncertainty in each parameter by assuming a Gaussian distribution for static ship draft, underway sinkage and trim, and a Rayleigh distribution for the vertical motion and velocity variances. The Rayleigh distribution reflects the most likely probability distribution of the waves. Using these distributions, the probability density of the largest motion excursion or the minimum $U K C_{\mathrm{Net}_{j}}$ is determined, and its area up to a minimum clearance of zero is calculated.

Under this definition of risk, it is necessary to compute the probability density of the net effective clearance and determine the area up to zero net effective clearance. The net effective clearance, therefore, is defined as the difference between the random variables that make up the effective 
channel depth and the effective vertical displacement of the ship. These random variables are a function of the uncertainty in each of the major parameters that make up the net effective clearance.

Thus, a risk analysis is performed to determine the probability of any one of the critical points of the deep draft vessel touching the channel bottom for inbound and outbound transits. The critical locations on the vessel usually are the bow at the keel, the rudder(s), and the port and starboard bilges at amidships. The risk analysis is performed for each of the wave conditions in wave climatology for the port. The significant wave height, the peak or modal period, primary wave direction, and distribution of energy in frequency and direction (i.e., directional wave spectrum) define the wave condition. The result of the risk analysis provides a probability of the vessel touching the channel bottom under each of the wave conditions for a specified project depth. It is assumed that if the risk is greater than some threshold value (normally 1 in 100) then the channel is inaccessible by the vessel. The days of accessibility of the channel are calculated by determining the persistence of the wave condition that produces the risk of 1 in 100 or greater. The risk calculation is performed for each wave condition and a range of project depths. When complete, the optimum channel depth is the one with the greatest number of days of accessibility per year and the least amount of dredging.

\section{CADET organization}

CADET is the interface to a set of computer programs that calculates $U K C_{N e t}$ and bottom touching risk probability for any number of ships and loading conditions over a range of multiple project depths. CADET manages the necessary internal data flow among the component programs and provides an interface structured in four basic modules for defining and performing calculations and actions relative to (a) Ship, (b) Project, (c) Analyses, and (d) Results. The two input modules for Ship and Project are explained in the following sections (Briggs and Henderson 2011; Briggs et al. 2012).

\section{Ship module}

The first module contains all of the ship parameters to define a ship relative to geometry and loading. Table 2 lists the values used in CADET for the nine categories defining the lightly and fully loaded Susan Maersk ship including (a) static draft and trim, (b) ship speeds, (c) loading parameters, 
Table 2. Input and derived parameters for Susan Maersk containership, CADET ship module.

\begin{tabular}{|c|c|c|c|c|}
\hline Parameter description & Symbol & Units & Light-loaded & Fully loaded \\
\hline \multicolumn{5}{|l|}{ General } \\
\hline Length overall & LOA & $\mathrm{ft}$ & 1138.40 & 1138.40 \\
\hline Length between perpendiculars & $L_{P P}$ & $\mathrm{ft}$ & 1087.93 & 1087.93 \\
\hline Station spacing & & $\mathrm{ft}$ & 54.40 & 54.40 \\
\hline Beam & $B$ & $\mathrm{ft}$ & 140.43 & 140.43 \\
\hline Block coefficient & $C_{B}$ & - & 0.67 & 0.67 \\
\hline Vertical center of buoyancy (ft above baseline) & $V_{C B}$ & $\mathrm{ft}$ & 25.32 & 26.17 \\
\hline Metacentric height & GM & $\mathrm{ft}$ & 1.97 & 2.48 \\
\hline \multicolumn{5}{|l|}{ Drafts } \\
\hline Draft forward & $T_{\text {Fwd }}$ & $\mathrm{ft}$ & 46.0 & 47.5 \\
\hline Fwd draft station (Usually 0) & & - & 0 & 0 \\
\hline Draft aft & $T_{\text {Aft }}$ & $\mathrm{ft}$ & 46.0 & 47.5 \\
\hline Aft draft station (Usually 20) & & - & 20 & 20 \\
\hline Error in Fwd draft & & $\mathrm{ft}$ & 0.1 & 0.1 \\
\hline Error in Aft draft & & $\mathrm{ft}$ & 0.1 & 0.1 \\
\hline \multicolumn{5}{|l|}{ Ship Speeds, knots (Max 8) } \\
\hline Initial & $V_{k}$ & kt & 8 & 8 \\
\hline Final & $V_{k}$ & kt & 16 & 16 \\
\hline Increment & $V_{k}$ & kt & 2 & 2 \\
\hline \multicolumn{5}{|l|}{ Loading } \\
\hline Roll damping factor, fractional percent & $\beta_{44}$ & - & 0.04 & 0.08 \\
\hline Vertical center of gravity (+ up from waterline) & $V_{C G}$ & $\mathrm{ft}$ & 16.8 & 14.7 \\
\hline Longitudinal center of gravity $\left(=L_{C B}\right)$ & $L_{C G}$ & $\mathrm{ft}$ & 563.03 & 563.71 \\
\hline Roll Gyradius, $0.41 * B$ & k4 & $\mathrm{ft}$ & 57.60 & 57.60 \\
\hline Pitch Gyradius, $0.25 * L_{P P}$ & $k_{6}$ & $\mathrm{ft}$ & 272.0 & 272.0 \\
\hline Motion Risk Parameter (0.01 typical) & $\alpha$ & - & 0.01 & 0.01 \\
\hline \multicolumn{5}{|l|}{ Water Depths } \\
\hline Initial & $h$ & $\mathrm{ft}$ & 50 & 50 \\
\hline Final & $h$ & $\mathrm{ft}$ & 64 & 64 \\
\hline Increment & $h$ & $\mathrm{ft}$ & 1 & 1 \\
\hline \multicolumn{5}{|l|}{ Wave Frequencies (max of 30) } \\
\hline Initial & $f_{\text {Init }}$ & $\mathrm{Hz}$ & 0.02 & 0.02 \\
\hline Final & $f_{\text {Final }}$ & $\mathrm{Hz}$ & 0.60 & 0.60 \\
\hline Increment & $f_{\text {Inc }}$ & $\mathrm{Hz}$ & 0.02 & 0.02 \\
\hline
\end{tabular}




\begin{tabular}{|c|c|c|c|c|}
\hline Parameter description & Symbol & Units & Light-loaded & Fully loaded \\
\hline \multicolumn{5}{|l|}{ Sinkage and trim (Squat) } \\
\hline Filename: Squat-BNT_ & & - & 33744S.dat & 48W6L3.dat \\
\hline Channel width & W & $\mathrm{ft}$ & 600 & 600 \\
\hline Outer water depth (-1=uniform depth) & Hout & $\mathrm{ft}$ & -1 & -1 \\
\hline Error in underway sinkage & & $\mathrm{ft}$ & 0.1 & 0.1 \\
\hline Error in underway trim angle & & deg & 0.01 & 0.01 \\
\hline \multicolumn{5}{|c|}{ Critical Point Locations, Primary Points (bottom touching offset 0.0 ) } \\
\hline \multicolumn{5}{|l|}{ Point Bow } \\
\hline X (Station) & $x$ & - & 0 & 0 \\
\hline $\mathrm{Y}(+$ port $)$ & $Y$ & $\mathrm{ft}$ & 0 & 0 \\
\hline Z (+ up from baseline) & $Z$ & $\mathrm{ft}$ & 0 & 0 \\
\hline \multicolumn{5}{|l|}{ Point Port Rudder } \\
\hline $\mathrm{X}$ (Station) & $x$ & - & 20 & 20 \\
\hline $\mathrm{Y}(+$ port $)$ & $Y$ & $\mathrm{ft}$ & 0 & 0 \\
\hline Z (+ up from baseline) & $Z$ & $\mathrm{ft}$ & 0 & 0 \\
\hline \multicolumn{5}{|c|}{ Point Stbd Rudder (repeat above since only 1 rudder in center) } \\
\hline X (Station) & $x$ & - & 20 & 20 \\
\hline$Y(+$ port $)$ & $Y$ & $\mathrm{ft}$ & 0 & 0 \\
\hline Z (+ up from baseline) & $Z$ & $\mathrm{ft}$ & 0 & 0 \\
\hline \multicolumn{5}{|l|}{ Point Port Bilge } \\
\hline X (Station) & $x$ & - & 10 & 10 \\
\hline$Y(+$ port $)$ & $Y$ & $\mathrm{ft}$ & 69.8 & 70.2 \\
\hline Z (+ up from baseline) & $Z$ & $\mathrm{ft}$ & 0 & 0 \\
\hline \multicolumn{5}{|l|}{ Point Stbd Bilge } \\
\hline X (Station) & $x$ & - & 10 & 10 \\
\hline$Y(+$ port $)$ & $Y$ & $\mathrm{ft}$ & -69.8 & -70.2 \\
\hline Z (+ up from baseline) & $Z$ & $\mathrm{ft}$ & 0 & 0 \\
\hline \multicolumn{5}{|l|}{ Alternate Points (User selects up to 4) } \\
\hline \multicolumn{5}{|l|}{ Point Alternate 1 (Center keel) } \\
\hline $\mathrm{X}$ (Station) & $x$ & - & 10 & 10 \\
\hline $\mathrm{Y}(+$ port $)$ & $Y$ & $\mathrm{ft}$ & 0 & 0 \\
\hline Z (+ up from baseline) & $Z$ & $\mathrm{ft}$ & 0 & 0 \\
\hline
\end{tabular}

(d) motion risk parameter, (e) water depths, (f) wave frequencies, (g) sinkage and trim, (h) critical point locations, and (i) ship motion transfer functions. 
The most critical input is the ship geometry file that is represented by the "ship lines" drawing. Ships are defined by a hull geometry file that is independent of loading conditions. The geometry file represents the ship in terms of hull offsets, from the keel to the deck-at-edge, at 21 equally spaced stations between the forward and aft perpendicular. These geometry data files can be prepared externally and imported into CADET, or they can be created using a built-in graphical geometry editor. The spacing between these 21 stations is determined by the ship's waterline length or the length between the forward and aft perpendiculars, $L_{p p}$. The ship's beam, $B$, represents the width at the waterline. It is a deterministic geometric parameter that is used to document the ship and to calculate some hydrostatic properties. The offsets do not necessarily have to correspond to $B$ exactly as CADET calculates beam at the waterline using the offsets in the ship lines.

\section{Draft and Ship Speed}

The static draft and trim are defined at either (a) the forward, $T_{F P}$, and aft, $T_{A P}$, perpendiculars or (b) draft at some longitudinal position and a trim angle in degrees. Up to eight ship speeds in knots can be entered. These speed values must be whole integers.

\section{Loading}

Multiple loading conditions can be defined for each ship in CADET. The ship loading parameters that affect the three vertical motions of heave, pitch, and roll include (a) longitudinal center of gravity, $L_{C G}$, (b) vertical center of gravity, $K G$, (c) roll damping factor, $\beta_{44}$ (fraction of critical damping), (d) roll mass radius of gyration, $k_{4}$, and (e) pitch mass radius of gyration, $k_{6}$.

Static equilibrium is based on Archimedes Principle where the weight, $W_{s}$, of the ship and cargo is balanced by the weight, $\mathrm{W}_{B}$, of the water displaced by the ship. The longitudinal center of gravity, $L_{C G}$, is usually located midway along the longitudinal axis of the ship. The center of buoyancy is the center of gravity of the fluid displaced by the ship. In the static condition, the longitudinal center of buoyancy, $L_{C B}$, is coincident with the $L_{C G}$. The vertical center of gravity, $K G$, is located along the vertical axis of the ship, approximately midway, as measured from the keel. 
In CADET the vertical center of gravity, $V_{C G}$, is defined differently and is entered as a vertical location relative to the waterline (positive up) that varies with the type of ship. Containerships have positive values of approximately 5 to $15 \mathrm{ft}$ since their cargo is stacked on top of the deck as well as in the holds.

CADET requires the roll damping factor, $\beta_{44}$, to account for the ship's dynamic roll characteristics. This factor is the fraction of critical damping and is typically equal to 0.08 to as large as 0.4 for containerships. The mass distribution properties of the ship are defined by the roll and pitch gyradii, $k_{4}$ and $k_{6}$, approximations given by

$$
\begin{aligned}
k_{4} & =0.41 B \\
k_{6} & =0.25 L_{p p}
\end{aligned}
$$

Motion risk parameter $\alpha$

As previously described, the motion risk parameter, $\alpha$, typically has a value of 0.01 for most design applications.

CADET sinkage and trim

The CADET sinkage and trim or squat module is discussed in Chapter 4 with the PIANC and Ankudinov ship squat formulas.

\section{Critical point locations}

The critical point locations $(j)$ previously discussed correspond with the five primary control points. They are located on the centerline at the $T_{F P}$ and $T_{A P}$ to examine the effects of pitch at the bow and rudder(s) and along the port and starboard bilge to include the effects of roll.

\section{Wave frequencies}

A total of 30 wave frequencies are input to define the range of frequencies containing significant wave energy that will be used to calculate the ship motion transfer functions or Response Amplitude Operators (RAOs) for heave, pitch, and roll. The user should input initial, final, and increment values of frequency in Hz. Although the RAOs at a particular frequency can be interpolated to match the specific wave frequency in the project module, it is important that the final frequency value matches the highest 
frequency with significant wave energy to insure highest accuracy in the RAOs. These RAOs are used in Equation 3 to determine the CADET predictions.

\section{Ship motion transfer functions}

Finally, ship motion heave, pitch, and roll RAOs are calculated using a frequency-domain, shallow water, strip-theory program SCORES (Kaplan 1996a and b). In a manner similar to that used to calculate sinkage and trim, CADET generates SCORES input files from the defined hull geometry, draft and trim, ship speeds, water depths, roll damping coefficient, and wave frequencies. SCORES is run in the background by CADET, and the motion transfer functions are extracted from the SCORES output files. The extracted transfer functions are written to compressed binary files for later use in determining the $A_{j}$ from Equation 4. Plotting of the transfer functions can be performed with different representations as needed (real/imaginary or amplitude/phase versus frequency, frequency of encounter, or nondimensional wave length).

\section{Project module}

A project in CADET includes channel reaches, waves, ships, tides, and comments. While CADET keeps track of all of these direct and logical associations between projects, channel reaches, wave spectra, ships, loading conditions, and sinkage and trim data, the user is responsible for ensuring that these associations are coherent.

\section{Reaches}

Reaches should be defined whenever the depth, width, cross-section, or alignment of the channel changes significantly. Reach input includes (a) reach number, (b) description, (c) length, (d) direction, (e) width, (f) bottom type, (g) begin depth, (h) terminal depth, (i) increment depth, (j) outer water depth, (k) over-dredge, (l) dredge variability, and (m) wave coefficient of variation. Table 3 lists the channel particulars for Ambrose Channel. Included are group ID, reach number, wave ID, reach ID, length, and alignment angle. Additional parameters required by CADET are also listed.

Reach numbers are automatically increased as new reaches are added. The description, bottom type (i.e., sandy, rock, etc.) and width (feet) are purely for documentation. The length input is in nautical miles. The reach 
direction is in degrees measured clockwise from north as with a compass. The beginning, terminal, and increment depth are in feet and should correspond with the water depths selected in the ship module used to calculate ship squat (Chapter 4) and RAOs. The outer water depth can be defined as a fixed or variable value for the range of water depths. A "-1" in this parameter will insure that an unrestricted channel cross-section is used for all depths. The next two inputs account for bottom variability. Over-dredge is the amount of additional clearance assumed due to advance maintenance or dredging tolerance. Typical values are $2 \mathrm{ft}$. The dredge variability is a tolerance for dredging execution to account for unevenness (i.e., nonhorizontal level) of the bottom. While the project depth is assumed to be flat with no variability or unevenness, a typical value of $0.85 \mathrm{ft}$ is specified for the over-dredge variability. The wave coefficient of variation is an indication of the reliability of the waves with a typical value of 0.4 .

Table 3. Ambrose Channel parameters.

\begin{tabular}{|c|c|c|c|c|c|c|}
\hline \multirow[b]{2}{*}{ Group ID } & \multirow{2}{*}{$\begin{array}{l}\text { Reach } \\
\text { No. }\end{array}$} & \multirow{2}{*}{$\begin{array}{l}\text { Wave } \\
\text { ID }\end{array}$} & \multirow[b]{2}{*}{ Reach ID } & \multicolumn{2}{|c|}{ Length } & \multirow{2}{*}{$\begin{array}{l}\text { Angle } \\
\text { (deg) }\end{array}$} \\
\hline & & & & (ft) & (NM) & \\
\hline \multirow{2}{*}{$\begin{array}{l}\text { Phase } 1 \\
211 \text { waves }\end{array}$} & 1 & $100-311$ & Channel & 2,000 & 0.33 & 117 \\
\hline & 2 & $400-611$ & Mound & 2,000 & 0.33 & 105 \\
\hline \multirow{2}{*}{$\begin{array}{l}\text { Phase } 2 \\
24 \text { waves }\end{array}$} & 1 & $119-309$ & Channel & 2,000 & 0.33 & 117 \\
\hline & 2 & $419-609$ & Mound & 2,000 & 0.33 & 105 \\
\hline
\end{tabular}

Notes:

1. Phase 1 consists of 211 waves.

2. Phase 2 consists of 24 waves.

3. Angle = channel alignment relative to outbound vessel, clockwise from north. For channel reach, Angle = $297 \mathrm{deg}-180 \mathrm{deg}=117 \mathrm{deg}$ since channel is aligned with NW/SE. For mound reach, Angle = 105 deg as aligned with straight path toward main Ambrose Channel from mound area.

4. Channel width $=2,000 \mathrm{ft}$.

5. Effective depth variability $=0.1 \mathrm{ft}$.

6. Bottom type $=$ sandy for channel reach and hard for mound reach.

7. Depth increment $=1 \mathrm{ft}$.

8. Overdredge allowance $=2 \mathrm{ft}$ for channel reach and $0 \mathrm{ft}$ for mound reach.

9. Dredge variability $=0.85 \mathrm{ft}$.

10. Wave coefficient of variability $=0.4$.

11. Risk level $=0.01$.

Waves

CADET requires directional wave spectra to predict vertical ship motions. The user can input one or more files as necessary for the project goals. In the typical application of CADET for design life predictions, it is customary to use something like a $20 \mathrm{yr}$ hindcast. The Wave Information Study (WIS) 
is a good source of data for coasts around the US (http://chl.erdc.usace.army. mil/wis). The user selects the WIS station that is closest to the project site and sorts it into joint distribution tables of wave height and period for fixed wave directions. The WIS outputs data in $22.5 \mathrm{deg}$ bins, so this is a good directional increment to use in CADET (although other values can be used). If the WIS station is greater than approximately $5 \mathrm{~nm}$ from the project site, the data should be transformed to the site. Also, if the channel is long, waves may transform from one end to the other, so the STWAVE type of program can be used to predict ratios relating incident wave conditions to output stations along the reaches of the channel (Stauble et al. 2001, Thompson 2002). Except for reflections, waves do not travel offshore from land. Therefore, the user can reduce the number of waves in this database by eliminating waves that are not possible due to blockage from land features. Wave directions should cover the full directional exposure of the channel.

Once the 20 yr hindcast database has been transformed to the project site, a final post-processing step is performed to compute statistical information. In this case, the user will want to minimize the number of individual cases according to combinations of wave height, period, and direction that are representative of the site and would significantly influence ship motions. Since deep-draft ships are relatively large, one might want to limit the number of waves to those with longer wave periods and larger wave heights that would actually affect the vertical ship motions. One might think that since the largest vertical ship motions occur for wave periods that coincide with the natural oscillation periods in heave, pitch, and roll that are typically of the order of $8 \mathrm{sec}$ or larger, it is reasonable to ignore wave spectra with peak wave periods below 5 or $6 \mathrm{sec}$. Similarly, one might think that it is reasonable to ignore the insignificant ship motions due to waves with heights less than 2 to $3 \mathrm{ft}$. Of course, this would be dependent on the size of the ship(s) in the study.

However, a better procedure is to retain all of the data, but set up "bins" for the sorting that tend to isolate the "tails" data on the low and high ends of wave period and height. The CEDAS (Coastal Engineering Design and Analysis System) has a NEMOS (Nearshore Evolution Modeling System) program that does sorting for joint distributions of wave period and height for fixed wave directions (NEMOS 2000). For instance, since the bins do not have to be evenly spaced, one can set up the lower and upper wave period and wave height bins to include relatively extreme or rare events in period and height. For instance, the lower wave period bin could include all 
wave periods from o to $5 \mathrm{sec}$. The upper wave period bin might include all periods between 17 and $23 \mathrm{sec}$, or whatever high period limit is contained in the dataset. Similarly for wave heights, bin size can be $2 \mathrm{ft}$ for the smaller waves with an upper bin to include all waves between 20 and $30 \mathrm{ft}$. Again, the number and increments for the bins should be based on the minimum and maximum values for the entire dataset. The NEMOS reports the distributions in percent and number of occurrences. The program has the option to report the mean values for each bin, so these should be used in building the wave parameter statistics for generating the empirical directional wave spectra. The number of occurrences relative to the total provides the wave probabilities for CADET. A good rule of thumb is to ignore bins that have less than 0.05 percent of the total number of occurrences as these represent very rare events on both low and high ends of the dataset. As mentioned previously, wave direction can be limited by the land features to include lower and upper directions that are possible. A fixed increment like $\mathbf{2 2 . 5}$ deg is a reasonable value although other values are also acceptable.

One of the main features in CADET is its risk-based predictions of $U K C_{\text {Net }}$. The wave climatology for each reach is composed of the set of directional wave spectra and their associated probability of occurrence. This probability is converted into the number of days per year that each of the individual wave components contributes to the total wave environment. The total of all wave probabilities should equal 1.0 or 365 days. However, the total can be less than these values since missing values are assumed to represent wave conditions that are either (a) small and not a concern for safe navigation or (b) conditions that are very rare and do not represent more than 0.05 percent of the total number of observations. The small waves, or calm water, could represent a substantial part of the year, (i.e., 208 calm water days in Ambrose Channel).

\section{Empirical directional wave spectrum}

In CADET, the directional wave spectrum, $S(f, \theta)$, is typically created using empirical formulas for the frequency spectrum, $\mathrm{S}(\mathrm{f})$, and the directional spreading function, $\mathrm{D}(\mathrm{f}, \theta)$, given by

$$
S(f, \theta)=S(f) D(f, \theta)
$$

It must satisfy the constraints that 


$$
S(f)=\sum_{0}^{2 \pi} S(f, \theta) \Delta \theta \quad ; \quad \sum_{0}^{2 \pi} D(f, \theta) \Delta \theta=1
$$

The TMA (Texel, MARSEN, ARSLOE) is a shallow-water spectral form (Bouws et al. 1985) for $S(f)$ that characterizes waves generated in deepwater which have propagated into shallow water. The TMA spectral parameters are the same as those in the more widely known JONSWAP (Joint North Sea Wave Program) deepwater spectrum. The TMA spectrum reduces to the JONSWAP spectrum in the deepwater limit. The TMA is defined as

$$
S(f)=\frac{\alpha g^{2}}{(2 \pi)^{4} f^{5}} \Phi(2 \pi f, h) e^{a} \gamma^{b}
$$

where:

$$
\begin{aligned}
\alpha & =\text { Phillip's constant (defined below) } \\
g & =\text { gravitational acceleration } \\
f & =\text { frequency } \\
f_{p} & =\text { peak spectral frequency } \\
h & =\text { water depth } \\
\Phi(2 \pi f, h) & =\text { function of frequency and depth } \\
\gamma & =\text { peak enhancement factor } \\
a, b & =\text { functions of frequency and peak spectral frequency. }
\end{aligned}
$$

Procedures for estimating $\alpha$ and $\gamma$ are discussed by Hughes (1984), Briggs (1988), and Briggs et al. (1987). The value for the Phillips constant $\alpha$ (1957) is calculated using an iterative procedure that compares the target wave height to the calculated value for a required tolerance. The parameter $\gamma$ controls the width of the frequency spectrum (small values give broad frequency peaks and large values give narrow peaks). Comparing sea and swell wave components, swell tends to have longer wave periods and correspondingly narrower frequency-space spectra. Table 4 provides some guidance in the selection of $\gamma$ based on wave period (Thompson et al. 1996).

The directional spreading function, $D(f, \theta)$, can be approximated using several different empirical formulas. One of the simplest is a $\cos ^{\mathrm{n}} \theta$ directional distribution (Borgman 1990; Smith et al. 2001a). It is given by

$$
D(f, \theta)=\frac{1}{\mathrm{C}} \cos ^{n}\left(\frac{\theta-\theta_{m}}{2}\right)
$$


Table 4. TMA spectral peakedness $y$ and directional spreading $n$ parameters.

\begin{tabular}{|l|l|l|}
\hline$T_{p, \text { sec }}$ & $V$ & $n$ \\
\hline$\leq 10$ & 3.3 & 4 \\
\hline 11 & 4 & 8 \\
\hline 12 & 4 & 10 \\
\hline 13 & 5 & 12 \\
\hline 14 & 5 & 16 \\
\hline 15 & 6 & 18 \\
\hline 16 & 6 & 20 \\
\hline 17 & 7 & 22 \\
\hline 18 & 7 & 26 \\
\hline 19 & 8 & 28 \\
\hline 20 & 8 & 30 \\
\hline
\end{tabular}

where:

$$
\begin{aligned}
C= & \text { conversion constant to insure that the constraint in Equation } 7 \\
& \text { is satisfied } \\
\theta= & \text { direction of the spectral component } \\
\theta_{m}= & \text { peak or dominant direction of the spectral component. }
\end{aligned}
$$

The SCORES module in CADET requires that $\theta$ be in twenty-four $15 \mathrm{deg}$ increments from o to $345 \mathrm{deg}$. The $n$ is the even-numbered exponent that determines the width of the directional spreading. As for frequency spreading, a small $n$ gives broader directional spreading and a large $n$ gives narrower spreading. Guidance as a function of wave period is provided in Table 4. Calculation of the directional-wave spectra from the WIS $20 \mathrm{yr}$ hindcast is described in Chapter 5 .

Ships

Multiple ships and loading conditions can be selected for each reach in a project in CADET. Thus, several types of "design" ships can be included in the overall evaluation of $U K C_{N e t}$ and channel accessibility. Since ship squat (i.e., sinkage and trim) is influenced by the channel cross-section, the user can accommodate changes in reach bathymetry by specifying different squat files for different reaches for the same ship. The light- and fully loaded Susan Maersk ships were used in this study. They were combined with the appropriate ship squat (i.e., sinkage and trim) from the CADET BNT ship squat module. A description of this program is contained in Chapter 4 . 


\section{Numerical Wave Models}

This chapter describes two numerical wave models that were used to examine wave transformation between offshore locations and Ambrose Channel and over the mound. The coastal wave transformation numerical models, STWAVE and CMS-Wave, were applied on a rectangular grid to provide a reliable representation of wave conditions at the entrance to the channel and the mound as well as waves in and along the channel and outside the channel. STWAVE runs on the HPC platforms with parallel processing while CMS-Wave runs more efficiently on a PC with multiple processors. In terms of wave transformation from deepwater to nearshore, both models have similar capabilities (e.g., wind input, wave generation and growth, wave transformation over long fetches, wave shoaling, refraction, breaking, and dissipation).

\section{STWAVE}

\section{Model description}

The purpose of STWAVE (STeady-state spectral WAVE model) is to provide a simple, robust numerical model for simulating nearshore wind-wave growth, propagation, and transformation (Smith 2001; Smith 2007; Smith and Zundel 2006; Smith et al. 1999; and Smith et al. 2001a). It is a finitedifference, phase-averaged spectral wave model based on the wave action balance equation. This directional spectral wave transformation model solves for the spatial variation of steady-state wave energy without the calculation of wave phase. It computes nearshore wave transformation including refraction, shoaling, and breaking as well as wind-wave generation.

STWAVE can operate in two wave transformation modes: half-plane and full-plane. The half-plane mode allows wave energy to propagate only from the offshore towards the nearshore $( \pm 87.5 \mathrm{deg}$ from the $x$-axis of the grid, which is typically the approximate shore-normal direction). All waves traveling in the negative $x$-direction, such as those reflected from the shoreline, steep bottom features, and structures as well as those generated by offshore-blowing winds, are neglected in half-plane simulations. The fullplane mode allows wave transformation and generation on the full 360 deg plane. Table 5 summarizes the features for each mode. Previously mentioned features that are not listed in this table are available in both modes. 
Table 5. Summary of half-plane and full-plane features

\begin{tabular}{|l|l|l|}
\hline Feature & Half Plane & Full Plane \\
\hline Wave transformation and generation on full 360 deg plane & & $\mathrm{x}$ \\
\hline Option for wave-current interaction & $\mathrm{x}$ & \\
\hline Option for direct input of wave parameters to create TMA spectrum & & $\mathrm{x}$ \\
\hline Direction bins restricted to 5 deg & $\mathrm{x}$ & \\
\hline DX and DY grid cell spacing must be the same & $\mathrm{x}$ & \\
\hline Requires iterative criteria & & $\mathrm{x}$ \\
\hline
\end{tabular}

The full-plane option of STWAVE is not intended to be a replacement for the half-plane version, but an addition. The half-plane version requires considerably lower memory requirements, executes faster, and is generally appropriate for most nearshore coastal applications with the exception of semi-enclosed bays and lakes where there is no obvious offshore direction. For these cases, the full-plane version should be applied since it allows wave transformation and generation in all directions. Some STWAVE model options are unique to either half-plane or full-plane mode. The primary output parameters from STWAVE are wave height, period, and direction. The calculated directional wave spectra, radiation stresses, and wave breaking index information may also be output for circulation modeling.

\section{Capabilities and assumptions}

STWAVE simulates depth-induced wave refraction and shoaling, currentinduced refraction and shoaling, depth- and steepness-induced wave breaking, wind-wave growth, and wave-wave interaction and white-capping that redistributes and dissipates energy in a growing wave field. The governing equations are similar between the half-plane and full-plane modes and also similar to equations used in the CMS-Wave. These will be described in the CMS-Wave section. Additional information about STWAVE and its application is available from related publications (Smith 2001; Smith 2007; Smith and Zundel 2006; Smith et al. 1998 and 1999; Smith et al. 2001a and 2001b; and Thompson 2002).

The basic assumptions made in STWAVE are the following:

1. Phase-averaged. STWAVE is based on the assumption that relative phases of the spectral components are random, and phase information is not tracked. A phase-resolving model should be applied to resolve detailed near-field reflection and diffraction patterns near coastal structures. 
2. Mild-bottom slope and negligible wave reflection. Waves reflected from the shoreline or from steep-bottom features are neglected.

3. Steady-state waves, currents, and winds. STWAVE is formulated as a steady-state model, which reduces computation time and is appropriate for wave conditions that vary slower than the time it takes for waves to transit the domain. For wave generation, the steady-state assumption means that the winds have remained steady sufficiently long for the waves to attain fetch-limited or fully developed conditions (waves are not limited by the duration of the winds).

4. Linear refraction and shoaling. STWAVE incorporates linear wave refraction, shoaling, and propagation, and, thus, does not represent wave asymmetry or other nonlinear wave features. Model accuracy is reduced (e.g., underestimated wave heights) at large Ursell numbers (e.g., nonlinear waves in shallow water).

5. Depth-uniform current. The wave-current interaction in the model is based on a current that is constant throughout the water column; the modification of refraction and shoaling due to strong vertical gradients is not represented.

6. Linear radiation stress. Radiation stress is calculated based on linear wave theory. Contributions of wave roller effects to radiation stresses in the surf zone are neglected.

\section{CMS-Wave}

\section{Model description}

CMS-Wave is similar to STWAVE in some ways and different in other areas because it includes several additional capabilities which are specific to coastal inlets and wave-structure interaction problems. It is a phaseaveraged, half- or full-plane spectral wave model for propagation of directional irregular waves over complicated coastal bathymetry where wave refraction, diffraction, reflection, shoaling, and breaking over currents occur simultaneously (Lin et al. 2008 and 2011). The model, previously called WABED (Wave-Action Balance Equation Diffraction), is part of the Coastal Modeling System (CMS) developed in the Coastal Inlets Research Program (CIRP), US Army Engineer Research and Development Center (ERDC). It solves for the Wave-Action Balance Equation using a forward-marching numerical scheme. The diffraction term is formulated from a parabolic approximation equation (Demirbilek et al. 2009 and Mase et al. 2005a). 


\section{Capability and features}

Because CMS-Wave is designed for coastal inlet applications, it has many special features for waves interacting with coastal inlet structures and adjacent beaches. These include wave reflection, various intensity of diffraction, floating breakwater, caisson, semi-permeable and nonpermeable rubble mound breakwaters, which are in addition to the general features such as wind-wave generation, bottom friction, and grid nesting capabilities. Another important feature of CMS-Wave is its coupling with CMS-Flow, a circulation and sediment transport model in the CMS package, designed to simulate the morphology evolution at inlets, channels, and along beaches. For this reason, additional features such as wave run-up and overtopping on beach face and structures, wave energy damping over muddy beds, nonlinear wave-wave interactions, and spatially varying cell sizes have recently been incorporated into the model. CMS-Wave also has a rapid mode that can reduce the computational runtime when doing long term simulations. Not all of these features were used in this study. Details of these CMS-Wave-specific features are discussed in Appendix A.

\section{Governing equations}

The governing equation for both STWAVE and CMS-Wave is the waveaction balance equation. For CMS-Wave it is defined as

$$
\frac{\partial\left(C_{x} N\right)}{\partial x}+\frac{\partial\left(C_{y} N\right)}{\partial y}+\frac{\partial\left(C_{\theta} N\right)}{\partial \theta}=D(\kappa, \sigma, \theta)-\varepsilon_{b} N-S
$$

where $x$ and $y$ are the horizontal coordinates; $C_{x}, C_{y}$, and $C_{\theta}$ are the characteristic velocity with respect to $x, y$, and $\theta$, respectively; $\varepsilon_{b}$ is the parameterization of wave breaking energy dissipation; and $S$ denotes additional source, $S_{i n}$, and sink, $S_{d s}$ (e.g., wind forcing, bottom friction loss, etc.) and a nonlinear wave-wave interaction term, $S_{n l}$.

The wave-action density, $N$, a function of frequency, $\sigma$, direction, $\theta$, and spectral wave energy density, $E(\sigma, \theta)$, is defined as

$$
N=\frac{E(\sigma, \theta)}{\sigma}
$$

where $E(\sigma, \theta)$ represents the wave energy per unit water-surface area per frequency and direction interval. In the presence of an ambient current, 
the wave-action density is conserved whereas the spectral wave density is not (Bretherton and Garrett 1968; Whitham 1974).

The first term $D(\kappa, \sigma, \theta)$ on the right side of Equation (10) is the wave diffraction term developed by Mase (2001). It takes into account the effect of an ambient horizontal current on waves. In CMS-Wave it is defined as

$$
D(\kappa, \sigma, \theta)=\frac{\kappa}{2 \sigma}\left[\left(C C_{g} \cos ^{2} \theta N_{y}\right)_{y}-\frac{C C_{g}}{2} \cos ^{2} \theta N_{y y}\right]
$$

where $\kappa$ is an empirical parameter representing the intensity of diffraction; $C$ and $C_{g}$ are wave celerity and group velocity, respectively; and $N_{y}$ and $N_{y y}$ denote the first and second derivatives of $N$ with respect to $y$, respectively. Wave diffraction is not modeled but simply approximated in STWAVE by a diffusion term (e.g., an arithmetically smoothed function of the wave heights at the three cells closest to the structure).

Thus, both wave diffraction and energy dissipation are included in the governing equation. Implementation of the numerical scheme in CMS-Wave is described by Mase (2001), Mase et al. (2005a), and Lin et al. (2008). Additional details on the wave theory in CMS-Wave are presented in Appendix A.

\section{Model setup and parameters}

Both STWAVE and CMS-Wave were run on the same rectangular grid using the half-plane versions of models to reduce the computational time. The same grid files and input files were used in both models. Figure 4 shows the model domain and bathymetry contours for Ambrose Channel and the mound. The model grid covers a rectangular area of $25 \mathrm{~km} \times 40 \mathrm{~km}$ with the long axis along the Ambrose Channel. It consists of $1000 \times 1600$ cells with constant cell spacing of $25 \mathrm{~m} \times 25 \mathrm{~m}$. The Ambrose Channel Entrance is located approximately in the center of the domain with the main channel running toward the northwest corner of the grid that leads to Port of New York/New Jersey. The submerged mound is located $1 \mathrm{~km}$ east of the Ambrose Channel Entrance.

Figure 5 shows the bathymetry contours of the submerged mound. Wind and water level input were not included in the present modeling so the local wave generation and tides are not simulated. The vertical datum is specified as Mean Sea Level (MSL). 
Figure 4. Wave transformation modeling domain for Ambrose Channel and mound (a) Google image and (b) STWAVE and CMS-Wave grid.

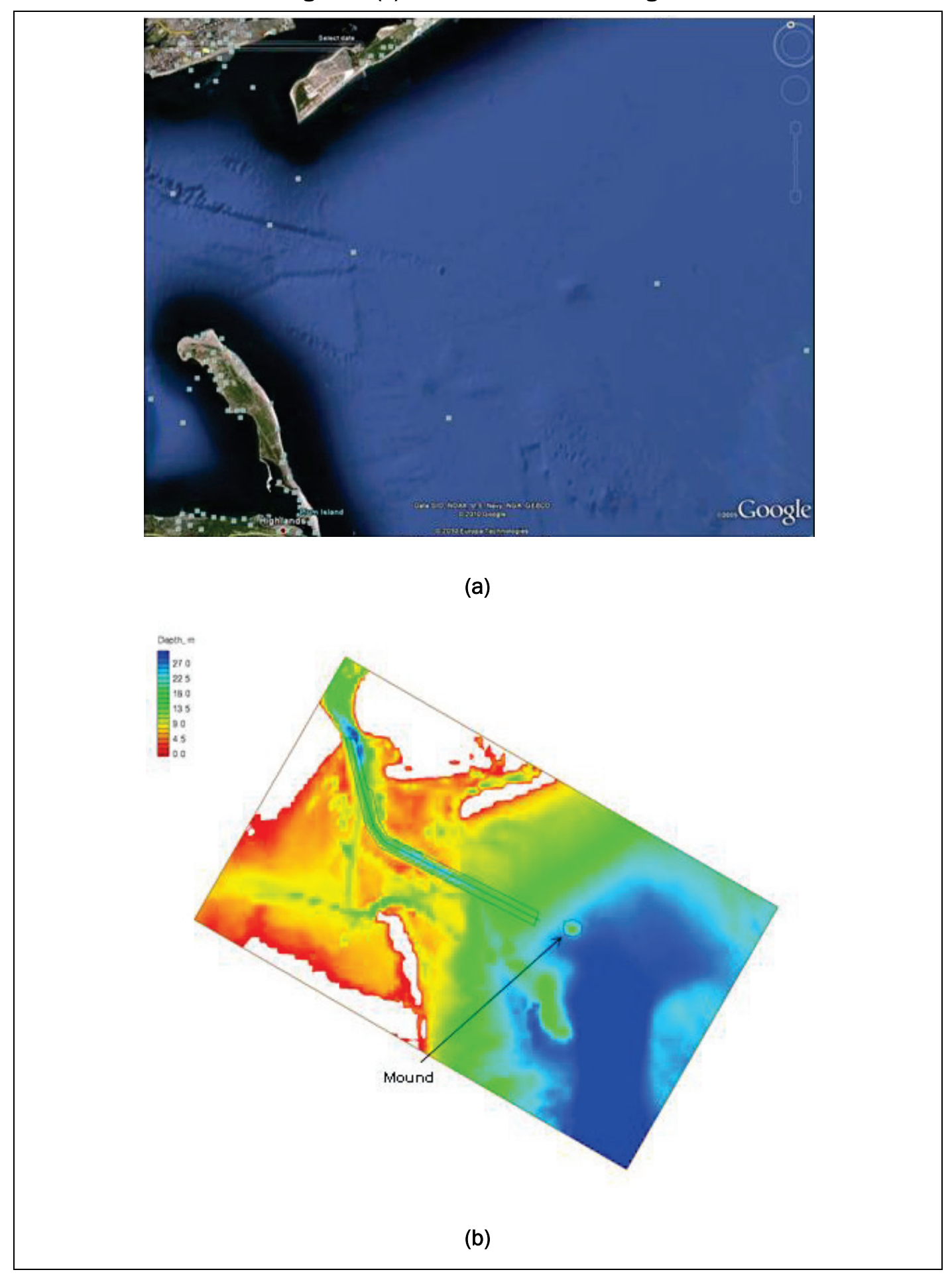


Figure 5. Mound reach bathymetry.

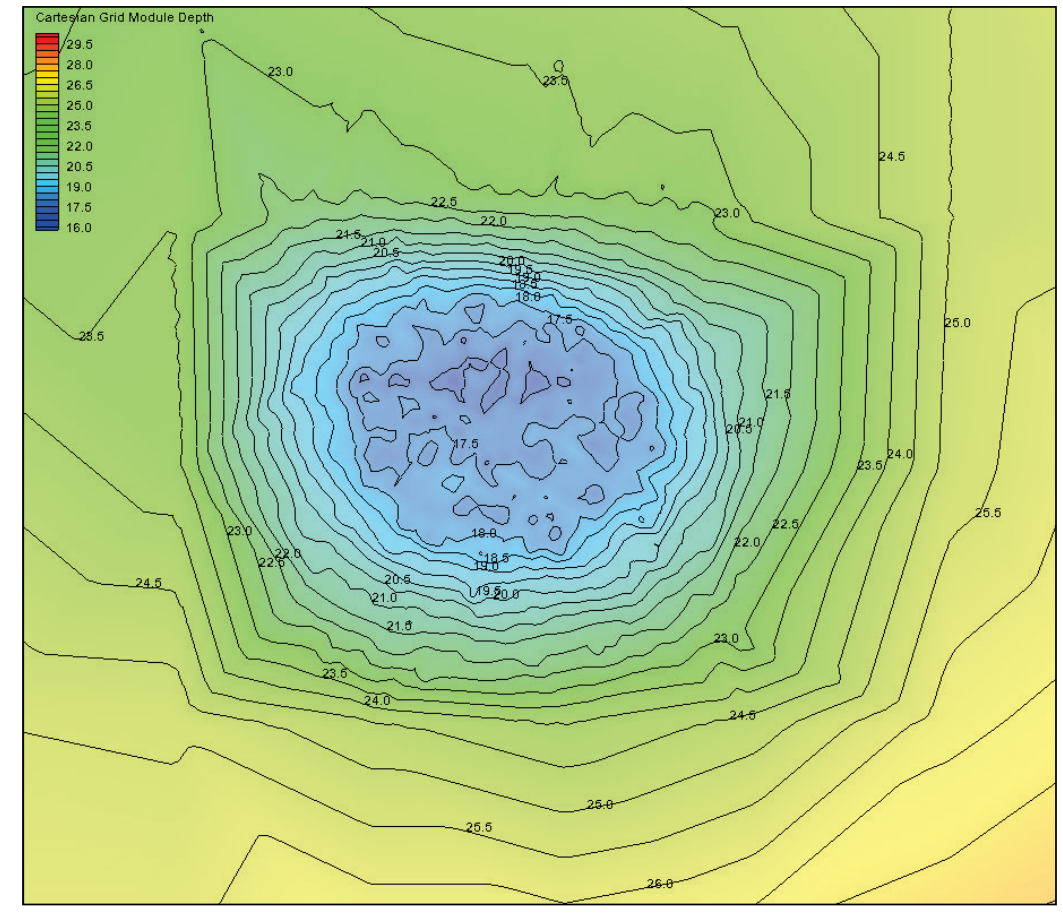

The default parameters were used (Appendix A) with the Extended Goda wave-breaking formula and a diffraction intensity of $\kappa=4$. A constant Darcy-Weisbach type friction coefficient of $c_{f}=0.005$ (default value) was specified to calculate the bottom friction. Wave propagation and transformation were computed on a spectral grid of 30 frequency bins (0.04 to $0.33 \mathrm{~Hz}$ with $0.01 \mathrm{~Hz}$ increment) and 35 direction bins (covering a half-plane with $5 \mathrm{deg}$ spacing). Incident wave information is provided along the sea boundary based on design wave conditions as the half-plane TMA directional spectrum. The Surface-water Modeling System (SMS) provides the interface for creating CMS-Wave and STWAVE grid which allows preparing model input parameters and generating the incident wave spectrum (Zundel 2006).

\section{Summary}

Two coastal wave transformation numerical models, STWAVE and CMSWave, were used to calculate wave parameters (height, period, and direction) at the entrance of the Ambrose Channel and over the mound in the vicinity. These directional spectral wave models were applied in the halfplane wave transformation mode, meaning that wave energy transformation was limited from offshore toward the coastline in a o to 180 deg sector of the primary incident wave direction in deep water. The reason for using two 
wave models is because STWAVE is adequate for the nearshore wave transformation outside the surf zone while CMS-Wave is designed specifically for navigation channels, and inlet and bay applications involving processes where waves interact with tides, currents, navigation channels, muddy bottoms, and coastal structures such as breakwaters, jetties, spurs, and groins. The results from both models were very similar. The main purpose of the wave modeling was to evaluate the wave refraction deformation, shoaling, and wave focusing at and in the lee of a submerged mound just east of the Ambrose Channel Entrance. Wave input information was based on design wave conditions and prepared by SMS to generate directional spectrum as input at the model grid sea boundary. Results obtained from these wave models are described in Chapter 5 . 


\section{Ship Squat Theory}

Ship squat for the lightly and fully loaded Susan Maersk containership in the Ambrose Channel and Mound ranges are compared for PIANC, Ankudinov, and CADET/BNT predictions. Because of the width of both channels, they are modeled as an "open" or unrestricted channel crosssection in this study as it is assumed that the effect of the trench will be minimal on the predicted squat, and any variability is included by using the average of all the squat predictors.

\section{PIANC squat formulas}

PIANC has many empirical formulas for predicting ship squat in entrance channels. Each formula has certain constraints based on the ship and channel conditions for which they were developed. No one formula works best for all channel and ship types. Thus, it is necessary to examine the squat predictions with more than one formula and compare the results based on the type of ship, channel, and formula constraints.

Five of the most "user friendly" and "popular" PIANC squat formulas include those of Barrass (2009), Eryuzlu et al. (1994), Huuska (1976), Römisch (1989), and Yoshimura (1986). Briggs (2006) programmed these formulas in a FORTRAN program, and PIANC (2013) provided updates. All of these formulas give predictions of bow squat $\left(S_{b}\right)$, but only the Römisch method explicitly gives predictions for stern squat $\left(S_{s}\right)$ for all channel types. Barrass gives $S_{s}$ for unrestricted channels (U), and for canals (C), and restricted (R) channels depending on the value of $C_{B}$. Of course, for channel design, maximum squat is the most important, and location at the bow or stern is not necessarily significant.

\section{Ankudinov squat formula}

The Ankudinov squat formulas are much more complicated than the PIANC squat formulas and were originally used in the Ship Tow Simulator (STS). The older versions in the STS tended to overpredict ship squat (Briggs 2009). However, recent modifications have given more realistic predictions that are comparable with the PIANC predictions (Briggs and Daggett 2009). Ankudinov squat predictions account for the effects of both ship and channel. Initial ship trim has recently been shown by 
German researchers (Härting et al. 2009) to be an important consideration in dynamic trim and resulting ship squat. Ankudinov includes mid-point sinkage and initial trim in his predictions.

Ankudinov and Jakobsen (1996) and Ankudinov et al. (1996 and 2000) proposed the MARSIM 2000 formula for maximum squat based on a midpoint sinkage $S_{m}$ and vessel trim $T_{r}$ in shallow water. The Ankudinov method has undergone considerable revision as new data was collected and compared. The most recent modifications from a study of ship squat in the St. Lawrence Seaway (Stocks et al. 2002) and emails and telecons in April 2009 (Ankudinov 2009 ${ }^{1}$ ) are contained in the FORTRAN programs.

The Ankudinov prediction is one of the most thorough but also the most complicated formulas for predicting ship squat. These components include factors to account for the effects of the ship and channel. The restriction on Depth Froude Number, $F_{n h}$, is for values less than or equal to 0.6. The maximum ship squat, $S_{M a x}$, is a function of two main components: the midpoint sinkage, $S_{m}$, and the vessel trim, $T_{r}$, given by

$$
S_{\text {Max }}=L_{p p}\left(S_{m} \mp 0.5 T_{r}\right)
$$

The $S_{\text {Max }}$ can be at the bow or stern depending on the value of $T_{r}$. The negative sign in the equation above is used for bow squat, $S_{b}$, and the positive sign for stern squat, $S_{s}$.

\section{CADET sinkage and trim}

Underway sinkage and trim may be provided externally by calculations or model test data and imported into CADET. Alternatively, it can be calculated within CADET using the BNT (Beck, Newman, and Tuck) potential flow program by Beck et al. (1975). Although included in CADET, BNT is completely independent and stand-alone. The user has the option to import squat data from other programs as long as the input format is the same. Since channel geometry can vary from reach to reach, CADET supports the ability to define multiple sets of sinkage and trim data sets for the same ship and loading condition.

\footnotetext{
1 Per discussion via telecoms and emails with Briggs.
} 
The BNT sinkage and trim prediction program is based on early work by Tuck (1966), investigating the dynamics of a slender ship in shallow water at various speeds for an infinitely wide channel and for a finite width channel such as a canal (Tuck 1967). This work was expanded to include a typically dredged channel with a finite-width inner channel of a certain depth and an infinitely wide outside channel of shallower depth (Beck et al. 1975).

Figure 6 is a schematic of the simplified channel cross-section used in BNT. In addition to the automatically specified inside-channel depth, $H$, the user has the option to include the channel width, $W$, and outside channel depth, $H_{\text {out }}$ (i.e., similar to PIANC $h_{T}$ trench height for restricted channels but measured from the water surface to the top of the trench). For unrestricted channel applications, the user can input "-1" in the $H_{\text {out }}$ input space to automatically ensure that the outer depths are equivalent to the inner channel depths regardless of depth increment.

Figure 6. BNT channel geometry variables.

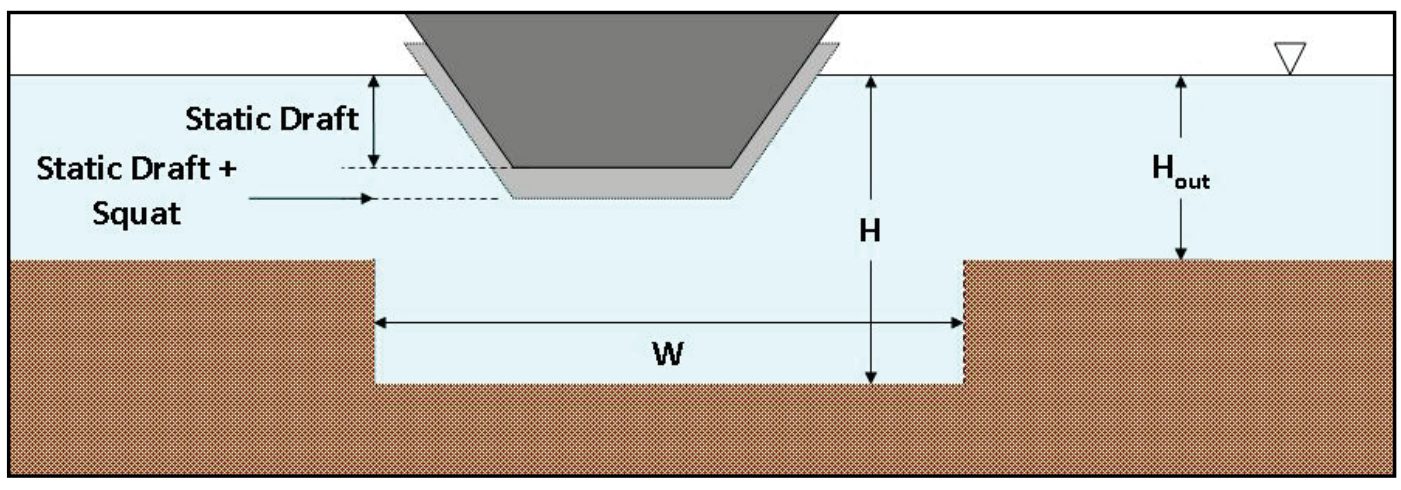

In his early work, Tuck (1966) calculated the dynamic pressure of slender ships in finite-water depth and infinite- and finite-water width by modeling the underwater area of the hull. This underwater area was defined by the 21 equally spaced stations along the ship's length. Therefore, the ship's geometry file, draft, speeds, and water depths are used in the BNT squat calculations. Within this analysis, the fluid is assumed to be inviscid and irrotational and the hull long and slender. Input hull definition is provided in terms of the waterline beam and sectional area at 20 stations along the hull. The dynamic pressure is obtained for each Depth Froude Number $F_{n h}$ by differentiating the velocity potential along the length of the hull. The sinkage and trim predictions are obtained from the dynamic pressure by calculating the vertical force and pitching moment which are translated to vertical sinkage and trim angle. The proper use of this BNT program 
requires that channel depths be of the same order as the draft of the ship, therefore satisfying the shallow-water approximations assumed in Tuck (1966).

The BNT program produces tabular listings and plots of midship sinkage, $S_{\text {Mid }}$, and trim, $T_{R}$, as a function of $F_{n h}$. Sinkage is measured in $\mathrm{ft}$, positive for downward movement. Trim in $\mathrm{ft}$ is the difference between sinkage at the bow and stern, positive for bow down. The equivalent bow, $S_{b}$, and stern, $S_{s}$, squat are given by

$$
\begin{aligned}
& S_{b}=S_{\text {Mid }}+0.5\left(T_{R}\right) \\
& S_{s}=S_{\text {Mid }}-0.5\left(T_{R}\right)
\end{aligned}
$$

This is a simplistic representation of the squat at the bow and stern as it assumes they are equally distant from the midpoint of the ship. In CADET, the squat is calculated for the actual distances to individual control points. 


\section{Waves}

This chapter is divided into two main sections: Phase 1 waves and Phase 2 waves. The Phase 1 waves consisted of 211 directional wave spectra from the WIS hindcast. In this phase, wave transformation between the hindcast site and the Ambrose Channel location was assumed to be insignificant. The entire dataset was used in the CADET predictions of vertical ship motions. Wave transformation was evaluated in the Phase 2 waves section using STWAVE and CMS-Wave numerical models. A subset of 24 waves from the Phase 1 waves was selected for further processing in CADET, based on these transformation results.

\section{Phase 1 waves}

\section{Deepwater hindcast waves}

The $20 \mathrm{yr}$ hindcast wave data for this study were provided by the Wave Information Study (WIS). Figure 7 shows the location of WIS Station 126 (WIS126) that was selected due to its proximity to the Ambrose Channel (Table 6). The WIS hindcast data is provided at 1-hour intervals over the

Figure 7. Locations of WIS126 WIS station and ALSN6 Ambrose Light Station in study area.

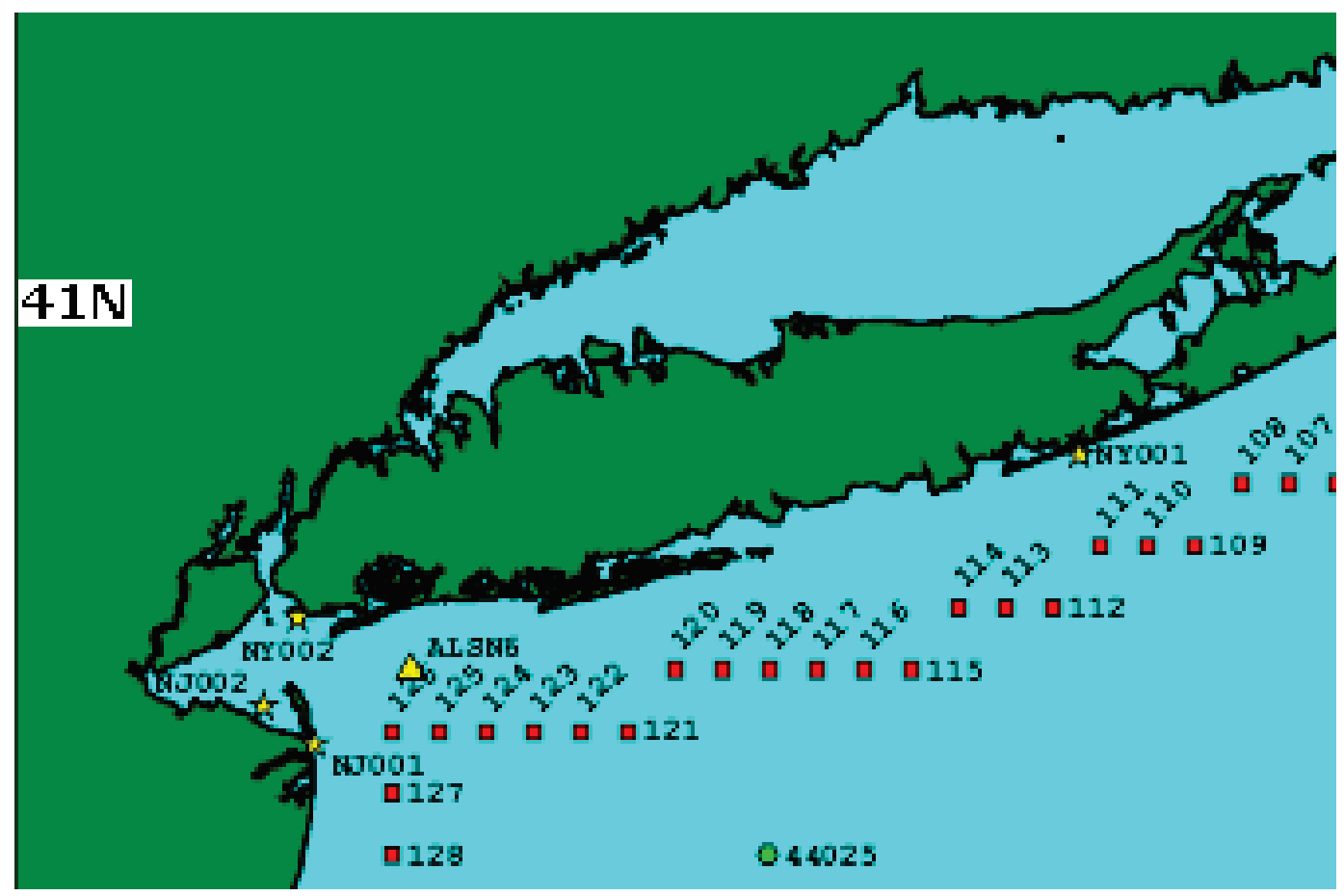


Table 6. Wave climate information.

\begin{tabular}{|l|l|l|l|l|}
\hline Source & Years & $\begin{array}{l}\text { Depth } \\
\text { (ft) }\end{array}$ & $\begin{array}{l}\text { Latitude } \\
\text { (deg N) }\end{array}$ & $\begin{array}{l}\text { Longitude } \\
\text { (deg W) }\end{array}$ \\
\hline WIS126 & $1980-1999$ & 68.9 & 40.42 & -73.83 \\
\hline
\end{tabular}

$20 \mathrm{yr}$ time period. It includes significant wave height, $H_{s}$, peak period, $T_{p}$, and peak direction, $\theta_{p}$. The $\theta_{p}$ represents the dominant wave direction for wave energy within the frequency band of peak energy. Wave directions in degrees are directions from which the waves are traveling, the same as meteorological conventions.

Figure 8 is a percent occurrence histogram of wave direction, period, and height. Direction bands are in $22.5 \mathrm{deg}$ increments from o to $360 \mathrm{deg}$. The numbers on top of the bars are the percentages or number of occurrences, and the numbers on the bottom of the bars are the mean values. The total number of points for this dataset is 175,310 . The most common wave direction, with 21.3 percent $(37,347)$ of the cases, is between 168.8 and 191.3 deg with a mean of $178.4 \mathrm{deg}$. The overall mean-wave direction is $164.1 \mathrm{deg}$.

Figure 8. WIS126 percent occurrence histogram of wave direction, period, and height, 1980 to 1999.

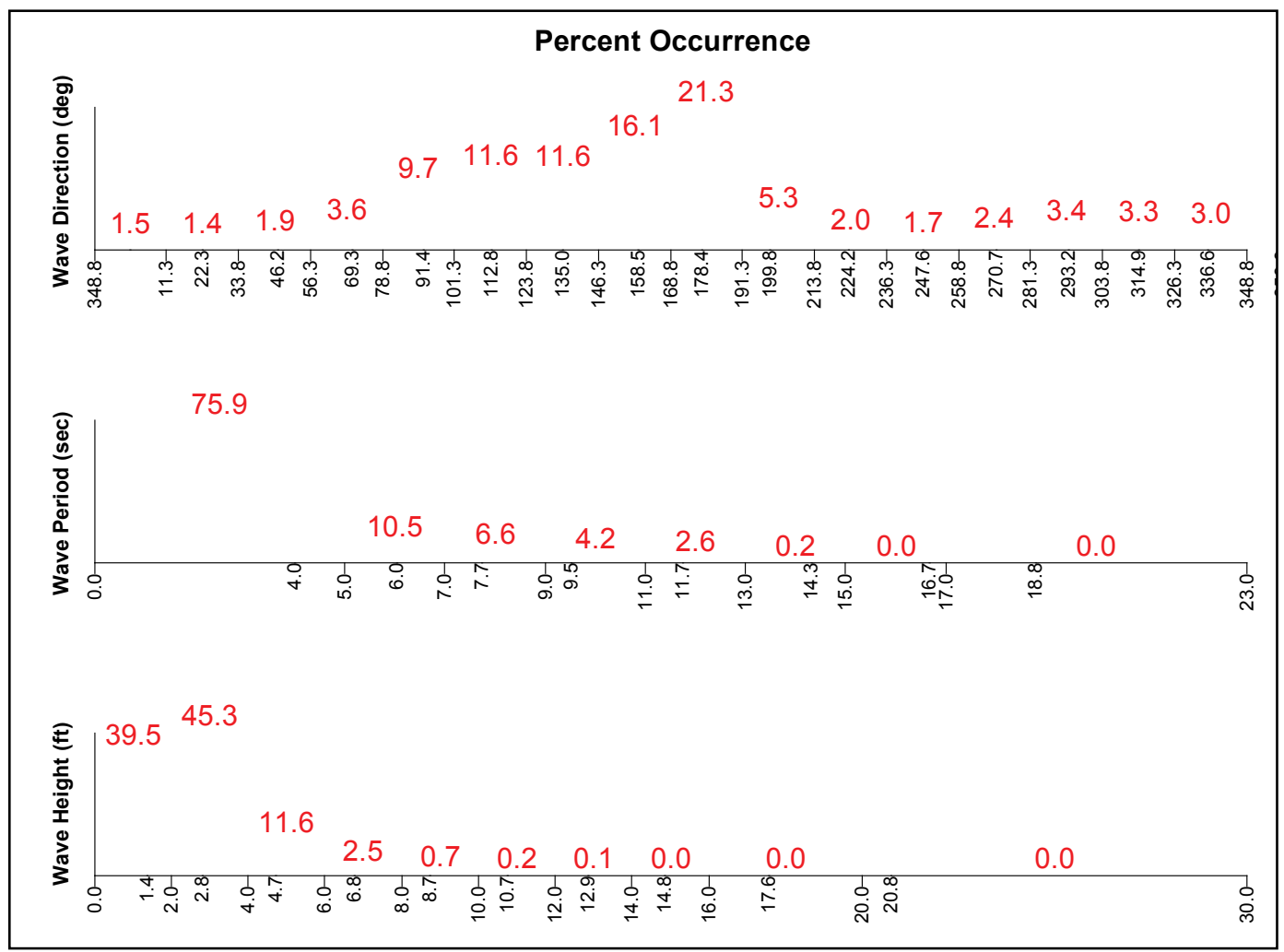


Wave periods range from 1 to $23 \mathrm{sec}$ with variable band limits. The most commonly occurring wave-period band, with 75.9 percent $(132,976)$ of the cases, is from 1 to $5 \mathrm{sec}$ with a mean of $4.0 \mathrm{sec}$. The overall mean wave period is $4.9 \mathrm{sec}$. Significant wave heights range from o to $22 \mathrm{ft}$ with variable band limits. The most common wave height, with 45.3 percent $(79,439)$ of the cases, is from 2 to $4 \mathrm{ft}$ with a mean of $2.8 \mathrm{ft}$. The overall mean-wave height is $2.6 \mathrm{ft}$. The largest significant wave height is $21.3 \mathrm{ft}$ with corresponding peak period of $12.5 \mathrm{sec}$ and wave direction of $91.4 \mathrm{deg}$. However, this is a very rare occurrence.

Figure 9a is a rose of $H_{s}$ that illustrates the percentage of waves coming from different directions. Figure $9 \mathrm{~b}$ is a similar rose for $T_{p}$. The length of the radial bars indicates the percentage from that particular wave direction. Thicker bars represent smaller $H_{s}$ or $T_{p}$ bands. The lowest bands are shown nearest the center of the rose. The radial bars become narrower toward the outer end of each bar indicating increasing wave heights or periods.

\section{Joint probability distributions}

The next step in the Phase 1 wave processing was to separate the data into joint probability or percent occurrence tables of $T_{p}$ vs. $H_{s}$ for a realistic set of direction bands. Because of the angle of the shore, wave directions outside the range of 56.25 to 213.75 deg would not impact the Ambrose Channel, so the set of direction bands was reduced. The total number of observations for the entire $20 \mathrm{yr}$ hindcast dataset is 175,310 . The limited dataset has 79.3 percent of these observations, or 139,071 observations. Table 7 summarizes the lower, upper, and mid-point direction band limits for the seven $22.5 \mathrm{deg}$ direction bands. The number of observations and the percent of the limited and total dataset are also listed for each band.

The $T_{p}$ vs. $H_{s}$ percent occurrence tables for each of the ten direction bands are contained in Appendix B (top table is the percent occurrence in the band, and the bottom table lists the corresponding number of occurrences). From these joint probability distributions of wave period and wave height, wave parameter statistics were gathered for generating empirical directional wave spectra representative of the WIS126 deepwater data.

A total of 211 different combinations of $T_{p}, H_{s}$, and $\theta_{p}$ were obtained. The ranges for these parameters were as follows:

- $3.7 \mathrm{sec} \leq T_{p} \leq 16.7 \mathrm{sec}$

- $2.7 \mathrm{ft} \leq \mathrm{Hs} \leq 20.8 \mathrm{ft}$

- $67.5 \mathrm{deg} \leq \theta_{p} \leq 202.5 \mathrm{deg}$ 
Figure 9. WIS126 wave roses for 1980 to 1999 (a) wave height and (b) peak wave period.

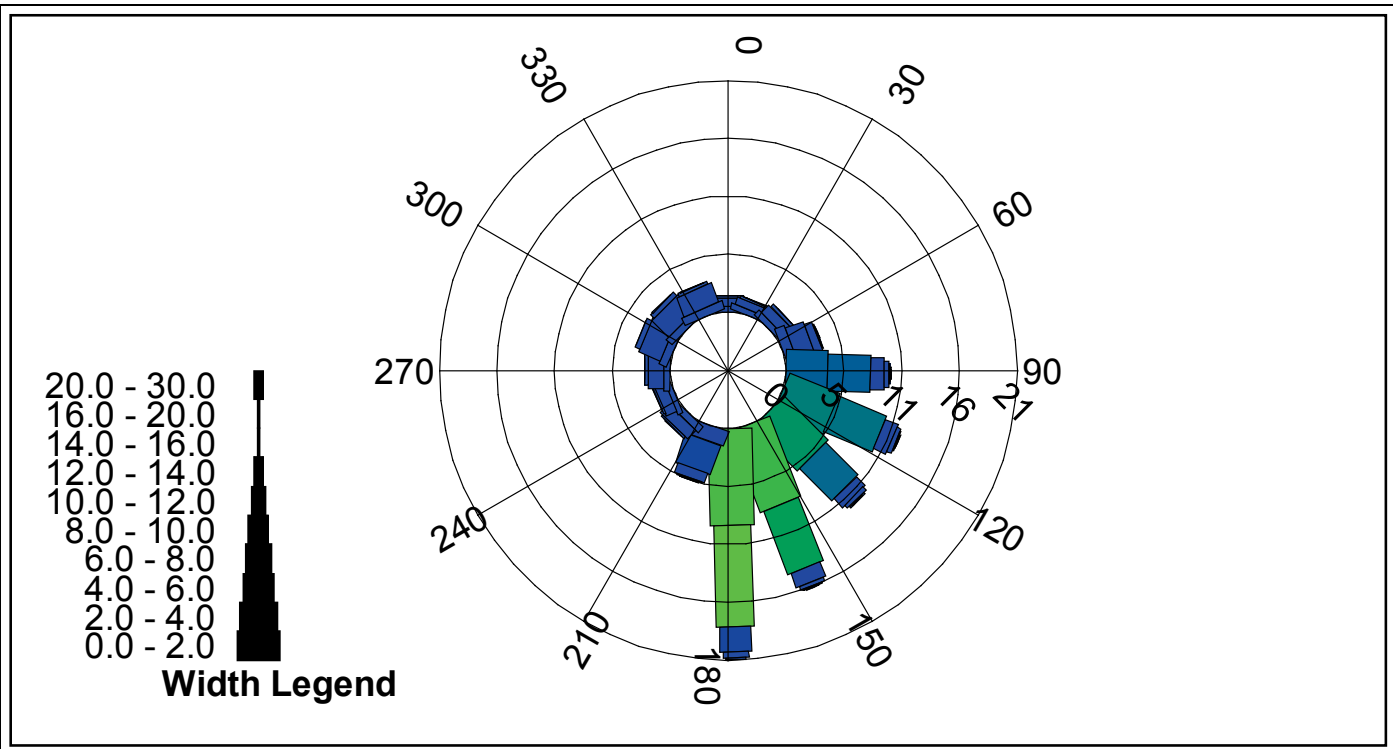

(a)

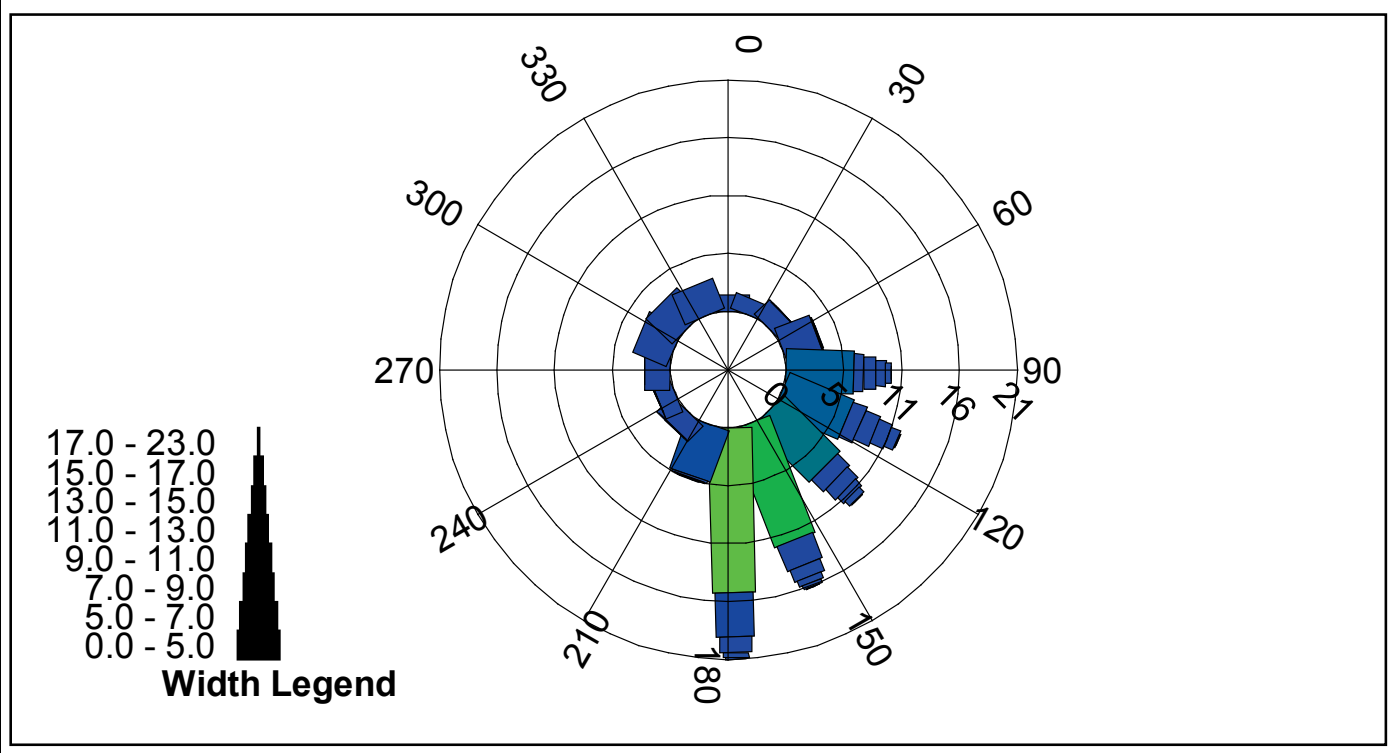

(b) 
Table 7. Band limits on wave direction.

\begin{tabular}{|c|c|c|c|c|c|c|}
\hline \multirow{2}{*}{$\begin{array}{l}\text { Band } \\
\text { No. }\end{array}$} & \multicolumn{3}{|c|}{ Direction band limits, deg } & \multirow{2}{*}{$\begin{array}{l}\text { No. } \\
\text { Observations }\end{array}$} & \multicolumn{2}{|c|}{ Percent } \\
\hline & Lower & Upper & Middle & & Limited & Total \\
\hline 1 & 56.25 & 78.74 & 67.5 & 6,324 & $4.5 \%$ & $3.6 \%$ \\
\hline 2 & 78.75 & 101.24 & 90.0 & 17,044 & $12.3 \%$ & $9.7 \%$ \\
\hline 3 & 101.25 & 123.74 & 112.5 & 20,398 & $14.7 \%$ & $11.6 \%$ \\
\hline 4 & 123.75 & 146.24 & 135.0 & 20,324 & $14.6 \%$ & $11.6 \%$ \\
\hline 5 & 146.25 & 168.74 & 157.5 & 28,310 & $20.4 \%$ & $16.1 \%$ \\
\hline 6 & 168.75 & 191.24 & 180.0 & 37,347 & $26.9 \%$ & $21.3 \%$ \\
\hline 7 & 191.25 & 213.74 & 202.5 & 9,324 & $6.7 \%$ & $5.3 \%$ \\
\hline
\end{tabular}

Notes:

1. Direction bands were 22.5 deg wide.

2. Total number of observations $=175,310$.

3. Total number of observations within direction band limits $=139,071$ or 79.3 percent of total.

4. Did not include observations if less than 0.05 percent (i.e., 0.0005 ) of total.

5. Minimum number of occurrences to keep based on total observations $=88$ ( 70 for direction-limited).

Wave bins that had less than 0.05 percent (i.e., 0.0005) of the total number of occurrences were eliminated as these represent very rare events on both low and high ends of the dataset. With the elimination of these rare occurrences and including all the very low wave energy days, a total of 208 days per year (57 percent of a year) are considered "calm" days. During these days, wave-induced vertical ship motions are insignificant and will not impact the available $U K C_{\text {Net }}$ in the Ambrose Entrance Channel.

\section{Directional wave spectra}

The final step in the process for the Phase 1 waves was to generate a directional wave spectra using a TMA frequency spectrum and a $\cos ^{n}$ spreading function. Spectral frequencies ranged from $0.01 \mathrm{~Hz}$ to $0.50 \mathrm{~Hz}$ in $0.01 \mathrm{~Hz}$ intervals to cover frequencies corresponding to one half to three times the peak frequency. Because of directional spreading and CADET requirements, the full circle of 360 deg was modeled in 15 deg increments. Spectral wave parameters were selected for each wave based on wave period, a standard approach for CHL studies. For the TMA spectrum, frequency spreading is a function of the $\gamma$ parameter that varied between 3.3 (broad) to 8 (narrow). For the directional $\cos ^{n}$ spreading function, the $n$ parameter ranged from 4 (broad) to 30 (narrow). These spectra formed the incident wave input at the beginning of the Entrance Reach 1 and the mound Reach 2 in the Ambrose Channel. 
Since the wave cases in Phase 1 were assumed to experience no transformation between the WIS126 buoy and the beginning of the channel and mound reaches, wave heights in both reaches had the same values for each wave case. Appendix C contains tables of the wave parameters, probabilities, and corresponding days per year for each of the 211 wave conditions in Phase 1.

\section{Phase 2 waves}

The main purpose of the Phase 2 waves was to evaluate the significance of wave transformation from the WIS126 hindcast site on the incident wave properties at the entrance and mound reaches. A secondary concern in Phase 2 was to evaluate any potential differences in incident wave conditions between the hindcast WIS126 waves and the measured NOAA Buoy 44025 waves (Figure 7). In other words, was there any reason to suspect one site represented a more realistic source of actual wave conditions in Ambrose Channel? Finally, many of the waves in Phase 1 were very small or extremely large. The small waves would not have any effect on waveinduced ship motions and the large waves represent very rare extreme events that would be avoided by the pilots. Therefore, both of these wave types could be eliminated from further investigation. Based on these reasons, it was decided to reduce the number of waves in Phase 1 and examine the magnitude of wave transformation, especially the relative differences between the channel and mound reaches.

\section{Preliminary STWAVE and CMS-Wave comparisons}

Wave transformation was evaluated using two different numerical models to make sure no significant transformation between the offshore sites was overlooked due to resolution issues. Both STWAVE and CMS-Wave grids (Chapter 3) were constructed to compare WIS126 and NOAA 44025 wave conditions and wave transformation to the channel and mound reaches.

Initially, 39 wave conditions from Phase 1 were selected for further study based on cases that indicated grounding in either the channel or mound reaches. Grounding was defined for the fully loaded, inbound ship at a speed of $12 \mathrm{kt}$ due to vertical, wave-induced ship motions without ship squat or any requirement to maintain a minimum net underkeel clearance, $U K C_{\mathrm{Min}}$, of $2 \mathrm{ft}$ in the channel and $4 \mathrm{ft}$ in the mound reach.

Since many of these cases fall into groups with the same wave period and direction, it was decided to further reduce this set of 39 waves to a subset 
of 10 waves. This subset included only limiting wave heights (vary with wave period) in each wave group that lead to grounding. The wave transformation was examined using the two numerical models, STWAVE and CMS-Wave. A water depth $h=53 \mathrm{ft}$ was used in the channel reach and $h=55 \mathrm{ft}$ in the mound reach. Table 8 lists the wave parameters selected for this wave transformation study. Transformed wave heights at the channel entrance and on the crest of the mound and the ratios between these values and incident heights at WIS126 were calculated.

Table 8. Subset of 10 preliminary wave cases, Phase 2.

\begin{tabular}{|l|l|l|l|}
\hline $\begin{array}{l}\text { Run } \\
\text { No. }\end{array}$ & $\begin{array}{l}H_{s} \\
\text { (ft) }\end{array}$ & $\begin{array}{l}T_{p} \\
(\mathbf{s e c})\end{array}$ & $\begin{array}{l}\theta \\
(\mathrm{deg})\end{array}$ \\
\hline 1 & 4.9 & 11.8 & 67.5 \\
\hline 2 & 6.3 & 11.6 & 90 \\
\hline 3 & 5.4 & 14.3 & 90 \\
\hline 4 & 3.3 & 11.9 & 112.5 \\
\hline 5 & 2.7 & 14.3 & 112.5 \\
\hline 6 & 3.2 & 11.8 & 135 \\
\hline 7 & 2.1 & 16.7 & 135 \\
\hline 8 & 4 & 11.7 & 157.5 \\
\hline 9 & 4.5 & 11.4 & 180 \\
\hline 10 & 4.3 & 11.5 & 202.5 \\
\hline
\end{tabular}

\section{Final STWAVE and CMS-Wave comparisons}

Based on analysis of these ratios of wave transformation in the preliminary comparisons between the two sites and the differences in the model predictions, a final set of 21 wave conditions was selected for comparison of wave transformation using incident wave height data from the hindcast WIS126 and measured NOAA 44025 buoy. The wave parameters for these waves are listed in Table 9. The wave height and period were held constant in each of the three subgroups while the wave direction varied from 90 to $150 \mathrm{deg}$, in increments of $10 \mathrm{deg}$. Again, transformed wave heights at the beginning of both the channel entrance and on the mound and the ratios between these incident heights were calculated. 
Table 9. Final set of 21 numerical model wave cases, Phase 2.

\begin{tabular}{|l|l|l|l|l|}
\hline $\begin{array}{l}\text { Run } \\
\text { No. }\end{array}$ & No. of Cases & $\begin{array}{l}H_{s} \\
(\mathrm{ft})\end{array}$ & $\begin{array}{l}T_{p} \\
(\mathrm{sec})\end{array}$ & $\begin{array}{l}\theta \\
\text { (deg) }\end{array}$ \\
\hline 1 to 7 & 7 & 6 & 10 & 90 to 150,10 \\
\hline 8 to 14 & 7 & 6 & 13 & 90 to 150,10 \\
\hline 15 to 21 & 7 & 1.5 & 8 & 90 to 150,10 \\
\hline
\end{tabular}

Based on these final comparisons, a group of 24 wave conditions were selected for Phase 2. Table 10 lists the wave parameters for these waves. The wave number and days/year corresponds with the equivalent wave from Phase 1. The "Inc" is the incident wave height at the WIS126 site while the "R1" and "R2" correspond to Reach 1 (channel entrance) and Reach 2 (on the mound), respectively. Ratios are listed that compare R1 wave height to incident wave height, R2 wave height to incident wave height, etc. In general, the wave heights were similar to the Phase 1 values and smaller on average. The channel entrance wave height ratios $\mathrm{R} 1 / \mathrm{Inc}$ ranged from 0.7 to 1.0 with an average of 0.9. The mound wave height ratios R2/Inc varied from 0.7 to 1.2 with an average of 0.9. In general, the mound wave height ratios were slightly larger than the ratios at the channel entrance, with $\mathrm{R} 2 / \mathrm{R} 1$ ratios ranging from 0.9 to 1.2 with an average of 1.1. In summary, the range of wave parameters for Phase 2 was:

- $9.4 \mathrm{sec} \leq T_{p} \leq 16.7 \mathrm{sec}$

- $1.9 \mathrm{ft} \leq H_{s} \leq 9.8 \mathrm{ft}$ - Channel entrance or Reach 1

- $2.0 \mathrm{ft} \leq H_{s} \leq 10.2 \mathrm{ft}-$ On the mound or Reach 2

- $67.5 \mathrm{deg} \leq \theta_{p} \leq 202.5 \mathrm{deg}$

\section{Directional wave spectra}

Directional spectra representing these waves were then re-created for CADET runs using the updated wave heights and water depths for the channel and mound reaches. For no tide conditions, a water depth of $h=53 \mathrm{ft}$ was used in the channel reach and $h=55,56$, and $57 \mathrm{ft}$ in the mound reach. High tide water levels of $h=58 \mathrm{ft}$ were used in the channel reach and $h=60,61$, and $62 \mathrm{ft}$ in the mound reach. Details of the directional wave parameters for these waves are contained in Appendix C. 
Table 10. Wave cases in Phase 2.

\begin{tabular}{|c|c|c|c|c|c|c|c|c|c|}
\hline \multirow{2}{*}{$\begin{array}{l}\text { Wave } \\
\text { No. }\end{array}$} & \multirow[b]{2}{*}{ Days/yr } & \multirow{2}{*}{$\begin{array}{l}T_{p} \\
(\mathrm{sec})\end{array}$} & \multirow{2}{*}{$\begin{array}{l}\theta \\
\text { (deg) }\end{array}$} & \multicolumn{3}{|c|}{$H_{s}(\mathrm{ft})$} & \multicolumn{3}{|c|}{ Ratios } \\
\hline & & & & Inc & R1 & R2 & $\mathrm{R} 1 / \mathrm{Inc}$ & $\mathrm{R} 2 / \mathrm{Inc}$ & R2/R1 \\
\hline 19 & 0.01 & 9.40 & 67.5 & 10.8 & 9.79 & 10.2 & 0.91 & 0.94 & 1.04 \\
\hline 22 & 0.02 & 11.80 & 67.5 & 4.8 & 4.16 & 4.4 & 0.87 & 0.92 & 1.06 \\
\hline 46 & 0.06 & 9.50 & 90.0 & 8.8 & 8.25 & 8.5 & 0.94 & 0.96 & 1.03 \\
\hline 52 & 0.15 & 11.60 & 90.0 & 4.8 & 4.45 & 4.6 & 0.93 & 0.95 & 1.03 \\
\hline 61 & 0.01 & 14.30 & 90.0 & 4.8 & 4.38 & 4.6 & 0.91 & 0.95 & 1.04 \\
\hline 64 & 0.01 & 16.70 & 90.0 & 2.9 & 2.61 & 2.8 & 0.90 & 0.96 & 1.06 \\
\hline 82 & 0.04 & 9.50 & 112.5 & 8.7 & 8.38 & 9.4 & 0.96 & 1.08 & 1.12 \\
\hline 87 & 0.52 & 11.90 & 112.5 & 4.8 & 4.64 & 5.4 & 0.97 & 1.12 & 1.16 \\
\hline 92 & 0.07 & 14.30 & 112.5 & 4.8 & 4.70 & 5.5 & 0.98 & 1.15 & 1.18 \\
\hline 95 & 0.01 & 16.70 & 112.5 & 2.8 & 2.77 & 3.3 & 0.99 & 1.18 & 1.19 \\
\hline 115 & 0.10 & 9.50 & 135.0 & 8.7 & 8.25 & 9.1 & 0.95 & 1.04 & 1.10 \\
\hline 119 & 0.21 & 11.80 & 135.0 & 4.8 & 4.58 & 5.2 & 0.95 & 1.08 & 1.13 \\
\hline 125 & 0.05 & 14.30 & 135.0 & 4.8 & 4.58 & 5.3 & 0.95 & 1.11 & 1.17 \\
\hline 127 & 0.01 & 16.70 & 135.0 & 2.8 & 2.68 & 3.2 & 0.96 & 1.13 & 1.19 \\
\hline 147 & 0.04 & 9.50 & 157.5 & 8.8 & 7.33 & 7.5 & 0.83 & 0.85 & 1.02 \\
\hline 152 & 0.21 & 11.70 & 157.5 & 4.7 & 3.66 & 3.8 & 0.78 & 0.80 & 1.03 \\
\hline 157 & 0.12 & 14.30 & 157.5 & 4.7 & 3.39 & 3.6 & 0.72 & 0.76 & 1.05 \\
\hline 158 & 0.04 & 16.70 & 157.5 & 2.7 & 1.86 & 2.0 & 0.69 & 0.74 & 1.07 \\
\hline 177 & 0.03 & 9.50 & 180.0 & 8.7 & 8.02 & 7.5 & 0.92 & 0.86 & 0.93 \\
\hline 181 & 0.17 & 11.40 & 180.0 & 4.8 & 4.19 & 3.8 & 0.87 & 0.79 & 0.91 \\
\hline 205 & 0.01 & 9.50 & 202.5 & 10.5 & 7.91 & 8.4 & 0.75 & 0.80 & 1.06 \\
\hline 206 & 0.00 & 9.50 & 202.5 & 13.1 & 9.87 & 10.4 & 0.75 & 0.80 & 1.06 \\
\hline 208 & 0.03 & 11.50 & 202.5 & 4.7 & 3.19 & 3.4 & 0.68 & 0.72 & 1.06 \\
\hline 209 & 0.01 & 11.50 & 202.5 & 6.7 & 4.55 & 4.8 & 0.68 & 0.72 & 1.06 \\
\hline Min: & 0.00 & 9.4 & 67.5 & 2.7 & 1.9 & 2.0 & 0.7 & 0.7 & 0.9 \\
\hline Ave: & 0.08 & 12.2 & 136.9 & 6.2 & 5.3 & 5.7 & 0.9 & 0.9 & 1.1 \\
\hline Max: & 0.52 & 16.7 & 202.5 & 13.1 & 9.9 & 10.4 & 1.0 & 1.2 & 1.2 \\
\hline
\end{tabular}

Notes:

1. Inc $=$ Incident wave conditions.

2. R1 = Channel Reach 1. R2 = mound Reach 2.

3. Min $=$ Minimum, Ave $=$ Average, Max $=$ Maximum. 


\section{Summary}

In Phase 1, a joint probability distribution of wave height and period was created in seven 22.5-deg direction bands from 56.25 to $213.74 \mathrm{deg}$. It consisted of 139,071 observations representing 79.3 percent of the deepwater data from the WIS 20 yr hindcast buoy WIS126. A total of 211 empirical directional wave spectra were created from this joint probability distribution. Parameters for these directional spectra were based on wave period and height for a TMA frequency spectrum and $\cos ^{\mathrm{n}}$ directional spreading function.

In Phase 2, a subset of 24 directional wave spectra were simulated from the Phase 1 dataset based on an analysis of wave transformation between the offshore WIS126 hindcast site and the beginning of the channel entrance and top of mound reaches. The wave transformation was performed using both STWAVE and CMS-Wave numerical models. Incident waves in this study were obtained from two sources: WIS126 station and NOAA Buoy 44025. 


\section{Ship Squat Results}

This chapter compares PIANC, Ankudinov, and CADET predicted ship squat for both the lightly and fully loaded Susan Maersk in the main Ambrose Entrance Channel and over the mound. Although the CADET predictions are based on the BNT program, they are referred to as "CADET" or "CAD" in this report.

\section{Light-loaded ship}

\section{Entrance channel transit}

Figure 10 shows maximum predicted ship squat $S_{\operatorname{Max}}$ as a function of ship speed for the light-loaded ( $T=46.0 \mathrm{ft}$ ) Susan Maersk containership in the main entrance channel. Individual squat predictions for the Ankudinov, CADET, Barrass, Eryuzlu, Huuska/Guliev (1971), Römisch, and Yoshimura formulas are included. The last five predictors are the PIANC empirical predictions. This maximum squat can occur at the bow or stern of the ship. The "average" squat prediction line is also included since it is a good "design" value. The top plot (Figure 10a) shows the no tide condition in a water depth of $h=53 \mathrm{ft}$. Figure $10 \mathrm{~b}$ is the analogous figure for the high tide $(+5 \mathrm{ft})$ water depth of $h=58 \mathrm{ft}$. Table 11 lists the squat values that are plotted in these figures for each water depth.

For no tide conditions, the $U K C=7.0 \mathrm{ft}$ (i.e., $53.0-46.0 \mathrm{ft}$ ). Figure 10a shows that the CADET is on the "low" side and the Ankudinov predictions tend to be on the "high" side of the squat predictions. Using $V_{k}=12 \mathrm{kt}$ as an example, squat ranges from $S_{\operatorname{Max}}=1.44$ to $3.08 \mathrm{ft}$, with an average of $2.38 \mathrm{ft}$. The minimum and maximum squat values correspond to the CADET (similar to Römisch prediction) and Barrass, respectively.

For the $+5 \mathrm{ft}$ tide, the $U K C=12.0 \mathrm{ft}$ (i.e., $58.0-46.0 \mathrm{ft}$ ). At $V_{k}=12 \mathrm{kt}$, squat ranges from $S_{M a x}=1.30$ to $3.08 \mathrm{ft}$, with an average of $2.21 \mathrm{ft}$. Again, the minimum and maximum squat values correspond to the CADET (similar to Römisch prediction) and Barrass, respectively.

Since the $U K C$ is larger than the predicted squat values, it would appear that there are no UKC concerns for both the "no tide" and high tide transits with the light-loaded ship. Of course, this does not include the 
Figure 10. Ship squat for light-loaded ( $T=46 \mathrm{ft}$ ) Susan Maersk containership during channel transit for Ankudinov, CADET, Barrass, Eryuzlu, Huuska, Römisch, and Yoshimura predictions

(a) no tide ( $h=53 \mathrm{ft})$ and (b) high tide $(h=58 \mathrm{ft})$.

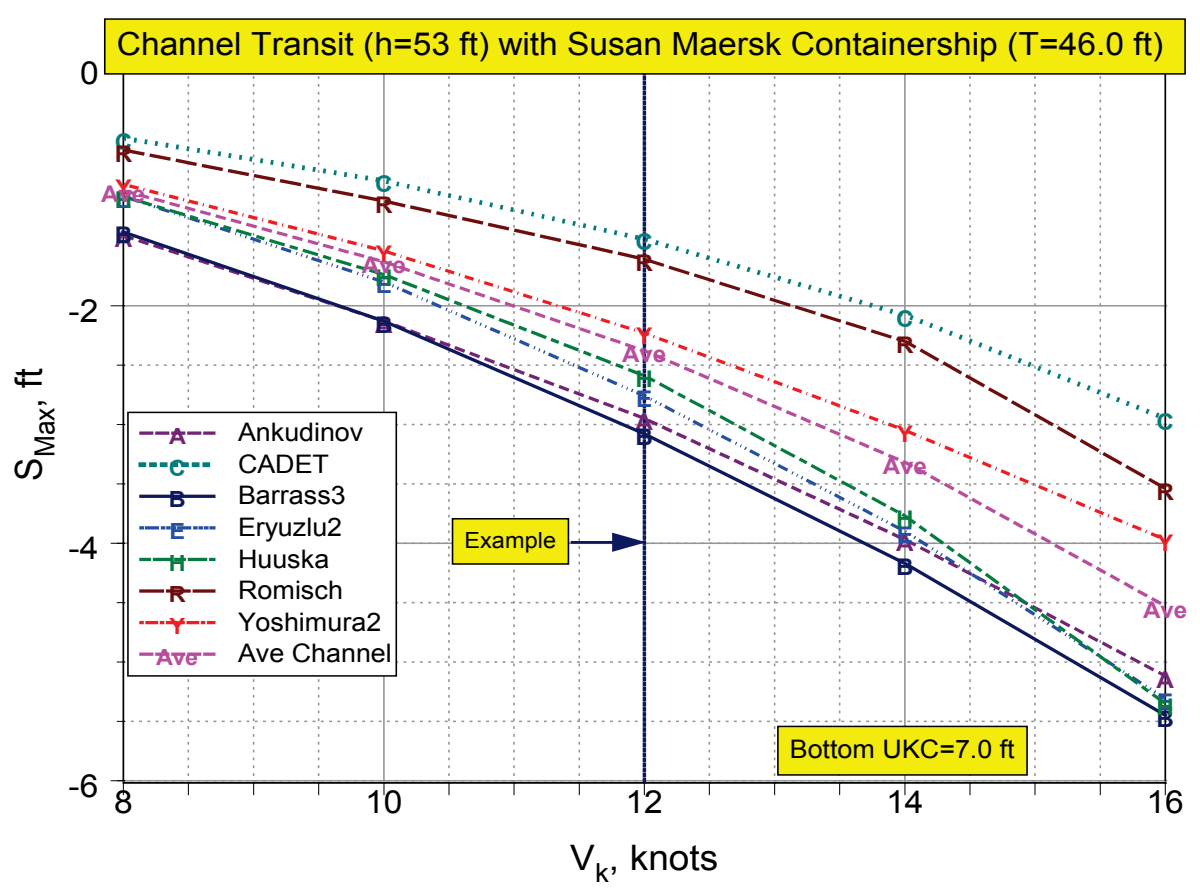

(a)

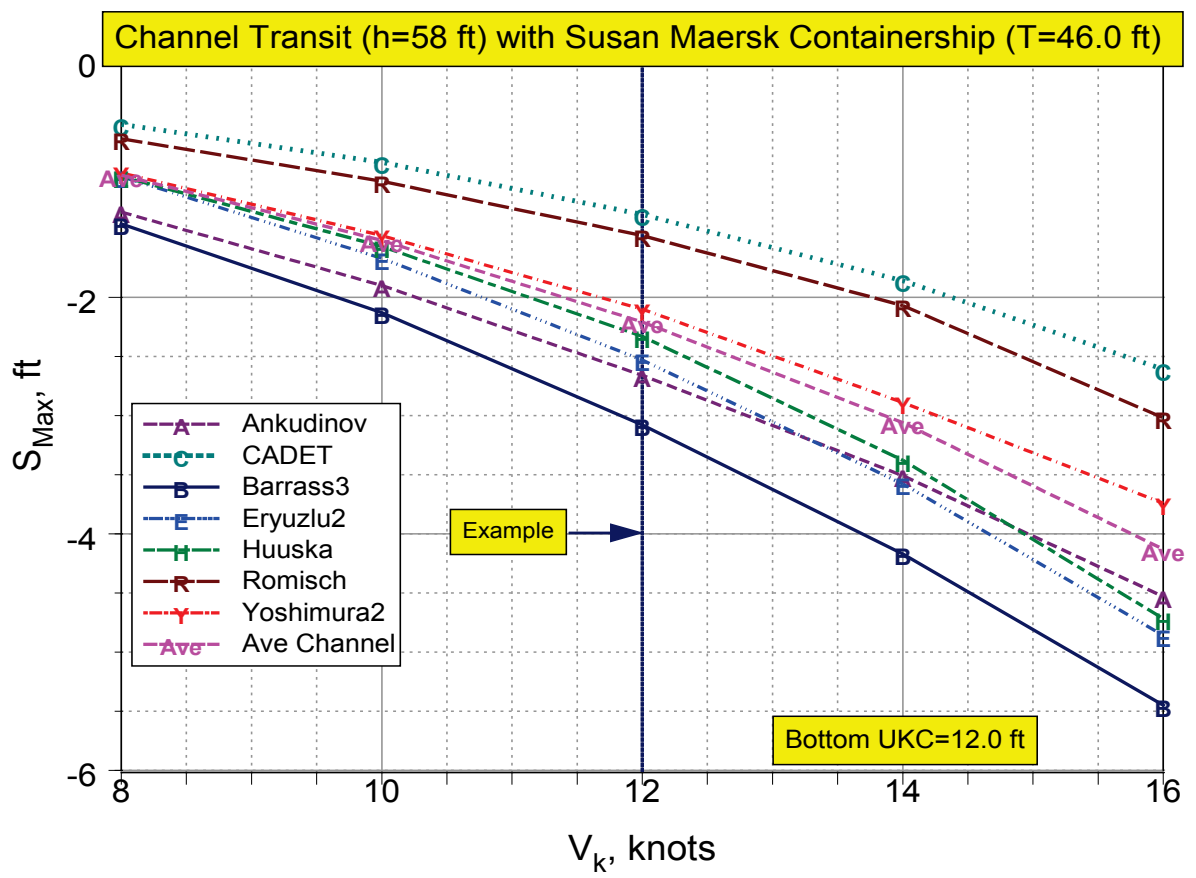

(b) 
Table 11. Ship squat predictions for light-loaded Susan Maersk in Ambrose Channel.

\begin{tabular}{|c|c|c|c|c|c|c|c|c|c|c|}
\hline $\begin{array}{l}\text { Spd } \\
\text { (kt) }\end{array}$ & $\begin{array}{l}\text { Ank } \\
\text { (ft) }\end{array}$ & $\begin{array}{l}\text { CAD } \\
\text { (ft) }\end{array}$ & $\begin{array}{l}\text { B3 } \\
\text { (ft) }\end{array}$ & $\begin{array}{l}\text { E2 } \\
\text { (ft) }\end{array}$ & $\begin{array}{l}\text { Hus } \\
\text { (ft) }\end{array}$ & $\begin{array}{l}\text { Röm } \\
\text { (ft) }\end{array}$ & \begin{tabular}{|l} 
Yosh \\
(ft)
\end{tabular} & $\begin{array}{l}S_{\text {Ave }} \\
(\mathrm{ft})\end{array}$ & $\begin{array}{l}S_{\text {Min }} \\
(\mathrm{ft})\end{array}$ & $\begin{array}{l}S_{\text {Max }} \\
\text { (ft) }\end{array}$ \\
\hline \multicolumn{11}{|c|}{$h=53 \mathrm{ft}$} \\
\hline 8 & 1.41 & 0.59 & 1.38 & 1.08 & 1.08 & 0.69 & 0.98 & 1.03 & 0.59 & 1.41 \\
\hline 10 & 2.13 & 0.95 & 2.13 & 1.80 & 1.74 & 1.12 & 1.54 & 1.63 & 0.95 & 2.13 \\
\hline 12 & 2.95 & 1.44 & 3.08 & 2.76 & 2.59 & 1.61 & 2.23 & 2.38 & 1.44 & 3.08 \\
\hline 14 & 3.97 & 2.08 & 4.17 & 3.90 & 3.77 & 2.30 & 3.05 & 3.32 & 2.08 & 4.17 \\
\hline 16 & 5.12 & 2.95 & 5.45 & 5.31 & 5.35 & 3.54 & 3.97 & 4.53 & 2.95 & 5.45 \\
\hline \multicolumn{11}{|c|}{$h=58 \mathrm{ft}$} \\
\hline 8 & 1.28 & 0.54 & 1.38 & 0.98 & 0.98 & 0.66 & 0.95 & 0.97 & 0.54 & 1.38 \\
\hline 10 & 1.90 & 0.86 & 2.13 & 1.67 & 1.57 & 1.02 & 1.48 & 1.52 & 0.86 & 2.13 \\
\hline 12 & 2.66 & 1.30 & 3.08 & 2.53 & 2.33 & 1.48 & 2.10 & 2.21 & 1.30 & 3.08 \\
\hline 14 & 3.51 & 1.86 & 4.17 & 3.58 & 3.38 & 2.07 & 2.89 & 3.06 & 1.86 & 4.17 \\
\hline 16 & 4.53 & 2.61 & 5.45 & 4.86 & 4.72 & 3.02 & 3.74 & 4.13 & 2.61 & 5.45 \\
\hline \multicolumn{11}{|c|}{ Notes: } \\
\hline \multicolumn{11}{|c|}{ Ank $=$ Ankudinov } \\
\hline \multicolumn{11}{|c|}{$C A D=C A D E T$} \\
\hline \multicolumn{11}{|c|}{ B3 $=$ Barrass version 3} \\
\hline \multicolumn{11}{|c|}{ E2 = Eryuzlu version 2} \\
\hline \multicolumn{11}{|c|}{ Hus $=$ Huuska $/$ Guliev } \\
\hline \multicolumn{11}{|c|}{ Röm = Römisch } \\
\hline \multirow{2}{*}{\multicolumn{11}{|c|}{ Yosh = Yoshimura }} \\
\hline$S_{\text {Ave, }}$ & ,,$S_{\operatorname{Max}}=$ & & & & & & & & & \\
\hline
\end{tabular}

required $U K C_{M i n}$ and wave-induced vertical motions for heave, pitch, and roll. These will be discussed in the next chapter and, of course, will reduce the final $U K C_{N e t}$. Also, note that the Barrass predictions do not change as the tide level changes (i.e., fixed $3.08 \mathrm{ft}$ prediction) since this predictor does not incorporate water depth as a parameter in an open or unrestricted channel.

\section{Mound transit}

Figure 11 is the analogous figure for mound transits with no tide and $+5 \mathrm{ft}$ high tide water depths of $h=55$ and $60 \mathrm{ft}$, respectively. Table 12 lists the corresponding squat values for the light-loaded Susan Maersk at these two water depths over the mound. In general, one can expect the ship squat to be slightly smaller for the mound transits because of the deeper water depths required to accommodate the additional $2 \mathrm{ft}$ underkeel clearance for hard bottom compared to the channel with soft bottom. 
Figure 11. Ship squat for light-loaded ( $T=46 \mathrm{ft}$ ) Susan Maersk containership during mound transit for Ankudinov, CADET, Barrass, Eryuzlu, Huuska, Römisch, and Yoshimura predictions

(a) no tide ( $h=55 \mathrm{ft})$ and (b) high tide $(h=60 \mathrm{ft})$.

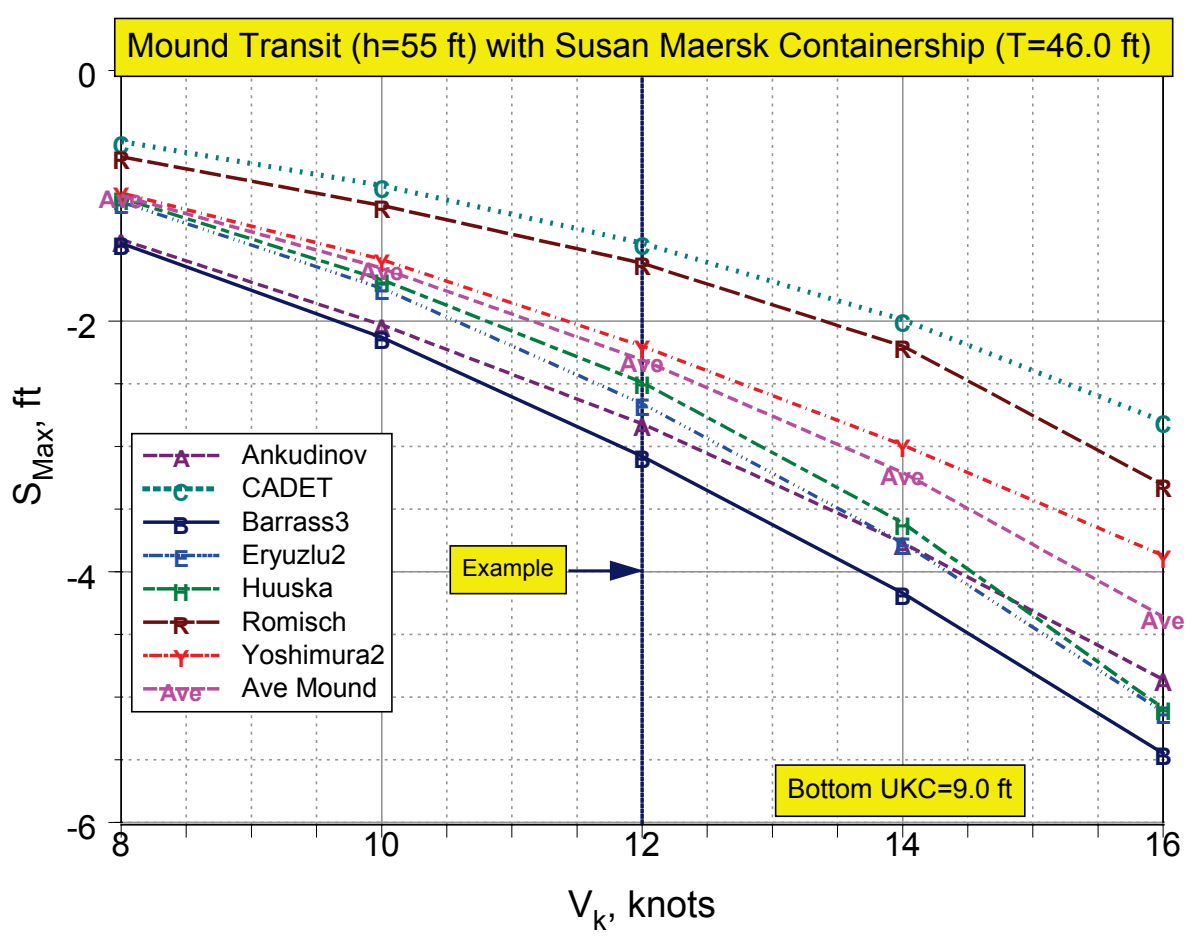

(a)

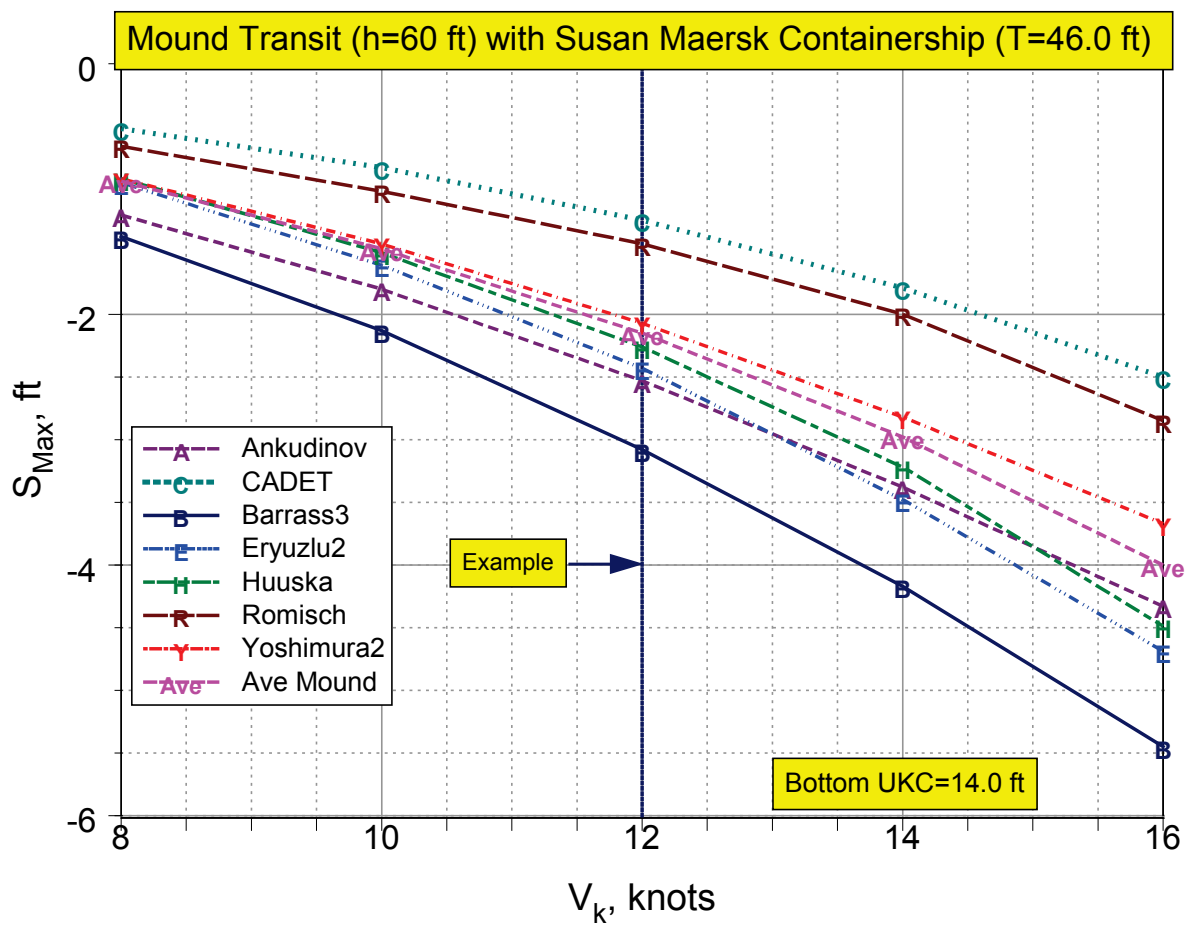

(b) 
Table 12. Ship squat predictions for light-loaded Susan Maersk during mound transit.

\begin{tabular}{|l|l|l|l|l|l|l|l|l|l|l|l|}
\hline $\begin{array}{l}\text { Spd } \\
(\mathrm{kt})\end{array}$ & $\begin{array}{l}\text { Ank } \\
(\mathrm{ft})\end{array}$ & $\begin{array}{l}\text { CAD } \\
(\mathrm{ft})\end{array}$ & $\begin{array}{l}\text { B3 } \\
(\mathrm{ft})\end{array}$ & $\begin{array}{l}\text { E2 } \\
(\mathrm{ft})\end{array}$ & $\begin{array}{l}\text { Hus } \\
(\mathrm{ft})\end{array}$ & $\begin{array}{l}\text { Röm } \\
(\mathrm{ft})\end{array}$ & $\begin{array}{l}\text { Yosh } \\
(\mathrm{ft})\end{array}$ & $\begin{array}{l}S_{\text {Ave }} \\
(\mathrm{ft})\end{array}$ & $\begin{array}{l}S_{\text {Min }} \\
(\mathrm{ft})\end{array}$ & $\begin{array}{l}S_{\text {Max }} \\
(\mathrm{ft})\end{array}$ \\
\hline $\mathrm{h}=55 \mathrm{ft}$ \\
\hline 8 & 1.35 & 0.57 & 1.38 & 1.05 & 1.02 & 0.69 & 0.98 & 1.00 & 0.57 & 1.38 \\
\hline 10 & 2.03 & 0.92 & 2.13 & 1.74 & 1.67 & 1.08 & 1.51 & 1.58 & 0.92 & 2.13 \\
\hline 12 & 2.82 & 1.38 & 3.08 & 2.66 & 2.49 & 1.54 & 2.20 & 2.31 & 1.38 & 3.08 \\
\hline 14 & 3.77 & 1.99 & 4.17 & 3.77 & 3.61 & 2.20 & 2.99 & 3.21 & 1.99 & 4.17 \\
\hline 16 & 4.86 & 2.80 & 5.45 & 5.12 & 5.09 & 3.31 & 3.87 & 4.36 & 2.80 & 5.45 \\
\hline$h=60 \mathrm{ft}$ & & & & & & & & \\
\hline 8 & 1.21 & 0.52 & 1.38 & 0.95 & 0.92 & 0.66 & 0.92 & 0.94 & 0.52 & 1.38 \\
\hline 10 & 1.80 & 0.83 & 2.13 & 1.61 & 1.51 & 1.02 & 1.44 & 1.48 & 0.83 & 2.13 \\
\hline 12 & 2.53 & 1.25 & 3.08 & 2.43 & 2.26 & 1.44 & 2.07 & 2.15 & 1.25 & 3.08 \\
\hline 14 & 3.38 & 1.79 & 4.17 & 3.48 & 3.22 & 2.00 & 2.82 & 2.98 & 1.79 & 4.17 \\
\hline 16 & 4.33 & 2.50 & 5.45 & 4.69 & 4.49 & 2.85 & 3.67 & 4.00 & 2.50 & 5.45 \\
\hline
\end{tabular}

Notes:

Ank $=$ Ankudinov

CAD = CADET

$\mathrm{B} 3=$ Barrass version 3

E2 = Eryuzlu version 2

Hus $=$ Huuska/Guliev

Röm $=$ Römisch

Yosh $=$ Yoshimura

$S_{\text {Ave }}, S_{\text {Min }}, S_{\operatorname{Max}}=$ Average, minimum, and maximum of all 7 squat predictions

For the no tide case of $h=55 \mathrm{ft}$, the $U K C=9.0 \mathrm{ft}$ (i.e., $55.0-46.0 \mathrm{ft}$ ).

Figure 11a shows that the squat predictions are bracketed as before on the "low" side by CADET and on the "high" side by Barrass. Again using $V_{k}=$ $12 \mathrm{kt}$ as an example, squat ranges from $S_{\operatorname{Max}}=1.38$ to $3.08 \mathrm{ft}$, with an average of $2.31 \mathrm{ft}$. The minimum squat values correspond to the CADET predictions, but are reasonably close to those of Römisch. The maximum squat values correspond with the Barrass predictions.

For the $+5 \mathrm{ft}$ tide, the $U K C=14.0 \mathrm{ft}$ (i.e., $60.0-46.0 \mathrm{ft}$ ). At $V_{k}=12 \mathrm{kt}$, squat ranges from $S_{\operatorname{Max}}=1.25$ to $3.08 \mathrm{ft}$, with an average of $2.15 \mathrm{ft}$. Again, the minimum and maximum squat values correspond to the CADET (similar to Römisch prediction) and Barrass, respectively. 
Similarly to the channel transits, the $U K C$ is larger than the predicted squat values so that $U K C$ does not appear to be a problem for both extremes of water level for the mound transits. The deeper mound depths provide additional $U K C$ for the ship. Again, note that the Barrass predictions are fixed at $3.08 \mathrm{ft}$ even though the water depth and associated $U K C$ increased.

\section{Comparison of transits}

Suppose the ship begins transits in the entrance channel and "strays" over the mound. What is the difference in squat due to the deeper depth of the mound transit compared to the channel transit? In general, squat for the deeper mound transits are smaller than the shallower channel transits since the ship will not be influenced as much by the deeper bottom. Two ratios are calculated to quantify this change in squat for each of the Ankudinov, CADET, Barrass, Eryuzlu, Huuska/Guliev, Römisch, and Yoshimura predictors as a function of ship speed. The first is the squat difference, $S_{D i f}$, which is given by subtracting the squat values as

$$
S_{\text {Dif }}=S_{\text {Max }, \text { Channel }}-S_{\text {Max }, \text { Mound }}
$$

where $S_{\text {Max,Channel }}$ is the predicted squat at the channel and $S_{\text {Max,Mound }}$ is the predicted squat at the mound. The second ratio is the corresponding ratio of mound to channel squat, $S_{R}$, given by

$$
S_{R}=\frac{S_{\text {Max }, \text { Mound }}}{S_{\text {Max }, \text { Channel }}}
$$

Figure 12 compares $S_{D i f}$ for transits with no tide (Figure 12a) and $+5 \mathrm{ft} \mathrm{high}$ tide (Figure 12b) for all seven predictors. Table 13 lists $S_{D i f}$ and $S_{R}$ for both no tide and $+5 \mathrm{ft}$ tide advantage. Again, using $V_{k}=12 \mathrm{kt}$ as an example for no tide, squat values range from $S_{D i f}=0.0 \mathrm{ft}\left(S_{R}=1.00\right)$ for Barrass to $S_{D i f}=0.13 \mathrm{ft}\left(S_{R}=0.96\right)$ for Ankudinov predictors. The Barrass $S_{D i f}$ equals zero and the $S_{R}$ equals one since it is not affected by changes in depth between the channel and mound. The largest $S_{D i f}=0.26 \mathrm{ft}\left(S_{R}=0.95\right)$ for Ankudinov and Huuska/Guliev occurs at the fastest ship speed of $V_{k}=16 \mathrm{kt}$. Thus, at speeds of $V_{k}=12 \mathrm{kt}$ one can expect average decreases in squat over the deeper mound to $0.07 \mathrm{ft}$ or 3 percent compared to the same transit over the shallower entrance channel. These small differences are not significant for the "no tide" condition. Even for the fastest speeds, the differences in squat between channel and mound transits are relatively insignificant at $0.26 \mathrm{ft}$ or 5 percent. 
Figure 12. Ship squat differences for mound vs. channel transits with Susan Maersk containership ( $T=46.0 \mathrm{ft}$ ) (a) no tide predictions, (b) $+5 \mathrm{ft}$ tide advantage predictions.

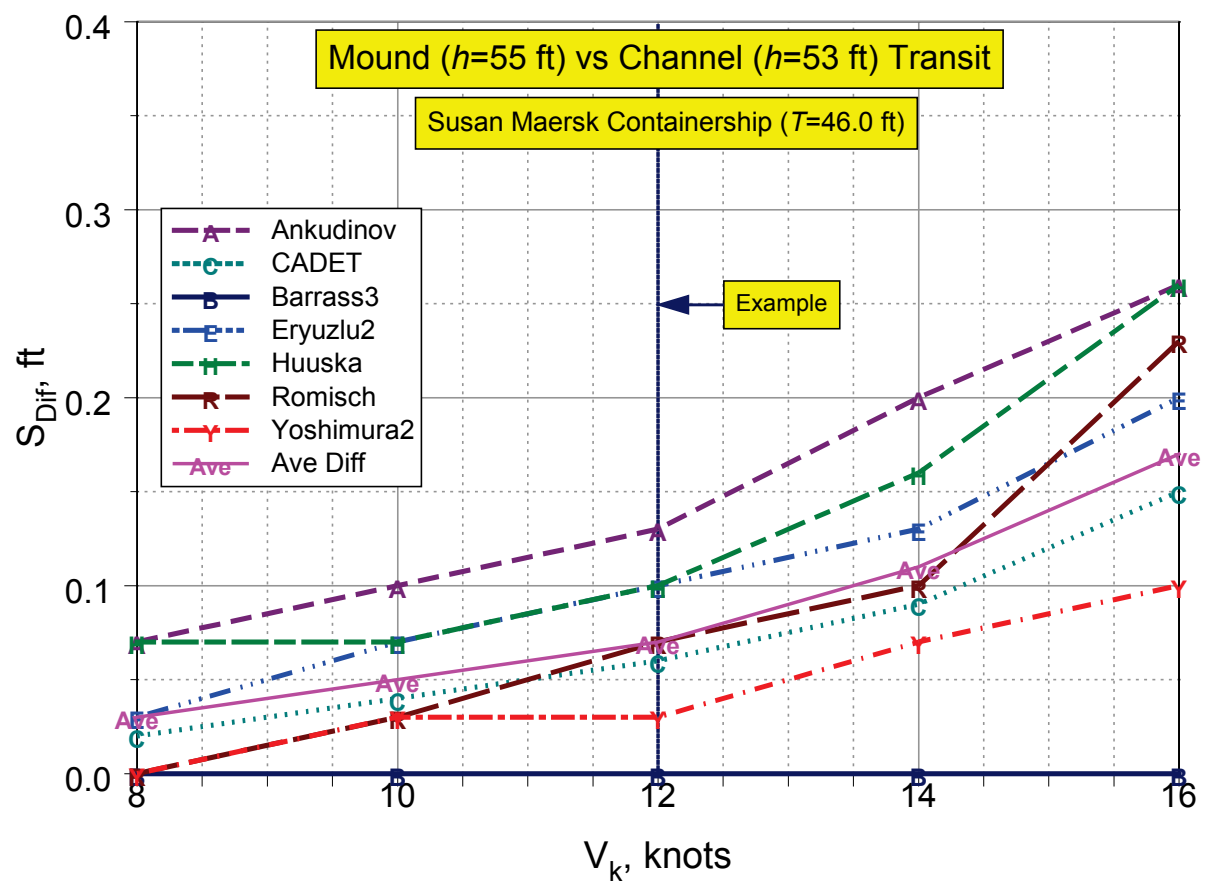

(a)

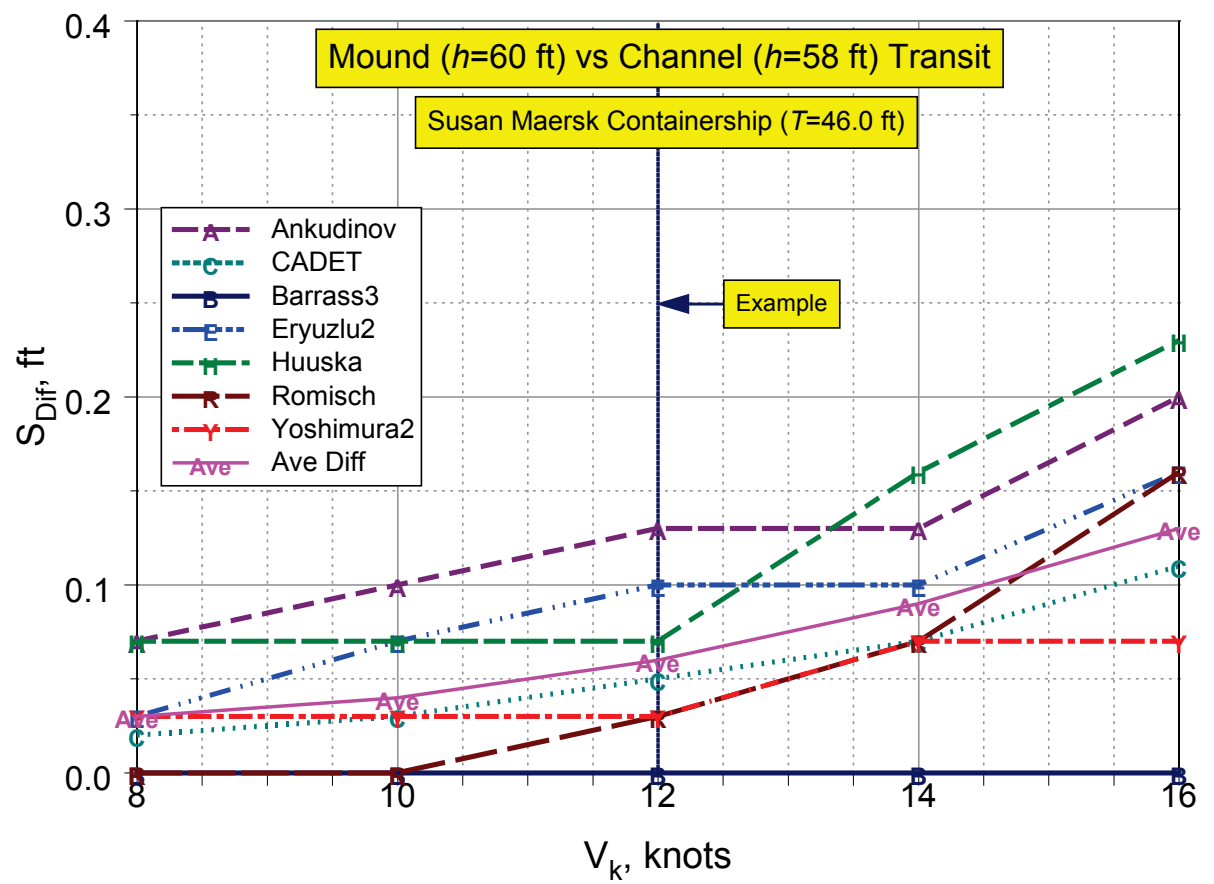

(b) 
Table 13. Effect of tides on squat differences $S_{D i f}$ and ratios $S_{R}$ for mound and channel transits for light-loaded Susan Maersk containership.

\begin{tabular}{|c|c|c|c|c|c|c|c|c|c|c|}
\hline $\begin{array}{l}\text { Spd } \\
\text { (kt) }\end{array}$ & $\begin{array}{l}\text { Ank } \\
\text { (ft) }\end{array}$ & $\begin{array}{l}\text { CAD } \\
\text { (ft) }\end{array}$ & $\begin{array}{l}\text { B3 } \\
\text { (ft) }\end{array}$ & $\begin{array}{l}\text { E2 } \\
\text { (ft) }\end{array}$ & $\begin{array}{l}\text { Hus } \\
\text { (ft) }\end{array}$ & \begin{tabular}{|l|} 
Röm \\
(ft)
\end{tabular} & \begin{tabular}{|l|} 
Yosh \\
(ft)
\end{tabular} & $\begin{array}{l}\begin{array}{l}S_{\text {Ave }} \\
\text { (ft) }\end{array}\end{array}$ & $\begin{array}{l}S_{\text {Min }} \\
\text { (ft) }\end{array}$ & $\begin{array}{l}S_{\text {Max }} \\
\text { (ft) }\end{array}$ \\
\hline \multicolumn{11}{|c|}{ No tide $S_{\text {Dif }}$} \\
\hline 8 & 0.07 & 0.02 & 0.00 & 0.03 & 0.07 & 0.00 & 0.00 & 0.03 & 0.00 & 0.07 \\
\hline 10 & 0.10 & 0.04 & 0.00 & 0.07 & 0.07 & 0.03 & 0.03 & 0.05 & 0.00 & 0.10 \\
\hline 12 & 0.13 & 0.06 & 0.00 & 0.10 & 0.10 & 0.07 & 0.03 & 0.07 & 0.00 & 0.13 \\
\hline 14 & 0.20 & 0.09 & 0.00 & 0.13 & 0.16 & 0.10 & 0.07 & 0.11 & 0.00 & 0.20 \\
\hline 16 & 0.26 & 0.15 & 0.00 & 0.20 & 0.26 & 0.23 & 0.10 & 0.17 & 0.00 & 0.26 \\
\hline \multicolumn{11}{|c|}{ No tide $S_{R}$} \\
\hline 8 & 0.95 & 0.96 & 1.00 & 0.97 & 0.94 & 1.00 & 1.00 & 0.97 & 0.94 & 1.00 \\
\hline 10 & 0.95 & 0.96 & 1.00 & 0.96 & 0.96 & 0.97 & 0.98 & 0.97 & 0.95 & 1.00 \\
\hline 12 & 0.96 & 0.96 & 1.00 & 0.96 & 0.96 & 0.96 & 0.99 & 0.97 & 0.96 & 1.00 \\
\hline 14 & 0.95 & 0.96 & 1.00 & 0.97 & 0.96 & 0.96 & 0.98 & 0.97 & 0.95 & 1.00 \\
\hline 16 & 0.95 & 0.95 & 1.00 & 0.96 & 0.95 & 0.94 & 0.98 & 0.96 & 0.94 & 1.00 \\
\hline \multicolumn{11}{|c|}{$+5 \mathrm{ft}$ tide $S_{\text {Dif }}$} \\
\hline 8 & 0.07 & 0.02 & 0.00 & 0.03 & 0.07 & 0.00 & 0.03 & 0.03 & 0.00 & 0.07 \\
\hline 10 & 0.10 & 0.03 & 0.00 & 0.07 & 0.07 & 0.00 & 0.03 & 0.04 & 0.00 & 0.10 \\
\hline 12 & 0.13 & 0.05 & 0.00 & 0.10 & 0.07 & 0.03 & 0.03 & 0.06 & 0.00 & 0.13 \\
\hline 14 & 0.13 & 0.07 & 0.00 & 0.10 & 0.16 & 0.07 & 0.07 & 0.09 & 0.00 & 0.16 \\
\hline 16 & 0.20 & 0.11 & 0.00 & 0.16 & 0.23 & 0.16 & 0.07 & 0.13 & 0.00 & 0.23 \\
\hline \multicolumn{11}{|c|}{$+5 \mathrm{ft}$ tide $S_{R}$} \\
\hline 8 & 0.95 & 0.96 & 1.00 & 0.97 & 0.93 & 1.00 & 0.97 & 0.97 & 0.93 & 1.00 \\
\hline 10 & 0.95 & 0.96 & 1.00 & 0.96 & 0.96 & 1.00 & 0.98 & 0.97 & 0.95 & 1.00 \\
\hline 12 & 0.95 & 0.96 & 1.00 & 0.96 & 0.97 & 0.98 & 0.98 & 0.97 & 0.95 & 1.00 \\
\hline 14 & 0.96 & 0.96 & 1.00 & 0.97 & 0.95 & 0.97 & 0.98 & 0.97 & 0.95 & 1.00 \\
\hline 16 & 0.96 & 0.96 & 1.00 & 0.97 & 0.95 & 0.95 & 0.98 & 0.97 & 0.95 & 1.00 \\
\hline
\end{tabular}

Notes:

Ank $=$ Ankudinov

$\mathrm{CAD}=\mathrm{CADET}$

B3 $=$ Barrass version 3

E2 = Eryuzlu version 2

Hus $=$ Huuska/Guliev

Röm $=$ Römisch

Yosh $=$ Yoshimura

$S_{\text {Ave, }} S_{\text {Min }}, S_{\operatorname{Max}}=$ Average, minimum, and maximum of all 7 squat predictions 
Figure $12 \mathrm{~b}$ is the corresponding comparison of $S_{D i f}$ for the case with $+5 \mathrm{ft}$ high tide. In general, the squat differences are smaller for this deeper depth scenario. Again, using $V_{k}=12 \mathrm{kt}$ as an example, increases in squat range from $S_{D i f}=0.0 \mathrm{ft}\left(S_{R}=1.00\right)$ for Barrass to $S_{D i f}=0.13 \mathrm{ft}\left(S_{R}=0.96\right)$ for Ankudinov predictors. The largest $S_{D i f}=0.23 \mathrm{ft}\left(S_{R}=0.95\right)$ for Huuska/Guliev occurs at $V_{k}=16 \mathrm{kt}$. Therefore, at speeds of $V_{k}=12 \mathrm{kt}$ in this deeper scenario with high tide, one can expect average decreases in squat over the deeper mound up to $0.06 \mathrm{ft}$ or 3 percent compared to the same transit over the shallower entrance channel. Again, these small differences are not significant for the high tide condition.

\section{Fully loaded ship}

\section{Entrance channel transit}

Figure 13 shows maximum predicted ship squat, $S_{\text {Max }}$, as a function of ship speed for the fully loaded ( $T=47.5 \mathrm{ft}$ ) Susan Maersk containership in the main entrance channel. This figure is similar to Figure 10 for the lightloaded ship. Figure 13a is for the no tide condition at a depth of $h=53 \mathrm{ft}$ and Figure $13 \mathrm{~b}$ is the analogous figure for the high tide $(+5 \mathrm{ft})$ water depth of $h=58 \mathrm{ft}$. Table 14 lists the squat values that are plotted in these figures for each water depth as a function of ship speed and predictor.

For the no tide condition, the $U K C=5.5 \mathrm{ft}$ (i.e., $53-47.5 \mathrm{ft}$ ). Figure 13a shows that the CADET and Römisch are on the "low" side and the Ankudinov and Barrass predictions are on the "high" side of the squat predictions. In this case, the Ankudinov and Barrass predictions overlap each other. Again using $V_{k}=12 \mathrm{kt}$ as an example, squat ranges from $S_{M a x}=1.46$ to $3.08 \mathrm{ft}$, with an average of $2.44 \mathrm{ft}$. The minimum and maximum squat values correspond to the CADET and Barrass predictions, respectively.

For the high tide condition shown in Figure $14 \mathrm{~b}$, the $U K C=10.5 \mathrm{ft}$ (i.e., $58.0-47.5 \mathrm{ft}$ ). The CADET and Barrass bracket the squat predictions. With $V_{k}=12 \mathrm{kt}$ as an example, squat ranges from $S_{\operatorname{Max}}=1.32$ to $3.08 \mathrm{ft}$, with an average of $2.26 \mathrm{ft}$. The minimum and maximum squat values correspond to the CADET and Barrass, respectively. The Barrass prediction is unchanged from the light-loaded ship as it is not affected by changes in the water depth and the ship draft is sufficient even as the light-loaded condition to produce the maximum squat. Also, the Barrass squat prediction is the maximum of all the predictions, the same as with the shallower depth of $h=53 \mathrm{ft}$. 
Figure 13. Ship squat for fully loaded ( $T=47.5 \mathrm{ft}$ ) Susan Maersk containership during channel transit for Ankudinov, CADET, Barrass, Eryuzlu, Huuska, Römisch, and Yoshimura predictions (a) no tide ( $h=53 \mathrm{ft}$ ) and (b) high tide ( $h=58 \mathrm{ft})$.

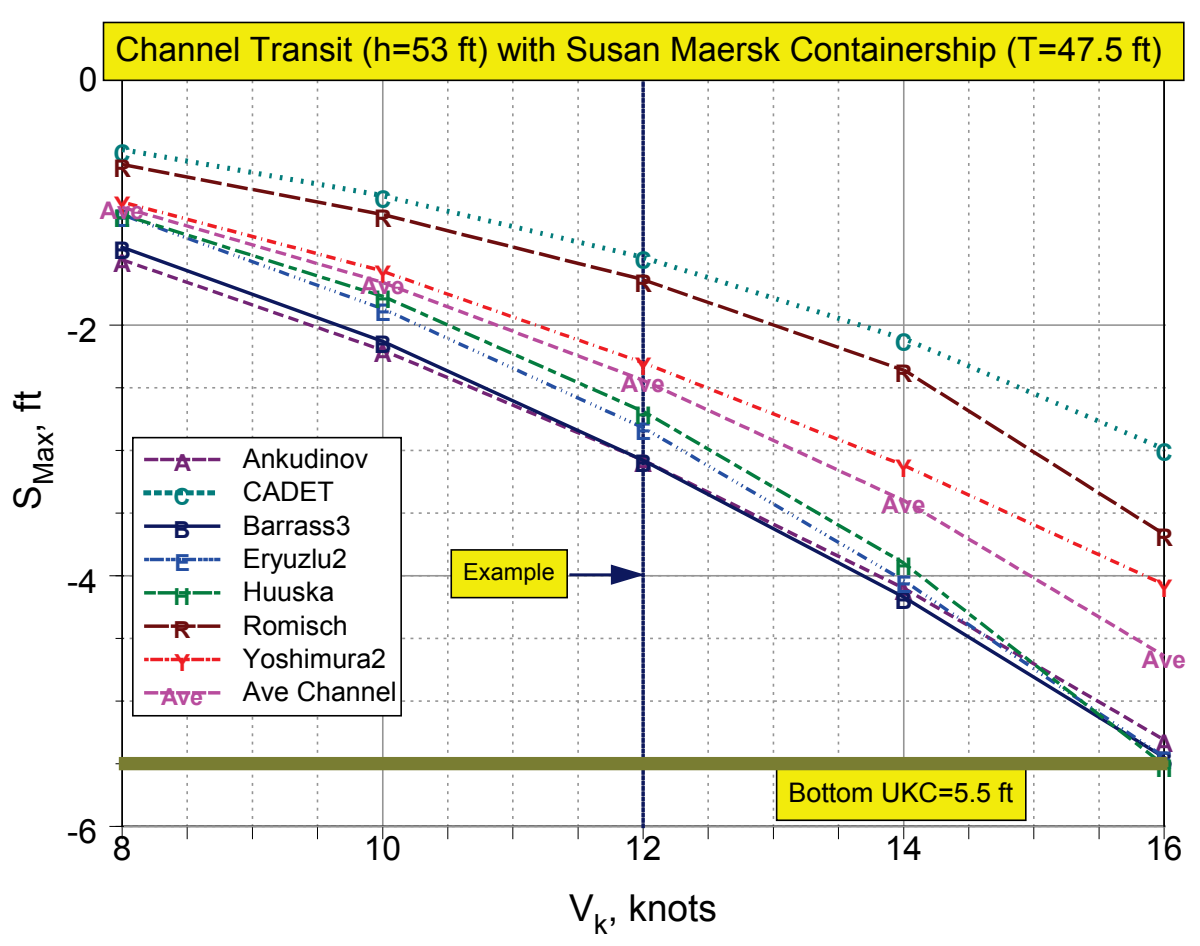

(a)

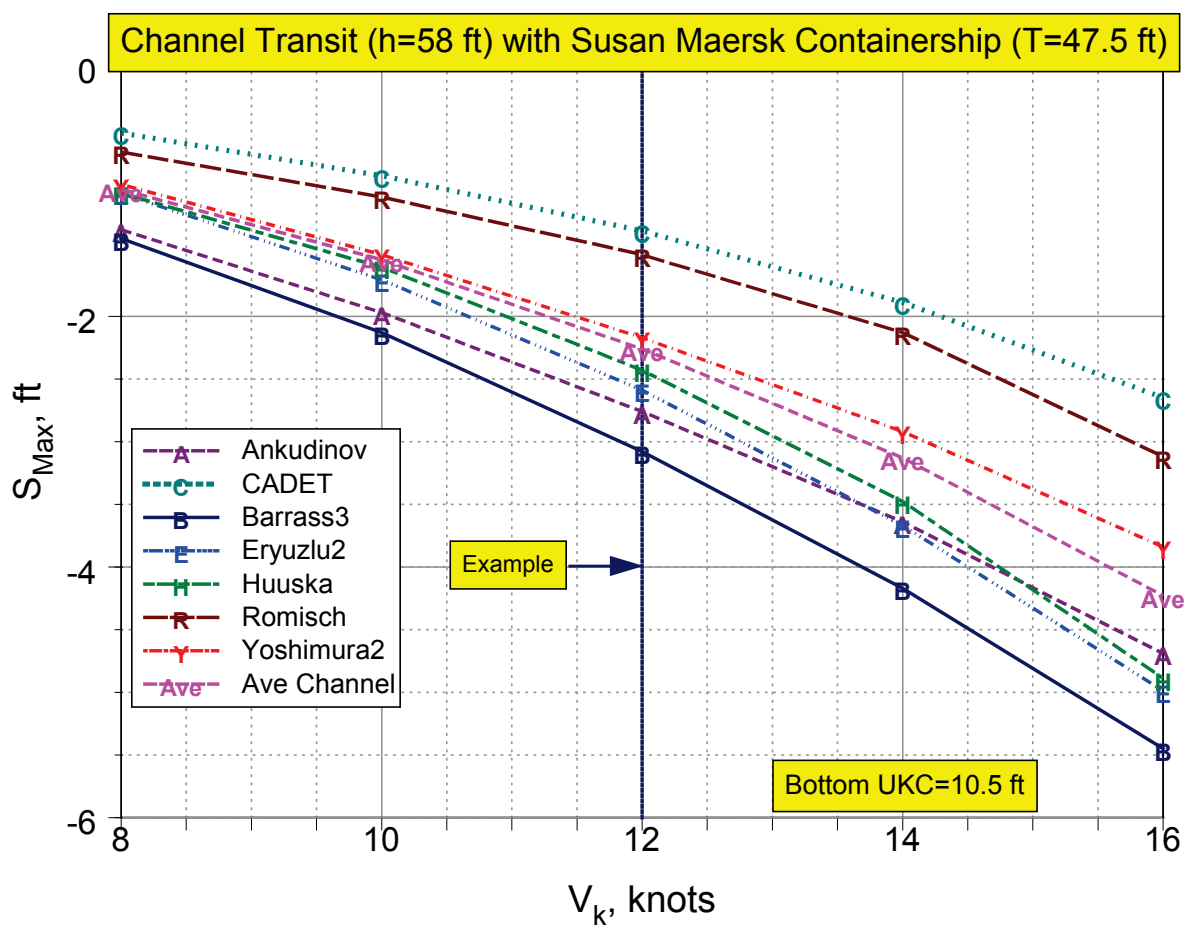

(b) 
Table 14. Ship squat predictions for fully loaded Susan Maersk during channel transit.

\begin{tabular}{|c|c|c|c|c|c|c|c|c|c|c|}
\hline $\begin{array}{l}\text { Spd } \\
\text { (kt) }\end{array}$ & $\begin{array}{l}\text { Ank } \\
\text { (ft) }\end{array}$ & $\begin{array}{l}\text { CAD } \\
\text { (ft) }\end{array}$ & $\begin{array}{l}\mathrm{B} 3 \\
\text { (ft) }\end{array}$ & $\begin{array}{l}\text { E2 } \\
\text { (ft) }\end{array}$ & $\begin{array}{l}\text { Hus } \\
\text { (ft) }\end{array}$ & $\begin{array}{l}\text { Röm } \\
\text { (ft) }\end{array}$ & $\begin{array}{l}\text { Yosh } \\
\text { (ft) }\end{array}$ & $\begin{array}{l}S_{\text {Ave }} \\
\text { (ft) }\end{array}$ & $\begin{array}{l}S_{\text {Min }} \\
(\mathrm{ft})\end{array}$ & $\begin{array}{l}S_{\text {Max }} \\
\text { (ft) }\end{array}$ \\
\hline \multicolumn{11}{|c|}{$h=53 \mathrm{ft}$} \\
\hline 8 & 1.48 & 0.60 & 1.38 & 1.12 & 1.12 & 0.72 & 1.02 & 1.06 & 0.60 & 1.48 \\
\hline 10 & 2.20 & 0.97 & 2.13 & 1.87 & 1.77 & 1.12 & 1.57 & 1.66 & 0.97 & 2.20 \\
\hline 12 & 3.08 & 1.46 & 3.08 & 2.82 & 2.69 & 1.64 & 2.30 & 2.44 & 1.46 & 3.08 \\
\hline 14 & 4.10 & 2.11 & 4.17 & 4.04 & 3.90 & 2.36 & 3.12 & 3.40 & 2.11 & 4.17 \\
\hline 16 & 5.31 & 2.99 & 5.45 & 5.45 & 5.51 & 3.67 & 4.07 & 4.64 & 2.99 & 5.51 \\
\hline \multicolumn{11}{|c|}{$h=58 \mathrm{ft}$} \\
\hline 8 & 1.31 & 0.54 & 1.38 & 1.02 & 1.02 & 0.69 & 0.95 & 0.99 & 0.54 & 1.38 \\
\hline 10 & 1.97 & 0.88 & 2.13 & 1.71 & 1.61 & 1.05 & 1.51 & 1.55 & 0.88 & 2.13 \\
\hline 12 & 2.76 & 1.32 & 3.08 & 2.59 & 2.43 & 1.51 & 2.17 & 2.26 & 1.32 & 3.08 \\
\hline 14 & 3.64 & 1.89 & 4.17 & 3.67 & 3.48 & 2.13 & 2.92 & 3.13 & 1.89 & 4.17 \\
\hline 16 & 4.69 & 2.65 & 5.45 & 4.99 & 4.89 & 3.12 & 3.84 & 4.23 & 2.65 & 5.45 \\
\hline \multicolumn{11}{|c|}{ Notes: } \\
\hline \multicolumn{11}{|c|}{ Ank = Ankudinov } \\
\hline \multicolumn{11}{|c|}{$\mathrm{CAD}=\mathrm{CADET}$} \\
\hline \multicolumn{11}{|c|}{ B3 = Barrass version 3} \\
\hline \multicolumn{11}{|c|}{ E2 = Eryuzlu version 2} \\
\hline \multicolumn{11}{|c|}{ Hus = Huuska/Guliev } \\
\hline \multicolumn{11}{|c|}{ Röm = Römisch } \\
\hline \multicolumn{11}{|c|}{ Yosh $=$ Yoshimura } \\
\hline$S_{\text {Ave }}$ & $S_{\text {Max }}$ & & & & & . & & & & \\
\hline
\end{tabular}

For the fully loaded ship with no tide, the $U K C$ is not much larger than the predicted squat. Therefore, this will be the worst case scenario for transits when one includes vertical ship motions and required $U K C_{M i n}$. Again, these values will be discussed in the next Chapter.

\section{Mound transit}

Figure 14 is the analogous figure for mound transits and the fully loaded Susan Maersk with no tide (Figure 14a) and $+5 \mathrm{ft}$ high tide (Figure 14b) in water depths of $h=55$ and $60 \mathrm{ft}$, respectively. Table 15 lists the corresponding squat values at these two water depths. 
Figure 14. Ship squat for fully loaded ( $T=47.5 \mathrm{ft}$ ) Susan Maersk containership during mound transit for Ankudinov, CADET, Barrass, Eryuzlu, Huuska, Römisch, and Yoshimura predictions

(a) no tide ( $h=55 \mathrm{ft}$ ) and (b) high tide $(h=60 \mathrm{ft})$.

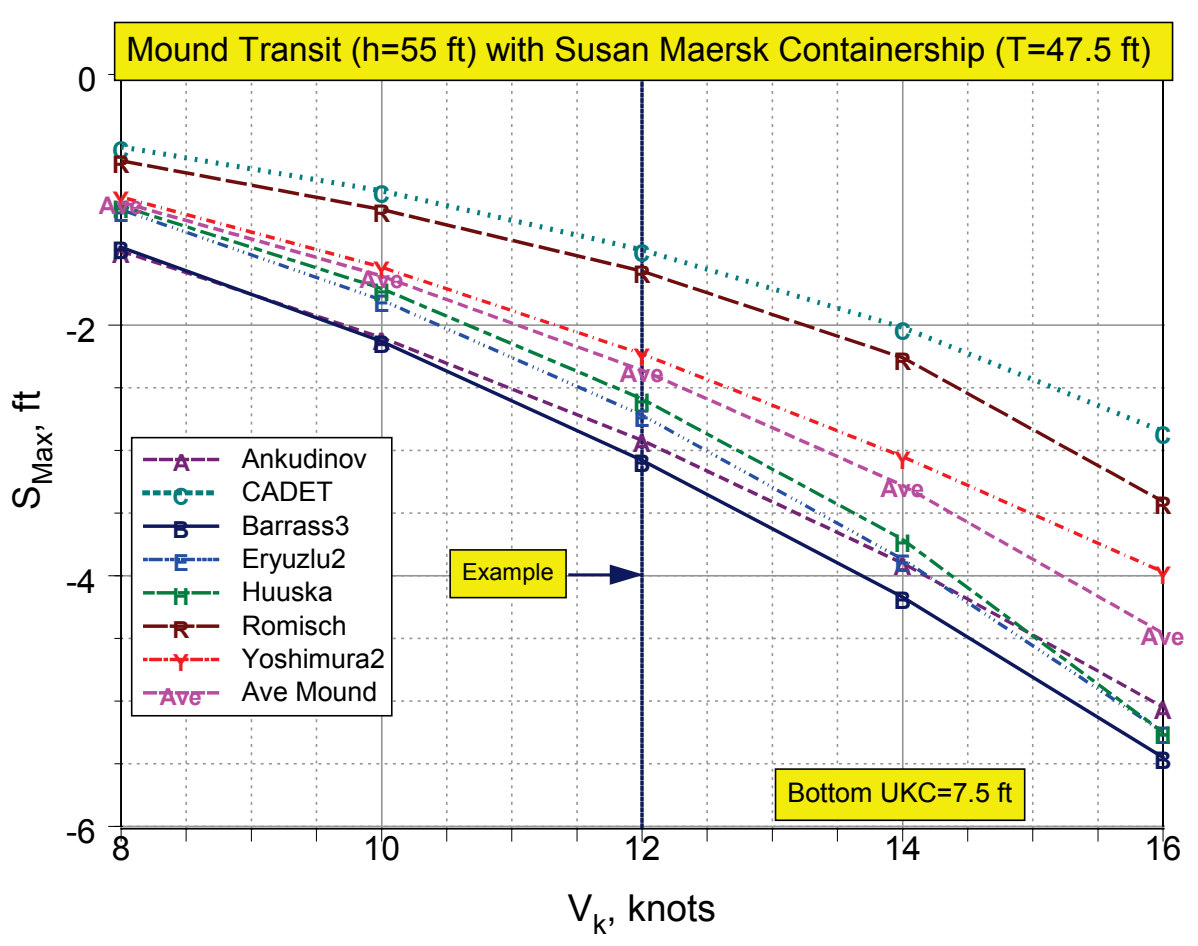

(a)

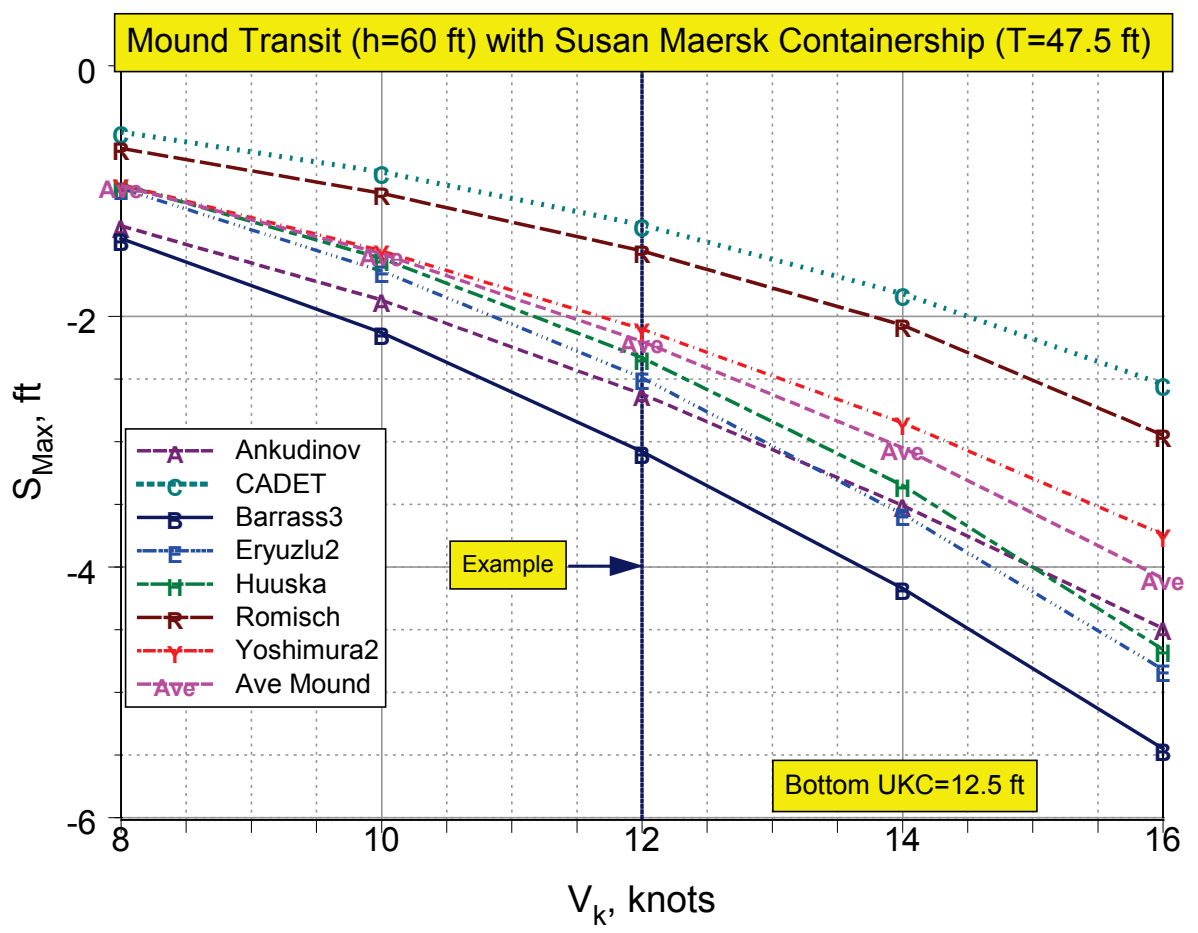

(b) 
Table 15. Ship squat predictions for fully loaded Susan Maersk during mound transit.

\begin{tabular}{|l|l|l|l|l|l|l|l|l|l|l|}
\hline $\begin{array}{l}\text { Spd } \\
(\mathrm{kt})\end{array}$ & $\begin{array}{l}\text { Ank } \\
(\mathrm{ft})\end{array}$ & $\begin{array}{l}\text { CAD } \\
(\mathrm{ft})\end{array}$ & $\begin{array}{l}\text { B3 } \\
(\mathrm{ft})\end{array}$ & $\begin{array}{l}\text { E2 } \\
(\mathrm{ft})\end{array}$ & $\begin{array}{l}\text { Hus } \\
(\mathrm{ft})\end{array}$ & $\begin{array}{l}\text { Röm } \\
(\mathrm{ft})\end{array}$ & $\begin{array}{l}\text { Yosh } \\
(\mathrm{ft})\end{array}$ & $\begin{array}{l}S_{\text {Ave }} \\
(\mathrm{ft})\end{array}$ & $\begin{array}{l}S_{\text {Min }} \\
(\mathrm{ft})\end{array}$ & $\begin{array}{l}S_{\text {Max }} \\
(\mathrm{ft})\end{array}$ \\
\hline $\mathrm{h}=55 \mathrm{ft}$ \\
\hline 8 & 1.41 & 0.58 & 1.38 & 1.08 & 1.05 & 0.69 & 0.98 & 1.02 & 0.58 & 1.41 \\
\hline 10 & 2.10 & 0.93 & 2.13 & 1.80 & 1.71 & 1.08 & 1.54 & 1.61 & 0.93 & 2.13 \\
\hline 12 & 2.92 & 1.40 & 3.08 & 2.72 & 2.59 & 1.57 & 2.23 & 2.36 & 1.40 & 3.08 \\
\hline 14 & 3.90 & 2.02 & 4.17 & 3.87 & 3.71 & 2.26 & 3.05 & 3.28 & 2.02 & 4.17 \\
\hline 16 & 5.05 & 2.85 & 5.45 & 5.25 & 5.25 & 3.41 & 3.97 & 4.46 & 2.85 & 5.45 \\
\hline$h=60 \mathrm{ft}$ & & & & & & & & \\
\hline 8 & 1.28 & 0.53 & 1.38 & 0.98 & 0.95 & 0.66 & 0.95 & 0.96 & 0.53 & 1.38 \\
\hline 10 & 1.87 & 0.85 & 2.13 & 1.64 & 1.54 & 1.02 & 1.48 & 1.50 & 0.85 & 2.13 \\
\hline 12 & 2.62 & 1.27 & 3.08 & 2.49 & 2.33 & 1.48 & 2.10 & 2.20 & 1.27 & 3.08 \\
\hline 14 & 3.51 & 1.82 & 4.17 & 3.58 & 3.35 & 2.07 & 2.85 & 3.05 & 1.82 & 4.17 \\
\hline 16 & 4.49 & 2.54 & 5.45 & 4.82 & 4.66 & 2.95 & 3.74 & 4.09 & 2.54 & 5.45 \\
\hline
\end{tabular}

Notes:

Ank $=$ Ankudinov

CAD = CADET

$\mathrm{B} 3=$ Barrass version 3

E2 = Eryuzlu version 2

Hus $=$ Huuska/Guliev

Röm = Römisch

Yosh $=$ Yoshimura

$S_{\text {Ave }}, S_{\operatorname{Min}}, S_{\operatorname{Max}}=$ Average, minimum, and maximum of all 7 squat predictions

For the no tide condition at a depth of $h=55 \mathrm{ft}$, the $U K C=7.5 \mathrm{ft}$ (i.e., 55.0 $-47.5 \mathrm{ft}$ ). Figure 14a shows that the CADET and Römisch are again on the "low" side and the Ankudinov and Barrass are on the "high" side of the predictions. Again, using $V_{k}=12 \mathrm{kt}$ as an example, squat ranges from $S_{M a x}$ $=1.40$ to $3.08 \mathrm{ft}$, with an average of $2.36 \mathrm{ft}$. The minimum squat values correspond to the CADET predictions. The maximum squat values correspond with the Barrass predictions.

For the high tide condition at $h=60 \mathrm{ft}, U K C=12.5 \mathrm{ft}$ (i.e., $60.0-47.5 \mathrm{ft}$ ). Figure $14 \mathrm{~b}$ shows that the CADET and Barrass again bracket the squat predictions. Using $V_{k}=12 \mathrm{kt}$ as an example, squat ranges from $S_{\text {Max }}=1.27$ to $3.08 \mathrm{ft}$, with an average of $2.20 \mathrm{ft}$. The minimum and maximum squat values correspond to the CADET and Barrass, respectively. Again, the Barrass prediction is the maximum of all the predictions, the same as for 
the channel transits since it does not vary due to open water changes in water depth.

\section{Comparison of transits}

As was done for the light-loaded ships, this section compares the differences $S_{\text {Dif }}$ and ratios $S_{R}$ in ship squat between the mound and channel transits. Figure 15 compares $S_{\text {Dif }}$ for transits with no tide (Figure 15a) and $+5 \mathrm{ft} \mathrm{high}$ tide (Figure 15b) for all seven predictors. Table 16 lists $S_{D i f}$ and $S_{R}$ for both no tide and $+5 \mathrm{ft}$ tide advantage conditions.

Again using $V_{k}=12 \mathrm{kt}$ as an example for the no tide condition, squat increases range from $S_{D i f}=0.0 \mathrm{ft}\left(S_{R}=1.00\right)$ for Barrass to $S_{D i f}=0.16 \mathrm{ft}$ $\left(S_{R}=1.18\right)$ for Ankudinov predictors. The largest $S_{D i f}=0.26 \mathrm{ft}\left(S_{R}=0.93\right)$ occurs for Römisch at the fastest ship speed of $V_{k}=16 \mathrm{kt}$. Thus, at speeds of $V_{k}=12 \mathrm{kt}$ one can expect average decreases in squat over the deeper mound up to $0.08 \mathrm{ft}$ or 3 percent compared to the same transit over the shallower entrance channel. Again, this is a relatively insignificant change in squat.

For the high tide condition, the squat differences are smaller for this deeper water scenario. Again, using $V_{k}=12 \mathrm{kt}$ as an example, increases in squat range from $S_{D i f}=0.0 \mathrm{ft}\left(S_{R}=1.00\right)$ for Barrass to $S_{D i f}=0.13 \mathrm{ft}\left(S_{R}=\right.$ 0.95) for Ankudinov predictors. Even at the fastest ship speed of $V_{k}=$ $16 \mathrm{kt}$, the largest $S_{D i f}=0.23 \mathrm{ft}\left(S_{R}=0.95\right)$ for Huuska/Guliev. Therefore, at speeds of $V_{k}=12 \mathrm{kt}$ in this deeper scenario with high tide, one can expect average decreases in squat over the deeper mound up to $0.07 \mathrm{ft}$ or 3 percent compared to the same transit over the shallower entrance channel.

\section{Summary}

Seven predictors of ship squat were compared for both the lightly and fully loaded Susan Maersk transits in the Ambrose Channel for a range of ship speeds from 8 to $16 \mathrm{kt}$. The purpose was to indicate (a) the relative amount of $U K C$ required for ship squat for Ankudinov, CADET, Barrass, Eryuzlu, Huuska/Guliev, Römisch, and Yoshimura predictors and (b) the effect of the deeper mound on ship squat relative to the shallower channel transits. The largest squat will occur for the fully loaded ship in the channel with the no tide conditions since the $U K C$ is the smallest and the ship will "feel" the bottom more. The $U K C$ in this case is $5.5 \mathrm{ft}$ (i.e., $53.0-47.5 \mathrm{ft}$ ). For a ship transiting the channel at a speed of $12 \mathrm{kt}$, squat can range from 1.46 to 
Figure 15. Ship squat differences for mound vs. channel transits with Susan Maersk containership ( $T=47.5 \mathrm{ft}$ ) (a) no tide predictions, (b) $+5 \mathrm{ft}$ tide advantage predictions.

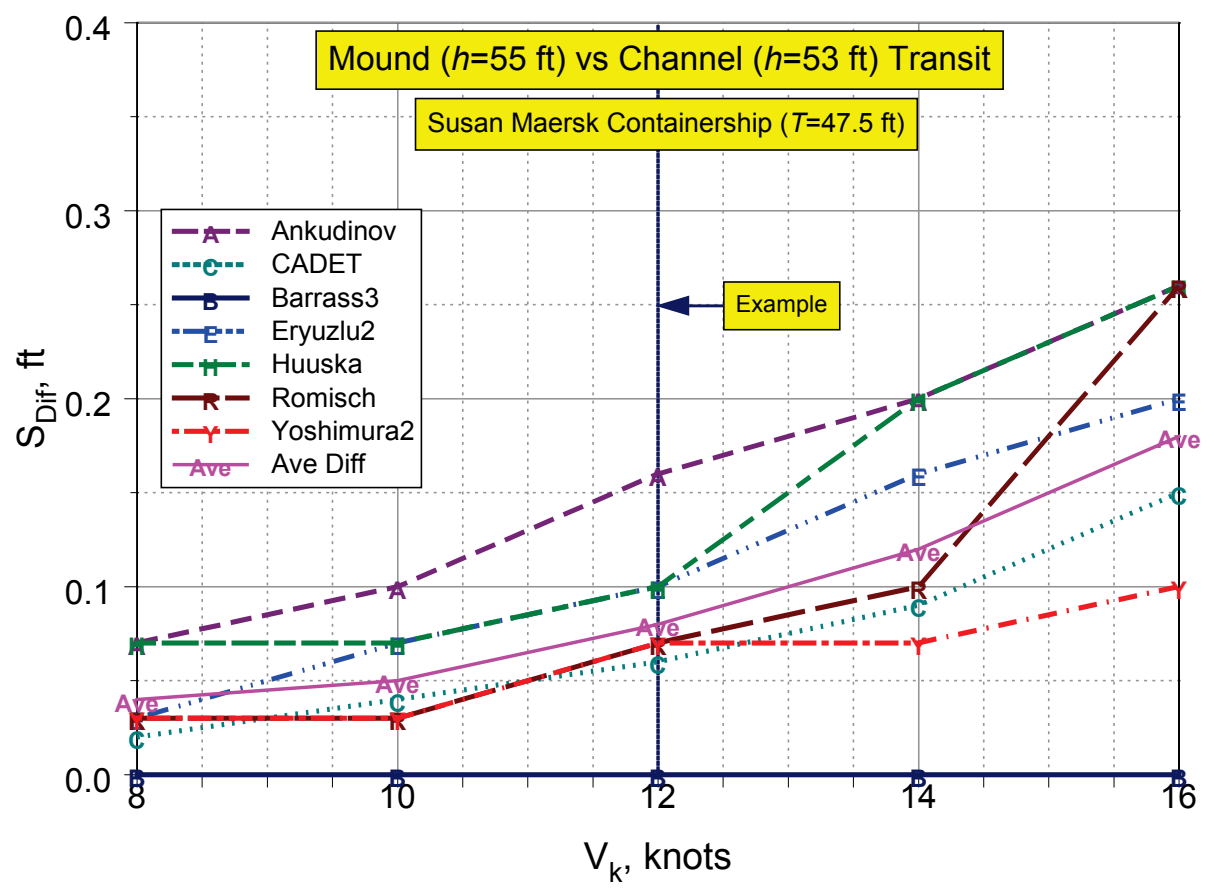

(a)

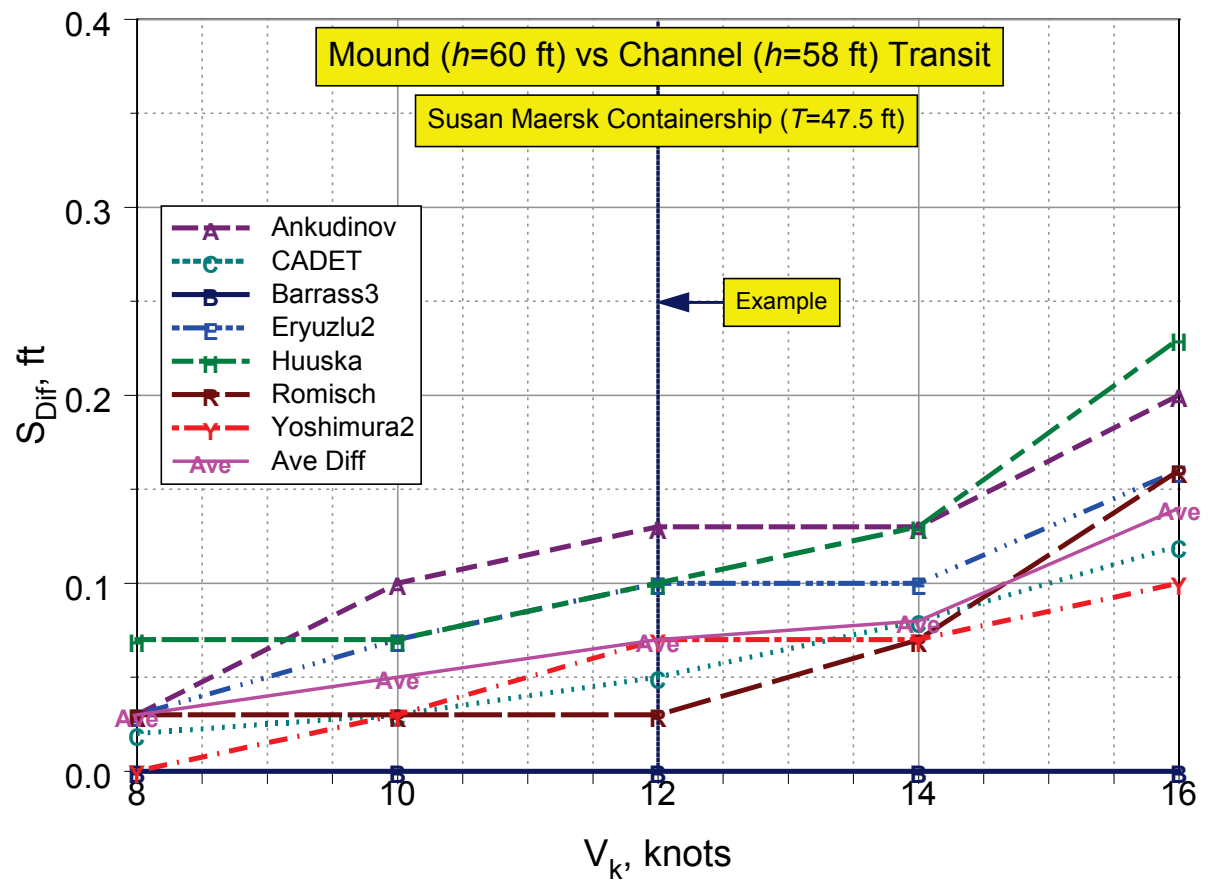

(b) 
Table 16. Effect of tides on squat differences $S_{D i f}$ and ratios $S_{R}$ for mound and channel transits for fully loaded Susan Maersk containership.

\begin{tabular}{|c|c|c|c|c|c|c|c|c|c|c|}
\hline $\begin{array}{l}\text { Spd } \\
\text { (kt) }\end{array}$ & $\begin{array}{l}\text { Ank } \\
\text { (ft) }\end{array}$ & $\begin{array}{l}\text { CAD } \\
\text { (ft) }\end{array}$ & $\begin{array}{l}\text { B3 } \\
\text { (ft) }\end{array}$ & $\begin{array}{l}\text { E2 } \\
\text { (ft) }\end{array}$ & $\begin{array}{l}\text { Hus } \\
\text { (ft) }\end{array}$ & \begin{tabular}{|l|} 
Röm \\
(ft)
\end{tabular} & \begin{tabular}{|l|} 
Yosh \\
(ft)
\end{tabular} & $\begin{array}{l}\begin{array}{l}S_{\text {Ave }} \\
\text { (ft) }\end{array}\end{array}$ & $\begin{array}{l}S_{\text {Min }} \\
\text { (ft) }\end{array}$ & $\begin{array}{l}S_{\text {Max }} \\
\text { (ft) }\end{array}$ \\
\hline \multicolumn{11}{|c|}{ No tide $S_{\text {Dif }}$} \\
\hline 8 & 0.07 & 0.02 & 0.00 & 0.03 & 0.07 & 0.03 & 0.03 & 0.04 & 0.00 & 0.07 \\
\hline 10 & 0.10 & 0.04 & 0.00 & 0.07 & 0.07 & 0.03 & 0.03 & 0.05 & 0.00 & 0.10 \\
\hline 12 & 0.16 & 0.06 & 0.00 & 0.10 & 0.10 & 0.07 & 0.07 & 0.08 & 0.00 & 0.16 \\
\hline 14 & 0.20 & 0.09 & 0.00 & 0.16 & 0.20 & 0.10 & 0.07 & 0.12 & 0.00 & 0.20 \\
\hline 16 & 0.26 & 0.15 & 0.00 & 0.20 & 0.26 & 0.26 & 0.10 & 0.18 & 0.00 & 0.26 \\
\hline \multicolumn{11}{|c|}{ No tide $S_{R}$} \\
\hline 8 & 0.96 & 0.96 & 1.00 & 0.97 & 0.94 & 0.95 & 0.97 & 0.96 & 0.94 & 1.00 \\
\hline 10 & 0.96 & 0.96 & 1.00 & 0.96 & 0.96 & 0.97 & 0.98 & 0.97 & 0.96 & 1.00 \\
\hline 12 & 0.95 & 0.96 & 1.00 & 0.97 & 0.96 & 0.96 & 0.97 & 0.97 & 0.95 & 1.00 \\
\hline 14 & 0.95 & 0.96 & 1.00 & 0.96 & 0.95 & 0.96 & 0.98 & 0.96 & 0.95 & 1.00 \\
\hline 16 & 0.95 & 0.95 & 1.00 & 0.96 & 0.95 & 0.93 & 0.98 & 0.96 & 0.93 & 1.00 \\
\hline \multicolumn{11}{|c|}{$+5 \mathrm{ft}$ tide $S_{\text {Dif }}$} \\
\hline 8 & 0.03 & 0.02 & 0.00 & 0.03 & 0.07 & 0.03 & 0.00 & 0.03 & 0.00 & 0.07 \\
\hline 10 & 0.10 & 0.03 & 0.00 & 0.07 & 0.07 & 0.03 & 0.03 & 0.05 & 0.00 & 0.10 \\
\hline 12 & 0.13 & 0.05 & 0.00 & 0.10 & 0.10 & 0.03 & 0.07 & 0.07 & 0.00 & 0.13 \\
\hline 14 & 0.13 & 0.08 & 0.00 & 0.10 & 0.13 & 0.07 & 0.07 & 0.08 & 0.00 & 0.13 \\
\hline 16 & 0.20 & 0.12 & 0.00 & 0.16 & 0.23 & 0.16 & 0.10 & 0.14 & 0.00 & 0.23 \\
\hline \multicolumn{11}{|c|}{$+5 \mathrm{ft}$ tide $S_{R}$} \\
\hline 8 & 0.98 & 0.96 & 1.00 & 0.97 & 0.94 & 0.95 & 1.00 & 0.97 & 0.94 & 1.00 \\
\hline 10 & 0.95 & 0.96 & 1.00 & 0.96 & 0.96 & 0.97 & 0.98 & 0.97 & 0.95 & 1.00 \\
\hline 12 & 0.95 & 0.96 & 1.00 & 0.96 & 0.96 & 0.98 & 0.97 & 0.97 & 0.95 & 1.00 \\
\hline 14 & 0.96 & 0.96 & 1.00 & 0.97 & 0.96 & 0.97 & 0.98 & 0.97 & 0.96 & 1.00 \\
\hline 16 & 0.96 & 0.96 & 1.00 & 0.97 & 0.95 & 0.95 & 0.97 & 0.97 & 0.95 & 1.00 \\
\hline
\end{tabular}

Notes:

Ank $=$ Ankudinov

$\mathrm{CAD}=\mathrm{CADET}$

B3 $=$ Barrass version 3

E2 = Eryuzlu version 2

Hus $=$ Huuska/Guliev

Röm $=$ Römisch

Yosh $=$ Yoshimura

$S_{\text {Ave, }} S_{\text {Min }}, S_{\operatorname{Max}}=$ Average, minimum, and maximum of all 7 squat predictions 
$3.08 \mathrm{ft}$, with an average of $2.44 \mathrm{ft}$. Even at a ship speed of $16 \mathrm{kt}$, the squat increases from a low of 2.99 to a high of $5.51 \mathrm{ft}$, with an average of $4.64 \mathrm{ft}$. Therefore, during transits where wave activity is relatively insignificant, ship squat should not be a problem, even at the fastest ship speeds. Of course, one will still want to maintain the required $U K C_{\text {Min }}$ of 2 to $4 \mathrm{ft}$ in the channel and mound reaches, respectively.

For the mound transits with the same fully loaded and no tide conditions, the $U K C$ is $7.5 \mathrm{ft}$ (i.e., $55.0-47.5 \mathrm{ft}$ ). For a ship transiting the channel at a speed of $12 \mathrm{kt}$, squat can range from 1.40 to $3.08 \mathrm{ft}$, with an average of $2.36 \mathrm{ft}$. Even at a ship speed of $16 \mathrm{kt}$, the squat increases from a low of 2.85 to a high of $5.45 \mathrm{ft}$, with an average of $4.46 \mathrm{ft}$. Again, during transits where wave activity is relatively insignificant, ship squat should not be a problem, even at the fastest ship speeds.

For the light-loaded ship, the predicted ship squat is slightly less, plus the shallower draft of $46 \mathrm{ft}$ provides an additional $1.5 \mathrm{ft}$ of $U K C$. Ship squat is not a problem for the high tide condition as the predicted squat is slightly lower and an additional $U K C$ of $5 \mathrm{ft}$ is available. 


\section{Ship Motions and Underkeel Clearance}

As noted in Chapter 2, CADET outputs the wave-induced vertical motion allowances, $A_{j}$, for each ship loading condition, channel reach, and water depth. These $A_{j}$ are based on Equation 4 and are output for each wave condition, transit direction, ship speed, and five critical points. They are composed of the combined effects of heave, pitch, and roll on each of the five critical points. Therefore, the CADET "vertical motion allowances" are equivalent to the generic term "wave-induced vertical ship motions" term.

The FORTRAN program ReadIn_CADET_Allow2 reads in these files and calculates the largest or maximum allowance over all five control points for each wave condition, transit direction, and ship speed. These "maximum values," $A_{M a x}$, are the vertical motion allowances that are used in this report. As previously discussed, $U K C$ is the project depth minus the static draft of the ship. The $U K C_{\text {Net }}$ is obtained by subtracting dynamic squat and these $A_{\text {Max }}$ from the $U K C$.

The first section in this chapter discusses maximum ship displacements which are an indication of the total clearance that is available for vertical ship motions and $U K C_{\text {Net }}$. Both lightly and fully loaded ships are discussed. The next section presents the Phase 1 wave results for the fully loaded ship. The final section describes the Phase 2 wave results for both the lightly and fully loaded ship.

\section{Maximum ship displacements}

The purpose of the maximum ship displacement, $D_{M a x}$, is to indicate the "space" in the water column above the bottom that is available to accommodate wave-induced vertical ship motions after average ship squat, $S_{A v e}$, is subtracted from the $U K C$. As long as the ship motions do not exceed $D_{M a x}$, the ship will be able to safely transit a particular reach without grounding. It is defined as

$$
D_{\text {Max }}=U K C-S_{A v e}
$$

For safety and maneuverability concerns in this study, the sponsor requested a minimum $U K C_{N e t}, U K C_{M i n}$, be maintained as follows: 
Channel transit, reach 1, soft bottom: $U K C_{\text {Min }}=2 \mathrm{ft}$

Mound transit, reach 2, hard bottom: $U K C_{\text {Min }}=4 \mathrm{ft}$

These values of $U K C_{\text {Min }}$ will add to the clearances required in this study.

\section{Light-loaded ship}

Table 17 lists maximum ship displacement $D_{\operatorname{Max}}$ for the channel and mound reaches as a function of ship speed, water depth, and tide level for the lightloaded ship. The mound reach includes a range of water depths up to $2 \mathrm{ft}$ deeper (i.e., $h=56$ and $57 \mathrm{ft}$ for no tide and $h=61$ and $62 \mathrm{ft}$ for high tide) as results indicate that these are reasonable values to dredge this reach to insure safe transits. The $S_{\text {Ave }}$ squat predictions from Chapter 5 are repeated in this table for reference. Although not listed in Chapter 5, the $S_{\text {Ave }}$ predictions for the two additional depths over the mound in Reach 2 were calculated and are shown in this table.

Table 17. Maximum ship displacements $D_{\text {Max }}$ for light-loaded ship.

\begin{tabular}{|c|c|c|c|c|c|c|c|c|}
\hline \multirow{3}{*}{$\begin{array}{l}\text { Speed } \\
\text { (kt) }\end{array}$} & \multicolumn{4}{|c|}{ Ship squat $S_{\text {Ave }}(\mathrm{ft})$} & \multicolumn{4}{|c|}{ Maximum ship displacements $D_{\operatorname{Max}}(\mathrm{ft})$} \\
\hline & \multirow{2}{*}{\begin{tabular}{|l|} 
Channel \\
$h=53 \mathrm{ft}$
\end{tabular}} & \multicolumn{3}{|c|}{ Mound } & \multirow{2}{*}{$\begin{array}{l}\text { Channel } \\
h=53 \mathrm{ft}\end{array}$} & \multicolumn{3}{|c|}{ Mound } \\
\hline & & $h=55 \mathrm{ft}$ & $h=56 \mathrm{ft}$ & $h=57 \mathrm{ft}$ & & $h=55 \mathrm{ft}$ & $h=56 \mathrm{ft}$ & $h=57 \mathrm{ft}$ \\
\hline \multicolumn{9}{|l|}{ No tide } \\
\hline 8 & 1.03 & 1.00 & 0.99 & 0.98 & 5.97 & 8.00 & 9.01 & 10.02 \\
\hline 10 & 1.63 & 1.58 & 1.56 & 1.54 & 5.37 & 7.42 & 8.44 & 9.46 \\
\hline 12 & 2.38 & 2.31 & 2.27 & 2.24 & 4.62 & 6.69 & 7.73 & 8.76 \\
\hline 14 & 3.32 & 3.21 & 3.16 & 3.11 & 3.68 & 5.79 & 6.84 & 7.89 \\
\hline 16 & 4.53 & 4.36 & 4.28 & 4.21 & 2.47 & 4.64 & 5.72 & 6.79 \\
\hline \multicolumn{9}{|c|}{ High tide $(+5 \mathrm{ft})$} \\
\hline & $h=58 \mathrm{ft}$ & $h=60 \mathrm{ft}$ & $h=61 \mathrm{ft}$ & $h=62 \mathrm{ft}$ & $h=58 \mathrm{ft}$ & $h=60 \mathrm{ft}$ & $h=61 \mathrm{ft}$ & $h=62 \mathrm{ft}$ \\
\hline 8 & 0.97 & 0.94 & 0.93 & 0.91 & 11.03 & 13.06 & 14.07 & 15.09 \\
\hline 10 & 1.52 & 1.48 & 1.45 & 1.44 & 10.48 & 12.52 & 13.55 & 14.56 \\
\hline 12 & 2.21 & 2.15 & 2.12 & 2.10 & 9.79 & 11.85 & 12.88 & 13.90 \\
\hline 14 & 3.06 & 2.98 & 2.94 & 2.89 & 8.94 & 11.02 & 12.06 & 13.11 \\
\hline 16 & 4.13 & 4.00 & 3.94 & 3.89 & 7.87 & 10.00 & 11.06 & 12.11 \\
\hline
\end{tabular}

Notes:

1. $U K C_{\text {Min }}=2 \mathrm{ft}$ for channel with soft bottom.

2. $U K C_{\text {Min }}=4 \mathrm{ft}$ for mound with hard bottom. 
For channel transits with a project depth of $h=53 \mathrm{ft}$ (no tide), $S_{\text {Ave }}$ ranges from 1.03 to $4.53 \mathrm{ft}$ with a corresponding $D_{\operatorname{Max}}$ of 5.97 to $2.47 \mathrm{ft}$ at ship speeds from $V_{k}=8$ to $16 \mathrm{kt}$. At $V_{k}=12 \mathrm{kt}, D_{\operatorname{Max}}=4.62 \mathrm{ft}$ which still leaves $2.62 \mathrm{ft}$ for ship motions after allowing for the $U K C_{\text {Min }}$ of $2 \mathrm{ft}$. This should be sufficient to prevent grounding at this ship speed. The faster ship speeds would probably require the use of some or all of the $U K C_{\operatorname{Min}}$ to prevent grounding as the $D_{\operatorname{Max}}$ are smaller.

For mound transits with a project depth of $h=55 \mathrm{ft}$ (no tide), $S_{\text {Ave }}$ ranges from 1.00 to $4.36 \mathrm{ft}$ with corresponding $D_{M a x}$ of 8.00 to $4.64 \mathrm{ft}$ for the same range of ship speeds. Although these values are larger than the channel transit values, the mound transit requires $U K C_{\operatorname{Min}}$ of $4 \mathrm{ft}$. At $V_{k}=12 \mathrm{kt}$, the $D_{\text {Max }}=6.69 \mathrm{ft}$ which leaves $2.69 \mathrm{ft}$ available for ship motions, about the same as the channel transit. The $D_{\operatorname{Max}}$ are reduced for faster ship speeds similarly to channel transits. The deeper mound depths of $h=56$ and $57 \mathrm{ft}$ will provide approximately 1 to $2 \mathrm{ft}$ additional $D_{\operatorname{Max}}$ due to the increased dredging. These deeper depths should provide sufficient $D_{\text {Max }}$ to accommodate ship motions and prevent grounding for the light-loaded ship.

Finally, for high tide transits in both channel and mound, ship squat values are reduced as expected due to the deeper water depths. The corresponding maximum ship displacement is also increased due to the tide. For lightloaded transits in the channel at $V_{k}=12 \mathrm{kt}$, the $D_{\operatorname{Max}}=9.79 \mathrm{ft}$ which leaves $7.79 \mathrm{ft}$ to accommodate ship motions after allowing for the $U K C_{\text {Min }}=2 \mathrm{ft}$. For mound transits at $V_{k}=12 \mathrm{kt}$, the $D_{M a x}=11.85 \mathrm{ft}$ which leaves $7.85 \mathrm{ft}$ to accommodate ship motions after allowing for the $U K C_{\text {Min }}=4 \mathrm{ft}$. These values should easily accommodate increased values of wave-induced ship motions without grounding.

\section{Fully loaded ship}

Table 18 lists maximum ship displacement $D_{\operatorname{Max}}$ for the channel and mound reaches as a function of ship speed, water depth, and tide level for the fully loaded ship. It is organized similarly to Table 17 for the lightloaded ship.

For channel transits ( $h=53 \mathrm{ft}$ and no tide) with the fully loaded ship, $S_{\text {Ave }}$ ranges from 1.06 to $4.64 \mathrm{ft}$ with a corresponding $D_{\operatorname{Max}}$ of 4.44 to $0.86 \mathrm{ft}$ at ship speeds from $V_{k}=8$ to $16 \mathrm{kt}$. At $V_{k}=12 \mathrm{kt}, D_{\operatorname{Max}}=3.06 \mathrm{ft}$ which only leaves $1.06 \mathrm{ft}$ for ship motions after allowing for the $U K C_{\text {Min }}$ of $2 \mathrm{ft}$. This should be sufficient to prevent grounding at this ship speed, but will 
Table 18. Maximum ship displacements $D_{\operatorname{Max}}$ for fully loaded ship.

\begin{tabular}{|l|l|l|l|l|l|l|l|l|l|}
\hline \multirow{2}{*}{$\begin{array}{l}\text { Speed } \\
\text { (kt) }\end{array}$} & \multicolumn{3}{|c|}{ Ship squat $S_{\text {Ave }}(\mathrm{ft})$} & \multicolumn{3}{c|}{ Maximum ship displacements $D_{\text {Max }}(\mathrm{ft})$} \\
\cline { 2 - 9 } & Channel & \multicolumn{3}{|c|}{ Mound } & Channel & \multicolumn{3}{c|}{ Mound } \\
\hline No tide & $h=55 \mathrm{ft}$ & $h=56 \mathrm{ft}$ & $h=57 \mathrm{ft}$ & $h=53 \mathrm{ft}$ & $h=55 \mathrm{ft}$ & $h=56 \mathrm{ft}$ & $h=57 \mathrm{ft}$ \\
\hline 8 & 1.06 & 1.02 & 1.01 & 1.00 & 4.44 & 6.48 & 7.49 & 8.50 \\
\hline 10 & 1.66 & 1.61 & 1.60 & 1.57 & 3.84 & 5.89 & 6.90 & 7.93 \\
\hline 12 & 2.44 & 2.36 & 2.33 & 2.29 & 3.06 & 5.14 & 6.17 & 7.21 \\
\hline 14 & 3.40 & 3.28 & 3.23 & 3.18 & 2.10 & 4.22 & 5.27 & 6.32 \\
\hline 16 & 4.64 & 4.46 & 4.38 & 4.31 & 0.86 & 3.04 & 4.12 & 5.19 \\
\hline High tide (+5 ft) & & & & & & & \\
\hline & $h=58 \mathrm{ft}$ & $h=60 \mathrm{ft}$ & $h=61 \mathrm{ft}$ & $h=62 \mathrm{ft}$ & $h=58 \mathrm{ft}$ & $h=60 \mathrm{ft}$ & $h=61 \mathrm{ft}$ & $h=62 \mathrm{ft}$ \\
\hline 8 & 0.99 & 0.96 & 0.95 & 0.93 & 9.51 & 11.54 & 12.55 & 13.57 \\
\hline 10 & 1.55 & 1.50 & 1.49 & 1.48 & 8.95 & 11.00 & 12.01 & 13.02 \\
\hline 12 & 2.26 & 2.20 & 2.17 & 2.14 & 8.24 & 10.30 & 11.33 & 12.36 \\
\hline 14 & 3.13 & 3.05 & 3.01 & 2.96 & 7.37 & 9.45 & 10.49 & 11.54 \\
\hline 16 & 4.23 & 4.09 & 4.03 & 3.98 & 6.27 & 8.41 & 9.47 & 10.52 \\
\hline
\end{tabular}

Notes:

1. $U K C_{\text {Min }}=2 \mathrm{ft}$ for channel with soft bottom.

2. $U K \mathrm{KMin}_{\mathrm{Min}}=4 \mathrm{ft}$ for mound with hard bottom.

probably require the use of some of the $U K C_{\text {Min }}$ for most wave conditions. Faster ship speeds would show similar trends, with $D_{\operatorname{Max}}$ continuing to decrease as speed increases. In Table 18 the value of $D_{M a x}=0.86 \mathrm{ft}$ at $V_{k}=16$ $\mathrm{kt}$ is highlighted in yellow to indicate that there is insufficient clearance to provide for the full $U K C_{\text {Min }}$ (i.e., $2 \mathrm{ft}$ channel and $4 \mathrm{ft}$ mound reach) at this speed.

For mound transits with a project depth of $h=55 \mathrm{ft}$ (no tide), $S_{\text {Ave }}$ ranges from 1.02 to $4.46 \mathrm{ft}$ with corresponding $D_{\operatorname{Max}}$ of 6.48 to $3.04 \mathrm{ft}$ for the same range of ship speeds. At $V_{k}=12 \mathrm{kt}$, the $D_{\operatorname{Max}}=5.14 \mathrm{ft}$ which leaves $1.14 \mathrm{ft}$ available for ship motions after allowing for the $U K C_{\text {Min }}$ of $4 \mathrm{ft}$, about the same as the channel transit. In Table 18 the $D_{\text {Max }}$ are reduced for faster ship speeds similarly to channel transits. The value of $D_{M a x}=3.04 \mathrm{ft}$ at $V_{k}=16 \mathrm{kt}$ is highlighted in yellow to indicate that there is insufficient clearance to provide for the full $U K C_{\text {Min }}$ at this speed. 
As before, the deeper mound depths of $h=56$ and $57 \mathrm{ft}$ will provide approximately 1 to $2 \mathrm{ft}$ additional $D_{\operatorname{Max}}$ due to the increased dredging. This is especially important for the fully loaded ship due its increased draft. At $V_{k}=12 \mathrm{kt}$, the $D_{\operatorname{Max}}=6.17$ to $7.21 \mathrm{ft}$ which leaves 2.17 to $3.21 \mathrm{ft}$ available for ship motions for project depths of $h=56$ and $57 \mathrm{ft}$, respectively. Of course, there is still the $U K C_{\text {Min }}=4 \mathrm{ft}$ available if necessary. These deeper depths should provide sufficient $D_{\operatorname{Max}}$ to accommodate ship motions and prevent grounding for the fully loaded ship.

Finally, for high tide transits in both channel and mound, maximum ship displacement is increased due to the tide. For fully loaded transits in the channel at $V_{k}=12 \mathrm{kt}$, the $D_{\operatorname{Max}}=8.24 \mathrm{ft}$ which leaves $6.24 \mathrm{ft}$ to accommodate ship motions after allowing for the $U K C_{\text {Min }}=2 \mathrm{ft}$. For mound transits at $V_{k}=$ $12 \mathrm{kt}$, the $D_{\mathrm{Max}}=10.30 \mathrm{ft}$ which leaves $6.30 \mathrm{ft}$ to accommodate ship motions after allowing for the $U K C_{\text {Min }}=4 \mathrm{ft}$. These values should easily accommodate increased values of wave-induced ship motions without grounding.

\section{Phase 1 waves - fully loaded ship}

The Phase 1 waves consisted of all 211 wave cases from the WIS hindcast. Only the fully loaded ship was tested in Phase 1 as this was the worst case scenario for UKC. In general, outbound transits are much less of a problem than inbound transits as their motions are much smaller. Therefore, most of the discussion will focus on the inbound transits since they produce the largest vertical ship motions.

In the first section, typical and extreme examples of CADET maximum allowances $A_{\mathrm{Max}}$ and corresponding net underkeel clearance $U K C_{N e t}$ are presented. The second section presents average and maximum $A_{M a x}$ and $U K C_{\text {Net }}$ statistics for all 211 waves in Phase 1. Appendix D contains full listings of Phase $1 A_{\text {Max }}$ for the fully loaded ship for inbound and outbound transits for all ship speeds at depths corresponding to no tide and high tide water levels. Appendix E contains corresponding listings of Phase 1 $U K C_{\text {Net. }}$

\section{Typical and extreme examples}

An example of a typical wave, ID 160, occurs 27.1 days/yr with a wave period of $4.3 \mathrm{~s}$ and wave height of $2.8 \mathrm{ft}$. The extreme wave example, ID 177 , occurs only 0.03 days/yr with a wave period of $9.5 \mathrm{~s}$ and height of $8.7 \mathrm{ft}$. Both waves are from $180.0 \mathrm{deg}$ (south), which is the most frequently 
occurring wave direction for Ambrose Channel. The extreme wave is not necessarily the largest wave of the 211 Phase 1 waves, but is one of the larger, more frequently occurring waves in this group.

\section{CADET $A_{\text {Max }}$ predictions}

Table 19 compares the CADET predictions of $A_{\text {Max }}$ allowances in the channel and mound reaches for the typical and extreme waves in Phase 1. The $A_{M a x}$ are listed for both inbound and outbound transits for each ship speed and for no tide and high tide water levels.

Table 19. Maximum vertical motion allowance $A_{\operatorname{Max}}(\mathrm{ft})$, Phase 1, fully loaded ship.

\begin{tabular}{|c|c|c|c|c|c|c|c|c|c|c|c|c|}
\hline \multirow[b]{2}{*}{ Reach } & \multirow{2}{*}{$\begin{array}{l}\text { Wave } \\
\text { ID }\end{array}$} & \multirow[b]{2}{*}{ Days/yr } & \multicolumn{5}{|c|}{ Inbound ship speed $V_{k}(\mathrm{kt})$} & \multicolumn{5}{|c|}{ Outbound ship speed $V_{k}(\mathrm{kt})$} \\
\hline & & & 8 & 10 & 12 & 14 & 16 & 8 & 10 & 12 & 14 & 16 \\
\hline \multicolumn{13}{|l|}{ No tide } \\
\hline \multirow{2}{*}{$\begin{array}{l}\text { Channel } \\
(h=53 \mathrm{ft})\end{array}$} & 160 & 27.1 & 0.05 & 0.10 & 0.08 & 0.11 & 0.19 & 0.02 & 0.04 & 0.04 & 0.05 & 0.09 \\
\hline & 177 & 0.04 & 2.25 & 2.28 & 2.24 & 2.13 & 2.46 & 1.80 & 1.79 & 1.82 & 1.79 & 1.80 \\
\hline \multirow{2}{*}{$\begin{array}{l}\text { Mound } \\
(h=55 \mathrm{ft})\end{array}$} & 160 & 27.1 & 0.05 & 0.08 & 0.07 & 0.10 & 0.16 & 0.03 & 0.05 & 0.05 & 0.06 & 0.11 \\
\hline & 177 & 0.04 & 2.34 & 2.33 & 2.34 & 2.28 & 2.26 & 2.14 & 2.11 & 2.15 & 2.12 & 2.10 \\
\hline \multicolumn{13}{|c|}{ High tide $(+5 \mathrm{ft})$} \\
\hline \multirow{2}{*}{$\begin{array}{l}\text { Channel } \\
(h=58 \mathrm{ft})\end{array}$} & 160 & 27.1 & 0.06 & 0.09 & 0.08 & 0.11 & 0.18 & 0.03 & 0.04 & 0.04 & 0.05 & 0.09 \\
\hline & 177 & 0.04 & 2.63 & 2.61 & 2.58 & 2.53 & 2.47 & 2.28 & 2.23 & 2.24 & 2.22 & 2.19 \\
\hline \multirow{2}{*}{$\begin{array}{l}\text { Mound } \\
(h=60 \mathrm{ft})\end{array}$} & 160 & 27.1 & 0.06 & 0.08 & 0.07 & 0.09 & 0.16 & 0.04 & 0.05 & 0.05 & 0.06 & 0.11 \\
\hline & 177 & 0.04 & 2.72 & 2.69 & 2.68 & 2.64 & 2.58 & 2.56 & 2.51 & 2.52 & 2.49 & 2.45 \\
\hline
\end{tabular}

Notes:

1. $U K C_{\text {Min }}=2 \mathrm{ft}$ for channel with soft bottom.

2. $U K C_{\text {Min }}=4 \mathrm{ft}$ for mound with hard bottom.

3. Wave ID 160 = typical wave case.

4. Wave ID 177 = extreme wave case.

Comparing Table 19 to Table 18 for the maximum possible ship displacements, $D_{M a x}$, the typical case (ID 160) with no tide will not pose any problems except for the $V_{k}=16 \mathrm{kt}$ case as it has the potential to ground at this speed since some of the $U K C_{M i n}$ is required. For the typical wave case, both inbound and outbound transits in the channel and mound reaches are okay as $A_{M a x}$ is less than the available $D_{\operatorname{Max}}$. For the channel reach, $A_{\operatorname{Max}}=$ $0.19 \mathrm{ft}$ is less than the $D_{\operatorname{Max}}=0.86 \mathrm{ft}$ available. Similarly, for the mound reach, $A_{\text {Max }}=0.16 \mathrm{ft}$ is also much less than the $D_{\operatorname{Max}}=3.04 \mathrm{ft}$ that is available. However, some of the required $U K C_{\text {Min }}$ (i.e., $2 \mathrm{ft}$ channel and $4 \mathrm{ft}$ 
mound) is used to prevent grounding. For the extreme wave case (ID 177), however, the channel reach during inbound transits would indicate grounding as $A_{\operatorname{Max}}=2.46 \mathrm{ft}$ is greater than the available $D_{\operatorname{Max}}=0.86 \mathrm{ft}$. All of the $U K C_{\text {Min }}$ is used, but it is not enough to prevent grounding. The mound reach does not indicate grounding during inbound transits for the extreme wave case since the $A_{\operatorname{Max}}=2.26 \mathrm{ft}$ is less than the available $D_{\operatorname{Max}}=3.04 \mathrm{ft}$. In this case, the $U K C_{\text {Min }}$ is used to prevent grounding.

In general for the extreme case and other larger wave cases, one should realize that the ship is not going to actually experience $A_{M a x}$ as large as predicted in most cases if the available $U K C$ is less than the predicted ship motion. The CADET program does not cut off the vertical motion prediction based on available UKC. Of course, once the ship is grounded, it cannot experience any greater vertical motion.

For inbound transits at the slower design speeds of $V_{k}=12 \mathrm{kt}$, the $D_{\operatorname{Max}}$ is $3.06 \mathrm{ft}$ in the channel at low tide. This is more than satisfactory to prevent grounding for the typical case $A_{M a x}$ of $0.08 \mathrm{ft}$, but not large enough to prevent incursion into the $U K C_{\text {Min }}$ for the extreme case with $A_{\text {Max }}$ of $2.24 \mathrm{ft}$. For the inbound mound transits with similar conditions, the $D_{\operatorname{Max}}=5.14 \mathrm{ft}$ from Table 18. As before, this is more than adequate to prevent grounding for the typical case with $A_{M a x}=0.07 \mathrm{ft}$, but not large enough for the extreme case with $A_{\operatorname{Max}}=2.34 \mathrm{ft}$. Again, grounding does not occur, just that there is incursion into the $U K C_{\text {Min }}$.

None of the high tide ship motions will pose any problems due to the additional $5 \mathrm{ft}$ of $U K C$.

\section{CADET UKC $\mathrm{Net}_{\text {predictions }}$}

Table 20 lists the corresponding $U K C_{\text {Net }}$ for the Phase 1 channel and mound reaches for the same typical and extreme wave conditions. The format is similar to the previous table for the $A_{M a x}$ in Table 19. Negative values are highlighted in red since they indicate the possibility of grounding. Caution should be exercised for values highlighted with yellow background. Although the ship has not grounded for these cases, it is within the required $U K C_{\text {Min }}$ values of $2 \mathrm{ft}$ for the channel and $4 \mathrm{ft}$ for the mound reaches.

Grounding is not a problem for the high tide water levels due to the additional $5 \mathrm{ft}$ of $U K C$. Therefore, only the no tide water level cases are discussed. Also, the extreme wave (ID 177) with the longer period and larger wave height produces significantly larger vertical motions than the typical wave case (ID 160). 
Table 20. Net underkeel clearance $U K C_{\text {Net }}(\mathrm{ft})$, Phase 1, fully loaded ship.

\begin{tabular}{|c|c|c|c|c|c|c|c|c|c|c|c|c|}
\hline \multirow[b]{2}{*}{ Reach } & \multirow{2}{*}{\begin{tabular}{|l|} 
Wave \\
ID
\end{tabular}} & \multirow[b]{2}{*}{ Days/yr } & \multicolumn{5}{|c|}{ Inbound ship speed $V_{k}(\mathrm{kt})$} & \multicolumn{5}{|c|}{ Outbound ship speed $V_{k}(\mathrm{kt})$} \\
\hline & & & 8 & 10 & 12 & 14 & 16 & 8 & 10 & 12 & 14 & 16 \\
\hline \multicolumn{13}{|l|}{ No tide } \\
\hline \multirow{2}{*}{$\begin{array}{l}\text { Channel } \\
(h=53 \mathrm{ft})\end{array}$} & 160 & 27.08 & 4.39 & 3.74 & 2.98 & 1.99 & 0.67 & 4.42 & 3.80 & 3.02 & 2.05 & 0.77 \\
\hline & 177 & 0.04 & 2.19 & 1.56 & 0.82 & -0.03 & -1.60 & 2.64 & 2.05 & 1.24 & 0.31 & -0.94 \\
\hline \multirow{2}{*}{$\begin{array}{l}\text { Mound } \\
(h=55 \mathrm{ft})\end{array}$} & 160 & 27.08 & 6.43 & 5.81 & 5.07 & 4.12 & 2.88 & 6.45 & 5.84 & 5.09 & 4.16 & 2.93 \\
\hline & 177 & 0.04 & 4.14 & 3.56 & 2.80 & 1.94 & 0.78 & 4.34 & 3.78 & 2.99 & 2.10 & 0.94 \\
\hline \multicolumn{13}{|c|}{ High tide $(+5 \mathrm{ft})$} \\
\hline \multirow{2}{*}{$\begin{array}{l}\text { Channel } \\
(h=58 \mathrm{ft})\end{array}$} & 160 & 27.08 & 9.45 & 8.86 & 8.16 & 7.26 & 6.09 & 9.48 & 8.91 & 8.20 & 7.32 & 6.18 \\
\hline & 177 & 0.04 & 6.88 & 6.34 & 5.66 & 4.84 & 3.80 & 7.23 & 6.72 & 6.00 & 5.15 & 4.08 \\
\hline \multirow{2}{*}{$\begin{array}{l}\text { Mound } \\
(\mathrm{h}=60 \mathrm{ft})\end{array}$} & 160 & 27.08 & 11.48 & 10.92 & 10.23 & 9.36 & 8.25 & 11.50 & 10.95 & 10.25 & 9.39 & 8.30 \\
\hline & 177 & 0.04 & 8.82 & 8.31 & 7.62 & 6.81 & 5.83 & 8.98 & 8.49 & 7.78 & 6.96 & 5.96 \\
\hline
\end{tabular}

Notes:

1. $U K C_{\operatorname{Min}}=2 \mathrm{ft}$ for channel with soft bottom.

2. $U K C_{\text {Min }}=4 \mathrm{ft}$ for mound with hard bottom.

3. Wave ID $160=$ typical wave case.

4. Wave ID 177 = extreme wave case.

For the typical wave and inbound and outbound transits, there is sufficient $U K C_{N e t}$ until $V_{k} \geq 14 \mathrm{kt}$ for both the channel and mound reaches. Grounding is not indicated, but the ship would be using some of the $U K C_{M i n}$ in both reaches. For the extreme wave in the channel reach, caution should be exercised for $V_{k}>8 \mathrm{kt}$ for inbound transits and $V_{\mathrm{k}}>10 \mathrm{kt}$ for outbound transits. The ship will ground at $V_{k}>12 \mathrm{kt}$ for inbound and $V_{k}>14 \mathrm{kt}$ for outbound transits. The ship will experience similar levels of $U K C_{N e t}$ during mound transits, but will not necessarily ground because of the larger $U K C_{\operatorname{Min}}$ of $4 \mathrm{ft}$ over the mound. It will experience incursions into the $U K C_{M i n}$, however, to prevent grounding. As expected, the $U K C_{\text {Net }}$ decreases as speed increases.

\section{Average and maximum statistics}

As mentioned previously, $A_{\operatorname{Max}}$ were calculated for each wave condition, transit direction, and ship speed. Average and maximum $A_{M a x}$ values over all 211 waves were calculated to facilitate comparisons among the different parameters affecting the fully loaded ship transits. The "maximum" $A_{\text {Max }}$ value represents the worst wave case in terms of its ability to produce the largest $A_{M a x}$. These statistics are presented in this section. 


\section{CADET A $A_{\text {Max }}$ predictions}

Table 21 lists the average and maximum $A_{\text {Max }}$ for both the channel and mound reaches for inbound and outbound transits. For the maximum wave, the Wave ID is also listed (see Appendix C). As for the typical and extreme wave examples, the inbound transits produce larger $A_{\text {Max }}$ statistics than the outbound transits.

Table 21. Vertical motion allowance statistics $A_{\operatorname{Max}}(\mathrm{ft})$, Phase 1, fully loaded ship.

\begin{tabular}{|c|c|c|c|c|c|c|c|c|c|c|c|}
\hline \multirow[b]{2}{*}{ Reach } & \multirow[b]{2}{*}{ Statistic } & \multicolumn{5}{|c|}{ Inbound ship speed $V_{k}(\mathrm{kt})$} & \multicolumn{5}{|c|}{ Outbound ship speed $V_{k}(\mathrm{kt})$} \\
\hline & & 8 & 10 & 12 & 14 & 16 & 8 & 10 & 12 & 14 & 16 \\
\hline \multicolumn{12}{|l|}{ No tide } \\
\hline \multirow{3}{*}{$\begin{array}{l}\text { Channel } \\
(h=53 \mathrm{ft})\end{array}$} & Average & 2.10 & 2.13 & 2.05 & 2.17 & 3.18 & 1.48 & 1.41 & 1.39 & 1.34 & 1.32 \\
\hline & Maximum & 12.11 & 11.54 & 10.80 & 13.53 & 22.89 & 9.58 & 9.07 & 8.58 & 8.27 & 7.49 \\
\hline & Wave ID & 163 & 163 & 163 & 163 & 163 & 163 & 163 & 163 & 163 & 163 \\
\hline \multirow{3}{*}{$\begin{array}{l}\text { Mound } \\
(h=55 \mathrm{ft})\end{array}$} & Average & 2.11 & 2.10 & 2.03 & 2.09 & 2.87 & 1.62 & 1.55 & 1.52 & 1.47 & 1.45 \\
\hline & Maximum & 9.42 & 8.82 & 8.67 & 11.75 & 19.70 & 8.52 & 8.04 & 8.10 & 7.80 & 7.53 \\
\hline & Wave ID & 427 & 427 & 427 & 463 & 463 & 611 & 611 & 611 & 611 & 611 \\
\hline \multicolumn{12}{|c|}{ High tide $(+5 \mathrm{ft})$} \\
\hline \multirow{3}{*}{$\begin{array}{l}\text { Channel } \\
(h=58 \mathrm{ft})\end{array}$} & Average & 2.21 & 2.18 & 2.08 & 2.12 & 2.73 & 1.78 & 1.69 & 1.63 & 1.60 & 1.58 \\
\hline & Maximum & 11.12 & 10.53 & 9.96 & 9.98 & 15.89 & 10.27 & 9.74 & 9.19 & 8.89 & 8.51 \\
\hline & Wave ID & 163 & 163 & 163 & 163 & 163 & 163 & 163 & 163 & 163 & 163 \\
\hline \multirow{3}{*}{$\begin{array}{l}\text { Mound } \\
(h=60 \mathrm{ft})\end{array}$} & Average & 2.21 & 2.17 & 2.07 & 2.07 & 2.64 & 1.88 & 1.79 & 1.72 & 1.68 & 1.67 \\
\hline & Maximum & 9.55 & 9.02 & 8.63 & 8.77 & 14.96 & 9.25 & 8.80 & 8.53 & 8.56 & 8.30 \\
\hline & Wave ID & 427 & 427 & 427 & 463 & 463 & 611 & 611 & 611 & 611 & 611 \\
\hline
\end{tabular}

Notes:

1. $U K C_{\text {Min }}=2 \mathrm{ft}$ for channel with soft bottom.

2. $U K C_{\text {Min }}=4 \mathrm{ft}$ for mound with hard bottom.

3. Wave ID = Wave ID for maximum wave. Mound Wave ID 463 same as Channel Wave ID 163.

Comparing average $A_{M a x}$ in Table 21 with $D_{\operatorname{Max}}$ in Table 18 for no tide water levels, inbound and outbound channel transits will not experience grounding until $V_{k} \geq 14 \mathrm{kt}$ as $A_{\operatorname{Max}}$ is less than $D_{M a x}$. Similarly, inbound and outbound mound transits will not experience grounding for all ship speeds since $A_{M a x}$ is less than $D_{M a x}$. Of course, some of the $U K C_{\text {Min }}$ will be used to prevent grounding for most ship speeds in both channel and mound reaches. Due to the increase in water level of $5 \mathrm{ft}$ at the high tide condition, all speeds are acceptable for average wave conditions in both channel and mound reaches. 
The maximum $A_{\text {Max }}$ are so large that transits at any speed and reach will pose a problem regardless of tide level. For the channel reach, Wave ID 163 produces the largest ship motions for both inbound (stern quartering) and outbound (bow quartering) transits at all ship speeds and both water depths. With a $T_{p}=14.3 \mathrm{~s}, H_{s}=17.7 \mathrm{ft}$, and $\theta_{m}=90 \mathrm{deg}$ it is a very rare probability of occurrence of only 0.00002 , or about $0.2 \mathrm{hr}$ per year. The maximum ship motions in the mound reach are produced by waves with similarly rare probabilities of occurrence. For inbound transits at $V_{k}=8$ to $12 \mathrm{kt}$, Wave ID 427 (similar to Channel Wave ID 127) produces stern quartering. With a $T_{p}=11.8 \mathrm{~s}, H_{s}=16.2 \mathrm{ft}$, and $\theta_{m}=67.5 \mathrm{deg}$ it has an even rarer probability of occurrence of 0.00001 , or about $0.05 \mathrm{hr}$ per year. For the faster inbound transits at $V_{k}=14$ to $16 \mathrm{kt}$, Wave ID 463 (similar to Channel Wave ID 163) produces stern quartering with the same probability of occurrence as the channel reach. Finally, for outbound transits at all ship speeds and both water depths, Wave ID 611 (similar to Channel Wave ID 211) produces beam seas with associated rolling. With a $T_{p}=11.5 \mathrm{~s}, H_{s}=$ $14.1 \mathrm{ft}$, and $\theta_{m}=202.5 \mathrm{deg}$ it has a similarly rare probability of occurrence of 0.00001 , or about $0.05 \mathrm{hr}$ per year. Of course, since these wave conditions occur so rarely, they can usually be avoided by the pilots.

In summary for inbound transits, the $A_{\operatorname{Max}}$ tend to decrease with decreases in speed and increases in depth due to tide. In general, the $A_{\text {Max }}$ for the mound reach are equal to or less than those in the channel reach. Therefore, the mound transit is not any more of a problem than channel transits for the equivalent wave conditions.

\section{CADET UKC $\mathrm{Net}_{\text {p }}$ predictions}

Table 22 compares $U K C_{N e t}$ statistics for average and minimum values over all 211 wave cases in Phase 1 . The format and color-coding of this table is similar to Table 20. Note that the "Min" $U K C_{N e t}$ corresponds with the "Max" $A_{\text {Max }}$ since $U K C_{\text {Net }}$ is obtained by subtracting the maximum $A_{M a x}$ from the $U K C$.

For no tide water levels, average wave conditions and inbound transits in the channel, the ship should exercise caution for $V_{k}>8 \mathrm{kt}$ and can expect grounding for $V_{k}>12 \mathrm{kt}$. Outbound transits show similar trends, but are delayed until 2-kt faster speeds. Mound transits exhibit similar $U K C_{N e t}$ values for both inbound and outbound transits, but will not experience grounding because of the additional required $U K C_{\text {Min }}$ of $4 \mathrm{ft}$. The "Min" $U K C_{N e t}$ represents the most extreme of all the 211 waves, so both channel 
Table 22. Net underkeel clearance $U K C_{\text {Net }}$ statistics (ft), Phase 1, fully loaded ship.

\begin{tabular}{|c|c|c|c|c|c|c|c|c|c|c|c|}
\hline \multirow[b]{2}{*}{ Reach } & \multirow[b]{2}{*}{ Statistic } & \multicolumn{5}{|c|}{ Inbound ship speed $V_{k}(\mathrm{kt})$} & \multicolumn{5}{|c|}{ Outbound ship speed $V_{k}(\mathrm{kt})$} \\
\hline & & 8 & 10 & 12 & 14 & 16 & 8 & 10 & 12 & 14 & 16 \\
\hline \multicolumn{12}{|l|}{ No tide } \\
\hline \multirow{2}{*}{$\begin{array}{l}\text { Channel } \\
(h=53 \mathrm{ft})\end{array}$} & Ave & 2.34 & 1.71 & 1.01 & -0.07 & -2.32 & 2.96 & 2.42 & 1.67 & 0.76 & -0.46 \\
\hline & Min & -7.67 & -7.70 & -7.74 & -11.43 & -22.03 & -5.14 & -5.23 & -5.52 & -6.17 & -6.63 \\
\hline \multirow{2}{*}{$\begin{array}{l}\text { Mound } \\
(h=55 \mathrm{ft})\end{array}$} & Ave & 4.37 & 3.79 & 3.11 & 2.13 & 0.17 & 4.85 & 4.34 & 3.62 & 2.75 & 1.59 \\
\hline & Min & -2.94 & -2.93 & -3.53 & -7.53 & -16.66 & -2.04 & -2.15 & -2.96 & -3.58 & -4.49 \\
\hline \multicolumn{12}{|c|}{ High tide $(+5 \mathrm{ft})$} \\
\hline \multirow{2}{*}{$\begin{array}{l}\text { Channel } \\
(h=58 \mathrm{ft})\end{array}$} & Ave & 7.30 & 6.77 & 6.16 & 5.25 & 3.54 & 7.73 & 7.26 & 6.60 & 5.77 & 4.69 \\
\hline & Min & -1.61 & -1.58 & -1.72 & -2.61 & -9.62 & -0.76 & -0.79 & -0.95 & -1.52 & -2.24 \\
\hline \multirow{2}{*}{$\begin{array}{l}\text { Mound } \\
(h=60 \mathrm{ft})\end{array}$} & Ave & 9.32 & 8.82 & 8.23 & 7.38 & 5.77 & 9.66 & 9.21 & 8.58 & \begin{tabular}{|l|}
7.77 \\
\end{tabular} & 6.73 \\
\hline & Min & 1.99 & 1.98 & 1.67 & 0.68 & -6.55 & 2.29 & 2.20 & 1.77 & 0.89 & 0.11 \\
\hline
\end{tabular}

Notes:

1. $U K C_{\operatorname{Min}}=2 \mathrm{ft}$ for channel with soft bottom.

2. $U K C_{\text {Min }}=4 \mathrm{ft}$ for mound with hard bottom.

3. Min corresponds with Max in AMax table.

and mound would experience grounding at all ship speeds and transit directions regardless of $U K C_{\text {Min }}$. Finally, trends are the same for both reaches and the $U K C_{\text {Net }}$ decreases as speed increases.

For the high tide water levels and average wave conditions, there are no grounding problems for both the channel and mound transits due to the increase in water level.

For the worst case minimum wave condition, the channel would experience grounding for all speeds and transit directions. Because of the additional $U K C_{\text {Min }}$ of $4 \mathrm{ft}$ over the mound, only $V_{k}>14$ kt inbound transits would ground. Other speeds and outbound transits should exercise caution as they are using some of the $U K C_{\text {Min }}$.

\section{Phase 2 waves}

The Phase 2 waves consisted of 24 wave cases that were transformed using STWAVE and CMS-Wave from the WIS hindcast and NOAA buoy offshore sites. Both lightly and fully loaded ships were tested in Phase 2. It was decided to use inbound transits at $V_{k}=12 \mathrm{kts}$ as the criterion in Phase 2 since this is the typical transit speed and inbound transits have larger ship 
motions than outbound transits. Dredge depths of $h=53 \mathrm{ft}$ in the channel reach and $h=55,56$, and $57 \mathrm{ft}$ in the mound reach were selected for comparisons. The high tide level is not a problem because of the additional $5 \mathrm{ft}$ of water level. Therefore, only the "no tide" water level is discussed.

In the first section, CADET $A_{\operatorname{Max}}$ and corresponding $U K C_{\text {Net }}$ for all 24 waves are presented for the light-loaded ship. The next section presents similar results for the fully loaded ship. Since only the inbound transits at $V_{k}=12 \mathrm{kts}$ are discussed in the text, full listings of inbound and outbound Phase $2 A_{\text {Max }}$ at all ship speeds are contained in Appendix F. Appendix G contains corresponding listings of Phase $2 U K C_{\text {Net }}$.

\section{Light-loaded ship}

\section{CADET A $A_{\text {Max }}$ predictions}

Table 23 lists vertical motion allowances, $A_{\text {Max }}$, due to the Phase 2 waves for the light-loaded ship transiting channel and mound reaches at $V_{k}=12$ kt. The mound reach includes the three optional water depths of $h=55$, 56 , and $57 \mathrm{ft}$. At the bottom of the table, some values are included for reference. These include the maximum ship displacement, $D_{M a x}$, values at $V_{k}=12 \mathrm{kt}$ from Table 18 and statistics showing the minimum, average, and maximum $A_{\text {Max }}$.

As a first comparison, all of the $A_{\operatorname{Max}}$ in both the channel and mound reaches are less than the $D_{\operatorname{Max}}$ values in Table 17. This indicates that there is "room" to accommodate the ship motions without grounding. However, some of the $U K C_{M i n}$ will be required in some wave cases.

The next comparison involves a discussion of the relative magnitudes between the channel and mound $A_{M a x}$. Yellow highlights in Table 23 indicate those mound $A_{\text {Max }}$ which are at least $0.3 \mathrm{ft}$ larger than the corresponding channel reach value. This value corresponds to approximately 10 percent of the maximum channel $A_{M a x}$. This value was selected as it seems statistically significant when comparing channel and mound values. If the mound $A_{M a x}$ is not at least $0.3 \mathrm{ft}$ larger than the channel $A_{M a x}$, one can conclude that there is no significant difference between transits in the two reaches. Only 6 wave cases are highlighted for the light-loaded ship. 
Table 23. Wave motion allowances $A_{\operatorname{Max}}(\mathrm{ft})$, Phase 2, light-loaded ship, $12 \mathrm{kt}$ inbound transits.

\begin{tabular}{|c|c|c|c|c|c|}
\hline \multirow{2}{*}{$\begin{array}{l}\text { Wave } \\
\text { ID }\end{array}$} & \multirow[b]{2}{*}{ Days/yr } & \multirow{2}{*}{$\begin{array}{l}\text { Channel } A_{\text {Max }} \\
h=53 \mathrm{ft}\end{array}$} & \multicolumn{3}{|c|}{ Mound $A_{\text {Max }}$} \\
\hline & & & $h=55 \mathrm{ft}$ & $h=56 \mathrm{ft}$ & $h=57 \mathrm{ft}$ \\
\hline 19 & 0.01 & 2.68 & 2.07 & 2.17 & 2.25 \\
\hline 22 & 0.02 & 2.49 & 1.88 & 1.95 & 2.01 \\
\hline 46 & 0.06 & 2.36 & 1.58 & 1.65 & 1.73 \\
\hline 52 & 0.15 & 2.27 & 1.31 & 1.36 & 1.42 \\
\hline 61 & 0.01 & 3.23 & 1.96 & 2.01 & 2.05 \\
\hline 64 & 0.01 & 3.34 & 2.08 & 2.11 & 2.15 \\
\hline 82 & 0.04 & 2.38 & 1.70 & 1.78 & 1.86 \\
\hline 87 & 0.52 & 2.37 & 1.64 & 1.71 & 1.78 \\
\hline 92 & 0.07 & 2.92 & 2.12 & 2.18 & 2.24 \\
\hline 95 & 0.01 & 3.06 & 2.08 & 2.13 & 2.18 \\
\hline 115 & 0.10 & 2.34 & 1.84 & 1.93 & 2.01 \\
\hline 119 & 0.21 & 2.38 & 2.00 & 2.07 & 2.14 \\
\hline 125 & 0.05 & 3.00 & 2.94 & 2.99 & 3.03 \\
\hline 127 & 0.01 & 3.07 & 3.37 & 3.39 & 3.40 \\
\hline 147 & 0.04 & 2.10 & 1.77 & 1.85 & 1.92 \\
\hline 152 & 0.21 & 2.04 & 1.90 & 1.95 & 2.01 \\
\hline 157 & 0.12 & 2.64 & 2.85 & 2.83 & 2.81 \\
\hline 158 & 0.04 & 2.62 & 3.23 & 3.16 & 3.08 \\
\hline 177 & 0.03 & 2.24 & 2.00 & 2.07 & 2.15 \\
\hline 181 & 0.17 & 2.18 & 2.02 & 2.08 & 2.13 \\
\hline 205 & 0.01 & 2.06 & 2.40 & 2.47 & 2.55 \\
\hline 206 & 0.00 & 2.56 & 2.79 & 2.89 & 2.98 \\
\hline 208 & 0.03 & 1.80 & 2.06 & 2.10 & 2.13 \\
\hline 209 & 0.01 & 2.59 & 2.78 & 2.84 & 2.89 \\
\hline \multicolumn{6}{|c|}{ Reference values } \\
\hline \multicolumn{2}{|c|}{$D_{\operatorname{Max}}, V_{k}=12 \mathrm{kt}$} & 4.62 & 6.69 & 7.73 & 8.76 \\
\hline \multicolumn{2}{|c|}{ Minimum } & 1.80 & 1.31 & 1.36 & 1.42 \\
\hline \multicolumn{2}{|c|}{ Average } & 2.53 & 2.18 & 2.24 & 2.29 \\
\hline \multicolumn{2}{|c|}{ Maximum } & 3.34 & 3.37 & 3.39 & 3.40 \\
\hline
\end{tabular}

Notes:

1. Yellow highlight $=A_{\text {Max }, \text { Mound }} \geq A_{\text {Max }, \text { Channel }}+0.3 \mathrm{ft}$. 


\section{CADET UKC $\mathrm{Net}_{\text {ped }}$ predictions}

Table 24 is the corresponding table for the $U K C_{\text {Net }}$ for the light-loaded transits in the channel and mound reaches at $V_{k}=12 \mathrm{kt}$. Values highlighted in yellow indicate $U K C_{\text {Net }}$ values less than the required $U K C_{\text {Min }} 2 \mathrm{ft}$ for the channel reach and $4 \mathrm{ft}$ for the mound reach. Grounding is not indicated for any of the Phase 2 waves. Thus, the highlighted values just indicate where some of the $U K C_{M i n}$ is used in a reach.

Only 10 of the Phase 2 wave cases are highlighted for channel reach only, mound reach only, or both channel and mound reaches. All of the highlighted waves in the mound reach occur for the shallower depth of $h=$ $55 \mathrm{ft}$. The worst case for incursion into the $U K C_{M i n}$ for the channel reach is $U K C_{N e t}=1.28 \mathrm{ft}$ for Wave ID 64. The worst incursion for the mound reach is $U K C_{N e t}=2.97 \mathrm{ft}$ at $h=55 \mathrm{ft}$ for Wave ID 127. The average $U K C_{N e t}$ for both channel and mound reaches is slightly above the $U K C_{\text {Min. }}$. Only Wave ID 87, 119 , and 158 show incursions into the $U K C_{\text {Min }}$ for the mound and not the channel reach. In general, transits in the mound reach do not experience significantly smaller $U K C_{N e t}$ than similar transits in the channel reach. However, the mound $U K C_{\text {Min }}$ incursions can be avoided by dredging the mound reach an additional $1 \mathrm{ft}$ to $h=56 \mathrm{ft}$.

\section{Fully loaded ship}

\section{CADET A $A_{\text {Max }}$ predictions}

Table 25 lists the $A_{\operatorname{Max}}$ due to the Phase 2 waves for the fully loaded ship transiting channel and mound reaches at $V_{k}=12 \mathrm{kt}$. The table is organized similarly to Table 23 for the light-loaded ship.

Again, as a first comparison, all of the $A_{M a x}$ in both the channel and mound reaches are less than the $D_{\operatorname{Max}}$ values in Table 18 . This indicates that there is "room" to accommodate the ship motions without grounding. However, more of the $U K C_{M i n}$ will be required in most cases relative to the lightloaded ship. As for the light-loaded ship, the second comparison involves a discussion of the relative magnitudes between the channel and mound $A_{\text {Max. }}$. Yellow highlights in the table indicate those mound $A_{\text {Max }}$ which are at least $0.3 \mathrm{ft}$ larger than the corresponding channel reach value (i.e., approximately 10 percent). Eleven wave cases are highlighted for the fully loaded ship since it has more draft than the light-loaded ship. 
Table 24. Net underkeel clearance $U K C_{\text {Net }}(\mathrm{ft})$, Phase 2, light-loaded ship, $12 \mathrm{kt}$ inbound transits.

\begin{tabular}{|c|c|c|c|c|c|}
\hline \multirow{2}{*}{$\begin{array}{l}\text { Wave } \\
\text { ID }\end{array}$} & \multirow[b]{2}{*}{ Days/yr } & \multirow{2}{*}{$\begin{array}{l}\text { Channel } U K C_{\text {Net }} \\
h=53 \mathrm{ft}\end{array}$} & \multicolumn{3}{|c|}{ Mound $U K C_{\text {Net }}$} \\
\hline & & & $h=55 \mathrm{ft}$ & $h=56 \mathrm{ft}$ & $h=57 \mathrm{ft}$ \\
\hline 19 & 0.01 & 1.94 & 3.89 & 4.95 & 5.92 \\
\hline 22 & 0.02 & 2.13 & 4.20 & 5.27 & 6.32 \\
\hline 46 & 0.06 & 2.26 & 4.31 & 5.37 & 6.38 \\
\hline 52 & 0.15 & 2.35 & 4.54 & 5.61 & 6.67 \\
\hline 61 & 0.01 & 1.39 & 3.89 & 5.02 & 6.13 \\
\hline 64 & 0.01 & 1.28 & 3.86 & 5.02 & 6.19 \\
\hline 82 & 0.04 & 2.24 & 4.08 & 5.15 & 6.14 \\
\hline 87 & 0.52 & 2.25 & 3.99 & 5.07 & 6.15 \\
\hline 92 & 0.07 & 1.70 & 3.52 & 4.65 & 5.78 \\
\hline 95 & 0.01 & 1.56 & 3.49 & 4.68 & 5.88 \\
\hline 115 & 0.10 & 2.28 & 4.10 & 5.16 & 6.16 \\
\hline 119 & 0.21 & 2.24 & 3.85 & 4.92 & 5.99 \\
\hline 125 & 0.05 & 1.62 & 3.03 & 4.16 & 5.28 \\
\hline 127 & 0.01 & 1.55 & 2.97 & 4.15 & 5.33 \\
\hline 147 & 0.04 & 2.52 & 4.57 & 5.56 & 6.53 \\
\hline 152 & 0.21 & 2.58 & 4.45 & 5.46 & 6.47 \\
\hline 157 & 0.12 & 1.98 & 3.77 & 4.87 & 5.93 \\
\hline 158 & 0.04 & 2.00 & 3.83 & 4.98 & 6.10 \\
\hline 177 & 0.03 & 2.38 & 4.58 & 5.55 & 6.51 \\
\hline 181 & 0.17 & 2.44 & 4.53 & 5.53 & 6.52 \\
\hline 205 & 0.01 & 2.56 & 4.43 & 5.38 & 6.33 \\
\hline 206 & 0.00 & 2.06 & 4.05 & 4.99 & 5.93 \\
\hline 208 & 0.03 & 2.82 & 4.77 & 5.76 & 6.75 \\
\hline 209 & 0.01 & 2.03 & 4.09 & 5.06 & 6.04 \\
\hline \multicolumn{6}{|c|}{ Statistics } \\
\hline \multicolumn{2}{|c|}{ Minimum } & 1.28 & 2.97 & 4.15 & 5.28 \\
\hline \multicolumn{2}{|c|}{ Average } & 2.09 & 4.03 & 5.10 & 6.14 \\
\hline \multicolumn{2}{|c|}{ Maximum } & 2.82 & 4.77 & 5.76 & 6.75 \\
\hline
\end{tabular}

Notes:

1. Yellow highlight $=U K C_{\text {Net }}<U K C_{\text {Min }}=2 \mathrm{ft}$ Channel, $4 \mathrm{ft}$ mound. 
Table 25. Wave motion allowances $A_{\max }$ (ft), Phase 2, fully loaded ship, $12 \mathrm{kt}$ inbound transits.

\begin{tabular}{|c|c|c|c|c|c|}
\hline \multirow{2}{*}{$\begin{array}{l}\text { Wave } \\
\text { ID }\end{array}$} & \multirow[b]{2}{*}{ Days/yr } & \multirow{2}{*}{$\begin{array}{l}\text { Channel } A_{\text {Max }} \\
h=53 \mathrm{ft}\end{array}$} & \multicolumn{3}{|c|}{ Mound $A_{\text {Max }}$} \\
\hline & & & $h=55 \mathrm{ft}$ & $h=56 \mathrm{ft}$ & $h=57 \mathrm{ft}$ \\
\hline 19 & 0.01 & 2.41 & 2.64 & 2.68 & 2.74 \\
\hline 22 & 0.02 & 2.45 & 2.36 & 2.30 & 2.32 \\
\hline 46 & 0.06 & 2.09 & 2.24 & 2.27 & 2.31 \\
\hline 52 & 0.15 & 1.98 & 1.83 & 1.79 & 1.80 \\
\hline 61 & 0.01 & 2.66 & 2.08 & 2.03 & 2.01 \\
\hline 64 & 0.01 & 2.45 & 1.82 & 1.72 & 1.64 \\
\hline 82 & 0.04 & 2.12 & 2.47 & 2.49 & 2.54 \\
\hline 87 & 0.52 & 1.94 & 2.28 & 2.23 & 2.23 \\
\hline 92 & 0.07 & 1.99 & 2.25 & 2.21 & 2.19 \\
\hline 95 & 0.01 & 1.98 & 2.07 & 1.95 & 1.86 \\
\hline 115 & 0.10 & 2.08 & 2.43 & 2.46 & 2.52 \\
\hline 119 & 0.21 & 1.96 & 2.59 & 2.53 & 2.54 \\
\hline 125 & 0.05 & 2.15 & 3.11 & 3.02 & 2.99 \\
\hline 127 & 0.01 & 1.98 & 2.77 & 2.68 & 2.61 \\
\hline 147 & 0.04 & 1.86 & 2.04 & 2.08 & 2.13 \\
\hline 152 & 0.21 & 1.86 & 2.21 & 2.16 & 2.19 \\
\hline 157 & 0.12 & 2.33 & 2.91 & 2.81 & 2.78 \\
\hline 158 & 0.04 & 2.13 & 2.63 & 2.52 & 2.44 \\
\hline 177 & 0.03 & 2.03 & 2.02 & 2.07 & 2.14 \\
\hline 181 & 0.17 & 2.13 & 2.10 & 2.07 & 2.11 \\
\hline 205 & 0.01 & 1.93 & 2.15 & 2.21 & 2.29 \\
\hline 206 & 0.00 & 2.40 & 2.51 & 2.58 & 2.67 \\
\hline 208 & 0.03 & 1.74 & 1.85 & 1.84 & 1.88 \\
\hline 209 & 0.01 & 2.50 & 2.51 & 2.49 & 2.55 \\
\hline \multicolumn{6}{|c|}{ Reference values } \\
\hline \multicolumn{2}{|c|}{$D_{\text {Max }}, V_{k}=12 \mathrm{kt}$} & 3.06 & 5.14 & 6.17 & 7.21 \\
\hline \multicolumn{2}{|c|}{ Minimum } & 1.74 & 1.82 & 1.72 & 1.64 \\
\hline \multicolumn{2}{|c|}{ Average } & 2.13 & 2.33 & 2.30 & 2.31 \\
\hline \multicolumn{2}{|c|}{ Maximum } & 2.66 & 3.11 & 3.02 & 2.99 \\
\hline
\end{tabular}

Notes:

1. Yellow highlight $=A_{\text {Max }, \text { Mound }} \geq A_{\text {Max }, \text { Channel }}+0.3 \mathrm{ft}$. 


\section{CADET UKC $\mathrm{Net}_{\text {ped }}$ predictions}

Table 26 is the corresponding table for the $U K C_{\text {Net }}$ for the fully loaded transits in the channel and mound reaches at $V_{k}=12 \mathrm{kt}$. Values highlighted in yellow indicate $U K C_{N e t}$ values less than the required $U K C_{M i n}$ $=2 \mathrm{ft}$ for the channel reach and $4 \mathrm{ft}$ for the mound reaches. Similarly to the light-loaded ships in Table 24, grounding is not indicated for any of the Phase 2 waves. Thus, the highlighted values just indicate where some of the $U K C_{M i n}$ is required in a reach.

All of the channel and mound reach optional depth at $h=55 \mathrm{ft}$ are highlighted. Fifteen of the mound reach with a depth of $h=56 \mathrm{ft}$ are highlighted. However, none of the mound reaches with depths of $h=57 \mathrm{ft}$ are highlighted. The worst case for incursion into the $U K C_{M i n}$ for the channel reach is $U K C_{N e t}=0.40 \mathrm{ft}$ for Wave ID 61. The worst incursion for the mound reach is $U K C_{N e t}=2.03 \mathrm{ft}$ at $h=55 \mathrm{ft}$ for Wave ID 125. The average $U K C_{N e t}$ for both channel and mound reaches is less than the $U K C_{\text {Min }}$ until $h=57 \mathrm{ft}$. In general, transits in the mound reach do not cause significantly smaller $U K C_{N e t}$ than similar transits in the channel reach. However, the mound incursions can be avoided by dredging the mound reach an additional $2 \mathrm{ft}$ to $h=57 \mathrm{ft}$.

\section{Summary}

Maximum wave-induced vertical ship motions, $A_{M a x}$, and corresponding net underkeel clearance, $U K C_{N e t}$, for Phase 1 and Phase 2 waves were discussed and compared with the maximum ship displacement, $D_{\operatorname{Max}}$. The $A_{\text {Max }}$ represent the maximum ship motion at any of the five critical points along the bottom of the ship due to the combined effects of heave, pitch, and roll. The $D_{\operatorname{Max}}$ indicates the "space" above the bottom in the water column that is available to accommodate, $A_{\text {Max }}$, after subtracting average ship squat, $S_{\text {Ave }}$. The $U K C_{\text {Net }}$ is the remaining clearance between the ship and the channel bottom after subtracting $S_{A v e}$ and $A_{M a x}$ from the UKC. For safety and maneuverability concerns in this study, the sponsor requested a $U K C_{\text {Min }}$ of $2 \mathrm{ft}$ for channel transits and $4 \mathrm{ft}$ for mound transits.

The Phase 1 waves consisted of all 211 wave cases from the WIS hindcast. Only the fully loaded ship was tested in Phase 1 as this was the worst case scenario for $U K C$. In general, outbound transits are much less of a problem than inbound transits as their motions are much smaller. Examples of $A_{M a x}$ and corresponding $U K C_{N e t}$ for a typical and extreme wave case were 
Table 26. Net underkeel clearance $U K C_{\text {Net }}$ (ft), Phase 2, fully loaded ship, $12 \mathrm{kt}$ inbound transits.

\begin{tabular}{|c|c|c|c|c|c|}
\hline \multirow{2}{*}{$\begin{array}{l}\text { Wave } \\
\text { ID }\end{array}$} & \multirow[b]{2}{*}{ Days/yr } & \multirow{2}{*}{$\begin{array}{l}\text { Channel } U K C_{\text {Net }} \\
h=53 \mathrm{ft}\end{array}$} & \multicolumn{3}{|c|}{ Mound $U K C_{N e t}$} \\
\hline & & & $h=55 \mathrm{ft}$ & $h=56 \mathrm{ft}$ & $h=57 \mathrm{ft}$ \\
\hline 19 & 0.01 & 0.65 & 2.50 & 3.49 & 4.47 \\
\hline 22 & 0.02 & 0.61 & 2.78 & 3.87 & 4.89 \\
\hline 46 & 0.06 & 0.97 & 2.90 & 3.90 & 4.90 \\
\hline 52 & 0.15 & 1.08 & 3.31 & 4.38 & 5.41 \\
\hline 61 & 0.01 & 0.40 & 3.06 & 4.14 & 5.20 \\
\hline 64 & 0.01 & 0.61 & 3.32 & 4.45 & 5.57 \\
\hline 82 & 0.04 & 0.94 & 2.67 & 3.68 & 4.67 \\
\hline 87 & 0.52 & 1.12 & 2.86 & 3.94 & 4.98 \\
\hline 92 & 0.07 & 1.07 & 2.89 & 3.96 & 5.02 \\
\hline 95 & 0.01 & 1.08 & 3.07 & 4.22 & 5.35 \\
\hline 115 & 0.10 & 0.98 & 2.71 & 3.71 & 4.69 \\
\hline 119 & 0.21 & 1.10 & 2.55 & 3.64 & 4.67 \\
\hline 125 & 0.05 & 0.91 & 2.03 & 3.15 & 4.22 \\
\hline 127 & 0.01 & 1.08 & 2.37 & 3.49 & 4.60 \\
\hline 147 & 0.04 & 1.20 & 3.10 & 4.09 & 5.08 \\
\hline 152 & 0.21 & 1.20 & 2.93 & 4.01 & 5.02 \\
\hline 157 & 0.12 & 0.73 & 2.23 & 3.36 & 4.43 \\
\hline 158 & 0.04 & 0.93 & 2.51 & 3.65 & 4.77 \\
\hline 177 & 0.03 & 1.03 & 3.12 & 4.10 & 5.07 \\
\hline 181 & 0.17 & 0.93 & 3.04 & 4.10 & 5.10 \\
\hline 205 & 0.01 & 1.13 & 2.99 & 3.96 & 4.92 \\
\hline 206 & 0.00 & 0.66 & 2.63 & 3.59 & 4.54 \\
\hline 208 & 0.03 & 1.32 & 3.29 & 4.33 & 5.33 \\
\hline 209 & 0.01 & 0.56 & 2.63 & 3.68 & 4.66 \\
\hline \multicolumn{6}{|c|}{ Statistics } \\
\hline \multicolumn{2}{|c|}{ Minimum } & 0.40 & 2.03 & 3.15 & 4.22 \\
\hline \multicolumn{2}{|c|}{ Average } & 0.93 & 2.81 & 3.87 & 4.90 \\
\hline \multicolumn{2}{|c|}{ Maximum } & 1.32 & 3.32 & 4.45 & 5.57 \\
\hline
\end{tabular}

Notes:

1. Yellow highlight $=U K C_{N e t}<U K C_{M i n}=2 \mathrm{ft}$ Channel, $4 \mathrm{ft}$ mound. 
discussed and compared with $D_{\text {Max }}$. An example of a typical wave, ID 160, occurs 27.1 days/yr with a wave period of $4.3 \mathrm{sec}$ and wave height of $2.8 \mathrm{ft}$. The extreme wave example, ID 177, occurs only 0.03 days/yr with a wave period of $9.5 \mathrm{sec}$ and height of $8.7 \mathrm{ft}$. Both waves are from $180.0 \mathrm{deg}$ (south), which is the most frequently occurring wave direction for Ambrose Channel. Average and maximum $A_{M a x}$ and $U K C_{N e t}$ statistics for all 211 waves were also presented and discussed.

For the typical wave case, both inbound and outbound transits in the channel and mound reaches at the design speed of $12 \mathrm{kt}$ do not pose a problem for grounding as the $A_{M a x}$ is less than the $D_{\operatorname{Max}}$ and $U K C_{\text {Net }}$ is larger than $U K C_{\text {Min. }}$. Faster speeds are possible, but will require incursion into the $U K C_{M i n}$. There is no problem of grounding for the high tide level of $+5 \mathrm{ft}$ due to the additional water level.

The extreme wave case represents the worst combination of waves and ship squat and occurs very infrequently, a situation that the pilots can usually avoid. Because of the large $A_{\text {Max }}$ produced by these waves, pilots should exercise caution for inbound channel transits greater than $8 \mathrm{kt}$ and outbound greater than $10 \mathrm{kt}$ due to incursion into the $U K C_{M i n}$. Grounding is indicated for speeds greater than $14 \mathrm{kt}$ for inbound and $16 \mathrm{kt}$ for outbound. Mound transits show similar trends, but no grounding due to the larger $U K C_{\text {Min. }}$ Again, there is no problem of grounding for the high tide level of $+5 \mathrm{ft}$ due to the additional water level.

The results for the average wave cases are between those of the typical and extreme wave cases. The pilots should exercise caution during inbound channel transits for speeds greater than $8 \mathrm{kt}$ and can expect grounding for speeds greater than $12 \mathrm{kt}$. Outbound transits show similar trends, but are delayed by $2 \mathrm{kt}$ to speeds greater than $14 \mathrm{kt}$. Mound transits show similar trends for both inbound and outbound transits, but will not experience grounding due to the larger $U K C_{\text {Min }}$. As before, there are no grounding problems at the high tide level.

Finally, for the maximum wave case in Phase 1 with no tide, grounding is indicated for all ship speeds for both inbound and outbound transits in channel and mound reaches. This is an extremely large wave which the pilots will usually be able to avoid. For high tide conditions, grounding is still indicated in the channel reach for all speeds in both transit directions. The mound reach, however, only indicates grounding for speeds greater 
than $14 \mathrm{kt}$ for inbound transits. The pilots should exercise caution for the other transit directions and slower speeds due to incursion in the $U K C_{\text {Min }}$.

The Phase 2 waves consisted of 24 wave cases that were transformed using STWAVE and CMS-Wave from the WIS hindcast and NOAA buoy offshore sites. Both lightly and fully loaded ships were tested in Phase 2. It was decided to use inbound transits at $V_{k}=12 \mathrm{kts}$ as the criterion in Phase 2 since this is the typical transit speed and inbound transits have larger ship motions than outbound transits. Dredge depths of $h=53 \mathrm{ft}$ in the channel reach and $h=55,56$, and $57 \mathrm{ft}$ in the mound reach were selected for comparisons. The high tide level is not a problem because of the additional $5 \mathrm{ft}$ of water level. Therefore, only the "no tide" water level is discussed.

For the light-loaded ship at $12 \mathrm{kt}$, only 10 of the 24 Phase 2 wave cases indicated incursion into the $U K C_{M i n}$. Grounding was not indicated for any of the Phase 2 waves. Values of $A_{\operatorname{Max}}$ in the mound transits were flagged if they exceeded $0.3 \mathrm{ft}$ of the corresponding value in the channel transit. This was approximately 10 percent of the maximum channel, $A_{M a x}$, for Phase 2 wave cases. In general, transits in the mound reach did not experience significantly smaller $U K C_{\text {Net }}$ than similar transits in the channel reach. Moreover, the mound $U K C_{\operatorname{Min}}$ incursions can be avoided by dredging the mound reach an additional $1 \mathrm{ft}$ to $h=56 \mathrm{ft}$.

For the fully loaded ship at $12 \mathrm{kt}$, all of the Phase 2 waves indicated incursion into the $U K C_{\text {Min }}$ for the channel reach and the mound reach with a depth of $55 \mathrm{ft}$. This was due to the deeper draft of the fully loaded ship; however, as for the light-loaded ship, there was no grounding indicated. As the mound reach was deepened, the number of incursions decreased so that at $h=56 \mathrm{ft}$ there were only 15 incursions. The optimal depth for the mound reach is $h=57 \mathrm{ft}$ since this depth indicated no incursions into the $U K C_{\text {Min. }}$. As before for the light-loaded ship, transits in the mound reach did not experience significantly smaller $U K C_{N e t}$ than similar transits in the channel reach. 


\section{Summary and Conclusions}

New York Harbor Pilots have expressed concern about a high spot about 1.5 miles seaward of the new limit of the Ambrose Channel. This "mound" is immediately adjacent to the Sea Buoy, where the old Ambrose Light Tower was located. It is approximately 2,000 ft in diameter with a depth of $53 \mathrm{ft}$ MLLW and is probably construction rubble (i.e., hard material). Now that the Tower is no longer marking this mound, the pilots are concerned about navigation safety should a ship stray across this mound from the normal confines of Ambrose Channel.

The New York District (NAN) asked the US Army Engineer Research and Development Center (ERDC), Coastal and Hydraulics Laboratory (CHL), to evaluate the relative safety between transits over the mound to those in the main entrance channel. The static underkeel clearance (UKC) is the vertical "room" under the ship after subtracting the draft from the project depth. The $U K C$ is composed of six factors, the most significant of which are the wave response allowance due to wave-induced ship motions and ship squat. The net underkeel clearance $\left(U K C_{N e t}\right)$ is the minimum margin between the channel bed and the keel of the ship in the most unfavorable conditions that should be maintained to insure additional safety against grounding and maintain ship maneuverability.

The design ship for this study was the Susan Maersk Post-Panamax containership. It was completed in 1997 with a capacity of 8,680 TEU (twenty foot equivalents) and a length overall of $1,138 \mathrm{ft}$. Ship speeds range from $8 \mathrm{kt}$ to $16 \mathrm{kt}$, with typical ship speeds of $12 \mathrm{kt}$. In addition to the fully loaded draft of $47.5 \mathrm{ft}$, a light-loaded draft of $46 \mathrm{ft}$ was also investigated since the lighter ship will respond to waves differently than the fully loaded ship.

The Channel Analysis and Design Evaluation Tool (CADET) is a risk-based method that was used to predict vertical ship motions due to heave, pitch, and roll in each transit scenario. Ship squat was predicted and compared among PIANC, Ankudinov, and CADET ship squat predictors. The CADET vertical motion allowances along with average ship squat predictions were subtracted from $U K C$ to provide a risk-based method of evaluating the $U K C_{N e t}$ for the two transit scenarios. 
The first step in the analysis was to define the wave climate in the Ambrose Channel. Because of the angle of the shore, wave directions outside the range of 56.25 to 213.75 deg will not impact the Ambrose Channel. Therefore, a joint probability distribution of wave height and period was created in seven 22.5-deg direction bands within this direction-limited range. It consisted of 139,071 observations representing 79.3 percent of the 175,310 deepwater data from the WIS 20 yr hindcast buoy WIS126. From these joint probability distributions of wave period and wave height, wave parameter statistics were gathered for generating empirical directional wave spectra representative of the WIS126 deepwater data. A total of 211 directional spectra were simulated based on a TMA frequency spectrum and $\cos ^{\mathrm{n}}$ directional spreading function. In this Phase 1 wave dataset, it was assumed that wave transformation between the WIS126 buoy and the Ambrose Channel was not significant.

A Phase 2 wave dataset was created after preliminary analysis of the ship motion allowances from Phase 1. Only waves that produced a significant effect on transit safety in the main channel were retained in the Phase 2 dataset. These waves were then examined in detail in the numerical models STWAVE and CMS-Wave to determine wave transformation in both main channel and mound locations. The transformed wave parameters were used to create 24 new directional wave spectra in Phase 2 for input to CADET.

Two coastal wave transformation numerical models, STWAVE and CMSWave, were used to calculate wave parameters (height, period, and direction) at the entrance of the Ambrose Channel and over the mound in the vicinity. These directional spectral wave models were applied in the half-plane wave transformation mode, meaning that wave energy transformation was limited from offshore toward the coastline in a o to 180 deg sector of the primary incident wave direction in deep water. The reason for using two wave models was because STWAVE is adequate for the nearshore wave transformation outside the surf zone while CMS-Wave is designed specifically for inlet and bay applications involving processes where waves interact with tides, currents, navigation channels, muddy bottoms, and coastal structures such as breakwaters, jetties, spurs, and groins. The results from both models were very similar. The main purpose of the wave modeling was to evaluate the wave refraction deformation, shoaling, and wave focusing at and in the lee of a submerged mound, just east of the Ambrose Channel Entrance. Wave input information was based 
on design wave conditions and prepared by SMS to generate directional spectrum as input at the model grid sea boundary.

Ship squat was compared for PIANC, Ankudinov, and CADET predictions. The five PIANC empirical squat formulas included those of Barrass, Eryuzlu, Huuska, Römisch, and Yoshimura. The Ankudinov formula was originally used in the Ship-Tow Simulator. The CADET squat formula is based on the work of Beck, Newman, and Tuck.

Seven predictors of ship squat were compared for both the lightly and fully loaded Susan Maersk transits in the Ambrose Channel for a range of ship speeds from 8 to $16 \mathrm{kt}$. The purpose was to indicate (a) the relative amount of $U K C$ required for ship squat for Ankudinov, CADET, Barrass, Eryuzlu, Huuska/Guliev, Römisch, and Yoshimura predictors and (b) the effect of the deeper mound on ship squat relative to the shallower channel transits. The largest squat will occur for the fully loaded ship in the channel with the no tide conditions since the $U K C$ is the smallest and the ship will "feel" the bottom more. The $U K C$ in this case is $5.5 \mathrm{ft}$ (i.e., $53.0-47.5 \mathrm{ft}$ ). For a ship transiting the channel at a speed of $12 \mathrm{kt}$, squat can range from 1.46 to $3.08 \mathrm{ft}$, with an average of $2.44 \mathrm{ft}$. Even at a ship speed of $16 \mathrm{kt}$, the squat increases from a low of 2.99 to a high of $5.51 \mathrm{ft}$, with an average of $4.64 \mathrm{ft}$. Therefore, during transits where wave activity is relatively insignificant, ship squat should not be a problem, even at the fastest ship speeds. Of course, one will still want to maintain the $U K C_{M i n}$ of 2 to $4 \mathrm{ft}$ in the channel and mound reaches, respectively.

For the mound transits with the same fully loaded and no tide conditions, the $U K C$ is $7.5 \mathrm{ft}$ (i.e., $55.0-47.5 \mathrm{ft}$ ). For a ship transiting the channel at a speed of $12 \mathrm{kt}$, squat can range from 1.40 to $3.08 \mathrm{ft}$, with an average of $2.36 \mathrm{ft}$. Even at a ship speed of $16 \mathrm{kt}$, the squat increases from a low of 2.85 to a high of $5.45 \mathrm{ft}$, with an average of $4.46 \mathrm{ft}$. Again, during transits where wave activity is relatively insignificant, ship squat should not be a problem, even at the fastest ship speeds.

For the light-loaded ship, the predicted ship squat is slightly less, plus the shallower draft of $46 \mathrm{ft}$ provides an additional $1.5 \mathrm{ft}$ of $U K C$. Ship squat is not a problem for the high tide condition as the predicted squat is slightly lower and an additional $U K C$ of $5 \mathrm{ft}$ is available. 
Wave-induced vertical ship motions are composed of the combined effects of heave, pitch, and roll at the five critical points on the bottom of the ship. CADET calculates these vertical motion allowances for each ship loading condition, channel reach, and water depth. The allowances are output for each wave condition, transit direction, ship speed, and critical or alternative points. The FORTRAN program ReadIn_CADET_Allow2 reads in these files and calculates the largest allowance over all five critical points for each wave condition, ship speed, and transit direction. These "maximum" values are used for comparisons in this report.

Maximum wave-induced vertical ship motions, $A_{M a x}$, and corresponding $U K C_{N e t}$ for Phase 1 and Phase 2 waves were discussed and compared with the maximum ship displacement, $D_{\operatorname{Max}}$. The $A_{\operatorname{Max}}$ represents the maximum ship motion at any of the five critical points along the bottom of the ship due to the combined effects of heave, pitch, and roll. The $D_{\text {Max }}$ indicates the "space" above the bottom in the water column that is available to accommodate $A_{\text {Max }}$ after subtracting average ship squat, $S_{\text {Ave }}$. The $U K C_{N e t}$ is the remaining clearance between the ship and the channel bottom after subtracting $S_{A v e}$ and $A_{M a x}$ from the UKC. For safety and maneuverability concerns in this study, the sponsor requested a minimum $U K C_{\text {Min }}$ of $2 \mathrm{ft}$ for channel transits and $4 \mathrm{ft}$ for mound transits.

The Phase 1 waves consisted of all 211 wave cases from the WIS hindcast. Only the fully loaded ship was tested in Phase 1 as this was the worst case scenario for UKC. In general, outbound transits are much less of a problem than inbound transits as their motions are much smaller. Examples of $A_{M a x}$ and corresponding $U K C_{\text {Net }}$ for a typical and extreme wave case were discussed and compared with $D_{M a x}$. An example of a typical wave, ID 160, occurs 27.1 days/yr with a wave period of $4.3 \mathrm{~s}$ and wave height of $2.8 \mathrm{ft}$. The extreme wave example, ID 177, occurs only 0.03 days/yr with a wave period of $9.5 \mathrm{~s}$ and height of $8.7 \mathrm{ft}$. Both waves are from $180.0 \mathrm{deg}$ (south), which is the most frequently occurring wave direction for Ambrose Channel. Average and maximum $A_{M a x}$ and $U K C_{N e t}$ statistics for all 211 waves were also presented and discussed.

For the typical wave case, both inbound and outbound transits in the channel and mound reaches at the design speed of $12 \mathrm{kt}$ do not pose a problem for grounding as the $A_{M a x}$ is less than the $D_{\operatorname{Max}}$ and $U K C_{\text {Net }}$ is larger than $U K C_{\text {Min. }}$. Faster speeds are possible, but will require incursion 
into the $U K C_{\text {Min }}$. There is no problem of grounding for the high tide level of $+5 \mathrm{ft}$ due to the additional water level.

The extreme wave case represents the worst combination of waves and ship squat and occurs very infrequently, a situation that the pilots can usually avoid. Because of the large $A_{\text {Max }}$ produced by these waves, pilots should exercise caution for inbound channel transits greater than $8 \mathrm{kt}$ and outbound greater than $10 \mathrm{kt}$ due to incursion into the $U K C_{\text {Min. }}$. Grounding is indicated for speeds greater than $14 \mathrm{kt}$ for inbound and $16 \mathrm{kt}$ for outbound. Mound transits show similar trends, but no grounding due to the larger $U K C_{M i n}$. Again, there is no problem of grounding for the high tide level of $+5 \mathrm{ft}$ due to the additional water level.

The results for the average wave cases are between those of the typical and extreme wave cases. The pilots should exercise caution during inbound channel transits for speeds greater than $8 \mathrm{kt}$ and can expect grounding for speeds greater than $12 \mathrm{kt}$. Outbound transits show similar trends, but are delayed by $2 \mathrm{kt}$ to speeds greater than $14 \mathrm{kt}$. Mound transits show similar trends for both inbound and outbound transits, but will not experience grounding due to the larger $U K C_{\text {Min }}$. As before, there are no grounding problems at the high tide level.

Finally, for the maximum wave case in Phase 1 with no tide, grounding is indicated for all ship speeds for both inbound and outbound transits in channel and mound reaches. This is an extremely large wave which the pilots will usually be able to avoid. For high tide conditions, grounding is still indicated in the channel reach for all speeds in both transit directions. The mound reach, however, only indicates grounding for speeds greater than $14 \mathrm{kt}$ for inbound transits. The pilots should exercise caution for the other transit directions and slower speeds due to incursion in the $U K C_{M i n}$.

The Phase 2 waves consisted of 24 wave cases that were transformed using STWAVE and CMS-Wave from the WIS hindcast and NOAA buoy offshore sites. Both lightly and fully loaded ships were tested in Phase 2. It was decided to use inbound transits at $V_{k}=12 \mathrm{kts}$ as the criterion in Phase 2 since this is the typical transit speed and inbound transits have larger ship motions than outbound transits. Dredge depths of $h=53 \mathrm{ft}$ in the channel reach and $h=55,56$, and $57 \mathrm{ft}$ in the mound reach were selected for comparisons. The high tide level is not a problem because of the additional $5 \mathrm{ft}$ of water level. Therefore, only the "no tide" water level is discussed. 
For the light-loaded ship at $12 \mathrm{kt}$, only 10 of the 24 Phase 2 wave cases indicated incursion into the $U K C_{M i n}$. Grounding was not indicated for any of the Phase 2 waves. Values of $A_{\operatorname{Max}}$ in the mound transits were flagged if they exceeded $0.3 \mathrm{ft}$ of the corresponding value in the channel transit. This was approximately 10 percent of the maximum channel $A_{\operatorname{Max}}$ for Phase 2 wave cases. In general, transits in the mound reach did not experience significantly smaller $U K C_{N e t}$ than similar transits in the channel reach. Moreover, the mound $U K C_{\text {Min }}$ incursions can be avoided by dredging the mound reach an additional $1 \mathrm{ft}$ to $h=56 \mathrm{ft}$.

For the fully loaded ship at $12 \mathrm{kt}$, all of the Phase 2 waves indicated incursion into the $U K C_{\operatorname{Min}}$ for the channel reach and the mound reach with a depth of $55 \mathrm{ft}$. This was due to the deeper draft of the fully loaded ship; however, as for the light-loaded ship, there was no grounding indicated. As the mound reach was deepened, the number of incursions decreased so that at $h=56 \mathrm{ft}$ there were only 15 incursions. The optimal depth for the mound reach is $h=57 \mathrm{ft}$ since this depth indicated no incursions into the $U K C_{\text {Min. }}$. As before, for the light-loaded ship transits in the mound reach did not experience significantly smaller $U K C_{N e t}$, than similar transits in the channel reach. 


\section{References}

Ankudinov, V. K., and B. K. Jakobsen. 1996. Squat predictions at an early stage of design, Workshop on Ship Squat in Restricted Waters (October 4, Washington), SNAME, Jersey City, NJ, pp. 48-69.

Ankudinov, V., L. Daggett, C. Huval, and C. Hewlett. 1996. Squat predictions for maneuvering applications, International Conference on Marine Simulation and Ship Maneuverability, MARSIM '96, Balkema, Rotterdam, The Netherlands: Copenhagen, Denmark, pp. 467-495, September 9-13, 1996.

Ankudinov, V., L. L. Daggett, J. C, Hewlett, and B. K. Jakobsen. 200o. Prototype measurement of ship sinkage in confined water, International Conference on Marine Simulation and Ship Maneuverability (MARSIM 20oo), Orlando, FL, May 8-12.

Barrass, C. B. 2009. Ship Squat and Interaction, Witherby Seamanship International Ltd Publishing, Edinburgh, Scotland, UK, 182 pp.

Battjes, J. A. 1972. Set-up due to irregular waves, In Proceedings $13^{\text {th }}$ International Conference on Coastal Engineering, ASCE, 1993-2004.

Battjes, J. A., and J. Janssen. 1978. Energy loss and set-up due to breaking of random waves, In Proceedings $16^{\text {th }}$ International Conference Coastal Engineering, ASCE, 569-587.

Beck, R. F., J. N. Newman, and E. O. Tuck. 1975. Hydrodynamic forces on ships in dredged channels, Journal of Ship Research, 9(3).

Borgman, L. E. 1990. Irregular ocean waves: kinematics and forces, Chapter 4, The Sea.

B. Le Mehaute and D. Hanes (ed.). New York, NY: John Wiley and Sons, 121-168.

Bouws, E., and G. J. Komen. 1983. On the balance between growth and dissipation in extreme, depth limited wind-sea in the southern North Sea, Journal of Physical Oceanography 13(1): 653-1,658.

Bouws, E., H. Gunther, W. Rosenthal, and C. Vincent. 1985. Similarity of the wind wave spectrum in finite depth water, J. Geophys. Res., 90(C1): 975-986.

Bretherton, F. P., and C. J. R. Garrett. 1968. Wave trains in inhomogeneous moving media, In Proceedings Royal Society of London A(302):529-554.

Briggs, M. J. 2006. Ship squat predictions for Ship/Tow Simulator. ERDC/CHL CHETNI-72, Vicksburg, MS: US Army Engineer Research and Development Center.

Briggs, M. J. 1988. Unidirectional spectral wave generation and analysis in wave basins. Tech. Rept. CERC 88-11. Vicksburg, MS: USACE, Waterways Experiment Station. 
Briggs, M. J. 2009. Ankudinov ship squat predictions - Part I: Theory and FORTRAN programs, ERDC/CHL CHETN-IX-19, Vicksburg, MS: US Army Engineer Research and Development Center.

Briggs, M. J. and L. Daggett. 2009. Ankudinov ship squat predictions - Part II: Laboratory and field comparisons and validations, ERDC/CHL CHETN-IX-20, Vicksburg, MS: US Army Engineer Research and Development Center.

Briggs, M. J. and W. G. Henderson. 2011. Vertical ship motion study for Savannah, GA Entrance Channel, ERDC/CHL TR-11-5, Vicksburg, MS: US Army Engineer Research and Development Center,pp. 221.

Briggs, M. J., L. E. Borgman, and D. G. Outlaw. 1987. Generation and analysis of directional spectral waves in a laboratory basin. In Proc. Offshore Tech. Conf., Houston, TX, 495-502.

Briggs, M.J., Silver, A.L, and Kopp, P.J. 2004. CADET: A tool for predicting underkeel clearance in deep-draft entrance channels, CEO6, Baltimore, $\mathrm{MD}$, Oct.

Briggs, M. J., A. L. Silver, and L. E. Borgman. 2006. Risk-based predictions for ship underkeel clearance, ICCE 2006, San Diego, CA.

Briggs, M. J., A. L. Silver, and P. J. Kopp. 2012. Chapter 6: Risk-Based channel depth design Using CADET, Series on Coastal and Ocean Engineering Practice, Editor: Y. Kim, Vol. 1, World Scientific Press, Singapore,319-366.

Briggs, M. J., P. J. Kopp, F. A. Santangelo, and A. L. Silver. 2010. Comparison of CADET vertical ship motions with DGPS in Ambrose Channel, PORTS 201O, Jacksonville, FL, April, 689-698.

Briggs, M. J., A. L. Silver, P. J. Kopp, F. A. Santangelo, and I. A. Mathis. 2013. Validation of a risk-based numerical model for predicting deep-draft underkeel clearance, ASCE, Journal of Waterway, Port, Coastal, and Ocean Engineering, 139(4): 267-276.

Buttolph, A. M., C. W. Reed, N. C. Kraus, N. Ono, M. Larson, B. Camenen, H. Hanson, T. Wamsley, and A. Zundel. 2006. Two-dimensional depth-averaged circulation model CMS-M2D: Version 3.o: Report 2, sediment transport and morphology change. ERDC/CHL TR-06-9. Vicksburg, MS: US Army Engineer Research and Development Center.

Chawla, A., and J. T. Kirby. 2002. Monochromatic and random wave breaking at blocking points, Journal of Geophysical Research 107(C7), 10.1029/2001JCo01042.

Collins, J. I. 1972. Prediction of shallow water spectra, Journal of Geophysical Research 77(15):2693-2707.

d'Angremond, K., J. W. Van der Meer, and R. J. de Jong.1996. Wave transmission at lowcrested structures, In Proceedings 25th International Conference on Coastal Engineering, Orlando, FL. USA, ASCE, 2418-2427.

Dean, R. G., and R. A. Dalrymple. 1984. Water wave mechanics for engineers and scientists. Englewood Cliffs, NJ: Prentice-Hall, Inc. 
Demirbilek, Z., and V. Panchang. 1998. CGWAVE: A coastal surface-water wave model of the mild-slope equation. CHL-98-26. Vicksburg, MS: US Army Engineer Waterways Experiment Station.

Demirbilek, Z., L. Lin, and A. Zundel. 2007. WABED model in the SMS: Part 2. Graphical interface. ERDC/CHL CHETN-I-74. Vicksburg, MS: US Army Engineer Research and Development Center.

Demirbilek, Z., L. Lin, and O. G. Nwogu. 2008. Wave modeling for jetty rehabilitation at the Mouth of the Columbia River, Washington/Oregon, USA. ERDC/CHL TRo8-3. Vicksburg, MS: US Army Engineer Research and Development Center.

Demirbilek, Z., M. Mohr, and S. Chader. 2010. Phase 1 study final letter report: Wave modeling for Cleveland Harbor, Ohio, Letter Report, Jul 2010, p.77.

Demirbilek, Z., L. Lin, W.C. Seabergh, H. Mase, and J. Zheng. 2009. Laboratory and numerical studies of hydrodynamics near jetties, Coastal Engineering 51(2): 143175 .

Eryuzlu, N.E., Y. L. Cao, F. D’Agnolo. 1994. Underkeel requirements for large vessels in shallow waterways, 28th International Navigation Congress, PIANC, Paper S II2, Sevilla, Spain, 17-25.

Goda, Y. 1985. Random seas and design of maritime structures. University of Tokyo Press.

Guliev, U. M. 1971. On squat calculations for vessels going in shallow water and through channels, PIANC Bulletin 1971, Vol. 1, No. 7, 17-20.

Hardy, T. A. 1993. The attenuation of spectral transformation of wind waves on a coral reef. Queensland, Australia: James Cook University of North Queensland, Townsville, $336 \mathrm{p}$.

Härting, A., A. Laupichler, and J. Reinking. 2009. Consideration on the squat of unevenly trimmed ships, Ocean Engineering, 36, Elsevier, February, 193-201.

Hasselmann, K., T. P. Barnett, E. Bouws, H. Carlson, D. E. Cartwright, K. Enke, J. A. Ewing, H. Gienapp, D. E. Hasselmann, P. Kruseman, A. Meerbrug, P. Muller, D. J. Olbers, K. Richter, W. Sell, and H. Walden. 1973. Measurements of windwave growth and swell decay during the Joint North Sea Wave Project (JONSWAP), Deutsche Hydrographische Zeitschrift A80(12): 95 p.

Hearn, C. J. 1999. Wave-breaking hydrodynamics within coral reef systems and the effect of changing relative sea level, Journal of Geophysical Research 104(C12):30,00730,019.

Hughes, S. A. 1984. The TMA Shallow-Water Spectrum Description and Applications. Tech. Rept. CERC-84-7. Vicksburg, MS: U.S. Army Engr. Waterways Experiment Station.

Huuska, O. 1976. On the evaluation of underkeel clearances in finnish waterways, Helsinki University of Technology, Ship Hydrodynamics Laboratory, Otaniemi, Report No. 9. 
Iwagaki, Y., T. Asano, Y. Yamanaka, and F. Nagai. 1980. Wave breaking due to currents, Annual Journal of Coastal Engineering 27:30-34, JSCE (in Japanese).

Jenkins, A. D., and O. M. Phillips. 2001. A simple formula for nonlinear wave-wave interaction, Journal of Offshore and Polar Engineering 11(2):81-86.

Jonsson, I. G. 1990. Wave-current interactions, Chapter 7, The Sea. B. Le Mehaute and D. Hanes (ed.). New York, NY: John Wiley and Sons, 65-120.

Kaplan, P. 1996a. Technical manual for SCORES II program - Finite Depth Version, Hydrodynamics, Inc., Report No. 96-101A, Jun.

Kaplan, P. 1996b. Sample Calculations and Verification of SCORES II - Finite Depth Program, Hydrodynamics, Inc., Report No. 96-101B, June.

Komar, P. D. 1998. Beach processes and sedimentation. $2^{\text {nd }}$ ed. Upper Saddle River, NJ: Prentice-Hall, Inc.

Kopp, P. J., and A. L. Silver. 2005. Program documentation for the channel analysis and design evaluation tool (CADET), David Taylor Model Basin, Carderock Division, Naval Surface Warfare Center NSWCCD-50-TR-2005/004, May.

Lamb, H., 1932. Hydrodynamics. 6th ed. New York: Dover Publications.

Larson, M., and N. C. Kraus. 2002. NMLONG: Numerical model for simulating longshore current. ERDC/CHL TR-02-22. Vicksburg, MS: US Army Engineer Research and Development Center.

Lin, L., and R.-Q. Lin. 2004a. Wave Breaking Function, Proceedings $8^{\text {th }}$ International Workshop on Wave Hindcasting and Prediction. Oahu, Hawaii: North Shore. November 14-19.

Lin, R.-Q., and L. Lin. 2004b. Wind input function, In Proceedings $8^{\text {th }}$ International Workshop on Wave Hindcasting and Prediction. North Shore, Oahu, Hawaii. November 14-19.

Lin, L., and Z. Demirbilek. 2005. Evaluation of two numerical wave models with inlet physical model, J. Waterway, Port, Coastal, and Ocean Engineering, 131(4): 149-161.

Lin, L., Z. Demirbilek, and F. Yamada. 2008. CMS-Wave: A nearshore spectral wave processes model for coastal inlets and navigation projects. ERDC/CHL TR-o813, Vicksburg, MS: US Army Engineer Research and Development Center.

Lin, L., Z. Demirbilek, J. Zheng, and H. Mase. 2010. Rapid calculation of nonlinear wavewave interactions in wave-action balance equation, In Proceedings of the International Conference on Coastal Engineering, No. 32. Shanghai, China. Retrieved from http://journals.tdl.org/ICCE/

Lin, L., H. Mase, F. Yamada, and Z. Demirbilek. 2006. Wave-action balance equation diffraction (WABED) model: Test of wave diffraction and reflection at inlets, ERDC/CHL CHETN-III-73, Vicksburg, MS: US Army Engineer Research and Development Center. 
Lin, L., Z. Demirbilek, and H. Mase. 2011. Recent capabilities of CMS-Wave: A coastal wave model for inlets and navigation projects, In Proceedings, Symposium to honor Dr. Nicholas Kraus. Journal of Coastal Research, Special Issue 59: 7-14.

Lowe, R. J., J. L. Falter, M. D. Bandet, G. Pawlak, M. J. Atkinson, S. G. Monismith, and J. R. Koseff. 2005. Spectral wave dissipation over a barrier reef, Journal of Geophysical Research 110(Co4001), doi:10.1029/2004JC002711, 16 p.

Macagno, E. O. 1953. Houle dans un can presentent un passage en charge, La Houille Blanche 9(1):10-37.

Mase, H. 2001. Multidirectional random wave transformation model based on energy balance equation, Coastal Engineering Journal 43(4):317-337 JSCE.

Mase, H., H. Amamori, and T. Takayama. 2005a. Wave prediction model in wave-current coexisting field, In Proceedings $12^{\text {th }}$ Canadian Coastal Conference (CD-ROM).

Mase, H., K. Oki, T. S. Hedges, and H. J. Li. 2005b. Extended energy-balance-equation wave model for multidirectional random wave transformation, Ocean Engineering 32(8-9):961-985.

Miche, M. 1951. Le pouvoir reflechissant des ouvrages maritimes exposes a 1'action de la houle. Annals des Ponts et Chau.ssess. 121e Annee: 285-319 (translated by Lincoln and Chevron, University of California, Berkeley, Wave Research Laboratory, Series 3, Issue 363, June 1954).

NEMOS. 2000. Nearshore evolution modeling system, Version 1.01C. Vicksburg, MS, VeriTech, Inc.

Ochi, M.K. 1973. On prediction of extreme values, Journal of Ship Research, 17.

Phillips, O. M. 1957. On the generation of waves by turbulent wind. Journal of Fluid Mechanics 2:417-445.

PIANC. 1997. Approach Channels: A Guide for Design, Final Report of the Joint PIANCIAPH Working Group II-3O in cooperation with IMPA and IALA, Supplement to Bulletin No. 95, June.

PIANC. 2013. Approach Channels: A Guide for Design, Final Report of the Joint PIANCIAPH Working Group 49 in cooperation with IMPA and IALA, (In publication).

Römisch, K. 1989. Empfehlungen zur Bemessung von Hafeneinfahrten, Wasserbauliche Mitteilungen der Technischen Universität Dresden, Heft 1, 39-63.

Sakai, S., N. Kobayashi, and K. Koike. 1989. Wave breaking criterion with opposing current on sloping bottom: an extension of Goda's breaker index, Annual Journal of Coastal Engineering 36:56-59, JSCE (in Japanese).

Silver, A. L. 1992. Environmental monitoring and operator guidance system (EMOGS) for Shallow Water Ports, Ports '92, ASCE, Seattle, WA, Jul, 535-547.

Silver, A.L. and Dalzell, J. F. 1997. Risk-based Decisions for Entrance Channel Operation and Design, 7th ISOPE Conference, May, 815-822. 
Smith, J. M. 2001. Modeling nearshore transformation with STWAVE. ERDC/CHL CHETN I-64. Vicksburg, MS: US Army Engineer Research and Development Center. http://chl.erdc.usace.army.mil/chetn.

Smith, J. M. 2007. Full-plane STWAVE with Bottom Friction: II. Model overview. CHETN-I-75. Vicksburg, MS: US Army Engineer Research and Development Center. http://chl.erdc.usace.army.mil/chetn.

Smith J. M. and A. Zundel. 2006. Full Plane STWAVE: SMS graphical interface. ERDC/CHL CHETN-I-71. Vicksburg, MS: US Army Engineer Research and Development Center.

Smith, J. M., D. T. Resio, and C. L. Vincent. 1997. Current-induced breaking at an idealized inlet, In Proc. Coastal Dynamics '97. ASCE. 993-1002.

Smith, J. M., D. T. Resio, and A. Zundel. 1999. STWAVE: Steady-state spectral wave model, Report 1: User's manual for STWAVE Version 2.o. Instruction Report CHL-99-1. Vicksburg, MS: US Army Engineer Waterways Experiment Station.

Smith, J. M., A. R. Sherlock, and D. T. Resio. 2001a. STWAVE: Steady-state spectral wave model user's manual for STWAVE, Version 3.o, Special Report ERDC/CHL SR-01-1,Vicksburg, MS: US Army Engineer Research and Development Center, Coastal and Hydraulics Laboratory.

Smith, J. M., D. K. Stauble, B. P. Williams, and M. J. Wutkowski. 2001b. Impact of Savannah Harbor deep draft navigation project on Tybee Island Shelf and shoreline, Special Report ERDC/CHL TR-08-5, Vicksburg, MS: US Army Engineer Research and Development Center.

Smith, J. M., W. C. Seabergh, G. S. Harkins, and M. J. Briggs. 1998. Wave breaking on a current at an idealized inlet. CHL-98-31. Vicksburg, MS: US Army Engineer Waterways Experiment Station.

Stauble, D. K., J. E. Davis, J. Z. Gailani, L. Lin, E. F. Thompson, H. Benson, T. C. Pratt, and M. P. Rollings. 2001. Construction, Monitoring and Data Analysis of a Nearshore Mixed-Sediment Mound, Mobile Bay Entrance, Alabama. Technical Report ERDC/CHL-o1-xx (Draft), Vicksburg, MS: US Army Engineer Research and Development Center.

Stocks, D. T., L. L. Daggett, and Y. Page. 2002. Maximization of Ship Draft in the St. Lawrence Seaway Volume I: Squat Study. Prepared for Transportation Development Centre, Transport Canada, June.

Thompson, E. F., L. L. Hadley, W. A. Brandon, D. D. McGeehee, and J. M. Hubertz. 1996. Wave Response of Kahului Harbor, Maui, Hawaii. Technical Report ERDC/CHL-96-11. Vicksburg, MS: US Army Engineer Research and Development Center.

Thompson, E. F. 2002. Wave Modeling, Navigation Study for Savannah Harbor, Georgia, ERDC/CHL TR-02-xx (DRAFT), Vicksburg, MS: US Army Engineer Research and Development Center. August, 24 pages.

Tuck, E. O. 1966. Shallow-Water Flows Past Slender Bodies. Journal of Fluid Mechanics, 26(1): pp. 81-95. 
Tuck, E. O. 1967. Sinkage and Trim in Shallow water of Finite Width, Schiffstechnik, 14(73): pp. 92-94.

Yoshimura, Y. 1986. Mathematical model for the maneuvering ship motion in shallow water, Journal of the Kansai Society of Naval Architects, Japan, No. 200.

Vincent, C. L.,and M. J. Briggs. 1989. Refraction-Diffraction of Irregular Waves over A Mound, ASCE WPCOE, 115(2), Mar.

Whitham, G. B. 1974. Linear and nonlinear waves. New York, NY: John Wiley.

Zheng, J., H. Mase, Z. Demirbilek, and L. Lin. 2008. Implementation and evaluation of alternative wave breaking formulas in a coastal spectral wave model, Ocean Engineering, 35: 1090- 1101.

Zundel, A. 2006. Surface-water modeling system reference manual - Version 9.2. Provo, UT: Brigham Young University Environmental Modeling Research Laboratory. 


\section{Appendix A: CMS-Wave Numerical Model Capabilities for Navigation Projects}

Two numerical wave models were used in this study to predict wave parameters at the Ambrose Channel Entrance and on the nearby mound. These models were described in Chapter 3 and estimates were discussed in Chapter 5. Because CMS-Wave has several additional features geared for navigation projects, this appendix contains descriptions of several of the CMS-Wave capabilities and a listing of the input control parameters used in the code. The capabilities include (a) wave diffraction, (b) wave-current interaction, (c) wave reflection, (d) wave breaking, (e) wind forcing and whitecapping dissipation, (f) wave generation with arbitrary wind direction, (g) bottom friction loss, (h) wave runup, (i) wave transmission and overtopping, (j) grid nesting, (k) variable rectangular-cell grid, (l) nonlinear wave-wave interaction, (m) wave dissipation over muddy bottom, (n) fullplane and wind field input capabilities, and (o) fast-mode calculations.

A summary of the control parameters used in CMS-Wave are presented at the end of this appendix. A discussion of the default values is also provided.

Interested readers may consult publications listed in the References section which specifically deal with these features and their applications to practical problems (Lin and Lin 2004a and 2004b; Lin et al. 2008; Lin et al. 2010; Lin et al. 2011; Demirbilek et al. 2007; Demirbilek et al. 2008; Demirbilek et al. 2009; Demirbilek et al. 2010; and Zheng at al. 2008).

\section{Capability descriptions}

\section{Wave diffraction}

In applications, the diffraction intensity parameter $\kappa$ (see Equations 10 and 12 in Chapter 3) needs to be calibrated and optimized for structures. The model omits the diffraction effect for $\kappa=0$ and calculates diffraction for $\kappa>0$. Large $\kappa(>15)$ should be avoided as it can cause artificial wave energy losses. In practice, values of $\kappa$ between $\mathrm{o}$ (no diffraction) and 4 (strong diffraction) have been determined in comparison to measurements. A default value of $\kappa=2.5$ was used by Mase (2001) and Mase et al. (2005a) to 
simulate wave diffraction for both narrow and wide gaps between breakwaters. In CMS-Wave, the default value of $\kappa$ is 4 corresponding to strong diffraction. This default $(\kappa)$ is recommended for wave diffraction at a semi-infinite long breakwater or at a narrow gap (e.g., harbor entrance or jettied inlet), with the opening equal or less than one wavelength (Demirbilek and Panchang 1998). For a relatively wider gap, with an opening greater than one wavelength, $\kappa=3$ is recommended. The exact value of $\kappa$ in an application is dependent on the structure geometry and adjacent bathymetry, and it may need to be verified with measurements.

\section{Wave-current interaction}

The characteristic velocties $C_{x}, C_{y}$, and $C_{\theta}$ in Equation (10) are expressed as follows:

$$
\begin{gathered}
C_{x}=C_{g} \cos \theta+U \\
C_{y}=C_{g} \sin \theta+V \\
C_{\theta}=\frac{\sigma}{\sinh 2 k h}\left(\sin \theta \frac{\partial h}{\partial x}-\cos \theta \frac{\partial h}{\partial y}\right) \\
+\cos \theta \sin \theta \frac{\partial U}{\partial x}-\cos ^{2} \theta \frac{\partial U}{\partial y}+\sin ^{2} \theta \frac{\partial V}{\partial x}-\sin \theta \cos \theta \frac{\partial V}{\partial y}
\end{gathered}
$$

where $U$ and $V$ are the depth-averaged horizontal current velocity components along the $x$ and $y$ axes, $k$ is wave number, and $h$ is water depth. The dispersion relationships between the relative angular frequency, $\sigma$, the absolute angular frequency, $\omega$, the wave number vector, $\vec{k}$, and the current velocity vector, $|\vec{U}|=\sqrt{U^{2}+V^{2}}$ are

$$
\sigma=\omega-\vec{k} \cdot \vec{U}
$$

and

$$
\sigma^{2}=g k \tanh (k h)
$$

where $\vec{k} \cdot \vec{U}$ is the Doppler-shifting term (e.g., Jonsson 1990; Chawla and Kirby 2002; Demirbilek and Panchang 1998; Sakai et al. 1989; and Smith et 
al. 1997), and $g$ is the gravitational acceleration. The main difference between the wave transformation models with and without ambient currents lies in the solution of the intrinsic frequency. In treatment of the dispersion relation with the Doppler shift, there is no solution corresponding to wave blocking, if intrinsic group velocity, $C_{g}$, is weaker than an opposing current (; Larson and Kraus 2002 and Smith et al. 1998):

$$
C_{g}=\frac{d \sigma}{d k}<\vec{U} \cdot \vec{k} / k
$$

Under the wave blocking condition, waves cannot propagate into a strong opposing current. The wave energy is most likely to dissipate through breaking with a small portion of energy either reflected or transformed to lower frequency components in the wave blocking condition. In CMSWave, the wave-action corresponding to the wave blocking is set to zero for the corresponding frequency and direction bin.

\section{Wave reflection}

The wave energy reflected at a beach or upon the surface of a structure is calculated under assumptions that the incident and reflected wave angles are equal and that the reflected energy is a given fraction of the incident wave energy. The reflected wave action, $N_{r}$, is assumed linearly proportional to the incident wave action $N_{i}$ :

$$
N_{r}=K_{r}^{2} N_{i}
$$

where $K_{r}$ is a reflection coefficient $\left(K_{r}=\mathrm{o}\right.$ for no reflection and $K_{r}=1$ for full reflection) defined as the ratio of reflected to incident wave height (Dean and Dalrymple 1984).

CMS-Wave calculates the wave energy reflection at a sidewall or a lateral solid boundary within the wave transformation routine. It can also calculate wave reflection off the beach or detached breakwater using a backward marching calculation routine (Mase et al. 2005a). Users should be aware that, while the computer run time with the forward reflection can be efficient, the time is almost double for the backward reflection routine. 


\section{Wave breaking}

The simplest wave breaking criterion in finite depth is a linear function of the ratio of wave height to depth. For random waves, the criterion is the same as the one used in STWAVE (Smith et al. 1999)

$$
\frac{H_{b}}{h} \leq 0.64
$$

where $H_{b}$ denotes the significant breaking wave height. CMS-Wave applies a revised limiting steepness criterion originally proposed by Miche (1951) for random waves as

$$
H_{b} \leq \frac{0.64}{k_{p}} \tanh \left(k_{p} h\right)
$$

where $k_{p}$ is the wave number corresponding to the spectral peak. In the shallow water condition ( $k_{p} h$ small), Equation (A9) reduces asymptotically to Equation (A8). Iwagaki et al. (1980) verified that Miche's breaker criterion could replicate laboratory measurements over a sloping beach with a current present provided that the wavelength was calculated with the current included in the dispersion equation.

In CMS-Wave, the depth-limited spectral energy dissipation can be selected from four different formulas: (a) Extended Goda formulation (Sakai et al. 1989), (b) Extended Miche (Battjes 1972; Mase et al. 2005b), (c) Battjes and Janssen (1978), and (d) Chawla and Kirby (2002). These formulas are considered more accurate for wave breaking on a current and can be divided into two generic categories (Zheng et al. 2008). The first class of formulations attempt to simulate the energy dissipation due to wave breaking by truncating the tail of the Rayleigh distribution of wave height on the basis of some breaker criterion. The Extended Goda and Extended Miche formulas belong to this class. The second category of wave breaking formulas uses a bore model analogy (Battjes and Janssen 1978) to estimate the total energy dissipation. The Battjes and Janssen formula and Chawla and Kirby formula are in this class. The spectral energy dissipation is calculated based on one of these four wave breaking formulas, while the computed wave height is further limited by Equations (A8) and (A9). 


\section{Wind forcing and white-capping dissipation}

The evolution of waves in the large-scale, open coast is more affected by wind-ocean-wave interactions than the nearshore wave-current-bottom processes. The result is a nonlinear wave field that is balanced between wind forcing, whitecapping, and wave growth. The surface wind can feed energy into the existing waves and also generate new waves. On the other hand, the energy can dissipate through whitecapping from turbulencewave interactions and air-wave-water interactions. In CMS-Wave, these wind forcing and whitecapping processes are modeled as separate sink and source terms (Lin and Lin 2004a and b).

\section{Wave generation with arbitrary wind direction}

In the case of wind forcing only and with zero wave energy input at the sea boundary, CMS-Wave can simulate full-plane wave generation. The model will execute an internal grid rotation based on the given wind direction to calculate the wave field and map the result back to the original grid. This feature is convenient for local wave generation by wind in a lake, bay, or estuary, neglecting swell from the ocean.

\section{Bottom friction loss}

Bottom friction loss (sink), $S_{d s}$, is calculated by a drag law model (Collins 1972)

$$
S_{d s}=-c_{f} \frac{\sigma^{2}}{g} \frac{\left\langle u_{b}\right\rangle}{\sinh ^{2} k h} N
$$

with

$$
\left\langle u_{b}\right\rangle=\frac{1}{2} \sqrt{\frac{g}{h} E_{\text {total }}}
$$

where $\left\langle u_{b}\right\rangle$ presents the ensemble mean of horizontal wave orbital velocity at the sea bed, $E_{\text {total }}$ is the total energy density at a grid cell, and $c_{f}$ is the Darcy-Weisbach type friction coefficient. The relationship between $c_{f}$ and the Darcy-Weisbach friction factor $f_{D W}$ is $c_{f}=f_{D W} / 8$.

Typical values of $c_{f}$ for a sandy-bottom range from 0.004 to 0.007 based on the JONSWAP experiment and North Sea measurements (Bouws and 
Komen 1983 and Hasselmann et al. 1973). Values of $c_{f}$ applied for coral reefs range from 0.05 to 0.40 (Hardy 1993; Hearn 1999 and Lowe et al. 2005). CMS-Wave uses a default value of $c_{f}=0.005$.

If the Manning's friction coefficient $n$ is used instead of the Darcy-Weisbach type coefficient, the relationship between the two drag coefficients (in the SI system) is defined as

$$
c_{f}=\frac{g n^{2}}{h^{1 / 3}}
$$

Estimates of the Manning's coefficient, $n$, are available in most fluid mechanics reference books (e.g., 0.01 to 0.05 for smooth to rocky/weedy channels).

\section{Wave run-up}

Wave run-up is the maximum shoreward wave swash on the beach face for engineering structures such as jetties and breakwaters by wave breaking at the shore. Wave run-up is significant for beach erosion as well as wave overtopping of seawalls and jetties. The total wave run-up consists of two components: (a) rise of the mean water level by wave breaking at the shore known as the wave setup, and (b) swash of incident waves. In CMS-Wave, the wave setup is computed based on the wave radiation stresses in the horizontal momentum equations by neglecting current, surface wind drag, and bottom stresses as

$$
\begin{aligned}
& \frac{\partial \eta}{\partial x}=-\frac{1}{\rho g h}\left(\frac{\partial S_{x x}}{\partial x}+\frac{\partial S_{x y}}{\partial y}\right) \\
& \frac{\partial \eta}{\partial y}=-\frac{1}{\rho g h}\left(\frac{\partial S_{x y}}{\partial x}+\frac{\partial S_{y y}}{\partial y}\right)
\end{aligned}
$$

where $\rho$ is the water density, and $S_{x x}, S_{x y}$, and $S_{x y}$ are radiation components from the excess momentum flux due to waves. By using linear wave theory (Dean and Dalrymple 1984), $S_{x x}, S_{x y}$, and $S_{x y}$ are expressed as

$$
S_{x x}=E(\sigma, \theta) \int\left[n_{k}\left(\cos ^{2} \theta+1\right)-\frac{1}{2}\right] d \theta
$$




$$
\begin{gathered}
S_{x x}=E(\sigma, \theta) \int\left[n_{k}\left(\sin ^{2} \theta+1\right)-\frac{1}{2}\right] d \theta \\
S_{y y}=\frac{E}{2} n_{k} \sin 2 \theta
\end{gathered}
$$

where $n_{k}=\frac{1}{2}+\frac{k h}{\sinh 2 k h}$. Equations (A13) and (A14) also calculate the water level depression from the still-water level due to waves known as wave setdown outside the breaker zone. Equation (A13) mainly controls wave setup and setdown calculations, whereas Equation (A14) predominantly acts to smooth the water level alongshore.

The swash oscillation of incident natural waves on the beach face is a random process. The most landward swash excursion corresponds to the maximum wave run-up. In the engineering application, a $2 \%$ exceedance of all vertical levels, denoted as $R_{2} \%$, from the swash is usually estimated for the wave run-up (Komar 1998). This quantity is approximately equal to the local wave setup on the beach or at structures such as seawalls and jetties. The total wave run-up is estimated as

$$
R_{2 \%}=2|\eta|
$$

In CMS-Wave, $R_{2} \%$ is calculated at the land-water interface and averaged with the local depth to determine if the water can flood the proceeding dry cell. If the wave run-up level is higher than the adjacent land cell elevation, CMS-Wave can flood the dry cells and simulate wave overtopping and overwash. This feature is useful in coupling CMS-Wave to CMS-Flow (Buttolph et al. 2006) for calculating beach erosion or breaching. Calculated quantities of $\partial S_{x x} / \partial x, \partial S_{x y} / \partial x, \partial S_{x y} / \partial y$, and $\partial S_{y y} / \partial y$ are saved as input to CMS-Flow. CMS-Wave reports the calculated fields of wave setup and maximum water level defined as

$$
\text { Maximum water level }=\operatorname{Max}\left(R_{2 \%}, \eta+H_{s} / 2\right)
$$

where $H_{\mathrm{s}}=4 \sqrt{E_{\text {total }}}$ is the significant wave height. 


\section{Wave transmission and overtopping}

CMS-Wave applies a simple analytical formula to compute the wave transmission coefficient $\left(K_{t}\right)$ of a rigidly moored rectangular breakwater of width, $B_{c}$, and draft, $D_{c}$ (Macagno 1953)

$$
K_{t}=\left[1+\left(\frac{k B_{c} \sinh \frac{k h}{2 \pi}}{2 \cosh k\left(h-D_{c}\right)}\right)^{2}\right]^{-\frac{1}{2}}
$$

Wave transmission over a structure or breakwater is mainly caused by the fall of the overtopping water mass. Therefore, the ratio of the structure crest elevation to the incident wave height is the prime parameter governing the wave transmission. CMS-Wave calculates the rate of overtopping of a vertical breakwater based on the simple expression (Goda 1985) as

$$
K_{t}=0.3\left(1.5-\frac{h_{c}}{H_{i}}\right), \text { for } 0 \leq \frac{h_{c}}{H_{i}} \leq 1.25
$$

where $h_{c}$ is the crest elevation of the breakwater above the still-water level, and $H_{i}$ is the incident wave height. For a composite breakwater which is protected by armor units along its front, Equation (A21) is modified as

$$
K_{t}=0.3\left(1.1-\frac{h_{c}}{H_{i}}\right), \quad \text { for } \quad 0 \leq \frac{h_{c}}{H_{i}} \leq 0.75
$$

For rubble-mound breakwaters, the calculation of wave transmission is more complicated because the overtopping rate also depends on the specific design of the breakwater (e. g., toe apron protection, front slope, armor unit shape and size, thickness of armor layers). In practice, Equation (A22) still can be applied using a finer spatial resolution with the proper bathymetry and adequate bottom friction coefficients to represent the breakwater.

For permeable rubble-mound breakwaters, the transmission is calculated from d'Angremond et al. (1996) formula:

$$
K_{t}=0.64\left(\frac{B}{H_{i}}\right)^{-0.31}\left[1-\exp \left(-\frac{\xi}{2}\right)\right]-0.4 \frac{h_{c}}{H_{i}}, \text { for } B<10 H_{i}
$$


where $B$ is the crest width, and $\xi$ is the Iribarren parameter defined as the fore-slope of the breakwater divided by the square-root of deepwater incident wave steepness. In practice, Equations (A21) to (A23) are applicable for both monochromatic and random waves.

\section{Grid nesting}

Grid nesting is applied by saving wave spectra at selected locations from a coarse grid (parent grid) and inputting them along the offshore boundary of the smaller fine grid (child grid). For simple and quick applications, a single-location spectrum saved from the parent grid can be used as the wave forcing for the entire sea boundary of the child grid. If multi-location spectra were saved from the parent grid, they are then interpolated and extrapolated for more realistic wave forcing along the sea boundary of the child grid.

Multiple grid nesting (e.g., several co-existing child grids and grand-child grids) is supported by CMS-Wave. The parent and child grids can have different orientations, but need to reside in the same horizontal coordinate system. Because CMS-Wave is a half-plane model, the difference between grid orientations between parent and child grids should be small (no greater than $45 \mathrm{deg}$ ) for passing sufficient wave energy from the parent to child grids.

\section{Variable rectangular-cell grid}

CMS-Wave can run on a grid with variable rectangular cells. This feature is suited to large-domain applications in which wider spacing cells can be specified in the offshore where wave property variation is small and away from the area of interest to save computational time. A limit on the shorenormal to shore-parallel spacing ratio in a cell is not required as long as the calculated shoreward waves are found to be numerically stable.

\section{Nonlinear wave-wave interaction}

Nonlinear wave-wave interaction is a conserved energy transfer from higher to lower frequencies. The mechanism can produce transverse waves and energy diffusion in the frequency and direction domains. The effect is more pronounced in the intermediate to shallow water depth. Directional spreading of the wave spectrum tends to increase as the wavelength decreases (Jenkins and Phillips 2001). 
The exact computation of the nonlinear energy transfer involves sixdimensional integrations. This is computationally too taxing in practical engineering nearshore wave transformation models. Mase et al. (2005a) have shown that calculated wave fields differ with and without nonlinear energy transfer. CMS-Wave uses a theoretically-based formula proposed by Jenkins and Phillips (2001) to calculate the nonlinear wave-wave interaction.

In finite water depth, the nonlinear wave-wave interaction function can be expressed as (Lin et al. 2010)

$$
S_{n l}=a \frac{\partial F}{\partial \sigma}+b \frac{\partial^{2} F}{\partial \theta^{2}}
$$

where $a=\frac{1}{2 n^{2}}\left[1+(2 n-1)^{2} \cosh 2 k h\right]-1$ is a function of $k h, b=\frac{a}{n \sigma}$, and

$$
F=k^{3} \sigma^{5} \frac{n^{4}}{(2 \pi)^{2} g}\left[\left(\frac{\sigma_{m}}{\sigma}\right)^{4} E\right]^{3}
$$

\section{Wave dissipation over muddy bed}

The calculation of wave dissipation over muddy beds in CMS-Wave is based on the assumption that the turbulent eddy viscosity is several orders of magnitude greater than the kinematic viscosity of sea water. By neglecting the kinematic viscous effect, the wave dissipation over a muddy bed can be expressed as (Lamb 1932)

$$
S_{d p}=-4 v_{t} k^{2} E
$$

where the turbulent eddy viscosity, $v_{t}$, is equal to a maximum viscosity, $v_{t \text {, max }}$, representing the wave breaking condition times the ratio of wave height over depth.

\section{Full-plane and wind field input capabilities}

The full-plane capability of CMS-Wave is ideal for calculating waves in a bay or estuary connected to a major water body. This capability is also essential to simulate storm waves in the open coast or around an island. In the case of strong wind-wave interactions, especially under a hurricane, 
CMS-Wave can read wind field information for more realistic calculation of wave generation, dissipation, and growth.

\section{Fast mode calculations}

CMS-Wave can run in a fast mode for simple and quick applications. The fast mode calculates the half-plane spectral transformation on either five directional bins (each 30-deg angle for a broad-band input spectrum) or seven directional bins (each 5-deg angle for a narrow-band input spectrum or 25-deg angle with wind input) to minimize simulation time. It runs at least five times faster than the normal mode, which operates with 35 directional bins. The fast-mode option is suited for a long or time-pressing simulation if users are seeking preliminary solutions. The wave direction estimated in the fast mode is expected to be less accurate than the standard mode because the directional calculation is based on fewer bins.

\section{Summary of CMS-Wave control parameters with default values}

This section describes the control parameters and associated default values for input parameters used in CMS-Wave. The full-plane CMS-Wave has 25 model control parameters in the *.std file. The first 15 parameters are the same as in the CMS-Wave TR (Lin et al. 2008). The remaining 10 parameters are new.

1st 2nd 3rd 4th $5^{\text {th }} 6$ th

iprp icur ibk irs kout ibnd

7th 8th 9th 10th 11th 12th 13th 14th 15th

iwet ibf iark iarkr akap bf ark arkr iwvbk

16th 17th 18th 19th 20th 21st 22nd 23rd 24th 25th

nonln igrav irunup imud iwnd isolv ixmdf iproc iview iroll

The first 6 parameters are required in the ${ }^{*}$.std and the remaining parameters starting any parameter after the 6th will be assigned to default values if not specified in ${ }^{*}$. std. The description of the $1^{\text {st }}$ to $25^{\text {th }}$ parameters is given below.

iprp $=\mathrm{o}$ (wave propagation with wind input in *.eng)

1 (wave propagation only, neglect wind input in *.eng)

-1 (fast mode) 
2 (forced grid internal rotation)

3 (without lateral energy flux)

icur $=0$ (no current input)

1 (with current input *.cur)

2 (with *.cur, use only the 1st set current data)

$\mathrm{ibk}=\mathrm{o}$ (no wave break info output)

1 (output breaking indices *.brk)

2 (output energy dissipation rate *.brk)

irs $=0$ (no wave radiation stress calc)

1 (output radiation stress *.rad)

2 (calculate/output setup/max-water-level + ${ }^{*}$.rad)

kout $=$ number of special wave output location, output spectrum in *.obs and parameters in selhts.out

ibnd $=0$ (no input a parent spectrum *.nst)

1 (read *.nst, averaging input spectrum)

2 (read *.nst, spatially variable spectrum input)

iwet $=\mathrm{o}$ (allow wet/dry, default)

1 (without wet/dry)

-1 (allow wet/dry, output swell and local sea files)

-2 (output combined steering wav files)

-3 (output swell, local sea, and combined wav files)

$\mathrm{ibf}=\mathrm{o}$ (no bottom friction calc)

1 (constant Darcy-Weisbach coefficient, $C_{f}$ )

2 (read variable $C_{f}$ file, *.fric)

3 (constant Manning $\mathrm{n}$ )

4 (read variable Manning n file, ${ }^{*}$.fric)

iark $=\mathrm{o}$ (without forward reflection)

1 (with forward reflection)

iarkr $=\mathrm{o}$ (without backward reflection)

1 (with backward reflection) 
akap $=0$ to 4 (diffraction intensity)

o for zero diffraction

4 for strong diffraction, default

$\mathrm{bf}=$ constant bottom friction coefficient, $C_{f}$ or $\mathrm{n}$

(typical value is 0.005 for $C_{f}$ and 0.025 for Manning n)

ark $=0$ to 1 (constant forward reflection coefficient, global specification)

o for zero reflection

1 for 100 percent or fully reflection

arkr $=0$ to 1 (constant backward reflection coefficient, global specification)

o for zero reflection

1 for 100 percent or fully reflection

iwvbk = o to 3 (option for the primary wave breaking formula:

o for Goda-extended

1 for Miche-extended

2 for Battjes and Janssen

3 for Chawla and Kirby

nonln $=o$ (none, default)

1 (nonlinear wave-wave interaction)

igrav $=0$ (none, default)

1 (infra-gravity wave enter inlets)

irunup $=\mathrm{o}$ (none, default)

1 (automatic, run-up relative to absolute datum)

2 (automatic, run-up relative to updated MWL)

imud $=0$ (mud.dat, default)

1 (none) --- need for users who may not want to include mud effect as the mud.dat exists (typical max kinematic viscosity in mud.dat is $0.04 \mathrm{~m} * \mathrm{~m} / \mathrm{sec})$

iwnd $=0$ (wind.dat, default)

1 (none) --- need in steering if users decide not to use the wind field input when the wind file exists 
isolv $=0$ (GSR solver, default $)$

1 (ADI)

ixmdf $=0$ (output ASCII, default)

1 (output xmdf)

2 (input \& output xmdf)

iproc $=\mathrm{o}$ (same as 1 , default)

$n(n$ processors for isolv $=0)---$ approx. processor $=($ total row $) / 300$

iview $=0$ (half-plane, default)

1 (full-plane with wave input *.eng)

2 (full-plane with *.eng and additional wave.spc) --- for the full plane, users can provide additional input wave spectrum file wave.spc (same format as the *.eng) along the opposite side boundary (an imaginary origin for this wave.spc at the opposite corner; users can use SMS to rotate the CMS-Wave grid 180 deg to generate this wave.spc)

iroll $=\mathrm{o}$ to 4 (wave roller effect)

o for no effect, default

4 for strong effect (more effective for finer resolution in the surf zone, say, for cross-shore spacing $<10 \mathrm{~m}$ ) 


\section{Appendix B: WIS126 Tp vs. $H_{s}$ Percent Occurrence Tables for Each Direction Band in Phase 1 Waves}


Figure B1. WIS126 $T_{p}$ vs. $H_{s}$ percent occurrence table for direction band centered at $\theta_{p}=67.5 \mathrm{deg}$ (a) percent and (b) number of observations.

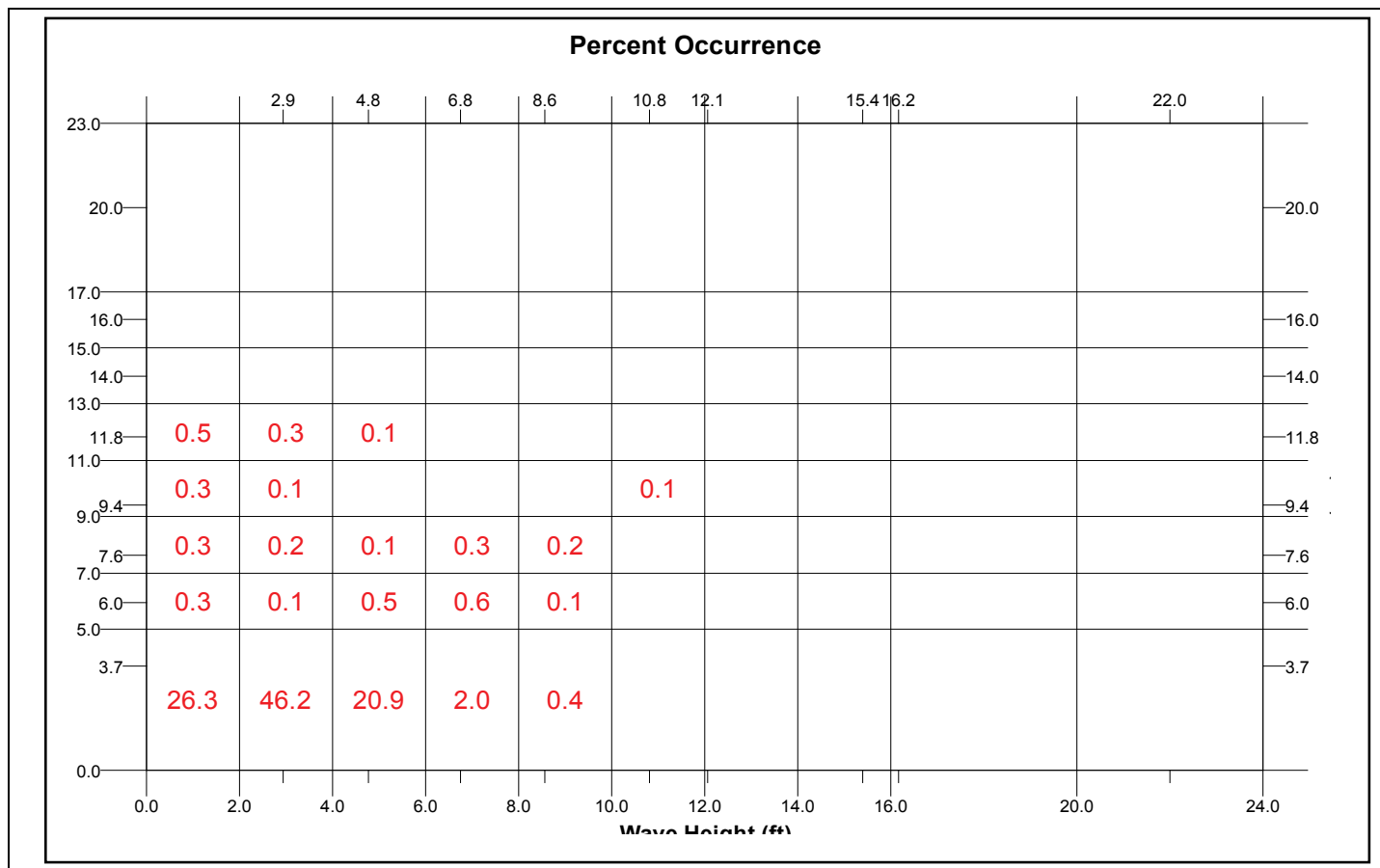

(a)

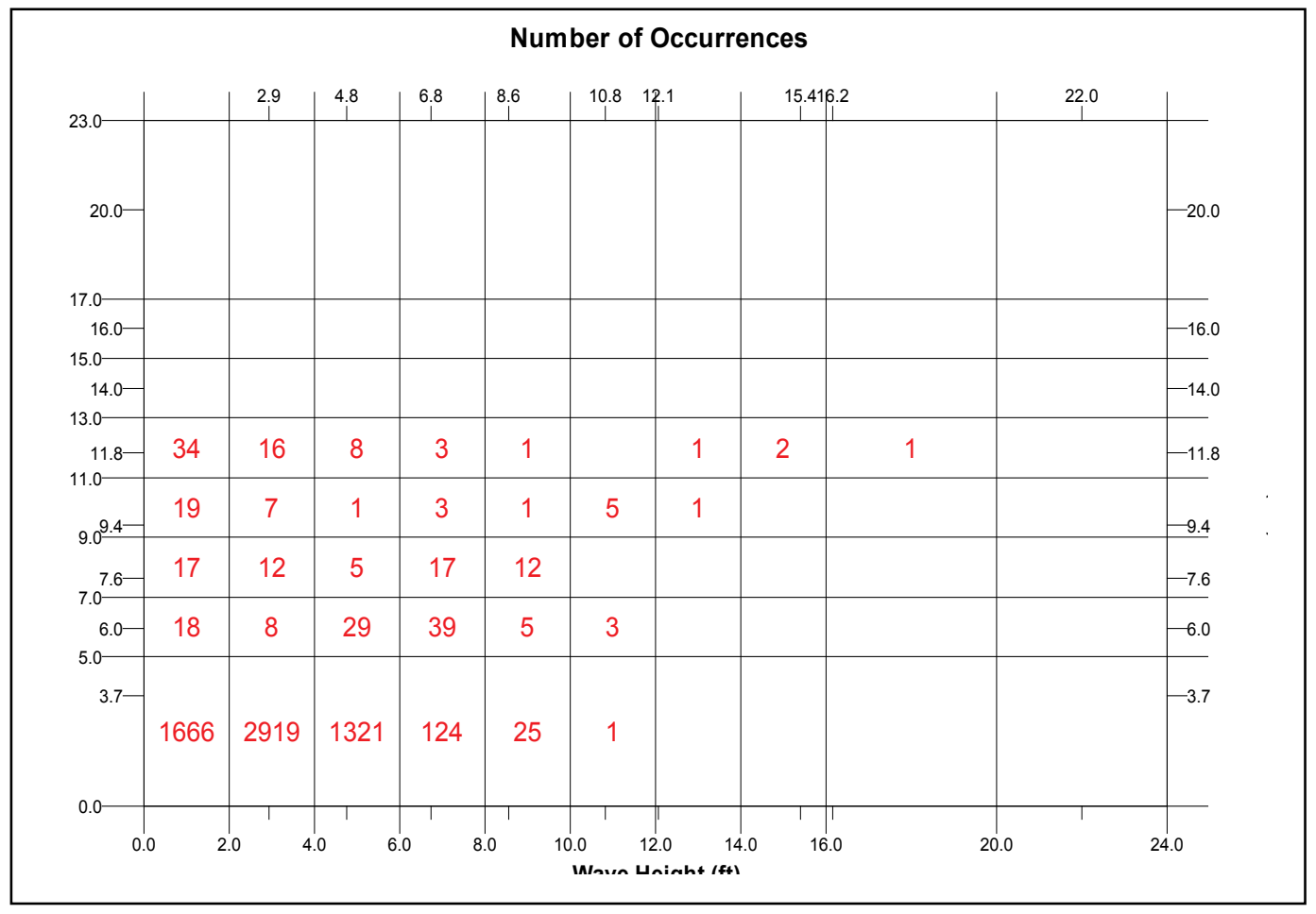

(b) 
Figure B2. WIS126 $T_{p}$ vs. $H_{s}$ percent occurrence table for direction band centered at $\theta_{p}=90 \mathrm{deg}$ (a) percent and (b) number of observations.

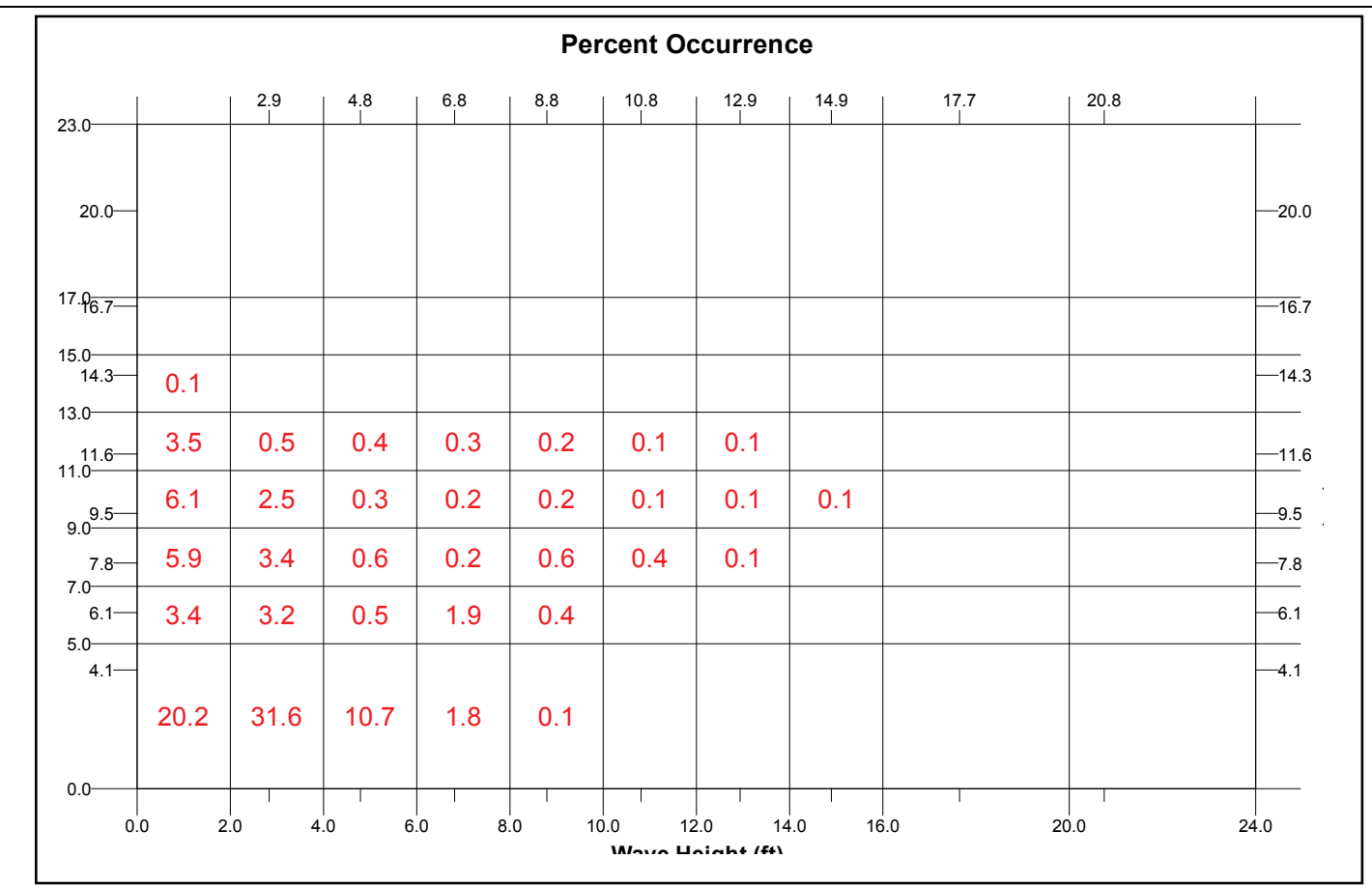

(a)

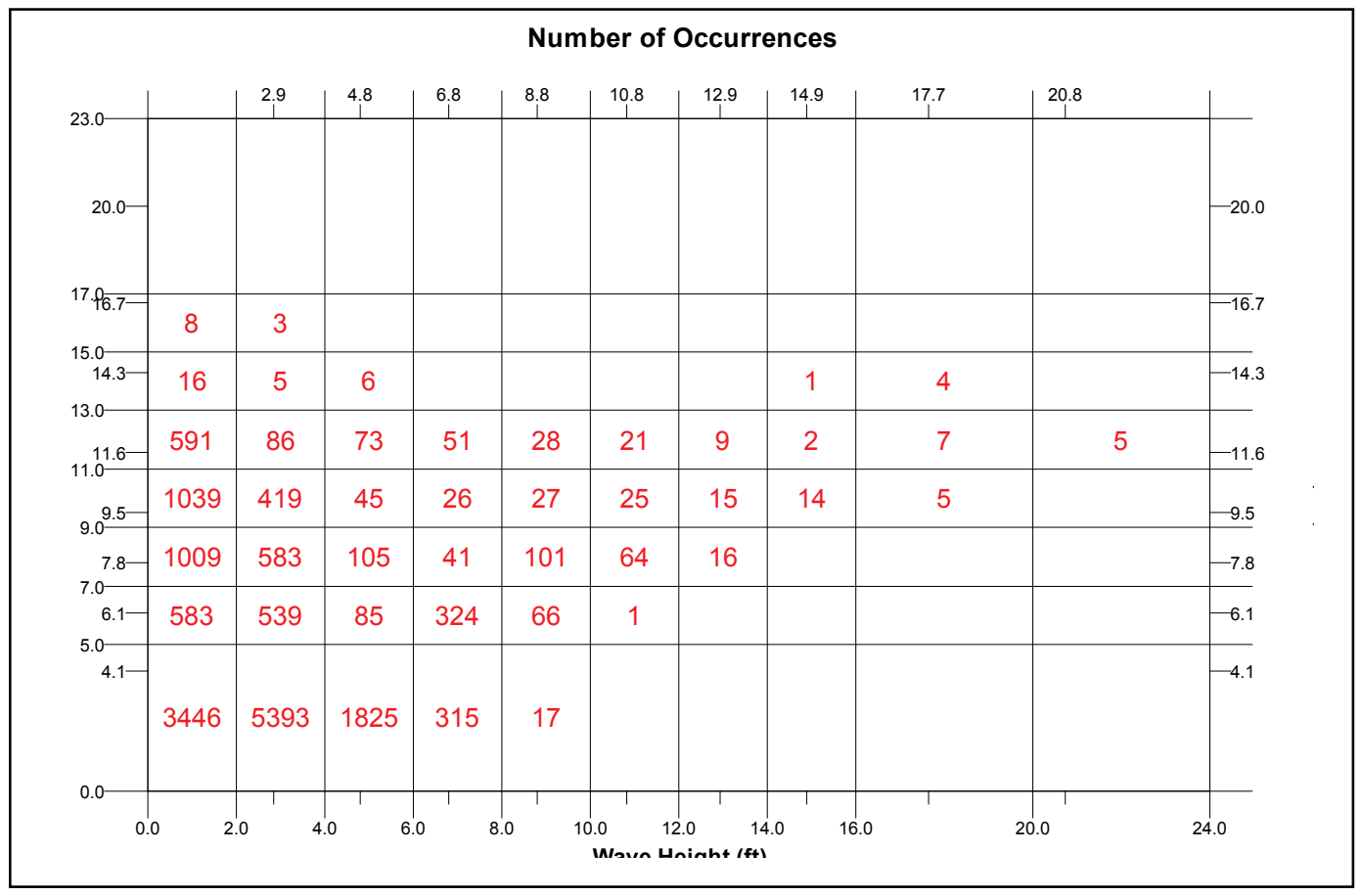

(b) 
Figure B3. WIS126 $T_{p}$ vs. $H_{s}$ percent occurrence table for direction band centered at $\theta_{p}=112.5 \mathrm{deg}$ (a) percent and (b) number of observations.

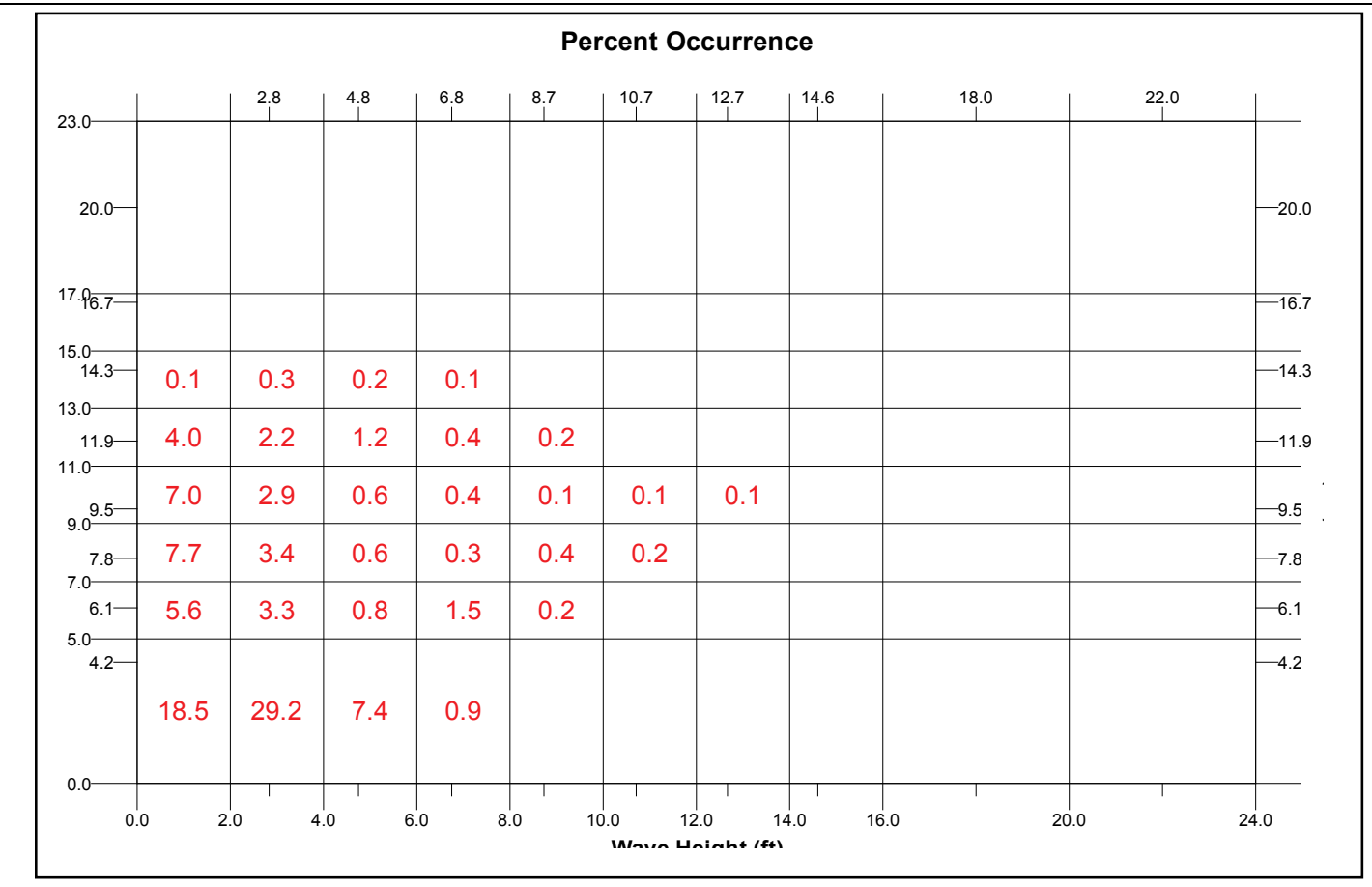

(a)

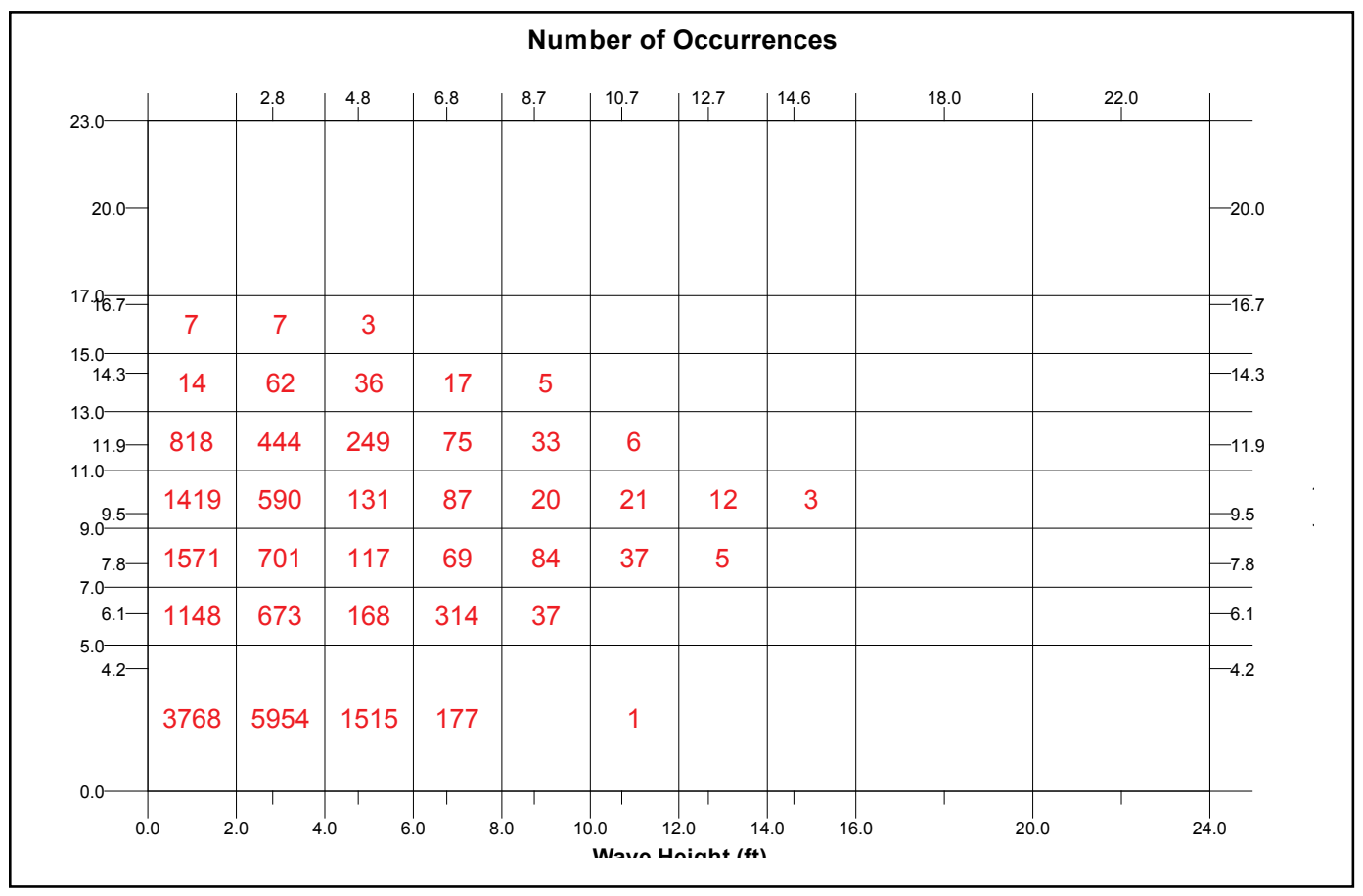

(b) 
Figure B4. WIS126 $T_{p}$ vs. $H_{s}$ percent occurrence table for direction band centered at $\theta_{p}=135$ deg (a) percent and (b) number of observations.

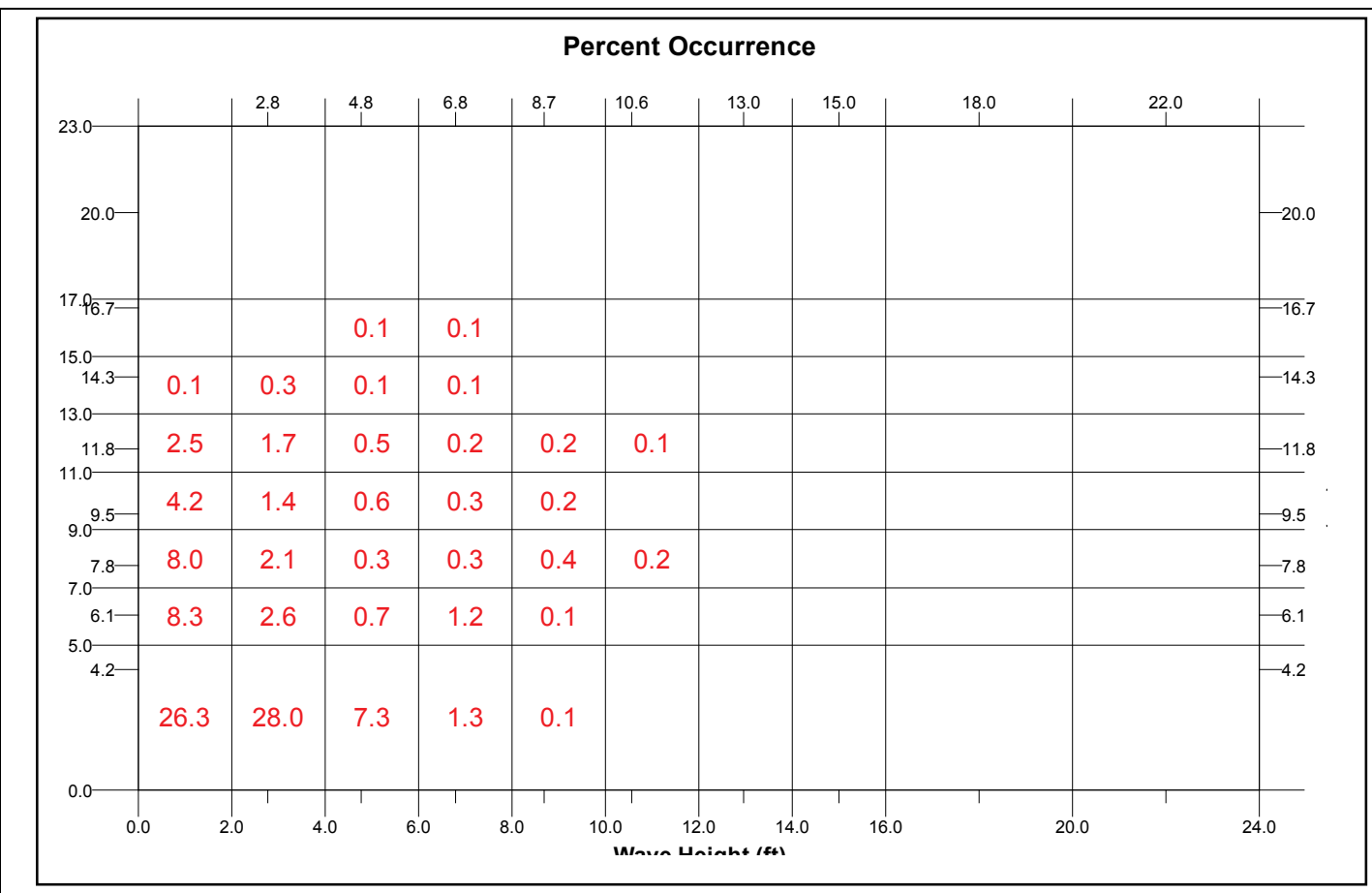

(a)

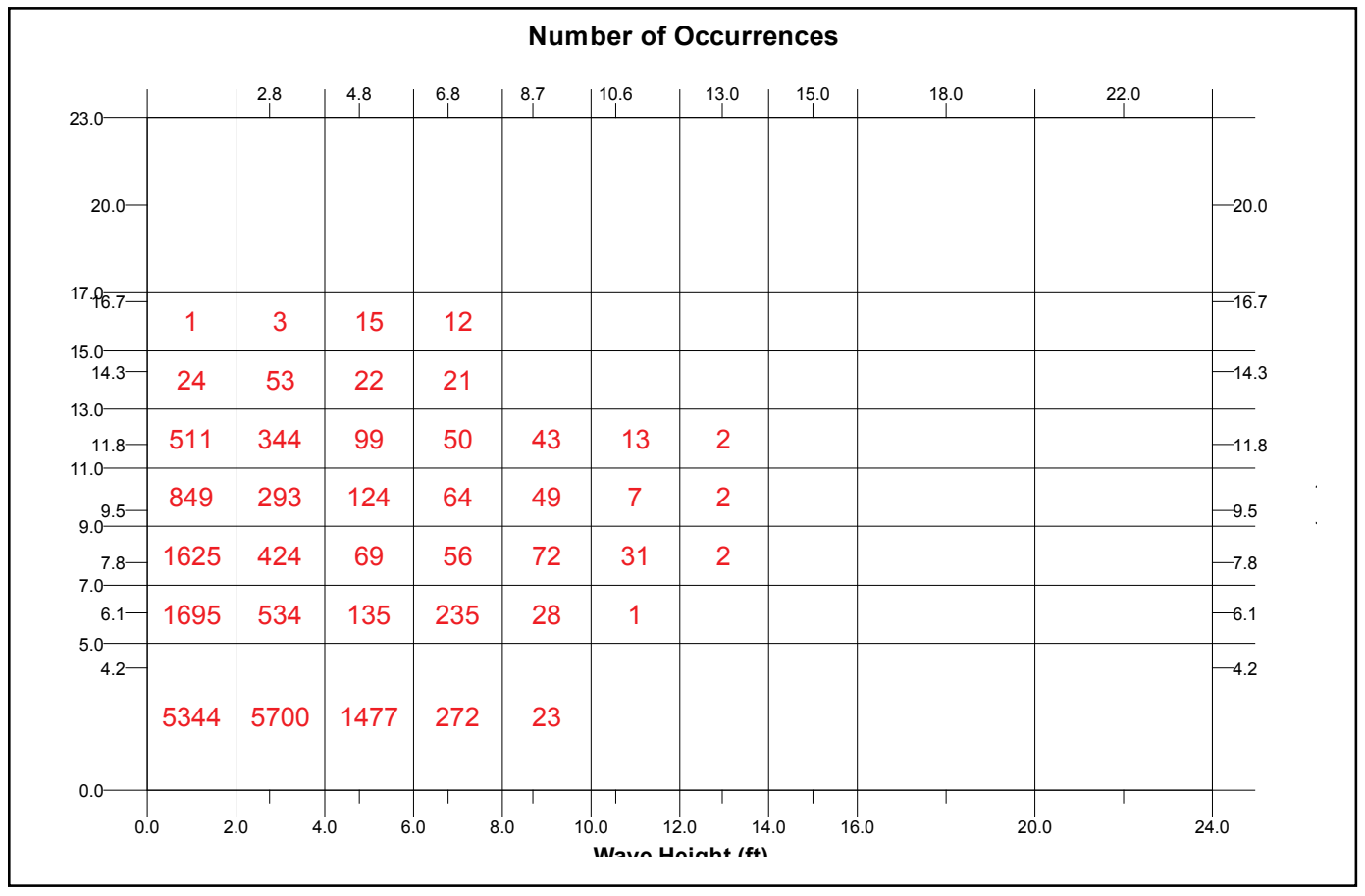

(b) 
Figure B5. WIS126 $T_{p}$ vs. $H_{s}$ percent occurrence table for direction band centered at $\theta_{p}=157.5 \mathrm{deg}$ (a) percent and (b) number of observations.

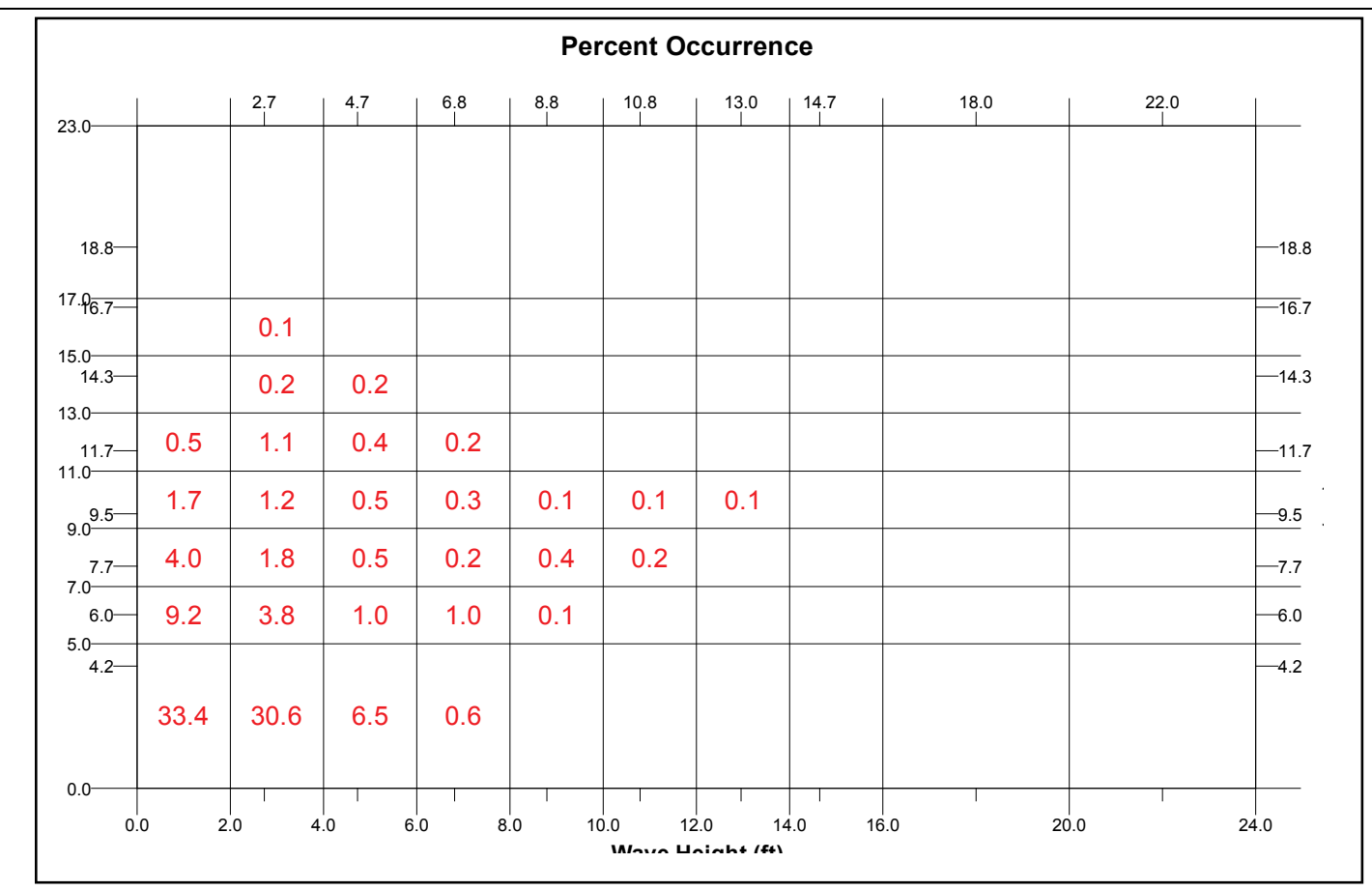

(a)

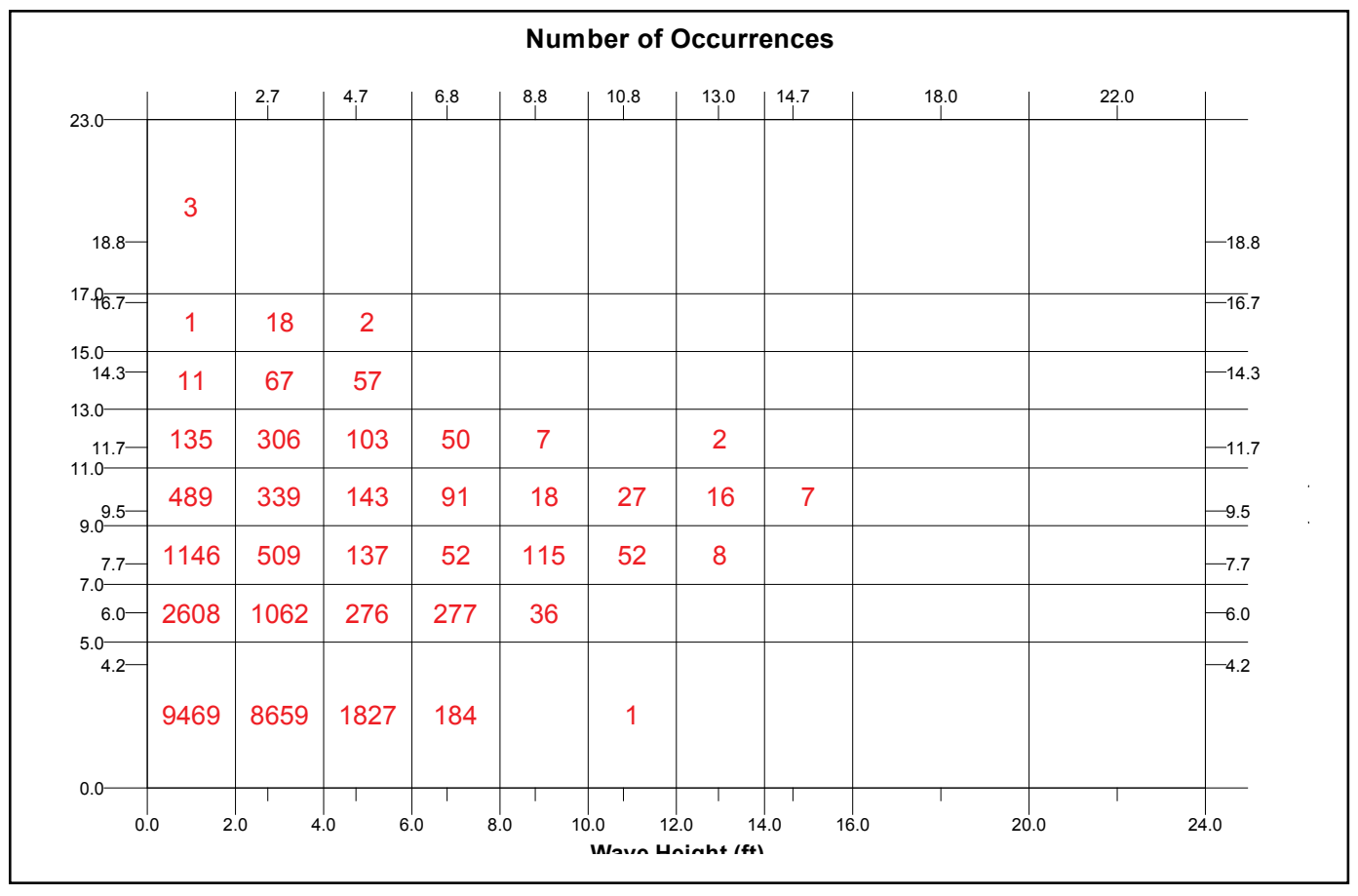

(b) 
Figure B6. WIS126 $T_{p}$ vs. $H_{s}$ percent occurrence table for direction band centered at $\theta_{p}=180 \mathrm{deg}$ (a) percent and (b) number of observations.

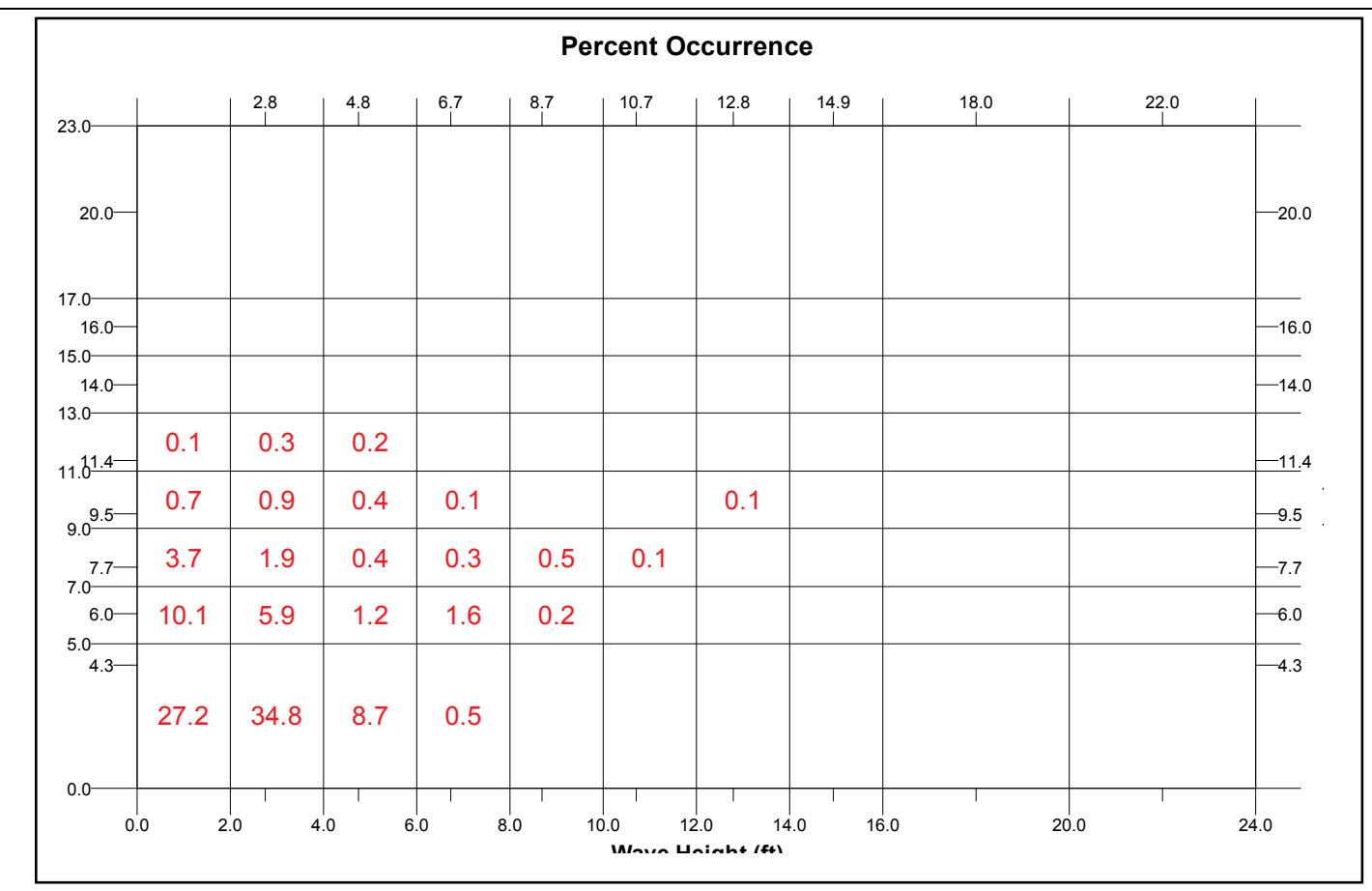

(a)

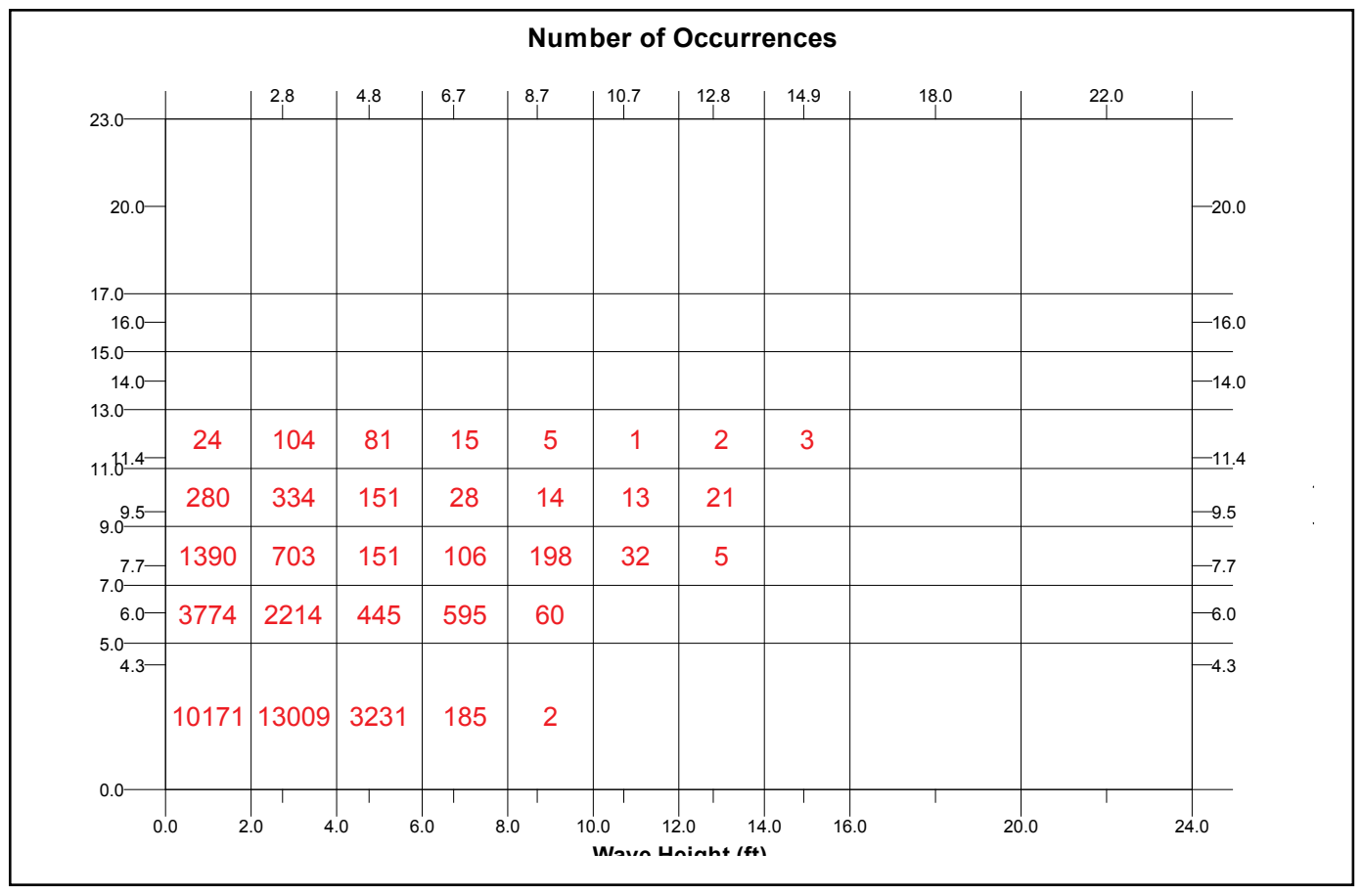

(b) 
Figure B7. WIS126 $T_{p}$ vs. $H_{s}$ percent occurrence table for direction band centered at $\theta_{p}=\mathbf{2 0 2 . 5}$ deg (a) percent and (b) number of observations.

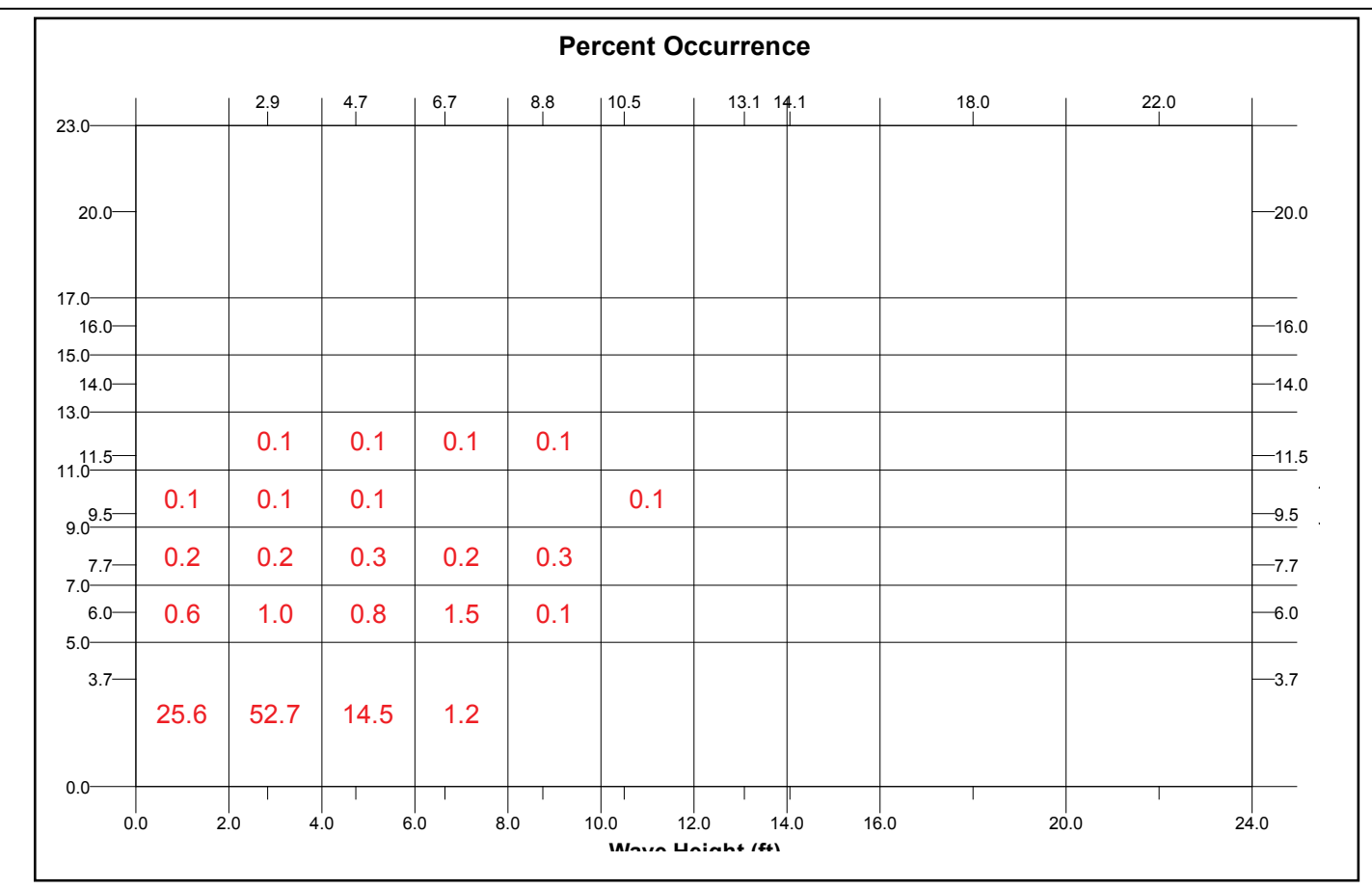

(a)

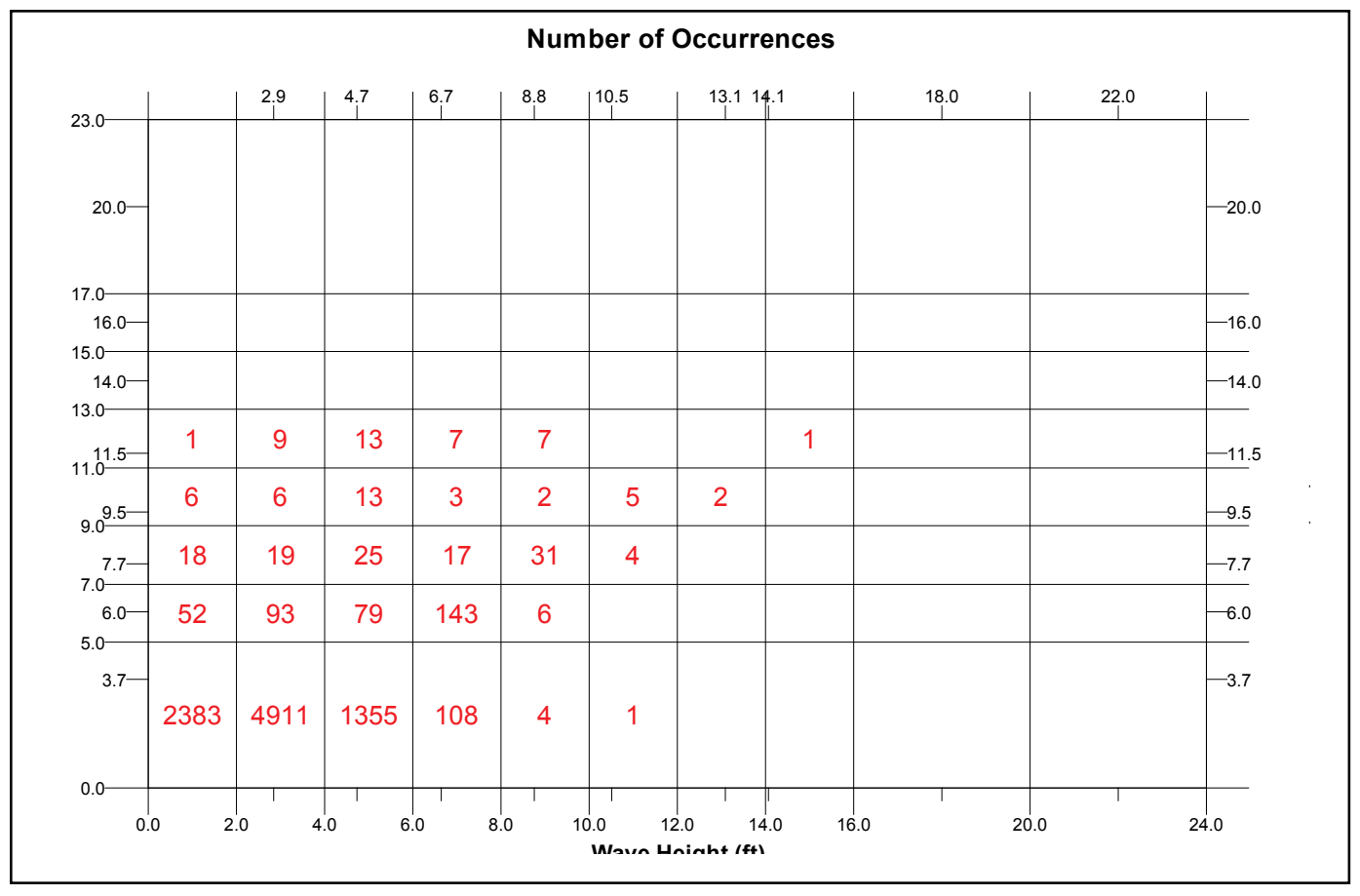

(b) 


\section{Appendix C: Phase 1 and Phase 2 Wave Climatology in the Ambrose Channel Reaches}

Table C1. Wave climatology in Ambrose Channel, Phase 1, Channel Reach 1.

\begin{tabular}{|l|l|l|l|l|l|l|l|l|l|}
\hline No. & ID & $H_{s}(\mathrm{ft})$ & $T_{p}(\mathrm{sec})$ & Direction (deg) & $\alpha$ & $\mathrm{Y}$ & $n$ & Probability & Days/yr \\
\hline 1 & 101 & 2.9 & 3.7 & 67.5 & 0.014273 & 3.3 & 4 & 0.01665 & 6.10 \\
\hline 2 & 102 & 4.8 & 3.7 & 67.5 & 0.039145 & 3.3 & 4 & 0.00754 & 2.74 \\
\hline 3 & 103 & 6.8 & 3.7 & 67.5 & 0.078601 & 3.3 & 4 & 0.00071 & 0.26 \\
\hline 4 & 104 & 8.6 & 3.7 & 67.5 & 0.125751 & 3.3 & 4 & 0.00014 & 0.04 \\
\hline 5 & 105 & 10.8 & 3.7 & 67.5 & 0.198356 & 3.3 & 4 & 0.00001 & 0.00 \\
\hline 6 & 106 & 2.9 & 6 & 67.5 & 0.002402 & 3.3 & 4 & 0.00005 & 0.00 \\
\hline 7 & 107 & 4.8 & 6 & 67.5 & 0.006588 & 3.3 & 4 & 0.00017 & 0.07 \\
\hline 8 & 108 & 6.8 & 6 & 67.5 & 0.013227 & 3.3 & 4 & 0.00022 & 0.07 \\
\hline 9 & 109 & 8.6 & 6 & 67.5 & 0.021162 & 3.3 & 4 & 0.00003 & 0.00 \\
\hline 10 & 110 & 10.8 & 6 & 67.5 & 0.033380 & 3.3 & 4 & 0.00002 & 0.00 \\
\hline 11 & 111 & 2.9 & 7.6 & 67.5 & 0.001213 & 3.3 & 4 & 0.00007 & 0.04 \\
\hline 12 & 112 & 4.8 & 7.6 & 67.5 & 0.003326 & 3.3 & 4 & 0.00003 & 0.00 \\
\hline 13 & 113 & 6.8 & 7.6 & 67.5 & 0.006678 & 3.3 & 4 & 0.00010 & 0.04 \\
\hline 14 & 114 & 8.6 & 7.6 & 67.5 & 0.010684 & 3.3 & 4 & 0.00007 & 0.04 \\
\hline 15 & 115 & 2.9 & 9.4 & 67.5 & 0.000712 & 3.3 & 4 & 0.00004 & 0.00 \\
\hline 16 & 116 & 4.8 & 9.4 & 67.5 & 0.001952 & 3.3 & 4 & 0.00001 & 0.00 \\
\hline 17 & 117 & 6.8 & 9.4 & 67.5 & 0.003920 & 3.3 & 4 & 0.00002 & 0.00 \\
\hline 18 & 118 & 8.6 & 9.4 & 67.5 & 0.006272 & 3.3 & 4 & 0.00001 & 0.00 \\
\hline 19 & 119 & 10.8 & 9.4 & 67.5 & 0.009893 & 3.3 & 4 & 0.00003 & 0.00 \\
\hline 20 & 120 & 12.1 & 9.4 & 67.5 & 0.012420 & 3.3 & 4 & 0.00001 & 0.00 \\
\hline 21 & 121 & 2.9 & 11.8 & 67.5 & 0.000391 & 4 & 10 & 0.00009 & 0.04 \\
\hline 22 & 122 & 4.8 & 11.8 & 67.5 & 0.001073 & 4 & 10 & 0.00005 & 0.00 \\
\hline 23 & 123 & 6.8 & 11.8 & 67.5 & 0.002154 & 4 & 10 & 0.00002 & 0.00 \\
\hline 24 & 124 & 8.6 & 11.8 & 67.5 & 0.003446 & 4 & 10 & 0.00001 & 0.00 \\
\hline 25 & 125 & 12.1 & 11.8 & 67.5 & 0.006824 & 4 & 10 & 0.00001 & 0.00 \\
\hline 26 & 126 & 15.4 & 11.8 & 67.5 & 0.011055 & 4 & 10 & 0.00001 & 0.00 \\
\hline 27 & 127 & 16.2 & 11.8 & 67.5 & 0.012234 & 4 & 10 & 0.00001 & 0.00 \\
\hline 28 & 128 & 2.9 & 4.1 & 90 & 0.009410 & 3.3 & 4 & 0.03076 & 11.24 \\
\hline 29 & 129 & 4.8 & 4.1 & 90 & 0.025809 & 3.3 & 4 & 0.01041 & 3.80 \\
\hline 30 & 130 & 6.8 & 4.1 & 90 & 0.051822 & 3.3 & 4 & 0.00180 & 0.66 \\
\hline 31 & 131 & 8.8 & 4.1 & 90 & 0.086812 & 3.3 & 4 & 0.00010 & 0.04 \\
\hline 32 & 132 & 2.9 & 6.1 & 90 & 0.002255 & 3.3 & 4 & 0.00307 & 1.13 \\
\hline 33 & 133 & 4.8 & 6.1 & 90 & 0.006184 & 3.3 & 4 & 0.00048 & 0.18 \\
\hline
\end{tabular}




\begin{tabular}{|c|c|c|c|c|c|c|c|c|c|}
\hline No. & ID & $H_{s}(\mathrm{ft})$ & $T_{p}(\mathrm{sec})$ & Direction (deg) & $\alpha$ & $\bar{Y}$ & $n$ & Probability & Days/yr \\
\hline 34 & 134 & 6.8 & 6.1 & 90 & 0.012417 & 3.3 & 4 & 0.00185 & 0.66 \\
\hline 35 & 135 & 8.8 & 6.1 & 90 & 0.020800 & 3.3 & 4 & 0.00038 & 0.15 \\
\hline 36 & 136 & 10.8 & 6.1 & 90 & 0.031334 & 3.3 & 4 & 0.00001 & 0.00 \\
\hline 37 & 137 & 2.9 & 7.8 & 90 & 0.001137 & 3.3 & 4 & 0.00333 & 1.20 \\
\hline 38 & 138 & 4.8 & 7.8 & 90 & 0.003118 & 3.3 & 4 & 0.00060 & 0.22 \\
\hline 39 & 139 & 6.8 & 7.8 & 90 & 0.006260 & 3.3 & 4 & 0.00023 & 0.07 \\
\hline 40 & 140 & 8.8 & 7.8 & 90 & 0.010487 & 3.3 & 4 & 0.00058 & 0.22 \\
\hline 41 & 141 & 10.8 & 7.8 & 90 & 0.015798 & 3.3 & 4 & 0.00037 & 0.15 \\
\hline 42 & 142 & 12.9 & 7.8 & 90 & 0.022542 & 3.3 & 4 & 0.00009 & 0.04 \\
\hline 43 & 143 & 2.9 & 9.5 & 90 & 0.000681 & 3.3 & 4 & 0.00239 & 0.88 \\
\hline 44 & 144 & 4.8 & 9.5 & 90 & 0.001867 & 3.3 & 4 & 0.00026 & 0.11 \\
\hline 45 & 145 & 6.8 & 9.5 & 90 & 0.003749 & 3.3 & 4 & 0.00015 & 0.04 \\
\hline 46 & 146 & 8.8 & 9.5 & 90 & 0.006281 & 3.3 & 4 & 0.00015 & 0.07 \\
\hline 47 & 147 & 10.8 & 9.5 & 90 & 0.009461 & 3.3 & 4 & 0.00014 & 0.04 \\
\hline 48 & 148 & 12.9 & 9.5 & 90 & 0.013500 & 3.3 & 4 & 0.00009 & 0.04 \\
\hline 49 & 149 & 14.9 & 9.5 & 90 & 0.018012 & 3.3 & 4 & 0.00008 & 0.04 \\
\hline 50 & 150 & 17.7 & 9.5 & 90 & 0.025420 & 3.3 & 4 & 0.00003 & 0.00 \\
\hline 51 & 151 & 2.9 & 11.6 & 90 & 0.000430 & 4 & 10 & 0.00049 & 0.18 \\
\hline 52 & 152 & 4.8 & 11.6 & 90 & 0.001179 & 4 & 10 & 0.00042 & 0.15 \\
\hline 53 & 153 & 6.8 & 11.6 & 90 & 0.002367 & 4 & 10 & 0.00029 & 0.11 \\
\hline 54 & 154 & 8.8 & 11.6 & 90 & 0.003965 & 4 & 10 & 0.00016 & 0.07 \\
\hline 55 & 155 & 10.8 & 11.6 & 90 & 0.005973 & 4 & 10 & 0.00012 & 0.04 \\
\hline 56 & 156 & 12.9 & 11.6 & 90 & 0.008523 & 4 & 10 & 0.00005 & 0.04 \\
\hline 57 & 157 & 14.9 & 11.6 & 90 & 0.011371 & 4 & 10 & 0.00001 & 0.00 \\
\hline 58 & 158 & 17.7 & 11.6 & 90 & 0.016048 & 4 & 10 & 0.00004 & 0.00 \\
\hline 59 & 159 & 20.8 & 11.6 & 90 & 0.022163 & 4 & 10 & 0.00003 & 0.00 \\
\hline 60 & 160 & 2.9 & 14.3 & 90 & 0.000287 & 5 & 16 & 0.00003 & 0.00 \\
\hline 61 & 161 & 4.8 & 14.3 & 90 & 0.000786 & 5 & 16 & 0.00003 & 0.00 \\
\hline 62 & 162 & 14.9 & 14.3 & 90 & 0.007580 & 5 & 16 & 0.00001 & 0.00 \\
\hline 63 & 163 & 17.7 & 14.3 & 90 & 0.010698 & 5 & 16 & 0.00002 & 0.00 \\
\hline 64 & 164 & 2.9 & 16.7 & 90 & 0.000093 & 7 & 22 & 0.00002 & 0.00 \\
\hline 65 & 165 & 2.8 & 4.2 & 112.5 & 0.008003 & 3.3 & 4 & 0.03396 & 12.41 \\
\hline 66 & 166 & 4.8 & 4.2 & 112.5 & 0.023547 & 3.3 & 4 & 0.00864 & 3.14 \\
\hline 67 & 167 & 6.8 & 4.2 & 112.5 & 0.047281 & 3.3 & 4 & 0.00101 & 0.37 \\
\hline 68 & 168 & 10.7 & 4.2 & 112.5 & 0.117118 & 3.3 & 4 & 0.00001 & 0.00 \\
\hline 69 & 169 & 2.8 & 6.1 & 112.5 & 0.002102 & 3.3 & 4 & 0.00384 & 1.39 \\
\hline 70 & 170 & 4.8 & 6.1 & 112.5 & 0.006184 & 3.3 & 4 & 0.00096 & 0.37 \\
\hline 71 & 171 & 6.8 & 6.1 & 112.5 & 0.012417 & 3.3 & 4 & 0.00179 & 0.66 \\
\hline 72 & 172 & 8.7 & 6.1 & 112.5 & 0.020330 & 3.3 & 4 & 0.00021 & 0.07 \\
\hline 73 & 173 & 2.8 & 7.8 & 112.5 & 0.001060 & 3.3 & 4 & 0.00400 & 1.46 \\
\hline
\end{tabular}




\begin{tabular}{|c|c|c|c|c|c|c|c|c|c|}
\hline No. & ID & $H_{s}(\mathrm{ft})$ & $T_{p}(\mathrm{sec})$ & Direction (deg) & $\alpha$ & $Y$ & $n$ & Probability & Days/yr \\
\hline 74 & 174 & 4.8 & 7.8 & 112.5 & 0.003118 & 3.3 & 4 & 0.00067 & 0.26 \\
\hline 75 & 175 & 6.8 & 7.8 & 112.5 & 0.006260 & 3.3 & 4 & 0.00039 & 0.15 \\
\hline 76 & 176 & 8.7 & 7.8 & 112.5 & 0.010250 & 3.3 & 4 & 0.00048 & 0.18 \\
\hline 77 & 177 & 10.7 & 7.8 & 112.5 & 0.015507 & 3.3 & 4 & 0.00021 & 0.07 \\
\hline 78 & 178 & 12.7 & 7.8 & 112.5 & 0.021848 & 3.3 & 4 & 0.00003 & 0.00 \\
\hline 79 & 179 & 2.8 & 9.5 & 112.5 & 0.000635 & 3.3 & 4 & 0.00337 & 1.24 \\
\hline 80 & 180 & 4.8 & 9.5 & 112.5 & 0.001867 & 3.3 & 4 & 0.00075 & 0.26 \\
\hline 81 & 181 & 6.8 & 9.5 & 112.5 & 0.003749 & 3.3 & 4 & 0.00050 & 0.18 \\
\hline 82 & 182 & 8.7 & 9.5 & 112.5 & 0.006139 & 3.3 & 4 & 0.00011 & 0.04 \\
\hline 83 & 183 & 10.7 & 9.5 & 112.5 & 0.009287 & 3.3 & 4 & 0.00012 & 0.04 \\
\hline 84 & 184 & 12.7 & 9.5 & 112.5 & 0.013085 & 3.3 & 4 & 0.00007 & 0.04 \\
\hline 85 & 185 & 14.6 & 9.5 & 112.5 & 0.017294 & 3.3 & 4 & 0.00002 & 0.00 \\
\hline 86 & 186 & 2.8 & 11.9 & 112.5 & 0.000346 & 4 & 10 & 0.00253 & 0.91 \\
\hline 87 & 187 & 4.8 & 11.9 & 112.5 & 0.001017 & 4 & 10 & 0.00142 & 0.51 \\
\hline 88 & 188 & 6.8 & 11.9 & 112.5 & 0.002042 & 4 & 10 & 0.00043 & 0.15 \\
\hline 89 & 189 & 8.7 & 11.9 & 112.5 & 0.003343 & 4 & 10 & 0.00019 & 0.07 \\
\hline 90 & 190 & 10.7 & 11.9 & 112.5 & 0.005057 & 4 & 10 & 0.00003 & 0.00 \\
\hline 91 & 191 & 2.8 & 14.3 & 112.5 & 0.000267 & 5 & 16 & 0.00035 & 0.15 \\
\hline 92 & 192 & 4.8 & 14.3 & 112.5 & 0.000786 & 5 & 16 & 0.00021 & 0.07 \\
\hline 93 & 193 & 6.8 & 14.3 & 112.5 & 0.001578 & 5 & 16 & 0.00010 & 0.04 \\
\hline 94 & 194 & 8.7 & 14.3 & 112.5 & 0.002583 & 5 & 16 & 0.00003 & 0.00 \\
\hline 95 & 195 & 2.8 & 16.7 & 112.5 & 0.000087 & 7 & 22 & 0.00004 & 0.00 \\
\hline 96 & 196 & 4.8 & 16.7 & 112.5 & 0.000254 & 7 & 22 & 0.00002 & 0.00 \\
\hline 97 & 197 & 2.8 & 4.2 & 135 & 0.008003 & 3.3 & 4 & 0.03251 & 11.86 \\
\hline 98 & 198 & 4.8 & 4.2 & 135 & 0.023547 & 3.3 & 4 & 0.00843 & 3.07 \\
\hline 99 & 199 & 6.8 & 4.2 & 135 & 0.047281 & 3.3 & 4 & 0.00155 & 0.58 \\
\hline 100 & 200 & 8.7 & 4.2 & 135 & 0.077414 & 3.3 & 4 & 0.00013 & 0.04 \\
\hline 101 & 201 & 2.8 & 6.1 & 135 & 0.002102 & 3.3 & 4 & 0.00305 & 1.10 \\
\hline 102 & 202 & 4.8 & 6.1 & 135 & 0.006184 & 3.3 & 4 & 0.00077 & 0.29 \\
\hline 103 & 203 & 6.8 & 6.1 & 135 & 0.012417 & 3.3 & 4 & 0.00134 & 0.47 \\
\hline 104 & 204 & 8.7 & 6.1 & 135 & 0.020330 & 3.3 & 4 & 0.00016 & 0.07 \\
\hline 105 & 205 & 10.6 & 6.1 & 135 & 0.030184 & 3.3 & 4 & 0.00001 & 0.00 \\
\hline 106 & 206 & 2.8 & 7.8 & 135 & 0.001060 & 3.3 & 4 & 0.00242 & 0.88 \\
\hline 107 & 207 & 4.8 & 7.8 & 135 & 0.003118 & 3.3 & 4 & 0.00039 & 0.15 \\
\hline 108 & 208 & 6.8 & 7.8 & 135 & 0.006260 & 3.3 & 4 & 0.00032 & 0.11 \\
\hline 109 & 209 & 8.7 & 7.8 & 135 & 0.010250 & 3.3 & 4 & 0.00041 & 0.15 \\
\hline 110 & 210 & 10.6 & 7.8 & 135 & 0.015218 & 3.3 & 4 & 0.00018 & 0.07 \\
\hline 111 & 211 & 13 & 7.8 & 135 & 0.022892 & 3.3 & 4 & 0.00001 & 0.00 \\
\hline 112 & 212 & 2.8 & 9.5 & 135 & 0.000635 & 3.3 & 4 & 0.00167 & 0.62 \\
\hline 113 & 213 & 4.8 & 9.5 & 135 & 0.001867 & 3.3 & 4 & 0.00071 & 0.26 \\
\hline
\end{tabular}




\begin{tabular}{|c|c|c|c|c|c|c|c|c|c|}
\hline No. & ID & $H_{s}(\mathrm{ft})$ & $T_{p}(\mathrm{sec})$ & Direction (deg) & $\alpha$ & $y$ & $n$ & Probability & Days/yr \\
\hline 114 & 214 & 6.8 & 9.5 & 135 & 0.003749 & 3.3 & 4 & 0.00037 & 0.15 \\
\hline 115 & 215 & 8.7 & 9.5 & 135 & 0.006139 & 3.3 & 4 & 0.00028 & 0.11 \\
\hline 116 & 216 & 10.6 & 9.5 & 135 & 0.009114 & 3.3 & 4 & 0.00004 & 0.00 \\
\hline 117 & 217 & 13 & 9.5 & 135 & 0.013710 & 3.3 & 4 & 0.00001 & 0.00 \\
\hline 118 & 218 & 2.8 & 11.8 & 135 & 0.000365 & 4 & 10 & 0.00196 & 0.73 \\
\hline 119 & 219 & 4.8 & 11.8 & 135 & 0.001073 & 4 & 10 & 0.00056 & 0.22 \\
\hline 120 & 220 & 6.8 & 11.8 & 135 & 0.002154 & 4 & 10 & 0.00029 & 0.11 \\
\hline 121 & 221 & 8.7 & 11.8 & 135 & 0.003527 & 4 & 10 & 0.00025 & 0.07 \\
\hline 122 & 222 & 10.6 & 11.8 & 135 & 0.005236 & 4 & 10 & 0.00007 & 0.04 \\
\hline 123 & 223 & 13 & 11.8 & 135 & 0.007877 & 4 & 10 & 0.00001 & 0.00 \\
\hline 124 & 224 & 2.8 & 14.3 & 135 & 0.000267 & 5 & 16 & 0.00030 & 0.11 \\
\hline 125 & 225 & 4.8 & 14.3 & 135 & 0.000786 & 5 & 16 & 0.00013 & 0.04 \\
\hline 126 & 226 & 6.8 & 14.3 & 135 & 0.001578 & 5 & 16 & 0.00012 & 0.04 \\
\hline 127 & 227 & 2.8 & 16.7 & 135 & 0.000087 & 7 & 22 & 0.00002 & 0.00 \\
\hline 128 & 228 & 4.8 & 16.7 & 135 & 0.000254 & 7 & 22 & 0.00009 & 0.04 \\
\hline 129 & 229 & 6.8 & 16.7 & 135 & 0.000511 & 7 & 22 & 0.00007 & 0.04 \\
\hline 130 & 230 & 2.7 & 4.2 & 157.5 & 0.007441 & 3.3 & 4 & 0.04939 & 18.03 \\
\hline 131 & 231 & 4.7 & 4.2 & 157.5 & 0.022576 & 3.3 & 4 & 0.01042 & 3.80 \\
\hline 132 & 232 & 6.8 & 4.2 & 157.5 & 0.047281 & 3.3 & 4 & 0.00105 & 0.37 \\
\hline 133 & 233 & 10.8 & 4.2 & 157.5 & 0.119318 & 3.3 & 4 & 0.00001 & 0.00 \\
\hline 134 & 234 & 2.7 & 6 & 157.5 & 0.002082 & 3.3 & 4 & 0.00606 & 2.23 \\
\hline 135 & 235 & 4.7 & 6 & 157.5 & 0.006316 & 3.3 & 4 & 0.00157 & 0.58 \\
\hline 136 & 236 & 6.8 & 6 & 157.5 & 0.013227 & 3.3 & 4 & 0.00158 & 0.58 \\
\hline 137 & 237 & 8.8 & 6 & 157.5 & 0.022158 & 3.3 & 4 & 0.00021 & 0.07 \\
\hline 138 & 238 & 2.7 & 7.7 & 157.5 & 0.001021 & 3.3 & 4 & 0.00290 & 1.06 \\
\hline 139 & 239 & 4.7 & 7.7 & 157.5 & 0.003098 & 3.3 & 4 & 0.00078 & 0.29 \\
\hline 140 & 240 & 6.8 & 7.7 & 157.5 & 0.006489 & 3.3 & 4 & 0.00030 & 0.11 \\
\hline 141 & 241 & 8.8 & 7.7 & 157.5 & 0.010870 & 3.3 & 4 & 0.00066 & 0.26 \\
\hline 142 & 242 & 10.8 & 7.7 & 157.5 & 0.016376 & 3.3 & 4 & 0.00030 & 0.11 \\
\hline 143 & 243 & 13 & 7.7 & 157.5 & 0.023730 & 3.3 & 4 & 0.00005 & 0.00 \\
\hline 144 & 244 & 2.7 & 9.5 & 157.5 & 0.000590 & 3.3 & 4 & 0.00193 & 0.69 \\
\hline 145 & 245 & 4.7 & 9.5 & 157.5 & 0.001790 & 3.3 & 4 & 0.00082 & 0.29 \\
\hline 146 & 246 & 6.8 & 9.5 & 157.5 & 0.003749 & 3.3 & 4 & 0.00052 & 0.18 \\
\hline 147 & 247 & 8.8 & 9.5 & 157.5 & 0.006281 & 3.3 & 4 & 0.00010 & 0.04 \\
\hline 148 & 248 & 10.8 & 9.5 & 157.5 & 0.009461 & 3.3 & 4 & 0.00015 & 0.07 \\
\hline 149 & 249 & 13 & 9.5 & 157.5 & 0.013710 & 3.3 & 4 & 0.00009 & 0.04 \\
\hline 150 & 250 & 14.7 & 9.5 & 157.5 & 0.017532 & 3.3 & 4 & 0.00004 & 0.00 \\
\hline 151 & 251 & 2.7 & 11.7 & 157.5 & 0.000356 & 4 & 10 & 0.00175 & 0.62 \\
\hline 152 & 252 & 4.7 & 11.7 & 157.5 & 0.001081 & 4 & 10 & 0.00059 & 0.22 \\
\hline 153 & 253 & 6.8 & 11.7 & 157.5 & 0.002264 & 4 & 10 & 0.00029 & 0.11 \\
\hline
\end{tabular}




\begin{tabular}{|c|c|c|c|c|c|c|c|c|c|}
\hline No. & ID & $H_{s}(\mathrm{ft})$ & $T_{p}(\mathrm{sec})$ & Direction (deg) & $\alpha$ & $\bar{Y}$ & $n$ & Probability & Days/yr \\
\hline 154 & 254 & 8.8 & 11.7 & 157.5 & 0.003793 & 4 & 10 & 0.00004 & 0.00 \\
\hline 155 & 255 & 13 & 11.7 & 157.5 & 0.008279 & 4 & 10 & 0.00001 & 0.00 \\
\hline 156 & 256 & 2.7 & 14.3 & 157.5 & 0.000248 & 5 & 16 & 0.00038 & 0.15 \\
\hline 157 & 257 & 4.7 & 14.3 & 157.5 & 0.000753 & 5 & 16 & 0.00033 & 0.11 \\
\hline 158 & 258 & 2.7 & 16.7 & 157.5 & 0.000080 & 7 & 22 & 0.00010 & 0.04 \\
\hline 159 & 259 & 4.7 & 16.7 & 157.5 & 0.000244 & 7 & 22 & 0.00001 & 0.00 \\
\hline 160 & 260 & 2.8 & 4.3 & 180 & 0.007314 & 3.3 & 4 & 0.07421 & 27.08 \\
\hline 161 & 261 & 4.8 & 4.3 & 180 & 0.021518 & 3.3 & 4 & 0.01843 & 6.72 \\
\hline 162 & 262 & 6.7 & 4.3 & 180 & 0.041945 & 3.3 & 4 & 0.00106 & 0.40 \\
\hline 163 & 263 & 8.7 & 4.3 & 180 & 0.070744 & 3.3 & 4 & 0.00001 & 0.00 \\
\hline 164 & 264 & 2.8 & 6 & 180 & 0.002239 & 3.3 & 4 & 0.01263 & 4.60 \\
\hline 165 & 265 & 4.8 & 6 & 180 & 0.006588 & 3.3 & 4 & 0.00254 & 0.91 \\
\hline 166 & 266 & 6.7 & 6 & 180 & 0.012841 & 3.3 & 4 & 0.00339 & 1.24 \\
\hline 167 & 267 & 8.7 & 6 & 180 & 0.021657 & 3.3 & 4 & 0.00034 & 0.11 \\
\hline 168 & 268 & 2.8 & 7.7 & 180 & 0.001098 & 3.3 & 4 & 0.00401 & 1.46 \\
\hline 169 & 269 & 4.8 & 7.7 & 180 & 0.003232 & 3.3 & 4 & 0.00086 & 0.33 \\
\hline 170 & 270 & 6.7 & 7.7 & 180 & 0.006299 & 3.3 & 4 & 0.00060 & 0.22 \\
\hline 171 & 271 & 8.7 & 7.7 & 180 & 0.010625 & 3.3 & 4 & 0.00113 & 0.40 \\
\hline 172 & 272 & 10.7 & 7.7 & 180 & 0.016074 & 3.3 & 4 & 0.00018 & 0.07 \\
\hline 173 & 273 & 12.8 & 7.7 & 180 & 0.023005 & 3.3 & 4 & 0.00003 & 0.00 \\
\hline 174 & 274 & 2.8 & 9.5 & 180 & 0.000635 & 3.3 & 4 & 0.00191 & 0.69 \\
\hline 175 & 275 & 4.8 & 9.5 & 180 & 0.001867 & 3.3 & 4 & 0.00086 & 0.33 \\
\hline 176 & 276 & 6.7 & 9.5 & 180 & 0.003640 & 3.3 & 4 & 0.00016 & 0.07 \\
\hline 177 & 277 & 8.7 & 9.5 & 180 & 0.006139 & 3.3 & 4 & 0.00008 & 0.04 \\
\hline 178 & 278 & 10.7 & 9.5 & 180 & 0.009287 & 3.3 & 4 & 0.00007 & 0.04 \\
\hline 179 & 279 & 12.8 & 9.5 & 180 & 0.013291 & 3.3 & 4 & 0.00012 & 0.04 \\
\hline 180 & 280 & 2.8 & 11.4 & 180 & 0.000429 & 4 & 10 & 0.00059 & 0.22 \\
\hline 181 & 281 & 4.8 & 11.4 & 180 & 0.001262 & 4 & 10 & 0.00046 & 0.18 \\
\hline 182 & 282 & 6.7 & 11.4 & 180 & 0.002461 & 4 & 10 & 0.00009 & 0.04 \\
\hline 183 & 283 & 8.7 & 11.4 & 180 & 0.004150 & 4 & 10 & 0.00003 & 0.00 \\
\hline 184 & 284 & 10.7 & 11.4 & 180 & 0.006279 & 4 & 10 & 0.00001 & 0.00 \\
\hline 185 & 285 & 12.8 & 11.4 & 180 & 0.008987 & 4 & 10 & 0.00001 & 0.00 \\
\hline 186 & 286 & 14.9 & 11.4 & 180 & 0.012178 & 4 & 10 & 0.00002 & 0.00 \\
\hline 187 & 287 & 2.9 & 3.7 & 202.5 & 0.014273 & 3.3 & 4 & 0.02801 & 10.22 \\
\hline 188 & 288 & 4.7 & 3.7 & 202.5 & 0.037530 & 3.3 & 4 & 0.00773 & 2.81 \\
\hline 189 & 289 & 6.7 & 3.7 & 202.5 & 0.076305 & 3.3 & 4 & 0.00062 & 0.22 \\
\hline 190 & 290 & 8.8 & 3.7 & 202.5 & 0.131671 & 3.3 & 4 & 0.00002 & 0.00 \\
\hline 191 & 291 & 10.5 & 3.7 & 202.5 & 0.187485 & 3.3 & 4 & 0.00001 & 0.00 \\
\hline 192 & 292 & 2.9 & 6 & 202.5 & 0.002402 & 3.3 & 4 & 0.00053 & 0.18 \\
\hline 193 & 293 & 4.7 & 6 & 202.5 & 0.006316 & 3.3 & 4 & 0.00045 & 0.18 \\
\hline
\end{tabular}




\begin{tabular}{|l|l|l|l|l|l|l|l|l|l|}
\hline No. & ID & $H_{s}(\mathrm{ft})$ & $T_{p}(\mathrm{sec})$ & Direction (deg) & $\alpha$ & $\mathrm{Y}$ & $n$ & Probability & Days/yr \\
\hline 194 & 294 & 6.7 & 6 & 202.5 & 0.012841 & 3.3 & 4 & 0.00082 & 0.29 \\
\hline 195 & 295 & 8.8 & 6 & 202.5 & 0.022158 & 3.3 & 4 & 0.00003 & 0.00 \\
\hline 196 & 296 & 2.9 & 7.7 & 202.5 & 0.001178 & 3.3 & 4 & 0.00011 & 0.04 \\
\hline 197 & 297 & 4.7 & 7.7 & 202.5 & 0.003098 & 3.3 & 4 & 0.00014 & 0.04 \\
\hline 198 & 298 & 6.7 & 7.7 & 202.5 & 0.006299 & 3.3 & 4 & 0.00010 & 0.04 \\
\hline 199 & 299 & 8.8 & 7.7 & 202.5 & 0.010870 & 3.3 & 4 & 0.00018 & 0.07 \\
\hline 200 & 300 & 10.5 & 7.7 & 202.5 & 0.015478 & 3.3 & 4 & 0.00002 & 0.00 \\
\hline 201 & 301 & 2.9 & 9.5 & 202.5 & 0.000681 & 3.3 & 4 & 0.00003 & 0.00 \\
\hline 202 & 302 & 4.7 & 9.5 & 202.5 & 0.001790 & 3.3 & 4 & 0.00007 & 0.04 \\
\hline 203 & 303 & 6.7 & 9.5 & 202.5 & 0.003640 & 3.3 & 4 & 0.00002 & 0.00 \\
\hline 204 & 304 & 8.8 & 9.5 & 202.5 & 0.006281 & 3.3 & 4 & 0.00001 & 0.00 \\
\hline 205 & 305 & 10.5 & 9.5 & 202.5 & 0.008943 & 3.3 & 4 & 0.00003 & 0.00 \\
\hline 206 & 306 & 13.1 & 9.5 & 202.5 & 0.013922 & 3.3 & 4 & 0.00001 & 0.00 \\
\hline 207 & 307 & 2.9 & 11.5 & 202.5 & 0.000446 & 4 & 10 & 0.00005 & 0.04 \\
\hline 208 & 308 & 4.7 & 11.5 & 202.5 & 0.001174 & 4 & 10 & 0.00007 & 0.04 \\
\hline 209 & 309 & 6.7 & 11.5 & 202.5 & 0.002386 & 4 & 10 & 0.00004 & 0.00 \\
\hline 210 & 310 & 8.8 & 11.5 & 202.5 & 0.004118 & 4 & 10 & 0.00004 & 0.00 \\
\hline 211 & 311 & 14.1 & 11.5 & 202.5 & 0.010576 & 4 & 10 & 0.00001 & 0.00 \\
\hline Min: & 2.7 & 3.7 & 67.5 & & & & Total Days: & 157.0 \\
\hline Ave: & 7.4 & 8.9 & 132.0 & & & & Calm Days: & 208.0 \\
\hline Maxi: & 20.8 & 16.7 & 202.5 & & & & & \\
\hline No: & & & & & & & \\
\hline
\end{tabular}

Notes:

BOLD = 24 waves in Phase 2, but different wave heights.

Min = minimum value in Phase 1, Ave = average value in Phase 1, Max = maximum value in Phase 1. 
Table C2. Wave climatology in Ambrose Mound, Phase 1, Mound Reach 2.

\begin{tabular}{|c|c|c|c|c|c|c|c|c|c|}
\hline No. & ID & $H_{s}(\mathrm{ft})$ & $T_{p}(\mathrm{sec})$ & Direction (deg) & $\alpha$ & $Y$ & $n$ & Probability & Days/yr \\
\hline 1 & 401 & 2.9 & 3.7 & 67.5 & 0.014263 & 3.3 & 4 & 0.01665 & 6.10 \\
\hline 2 & 402 & 4.8 & 3.7 & 67.5 & 0.039118 & 3.3 & 4 & 0.00754 & 2.74 \\
\hline 3 & 403 & 6.8 & 3.7 & 67.5 & 0.078547 & 3.3 & 4 & 0.00071 & 0.26 \\
\hline 4 & 404 & 8.6 & 3.7 & 67.5 & 0.125665 & 3.3 & 4 & 0.00014 & 0.04 \\
\hline 5 & 405 & 10.8 & 3.7 & 67.5 & 0.198220 & 3.3 & 4 & 0.00001 & 0.00 \\
\hline 6 & 406 & 2.9 & 6 & 67.5 & 0.002368 & 3.3 & 4 & 0.00005 & 0.00 \\
\hline 7 & 407 & 4.8 & 6 & 67.5 & 0.006493 & 3.3 & 4 & 0.00017 & 0.07 \\
\hline 8 & 408 & 6.8 & 6 & 67.5 & 0.013037 & 3.3 & 4 & 0.00022 & 0.07 \\
\hline 9 & 409 & 8.6 & 6 & 67.5 & 0.020858 & 3.3 & 4 & 0.00003 & 0.00 \\
\hline 10 & 410 & 10.8 & 6 & 67.5 & 0.032901 & 3.3 & 4 & 0.00002 & 0.00 \\
\hline 11 & 411 & 2.9 & 7.6 & 67.5 & 0.001186 & 3.3 & 4 & 0.00007 & 0.04 \\
\hline 12 & 412 & 4.8 & 7.6 & 67.5 & 0.003251 & 3.3 & 4 & 0.00003 & 0.00 \\
\hline 13 & 413 & 6.8 & 7.6 & 67.5 & 0.006528 & 3.3 & 4 & 0.00010 & 0.04 \\
\hline 14 & 414 & 8.6 & 7.6 & 67.5 & 0.010445 & 3.3 & 4 & 0.00007 & 0.04 \\
\hline 15 & 415 & 2.9 & 9.4 & 67.5 & 0.000692 & 3.3 & 4 & 0.00004 & 0.00 \\
\hline 16 & 416 & 4.8 & 9.4 & 67.5 & 0.001898 & 3.3 & 4 & 0.00001 & 0.00 \\
\hline 17 & 417 & 6.8 & 9.4 & 67.5 & 0.003812 & 3.3 & 4 & 0.00002 & 0.00 \\
\hline 18 & 418 & 8.6 & 9.4 & 67.5 & 0.006098 & 3.3 & 4 & 0.00001 & 0.00 \\
\hline 19 & 419 & 10.8 & 9.4 & 67.5 & 0.009619 & 3.3 & 4 & 0.00003 & 0.00 \\
\hline 20 & 420 & 12.1 & 9.4 & 67.5 & 0.012075 & 3.3 & 4 & 0.00001 & 0.00 \\
\hline 21 & 421 & 2.9 & 11.8 & 67.5 & 0.000379 & 4 & 10 & 0.00009 & 0.04 \\
\hline 22 & 422 & 4.8 & 11.8 & 67.5 & 0.001039 & 4 & 10 & 0.00005 & 0.00 \\
\hline 23 & 423 & 6.8 & 11.8 & 67.5 & 0.002087 & 4 & 10 & 0.00002 & 0.00 \\
\hline 24 & 424 & 8.6 & 11.8 & 67.5 & 0.003339 & 4 & 10 & 0.00001 & 0.00 \\
\hline 25 & 425 & 12.1 & 11.8 & 67.5 & 0.006611 & 4 & 10 & 0.00001 & 0.00 \\
\hline 26 & 426 & 15.4 & 11.8 & 67.5 & 0.010710 & 4 & 10 & 0.00001 & 0.00 \\
\hline 27 & 427 & 16.2 & 11.8 & 67.5 & 0.011852 & 4 & 10 & 0.00001 & 0.00 \\
\hline 28 & 428 & 2.9 & 4.1 & 90 & 0.009391 & 3.3 & 4 & 0.03076 & 11.24 \\
\hline 29 & 429 & 4.8 & 4.1 & 90 & 0.025756 & 3.3 & 4 & 0.01041 & 3.80 \\
\hline 30 & 430 & 6.8 & 4.1 & 90 & 0.051715 & 3.3 & 4 & 0.00180 & 0.66 \\
\hline 31 & 431 & 8.8 & 4.1 & 90 & 0.086633 & 3.3 & 4 & 0.00010 & 0.04 \\
\hline 32 & 432 & 2.9 & 6.1 & 90 & 0.002221 & 3.3 & 4 & 0.00307 & 1.13 \\
\hline 33 & 433 & 4.8 & 6.1 & 90 & 0.006091 & 3.3 & 4 & 0.00048 & 0.18 \\
\hline 34 & 434 & 6.8 & 6.1 & 90 & 0.012231 & 3.3 & 4 & 0.00185 & 0.66 \\
\hline 35 & 435 & 8.8 & 6.1 & 90 & 0.020488 & 3.3 & 4 & 0.00038 & 0.15 \\
\hline 36 & 436 & 10.8 & 6.1 & 90 & 0.030865 & 3.3 & 4 & 0.00001 & 0.00 \\
\hline 37 & 437 & 2.9 & 7.8 & 90 & 0.001110 & 3.3 & 4 & 0.00333 & 1.20 \\
\hline 38 & 438 & 4.8 & 7.8 & 90 & 0.003045 & 3.3 & 4 & 0.00060 & 0.22 \\
\hline 39 & 439 & 6.8 & 7.8 & 90 & 0.006114 & 3.3 & 4 & 0.00023 & 0.07 \\
\hline
\end{tabular}




\begin{tabular}{|c|c|c|c|c|c|c|c|c|c|}
\hline No. & ID & $H_{s}(\mathrm{ft})$ & $T_{p}(\mathrm{sec})$ & Direction (deg) & $\alpha$ & $Y$ & $n$ & Probability & Days/yr \\
\hline 40 & 440 & 8.8 & 7.8 & 90 & 0.010242 & 3.3 & 4 & 0.00058 & 0.22 \\
\hline 41 & 441 & 10.8 & 7.8 & 90 & 0.015429 & 3.3 & 4 & 0.00037 & 0.15 \\
\hline 42 & 442 & 12.9 & 7.8 & 90 & 0.022015 & 3.3 & 4 & 0.00009 & 0.04 \\
\hline 43 & 443 & 2.9 & 9.5 & 90 & 0.000662 & 3.3 & 4 & 0.00239 & 0.88 \\
\hline 44 & 444 & 4.8 & 9.5 & 90 & 0.001815 & 3.3 & 4 & 0.00026 & 0.11 \\
\hline 45 & 445 & 6.8 & 9.5 & 90 & 0.003644 & 3.3 & 4 & 0.00015 & 0.04 \\
\hline 46 & 446 & 8.8 & 9.5 & 90 & 0.006104 & 3.3 & 4 & 0.00015 & 0.07 \\
\hline 47 & 447 & 10.8 & 9.5 & 90 & 0.009195 & 3.3 & 4 & 0.00014 & 0.04 \\
\hline 48 & 448 & 12.9 & 9.5 & 90 & 0.013121 & 3.3 & 4 & 0.00009 & 0.04 \\
\hline 49 & 449 & 14.9 & 9.5 & 90 & 0.017506 & 3.3 & 4 & 0.00008 & 0.04 \\
\hline 50 & 450 & 17.7 & 9.5 & 90 & 0.024706 & 3.3 & 4 & 0.00003 & 0.00 \\
\hline 51 & 451 & 2.9 & 11.6 & 90 & 0.000417 & 4 & 10 & 0.00049 & 0.18 \\
\hline 52 & 452 & 4.8 & 11.6 & 90 & 0.001143 & 4 & 10 & 0.00042 & 0.15 \\
\hline 53 & 453 & 6.8 & 11.6 & 90 & 0.002294 & 4 & 10 & 0.00029 & 0.11 \\
\hline 54 & 454 & 8.8 & 11.6 & 90 & 0.003843 & 4 & 10 & 0.00016 & 0.07 \\
\hline 55 & 455 & 10.8 & 11.6 & 90 & 0.005789 & 4 & 10 & 0.00012 & 0.04 \\
\hline 56 & 456 & 12.9 & 11.6 & 90 & 0.008261 & 4 & 10 & 0.00005 & 0.04 \\
\hline 57 & 457 & 14.9 & 11.6 & 90 & 0.011022 & 4 & 10 & 0.00001 & 0.00 \\
\hline 58 & 458 & 17.7 & 11.6 & 90 & 0.015555 & 4 & 10 & 0.00004 & 0.00 \\
\hline 59 & 459 & 20.8 & 11.6 & 90 & 0.021482 & 4 & 10 & 0.00003 & 0.00 \\
\hline 60 & 460 & 2.9 & 14.3 & 90 & 0.000277 & 5 & 16 & 0.00003 & 0.00 \\
\hline 61 & 461 & 4.8 & 14.3 & 90 & 0.000760 & 5 & 16 & 0.00003 & 0.00 \\
\hline 62 & 462 & 14.9 & 14.3 & 90 & 0.007334 & 5 & 16 & 0.00001 & 0.00 \\
\hline 63 & 463 & 17.7 & 14.3 & 90 & 0.010350 & 5 & 16 & 0.00002 & 0.00 \\
\hline 64 & 464 & 2.9 & 16.7 & 90 & 0.000089 & 7 & 22 & 0.00002 & 0.00 \\
\hline 65 & 465 & 2.8 & 4.2 & 112.5 & 0.007982 & 3.3 & 4 & 0.03396 & 12.41 \\
\hline 66 & 466 & 4.8 & 4.2 & 112.5 & 0.023486 & 3.3 & 4 & 0.00864 & 3.14 \\
\hline 67 & 467 & 6.8 & 4.2 & 112.5 & 0.047158 & 3.3 & 4 & 0.00101 & 0.37 \\
\hline 68 & 468 & 10.7 & 4.2 & 112.5 & 0.116814 & 3.3 & 4 & 0.00001 & 0.00 \\
\hline 69 & 469 & 2.8 & 6.1 & 112.5 & 0.002070 & 3.3 & 4 & 0.00384 & 1.39 \\
\hline 70 & 470 & 4.8 & 6.1 & 112.5 & 0.006091 & 3.3 & 4 & 0.00096 & 0.37 \\
\hline 71 & 471 & 6.8 & 6.1 & 112.5 & 0.012231 & 3.3 & 4 & 0.00179 & 0.66 \\
\hline 72 & 472 & 8.7 & 6.1 & 112.5 & 0.020025 & 3.3 & 4 & 0.00021 & 0.07 \\
\hline 73 & 473 & 2.8 & 7.8 & 112.5 & 0.001035 & 3.3 & 4 & 0.00400 & 1.46 \\
\hline 74 & 474 & 4.8 & 7.8 & 112.5 & 0.003045 & 3.3 & 4 & 0.00067 & 0.26 \\
\hline 75 & 475 & 6.8 & 7.8 & 112.5 & 0.006114 & 3.3 & 4 & 0.00039 & 0.15 \\
\hline 76 & 476 & 8.7 & 7.8 & 112.5 & 0.010010 & 3.3 & 4 & 0.00048 & 0.18 \\
\hline 77 & 477 & 10.7 & 7.8 & 112.5 & 0.015144 & 3.3 & 4 & 0.00021 & 0.07 \\
\hline 78 & 478 & 12.7 & 7.8 & 112.5 & 0.021337 & 3.3 & 4 & 0.00003 & 0.00 \\
\hline 79 & 479 & 2.8 & 9.5 & 112.5 & 0.000617 & 3.3 & 4 & 0.00337 & 1.24 \\
\hline
\end{tabular}




\begin{tabular}{|c|c|c|c|c|c|c|c|c|c|}
\hline No. & ID & $H_{s}(\mathrm{ft})$ & $T_{p}(\mathrm{sec})$ & Direction (deg) & $\alpha$ & $Y$ & $n$ & Probability & Days/yr \\
\hline 80 & 480 & 4.8 & 9.5 & 112.5 & 0.001815 & 3.3 & 4 & 0.00075 & 0.26 \\
\hline 81 & 481 & 6.8 & 9.5 & 112.5 & 0.003644 & 3.3 & 4 & 0.00050 & 0.18 \\
\hline 82 & 482 & 8.7 & 9.5 & 112.5 & 0.005966 & 3.3 & 4 & 0.00011 & 0.04 \\
\hline 83 & 483 & 10.7 & 9.5 & 112.5 & 0.009026 & 3.3 & 4 & 0.00012 & 0.04 \\
\hline 84 & 484 & 12.7 & 9.5 & 112.5 & 0.012717 & 3.3 & 4 & 0.00007 & 0.04 \\
\hline 85 & 485 & 14.6 & 9.5 & 112.5 & 0.016808 & 3.3 & 4 & 0.00002 & 0.00 \\
\hline 86 & 486 & 2.8 & 11.9 & 112.5 & 0.000335 & 4 & 10 & 0.00253 & 0.91 \\
\hline 87 & 487 & 4.8 & 11.9 & 112.5 & 0.000985 & 4 & 10 & 0.00142 & 0.51 \\
\hline 88 & 488 & 6.8 & 11.9 & 112.5 & 0.001977 & 4 & 10 & 0.00043 & 0.15 \\
\hline 89 & 489 & 8.7 & 11.9 & 112.5 & 0.003238 & 4 & 10 & 0.00019 & 0.07 \\
\hline 90 & 490 & 10.7 & 11.9 & 112.5 & 0.004898 & 4 & 10 & 0.00003 & 0.00 \\
\hline 91 & 491 & 2.8 & 14.3 & 112.5 & 0.000258 & 5 & 16 & 0.00035 & 0.15 \\
\hline 92 & 492 & 4.8 & 14.3 & 112.5 & 0.000760 & 5 & 16 & 0.00021 & 0.07 \\
\hline 93 & 493 & 6.8 & 14.3 & 112.5 & 0.001527 & 5 & 16 & 0.00010 & 0.04 \\
\hline 94 & 494 & 8.7 & 14.3 & 112.5 & 0.002499 & 5 & 16 & 0.00003 & 0.00 \\
\hline 95 & 495 & 2.8 & 16.7 & 112.5 & 0.000083 & 7 & 22 & 0.00004 & 0.00 \\
\hline 96 & 496 & 4.8 & 16.7 & 112.5 & 0.000245 & 7 & 22 & 0.00002 & 0.00 \\
\hline 97 & 497 & 2.8 & 4.2 & 135 & 0.007982 & 3.3 & 4 & 0.03251 & 11.86 \\
\hline 98 & 498 & 4.8 & 4.2 & 135 & 0.023486 & 3.3 & 4 & 0.00843 & 3.07 \\
\hline 99 & 499 & 6.8 & 4.2 & 135 & 0.047158 & 3.3 & 4 & 0.00155 & 0.58 \\
\hline 100 & 500 & 8.7 & 4.2 & 135 & 0.077213 & 3.3 & 4 & 0.00013 & 0.04 \\
\hline 101 & 501 & 2.8 & 6.1 & 135 & 0.002070 & 3.3 & 4 & 0.00305 & 1.10 \\
\hline 102 & 502 & 4.8 & 6.1 & 135 & 0.006091 & 3.3 & 4 & 0.00077 & 0.29 \\
\hline 103 & 503 & 6.8 & 6.1 & 135 & 0.012231 & 3.3 & 4 & 0.00134 & 0.47 \\
\hline 104 & 504 & 8.7 & 6.1 & 135 & 0.020025 & 3.3 & 4 & 0.00016 & 0.07 \\
\hline 105 & 505 & 10.6 & 6.1 & 135 & 0.029732 & 3.3 & 4 & 0.00001 & 0.00 \\
\hline 106 & 506 & 2.8 & 7.8 & 135 & 0.001035 & 3.3 & 4 & 0.00242 & 0.88 \\
\hline 107 & 507 & 4.8 & 7.8 & 135 & 0.003045 & 3.3 & 4 & 0.00039 & 0.15 \\
\hline 108 & 508 & 6.8 & 7.8 & 135 & 0.006114 & 3.3 & 4 & 0.00032 & 0.11 \\
\hline 109 & 509 & 8.7 & 7.8 & 135 & 0.010010 & 3.3 & 4 & 0.00041 & 0.15 \\
\hline 110 & 510 & 10.6 & 7.8 & 135 & 0.014862 & 3.3 & 4 & 0.00018 & 0.07 \\
\hline 111 & 511 & 13 & 7.8 & 135 & 0.022357 & 3.3 & 4 & 0.00001 & 0.00 \\
\hline 112 & 512 & 2.8 & 9.5 & 135 & 0.000617 & 3.3 & 4 & 0.00167 & 0.62 \\
\hline 113 & 513 & 4.8 & 9.5 & 135 & 0.001815 & 3.3 & 4 & 0.00071 & 0.26 \\
\hline 114 & 514 & 6.8 & 9.5 & 135 & 0.003644 & 3.3 & 4 & 0.00037 & 0.15 \\
\hline 115 & 515 & 8.7 & 9.5 & 135 & 0.005966 & 3.3 & 4 & 0.00028 & 0.11 \\
\hline 116 & 516 & 10.6 & 9.5 & 135 & 0.008858 & 3.3 & 4 & 0.00004 & 0.00 \\
\hline 117 & 517 & 13 & 9.5 & 135 & 0.013325 & 3.3 & 4 & 0.00001 & 0.00 \\
\hline 118 & 518 & 2.8 & 11.8 & 135 & 0.000353 & 4 & 10 & 0.00196 & 0.73 \\
\hline 119 & 519 & 4.8 & 11.8 & 135 & 0.001039 & 4 & 10 & 0.00056 & 0.22 \\
\hline
\end{tabular}




\begin{tabular}{|c|c|c|c|c|c|c|c|c|c|}
\hline No. & ID & $H_{s}(\mathrm{ft})$ & $T_{p}(\mathrm{sec})$ & Direction (deg) & $\alpha$ & $Y$ & $n$ & Probability & Days/yr \\
\hline 120 & 520 & 6.8 & 11.8 & 135 & 0.002087 & 4 & 10 & 0.00029 & 0.11 \\
\hline 121 & 521 & 8.7 & 11.8 & 135 & 0.003417 & 4 & 10 & 0.00025 & 0.07 \\
\hline 122 & 522 & 10.6 & 11.8 & 135 & 0.005073 & 4 & 10 & 0.00007 & 0.04 \\
\hline 123 & 523 & 13 & 11.8 & 135 & 0.007631 & 4 & 10 & 0.00001 & 0.00 \\
\hline 124 & 524 & 2.8 & 14.3 & 135 & 0.000258 & 5 & 16 & 0.00030 & 0.11 \\
\hline 125 & 525 & 4.8 & 14.3 & 135 & 0.000760 & 5 & 16 & 0.00013 & 0.04 \\
\hline 126 & 526 & 6.8 & 14.3 & 135 & 0.001527 & 5 & 16 & 0.00012 & 0.04 \\
\hline 127 & 527 & 2.8 & 16.7 & 135 & 0.000083 & 7 & 22 & 0.00002 & 0.00 \\
\hline 128 & 528 & 4.8 & 16.7 & 135 & 0.000245 & 7 & 22 & 0.00009 & 0.04 \\
\hline 129 & 529 & 6.8 & 16.7 & 135 & 0.000493 & 7 & 22 & 0.00007 & 0.04 \\
\hline 130 & 530 & 2.7 & 4.2 & 157.5 & 0.007422 & 3.3 & 4 & 0.04939 & 18.03 \\
\hline 131 & 531 & 4.7 & 4.2 & 157.5 & 0.022517 & 3.3 & 4 & 0.01042 & 3.80 \\
\hline 132 & 532 & 6.8 & 4.2 & 157.5 & 0.047158 & 3.3 & 4 & 0.00105 & 0.37 \\
\hline 133 & 533 & 10.8 & 4.2 & 157.5 & 0.119008 & 3.3 & 4 & 0.00001 & 0.00 \\
\hline 134 & 534 & 2.7 & 6 & 157.5 & 0.002052 & 3.3 & 4 & 0.00606 & 2.23 \\
\hline 135 & 535 & 4.7 & 6 & 157.5 & 0.006225 & 3.3 & 4 & 0.00157 & 0.58 \\
\hline 136 & 536 & 6.8 & 6 & 157.5 & 0.013037 & 3.3 & 4 & 0.00158 & 0.58 \\
\hline 137 & 537 & 8.8 & 6 & 157.5 & 0.021840 & 3.3 & 4 & 0.00021 & 0.07 \\
\hline 138 & 538 & 2.7 & 7.7 & 157.5 & 0.000998 & 3.3 & 4 & 0.00290 & 1.06 \\
\hline 139 & 539 & 4.7 & 7.7 & 157.5 & 0.003028 & 3.3 & 4 & 0.00078 & 0.29 \\
\hline 140 & 540 & 6.8 & 7.7 & 157.5 & 0.006341 & 3.3 & 4 & 0.00030 & 0.11 \\
\hline 141 & 541 & 8.8 & 7.7 & 157.5 & 0.010622 & 3.3 & 4 & 0.00066 & 0.26 \\
\hline 142 & 542 & 10.8 & 7.7 & 157.5 & 0.016002 & 3.3 & 4 & 0.00030 & 0.11 \\
\hline 143 & 543 & 13 & 7.7 & 157.5 & 0.023188 & 3.3 & 4 & 0.00005 & 0.00 \\
\hline 144 & 544 & 2.7 & 9.5 & 157.5 & 0.000573 & 3.3 & 4 & 0.00193 & 0.69 \\
\hline 145 & 545 & 4.7 & 9.5 & 157.5 & 0.001740 & 3.3 & 4 & 0.00082 & 0.29 \\
\hline 146 & 546 & 6.8 & 9.5 & 157.5 & 0.003644 & 3.3 & 4 & 0.00052 & 0.18 \\
\hline 147 & 547 & 8.8 & 9.5 & 157.5 & 0.006104 & 3.3 & 4 & 0.00010 & 0.04 \\
\hline 148 & 548 & 10.8 & 9.5 & 157.5 & 0.009195 & 3.3 & 4 & 0.00015 & 0.07 \\
\hline 149 & 549 & 13 & 9.5 & 157.5 & 0.013325 & 3.3 & 4 & 0.00009 & 0.04 \\
\hline 150 & 550 & 14.7 & 9.5 & 157.5 & 0.017039 & 3.3 & 4 & 0.00004 & 0.00 \\
\hline 151 & 551 & 2.7 & 11.7 & 157.5 & 0.000345 & 4 & 10 & 0.00175 & 0.62 \\
\hline 152 & 552 & 4.7 & 11.7 & 157.5 & 0.001048 & 4 & 10 & 0.00059 & 0.22 \\
\hline 153 & 553 & 6.8 & 11.7 & 157.5 & 0.002194 & 4 & 10 & 0.00029 & 0.11 \\
\hline 154 & 554 & 8.8 & 11.7 & 157.5 & 0.003675 & 4 & 10 & 0.00004 & 0.00 \\
\hline 155 & 555 & 13 & 11.7 & 157.5 & 0.008023 & 4 & 10 & 0.00001 & 0.00 \\
\hline 156 & 556 & 2.7 & 14.3 & 157.5 & 0.000240 & 5 & 16 & 0.00038 & 0.15 \\
\hline 157 & 557 & 4.7 & 14.3 & 157.5 & 0.000729 & 5 & 16 & 0.00033 & 0.11 \\
\hline 158 & 558 & 2.7 & 16.7 & 157.5 & 0.000078 & 7 & 22 & 0.00010 & 0.04 \\
\hline 159 & 559 & 4.7 & 16.7 & 157.5 & 0.000235 & 7 & 22 & 0.00001 & 0.00 \\
\hline
\end{tabular}




\begin{tabular}{|c|c|c|c|c|c|c|c|c|c|}
\hline No. & ID & $H_{s}(\mathrm{ft})$ & $T_{p}(\mathrm{sec})$ & Direction (deg) & $\alpha$ & $Y$ & $n$ & Probability & Days/yr \\
\hline 160 & 560 & 2.8 & 4.3 & 180 & 0.007290 & 3.3 & 4 & 0.07421 & 27.08 \\
\hline 161 & 561 & 4.8 & 4.3 & 180 & 0.021449 & 3.3 & 4 & 0.01843 & 6.72 \\
\hline 162 & 562 & 6.7 & 4.3 & 180 & 0.041810 & 3.3 & 4 & 0.00106 & 0.40 \\
\hline 163 & 563 & 8.7 & 4.3 & 180 & 0.070516 & 3.3 & 4 & 0.00001 & 0.00 \\
\hline 164 & 564 & 2.8 & 6 & 180 & 0.002207 & 3.3 & 4 & 0.01263 & 4.60 \\
\hline 165 & 565 & 4.8 & 6 & 180 & 0.006493 & 3.3 & 4 & 0.00254 & 0.91 \\
\hline 166 & 566 & 6.7 & 6 & 180 & 0.012657 & 3.3 & 4 & 0.00339 & 1.24 \\
\hline 167 & 567 & 8.7 & 6 & 180 & 0.021346 & 3.3 & 4 & 0.00034 & 0.11 \\
\hline 168 & 568 & 2.8 & 7.7 & 180 & 0.001073 & 3.3 & 4 & 0.00401 & 1.46 \\
\hline 169 & 569 & 4.8 & 7.7 & 180 & 0.003158 & 3.3 & 4 & 0.00086 & 0.33 \\
\hline 170 & 570 & 6.7 & 7.7 & 180 & 0.006156 & 3.3 & 4 & 0.00060 & 0.22 \\
\hline 171 & 571 & 8.7 & 7.7 & 180 & 0.010382 & 3.3 & 4 & 0.00113 & 0.40 \\
\hline 172 & 572 & 10.7 & 7.7 & 180 & 0.015707 & 3.3 & 4 & 0.00018 & 0.07 \\
\hline 173 & 573 & 12.8 & 7.7 & 180 & 0.022480 & 3.3 & 4 & 0.00003 & 0.00 \\
\hline 174 & 574 & 2.8 & 9.5 & 180 & 0.000617 & 3.3 & 4 & 0.00191 & 0.69 \\
\hline 175 & 575 & 4.8 & 9.5 & 180 & 0.001815 & 3.3 & 4 & 0.00086 & 0.33 \\
\hline 176 & 576 & 6.7 & 9.5 & 180 & 0.003537 & 3.3 & 4 & 0.00016 & 0.07 \\
\hline 177 & 577 & 8.7 & 9.5 & 180 & 0.005966 & 3.3 & 4 & 0.00008 & 0.04 \\
\hline 178 & 578 & 10.7 & 9.5 & 180 & 0.009026 & 3.3 & 4 & 0.00007 & 0.04 \\
\hline 179 & 579 & 12.8 & 9.5 & 180 & 0.012918 & 3.3 & 4 & 0.00012 & 0.04 \\
\hline 180 & 580 & 2.8 & 11.4 & 180 & 0.000416 & 4 & 10 & 0.00059 & 0.22 \\
\hline 181 & 581 & 4.8 & 11.4 & 180 & 0.001224 & 4 & 10 & 0.00046 & 0.18 \\
\hline 182 & 582 & 6.7 & 11.4 & 180 & 0.002386 & 4 & 10 & 0.00009 & 0.04 \\
\hline 183 & 583 & 8.7 & 11.4 & 180 & 0.004024 & 4 & 10 & 0.00003 & 0.00 \\
\hline 184 & 584 & 10.7 & 11.4 & 180 & 0.006088 & 4 & 10 & 0.00001 & 0.00 \\
\hline 185 & 585 & 12.8 & 11.4 & 180 & 0.008714 & 4 & 10 & 0.00001 & 0.00 \\
\hline 186 & 586 & 14.9 & 11.4 & 180 & 0.011809 & 4 & 10 & 0.00002 & 0.00 \\
\hline 187 & 587 & 2.9 & 3.7 & 202.5 & 0.014263 & 3.3 & 4 & 0.02801 & 10.22 \\
\hline 188 & 588 & 4.7 & 3.7 & 202.5 & 0.037504 & 3.3 & 4 & 0.00773 & 2.81 \\
\hline 189 & 589 & 6.7 & 3.7 & 202.5 & 0.076252 & 3.3 & 4 & 0.00062 & 0.22 \\
\hline 190 & 590 & 8.8 & 3.7 & 202.5 & 0.131581 & 3.3 & 4 & 0.00002 & 0.00 \\
\hline 191 & 591 & 10.5 & 3.7 & 202.5 & 0.187356 & 3.3 & 4 & 0.00001 & 0.00 \\
\hline 192 & 592 & 2.9 & 6 & 202.5 & 0.002368 & 3.3 & 4 & 0.00053 & 0.18 \\
\hline 193 & 593 & 4.7 & 6 & 202.5 & 0.006225 & 3.3 & 4 & 0.00045 & 0.18 \\
\hline 194 & 594 & 6.7 & 6 & 202.5 & 0.012657 & 3.3 & 4 & 0.00082 & 0.29 \\
\hline 195 & 595 & 8.8 & 6 & 202.5 & 0.021840 & 3.3 & 4 & 0.00003 & 0.00 \\
\hline 196 & 596 & 2.9 & 7.7 & 202.5 & 0.001152 & 3.3 & 4 & 0.00011 & 0.04 \\
\hline 197 & 597 & 4.7 & 7.7 & 202.5 & 0.003028 & 3.3 & 4 & 0.00014 & 0.04 \\
\hline 198 & 598 & 6.7 & 7.7 & 202.5 & 0.006156 & 3.3 & 4 & 0.00010 & 0.04 \\
\hline 199 & 599 & 8.8 & 7.7 & 202.5 & 0.010622 & 3.3 & 4 & 0.00018 & 0.07 \\
\hline
\end{tabular}




\begin{tabular}{|l|l|l|l|l|l|l|l|l|l|}
\hline No. & ID & $H_{s}(\mathrm{ft})$ & $T_{p}(\mathrm{sec})$ & Direction (deg) & $\alpha$ & $Y$ & $n$ & Probability & Days/yr \\
\hline 200 & 600 & 10.5 & 7.7 & 202.5 & 0.015125 & 3.3 & 4 & 0.00002 & 0.00 \\
\hline 201 & 601 & 2.9 & 9.5 & 202.5 & 0.000662 & 3.3 & 4 & 0.00003 & 0.00 \\
\hline 202 & 602 & 4.7 & 9.5 & 202.5 & 0.001740 & 3.3 & 4 & 0.00007 & 0.04 \\
\hline 203 & 603 & 6.7 & 9.5 & 202.5 & 0.003537 & 3.3 & 4 & 0.00002 & 0.00 \\
\hline 204 & 604 & 8.8 & 9.5 & 202.5 & 0.006104 & 3.3 & 4 & 0.00001 & 0.00 \\
\hline 205 & 605 & 10.5 & 9.5 & 202.5 & 0.008691 & 3.3 & 4 & 0.00003 & 0.00 \\
\hline 206 & 606 & 13.1 & 9.5 & 202.5 & 0.013531 & 3.3 & 4 & 0.00001 & 0.00 \\
\hline 207 & 607 & 2.9 & 11.5 & 202.5 & 0.000433 & 4 & 10 & 0.00005 & 0.04 \\
\hline 208 & 608 & 4.7 & 11.5 & 202.5 & 0.001138 & 4 & 10 & 0.00007 & 0.04 \\
\hline 209 & 609 & 6.7 & 11.5 & 202.5 & 0.002314 & 4 & 10 & 0.00004 & 0.00 \\
\hline 210 & 610 & 8.8 & 11.5 & 202.5 & 0.003992 & 4 & 10 & 0.00004 & 0.00 \\
\hline 211 & 611 & 14.1 & 11.5 & 202.5 & 0.010253 & 4 & 10 & 0.00001 & 0.00 \\
\hline Min: & 2.7 & 3.7 & 67.5 & & & & Total Days: & 157.0 \\
\hline Ave: & 7.4 & 8.9 & 132.0 & & & & Calm Days: & 208.0 \\
\hline Max: & 20.8 & 16.7 & 202.5 & & & & & \\
\hline
\end{tabular}

Notes:

BOLD = 24 waves in Phase 2, but different wave heights.

Min = minimum value in Phase 1, Ave = average value in Phase 1, Max = maximum value in Phase 1. 
Table C3. Wave climatology in Ambrose Channel, Phase 2, Channel Reach 1.

\begin{tabular}{|c|c|c|c|c|c|c|c|c|c|}
\hline No. & ID & $H_{s}(\mathrm{ft})$ & $T_{p}(\mathrm{sec})$ & Direction (deg) & $\alpha$ & $\mathrm{Y}$ & $n$ & Probability & Days/yr \\
\hline 19 & 119 & 9.8 & 9.4 & 67.5 & 0.008146 & 3.3 & 4 & 0.0000 & 0.01 \\
\hline 22 & 122 & 4.2 & 11.8 & 67.5 & 0.000821 & 4 & 10 & 0.0000 & 0.02 \\
\hline 46 & 146 & 8.2 & 9.5 & 90 & 0.005453 & 3.3 & 4 & 0.0002 & 0.06 \\
\hline 52 & 152 & 4.4 & 11.6 & 90 & 0.00099 & 4 & 10 & 0.0004 & 0.15 \\
\hline 61 & 161 & 4.4 & 14.3 & 90 & 0.00066 & 5 & 16 & 0.0000 & 0.01 \\
\hline 64 & 164 & 2.6 & 16.7 & 90 & 0.000075 & 7 & 22 & 0.0000 & 0.01 \\
\hline 82 & 182 & 8.4 & 9.5 & 112.5 & 0.005722 & 3.3 & 4 & 0.0001 & 0.04 \\
\hline 87 & 187 & 4.6 & 11.9 & 112.5 & 0.000934 & 4 & 10 & 0.0014 & 0.52 \\
\hline 92 & 192 & 4.7 & 14.3 & 112.5 & 0.000753 & 5 & 16 & 0.0002 & 0.07 \\
\hline 95 & 195 & 2.8 & 16.7 & 112.5 & 0.000087 & 7 & 22 & 0.0000 & 0.01 \\
\hline 115 & 215 & 8.2 & 9.5 & 135 & 0.005453 & 3.3 & 4 & 0.0003 & 0.10 \\
\hline 119 & 219 & 4.6 & 11.8 & 135 & 0.000985 & 4 & 10 & 0.0006 & 0.21 \\
\hline 125 & 225 & 4.6 & 14.3 & 135 & 0.000722 & 5 & 16 & 0.0001 & 0.05 \\
\hline 127 & 227 & 2.7 & 16.7 & 135 & 0.00008 & 7 & 22 & 0.0000 & 0.01 \\
\hline 147 & 247 & 7.3 & 9.5 & 157.5 & 0.004321 & 3.3 & 4 & 0.0001 & 0.04 \\
\hline 152 & 252 & 3.7 & 11.7 & 157.5 & 0.00067 & 4 & 10 & 0.0006 & 0.21 \\
\hline 157 & 257 & 3.4 & 14.3 & 157.5 & 0.000394 & 5 & 16 & 0.0003 & 0.12 \\
\hline 158 & 258 & 1.9 & 16.7 & 157.5 & 0.00004 & 7 & 22 & 0.0001 & 0.04 \\
\hline 177 & 277 & 8 & 9.5 & 180 & 0.00519 & 3.3 & 4 & 0.0001 & 0.03 \\
\hline 181 & 281 & 4.2 & 11.4 & 180 & 0.000966 & 4 & 10 & 0.0005 & 0.17 \\
\hline 205 & 305 & 7.9 & 9.5 & 202.5 & 0.005061 & 3.3 & 4 & 0.0000 & 0.01 \\
\hline 206 & 306 & 9.8 & 9.5 & 202.5 & 0.00779 & 3.3 & 4 & 0.0000 & 0.00 \\
\hline 208 & 308 & 3.2 & 11.5 & 202.5 & 0.000544 & 4 & 10 & 0.0001 & 0.03 \\
\hline 209 & 309 & 4.6 & 11.5 & 202.5 & 0.001124 & 4 & 10 & 0.0000 & 0.01 \\
\hline \multicolumn{2}{|l|}{ Min: } & 1.9 & 9.4 & 67.5 & & & & Total Days: & 1.9 \\
\hline \multicolumn{2}{|l|}{ Ave: } & 5.3 & 12.2 & 136.9 & & & & & \\
\hline \multicolumn{2}{|l|}{ Max: } & 9.8 & 16.7 & 202.5 & & & & & \\
\hline
\end{tabular}

Notes:

Min = minimum value in Phase 2, Ave = average value in Phase 2, Max = maximum value in Phase 2. 
Table C4. Wave climatology in Ambrose Mound, Phase 2, Mound Reach 2.

\begin{tabular}{|c|c|c|c|c|c|c|c|c|c|}
\hline No. & ID & $H_{s}(\mathrm{ft})$ & $T_{p}(\mathrm{sec})$ & Direction (deg) & $\alpha$ & $Y$ & $n$ & Probability & Days/yr \\
\hline 19 & 419 & 10.2 & 9.4 & 67.5 & 0.008579 & 3.3 & 4 & 0.0000 & 0.01 \\
\hline 22 & 422 & 4.4 & 11.8 & 67.5 & 0.000873 & 4.0 & 10 & 0.0000 & 0.02 \\
\hline 46 & 446 & 8.5 & 9.5 & 90.0 & 0.005695 & 3.3 & 4 & 0.0002 & 0.06 \\
\hline 52 & 452 & 4.6 & 11.6 & 90.0 & 0.001049 & 4.0 & 10 & 0.0004 & 0.15 \\
\hline 61 & 461 & 4.6 & 14.3 & 90.0 & 0.000698 & 5.0 & 16 & 0.0000 & 0.01 \\
\hline 64 & 464 & 2.8 & 16.7 & 90.0 & 0.000083 & 7.0 & 22 & 0.0000 & 0.01 \\
\hline 82 & 482 & 9.4 & 9.5 & 112.5 & 0.006965 & 3.3 & 4 & 0.0001 & 0.04 \\
\hline 87 & 487 & 5.4 & 11.9 & 112.5 & 0.001247 & 4.0 & 10 & 0.0014 & 0.52 \\
\hline 92 & 492 & 5.5 & 14.3 & 112.5 & 0.000998 & 5.0 & 16 & 0.0002 & 0.07 \\
\hline 95 & 495 & 3.3 & 16.7 & 112.5 & 0.000116 & 7.0 & 22 & 0.0000 & 0.01 \\
\hline 115 & 515 & 9.1 & 9.5 & 135.0 & 0.006527 & 3.3 & 4 & 0.0003 & 0.10 \\
\hline 119 & 519 & 5.2 & 11.8 & 135.0 & 0.001220 & 4.0 & 10 & 0.0006 & 0.21 \\
\hline 125 & 525 & 5.3 & 14.3 & 135.0 & 0.000927 & 5.0 & 16 & 0.0001 & 0.05 \\
\hline 127 & 527 & 3.2 & 16.7 & 135.0 & 0.000109 & 7.0 & 22 & 0.0000 & 0.01 \\
\hline 147 & 547 & 7.5 & 9.5 & 157.5 & 0.004433 & 3.3 & 4 & 0.0001 & 0.04 \\
\hline 152 & 552 & 3.8 & 11.7 & 157.5 & 0.000685 & 4.0 & 10 & 0.0006 & 0.21 \\
\hline 157 & 557 & 3.6 & 14.3 & 157.5 & 0.000427 & 5.0 & 16 & 0.0003 & 0.12 \\
\hline 158 & 558 & 2.0 & 16.7 & 157.5 & 0.000043 & 7.0 & 22 & 0.0001 & 0.04 \\
\hline 177 & 577 & 7.5 & 9.5 & 180.0 & 0.004433 & 3.3 & 4 & 0.0001 & 0.03 \\
\hline 181 & 581 & 3.8 & 11.4 & 180.0 & 0.000767 & 4.0 & 10 & 0.0005 & 0.17 \\
\hline 205 & 605 & 8.4 & 9.5 & 202.5 & 0.005562 & 3.3 & 4 & 0.0000 & 0.01 \\
\hline 206 & 606 & 9.8 & 9.5 & 202.5 & 0.007571 & 3.3 & 4 & 0.0000 & 0.00 \\
\hline 208 & 608 & 3.4 & 11.5 & 202.5 & 0.000595 & 4.0 & 10 & 0.0001 & 0.03 \\
\hline 209 & 609 & 4.6 & 11.5 & 202.5 & 0.001090 & 4.0 & 10 & 0.0000 & 0.01 \\
\hline \multicolumn{2}{|l|}{ Min: } & 2.0 & 9.4 & 67.5 & & & & Total Days: & 1.9 \\
\hline \multicolumn{2}{|l|}{ Ave: } & 5.7 & 12.2 & 136.9 & & & & & \\
\hline \multicolumn{2}{|l|}{ Max: } & 10.2 & 16.7 & 202.5 & & & & & \\
\hline
\end{tabular}

Notes:

1. Min = minimum value in Phase 2, Ave = average value in Phase 2, Max = maximum value in Phase 2. 


\section{Appendix D: Wave-induced Vertical Motion Allowances (ft) for Phase 1, Reach 1 Channel ( $h=53 \mathrm{ft}$ ) and Reach 2 Mound $(h=55 \mathrm{ft}$ ), Fully loaded ( $T=47.5 \mathrm{ft}$ ) Susan Maersk}

Table D1. Wave-induced vertical motion allowances (ft), Phase 1, Channel Reach 1, $h=53 \mathrm{ft}$, fully loaded Susan Maersk, inbound and outbound transits.

\begin{tabular}{|c|c|c|c|c|c|c|c|c|c|c|c|c|}
\hline \multirow{2}{*}{$\begin{array}{l}\text { Wave } \\
\text { No. }\end{array}$} & \multirow{2}{*}{$\begin{array}{l}\text { Wave } \\
\text { ID }\end{array}$} & \multirow[b]{2}{*}{ Days/yr } & \multicolumn{5}{|c|}{ Inbound Ship speed (kt) } & \multicolumn{5}{|c|}{ Outbound Ship speed (kt) } \\
\hline & & & 8 & 10 & 12 & 14 & 16 & 8 & 10 & 12 & 14 & 16 \\
\hline 1 & 101 & 6.10 & 0.02 & 0.05 & 0.04 & 0.06 & 0.09 & 0.01 & 0.01 & 0.01 & 0.02 & 0.04 \\
\hline 2 & 102 & 2.74 & 0.04 & 0.08 & 0.06 & 0.09 & 0.14 & 0.01 & 0.02 & 0.02 & 0.03 & 0.06 \\
\hline 3 & 103 & 0.26 & 0.05 & 0.11 & 0.09 & 0.13 & 0.20 & 0.02 & 0.03 & 0.03 & 0.05 & 0.08 \\
\hline 4 & 104 & 0.04 & 0.07 & 0.14 & 0.11 & 0.17 & 0.26 & 0.02 & 0.04 & 0.04 & 0.06 & 0.11 \\
\hline 5 & 105 & 0.00 & 0.08 & 0.18 & 0.14 & 0.21 & 0.32 & 0.03 & 0.05 & 0.06 & 0.08 & 0.13 \\
\hline 6 & 106 & 0.00 & 0.19 & 0.30 & 0.30 & 0.29 & 0.54 & 0.09 & 0.12 & 0.13 & 0.13 & 0.22 \\
\hline 7 & 107 & 0.07 & 0.31 & 0.49 & 0.49 & 0.48 & 0.89 & 0.15 & 0.20 & 0.22 & 0.22 & 0.36 \\
\hline 8 & 108 & 0.07 & 0.44 & 0.69 & 0.69 & 0.68 & 1.26 & 0.21 & 0.28 & 0.31 & 0.31 & 0.51 \\
\hline 9 & 109 & 0.00 & 0.56 & 0.88 & 0.88 & 0.86 & 1.60 & 0.27 & 0.35 & 0.39 & 0.40 & 0.65 \\
\hline 10 & 110 & 0.00 & 0.70 & 1.10 & 1.10 & 1.09 & 2.01 & 0.34 & 0.45 & 0.49 & 0.50 & 0.82 \\
\hline 11 & 111 & 0.04 & 0.34 & 0.43 & 0.43 & 0.40 & 0.59 & 0.21 & 0.24 & 0.25 & 0.24 & 0.27 \\
\hline 12 & 112 & 0.00 & 0.57 & 0.71 & 0.71 & 0.66 & 0.97 & 0.36 & 0.39 & 0.41 & 0.41 & 0.44 \\
\hline 13 & 113 & 0.04 & 0.80 & 1.01 & 1.00 & 0.93 & 1.38 & 0.50 & 0.55 & 0.58 & 0.57 & 0.62 \\
\hline 14 & 114 & 0.04 & 1.01 & 1.27 & 1.26 & 1.18 & 1.75 & 0.64 & 0.70 & 0.73 & 0.73 & 0.79 \\
\hline 15 & 115 & 0.00 & 0.72 & 0.74 & 0.72 & 0.68 & 0.83 & 0.54 & 0.54 & 0.55 & 0.54 & 0.54 \\
\hline 16 & 116 & 0.00 & 1.20 & 1.23 & 1.19 & 1.12 & 1.37 & 0.90 & 0.89 & 0.91 & 0.89 & 0.90 \\
\hline 17 & 117 & 0.00 & 1.69 & 1.74 & 1.69 & 1.59 & 1.94 & 1.28 & 1.26 & 1.29 & 1.27 & 1.27 \\
\hline 18 & 118 & 0.00 & 2.14 & 2.20 & 2.14 & 2.01 & 2.46 & 1.62 & 1.60 & 1.63 & 1.60 & 1.61 \\
\hline 19 & 119 & 0.00 & 2.69 & 2.76 & 2.69 & 2.53 & 3.09 & 2.03 & 2.01 & 2.04 & 2.01 & 2.03 \\
\hline 20 & 120 & 0.00 & 3.01 & 3.09 & 3.01 & 2.83 & 3.46 & 2.27 & 2.25 & 2.29 & 2.25 & 2.27 \\
\hline 21 & 121 & 0.04 & 1.85 & 1.75 & 1.71 & 1.60 & 1.89 & 1.39 & 1.29 & 1.27 & 1.21 & 1.16 \\
\hline 22 & 122 & 0.00 & 3.06 & 2.90 & 2.83 & 2.64 & 3.13 & 2.31 & 2.13 & 2.10 & 2.01 & 1.93 \\
\hline 23 & 123 & 0.00 & 4.33 & 4.11 & 4.01 & 3.75 & 4.43 & 3.27 & 3.03 & 2.98 & 2.84 & 2.73 \\
\hline
\end{tabular}




\begin{tabular}{|c|c|c|c|c|c|c|c|c|c|c|c|c|}
\hline \multirow{2}{*}{$\begin{array}{l}\text { Wave } \\
\text { No. }\end{array}$} & \multirow{2}{*}{$\begin{array}{l}\text { Wave } \\
\text { ID }\end{array}$} & \multirow[b]{2}{*}{ Days/yr } & \multicolumn{5}{|c|}{ Inbound Ship speed (kt) } & \multicolumn{5}{|c|}{ Outbound Ship speed (kt) } \\
\hline & & & 8 & 10 & 12 & 14 & 16 & 8 & 10 & 12 & 14 & 16 \\
\hline 24 & 124 & 0.00 & 5.48 & & 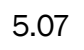 & & & 3 & 33 & 77 & 3.60 & 16 \\
\hline 25 & 5 & 0 & 1 & 7.31 & & 7 & 39 & 82 & 38 & 5.30 & 5.06 & 4.86 \\
\hline 26 & 6 & 0 & 32 & & & & 4 & 7.40 & 85 & 6.74 & 6.44 & 6.19 \\
\hline 27 & 27 & 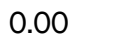 & .33 & 9.79 & 5 & 0.00 & .56 & 7.79 & 7.21 & 7.09 & 6.78 & 6.51 \\
\hline 28 & 28 & 24 & 5 & 0.10 & 8 & 0.11 & 18 & 0.01 & 01 & 0.02 & 0.02 & 0.04 \\
\hline 29 & 129 & 3.80 & .08 & 16 & & 18 & 9 & 0.02 & 0.02 & 0.03 & 0.04 & 0.06 \\
\hline 30 & 130 & 0.66 & .11 & 0.23 & 19 & 0.26 & 0.42 & 0.02 & 0.03 & 0.04 & 0.05 & 0.09 \\
\hline 31 & 31 & 4 & 0.14 & 0.30 & 0.25 & 0.33 & 0.54 & 0.03 & 0.04 & 0.05 & 0.06 & 0.12 \\
\hline 32 & 32 & 1.13 & 22 & 0 & 4 & 0.33 & 0.61 & 0.08 & .09 & 0.10 & 0.10 & 0.14 \\
\hline 33 & 133 & 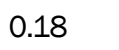 & 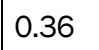 & 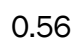 & 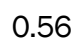 & 0.54 & 1.00 & 0.12 & 0.14 & 0.16 & 0.16 & 0.22 \\
\hline 34 & 134 & 0.66 & 0.51 & 0.80 & 9 & 0.77 & 1.42 & 0.18 & 0.20 & 0.22 & 0.23 & 0.32 \\
\hline 35 & 5 & 5 & 66 & 1.03 & 2 & 0.99 & 84 & 0.23 & 0.26 & 0.29 & 0.30 & 0.41 \\
\hline 36 & 136 & & & & 125 & 1.22 & 226 & 8 & 32 & 36 & 36 & 1 \\
\hline 37 & 137 & 1.20 & 40 & 0.49 & 0.48 & 0.44 & 0.66 & 0.20 & 0.21 & 0.21 & 0.22 & 0.22 \\
\hline 38 & 138 & 2 & 50 & or & 9 & (U) & $1 . \pm 0$ & 0.33 & 0.34 & 0.35 & 0.36 & 0.36 \\
\hline 39 & 139 & 0.07 & 0.93 & 1.15 & 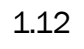 & 1.04 & 1.56 & 7 & 48 & 0.50 & 0.51 & 51 \\
\hline 40 & 10 & 22 & 21 & 48 & .45 & 1.35 & 2.01 & 0.61 & 0.62 & 0.65 & 0.66 & 0.66 \\
\hline 41 & 141 & & 110 & & & 105 & 217 & 5 & 7 & 0.80 & 81 & 0.82 \\
\hline 42 & 142 & 0.04 & 177 & 2 & 2.13 & 1 & 0 & 39 & 0.92 & 0.95 & 0.96 & 0.97 \\
\hline 43 & 43 & 38 & 0.76 & 0. & & 0.6 & 0.92 & 0.49 & 0.47 & 0.48 & 0.47 & $\mid 0.47$ \\
\hline 44 & & & & & & & & & 78 & 0.79 & 0.78 & 0.78 \\
\hline 45 & 15 & 0. & 9 & 1.84 & 75 & 1.62 & 2.16 & 1.14 & 1.11 & 1.12 & 1.11 & \begin{tabular}{|l|l} 
& 1.11
\end{tabular} \\
\hline 4 & 140 & & & & & & 2.80 & & 4 & 1 & 4 & 44 \\
\hline 47 & 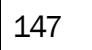 & & 12 & 2. & & 2.0 & . & 1.82 & 1.76 & 1.79 & 1.76 & 1.76 \\
\hline 48 & $+\varnothing$ & & 3.40 & 3 & & 3.0 & 4.1 & 2.17 & 2.10 & 2.13 & 2.11 & 2.11 \\
\hline 49 & 149 & 0.04 & 3.92 & 4.03 & 3.84 & 3.56 & 4.75 & 1 & 43 & 47 & 2.43 & 2.43 \\
\hline 50 & 150 & 0.00 & 4.66 & 4.78 & 4.56 & 4 & 5.64 & 98 & 2.89 & 2.93 & 2.89 & 2.89 \\
\hline 51 & 151 & & & & & & 1.98 & 0.92 & 0.83 & 0.80 & 0.77 & 0.73 \\
\hline 52 & 152 & 0.15 & 2.42 & 2.31 & 2.18 & 2 & 3.28 & 52 & 38 & 1.33 & 1.27 & 1.21 \\
\hline 53 & & & & & & & 4.64 & 2.15 & 1.96 & 1.89 & 1.80 & $\mid$\begin{tabular}{|l}
$\mid$ \\
1.71
\end{tabular} \\
\hline 54 & 154 & 0.07 & 4.45 & 4.23 & 4.00 & 3.66 & 6.01 & 2.79 & 2.53 & 2.44 & 2.33 & 2.21 \\
\hline 55 & & & & & & & & 2 & 11 & 0 & 35 & 2.71 \\
\hline 56 & & & & & & 5.37 & 8.81 & 4.09 & 3.72 & 3.58 & 3.41 & 3.24 \\
\hline
\end{tabular}




\begin{tabular}{|c|c|c|c|c|c|c|c|c|c|c|c|c|}
\hline \multirow{2}{*}{$\begin{array}{l}\text { Wave } \\
\text { No. }\end{array}$} & \multirow{2}{*}{$\begin{array}{l}\text { Wave } \\
\text { ID }\end{array}$} & \multirow[b]{2}{*}{ Days/yr } & \multicolumn{5}{|c|}{ Inbound Ship speed (kt) } & \multicolumn{5}{|c|}{ Outbound Ship speed (kt) } \\
\hline & & & 8 & 10 & 2 & 14 & 16 & 8 & 10 & 12 & 14 & 16 \\
\hline 57 & 1 & 0 & 3 & 7.16 & 6.77 & 0 & 8 & 72 & 29 & 13 & 94 & 74 \\
\hline 58 & & & 94 & 51 & & 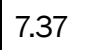 & 2.09 & 5.61 & 5.10 & 4.91 & 4.68 & 4.45 \\
\hline 59 & & 0 & .51 & 10.00 & & 8.66 & 14.22 & 6.59 & 5.99 & 5.77 & 5.50 & 5.23 \\
\hline 60 & SO & 0.00 & So & 1.89 & 1.77 & 2.21 & 3.75 & 57 & 1.48 & 1.40 & 1.35 & 1.23 \\
\hline 0. & 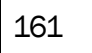 & 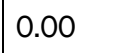 & 28 & 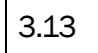 & 93 & 57 & 20 & 60 & 2.46 & 2.33 & 2.24 & 2.03 \\
\hline 62 & 62 & 0.00 & 10.19 & 9.71 & 09 & 11.39 & 19.27 & 8.07 & 7.63 & 7.23 & 6.96 & 6.30 \\
\hline 63 & 3 & 0.00 & 2.11 & 11.54 & 0.80 & 13.53 & 22.89 & 9.58 & 9.07 & 8.58 & 8.27 & 7.49 \\
\hline 64 & & 0.00 & 06 & 2.95 & 2.74 & 43 & 764 & .05 & 2.91 & 2.71 & 2.60 & 2.31 \\
\hline 65 & 5 & 12.41 & 0.05 & 0.11 & 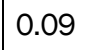 & 0.13 & 0.20 & 0.01 & 0.01 & 0.01 & 0.01 & 0.02 \\
\hline 66 & 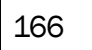 & +1 & 09 & (0.10 & 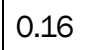 & 0.22 & .35 & 0.01 & 02 & 0.02 & 0.02 & 0.04 \\
\hline 67 & 67 & 037 & 0.13 & 0.27 & 0.23 & 0.30 & 0.49 & 0.02 & 0.02 & 0.03 & 0.03 & 0.05 \\
\hline 68 & 8 & 00 & .21 & 0.43 & 0.36 & 0.48 & 0.77 & .03 & 0.03 & 0.04 & 0.05 & 0.09 \\
\hline 69 & & & 0.22 & 0.35 & 0.34 & 0.33 & 0.61 & 6 & 66 & b7 & 07 & 08 \\
\hline 70 & 10 & 0.3 & 38 & 0.59 & 0.50 & 0.56 & 1.05 & 0.11 & 0.11 & 0.12 & 0.12 & 0.13 \\
\hline 71 & $T \perp$ & 20 & 0.53 & T. & 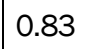 & 0.80 & 1.49 & 0.15 & 0.15 & 0.16 & 0.17 & 0.18 \\
\hline 72 & 172 & 0.07 & 0.68 & 1 & 1.06 & 1.02 & 1.91 & 9 & 20 & 0.21 & 0.22 & 0.23 \\
\hline 73 & 3 & 1.46 & 39 & 0.49 & $0.4 r$ & 0.44 & 0.67 & 0.17 & 0.17 & 0.17 & 0.18 & 0.18 \\
\hline 74 & & 0.26 & 0.67 & 0.84 & 0.81 & 0.76 & 1.14 & 9 & 29 & 0.30 & 30 & 31 \\
\hline 75 & 75 & 0.15 & 0.96 & 1 & 1.15 & 1.07 & 62 & 42 & 0.41 & 0.42 & 0.43 & 0.43 \\
\hline 76 & 76 & 0.18 & 1.22 & 1 & 1.4 & 1 & 2.0 & .53 & 0.53 & 0.54 & 0.55 & 0.56 \\
\hline 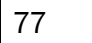 & & & & & & & & 6 & 5 & 66 & 67 & 0.68 \\
\hline 78 & 8 & 0.00 & 79 & 2.22 & .1 & 2.01 & 3.02 & 0.78 & 0.77 & 0.79 & 0.80 & 0.81 \\
\hline 79 & & & & 0.7 & 0.12 & & .91 & 2 & 0 & 0.40 & 10 & .39 \\
\hline 100 & & & & 1. & & & tor & 0.72 & 0.69 & 0.69 & 0.68 & 0.68 \\
\hline 81 & 1 & & & 1 & 1.74 & 1.59 & 2.4 & 1.02 & 0.97 & 0.98 & 0.97 & 0.96 \\
\hline 82 & 182 & ז & 2.29 & 2.3 & 2.20 & 2.04 & ז' & 1.31 & 1.25 & 1.26 & 1.24 & 1.23 \\
\hline 83 & 183 & 0.04 & 2.82 & 2.9 & 2.74 & 2.51 & 3.4 & 61 & 1.53 & 1.54 & 1.52 & 1.51 \\
\hline 8 & 184 & & & 3 & 3.25 & 2.98 & 4.15 & .91 & 1.82 & 1.83 & 1.80 & 1.79 \\
\hline 85 & 185 & 0.0 & 3.85 & 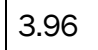 & 3.74 & 3.42 & ז & 19 & 09 & 2.11 & 2.07 & 2.06 \\
\hline 86 & & & & & & & 2.25 & 0.77 & 0.68 & 0.63 & 0.59 & 0.55 \\
\hline 87 & 181 & 0.51 & 2.31 & 2.23 & 2.04 & 2.06 & 3.86 & 1.32 & 1.17 & 1.08 & 1.02 & 0.94 \\
\hline 88 & & & & & & & & 7 & 1.66 & 54 & 4 & 1.34 \\
\hline 89 & & & & & & & 1. & 2.39 & 2.12 & | 1.97 & 1.84 & 1.71 \\
\hline
\end{tabular}




\begin{tabular}{|c|c|c|c|c|c|c|c|c|c|c|c|c|}
\hline \multirow{2}{*}{$\begin{array}{l}\text { Wave } \\
\text { No. }\end{array}$} & \multirow{2}{*}{$\begin{array}{l}\text { Wave } \\
\text { ID }\end{array}$} & \multirow[b]{2}{*}{ Days/yr } & \multicolumn{5}{|c|}{ Inbound Ship speed (kt) } & \multicolumn{5}{|c|}{ Outbound Ship speed (kt) } \\
\hline & & & 8 & 10 & 12 & 14 & 16 & 8 & 10 & 12 & 14 & 16 \\
\hline 90 & 30 & 0.00 & 5.29 & & & & & 4 & 61 & 42 & 27 & 0 \\
\hline 91 & 1 & & 2 & 1.34 & & 2.19 & 7 & 04 & 95 & 0.86 & 0.80 & 0.70 \\
\hline 92 & 2 & 7 & 4 & م0 & & 6 & 30 & 8 & 63 & 47 & 1.38 & 1.21 \\
\hline 93 & 93 & 0.04 & 3.46 & 3.25 & 000 & 5.32 & 93 & 2.52 & 2.31 & 2.08 & 1.95 & 1.71 \\
\hline 94 & 34 & 0.00 & 3 & 4.16 & 3.71 & 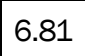 & 2 & 22 & .95 & 2.66 & 2.49 & 2.19 \\
\hline 95 & 95 & 0.00 & 1.68 & 59 & & & 7.06 & 1.71 & 1.59 & 1.41 & 1.32 & 1.14 \\
\hline 96 & 196 & 0.00 & 2.88 & 2.73 & 3.41 & 1.0 & 2.11 & 2.94 & 2.72 & 2.41 & 2.26 & 1.96 \\
\hline 97 & 7 & 86 & 0.05 & 0.11 & & 0.12 & .20 & 1 & 0.01 & 0.01 & 0.02 & 0.03 \\
\hline 98 & 198 & 3.07 & 0.09 & 0.19 & 0.16 & 0 & .34 & 0.01 & 0.02 & 0.02 & 0.03 & 0.05 \\
\hline 99 & 9 & 0.58 & 013 & 0.27 & 0.22 & 0.30 & 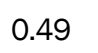 & 0.02 & 0.03 & 0.03 & 0.04 & 0.07 \\
\hline 100 & 200 & & 0.17 & 03 & 0 & 0.3 & 0.62 & 0.03 & 0.03 & 0.04 & 0.05 & 0.09 \\
\hline 101 & 201 & 1.10 & 22 & 0.34 & 0.34 & 0.33 & 61 & 0.06 & 0.07 & 0.07 & 0.08 & 0.09 \\
\hline 102 & 2 & 0.29 & 0.77 & & & 0.56 & 1.04 & 0.11 & 12 & 13 & 13 & 15 \\
\hline 103 & 203 & 0.47 & 0.53 & 0.83 & & 0. & 1.48 & 0.15 & 0.16 & 0.18 & 0.19 & 0.22 \\
\hline 104 & 204 & & & & & & & 20 & 0.21 & 0.23 & 0.24 & 0.28 \\
\hline 105 & 205 & 0.00 & 0.83 & 1.29 & 1.27 & 1.23 & 2.31 & c & 26 & 0.28 & 0.29 & 0.34 \\
\hline 106 & 206 & 50 & & 0.4 & & 0.4 & .0 & 8 & 0.18 & 0.18 & 0.18 & 0.19 \\
\hline 10 & 207 & & & & & 077 & & 30 & 30 & 0.31 & 31 & 0.32 \\
\hline 108 & 208 & 11 & 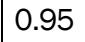 & 118 & 1 & 10 & 61 & c & 0.43 & 0.44 & 0.45 & 0.45 \\
\hline 109 & 209 & & & & & & 2.06 & & .55 & 0.56 & 0.57 & 0.58 \\
\hline 110 & 210 & & & & & & & & 57 & 68 & 69 & 0.70 \\
\hline 111 & 211 & & & 2 & & 2 & 3.0 & 82 & 0.82 & 0.84 & 0.85 & 0.86 \\
\hline 112 & 212 & & & & & & & & 41 & 42 & 0.41 & 0.41 \\
\hline 113 & 213 & 0.26 & 126 & & & & 1.56 & & 71 & 0.71 & 0.70 & 0.70 \\
\hline 114 & 214 & & & 1 & & 1.6 & 2.2 & 5 & 1.00 & 1.01 & 1.00 & $\mid 0.99$ \\
\hline 115 & 215 & 0. & 2.29 & 2.3 & & 2.0 & 2.00 & 1.34 & 1.28 & 1.30 & 1.28 & \begin{tabular}{|l|l} 
& 1.27
\end{tabular} \\
\hline 116 & 216 & 0.00 & 2.79 & 2 & 2.72 & 2 & 3.45 & 1 & 1.56 & 1.58 & 1.56 & 1.55 \\
\hline 117 & 217 & & & 0.5 & & & 4.20 & 2.01 & 1.92 & 1.94 & 1.91 & 1.90 \\
\hline 118 & 218 & 0.73 & 1.38 & 1 & & & 2.16 & 0.79 & 0.71 & 0.66 & 0.62 & 0.58 \\
\hline 119 & 219 & & & & & & 3.70 & & 1.21 & 1.14 & 1.07 & $\mid 1.00$ \\
\hline 120 & 220 & 0. & 3.30 & 3.1 & 2.92 & 2.8 & 5.24 & 1.92 & 1.71 & 1.61 & 1.52 & 1.42 \\
\hline 121 & 221 & & & & & & & & 9 & 2.06 & 4 & $\mid$\begin{tabular}{|l}
1.81 \\
\end{tabular} \\
\hline 122 & 22 & & & & & & & 2.99 & 2.67 & 2.51 & 2.36 & 2.21 \\
\hline
\end{tabular}




\begin{tabular}{|c|c|c|c|c|c|c|c|c|c|c|c|c|}
\hline \multirow{2}{*}{$\begin{array}{l}\text { Wave } \\
\text { No. }\end{array}$} & \multirow{2}{*}{$\begin{array}{l}\text { Wave } \\
\text { ID }\end{array}$} & \multirow[b]{2}{*}{ Days/yr } & \multicolumn{5}{|c|}{ Inbound Ship speed (kt) } & \multicolumn{5}{|c|}{ Dutbound Ship speed (kt) } \\
\hline & & & 8 & 10 & 2 & 14 & 16 & 8 & 10 & 12 & 14 & 16 \\
\hline 23 & 23 & 0.00 & 6.43 & 6.06 & & 8 & 3 & 57 & 28 & 08 & 90 & 71 \\
\hline 124 & 4 & 0.11 & & & & 2.19 & & 5 & 07 & 98 & 0.92 & 0.82 \\
\hline 125 & 25 & 004 & 44 & & & 76 & 2 & & 83 & 67 & 1.58 & 1.41 \\
\hline 126 & 26 & 0.04 & $T$ & 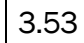 & & 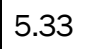 & U & 30 & 59 & 2.37 & 2.24 & 1.99 \\
\hline 127 & 227 & 0.00 & 0 & 1.91 & 206 & $r$ & 2 & 3 & 90 & 1.71 & 1.62 & 1.41 \\
\hline 128 & 228 & 0.04 & 43 & & & & 39 & 3.49 & 3.26 & 2.94 & 2.78 & 2.42 \\
\hline 129 & 229 & 0.04 & 4.86 & 1 & 501 & 11.12 & 17.55 & 94 & 4.62 & 4.17 & 3.93 & 3.43 \\
\hline 130 & 30 & .03 & 0.05 & 0.10 & & 1 & 0.18 & 0.01 & 02 & 0.02 & 0.03 & 0.05 \\
\hline 131 & 231 & 3 & 08 & 0 & & 0.19 & 32 & 02 & 03 & 0.04 & 0.05 & 0.09 \\
\hline 132 & 232 & 0.37 & 0.12 & 0.25 & 001 & 0.28 & 0.46 & 0.03 & 5 & 0.05 & 37 & 0.13 \\
\hline 133 & 233 & 0.00 & 0.19 & 0 & 0.33 & & 3 & 0.05 & 08 & 0.09 & 0.11 & 0.20 \\
\hline 134 & 34 & 23 & 9 & 0 & ת & 29 & 0.54 & 07 & 0.09 & 0.10 & 0.10 & 0.15 \\
\hline 35 & 235 & 0.58 & בקי & 0.52 & & 0.51 & 5050 & 012 & 5 & 17 & 17 & 26 \\
\hline 136 & 236 & & & & & & 1.37 & 0.18 & 0.22 & 0.24 & 0.24 & 0.38 \\
\hline 137 & 237 & 0.07 & 0.62 & & & & & 3 & 0.28 & 0.31 & 0.31 & 0.49 \\
\hline 138 & 238 & 1.06 & 0.35 & 0.43 & 0.43 & 0.40 & 0.59 & 9 & 20 & 21 & 0.21 & 0.21 \\
\hline 139 & 239 & 29 & 1 & & 0.74 & 69 & & 32 & 0.34 & 0.36 & 0.36 & 0.36 \\
\hline 140 & 240 & 0.11 & 0.88 & & & & & & 19 & 52 & 52 & 0.52 \\
\hline 141 & 11 & & 17 & 110 & & 1.30 & 01 & 1 & 0.64 & 0.67 & $\mid 0.67$ & 0.68 \\
\hline 142 & 42 & 0.11 & 1.39 & & & & 2.38 & 0.75 & 0.78 & 0.82 & 0.83 & 0.83 \\
\hline$I-$ & 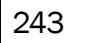 & & & & & & & & 4 & 99 & 0.99 & 1.00 \\
\hline 144 & 244 & 69 & 71 & 0.7 & 7 & 0.65 & .84 & 0.48 & 0.47 & .47 & 0.47 & 0.47 \\
\hline 14 & 245 & & & & & & & & & 33 & 32 & 0.82 \\
\hline 146 & 20 & & 1.79 & 1 & & & 2. & 21 & 1.18 & .20 & 1.18 & 1.18 \\
\hline 147 & 47 & 0.04 & 2.31 & & & 2.12 & 2.1 & 56 & 1.52 & 1.55 & 1.53 & 1.53 \\
\hline 148 & 248 & 0.07 & 2.84 & 2.91 & 2.79 & 2.60 & 3.37 & 92 & 37 & 1.90 & \begin{tabular}{|l|l} 
& 1.87
\end{tabular} & 1.88 \\
\hline 149 & 10 & 0.04 & 3.42 & 3 & 3.36 & 1 & 4.06 & 1 & 2.25 & 2.29 & 2.26 & 2.26 \\
\hline 150 & 250 & 0.00 & & & & & 4.05 & & 2.54 & 2.59 & 2.55 & 2.56 \\
\hline 15 & 1 & 0. & 40 & 1.43 & 1.37 & 1.26 & 1.86 & 01 & 92 & 0.89 & 0.85 & 0.82 \\
\hline 152 & 252 & & & & & & & & 60 & 1.56 & 1.49 & 1.42 \\
\hline 153 & 253 & 0.11 & 3.1 & 3.6 & 0. & 3.18 & 4.10 & 2.54 & 2.32 & 2.26 & 2.15 & 2.06 \\
\hline 154 & 254 & & & & & & & & 0 & 2 & 9 & \\
\hline 155 & 25 & 0.00 & 7.24 & 6.88 & 6.59 & 6.09 & 8.99 & 4.85 & 4.44 & 4.31 & 4.12 & 3.93 \\
\hline
\end{tabular}




\begin{tabular}{|c|c|c|c|c|c|c|c|c|c|c|c|c|}
\hline \multirow{2}{*}{$\begin{array}{l}\text { Wave } \\
\text { No. }\end{array}$} & \multirow{2}{*}{$\begin{array}{l}\text { Wave } \\
\text { ID }\end{array}$} & \multirow[b]{2}{*}{ Days/yr } & \multicolumn{5}{|c|}{ Inbound Ship speed (kt) } & \multicolumn{5}{|c|}{ Outbound Ship speed (kt) } \\
\hline & & & 8 & 10 & 12 & 14 & 16 & 8 & 10 & 12 & 14 & 16 \\
\hline 156 & 256 & 0.15 & 2.05 & 1.96 & 1.86 & 2.01 & 3.38 & 1.69 & 1.61 & 1.54 & 1.49 & 1.37 \\
\hline 157 & 257 & 0.11 & 3.58 & 3.42 & 3.24 & 3.50 & 5.89 & 2.95 & 2.81 & 2.69 & 2.60 & 2.38 \\
\hline 158 & 258 & 0.04 & 3.36 & 3.24 & 3.04 & 3.91 & 6.93 & 3.40 & 3.27 & 3.11 & 3.00 & 2.68 \\
\hline 159 & 259 & 0.00 & 5.86 & 5.65 & 5.29 & 6.82 & 12.07 & 5.92 & 5.70 & 5.41 & 5.23 & 4.67 \\
\hline 160 & 260 & 27.08 & 0.05 & 0.10 & 0.08 & 0.11 & 0.19 & 0.02 & 0.04 & 0.04 & 0.05 & 0.09 \\
\hline 161 & 261 & 6.72 & 0.08 & 0.17 & 0.15 & 0.19 & 0.32 & 0.04 & 0.07 & 0.07 & 0.09 & 0.16 \\
\hline 162 & 262 & 0.40 & 0.12 & 0.24 & 0.20 & 0.27 & 0.45 & 0.05 & 0.10 & 0.10 & 0.12 & 0.22 \\
\hline 163 & 263 & 0.00 & 0.15 & 0.31 & 0.26 & 0.35 & 0.58 & 0.07 & 0.12 & 0.13 & 0.16 & 0.29 \\
\hline 164 & 264 & 4.60 & 0.17 & 0.27 & 0.27 & 0.27 & 0.49 & 0.10 & 0.13 & 0.14 & 0.15 & 0.24 \\
\hline 165 & 265 & 0.91 & 0.30 & 0.46 & 0.47 & 0.46 & 0.85 & 0.16 & 0.22 & 0.25 & 0.25 & 0.42 \\
\hline 166 & 266 & 1.24 & 0.42 & 0.65 & 0.65 & 0.64 & 1.18 & 0.23 & 0.31 & 0.34 & 0.35 & 0.58 \\
\hline 167 & 267 & 0.11 & 0.54 & 0.84 & 0.84 & 0.84 & 1.54 & 0.30 & 0.41 & 0.44 & 0.45 & 0.75 \\
\hline 168 & 268 & 1.46 & 0.34 & 0.41 & 0.41 & 0.38 & 0.55 & 0.23 & 0.26 & 0.27 & 0.26 & 0.29 \\
\hline 169 & 269 & 0.33 & 0.58 & 0.70 & 0.70 & 0.64 & 0.94 & 0.40 & 0.44 & 0.46 & 0.45 & 0.50 \\
\hline 170 & 270 & 0.22 & 0.80 & 0.98 & 0.98 & 0.90 & 1.32 & 0.56 & 0.62 & 0.65 & 0.63 & 0.70 \\
\hline 171 & 271 & 0.40 & 1.04 & 1.27 & 1.27 & 1.17 & 1.71 & 0.73 & 0.80 & 0.84 & 0.82 & 0.92 \\
\hline 172 & 272 & 0.07 & 1.28 & 1.57 & 1.57 & 1.44 & 2.10 & 0.89 & 0.98 & 1.03 & 1.01 & 1.13 \\
\hline 173 & 273 & 0.00 & 1.54 & 1.88 & 1.87 & 1.72 & 2.52 & 1.07 & 1.18 & 1.23 & 1.21 & 1.35 \\
\hline 174 & 274 & 0.69 & 0.72 & 0.73 & 0.72 & 0.68 & 0.79 & 0.58 & 0.57 & 0.58 & 0.57 & 0.58 \\
\hline 175 & 275 & 0.33 & 1.24 & 1.26 & 1.23 & 1.17 & 1.36 & 0.99 & 0.99 & 1.00 & 0.98 & 0.99 \\
\hline 176 & 276 & 0.07 & 1.73 & 1.76 & 1.72 & 1.64 & 1.90 & 1.39 & 1.38 & 1.40 & 1.38 & 1.39 \\
\hline 177 & 277 & 0.04 & 2.25 & 2.28 & 2.24 & 2.13 & 2.46 & 1.80 & 1.79 & 1.82 & 1.79 & 1.80 \\
\hline 178 & 278 & 0.04 & 2.76 & 2.81 & 2.75 & 2.61 & 3.03 & 2.22 & 2.20 & 2.23 & 2.20 & 2.21 \\
\hline 179 & 279 & 0.04 & 3.30 & 3.36 & 3.29 & 3.13 & 3.63 & 2.65 & 2.63 & 2.67 & 2.63 & 2.65 \\
\hline 180 & 280 & 0.22 & 1.53 & 1.46 & 1.44 & 1.35 & 1.43 & 1.20 & 1.13 & 1.12 & 1.07 & 1.04 \\
\hline 181 & 281 & 0.18 & 2.62 & 2.50 & 2.46 & 2.32 & 2.45 & 2.07 & 1.93 & 1.92 & 1.84 & 1.78 \\
\hline 182 & 282 & 0.04 & 3.65 & 3.49 & 3.44 & 3.24 & 3.42 & 2.88 & 2.70 & 2.68 & 2.57 & 2.48 \\
\hline 183 & 283 & 0.00 & 4.74 & 4.54 & 4.47 & 4.21 & 4.45 & 3.75 & 3.50 & 3.48 & 3.33 & 3.23 \\
\hline 184 & 284 & 0.00 & 5.84 & 5.58 & 5.49 & 5.18 & 5.47 & 4.61 & 4.31 & 4.28 & 4.10 & 3.97 \\
\hline 185 & 285 & 0.00 & 6.98 & 6.67 & 6.57 & 6.20 & 6.55 & 5.51 & 5.15 & 5.12 & 4.91 & 4.75 \\
\hline 186 & 286 & 0.00 & 8.13 & 7.77 & 7.65 & 7.21 & 7.62 & 6.42 & 6.00 & 5.95 & 5.71 & 5.53 \\
\hline 187 & 287 & 10.22 & 0.02 & 0.03 & 0.03 & 0.04 & 0.07 & 0.01 & 0.03 & 0.02 & 0.03 & 0.06 \\
\hline 188 & 288 & 2.81 & 0.03 & 0.06 & 0.05 & 0.07 & 0.11 & 0.02 & 0.04 & 0.04 & 0.06 & 0.09 \\
\hline
\end{tabular}




\begin{tabular}{|c|c|c|c|c|c|c|c|c|c|c|c|c|}
\hline \multirow{2}{*}{$\begin{array}{l}\text { Wave } \\
\text { No. }\end{array}$} & \multirow{2}{*}{$\begin{array}{l}\text { Wave } \\
\text { ID }\end{array}$} & \multirow[b]{2}{*}{ Days/yr } & \multicolumn{5}{|c|}{ Inbound Ship speed (kt) } & \multicolumn{5}{|c|}{ Outbound Ship speed (kt) } \\
\hline & & & 8 & 10 & 12 & 14 & 16 & 8 & 10 & 12 & 14 & 16 \\
\hline 189 & 289 & 0.22 & 0.04 & 08 & .07 & 0.10 & 16 & 0.03 & 0.06 & 0.06 & 0.08 & 0.13 \\
\hline 190 & 290 & 0.00 & 0.05 & 0.10 & 0.09 & 0.13 & 0.21 & 0.04 & 0.08 & 0.07 & 0.11 & 0.17 \\
\hline 191 & 291 & 0.00 & 0.06 & 13 & 0.11 & 0.15 & 0.25 & 0.05 & 0.10 & 0.09 & 0.13 & 0.21 \\
\hline 192 & 292 & 0.18 & 0.15 & 0.23 & 0.23 & 0.24 & 0.42 & 0.13 & 0.19 & 0.20 & 0.20 & 0.35 \\
\hline 193 & 293 & 0.18 & 0.25 & 37 & 0.38 & 0.38 & 0.68 & 0.21 & 0.31 & 0.32 & 0.33 & 0.57 \\
\hline 194 & 294 & 0.29 & 0.35 & 0.52 & 0.54 & 0.54 & 0.97 & 0.30 & 0.44 & 0.46 & 0.47 & 0.81 \\
\hline 195 & 295 & 0.00 & 0.46 & 0.69 & 0.71 & 0.71 & 1.27 & 0.39 & 0.57 & 0.61 & 0.61 & 1.07 \\
\hline 196 & 296 & 0.04 & 0.31 & 37 & 0.38 & 0.35 & 0.4 & 0.29 & 0.33 & 0.34 & 0.32 & 0.41 \\
\hline 197 & 297 & 0.04 & 0.51 & 0.60 & 0.61 & 0.56 & 0.77 & 0.46 & 0.53 & 0.55 & 0.52 & 0.66 \\
\hline 198 & 298 & 0.04 & 0.72 & 86 & 37 & 0.80 & 1.10 & 0.66 & 0.76 & 0.79 & 0.75 & 0.95 \\
\hline 199 & 299 & 0.07 & 0.95 & 112 & 1.1 & 1.06 & 1.4 & 0.87 & 1.00 & 1.03 & 0.98 & \begin{tabular}{|l|l}
1.24 \\
\end{tabular} \\
\hline 200 & 300 & 0.00 & 1.13 & 1.34 & 1.37 & 1.26 & 1.73 & 1.03 & 1.19 & 1.23 & 1.17 & 1.48 \\
\hline 201 & 301 & 0.00 & 0.71 & 72 & 0.72 & 0.69 & .7 & 0.68 & 0.68 & 0.68 & 0.67 & 0.67 \\
\hline 202 & 302 & 0.04 & 1.16 & 1.17 & 1.17 & 1.13 & 1.14 & 1.10 & 1.10 & 1.11 & 1.08 & 1.09 \\
\hline 203 & 303 & 0.00 & 1.65 & 1.66 & 1.66 & 1.61 & 1.62 & 1.56 & 1.57 & 1.58 & 1.54 & 1.55 \\
\hline 204 & 304 & 0.00 & 2.1 & . & 21 & 2.11 & . & 05 & 2.06 & 2.08 & 2.02 & 2.04 \\
\hline 205 & 305 & 0.00 & 2.59 & 2.61 & 2.60 & 2.52 & 2.55 & 2.45 & 2.46 & 2.48 & 2.41 & 2.44 \\
\hline 206 & 306 & 0.00 & 3.23 & 3.26 & 3.25 & 3.14 & 3.18 & 3.06 & 3.07 & 3.09 & 3.01 & 3.04 \\
\hline 207 & 307 & 0.04 & 1.69 & 1.60 & 1.59 & 1.51 & 1.4 & 1.59 & 1.50 & 1.50 & 1.43 & \begin{tabular}{|l}
1.39 \\
\end{tabular} \\
\hline 208 & 308 & 0.04 & 2.73 & $2.5 \mathrm{~s}$ & 2.58 & 2.45 & 2.3 & 2.58 & 2.43 & 2.43 & 2.32 & 2.25 \\
\hline 209 & 309 & 0.00 & 3.90 & 3.70 & 3.68 & 3.50 & 3.39 & 3.68 & 3.47 & 3.46 & 3.30 & 3.20 \\
\hline 210 & 310 & 0.00 & 5.12 & 4.86 & 4.84 & 4.60 & 4.4 & 4.83 & 4.56 & 4.55 & 4.34 & 4.21 \\
\hline 211 & 311 & 0.00 & 8.21 & 7.78 & 7.75 & |7.37 & 7.15 & 7.74 & 7.31 & 7.29 & 6.95 & 6.74 \\
\hline
\end{tabular}


Table D2. Wave-induced vertical motion allowances (ft), Phase 1, Mound Reach 2, $h=55 \mathrm{ft}$, fully loaded Susan Maersk, inbound and outbound transits.

\begin{tabular}{|c|c|c|c|c|c|c|c|c|c|c|c|c|}
\hline \multirow{2}{*}{$\begin{array}{l}\text { Wave } \\
\text { No. }\end{array}$} & \multirow{2}{*}{$\begin{array}{l}\text { Wave } \\
\text { ID }\end{array}$} & \multirow[b]{2}{*}{ Days/yr } & \multicolumn{5}{|c|}{ Inbound Ship speed (kt) } & \multicolumn{5}{|c|}{ Outbound Ship speed (kt) } \\
\hline & & & 8 & 10 & 12 & 14 & 16 & 8 & 10 & 12 & 14 & 16 \\
\hline 1 & 401 & 6.10 & 0.03 & 0.05 & 0.04 & 0.06 & 0.09 & 0.01 & 0.01 & 0.01 & 0.01 & 0.02 \\
\hline 2 & 402 & 2.74 & 0.04 & 0.08 & 0.06 & 0.10 & 0.15 & 0.01 & 0.02 & 0.02 & 0.02 & 0.04 \\
\hline 3 & 403 & 0.26 & 0.06 & 0.12 & 0.09 & 0.14 & 0.21 & 0.01 & 0.02 & 0.02 & 0.03 & 0.06 \\
\hline 4 & 404 & 0.04 & 0.08 & 0.15 & 0.11 & 0.18 & 0.27 & 0.02 & 0.03 & 0.03 & 0.04 & 0.07 \\
\hline 5 & 405 & 0.00 & 0.10 & 0.19 & 0.14 & 0.22 & 0.34 & 0.02 & 0.04 & 0.04 & 0.05 & 0.09 \\
\hline 6 & 406 & 0.00 & 0.23 & 0.32 & 0.30 & 0.29 & 0.60 & 0.08 & 0.10 & 0.11 & 0.10 & 0.15 \\
\hline 7 & 407 & 0.07 & 0.37 & 0.54 & 0.49 & 0.48 & 0.99 & 0.14 & 0.16 & 0.17 & 0.17 & 0.26 \\
\hline 8 & 408 & 0.07 & 0.53 & 0.76 & 0.69 & 0.68 & 1.40 & 0.20 & 0.23 & 0.25 & 0.24 & 0.36 \\
\hline 9 & 409 & 0.00 & 0.67 & 0.96 & 0.88 & 0.86 & 1.77 & 0.25 & 0.29 & 0.31 & 0.31 & 0.46 \\
\hline 10 & 410 & 0.00 & 0.84 & 1.20 & 1.10 & 1.08 & 2.23 & 0.31 & 0.37 & 0.39 & 0.39 & 0.57 \\
\hline 11 & 411 & 0.04 & 0.38 & 0.46 & 0.43 & 0.40 & 0.61 & 0.21 & 0.22 & 0.23 & 0.23 & 0.23 \\
\hline 12 & 412 & 0.00 & 0.63 & 0.76 & 0.72 & 0.66 & 1.01 & 0.35 & 0.36 & 0.37 & 0.38 & 0.37 \\
\hline 13 & 413 & 0.04 & 0.90 & 1.08 & 1.02 & 0.93 & 1.43 & 0.50 & 0.51 & 0.53 & 0.53 & 0.53 \\
\hline 14 & 414 & 0.04 & 1.14 & 1.37 & 1.29 & 1.18 & 1.81 & 0.63 & 0.65 & 0.67 & 0.67 & 0.67 \\
\hline 15 & 415 & 0.00 & 0.76 & 0.77 & 0.75 & 0.71 & 0.81 & 0.54 & 0.53 & 0.54 & 0.53 & 0.52 \\
\hline 16 & 416 & 0.00 & 1.26 & 1.28 & 1.24 & 1.18 & 1.35 & 0.90 & 0.87 & 0.89 & 0.88 & 0.87 \\
\hline 17 & 417 & 0.00 & 1.79 & 1.81 & 1.75 & 1.68 & 1.91 & 1.27 & 1.24 & 1.26 & 1.24 & 1.23 \\
\hline 18 & 418 & 0.00 & 2.26 & 2.29 & 2.22 & 2.12 & 2.42 & 1.61 & 1.56 & 1.59 & 1.57 & 1.55 \\
\hline 19 & 419 & 0.00 & 2.84 & 2.87 & 2.78 & 2.66 & 3.04 & 2.02 & 1.96 & 2.00 & 1.97 & 1.95 \\
\hline 20 & 420 & 0.00 & 3.18 & 3.22 & 3.12 & 2.99 & 3.40 & 2.27 & 2.20 & 2.24 & 2.21 & 2.19 \\
\hline 21 & 421 & 0.04 & 1.68 & 1.58 & 1.55 & 1.47 & 1.85 & 1.23 & 1.12 & 1.08 & 1.04 & 0.99 \\
\hline 22 & 422 & 0.00 & 2.79 & 2.61 & 2.57 & 2.43 & 3.06 & 2.03 & 1.85 & 1.79 & 1.72 & 1.64 \\
\hline 23 & 423 & 0.00 & 3.95 & 3.70 & 3.64 & 3.44 & 4.34 & 2.88 & 2.62 & 2.54 & 2.44 & 2.33 \\
\hline 24 & 424 & 0.00 & 5.00 & 4.68 & 4.60 & 4.35 & 5.49 & 3.64 & 3.31 & 3.22 & 3.08 & 2.94 \\
\hline 25 & 425 & 0.00 & 7.03 & 6.59 & 6.48 & 6.12 & 7.72 & 5.12 & 4.66 & 4.52 & 4.33 & 4.14 \\
\hline 26 & 426 & 0.00 & 8.95 & 8.39 & 8.24 & 7.79 & 9.82 & 6.52 & 5.93 & 5.76 & 5.52 & 5.27 \\
\hline 27 & 427 & 0.00 & 9.42 & 8.82 & 8.67 & 8.20 & 10.34 & 6.86 & 6.24 & 6.06 & 5.80 & 5.54 \\
\hline 28 & 428 & 11.24 & 0.05 & 0.10 & 0.08 & 0.11 & 0.18 & 0.01 & 0.01 & 0.01 & 0.01 & 0.02 \\
\hline 29 & 429 & 3.80 & 0.09 & 0.16 & 0.13 & 0.19 & 0.30 & 0.01 & 0.02 & 0.02 & 0.02 & 0.04 \\
\hline 30 & 430 & 0.66 & 0.13 & 0.23 & 0.18 & 0.26 & 0.42 & 0.02 & 0.02 & 0.03 & 0.03 & 0.06 \\
\hline 31 & 431 & 0.04 & 0.16 & 0.30 & 0.23 & 0.34 & 0.54 & 0.02 & 0.03 & 0.03 & 0.04 & 0.07 \\
\hline
\end{tabular}




\begin{tabular}{|c|c|c|c|c|c|c|c|c|c|c|c|c|}
\hline \multirow{2}{*}{$\begin{array}{l}\text { Wave } \\
\text { No. }\end{array}$} & \multirow{2}{*}{$\begin{array}{l}\text { Wave } \\
\text { ID }\end{array}$} & \multirow[b]{2}{*}{ Days/yr } & \multicolumn{5}{|c|}{ Inbound Ship speed (kt) } & \multicolumn{5}{|c|}{ Outbound Ship speed (kt) } \\
\hline & & & 8 & 10 & 12 & 14 & 16 & 8 & 10 & 12 & 14 & 16 \\
\hline 32 & 432 & 1.13 & 0.25 & 0.36 & 0.32 & 0.31 & 0.66 & 0.07 & 0.08 & 0.08 & 0.08 & 0.09 \\
\hline 33 & 433 & 0.18 & 0.41 & 0.59 & 0.54 & 0.52 & 1.09 & 0.12 & 0.13 & 0.13 & 0.14 & 0.14 \\
\hline 34 & 434 & 0.66 & 0.59 & 0.83 & 0.76 & 0.73 & 1.54 & 0.17 & 0.18 & 0.19 & 0.19 & 0.20 \\
\hline 35 & 435 & 0.15 & 0.76 & 1.08 & 0.98 & 0.95 & 1.99 & 0.22 & 0.23 & 0.25 & 0.25 & 0.26 \\
\hline 36 & 436 & 0.00 & 0.93 & 1.32 & 1.21 & 1.16 & 2.45 & 0.27 & 0.28 & 0.30 & 0.31 & 0.33 \\
\hline 37 & 437 & 1.20 & 0.43 & 0.51 & 0.47 & 0.43 & 0.66 & 0.21 & 0.20 & 0.21 & 0.21 & 0.21 \\
\hline 38 & 438 & 0.22 & 0.71 & 0.84 & 0.78 & 0.71 & 1.09 & 0.34 & 0.34 & 0.34 & 0.35 & 0.35 \\
\hline 39 & 439 & 0.07 & 1.01 & 1.19 & 1.10 & 1.01 & 1.55 & 0.48 & 0.48 & 0.49 & 0.49 & 0.49 \\
\hline 40 & 440 & 0.22 & 1.30 & 1.54 & 1.43 & 1.31 & 2.01 & 0.62 & 0.62 & 0.63 & 0.63 & 0.64 \\
\hline 41 & 441 & 0.15 & 1.60 & 1.88 & 1.75 & 1.60 & 2.46 & 0.77 & 0.76 & 0.77 & 0.78 & 0.78 \\
\hline 42 & 442 & 0.04 & 1.91 & 2.25 & 2.09 & 1.91 & 2.94 & 0.92 & 0.91 & 0.92 & 0.93 & 0.94 \\
\hline 43 & 443 & 0.88 & 0.79 & 0.80 & 0.76 & 0.72 & 0.87 & 0.50 & 0.48 & 0.48 & 0.47 & 0.47 \\
\hline 44 & 444 & 0.11 & 1.31 & 1.32 & 1.26 & 1.20 & 1.44 & 0.83 & 0.79 & 0.80 & 0.78 & 0.77 \\
\hline 45 & 445 & 0.04 & 1.85 & 1.87 & 1.79 & 1.70 & 2.03 & 1.17 & 1.12 & 1.13 & 1.11 & 1.09 \\
\hline 46 & 446 & 0.07 & 2.40 & 2.42 & 2.31 & 2.20 & 2.63 & 1.52 & 1.45 & 1.46 & 1.44 & 1.41 \\
\hline 47 & 447 & 0.04 & 2.94 & 2.96 & 2.84 & 2.70 & 3.23 & 1.87 & 1.78 & 1.79 & 1.76 & 1.73 \\
\hline 48 & 448 & 0.04 & 3.52 & 3.54 & 3.39 & 3.22 & 3.86 & 2.23 & 2.12 & 2.14 & 2.11 & 2.07 \\
\hline 49 & 449 & 0.04 & 4.06 & 4.09 & 3.91 & 3.72 & 4.46 & 2.58 & 2.45 & 2.47 & 2.43 & 2.39 \\
\hline 50 & 450 & 0.00 & 4.83 & 4.86 & 4.65 & 4.42 & 5.30 & 3.06 & 2.92 & 2.94 & 2.89 & 2.84 \\
\hline 51 & 451 & 0.18 & 1.30 & 1.21 & 1.15 & 1.07 & 1.79 & 0.82 & 0.73 & 0.69 & 0.65 & 0.61 \\
\hline 52 & 452 & 0.15 & 2.16 & 2.01 & 1.91 & 1.77 & 2.96 & 1.36 & 1.21 & 1.14 & 1.07 & 1.01 \\
\hline 53 & 453 & 0.11 & 3.06 & 2.85 & 2.70 & 2.50 & 4.19 & 1.93 & 1.72 & 1.61 & 1.52 & 1.43 \\
\hline 54 & 454 & 0.07 & 3.96 & 3.69 & 3.49 & 3.24 & 5.43 & 2.50 & 2.23 & 2.09 & 1.97 & 1.85 \\
\hline 55 & 455 & 0.04 & 4.86 & 4.52 & 4.29 & 3.98 & 6.66 & 3.07 & 2.73 & 2.56 & 2.42 & 2.27 \\
\hline 56 & 456 & 0.04 & 5.81 & 5.40 & 5.12 & 4.75 & 7.96 & 3.67 & 3.26 & 3.06 & 2.89 & 2.71 \\
\hline 57 & 457 & 0.00 & 6.71 & 6.24 & 5.92 & 5.49 & 9.19 & 4.23 & 3.77 & 3.53 & 3.34 & 3.13 \\
\hline 58 & 458 & 0.00 & 7.97 & 7.41 & 7.03 & 6.52 & 10.92 & 5.03 & 4.48 & 4.20 & 3.96 & 3.72 \\
\hline 59 & 459 & 0.00 & 9.37 & 8.71 & 8.26 & 7.66 & 12.83 & 5.91 & 5.26 & 4.93 & 4.66 & 4.37 \\
\hline 60 & 460 & 0.00 & 1.51 & 1.40 & 1.31 & 1.92 & 3.22 & 1.25 & 1.16 & 1.06 & 1.01 & 0.91 \\
\hline 61 & 461 & 0.00 & 2.51 & 2.33 & 2.16 & 3.18 & 5.34 & 2.06 & 1.92 & 1.76 & 1.67 & 1.51 \\
\hline 62 & 462 & 0.00 & 7.79 & 7.22 & 6.71 & 9.89 & 16.58 & 6.41 & 5.95 & 5.48 & 5.19 & 4.69 \\
\hline 63 & 463 & 0.00 & 9.25 & 8.58 & 7.97 & 11.75 & 19.70 & 7.62 & 7.07 & 6.51 & 6.17 & 5.57 \\
\hline 64 & 464 & 0.00 & 1.91 & 1.82 & 1.89 & 3.90 & 6.28 & 2.17 & 2.05 & 1.87 & 1.77 & 1.58 \\
\hline
\end{tabular}




\begin{tabular}{|c|c|c|c|c|c|c|c|c|c|c|c|c|}
\hline \multirow{2}{*}{$\begin{array}{l}\text { Wave } \\
\text { No. }\end{array}$} & \multirow{2}{*}{$\begin{array}{l}\text { Wave } \\
\text { ID }\end{array}$} & \multirow[b]{2}{*}{ Days/yr } & \multicolumn{5}{|c|}{ Inbound Ship speed (kt) } & \multicolumn{5}{|c|}{ Outbound Ship speed (kt) } \\
\hline & & & 8 & 10 & 12 & 14 & 16 & 8 & 10 & 12 & 14 & 16 \\
\hline 65 & 465 & 12.41 & 0.06 & 0.11 & 0.08 & 0.12 & 0.20 & 0.01 & 0.01 & 0.01 & 0.01 & 0.02 \\
\hline 66 & 466 & 3.14 & 0.10 & 0.19 & 0.15 & 0.21 & 0.34 & 0.01 & 0.02 & 0.02 & 0.02 & 0.04 \\
\hline 67 & 467 & 0.37 & 0.15 & 0.26 & 0.21 & 0.30 & 0.48 & 0.02 & 0.02 & 0.03 & 0.03 & 0.05 \\
\hline 68 & 468 & 0.00 & 0.23 & 0.42 & 0.32 & 0.47 & 0.75 & 0.03 & 0.04 & 0.04 & 0.04 & 0.08 \\
\hline 69 & 469 & 1.39 & 0.24 & 0.35 & 0.31 & 0.30 & 0.64 & 0.07 & 0.07 & 0.07 & 0.08 & 0.08 \\
\hline 70 & 470 & 0.37 & 0.42 & 0.59 & 0.54 & 0.52 & 1.10 & 0.12 & 0.12 & 0.13 & 0.13 & 0.13 \\
\hline 71 & 471 & 0.66 & 0.59 & 0.84 & 0.77 & 0.73 & 1.56 & 0.16 & 0.17 & 0.18 & 0.18 & 0.18 \\
\hline 72 & 472 & 0.07 & 0.76 & 1.08 & 0.98 & 0.94 & 1.99 & 0.21 & 0.22 & 0.23 & 0.23 & 0.23 \\
\hline 73 & 473 & 1.46 & 0.42 & 0.49 & 0.46 & 0.42 & 0.64 & 0.19 & 0.19 & 0.19 & 0.19 & 0.20 \\
\hline 74 & 474 & 0.26 & 0.71 & 0.84 & 0.78 & 0.71 & 1.10 & 0.33 & 0.33 & 0.33 & 0.33 & 0.34 \\
\hline 75 & 475 & 0.15 & 1.01 & 1.19 & 1.11 & 1.01 & 1.56 & 0.47 & 0.46 & 0.47 & 0.47 & 0.47 \\
\hline 76 & 476 & 0.18 & 1.29 & 1.53 & 1.42 & 1.29 & 2.00 & 0.60 & 0.59 & 0.60 & 0.60 & 0.61 \\
\hline 77 & 477 & 0.07 & 1.59 & 1.88 & 1.74 & 1.59 & 2.46 & 0.74 & 0.73 & 0.74 & 0.74 & 0.75 \\
\hline 78 & 478 & 0.00 & 1.89 & 2.23 & 2.07 & 1.89 & 2.91 & 0.88 & 0.86 & 0.88 & 0.88 & 0.89 \\
\hline 79 & 479 & 1.24 & 0.76 & 0.77 & 0.73 & 0.69 & 0.84 & 0.47 & 0.45 & 0.45 & 0.44 & 0.43 \\
\hline 80 & 480 & 0.26 & 1.31 & 1.32 & 1.26 & 1.19 & 1.44 & 0.81 & 0.77 & 0.77 & 0.76 & 0.75 \\
\hline 81 & 481 & 0.18 & 1.85 & 1.86 & 1.78 & 1.69 & 2.04 & 1.15 & 1.09 & 1.09 & 1.08 & 1.06 \\
\hline 82 & 482 & 0.04 & 2.37 & 2.39 & 2.28 & 2.16 & 2.61 & 1.47 & 1.39 & 1.40 & 1.38 & 1.35 \\
\hline 83 & 483 & 0.04 & 2.91 & 2.93 & 2.80 & 2.66 & 3.21 & 1.80 & 1.71 & 1.72 & 1.69 & 1.66 \\
\hline 84 & 484 & 0.04 & 3.46 & 3.48 & 3.32 & 3.16 & 3.81 & 2.14 & 2.03 & 2.05 & 2.01 & 1.97 \\
\hline 85 & 485 & 0.00 & 3.98 & 4.00 & 3.82 & 3.63 & 4.38 & 2.46 & 2.34 & 2.35 & 2.31 & 2.27 \\
\hline 86 & 486 & 0.91 & 1.36 & 1.25 & 1.18 & 1.10 & 1.95 & 0.85 & 0.75 & 0.70 & 0.66 & 0.61 \\
\hline 87 & 487 & 0.51 & 2.33 & 2.14 & 2.02 & 1.90 & 3.35 & 1.46 & 1.29 & 1.20 & 1.13 & 1.05 \\
\hline 88 & 488 & 0.15 & 3.30 & 3.03 & 2.87 & 2.69 & 4.74 & 2.07 & 1.83 & 1.70 & 1.59 & 1.48 \\
\hline 89 & 489 & 0.07 & 4.22 & 3.88 & 3.67 & 3.44 & 6.07 & 2.65 & 2.35 & 2.18 & 2.04 & 1.90 \\
\hline 90 & 490 & 0.00 & 5.19 & 4.77 & 4.51 & 4.23 & 7.47 & 3.27 & 2.89 & 2.68 & 2.51 & 2.33 \\
\hline 91 & 491 & 0.15 & 1.35 & 1.25 & 1.14 & 1.85 & 3.10 & 1.09 & 1.01 & 0.91 & 0.86 & 0.77 \\
\hline 92 & 492 & 0.07 & 2.32 & 2.14 & 1.96 & 3.16 & 5.32 & 1.88 & 1.73 & 1.57 & 1.47 & 1.32 \\
\hline 93 & 493 & 0.04 & 3.29 & 3.03 & 2.77 & 4.48 & 7.55 & 2.66 & 2.44 & 2.22 & 2.09 & 1.86 \\
\hline 94 & 494 & 0.00 & 4.21 & 3.87 & 3.55 & 5.74 & 9.66 & 3.40 & 3.13 & 2.84 & 2.67 & 2.38 \\
\hline 95 & 495 & 0.00 & 1.57 & 1.48 & 1.75 & 3.79 & 5.96 & 1.80 & 1.67 & 1.51 & 1.42 & 1.25 \\
\hline 96 & 496 & 0.00 & 2.68 & 2.53 & 3.01 & 6.51 & 10.21 & 3.08 & 2.87 & 2.59 & 2.43 & 2.14 \\
\hline 97 & 497 & 11.86 & 0.06 & 0.10 & 0.08 & 0.12 & 0.19 & 0.01 & 0.02 & 0.02 & 0.02 & 0.04 \\
\hline
\end{tabular}




\begin{tabular}{|c|c|c|c|c|c|c|c|c|c|c|c|c|}
\hline \multirow{2}{*}{$\begin{array}{l}\text { Wave } \\
\text { No. }\end{array}$} & \multirow{2}{*}{$\begin{array}{l}\text { Wave } \\
\text { ID }\end{array}$} & \multirow[b]{2}{*}{ Days/yr } & \multicolumn{5}{|c|}{ Inbound Ship speed (kt) } & \multicolumn{5}{|c|}{ Outbound Ship speed (kt) } \\
\hline & & & 8 & 10 & 12 & 14 & 16 & 8 & 10 & 12 & 14 & 16 \\
\hline 98 & 498 & 3.07 & 0.10 & 0.18 & 0.14 & 0.20 & 0.32 & 0.02 & 0.03 & 0.03 & 0.04 & 0.07 \\
\hline 99 & 499 & 0.58 & 0.14 & 0.25 & 0.20 & 0.28 & 0.46 & 0.03 & 0.04 & 0.04 & 0.05 & 0.10 \\
\hline 100 & 500 & 0.04 & 0.18 & 0.32 & 0.25 & 0.36 & 0.58 & 0.04 & 0.05 & 0.06 & 0.07 & 0.13 \\
\hline 101 & 501 & 1.10 & 0.23 & 0.33 & 0.30 & 0.29 & 0.61 & 0.08 & 0.09 & 0.10 & 0.10 & 0.13 \\
\hline 102 & 502 & 0.29 & 0.40 & 0.56 & 0.52 & 0.50 & 1.04 & 0.14 & 0.15 & 0.16 & 0.17 & 0.22 \\
\hline 103 & 503 & 0.47 & 0.57 & 0.80 & 0.73 & 0.71 & 1.48 & 0.19 & 0.22 & 0.23 & 0.23 & 0.31 \\
\hline 104 & 504 & 0.07 & 0.73 & 1.02 & 0.94 & 0.91 & 1.89 & 0.25 & 0.28 & 0.30 & 0.30 & 0.39 \\
\hline 105 & 505 & 0.00 & 0.88 & 1.25 & 1.14 & 1.11 & 2.31 & 0.30 & 0.34 & 0.36 & 0.37 & 0.48 \\
\hline 106 & 506 & 0.88 & 0.41 & 0.48 & 0.45 & 0.41 & 0.62 & 0.22 & 0.22 & 0.23 & 0.23 & 0.23 \\
\hline 107 & 507 & 0.15 & 0.70 & 0.82 & 0.77 & 0.70 & 1.06 & 0.37 & 0.38 & 0.39 & 0.39 & 0.39 \\
\hline 108 & 508 & 0.11 & 0.99 & 1.16 & 1.09 & 0.99 & 1.50 & 0.53 & 0.53 & 0.55 & 0.55 & 0.56 \\
\hline 109 & 509 & 0.15 & 1.27 & 1.48 & 1.39 & 1.26 & 1.92 & 0.68 & 0.68 & 0.70 & 0.71 & 0.71 \\
\hline 110 & 510 & 0.07 & 1.54 & 1.81 & 1.69 & 1.54 & 2.34 & 0.82 & 0.83 & 0.86 & 0.86 & 0.87 \\
\hline 111 & 511 & 0.00 & 1.89 & 2.22 & 2.08 & 1.89 & 2.87 & 1.01 & 1.02 & 1.05 & 1.06 & 1.06 \\
\hline 112 & 512 & 0.62 & 0.77 & 0.77 & 0.74 & 0.71 & 0.82 & 0.52 & 0.51 & 0.51 & 0.51 & 0.50 \\
\hline 113 & 513 & 0.26 & 1.31 & 1.32 & 1.28 & 1.22 & 1.41 & 0.90 & 0.87 & 0.88 & 0.87 & 0.86 \\
\hline 114 & 514 & 0.15 & 1.86 & 1.87 & 1.81 & 1.73 & 1.99 & 1.28 & 1.23 & 1.25 & 1.23 & 1.21 \\
\hline 115 & 515 & 0.11 & 2.38 & 2.40 & 2.31 & 2.21 & 2.55 & 1.63 & 1.57 & 1.59 & 1.57 & 1.55 \\
\hline 116 & 516 & 0.00 & 2.90 & 2.92 & 2.82 & 2.70 & 3.11 & 1.99 & 1.91 & 1.94 & 1.92 & 1.89 \\
\hline 117 & 517 & 0.00 & 3.56 & 3.58 & 3.46 & 3.31 & 3.81 & 2.44 & 2.35 & 2.38 & 2.35 & 2.32 \\
\hline 118 & 518 & 0.73 & 1.53 & 1.43 & 1.39 & 1.31 & 1.83 & 1.06 & 0.96 & 0.92 & 0.88 & 0.84 \\
\hline 119 & 519 & 0.22 & 2.62 & 2.45 & 2.38 & 2.24 & 3.14 & 1.82 & 1.65 & 1.58 & 1.51 & 1.44 \\
\hline 120 & 520 & 0.11 & 3.71 & 3.47 & 3.38 & 3.17 & 4.45 & 2.59 & 2.34 & 2.25 & 2.14 & 2.04 \\
\hline 121 & 521 & 0.07 & 4.75 & 4.44 & 4.32 & 4.06 & 5.69 & 3.31 & 2.99 & 2.87 & 2.74 & 2.61 \\
\hline 122 & 522 & 0.04 & 5.79 & 5.40 & 5.26 & 4.95 & 6.94 & 4.03 & 3.65 & 3.50 & 3.34 & 3.18 \\
\hline 123 & 523 & 0.00 & 7.10 & 6.63 & 6.46 & 6.07 & 8.51 & 4.94 & 4.47 & 4.29 & 4.10 & 3.90 \\
\hline 124 & 524 & 0.11 & 1.82 & 1.72 & 1.64 & 1.85 & 3.06 & 1.55 & 1.47 & 1.40 & 1.35 & 1.24 \\
\hline 125 & 525 & 0.04 & 3.12 & 2.94 & 2.81 & 3.17 & 5.25 & 2.66 & 2.52 & 2.39 & 2.31 & 2.12 \\
\hline 126 & 526 & 0.04 & 4.42 & 4.17 & 3.98 & 4.49 & 7.43 & 3.76 & 3.57 & 3.39 & 3.27 & 3.00 \\
\hline 127 & 527 & 0.00 & 2.69 & 2.58 & 2.42 & 3.57 & 6.13 & 2.94 & 2.85 & 2.67 & 2.58 & 2.34 \\
\hline 128 & 528 & 0.04 & 4.60 & 4.43 & 4.15 & 6.12 & 10.52 & 5.04 & 4.88 & 4.58 & 4.42 & 4.01 \\
\hline 129 & 529 & 0.04 & 6.53 & 6.28 & 5.88 & 8.67 & 14.90 & 7.15 & 6.91 & 6.49 & 6.26 & 5.68 \\
\hline 130 & 530 & 18.03 & 0.05 & 0.09 & 0.07 & 0.10 & 0.16 & 0.02 & 0.03 & 0.03 & 0.04 & 0.07 \\
\hline
\end{tabular}




\begin{tabular}{|c|c|c|c|c|c|c|c|c|c|c|c|c|}
\hline \multirow{2}{*}{$\begin{array}{l}\text { Wave } \\
\text { No. }\end{array}$} & \multirow{2}{*}{$\begin{array}{l}\text { Wave } \\
\text { ID }\end{array}$} & \multirow[b]{2}{*}{ Days/yr } & \multicolumn{5}{|c|}{ Inbound Ship speed (kt) } & \multicolumn{5}{|c|}{ Outbound Ship speed (kt) } \\
\hline & & & 8 & 10 & 12 & 14 & 16 & 8 & 10 & 12 & 14 & 16 \\
\hline 131 & 531 & 3.80 & 0.08 & 0.15 & 0.12 & 0.17 & 0.28 & 0.03 & 0.05 & 0.05 & 0.06 & 0.11 \\
\hline 132 & 532 & 0.37 & 0.12 & 0.22 & 0.17 & 0.25 & 0.41 & 0.04 & 0.07 & 0.07 & 0.09 & 0.16 \\
\hline 133 & 533 & 0.00 & 0.19 & 0.35 & 0.28 & 0.40 & 0.65 & 0.07 & 0.11 & 0.11 & 0.15 & 0.26 \\
\hline 134 & 534 & 2.23 & 0.20 & 0.28 & 0.26 & 0.25 & 0.51 & 0.09 & 0.12 & 0.12 & 0.12 & 0.20 \\
\hline 135 & 535 & 0.58 & 0.34 & 0.48 & 0.45 & 0.44 & 0.89 & 0.16 & 0.20 & 0.21 & 0.20 & 0.35 \\
\hline 136 & 536 & 0.58 & 0.49 & 0.70 & 0.65 & 0.64 & 1.29 & 0.23 & 0.29 & 0.31 & 0.30 & 0.50 \\
\hline 137 & 537 & 0.07 & 0.64 & 0.90 & 0.84 & 0.82 & 1.67 & 0.30 & 0.38 & 0.40 & 0.38 & 0.65 \\
\hline 138 & 538 & 1.06 & 0.36 & 0.42 & 0.40 & 0.36 & 0.54 & 0.24 & 0.25 & 0.26 & 0.26 & 0.25 \\
\hline 139 & 539 & 0.29 & 0.62 & 0.73 & 0.70 & 0.63 & 0.93 & 0.41 & 0.43 & 0.45 & 0.45 & 0.44 \\
\hline 140 & 540 & 0.11 & 0.90 & 1.06 & 1.01 & 0.92 & 1.35 & 0.59 & 0.63 & 0.65 & 0.65 & 0.64 \\
\hline 141 & 541 & 0.26 & 1.17 & 1.37 & 1.30 & 1.19 & 1.75 & 0.77 & 0.81 & 0.84 & 0.84 & 0.83 \\
\hline 142 & 542 & 0.11 & 1.43 & 1.68 & 1.60 & 1.46 & 2.14 & 0.94 & 1.00 & 1.03 & 1.03 & 1.02 \\
\hline 143 & 543 & 0.00 & 1.72 & 2.02 & 1.93 & 1.76 & 2.58 & 1.13 & 1.20 & 1.24 & 1.23 & 1.22 \\
\hline 144 & 544 & 0.69 & 0.74 & 0.74 & 0.73 & 0.71 & 0.74 & 0.59 & 0.57 & 0.59 & 0.58 & 0.57 \\
\hline 145 & 545 & 0.29 & 1.29 & 1.29 & 1.27 & 1.23 & 1.28 & 1.02 & 1.00 & 1.02 & 1.01 & 1.00 \\
\hline 146 & 546 & 0.18 & 1.87 & 1.87 & 1.84 & 1.78 & 1.86 & 1.48 & 1.45 & 1.48 & 1.46 & 1.44 \\
\hline 147 & 547 & 0.04 & 2.42 & 2.42 & 2.38 & 2.30 & 2.40 & 1.91 & 1.87 & 1.91 & 1.89 & 1.87 \\
\hline 148 & 548 & 0.07 & 2.97 & 2.97 & 2.92 & 2.83 & 2.95 & 2.35 & 2.30 & 2.34 & 2.32 & 2.29 \\
\hline 149 & 549 & 0.04 & 3.57 & 3.58 & 3.52 & 3.40 & 3.55 & 2.83 & 2.77 & 2.82 & 2.79 & 2.76 \\
\hline 150 & 550 & 0.00 & 4.04 & 4.04 & 3.98 & 3.85 & 4.02 & 3.20 & 3.13 & 3.19 & 3.15 & 3.12 \\
\hline 151 & 551 & 0.62 & 1.67 & 1.57 & 1.57 & 1.50 & 1.52 & 1.33 & 1.22 & 1.21 & 1.16 & 1.12 \\
\hline 152 & 552 & 0.22 & 2.91 & 2.74 & 2.73 & 2.60 & 2.66 & 2.31 & 2.13 & 2.10 & 2.02 & 1.95 \\
\hline 153 & 553 & 0.11 & 4.21 & 3.97 & 3.95 & 3.77 & 3.84 & 3.35 & 3.08 & 3.04 & 2.93 & 2.82 \\
\hline 154 & 554 & 0.00 & 5.45 & 5.14 & 5.12 & 4.88 & 4.97 & 4.33 & 3.99 & 3.94 & 3.79 & 3.64 \\
\hline 155 & 555 & 0.00 & 8.05 & 7.59 & 7.56 & 7.21 & 7.35 & 6.40 & 5.90 & 5.82 & 5.60 & 5.38 \\
\hline 156 & 556 & 0.15 & 2.33 & 2.22 & 2.18 & 2.10 & 2.58 & 2.17 & 2.08 & 2.02 & 1.98 & 1.87 \\
\hline 157 & 557 & 0.11 & 4.07 & 3.87 & 3.79 & 3.66 & 4.49 & 3.77 & 3.63 & 3.52 & 3.46 & 3.25 \\
\hline 158 & 558 & 0.04 & 3.87 & 3.73 & 3.55 & 3.47 & 4.97 & 4.46 & 4.37 & 4.25 & 4.16 & 3.84 \\
\hline 159 & 559 & 0.00 & 6.74 & 6.49 & 6.19 & 6.04 & 8.65 & 7.77 & 7.61 & 7.40 & 7.24 & 6.69 \\
\hline 160 & 560 & 27.08 & 0.05 & 0.08 & 0.07 & 0.10 & 0.16 & 0.03 & 0.05 & 0.05 & 0.06 & 0.11 \\
\hline 161 & 561 & 6.72 & 0.08 & 0.14 & 0.12 & 0.16 & 0.27 & 0.05 & 0.09 & 0.08 & 0.11 & 0.19 \\
\hline 162 & 562 & 0.40 & 0.11 & 0.20 & 0.16 & 0.23 & 0.38 & 0.07 & 0.13 & 0.11 & 0.15 & 0.27 \\
\hline 163 & 563 & 0.00 & 0.14 & 0.25 & 0.21 & 0.30 & 0.50 & 0.10 & 0.17 & 0.15 & 0.20 & 0.35 \\
\hline
\end{tabular}




\begin{tabular}{|c|c|c|c|c|c|c|c|c|c|c|c|c|}
\hline \multirow{2}{*}{$\begin{array}{l}\text { Wave } \\
\text { No. }\end{array}$} & \multirow{2}{*}{$\begin{array}{l}\text { Wave } \\
\text { ID }\end{array}$} & \multirow[b]{2}{*}{ Days/yr } & \multicolumn{5}{|c|}{ Inbound Ship speed (kt) } & \multicolumn{5}{|c|}{ Outbound Ship speed (kt) } \\
\hline & & & 8 & 10 & 12 & 14 & 16 & 8 & 10 & 12 & 14 & 16 \\
\hline 164 & 564 & 4.60 & 0.17 & 0.24 & 0.23 & 0.23 & 0.44 & 0.13 & 0.17 & 0.17 & 0.17 & 0.30 \\
\hline 165 & 565 & 0.91 & 0.30 & 0.41 & 0.39 & 0.39 & 0.76 & 0.22 & 0.29 & 0.29 & 0.29 & 0.52 \\
\hline 166 & 566 & 1.24 & 0.41 & 0.58 & 0.55 & 0.54 & 1.06 & 0.30 & 0.41 & 0.41 & 0.40 & 0.73 \\
\hline 167 & 567 & 0.11 & 0.54 & 0.75 & 0.71 & 0.70 & 1.37 & 0.40 & 0.53 & 0.53 & 0.52 & 0.95 \\
\hline 168 & 568 & 1.46 & 0.34 & 0.39 & 0.38 & 0.36 & 0.48 & 0.29 & 0.32 & 0.32 & 0.31 & 0.35 \\
\hline 169 & 569 & 0.33 & 0.58 & 0.67 & 0.66 & 0.62 & 0.82 & 0.49 & 0.54 & 0.55 & 0.54 & 0.60 \\
\hline 170 & 570 & 0.22 & 0.82 & 0.93 & 0.92 & 0.86 & 1.14 & 0.69 & 0.76 & 0.77 & 0.75 & 0.83 \\
\hline 171 & 571 & 0.40 & 1.06 & 1.21 & 1.19 & 1.12 & 1.48 & 0.90 & 0.98 & 1.00 & 0.97 & 1.08 \\
\hline 172 & 572 & 0.07 & 1.30 & 1.49 & 1.46 & 1.37 & 1.82 & 1.10 & 1.21 & 1.23 & 1.20 & 1.33 \\
\hline 173 & 573 & 0.00 & 1.56 & 1.78 & 1.75 & 1.64 & 2.18 & 1.32 & 1.45 & 1.47 & 1.43 & 1.60 \\
\hline 174 & 574 & 0.69 & 0.75 & 0.75 & 0.75 & 0.73 & 0.73 & 0.69 & 0.68 & 0.69 & 0.68 & 0.68 \\
\hline 175 & 575 & 0.33 & 1.29 & 1.29 & 1.29 & 1.26 & 1.25 & 1.18 & 1.16 & 1.19 & 1.17 & 1.16 \\
\hline 176 & 576 & 0.07 & 1.80 & 1.80 & 1.80 & 1.76 & 1.74 & 1.65 & 1.63 & 1.65 & 1.63 & 1.62 \\
\hline 177 & 577 & 0.04 & 2.34 & 2.33 & 2.34 & 2.28 & 2.26 & 2.14 & 2.11 & 2.15 & 2.12 & 2.10 \\
\hline 178 & 578 & 0.04 & 2.88 & 2.87 & 2.87 & 2.81 & 2.78 & 2.63 & 2.60 & 2.64 & 2.61 & 2.58 \\
\hline 179 & 579 & 0.04 & 3.44 & 3.43 & 3.44 & 3.36 & 3.32 & 3.15 & 3.11 & 3.16 & 3.12 & 3.09 \\
\hline 180 & 580 & 0.22 & 1.61 & 1.53 & 1.54 & 1.48 & 1.44 & 1.47 & 1.38 & 1.38 & 1.33 & 1.29 \\
\hline 181 & 581 & 0.18 & 2.77 & 2.62 & 2.64 & 2.55 & 2.46 & 2.51 & 2.36 & 2.37 & 2.29 & 2.22 \\
\hline 182 & 582 & 0.04 & 3.87 & 3.66 & 3.69 & 3.56 & 3.44 & 3.51 & 3.29 & 3.31 & 3.19 & 3.09 \\
\hline 183 & 583 & 0.00 & 5.02 & 4.76 & 4.80 & 4.62 & 4.46 & 4.56 & 4.28 & 4.30 & 4.15 & 4.02 \\
\hline 184 & 584 & 0.00 & 6.18 & 5.85 & 5.90 & 5.68 & 5.49 & 5.61 & 5.26 & 5.28 & 5.10 & 4.94 \\
\hline 185 & 585 & 0.00 & 7.39 & 7.00 & 7.06 & 6.80 & 6.57 & 6.71 & 6.29 & 6.32 & 6.10 & 5.91 \\
\hline 186 & 586 & 0.00 & 8.60 & 8.15 & 8.21 & 7.91 & 7.65 & 7.81 & 7.33 & 7.36 & 7.11 & 6.88 \\
\hline 187 & 587 & 10.22 & 0.01 & 0.03 & 0.02 & 0.03 & 0.06 & 0.02 & 0.03 & 0.03 & 0.04 & 0.07 \\
\hline 188 & 588 & 2.81 & 0.02 & 0.04 & 0.04 & 0.05 & 0.09 & 0.03 & 0.05 & 0.04 & 0.07 & 0.11 \\
\hline 189 & 589 & 0.22 & 0.03 & 0.06 & 0.05 & 0.08 & 0.13 & 0.04 & 0.08 & 0.06 & 0.10 & 0.15 \\
\hline 190 & 590 & 0.00 & 0.04 & 0.08 & 0.07 & 0.10 & 0.17 & 0.05 & 0.10 & 0.08 & 0.13 & 0.20 \\
\hline 191 & 591 & 0.00 & 0.05 & 0.10 & 0.08 & 0.12 & 0.20 & 0.07 & 0.12 & 0.10 & 0.15 & 0.24 \\
\hline 192 & 592 & 0.18 & 0.14 & 0.19 & 0.19 & 0.19 & 0.35 & 0.17 & 0.23 & 0.22 & 0.22 & 0.42 \\
\hline 193 & 593 & 0.18 & 0.23 & 0.31 & 0.31 & 0.31 & 0.57 & 0.27 & 0.37 & 0.36 & 0.35 & 0.69 \\
\hline 194 & 594 & 0.29 & 0.33 & 0.45 & 0.45 & 0.44 & 0.81 & 0.39 & 0.53 & 0.52 & 0.51 & 0.98 \\
\hline 195 & 595 & 0.00 & 0.44 & 0.59 & 0.59 & 0.57 & 1.07 & 0.51 & 0.70 & 0.68 & 0.66 & 1.28 \\
\hline 196 & 596 & 0.04 & 0.31 & 0.35 & 0.35 & 0.34 & 0.39 & 0.34 & 0.39 & 0.38 & 0.36 & 0.46 \\
\hline
\end{tabular}




\begin{tabular}{|l|l|l|l|l|l|l|l|l|l|l|l|l|}
\hline \multirow{2}{*}{$\begin{array}{l}\text { Wave } \\
\text { No. }\end{array}$} & Wave & & \multicolumn{4}{|c|}{ ID } \\
ID & Days/yr & 8 & 10 & 12 & 14 & 16 & 8 & 10 & 12 & 14 & 16 \\
\hline 197 & 597 & 0.04 & 0.51 & 0.56 & 0.57 & 0.55 & 0.64 & 0.55 & 0.63 & 0.62 & 0.59 & 0.75 \\
\hline 198 & 598 & 0.04 & 0.72 & 0.80 & 0.81 & 0.78 & 0.91 & 0.79 & 0.89 & 0.88 & 0.84 & 1.07 \\
\hline 199 & 599 & 0.07 & 0.95 & 1.06 & 1.06 & 1.03 & 1.20 & 1.03 & 1.17 & 1.16 & 1.10 & 1.40 \\
\hline 200 & 600 & 0.00 & 1.13 & 1.26 & 1.27 & 1.23 & 1.43 & 1.23 & 1.40 & 1.38 & 1.31 & 1.67 \\
\hline 201 & 601 & 0.00 & 0.73 & 0.73 & 0.74 & 0.73 & 0.72 & 0.77 & 0.76 & 0.77 & 0.75 & 0.75 \\
\hline 202 & 602 & 0.04 & 1.19 & 1.18 & 1.20 & 1.18 & 1.17 & 1.24 & 1.24 & 1.25 & 1.22 & 1.21 \\
\hline 203 & 603 & 0.00 & 1.70 & 1.68 & 1.71 & 1.68 & 1.66 & 1.77 & 1.77 & 1.78 & 1.74 & 1.72 \\
\hline 204 & 604 & 0.00 & 2.23 & 2.21 & 2.24 & 2.21 & 2.19 & 2.33 & 2.32 & 2.34 & 2.29 & 2.26 \\
\hline 205 & 605 & 0.00 & 2.66 & 2.63 & 2.67 & 2.63 & 2.61 & 2.78 & 2.77 & 2.79 & 2.73 & 2.70 \\
\hline 206 & 606 & 0.00 & 3.32 & 3.29 & 3.34 & 3.28 & 3.25 & 3.47 & 3.45 & 3.48 & 3.41 & 3.37 \\
\hline 207 & 607 & 0.04 & 1.67 & 1.57 & 1.58 & 1.52 & 1.47 & 1.75 & 1.65 & 1.66 & 1.60 & 1.55 \\
\hline 208 & 608 & 0.04 & 2.71 & 2.54 & 2.56 & 2.46 & 2.38 & 2.84 & 2.68 & 2.70 & 2.60 & 2.51 \\
\hline 209 & 609 & 0.00 & 3.86 & 3.63 & 3.65 & 3.51 & 3.40 & 4.05 & 3.82 & 3.85 & 3.70 & 3.58 \\
\hline 210 & 610 & 0.00 & 5.07 & 4.76 & 4.79 & 4.62 & 4.46 & 5.32 & 5.02 & 5.06 & 4.87 & 4.70 \\
\hline 211 & 611 & 0.00 & 8.13 & 7.64 & 7.67 & 7.40 & 7.16 & 8.52 & 8.04 & 8.10 & 7.80 & 7.53 \\
\hline
\end{tabular}


Table D3. Wave-induced vertical motion allowances (ft), Phase 1, Channel Reach 1, $h=58 \mathrm{ft}$, fully loaded Susan Maersk, inbound and outbound transits.

\begin{tabular}{|c|c|c|c|c|c|c|c|c|c|c|c|c|}
\hline \multirow{2}{*}{$\begin{array}{l}\text { Wave } \\
\text { No. }\end{array}$} & \multirow{2}{*}{$\begin{array}{l}\text { Wave } \\
\text { ID }\end{array}$} & \multirow[b]{2}{*}{ Days/yr } & \multicolumn{5}{|c|}{ Inbound Ship speed (kt) } & \multicolumn{5}{|c|}{ Outbound Ship speed (kt) } \\
\hline & & & 8 & 10 & 12 & 14 & 16 & 8 & 10 & 12 & 14 & 16 \\
\hline 1 & 101 & 6.10 & 0.03 & 0.04 & 0.04 & 0.06 & 0.09 & 0.01 & 0.02 & 0.01 & 0.02 & 0.03 \\
\hline 2 & 102 & 2.74 & 0.05 & 0.07 & 0.06 & 0.09 & 0.14 & 0.02 & 0.02 & 0.02 & 0.03 & 0.06 \\
\hline 3 & 103 & 0.26 & 0.07 & 0.11 & 0.08 & 0.13 & 0.2 & 0.02 & 0.04 & 0.03 & 0.05 & 0.08 \\
\hline 4 & 104 & 0.04 & 0.08 & 0.13 & 0.11 & 0.17 & 0.25 & 0.03 & 0.04 & 0.04 & 0.06 & 0.1 \\
\hline 5 & 105 & 0.00 & 0.11 & 0.17 & 0.13 & 0.21 & 0.32 & 0.04 & 0.06 & 0.05 & 0.07 & 0.13 \\
\hline 6 & 106 & 0.00 & 0.24 & 0.3 & 0.27 & 0.26 & 0.61 & 0.12 & 0.14 & 0.14 & 0.13 & 0.22 \\
\hline 7 & 107 & 0.07 & 0.4 & 0.5 & 0.45 & 0.42 & 1.01 & 0.19 & 0.23 & 0.23 & 0.22 & 0.37 \\
\hline 8 & 108 & 0.07 & 0.56 & 0.71 & 0.64 & 0.6 & 1.44 & 0.27 & 0.32 & 0.33 & 0.31 & 0.52 \\
\hline 9 & 109 & 0.00 & 0.71 & 0.9 & 0.81 & 0.76 & 1.82 & 0.34 & 0.4 & 0.41 & 0.39 & 0.66 \\
\hline 10 & 110 & 0.00 & 0.9 & 1.13 & 1.01 & 0.96 & 2.28 & 0.43 & 0.51 & 0.52 & 0.49 & 0.82 \\
\hline 11 & 111 & 0.04 & 0.41 & 0.46 & 0.43 & 0.4 & 0.6 & 0.28 & 0.29 & 0.3 & 0.29 & 0.29 \\
\hline 12 & 112 & 0.00 & 0.68 & 0.76 & 0.72 & 0.66 & 1 & 0.47 & 0.48 & 0.49 & 0.49 & 0.48 \\
\hline 13 & 113 & 0.04 & 0.97 & 1.08 & 1.02 & 0.93 & 1.42 & 0.66 & 0.69 & 0.7 & 0.69 & 0.68 \\
\hline 14 & 114 & 0.04 & 1.22 & 1.36 & 1.29 & 1.18 & 1.79 & 0.83 & 0.87 & 0.88 & 0.87 & 0.86 \\
\hline 15 & 115 & 0.00 & 0.84 & 0.83 & 0.82 & 0.8 & 0.78 & 0.69 & 0.68 & 0.68 & 0.67 & 0.66 \\
\hline 16 & 116 & 0.00 & 1.38 & 1.38 & 1.36 & 1.32 & 1.29 & 1.15 & 1.12 & 1.13 & 1.12 & 1.1 \\
\hline 17 & 117 & 0.00 & 1.96 & 1.95 & 1.92 & 1.87 & 1.83 & 1.63 & 1.59 & 1.6 & 1.58 & 1.56 \\
\hline 18 & 118 & 0.00 & 2.48 & 2.47 & 2.43 & 2.37 & 2.32 & 2.06 & 2.01 & 2.02 & 2 & 1.97 \\
\hline 19 & 119 & 0.00 & 3.12 & 3.1 & 3.05 & 2.98 & 2.91 & 2.58 & 2.53 & 2.54 & 2.52 & 2.48 \\
\hline 20 & 120 & 0.00 & 3.49 & 3.48 & 3.42 & 3.34 & 3.26 & 2.89 & 2.83 & 2.84 & 2.82 & 2.78 \\
\hline 21 & 121 & 0.04 & 1.93 & 1.83 & 1.76 & 1.75 & 1.68 & 1.64 & 1.52 & 1.45 & 1.44 & 1.39 \\
\hline 22 & 122 & 0.00 & 3.2 & 3.03 & 2.91 & 2.9 & 2.78 & 2.71 & 2.52 & 2.41 & 2.38 & 2.3 \\
\hline 23 & 123 & 0.00 & 4.53 & 4.29 & 4.12 & 4.11 & 3.94 & 3.84 & 3.57 & 3.41 & 3.37 & 3.26 \\
\hline 24 & 124 & 0.00 & 5.73 & 5.43 & 5.21 & 5.2 & 4.98 & 4.86 & 4.52 & 4.31 & 4.27 & 4.13 \\
\hline 25 & 125 & 0.00 & 8.07 & 7.64 & 7.33 & 7.32 & 7.01 & 6.84 & 6.36 & 6.07 & 6 & 5.81 \\
\hline 26 & 126 & 0.00 & 10.27 & 9.72 & 9.33 & 9.32 & 8.93 & 8.71 & 8.1 & 7.73 & 7.64 & 7.4 \\
\hline 27 & 127 & 0.00 & 10.8 & 10.22 & 9.82 & 9.81 & 9.39 & 9.16 & 8.52 & 8.13 & 8.04 & 7.78 \\
\hline 28 & 128 & 11.24 & 0.06 & 0.09 & 0.07 & 0.11 & 0.17 & 0.01 & 0.02 & 0.02 & 0.02 & 0.04 \\
\hline 29 & 129 & 3.80 & 0.1 & 0.15 & 0.12 & 0.18 & 0.29 & 0.02 & 0.03 & 0.03 & 0.03 & 0.06 \\
\hline 30 & 130 & 0.66 & 0.14 & 0.22 & 0.17 & 0.26 & 0.41 & 0.03 & 0.04 & 0.04 & 0.04 & 0.08 \\
\hline 31 & 131 & 0.04 & 0.18 & 0.28 & 0.23 & 0.33 & 0.53 & 0.03 & 0.05 & 0.05 & 0.06 & 0.11 \\
\hline
\end{tabular}




\begin{tabular}{|c|c|c|c|c|c|c|c|c|c|c|c|c|}
\hline \multirow{2}{*}{$\begin{array}{l}\text { Wave } \\
\text { No. }\end{array}$} & \multirow{2}{*}{$\begin{array}{l}\text { Wave } \\
\text { ID }\end{array}$} & \multirow[b]{2}{*}{ Days/yr } & \multicolumn{5}{|c|}{ Inbound Ship speed (kt) } & \multicolumn{5}{|c|}{ Outbound Ship speed (kt) } \\
\hline & & & 8 & 10 & 12 & 14 & 16 & 8 & 10 & 12 & 14 & 16 \\
\hline 32 & 132 & 1.13 & 0.28 & 0.35 & 0.31 & 0.29 & 0.72 & 0.1 & 0.1 & 0.11 & 0.11 & 0.13 \\
\hline 33 & 133 & 0.18 & 0.46 & 0.57 & 0.51 & 0.47 & 1.19 & 0.16 & 0.17 & 0.18 & 0.18 & 0.22 \\
\hline 34 & 134 & 0.66 & 0.65 & 0.81 & 0.72 & 0.67 & 1.69 & 0.23 & 0.25 & 0.26 & 0.25 & 0.31 \\
\hline 35 & 135 & 0.15 & 0.84 & 1.05 & 0.93 & 0.87 & 2.19 & 0.29 & 0.32 & 0.33 & 0.33 & 0.4 \\
\hline 36 & 136 & 0.00 & 1.03 & 1.29 & 1.14 & 1.06 & 2.68 & 0.36 & 0.39 & 0.41 & 0.4 & 0.49 \\
\hline 37 & 137 & 1.20 & 0.47 & 0.51 & 0.48 & 0.43 & 0.69 & 0.27 & 0.27 & 0.27 & 0.27 & 0.27 \\
\hline 38 & 138 & 0.22 & 0.78 & 0.85 & 0.79 & 0.71 & 1.13 & 0.44 & 0.45 & 0.45 & 0.45 & 0.45 \\
\hline 39 & 139 & 0.07 & 1.1 & 1.2 & 1.12 & 1.01 & 1.61 & 0.63 & 0.63 & 0.64 & 0.64 & 0.64 \\
\hline 40 & 140 & 0.22 & 1.42 & 1.56 & 1.44 & 1.31 & 2.08 & 0.82 & 0.82 & 0.83 & 0.83 & 0.83 \\
\hline 41 & 141 & 0.15 & 1.75 & 1.91 & 1.77 & 1.61 & 2.55 & 1 & 1 & 1.02 & 1.01 & 1.01 \\
\hline 42 & 142 & 0.04 & 2.09 & 2.28 & 2.12 & 1.92 & 3.05 & 1.2 & 1.2 & 1.22 & 1.21 & 1.21 \\
\hline 43 & 143 & 0.88 & 0.86 & 0.85 & 0.83 & 0.8 & 0.83 & 0.63 & 0.61 & 0.61 & 0.6 & 0.59 \\
\hline 44 & 144 & 0.11 & 1.42 & 1.41 & 1.37 & 1.33 & 1.38 & 1.05 & 1.01 & 1.01 & 1 & 0.98 \\
\hline 45 & 145 & 0.04 & 2.01 & 2 & 1.94 & 1.88 & 1.96 & 1.49 & 1.43 & 1.43 & 1.41 & 1.39 \\
\hline 46 & 146 & 0.07 & 2.6 & 2.58 & 2.51 & 2.43 & 2.53 & 1.93 & 1.86 & 1.85 & 1.83 & 1.8 \\
\hline 47 & 147 & 0.04 & 3.19 & 3.17 & 3.08 & 2.99 & 3.11 & 2.37 & 2.28 & 2.27 & 2.24 & 2.21 \\
\hline 48 & 148 & 0.04 & 3.82 & 3.79 & 3.68 & 3.57 & 3.71 & 2.83 & 2.72 & 2.71 & 2.68 & 2.63 \\
\hline 49 & 149 & 0.04 & 4.41 & 4.38 & 4.25 & 4.12 & 4.29 & 3.26 & 3.15 & 3.13 & 3.1 & 3.04 \\
\hline 50 & 150 & 0.00 & 5.24 & 5.2 & 5.05 & 4.89 & 5.1 & 3.88 & 3.74 & 3.72 & 3.68 & 3.61 \\
\hline 51 & 151 & 0.18 & 1.48 & 1.4 & 1.33 & 1.3 & 1.55 & 1.13 & 1.04 & 0.97 & 0.94 & 0.91 \\
\hline 52 & 152 & 0.15 & 2.45 & 2.31 & 2.2 & 2.15 & 2.57 & 1.88 & 1.72 & 1.61 & 1.56 & 1.5 \\
\hline 53 & 153 & 0.11 & 3.47 & 3.27 & 3.11 & 3.05 & 3.64 & 2.66 & 2.43 & 2.28 & 2.21 & 2.12 \\
\hline 54 & 154 & 0.07 & 4.49 & 4.24 & 4.03 & 3.94 & 4.72 & 3.44 & 3.15 & 2.96 & 2.86 & 2.75 \\
\hline 55 & 155 & 0.04 & 5.51 & 5.2 & 4.94 & 4.84 & 5.79 & 4.23 & 3.87 & 3.63 & 3.52 & 3.38 \\
\hline 56 & 156 & 0.04 & 6.58 & 6.21 & 5.91 & 5.78 & 6.91 & 5.05 & 4.62 & 4.33 & 4.2 & 4.03 \\
\hline 57 & 157 & 0.00 & 7.61 & 7.18 & 6.82 & 6.68 & 7.98 & 5.83 & 5.34 & 5.01 & 4.85 & 4.66 \\
\hline 58 & 158 & 0.00 & 9.04 & 8.53 & 8.1 & 7.93 & 9.49 & 6.93 & 6.34 & 5.95 & 5.76 & 5.53 \\
\hline 59 & 159 & 0.00 & 10.62 & 10.02 & 9.52 & 9.32 & 11.15 & 8.14 & 7.45 & 6.99 & 6.77 & 6.5 \\
\hline 60 & 160 & 0.00 & 1.82 & 1.72 & 1.63 & 1.63 & 2.6 & 1.68 & 1.59 & 1.5 & 1.46 & 1.39 \\
\hline 61 & 161 & 0.00 & 3.01 & 2.85 & 2.7 & 2.71 & 4.31 & 2.78 & 2.64 & 2.49 & 2.41 & 2.31 \\
\hline 62 & 162 & 0.00 & 9.36 & 8.87 & 8.39 & 8.4 & 13.37 & 8.64 & 8.2 & 7.74 & 7.49 & 7.16 \\
\hline 63 & 163 & 0.00 & 11.12 & 10.53 & 9.96 & 9.98 & 15.89 & 10.27 & 9.74 & 9.19 & 8.89 & 8.51 \\
\hline 64 & 164 & 0.00 & 2.57 & 2.47 & 2.33 & 2.93 & 4.96 & 3.06 & 2.98 & 2.83 & 2.75 & 2.62 \\
\hline
\end{tabular}




\begin{tabular}{|c|c|c|c|c|c|c|c|c|c|c|c|c|}
\hline \multirow{2}{*}{$\begin{array}{l}\text { Wave } \\
\text { No. }\end{array}$} & \multirow{2}{*}{$\begin{array}{l}\text { Wave } \\
\text { ID }\end{array}$} & \multirow[b]{2}{*}{ Days/yr } & \multicolumn{5}{|c|}{ Inbound Ship speed (kt) } & \multicolumn{5}{|c|}{ Outbound Ship speed (kt) } \\
\hline & & & 8 & 10 & 12 & 14 & 16 & 8 & 10 & 12 & 14 & 16 \\
\hline 65 & 165 & 12.41 & 0.07 & 0.11 & 0.09 & 0.12 & 0.2 & 0.01 & 0.01 & 0.01 & 0.01 & 0.02 \\
\hline 66 & 166 & 3.14 & 0.12 & 0.18 & 0.15 & 0.21 & 0.34 & 0.02 & 0.02 & 0.02 & 0.02 & 0.03 \\
\hline 67 & 167 & 0.37 & 0.17 & 0.26 & 0.21 & 0.3 & 0.48 & 0.02 & 0.03 & 0.03 & 0.03 & 0.05 \\
\hline 68 & 168 & 0.00 & 0.27 & 0.41 & 0.33 & 0.47 & 0.76 & 0.03 & 0.04 & 0.04 & 0.04 & 0.07 \\
\hline 69 & 169 & 1.39 & 0.28 & 0.35 & 0.31 & 0.28 & 0.73 & 0.08 & 0.08 & 0.08 & 0.08 & 0.08 \\
\hline 70 & 170 & 0.37 & 0.48 & 0.6 & 0.53 & 0.49 & 1.26 & 0.14 & 0.14 & 0.14 & 0.14 & 0.14 \\
\hline 71 & 171 & 0.66 & 0.68 & 0.85 & 0.75 & 0.69 & 1.78 & 0.19 & 0.2 & 0.2 & 0.21 & 0.21 \\
\hline 72 & 172 & 0.07 & 0.87 & 1.09 & 0.96 & 0.88 & 2.28 & 0.25 & 0.25 & 0.26 & 0.26 & 0.26 \\
\hline 73 & 173 & 1.46 & 0.47 & 0.51 & 0.46 & 0.41 & 0.69 & 0.23 & 0.23 & 0.23 & 0.23 & 0.23 \\
\hline 74 & 174 & 0.26 & 0.8 & 0.87 & 0.79 & 0.71 & 1.18 & 0.4 & 0.39 & 0.39 & 0.39 & 0.39 \\
\hline 75 & 175 & 0.15 & 1.13 & 1.23 & 1.12 & 1.01 & 1.67 & 0.56 & 0.55 & 0.55 & 0.55 & 0.55 \\
\hline 76 & 176 & 0.18 & 1.45 & 1.57 & 1.44 & 1.29 & 2.14 & 0.72 & 0.71 & 0.71 & 0.71 & 0.71 \\
\hline 77 & 177 & 0.07 & 1.79 & 1.93 & 1.77 & 1.58 & 2.63 & 0.89 & 0.87 & 0.87 & 0.87 & 0.87 \\
\hline 78 & 178 & 0.00 & 2.12 & 2.29 & 2.1 & 1.88 & 3.13 & 1.05 & 1.03 & 1.04 & 1.03 & 1.03 \\
\hline 79 & 179 & 1.24 & 0.81 & 0.81 & 0.78 & 0.75 & 0.82 & 0.56 & 0.53 & 0.52 & 0.51 & 0.5 \\
\hline 80 & 180 & 0.26 & 1.4 & 1.39 & 1.33 & 1.29 & 1.41 & 0.95 & 0.91 & 0.9 & 0.88 & 0.86 \\
\hline 81 & 181 & 0.18 & 1.98 & 1.97 & 1.89 & 1.82 & 2 & 1.35 & 1.29 & 1.27 & 1.25 & 1.22 \\
\hline 82 & 182 & 0.04 & 2.53 & 2.52 & 2.42 & 2.33 & 2.55 & 1.73 & 1.65 & 1.62 & 1.6 & 1.57 \\
\hline 83 & 183 & 0.04 & 3.11 & 3.09 & 2.98 & 2.87 & 3.14 & 2.13 & 2.02 & 2 & 1.97 & 1.93 \\
\hline 84 & 184 & 0.04 & 3.7 & 3.67 & 3.53 & 3.4 & 3.73 & 2.52 & 2.4 & 2.37 & 2.33 & 2.29 \\
\hline 85 & 185 & 0.00 & 4.25 & 4.22 & 4.06 & 3.91 & 4.29 & 2.9 & 2.76 & 2.73 & 2.68 & 2.63 \\
\hline 86 & 186 & 0.91 & 1.34 & 1.24 & 1.16 & 1.11 & 1.69 & 0.98 & 0.88 & 0.8 & 0.76 & 0.71 \\
\hline 87 & 187 & 0.51 & 2.3 & 2.13 & 2 & 1.9 & 2.91 & 1.69 & 1.51 & 1.38 & 1.3 & 1.22 \\
\hline 88 & 188 & 0.15 & 3.25 & 3.02 & 2.83 & 2.7 & 4.12 & 2.39 & 2.14 & 1.95 & 1.84 & 1.73 \\
\hline 89 & 189 & 0.07 & 4.16 & 3.86 & 3.62 & 3.45 & 5.27 & 3.06 & 2.74 & 2.49 & 2.35 & 2.21 \\
\hline 90 & 190 & 0.00 & 5.12 & 4.75 & 4.45 & 4.24 & 6.48 & 3.76 & 3.36 & 3.07 & 2.89 & 2.72 \\
\hline 91 & 191 & 0.15 & 1.3 & 1.2 & 1.12 & 1.52 & 2.57 & 1.2 & 1.1 & 1.01 & 0.95 & 0.88 \\
\hline 92 & 192 & 0.07 & 2.23 & 2.06 & 1.91 & 2.6 & 4.4 & 2.05 & 1.89 & 1.73 & 1.62 & 1.51 \\
\hline 93 & 193 & 0.04 & 3.16 & 2.93 & 2.71 & 3.69 & 6.24 & 2.91 & 2.68 & 2.45 & 2.3 & 2.14 \\
\hline 94 & 194 & 0.00 & 4.05 & 3.74 & 3.47 & 4.72 & 7.98 & 3.72 & 3.43 & 3.13 & 2.94 & 2.74 \\
\hline 95 & 195 & 0.00 & 1.52 & 1.44 & 1.5 & 2.93 & 4.83 & 1.92 & 1.8 & 1.65 & 1.55 & 1.44 \\
\hline 96 & 196 & 0.00 & 2.6 & 2.46 & 2.57 & 5.03 & 8.29 & 3.29 & 3.08 & 2.82 & 2.65 & 2.48 \\
\hline 97 & 197 & 11.86 & 0.07 & 0.11 & 0.08 & 0.12 & 0.2 & 0.01 & 0.01 & 0.01 & 0.01 & 0.02 \\
\hline
\end{tabular}




\begin{tabular}{|c|c|c|c|c|c|c|c|c|c|c|c|c|}
\hline \multirow{2}{*}{$\begin{array}{l}\text { Wave } \\
\text { No. }\end{array}$} & \multirow{2}{*}{$\begin{array}{l}\text { Wave } \\
\text { ID }\end{array}$} & \multirow[b]{2}{*}{ Days/yr } & \multicolumn{5}{|c|}{ Inbound Ship speed (kt) } & \multicolumn{5}{|c|}{ Outbound Ship speed (kt) } \\
\hline & & & 8 & 10 & 12 & 14 & 16 & 8 & 10 & 12 & 14 & 16 \\
\hline 98 & 198 & 3.07 & 0.12 & 0.18 & 0.15 & 0.21 & 0.34 & 0.02 & 0.02 & 0.02 & 0.02 & 0.04 \\
\hline 99 & 199 & 0.58 & 0.17 & 0.26 & 0.21 & 0.3 & 0.48 & 0.02 & 0.03 & 0.03 & 0.03 & 0.06 \\
\hline 100 & 200 & 0.04 & 0.21 & 0.33 & 0.26 & 0.38 & 0.61 & 0.03 & 0.04 & 0.04 & 0.04 & 0.08 \\
\hline 101 & 201 & 1.10 & 0.28 & 0.35 & 0.31 & 0.28 & 0.73 & 0.08 & 0.09 & 0.09 & 0.09 & 0.09 \\
\hline 102 & 202 & 0.29 & 0.48 & 0.6 & 0.52 & 0.48 & 1.25 & 0.14 & 0.15 & 0.15 & 0.15 & 0.15 \\
\hline 103 & 203 & 0.47 & 0.67 & 0.84 & 0.74 & 0.69 & 1.76 & 0.2 & 0.21 & 0.21 & 0.22 & 0.21 \\
\hline 104 & 204 & 0.07 & 0.86 & 1.08 & 0.95 & 0.88 & 2.26 & 0.26 & 0.26 & 0.27 & 0.28 & 0.27 \\
\hline 105 & 205 & 0.00 & 1.05 & 1.31 & 1.16 & 1.07 & 2.75 & 0.31 & 0.32 & 0.33 & 0.34 & 0.33 \\
\hline 106 & 206 & 0.88 & 0.46 & 0.5 & 0.46 & 0.41 & 0.68 & 0.24 & 0.23 & 0.24 & 0.23 & 0.24 \\
\hline 107 & 207 & 0.15 & 0.8 & 0.86 & 0.79 & 0.71 & 1.17 & 0.41 & 0.4 & 0.4 & 0.4 & 0.4 \\
\hline 108 & 208 & 0.11 & 1.13 & 1.22 & 1.12 & 1.01 & 1.66 & 0.58 & 0.57 & 0.57 & 0.57 & 0.57 \\
\hline 109 & 209 & 0.15 & 1.44 & 1.57 & 1.44 & 1.29 & 2.13 & 0.74 & 0.73 & 0.73 & 0.73 & 0.73 \\
\hline 110 & 210 & 0.07 & 1.76 & 1.91 & 1.75 & 1.57 & 2.59 & 0.9 & 0.89 & 0.89 & 0.89 & 0.89 \\
\hline 111 & 211 & 0.00 & 2.16 & 2.34 & 2.15 & 1.93 & 3.18 & 1.11 & 1.09 & 1.1 & 1.09 & 1.09 \\
\hline 112 & 212 & 0.62 & 0.82 & 0.81 & 0.78 & 0.75 & 0.82 & 0.57 & 0.54 & 0.54 & 0.53 & 0.52 \\
\hline 113 & 213 & 0.26 & 1.4 & 1.39 & 1.34 & 1.29 & 1.41 & 0.97 & 0.93 & 0.92 & 0.91 & 0.89 \\
\hline 114 & 214 & 0.15 & 1.99 & 1.97 & 1.9 & 1.83 & 1.99 & 1.38 & 1.32 & 1.31 & 1.29 & 1.26 \\
\hline 115 & 215 & 0.11 & 2.54 & 2.52 & 2.43 & 2.35 & 2.55 & 1.77 & 1.69 & 1.67 & 1.64 & 1.61 \\
\hline 116 & 216 & 0.00 & 3.1 & 3.08 & 2.97 & 2.86 & 3.11 & 2.15 & 2.06 & 2.04 & 2 & 1.96 \\
\hline 117 & 217 & 0.00 & 3.8 & 3.77 & 3.64 & 3.51 & 3.81 & 2.64 & 2.52 & 2.5 & 2.46 & 2.41 \\
\hline 118 & 218 & 0.73 & 35 & 26 & .19 & 1.14 & 1.64 & 1 & 0.9 & 0.83 & 0.79 & 0.75 \\
\hline 119 & 219 & 0.22 & 2.32 & 2.16 & 2.03 & 1.95 & 2.81 & 1.72 & 1.55 & 1.42 & 1.35 & 1.28 \\
\hline 120 & 220 & 0.11 & 3.29 & 3.06 & 2.88 & 2.77 & 3.99 & 2.43 & 2.19 & 2.01 & 1.91 & 1.81 \\
\hline 121 & 221 & 0.07 & 4.21 & 3.92 & 3.69 & 3.54 & 5.1 & 3.11 & 2.8 & 2.58 & 2.45 & 2.32 \\
\hline 122 & 222 & 0.04 & 5.12 & 4.78 & 4.49 & 4.32 & 6.22 & 3.79 & 3.42 & 3.14 & 2.98 & 2.83 \\
\hline 123 & 223 & 0.00 & 6.28 & 5.86 & 5.51 & 5.29 & 7.63 & 4.65 & 4.19 & 3.85 & 3.66 & 3.47 \\
\hline 124 & 224 & 0.11 & 1.41 & 1.31 & 1.22 & 1.54 & 2.57 & 1.3 & 1.21 & 1.12 & 1.06 & 0.99 \\
\hline 125 & 225 & 0.04 & 2.41 & 2.25 & 2.1 & 2.64 & 4.4 & 2.23 & 2.07 & 1.91 & 1.81 & 1.71 \\
\hline 126 & 226 & 0.04 & 3.42 & 3.19 & 2.98 & 3.74 & 6.24 & 3.16 & 2.94 & 2.71 & 2.57 & 2.42 \\
\hline 127 & 227 & 0.00 & 1.75 & 1.67 & 1.56 & 2.92 & 4.87 & 2.19 & 2.08 & 1.93 & 1.84 & 1.72 \\
\hline 128 & 228 & 0.04 & 3.01 & 2.87 & 2.68 & 5.01 & 8.35 & 3.76 & 3.57 & 3.31 & 3.15 & 2.96 \\
\hline 129 & 229 & 0.04 & 4.26 & 4.06 & 3.8 & 7.11 & 11.83 & 5.33 & 5.06 & 4.69 & 4.46 & 4.19 \\
\hline 130 & 230 & 18.03 & 0.06 & 0.09 & 0.08 & 0.11 & 0.18 & 0.01 & 0.02 & 0.02 & 0.02 & 0.05 \\
\hline
\end{tabular}




\begin{tabular}{|c|c|c|c|c|c|c|c|c|c|c|c|c|}
\hline \multirow{2}{*}{$\begin{array}{l}\text { Wave } \\
\text { No. }\end{array}$} & \multirow{2}{*}{$\begin{array}{l}\text { Wave } \\
\text { ID }\end{array}$} & \multirow[b]{2}{*}{ Days/yr } & \multicolumn{5}{|c|}{ Inbound Ship speed (kt) } & \multicolumn{5}{|c|}{ Outbound Ship speed (kt) } \\
\hline & & & 8 & 10 & 12 & 14 & 16 & 8 & 10 & 12 & 14 & 16 \\
\hline 131 & 231 & 3.80 & 0.11 & 0.16 & 0.13 & 0.19 & 0.31 & 0.03 & 0.04 & 0.04 & 0.04 & 0.08 \\
\hline 132 & 232 & 0.37 & 0.15 & 0.24 & 0.19 & 0.28 & 0.45 & 0.04 & 0.05 & 0.05 & 0.06 & 0.12 \\
\hline 133 & 233 & 0.00 & 0.25 & 0.38 & 0.31 & 0.44 & 0.71 & 0.06 & 0.08 & 0.09 & 0.1 & 0.18 \\
\hline 134 & 234 & 2.23 & 0.24 & 0.3 & 0.27 & 0.25 & 0.62 & 0.09 & 0.1 & 0.11 & 0.1 & 0.14 \\
\hline 135 & 235 & 0.58 & 0.42 & 0.53 & 0.47 & 0.44 & 1.09 & 0.16 & 0.18 & 0.18 & 0.18 & 0.25 \\
\hline 136 & 236 & 0.58 & 0.61 & 0.77 & 0.68 & 0.64 & 1.57 & 0.23 & 0.26 & 0.27 & 0.26 & 0.36 \\
\hline 137 & 237 & 0.07 & 0.79 & 0.99 & 0.88 & 0.83 & 2.03 & 0.29 & 0.33 & 0.35 & 0.34 & 0.47 \\
\hline 138 & 238 & 1.06 & 0.42 & 0.46 & 0.43 & 0.39 & 0.61 & 0.25 & 0.25 & 0.26 & 0.25 & 0.25 \\
\hline 139 & 239 & 0.29 & 0.72 & 0.8 & 0.74 & 0.67 & 1.07 & 0.43 & 0.44 & 0.45 & 0.44 & 0.44 \\
\hline 140 & 240 & 0.11 & 1.05 & 1.16 & 1.07 & 0.98 & 1.55 & 0.63 & 0.63 & 0.65 & 0.64 & 0.64 \\
\hline 141 & 241 & 0.26 & 1.36 & 1.49 & 1.39 & 1.26 & 2 & 0.81 & 0.82 & 0.84 & 0.83 & 0.83 \\
\hline 142 & 242 & 0.11 & 1.66 & 1.83 & 1.71 & 1.55 & 2.46 & 0.99 & 1.01 & 1.03 & 1.02 & 1.02 \\
\hline 143 & 243 & 0.00 & 2 & 2.21 & 2.06 & 1.87 & 2.96 & 1.2 & .21 & 1.24 & 1.23 & 1.23 \\
\hline 144 & 244 & 0.69 & 0.8 & 0.8 & 0.78 & 0.76 & 0.76 & 0.62 & 0.6 & 0.6 & 0.59 & 0.58 \\
\hline 145 & 245 & 0.29 & 1.4 & 1.39 & 1.36 & 1.32 & 1.33 & 1.08 & 1.04 & 1.04 & 1.03 & 1.01 \\
\hline 146 & 246 & 0.18 & 2.03 & 2.01 & 1.96 & 1.91 & 1.92 & 1.56 & .51 & 1.51 & 1.49 & 1.47 \\
\hline 147 & 247 & 0.04 & 2.62 & 2.6 & 2.54 & 2.47 & 2.49 & 2.02 & 1.95 & 1.95 & 1.93 & 1.9 \\
\hline 148 & 248 & 0.07 & 3.22 & 3.19 & 3.12 & 3.03 & 3.06 & 2.48 & 2.4 & 2.4 & 2.37 & 2.33 \\
\hline 149 & 249 & 0.04 & 3.87 & 3.85 & 3.75 & 3.65 & 3.68 & 2.98 & 2.89 & 2.89 & 2.85 & 2.81 \\
\hline 150 & 250 & 0.00 & 4.38 & 4.35 & 4.24 & 4.12 & 4.16 & 3.37 & 3.26 & 3.26 & 3.23 & 3.18 \\
\hline 151 & 251 & 0.62 & 1.54 & 1.45 & 1.39 & 1.37 & 1.48 & 1.22 & 1.12 & 1.06 & 1.04 & 1 \\
\hline 152 & 252 & 0.22 & 2.68 & 2.53 & 2.41 & 2.38 & 2.58 & 2.13 & 1.96 & 1.85 & 1.81 & 1.74 \\
\hline 153 & 253 & 0.11 & 3.87 & 3.66 & 3.49 & 3.45 & 3.73 & 3.08 & 2.83 & 2.68 & 2.61 & 2.52 \\
\hline 154 & 254 & 0.00 & 5.01 & 4.73 & 4.52 & 4.47 & 4.83 & 3.98 & 3.67 & 3.46 & 3.38 & 3.26 \\
\hline 155 & 255 & 0.00 & 7.4 & 6.99 & 6.68 & 6.6 & 7.13 & 5.88 & 5.42 & 5.12 & 5 & 4.82 \\
\hline 156 & 256 & 0.15 & 1.89 & 1.8 & 1.71 & 1.69 & 2.35 & 1.74 & 1.66 & 1.59 & 1.55 & 1.49 \\
\hline 157 & 257 & 0.11 & 3.3 & 3.14 & 2.98 & 2.94 & 4.1 & 3.04 & 2.9 & 2.76 & 2.69 & 2.59 \\
\hline 158 & 258 & 0.04 & 2.78 & 2.69 & 2.54 & 2.66 & 4.44 & 3.23 & 3.16 & 3.05 & 2.97 & 2.84 \\
\hline 159 & 259 & 0.00 & 4.84 & 4.68 & 4.42 & 4.64 & 7.73 & 5.62 & 5.5 & 5.31 & 5.18 & 4.95 \\
\hline 160 & 260 & 27.08 & 0.06 & 0.09 & 0.08 & 0.11 & 0.18 & 0.03 & 0.04 & 0.04 & 0.05 & 0.09 \\
\hline 161 & 261 & 6.72 & 0.11 & 0.16 & 0.13 & 0.19 & 0.31 & 0.05 & 0.07 & 0.07 & 0.08 & 0.15 \\
\hline 162 & 262 & 0.40 & 0.15 & 0.23 & 0.19 & 0.26 & 0.44 & 0.07 & 0.1 & 0.09 & 0.12 & 0.21 \\
\hline 163 & 263 & 0.00 & 0.19 & 0.29 & 0.24 & 0.34 & 0.57 & 0.09 & 0.13 & 0.12 & 0.15 & 0.27 \\
\hline
\end{tabular}




\begin{tabular}{|c|c|c|c|c|c|c|c|c|c|c|c|c|}
\hline \multirow{2}{*}{$\begin{array}{l}\text { Wave } \\
\text { No. }\end{array}$} & \multirow{2}{*}{$\begin{array}{l}\text { Wave } \\
\text { ID }\end{array}$} & \multirow[b]{2}{*}{ Days/yr } & \multicolumn{5}{|c|}{ Inbound Ship speed (kt) } & \multicolumn{5}{|c|}{ Outbound Ship speed (kt) } \\
\hline & & & 8 & 10 & 12 & 14 & 16 & 8 & 10 & 12 & 14 & 16 \\
\hline 164 & 264 & 4.60 & 0.22 & 0.28 & 0.25 & 0.24 & 0.56 & 0.12 & 0.15 & 0.15 & 0.14 & 0.25 \\
\hline 165 & 265 & 0.91 & 0.38 & 0.48 & 0.43 & 0.41 & 0.96 & 0.21 & 0.25 & 0.25 & 0.24 & 0.43 \\
\hline 166 & 266 & 1.24 & 0.53 & 0.67 & 0.6 & 0.57 & 1.34 & 0.29 & 0.35 & 0.35 & 0.33 & 0.6 \\
\hline 167 & 267 & 0.11 & 0.69 & 0.86 & 0.78 & 0.74 & 1.74 & 0.38 & 0.46 & 0.46 & 0.43 & 0.78 \\
\hline 168 & 268 & 1.46 & 0.41 & 0.45 & 0.43 & 0.4 & 0.56 & 0.3 & 0.32 & 0.32 & 0.32 & 0.31 \\
\hline 169 & 269 & 0.33 & 0.7 & 0.77 & 0.73 & 0.68 & 0.97 & 0.52 & 0.54 & 0.55 & 0.54 & 0.54 \\
\hline 170 & 270 & 0.22 & 0.98 & 1.07 & 1.02 & 0.95 & 1.35 & 0.73 & 0.76 & 0.77 & 0.76 & 0.75 \\
\hline 171 & 271 & 0.40 & 1.27 & 1.39 & 1.33 & 1.24 & 1.75 & 0.94 & 0.99 & 1 & 0.99 & 0.97 \\
\hline 172 & 272 & 0.07 & 1.56 & 1.71 & 1.63 & 1.52 & 2.16 & 1.16 & 1.21 & 1.23 & 1.21 & 1.2 \\
\hline 173 & 273 & 0.00 & 1.86 & 2.05 & 1.95 & 1.82 & 2.58 & 1.39 & 1.45 & 1.47 & 1.45 & 1.43 \\
\hline 174 & 274 & 0.69 & 0.85 & 0.84 & 0.83 & 0.81 & 0.8 & 0.73 & 0.72 & 0.72 & 0.71 & 0.7 \\
\hline 175 & 275 & 0.33 & 1.45 & 1.44 & 1.42 & 1.39 & 1.36 & 1.26 & 1.23 & 1.24 & 1.23 & 1.21 \\
\hline 176 & 276 & 0.07 & 2.02 & 2.01 & 1.99 & 1.95 & 1.91 & 1.75 & 1.72 & 1.73 & 1.71 & 1.69 \\
\hline 177 & 277 & 0.04 & 2.63 & 2.61 & 2.58 & 2.53 & 2.47 & 2.28 & 2.23 & 2.24 & 2.22 & 2.19 \\
\hline 178 & 278 & 0.04 & 3.23 & 3.21 & 3.17 & 3.11 & 3.04 & 2.8 & 2.74 & 2.76 & 2.73 & 2.69 \\
\hline 179 & 279 & 0.04 & 3.87 & 3.84 & 3.8 & 3.72 & 3.64 & 3.35 & 3.28 & 3.3 & 3.27 & 3.22 \\
\hline 180 & 280 & 0.22 & 1.64 & 1.57 & 1.52 & 1.52 & 1.46 & 1.42 & 1.33 & 1.28 & 1.28 & 1.24 \\
\hline 181 & 281 & 0.18 & 2.82 & 2.69 & 2.61 & 2.61 & 2.51 & 2.44 & 2.28 & 2.2 & 2.19 & 2.13 \\
\hline 182 & 282 & 0.04 & 3.93 & 3.75 & 3.64 & 3.64 & 3.51 & 3.4 & 3.19 & 3.08 & 3.06 & 2.97 \\
\hline 183 & 283 & 0.00 & 5.11 & 4.87 & 4.73 & 4.72 & 4.56 & 4.42 & 4.14 & 4 & 3.97 & 3.86 \\
\hline 184 & 284 & 0.00 & 6.28 & 5.99 & 5.81 & 5.81 & 5.6 & 43 & 5.09 & 4.91 & 4.88 & 4.74 \\
\hline 185 & 285 & 0.00 & 7.51 & 7.17 & 6.95 & 6.95 & 6.7 & 6.5 & 6.09 & 5.88 & 5.84 & 5.67 \\
\hline 186 & 286 & 0.00 & 8.75 & 8.35 & 8.09 & 8.09 & 7.8 & 7.56 & 7.09 & 6.84 & 6.8 & 6.6 \\
\hline 187 & 287 & 10.22 & 0.02 & 0.03 & 0.03 & 0.04 & 0.07 & 0.02 & 0.03 & 0.02 & 0.03 & 0.06 \\
\hline 188 & 288 & 2.81 & 0.03 & 0.05 & 0.04 & 0.07 & 0.11 & 0.03 & 0.04 & 0.04 & 0.06 & 0.09 \\
\hline 189 & 289 & 0.22 & 0.05 & 0.08 & 0.06 & 0.1 & 0.15 & 0.04 & 0.06 & 0.05 & 0.08 & 0.13 \\
\hline 190 & 290 & 0.00 & 0.06 & 0.1 & 0.08 & 0.13 & 0.2 & 0.05 & 0.08 & 0.07 & 0.1 & 0.17 \\
\hline 191 & 291 & 0.00 & 0.08 & 0.12 & 0.1 & 0.15 & 0.24 & 0.06 & 0.1 & 0.08 & 0.12 & 0.2 \\
\hline 192 & 292 & 0.18 & 0.19 & 0.24 & 0.22 & 0.21 & 0.46 & 0.17 & 0.2 & 0.19 & 0.18 & 0.38 \\
\hline 193 & 293 & 0.18 & 0.31 & 0.39 & 0.36 & 0.34 & 0.75 & 0.27 & 0.33 & 0.31 & 0.29 & 0.61 \\
\hline 194 & 294 & 0.29 & 0.44 & 0.55 & 0.51 & 0.48 & 1.07 & 0.38 & 0.47 & 0.45 & 0.41 & 0.88 \\
\hline 195 & 295 & 0.00 & 0.58 & 0.72 & 0.67 & 0.63 & 1.4 & 0.5 & 0.61 & 0.59 & 0.54 & 1.15 \\
\hline 196 & 296 & 0.04 & 0.39 & 0.42 & 0.41 & 0.39 & 0.49 & 0.36 & 0.39 & 0.39 & 0.37 & 0.41 \\
\hline
\end{tabular}




\begin{tabular}{|l|l|l|l|l|l|l|l|l|l|l|l|l|}
\hline \multirow{2}{*}{$\begin{array}{l}\text { Wave } \\
\text { No. }\end{array}$} & \multirow{2}{*}{$\begin{array}{l}\text { Wave } \\
\text { ID }\end{array}$} & Days/yr & 8 & 10 & 12 & 14 & 16 & 8 & 10 & 12 & 14 & 16 \\
\hline 197 & 297 & 0.04 & 0.63 & 0.68 & 0.67 & 0.64 & 0.79 & 0.59 & 0.63 & 0.63 & 0.61 & 0.67 \\
\hline 198 & 298 & 0.04 & 0.9 & 0.97 & 0.96 & 0.91 & 1.12 & 0.84 & 0.89 & 0.89 & 0.86 & 0.96 \\
\hline 199 & 299 & 0.07 & 1.18 & 1.28 & 1.26 & 1.2 & 1.48 & 1.1 & 1.17 & 1.17 & 1.14 & 1.26 \\
\hline 200 & 300 & 0.00 & 1.41 & 1.53 & 1.5 & 1.43 & 1.76 & 1.31 & 1.4 & 1.4 & 1.35 & 1.5 \\
\hline 201 & 301 & 0.00 & 0.86 & 0.85 & 0.85 & 0.84 & 0.83 & 0.83 & 0.82 & 0.82 & 0.82 & 0.8 \\
\hline 202 & 302 & 0.04 & 1.4 & 1.38 & 1.38 & 1.36 & 1.34 & 1.35 & 1.33 & 1.34 & 1.32 & 1.3 \\
\hline 203 & 303 & 0.00 & 1.99 & 1.97 & 1.97 & 1.95 & 1.91 & 1.92 & 1.9 & 1.91 & 1.89 & 1.86 \\
\hline 204 & 304 & 0.00 & 2.62 & 2.59 & 2.59 & 2.56 & 2.51 & 2.53 & 2.49 & 2.5 & 2.48 & 2.44 \\
\hline 205 & 305 & 0.00 & 3.12 & 3.09 & 3.09 & 3.05 & 3 & 3.02 & 2.97 & 2.99 & 2.96 & 2.91 \\
\hline 206 & 306 & 0.00 & 3.9 & 3.85 & 3.86 & 3.81 & 3.74 & 3.76 & 3.71 & 3.73 & 3.69 & 3.63 \\
\hline 207 & 307 & 0.04 & 1.87 & 1.77 & 1.72 & 1.73 & 1.67 & 1.8 & 1.7 & 1.65 & 1.65 & 1.61 \\
\hline 208 & 308 & 0.04 & 3.03 & 2.87 & 2.79 & 2.8 & 2.71 & 2.92 & 2.76 & 2.68 & 2.68 & 2.6 \\
\hline 209 & 309 & 0.00 & 4.32 & 4.1 & 3.98 & 3.99 & 3.87 & 4.17 & 3.94 & 3.82 & 3.83 & 3.71 \\
\hline 210 & 310 & 0.00 & 5.67 & 5.38 & 5.22 & 5.25 & 5.08 & 5.47 & 5.17 & 5.01 & 5.02 & 4.87 \\
\hline 211 & 311 & 0.00 & 9.09 & 8.63 & 8.37 & 8.4 & 8.14 & 8.77 & 8.29 & 8.04 & 8.05 & 7.81 \\
\hline
\end{tabular}


Table D4. Wave-induced vertical motion allowances (ft), Phase 1, Mound Reach 2, $h=60 \mathrm{ft}$, fully loaded Susan Maersk, inbound and outbound transits.

\begin{tabular}{|c|c|c|c|c|c|c|c|c|c|c|c|c|}
\hline \multirow{2}{*}{$\begin{array}{l}\text { Wave } \\
\text { No. }\end{array}$} & \multirow{2}{*}{$\begin{array}{l}\text { Wave } \\
\text { ID }\end{array}$} & \multirow[b]{2}{*}{ Days/yr } & \multicolumn{5}{|c|}{ Inbound Ship speed (kt) } & \multicolumn{5}{|c|}{ Outbound Ship speed (kt) } \\
\hline & & & 8 & 10 & 12 & 14 & 16 & 8 & 10 & 12 & 14 & 16 \\
\hline 1 & 401 & 6.10 & 0.03 & 0.05 & 0.04 & 0.05 & 0.09 & 0.01 & 0.01 & 0.01 & 0.01 & 0.02 \\
\hline 2 & 402 & 2.74 & 0.05 & 0.08 & 0.06 & 0.09 & 0.15 & 0.01 & 0.02 & 0.02 & 0.02 & 0.04 \\
\hline 3 & 403 & 0.26 & 0.08 & 0.11 & 0.09 & 0.13 & 0.21 & 0.02 & 0.02 & 0.02 & 0.03 & 0.05 \\
\hline 4 & 404 & 0.04 & 0.10 & 0.15 & 0.11 & 0.16 & 0.27 & 0.02 & 0.03 & 0.03 & 0.04 & 0.07 \\
\hline 5 & 405 & 0.00 & 0.12 & 0.18 & 0.14 & 0.20 & 0.34 & 0.03 & 0.04 & 0.04 & 0.04 & 0.09 \\
\hline 6 & 406 & 0.00 & 0.27 & 0.33 & 0.29 & 0.25 & 0.72 & 0.10 & 0.11 & 0.12 & 0.11 & 0.16 \\
\hline 7 & 407 & 0.07 & 0.45 & 0.55 & 0.48 & 0.42 & 1.19 & 0.17 & 0.19 & 0.19 & 0.19 & 0.26 \\
\hline 8 & 408 & 0.07 & 0.64 & 0.78 & 0.68 & 0.59 & 1.69 & 0.24 & 0.26 & 0.27 & 0.26 & 0.37 \\
\hline 9 & 409 & 0.00 & 0.80 & 0.98 & 0.86 & 0.75 & 2.13 & 0.30 & 0.33 & 0.34 & 0.33 & 0.47 \\
\hline 10 & 410 & 0.00 & 1.01 & 1.24 & 1.08 & 0.94 & 2.68 & 0.38 & 0.42 & 0.43 & 0.42 & 0.59 \\
\hline 11 & 411 & 0.04 & 0.45 & 0.48 & 0.44 & 0.41 & 0.67 & 0.27 & 0.27 & 0.27 & 0.27 & 0.27 \\
\hline 12 & 412 & 0.00 & 0.75 & 0.80 & 0.74 & 0.67 & 1.11 & 0.44 & 0.45 & 0.45 & 0.45 & 0.45 \\
\hline 13 & 413 & 0.04 & 1.06 & 1.13 & 1.04 & 0.95 & 1.57 & 0.63 & 0.63 & 0.64 & 0.63 & 0.63 \\
\hline 14 & 414 & 0.04 & 1.35 & 1.43 & 1.32 & 1.20 & 1.99 & 0.80 & 0.80 & 0.81 & 0.80 & 0.80 \\
\hline 15 & 415 & 0.00 & 0.85 & 0.84 & 0.82 & 0.80 & 0.80 & 0.67 & 0.65 & 0.65 & 0.64 & 0.63 \\
\hline 16 & 416 & 0.00 & 1.41 & 1.40 & 1.37 & 1.33 & 1.32 & 1.11 & 1.07 & 1.07 & 1.06 & 1.04 \\
\hline 17 & 417 & 0.00 & 2.00 & 1.98 & 1.93 & 1.88 & 1.87 & 1.57 & 1.52 & 1.52 & 1.50 & 1.47 \\
\hline 18 & 418 & 0.00 & 2.52 & 2.51 & 2.45 & 2.38 & 2.37 & 1.99 & 1.93 & 1.92 & 1.89 & 1.86 \\
\hline 19 & 419 & 0.00 & 3.17 & 3.15 & 3.07 & 2.98 & 2.98 & 2.50 & 2.42 & 2.41 & 2.38 & 2.33 \\
\hline 20 & 420 & 0.00 & 3.55 & 3.53 & 3.44 & 3.34 & 3.33 & 2.80 & 2.71 & 2.70 & 2.66 & 2.61 \\
\hline 21 & 421 & 0.04 & 1.71 & 1.61 & 1.54 & 1.53 & 1.55 & 1.43 & 1.32 & 1.24 & 1.21 & 1.17 \\
\hline 22 & 422 & 0.00 & 2.83 & 2.67 & 2.55 & 2.53 & 2.57 & 2.36 & 2.18 & 2.06 & 2.01 & 1.94 \\
\hline 23 & 423 & 0.00 & 4.01 & 3.79 & 3.62 & 3.58 & 3.64 & 3.35 & 3.10 & 2.92 & 2.85 & 2.75 \\
\hline 24 & 424 & 0.00 & 5.07 & 4.79 & 4.58 & 4.53 & 4.61 & 4.24 & 3.92 & 3.69 & 3.60 & 3.48 \\
\hline 25 & 425 & 0.00 & 7.13 & 6.74 & 6.44 & 6.37 & 6.48 & 5.96 & 5.51 & 5.20 & 5.07 & 4.90 \\
\hline 26 & 426 & 0.00 & 9.07 & 8.58 & 8.20 & 8.11 & 8.25 & 7.59 & 7.01 & 6.62 & 6.45 & 6.23 \\
\hline 27 & 427 & 0.00 & 9.55 & 9.02 & 8.62 & 8.53 & 8.68 & 7.98 & 7.38 & 6.96 & 6.79 & 6.55 \\
\hline 28 & 428 & 11.24 & 0.07 & 0.10 & 0.07 & 0.10 & 0.18 & 0.01 & 0.01 & 0.01 & 0.01 & 0.02 \\
\hline 29 & 429 & 3.80 & 0.11 & 0.16 & 0.12 & 0.17 & 0.29 & 0.01 & 0.02 & 0.02 & 0.02 & 0.04 \\
\hline 30 & 430 & 0.66 & 0.15 & 0.23 & 0.18 & 0.24 & 0.41 & 0.02 & 0.03 & 0.03 & 0.03 & 0.05 \\
\hline 31 & 431 & 0.04 & 0.20 & 0.29 & 0.23 & 0.31 & 0.54 & 0.03 & 0.03 & 0.04 & 0.03 & 0.06 \\
\hline
\end{tabular}




\begin{tabular}{|c|c|c|c|c|c|c|c|c|c|c|c|c|}
\hline \multirow{2}{*}{$\begin{array}{l}\text { Wave } \\
\text { No. }\end{array}$} & \multirow{2}{*}{$\begin{array}{l}\text { Wave } \\
\text { ID }\end{array}$} & \multirow[b]{2}{*}{ Days/yr } & \multicolumn{5}{|c|}{ Inbound Ship speed (kt) } & \multicolumn{5}{|c|}{ Outbound Ship speed (kt) } \\
\hline & & & 8 & 10 & 12 & 14 & 16 & 8 & 10 & 12 & 14 & 16 \\
\hline 32 & 432 & 1.13 & 0.30 & 0.36 & 0.31 & 0.27 & 0.82 & 0.09 & 0.09 & 0.09 & 0.09 & 0.09 \\
\hline 33 & 433 & 0.18 & 0.50 & 0.60 & .52 & 0.45 & 1.35 & 0.15 & 0.15 & 0.16 & 0.16 & 0.16 \\
\hline 34 & 434 & 0.66 & 0.71 & 0.85 & .74 & 0.63 & 1.91 & 0.21 & 0.22 & 0.22 & 0.22 & 0.22 \\
\hline 35 & 435 & 0.15 & 0.91 & 1.11 & 0.96 & 0.82 & 2.48 & 0.27 & 0.28 & 0.29 & 0.29 & 0.29 \\
\hline 36 & 436 & 0.00 & 1.12 & 1.36 & 1.17 & 1.00 & 3.04 & 0.34 & 0.34 & 0.35 & 0.35 & 0.35 \\
\hline 37 & 437 & 1.20 & 0.50 & 0.53 & 0.48 & 0.43 & 0.73 & 0.27 & 0.26 & 0.26 & 0.26 & 0.26 \\
\hline 38 & 438 & 0.22 & 0.83 & 0.87 & 0.79 & 0.72 & 1.20 & 0.44 & 0.43 & 0.43 & 0.43 & 0.43 \\
\hline 39 & 439 & 0.07 & 1.18 & 1.24 & 1.12 & 1.02 & 1.70 & 0.62 & 0.61 & 0.61 & 0.60 & 0.60 \\
\hline 40 & 440 & 0.22 & 1.52 & 1.60 & .45 & 1.32 & 2.20 & 0.80 & 0.79 & 0.79 & 0.78 & 0.78 \\
\hline 41 & 441 & 0.15 & 1.87 & 1.96 & 1.78 & 1.62 & 2.70 & 0.99 & 0.96 & 0.97 & 0.96 & 0.96 \\
\hline 42 & 442 & 0.04 & 2.23 & 2.34 & 2.13 & 1.93 & 3.23 & 1.18 & 1.15 & 1.15 & 1.14 & 1.15 \\
\hline 43 & 443 & 0.88 & 0.86 & 0.86 & 0.83 & 0.80 & 0.84 & 0.63 & 0.60 & 0.59 & 0.58 & 0.57 \\
\hline 44 & 444 & 0.11 & 1.43 & 1.42 & 1.37 & 1.33 & 1.39 & 1.04 & 0.99 & 0.98 & 0.96 & 0.94 \\
\hline 45 & 445 & 0.04 & 2.03 & 2.01 & 1.94 & 1.88 & 1.96 & 1.47 & 1.41 & 1.38 & 1.36 & 1.33 \\
\hline 46 & 446 & 0.07 & 2.62 & 2.60 & 2.52 & 2.43 & 2.54 & 1.91 & 1.82 & 1.79 & 1.76 & 1.72 \\
\hline 47 & 447 & 0.04 & 3.22 & 3.19 & 3.09 & 2.99 & 3.12 & 2.34 & 2.23 & 2.20 & 2.16 & 2.11 \\
\hline 48 & 448 & 0.04 & 3.85 & 3.81 & 3.69 & 3.57 & 3.73 & 2.80 & 2.67 & 2.63 & 2.58 & 2.52 \\
\hline 49 & 449 & 0.04 & 4.44 & 4.40 & 4.26 & 4.12 & 4.30 & 3.23 & 3.08 & 3.03 & 2.98 & 2.91 \\
\hline 50 & 450 & 0.00 & 5.28 & 5.22 & 5.06 & 4.89 & 5.11 & 3.84 & 3.66 & 3.60 & 3.54 & 3.45 \\
\hline 51 & 51 & 0.18 & 1.28 & 1.20 & .13 & 1.09 & 1.47 & 1.00 & 0.91 & 0.83 & 0.79 & 0.75 \\
\hline 52 & 452 & 0.15 & 2.12 & 1.99 & 1.88 & 1.81 & 2.43 & 1.66 & 1.50 & 1.38 & 1.31 & 1.24 \\
\hline 53 & 453 & 0.11 & 3.01 & 2.82 & 2.66 & 2.56 & 3.44 & 2.35 & 2.12 & 1.95 & 1.85 & 1.76 \\
\hline 54 & 54 & 0.07 & 3.89 & 3.65 & 3.44 & 3.31 & 4.45 & 3.04 & 2.75 & 2.53 & 2.40 & 2.28 \\
\hline 55 & 455 & 0.04 & 4.78 & 4.48 & 4.23 & 4.06 & 5.46 & 3.73 & 3.38 & 3.10 & 2.95 & 2.80 \\
\hline 56 & 456 & 0.04 & 5.70 & 5.35 & 5.05 & 4.85 & 6.52 & 4.46 & 4.03 & 3.71 & 3.52 & 3.35 \\
\hline 57 & 457 & 0.00 & 6.59 & 6.18 & 5.83 & 5.61 & 7.54 & 5.15 & 4.66 & 4.28 & 4.07 & 3.87 \\
\hline 58 & 58 & 0.00 & 7.83 & 7.34 & 6.93 & 6.66 & 8.95 & 6.12 & 5.53 & 5.09 & 4.83 & 4.59 \\
\hline 59 & 59 & 0.00 & 9.20 & 8.63 & 8.14 & 7.83 & 10.52 & 7.19 & 6.50 & 5.98 & 5.68 & 5.40 \\
\hline 60 & 460 & 0.00 & 1.42 & 1.33 & 1.25 & 1.43 & 2.45 & 1.40 & 1.30 & 1.20 & 1.14 & 1.08 \\
\hline 61 & 461 & 0.00 & 2.36 & 2.21 & 2.07 & 2.38 & 4.05 & 2.31 & 2.15 & 1.99 & 1.89 & 1.79 \\
\hline 62 & 462 & 0.00 & 7.33 & 6.85 & 6.44 & 7.38 & 12.59 & 7.18 & 6.68 & 6.19 & 5.86 & 5.56 \\
\hline 63 & 463 & 0.00 & 8.71 & 8.14 & 7.65 & 8.77 & 14.96 & 8.53 & 7.93 & 7.35 & 6.96 & 6.61 \\
\hline 64 & 464 & 0.00 & 1.80 & 1.72 & 1.62 & 2.63 & 4.68 & 2.34 & 2.23 & 2.08 & 1.98 & 1.88 \\
\hline
\end{tabular}




\begin{tabular}{|c|c|c|c|c|c|c|c|c|c|c|c|c|}
\hline \multirow{2}{*}{$\begin{array}{l}\text { Wave } \\
\text { No. }\end{array}$} & \multirow{2}{*}{$\begin{array}{l}\text { Wave } \\
\text { ID }\end{array}$} & \multirow[b]{2}{*}{ Days/yr } & \multicolumn{5}{|c|}{ Inbound Ship speed (kt) } & \multicolumn{5}{|c|}{ Outbound Ship speed (kt) } \\
\hline & & & 8 & 10 & 12 & 14 & 16 & 8 & 10 & 12 & 14 & 16 \\
\hline 65 & 465 & 12.41 & 0.07 & 0.11 & 0.08 & 0.11 & 0.20 & 0.01 & 0.01 & 0.01 & 0.01 & 0.02 \\
\hline 66 & 466 & 3.14 & 0.12 & 0.18 & 0.14 & 0.19 & 0.34 & 0.02 & 0.02 & 0.02 & 0.02 & 0.03 \\
\hline 67 & 467 & 0.37 & 0.18 & 0.26 & 0.20 & 0.27 & 0.48 & 0.02 & 0.03 & 0.03 & 0.03 & 0.05 \\
\hline 68 & 468 & 0.00 & 0.28 & 0.41 & 0.32 & 0.42 & 0.75 & 0.04 & 0.04 & 0.04 & 0.04 & 0.07 \\
\hline 69 & 469 & 1.39 & 0.29 & 0.35 & 0.31 & 0.26 & 0.80 & 0.08 & 0.08 & 0.09 & 0.09 & 0.09 \\
\hline 70 & 470 & 0.37 & 0.50 & 0.61 & 0.53 & 0.45 & 1.37 & 0.14 & 0.15 & 0.15 & 0.15 & 0.15 \\
\hline 71 & 471 & 0.66 & 0.71 & 0.86 & 0.74 & 0.63 & 1.94 & 0.20 & 0.21 & 0.21 & 0.21 & 0.21 \\
\hline 72 & 472 & 0.07 & 0.91 & 1.10 & 0.95 & 0.81 & 2.48 & 0.26 & 0.26 & 0.27 & 0.27 & 0.27 \\
\hline 73 & 473 & 1.46 & 0.49 & 0.51 & 0.46 & 0.42 & 0.71 & 0.25 & 0.24 & 0.24 & 0.24 & 0.24 \\
\hline 74 & 474 & 0.26 & 0.83 & 0.88 & 0.79 & 0.72 & 1.21 & 0.43 & 0.42 & 0.42 & 0.41 & 0.41 \\
\hline 75 & 475 & 0.15 & 1.18 & 1.24 & 1.12 & 1.02 & 1.71 & 0.61 & 0.59 & 0.59 & 0.58 & 0.58 \\
\hline 76 & 476 & 0.18 & 1.51 & 1.59 & 1.44 & 1.30 & 2.19 & 0.78 & 0.75 & 0.75 & 0.75 & 0.75 \\
\hline 77 & 477 & 0.07 & 1.86 & 1.96 & 1.77 & 1.60 & 2.70 & 0.96 & 0.93 & 0.93 & 0.92 & 0.92 \\
\hline 78 & 478 & 0.00 & 2.21 & 2.32 & 2.10 & 1.90 & 3.20 & 1.13 & 1.10 & 1.10 & 1.09 & 1.09 \\
\hline 79 & 479 & 1.24 & 0.83 & 0.82 & 0.79 & 0.77 & 0.81 & 0.59 & 0.56 & 0.55 & 0.54 & 0.53 \\
\hline 80 & 480 & 0.26 & 1.42 & 1.41 & 1.36 & 1.32 & 1.39 & 1.02 & 0.97 & 0.95 & 0.93 & 0.91 \\
\hline 81 & 481 & 0.18 & 2.02 & 2.00 & 1.93 & 1.87 & 1.97 & 1.44 & 1.37 & 1.35 & 1.32 & 1.29 \\
\hline 82 & 482 & 0.04 & 2.58 & 2.56 & 2.47 & 2.39 & 2.52 & 1.85 & 1.76 & 1.72 & 1.69 & 1.65 \\
\hline 83 & 483 & 0.04 & 3.17 & 3.14 & 3.04 & 2.94 & 3.09 & 2.27 & 2.16 & 2.12 & 2.08 & 2.03 \\
\hline 84 & 484 & 0.04 & 3.77 & 3.73 & 3.61 & 3.48 & 3.67 & 2.69 & 2.56 & 2.52 & 2.47 & 2.41 \\
\hline 85 & 485 & 0.00 & 4.33 & 4.29 & 4.15 & 4.01 & 4.22 & 3.10 & 2.95 & 2.89 & 2.84 & 2.77 \\
\hline 86 & 486 & 0.91 & 1.31 & 1.22 & 1.15 & 1.10 & 1.57 & 1.04 & 0.94 & 0.86 & 0.81 & 0.76 \\
\hline 87 & 487 & 0.51 & 2.25 & 2.10 & 1.98 & 1.89 & 2.69 & 1.79 & 1.61 & 1.47 & 1.38 & 1.31 \\
\hline 88 & 488 & 0.15 & 3.19 & 2.97 & 2.80 & 2.68 & 3.81 & 2.54 & 2.28 & 2.08 & 1.96 & 1.85 \\
\hline 89 & 489 & 0.07 & 4.09 & 3.80 & 3.59 & 3.43 & 4.88 & 3.24 & 2.92 & 2.66 & 2.50 & 2.37 \\
\hline 90 & 490 & 0.00 & 5.03 & 4.67 & 4.41 & 4.22 & 6.00 & 3.99 & 3.59 & 3.27 & 3.08 & 2.91 \\
\hline 91 & 491 & 0.15 & 1.27 & 1.18 & 1.10 & 1.36 & 2.37 & 1.25 & 1.15 & 1.06 & 0.99 & 0.93 \\
\hline 92 & 492 & 0.07 & 2.18 & 2.02 & 1.90 & 2.33 & 4.06 & 2.15 & 1.98 & 1.81 & 1.70 & 1.60 \\
\hline 93 & 493 & 0.04 & 3.09 & 2.87 & 2.69 & 3.30 & 5.76 & 3.04 & 2.80 & 2.57 & 2.41 & 2.27 \\
\hline 94 & 494 & 0.00 & 3.95 & 3.67 & 3.44 & 4.22 & 7.36 & 3.89 & 3.58 & 3.29 & 3.08 & 2.90 \\
\hline 95 & 495 & 0.00 & 1.52 & 1.44 & 1.38 & 2.54 & 4.53 & 2.00 & 1.88 & 1.74 & 1.63 & 1.54 \\
\hline 96 & 496 & 0.00 & 2.60 & 2.47 & 2.36 & 4.36 & 7.76 & 3.44 & 3.22 & 2.98 & 2.80 & 2.64 \\
\hline 97 & 497 & 11.86 & 0.07 & 0.10 & 0.08 & 0.11 & 0.19 & 0.01 & 0.02 & 0.02 & 0.02 & 0.04 \\
\hline
\end{tabular}




\begin{tabular}{|c|c|c|c|c|c|c|c|c|c|c|c|c|}
\hline \multirow{2}{*}{$\begin{array}{l}\text { Wave } \\
\text { No. }\end{array}$} & \multirow{2}{*}{$\begin{array}{l}\text { Wave } \\
\text { ID }\end{array}$} & \multirow[b]{2}{*}{ Days/yr } & \multicolumn{5}{|c|}{ Inbound Ship speed (kt) } & \multicolumn{5}{|c|}{ Outbound Ship speed (kt) } \\
\hline & & & 8 & 10 & 12 & 14 & 16 & 8 & 10 & 12 & 14 & 16 \\
\hline 98 & 498 & 3.07 & 0.12 & 0.17 & .14 & 0.18 & 0.32 & 0.02 & 0.03 & 0.03 & 0.03 & 0.06 \\
\hline 99 & 499 & 0.58 & 0.17 & 0.24 & 0.19 & 0.26 & 0.45 & 0.03 & 0.04 & 0.05 & 0.05 & 0.09 \\
\hline 100 & 500 & 0.04 & 0.21 & 0.31 & 0.25 & 0.33 & 0.58 & 0.04 & 0.06 & 0.06 & 0.06 & 0.12 \\
\hline 101 & 501 & 1.10 & 0.28 & 0.34 & 0.29 & 0.25 & 0.75 & 0.10 & 0.10 & 0.11 & 0.11 & 0.13 \\
\hline 102 & 502 & 0.29 & 0.48 & 0.58 & 0.51 & 0.43 & 1.29 & 0.17 & 0.18 & 0.18 & 0.18 & 0.22 \\
\hline 103 & 503 & 0.47 & 0.68 & 0.82 & 0.72 & 0.62 & 1.83 & 0.24 & 0.25 & 0.26 & 0.26 & 0.32 \\
\hline 104 & 504 & 0.07 & 0.87 & 1.05 & 0.92 & 0.79 & 2.34 & 0.31 & 0.33 & 0.33 & 0.33 & 0.40 \\
\hline 105 & 505 & 0.00 & 1.06 & 1.28 & 1.12 & 0.96 & 2.86 & 0.37 & 0.40 & 0.41 & 0.40 & 0.49 \\
\hline 106 & 506 & 0.88 & 0.47 & 0.50 & 0.46 & 0.42 & 0.68 & 0.28 & 0.28 & 0.28 & 0.28 & 0.28 \\
\hline 107 & 507 & .15 & 0.81 & 0.85 & .79 & 0.72 & 1.16 & 0.48 & 0.47 & 0.48 & 0.47 & 0.47 \\
\hline 108 & 508 & 0.11 & 15 & 1.21 & .12 & 1.03 & 1.65 & 0.68 & 0.67 & 0.68 & 0.67 & 0.67 \\
\hline 109 & 509 & 0.15 & 1.47 & 1.55 & 1.43 & 1.31 & 2.11 & 0.86 & 0.86 & 0.87 & 0.86 & 0.86 \\
\hline 110 & 510 & 0.07 & 1.79 & 1.89 & 1.75 & 1.60 & 2.57 & 1.05 & 1.05 & 1.05 & 1.05 & 1.05 \\
\hline 111 & 511 & 0.00 & 2.20 & 2.32 & 2.14 & 1.96 & 3.15 & 1.29 & 1.28 & 1.29 & 1.28 & 1.28 \\
\hline 112 & 512 & 0.62 & 0.85 & 0.84 & 0.82 & 0.79 & 0.79 & 0.65 & 0.63 & 0.62 & 0.61 & 0.60 \\
\hline 113 & 513 & 0.26 & 1.45 & 1.44 & 1.40 & 1.36 & 1.36 & 1.12 & 1.08 & 1.07 & 1.05 & 1.03 \\
\hline 114 & 514 & 0.15 & 2.06 & 2.04 & .99 & 1.93 & 1.93 & 1.58 & 1.52 & 1.51 & 1.49 & 1.46 \\
\hline 115 & 515 & 11 & 64 & .61 & 54 & .47 & 47 & .03 & 95 & L.93 & .90 & 1.86 \\
\hline 116 & 516 & 0.00 & 3.21 & 3.18 & 3.10 & 3.01 & 3.01 & 2.47 & 2.38 & 2.36 & 2.32 & 2.27 \\
\hline 117 & 517 & .00 & 3.94 & 3.90 & 3.80 & 3.69 & 3.69 & 3.03 & 2.91 & 2.89 & 2.84 & 2.78 \\
\hline 118 & 18 & 0.73 & .53 & 1.44 & .37 & .35 & .52 & 1.26 & .15 & 1.08 & 1.04 & 1.00 \\
\hline 119 & 519 & 22 & 63 & 2.47 & .36 & 2.31 & 2.60 & .15 & 1.98 & 1.85 & .79 & 1.72 \\
\hline 120 & 520 & 0.11 & 3.72 & 3.51 & 3.34 & 3.28 & 3.68 & 3.05 & 2.80 & 2.62 & 2.54 & 2.44 \\
\hline 121 & 521 & 0.07 & 4.76 & 4.49 & 4.27 & 4.20 & 4.71 & 3.90 & 3.58 & 3.36 & 3.25 & 3.12 \\
\hline 122 & 522 & 0.04 & 80 & 5.47 & .21 & 5.11 & 74 & .76 & 4.37 & 4.09 & 3.96 & 3.80 \\
\hline 123 & 523 & 0.00 & 7.11 & 6.70 & 6.38 & 6.27 & 7.05 & 5.83 & 5.36 & 5.01 & 4.85 & 4.67 \\
\hline 124 & 524 & 0.11 & 1.72 & 1.63 & 1.55 & 1.52 & 2.30 & 1.66 & 1.57 & 1.49 & 1.44 & 1.39 \\
\hline 125 & 525 & 0.04 & 2.95 & 2.80 & 2.65 & 2.60 & 3.94 & 2.85 & 2.70 & 2.55 & 2.47 & 2.38 \\
\hline 126 & 526 & 0.04 & 4.18 & 3.97 & 3.76 & 3.69 & 5.58 & 4.03 & 3.83 & 3.62 & 3.50 & 3.37 \\
\hline 127 & 527 & 0.00 & 2.41 & 2.33 & 2.19 & 2.49 & 4.32 & 2.98 & 2.91 & 2.78 & 2.70 & 2.60 \\
\hline 128 & 528 & 0.04 & 4.14 & 3.99 & 3.76 & 4.27 & 7.41 & 5.11 & 4.98 & 4.76 & 4.62 & 4.46 \\
\hline 129 & 529 & 0.04 & 5.86 & 5.65 & 5.33 & 6.05 & 10.51 & 7.24 & 7.06 & 6.74 & 6.55 & 6.32 \\
\hline 130 & 530 & 18.03 & 0.06 & 0.09 & 0.07 & 0.09 & 0.16 & 0.02 & 0.03 & 0.03 & 0.03 & 0.06 \\
\hline
\end{tabular}




\begin{tabular}{|c|c|c|c|c|c|c|c|c|c|c|c|c|}
\hline \multirow{2}{*}{$\begin{array}{l}\text { Wave } \\
\text { No. }\end{array}$} & \multirow{2}{*}{$\begin{array}{l}\text { Wave } \\
\text { ID }\end{array}$} & \multirow[b]{2}{*}{ Days/yr } & \multicolumn{5}{|c|}{ Inbound Ship speed (kt) } & \multicolumn{5}{|c|}{ Outbound Ship speed (kt) } \\
\hline & & & 8 & 10 & 12 & 14 & 16 & 8 & 10 & 12 & 14 & 16 \\
\hline 131 & 531 & 3.80 & 0.10 & 0.15 & .12 & 0.16 & 0.28 & 0.04 & 0.05 & 0.05 & 0.06 & 0.11 \\
\hline 132 & 532 & 0.37 & 0.15 & 0.22 & 0.17 & 0.23 & 0.40 & 0.05 & 0.08 & 0.07 & 0.08 & 0.16 \\
\hline 133 & 533 & 0.00 & 0.23 & 0.34 & 0.27 & 0.36 & 0.64 & 0.08 & 0.12 & 0.11 & 0.13 & 0.25 \\
\hline 134 & 534 & 23 & 0.23 & 0.29 & 0.25 & 0.22 & 0.61 & 0.11 & 0.13 & 0.13 & 0.12 & 0.21 \\
\hline 135 & 535 & 0.58 & 0.41 & 0.50 & 0.44 & 0.38 & 1.06 & 0.20 & 0.23 & 0.23 & 0.22 & 0.37 \\
\hline 136 & 536 & 0.58 & 0.59 & 0.72 & 0.63 & 0.56 & 1.54 & 0.28 & 0.33 & 0.33 & 0.31 & 0.54 \\
\hline 137 & 537 & 0.07 & 0.76 & 0.93 & 0.82 & 0.72 & 1.99 & 0.37 & 0.42 & 0.42 & 0.40 & 0.70 \\
\hline 138 & 538 & 1.06 & 0.42 & 0.45 & 0.42 & 0.39 & 0.59 & 0.30 & 0.30 & 0.31 & 0.30 & 0.30 \\
\hline 139 & 539 & 0.29 & 0.72 & 0.78 & 0.74 & 0.68 & 1.02 & 0.51 & 0.53 & 0.53 & 0.53 & 0.52 \\
\hline 140 & 540 & 0.11 & 1.05 & 1.13 & L.06 & 0.99 & 1.47 & 0.74 & 0.76 & 0.77 & 0.76 & 0.76 \\
\hline 141 & 541 & 0.26 & 1.36 & 1.46 & 1.38 & 1.28 & 1.91 & 0.96 & 0.98 & 1.00 & 0.98 & 0.98 \\
\hline 142 & 542 & 0.11 & 1.67 & 1.79 & 1.69 & 1.57 & 2.34 & 1.18 & 1.21 & 1.22 & 1.21 & 1.20 \\
\hline 143 & 543 & 0.00 & 2.01 & 2.16 & 2.03 & 1.89 & 2.82 & 1.42 & 1.45 & 1.47 & 1.45 & 1.45 \\
\hline 144 & 44 & 0.69 & 0.84 & 0.83 & 0.82 & 0.80 & 0.78 & 0.72 & 0.70 & 0.70 & 0.69 & 0.68 \\
\hline 145 & 545 & 0.29 & 1.46 & 1.45 & .43 & 1.40 & 1.36 & 1.25 & 1.21 & 1.21 & 1.20 & 1.18 \\
\hline 146 & 546 & 0.18 & 2.12 & 2.09 & 2.07 & 2.02 & 1.97 & 1.80 & 1.76 & 1.76 & 1.74 & 1.70 \\
\hline 147 & 547 & 0.04 & 2.74 & 2.71 & 2.67 & 2.62 & 2.55 & 2.34 & 2.27 & 2.28 & 2.25 & 2.21 \\
\hline 148 & 548 & 07 & 36 & 3.33 & 28 & 3.21 & 14 & 87 & 2.79 & 2.79 & .76 & 2.71 \\
\hline 149 & 549 & 0.04 & 4.05 & 4.00 & 3.95 & 3.86 & 3.78 & 3.45 & 3.36 & 3.36 & 3.32 & 3.26 \\
\hline 150 & 550 & 0.00 & 4.58 & 4.53 & 4.47 & 4.37 & 4.27 & 3.90 & 3.80 & 3.80 & 3.76 & 3.69 \\
\hline 151 & 51 & 0.62 & 73 & 1.65 & .58 & .58 & 1.52 & .51 & .41 & L.35 & 1.33 & 1.29 \\
\hline 152 & 552 & 22 & 02 & 2.87 & .76 & 2.76 & 2.65 & .63 & 2.46 & 2.35 & .32 & 2.25 \\
\hline 153 & 553 & 0.11 & 4.37 & 4.15 & 3.99 & 3.99 & 3.83 & 3.81 & 3.56 & 3.40 & 3.36 & 3.26 \\
\hline 154 & 554 & .00 & 5.66 & 5.37 & 5.17 & 5.16 & 4.96 & 4.94 & 4.61 & 4.40 & 4.35 & 4.22 \\
\hline 155 & 555 & 0.00 & 36 & 7.94 & 64 & 7.63 & 33 & .29 & 6.81 & 6.50 & 6.42 & 6.23 \\
\hline 156 & 556 & 0.15 & 2.23 & 2.13 & 2.04 & 2.03 & 1.97 & 2.11 & 2.02 & 1.96 & 1.94 & 1.88 \\
\hline 157 & 557 & 0.11 & 3.88 & 3.71 & .56 & 3.54 & 3.43 & 3.67 & 3.53 & 3.42 & 3.38 & 3.27 \\
\hline 158 & 558 & 0.04 & 3.32 & 3.21 & 3.07 & 3.02 & 3.39 & 3.95 & 3.88 & 3.81 & 3.76 & 3.62 \\
\hline 159 & 559 & 0.00 & 5.78 & 5.60 & 5.34 & 5.26 & 5.91 & 6.87 & 6.77 & 6.64 & 6.56 & 6.31 \\
\hline 160 & 560 & 27.08 & 0.06 & 0.08 & 0.07 & 0.09 & 0.16 & 0.04 & 0.05 & 0.05 & 0.06 & 0.11 \\
\hline 161 & 561 & 6.72 & 0.10 & 0.14 & 0.12 & 0.15 & 0.27 & 0.06 & 0.09 & 0.08 & 0.10 & 0.19 \\
\hline 162 & 562 & 0.40 & 0.13 & 0.19 & 0.16 & 0.21 & 0.38 & 0.09 & 0.13 & 0.11 & 0.14 & 0.26 \\
\hline 163 & 563 & 0.00 & 0.17 & 0.25 & 0.21 & 0.27 & 0.49 & 0.12 & 0.17 & 0.15 & 0.18 & 0.34 \\
\hline
\end{tabular}




\begin{tabular}{|c|c|c|c|c|c|c|c|c|c|c|c|c|}
\hline \multirow{2}{*}{$\begin{array}{l}\text { Wave } \\
\text { No. }\end{array}$} & \multirow{2}{*}{$\begin{array}{l}\text { Wave } \\
\text { ID }\end{array}$} & \multirow[b]{2}{*}{ Days/yr } & \multicolumn{5}{|c|}{ Inbound Ship speed (kt) } & \multicolumn{5}{|c|}{ Outbound Ship speed (kt) } \\
\hline & & & 8 & 10 & 12 & 14 & 16 & 8 & 10 & 12 & 14 & 16 \\
\hline 164 & 564 & 4.60 & 0.21 & 0.25 & 0.23 & 0.20 & 0.52 & 0.15 & 0.18 & 0.17 & 0.16 & 0.34 \\
\hline 165 & 565 & 0.91 & 0.36 & 0.43 & 0.39 & 0.34 & 0.89 & 0.26 & 0.31 & 0.30 & 0.27 & 0.59 \\
\hline 166 & 566 & 1.24 & 0.50 & 0.60 & 0.54 & 0.48 & 1.24 & 0.37 & 0.43 & 0.41 & 0.38 & 0.82 \\
\hline 167 & 567 & 0.11 & 0.65 & 0.78 & 0.71 & 0.62 & 1.61 & 0.48 & 0.56 & 0.54 & 0.49 & 1.07 \\
\hline 168 & 568 & 1.46 & 0.41 & 0.43 & 0.42 & 0.40 & 0.51 & 0.35 & 0.37 & 0.37 & 0.36 & 0.37 \\
\hline 169 & 569 & 0.33 & 0.70 & 0.74 & 0.72 & 0.68 & 0.88 & 0.61 & 0.63 & 0.63 & 0.62 & 0.64 \\
\hline 170 & 570 & 0.22 & 0.97 & 1.03 & 1.00 & 0.95 & 1.23 & 0.85 & 0.88 & 0.88 & 0.86 & 0.89 \\
\hline 171 & 571 & 0.40 & 1.26 & 1.34 & 1.30 & 1.24 & 1.60 & 1.10 & 1.15 & 1.15 & 1.12 & 1.16 \\
\hline 172 & 572 & 0.07 & 1.55 & 1.65 & 1.60 & 1.53 & 1.97 & 1.35 & 1.41 & 1.41 & 1.38 & 1.42 \\
\hline 173 & 573 & 0.00 & 1.86 & 1.97 & 1.92 & 1.82 & 2.36 & 1.62 & 1.69 & 1.69 & 1.65 & 1.70 \\
\hline 174 & 574 & 0.69 & 0.87 & 0.86 & 0.86 & 0.85 & 0.83 & 0.82 & 0.81 & 0.81 & 0.80 & 0.79 \\
\hline 175 & 575 & 0.33 & 1.50 & 1.48 & 1.48 & 1.45 & 1.42 & 1.41 & 1.39 & 1.39 & 1.37 & 1.35 \\
\hline 176 & 576 & 0.07 & 2.09 & 2.07 & 2.06 & 2.03 & 1.99 & 1.97 & 1.93 & 1.94 & 1.92 & 1.88 \\
\hline 177 & 577 & 0.04 & 2.72 & 2.69 & 2.68 & 2.64 & 2.58 & 2.56 & 2.51 & 2.52 & 2.49 & 2.45 \\
\hline 178 & 578 & 0.04 & 3.35 & 3.30 & 3.29 & 3.24 & 3.18 & 3.15 & 3.09 & 3.10 & 3.06 & 3.01 \\
\hline 179 & 579 & 0.04 & 4.00 & 3.95 & 3.94 & 3.88 & 3.80 & 3.77 & 3.70 & 3.71 & 3.67 & 3.60 \\
\hline 180 & 580 & 0.22 & 1.74 & 1.67 & 1.62 & 1.62 & 1.57 & 1.64 & 1.55 & 1.51 & 1.50 & 1.46 \\
\hline 181 & 581 & 0.18 & 2.99 & 2.86 & 2.78 & 2.78 & 2.70 & 2.81 & 2.67 & 2.58 & 2.58 & 2.51 \\
\hline 182 & 582 & 0.04 & 4.18 & 3.99 & 3.88 & 3.89 & 3.77 & 3.93 & 3.72 & 3.61 & 3.60 & 3.50 \\
\hline 183 & 583 & 0.00 & 5.43 & 5.18 & 5.04 & 5.05 & 4.89 & 5.10 & 4.83 & 4.68 & 4.68 & 4.55 \\
\hline 184 & 584 & 0.00 & 6.67 & 6.37 & 6.19 & 6.21 & 6.02 & 6.28 & 5.94 & 5.76 & 5.75 & 5.60 \\
\hline 185 & 585 & 0.00 & 7.98 & 7.62 & 7.41 & 7.43 & 7.20 & 7.51 & 7.11 & 6.89 & 6.88 & 6.70 \\
\hline 186 & 586 & 0.00 & 9.29 & 8.87 & 8.63 & 8.65 & 8.38 & 8.74 & 8.28 & 8.02 & 8.01 & 7.79 \\
\hline 187 & 587 & 10.22 & 0.02 & 0.03 & 0.02 & 0.03 & 0.05 & 0.02 & 0.03 & 0.03 & 0.04 & 0.06 \\
\hline 188 & 588 & 2.81 & 0.03 & 0.04 & 0.04 & 0.05 & 0.09 & 0.04 & 0.05 & 0.04 & 0.06 & 0.10 \\
\hline 189 & 589 & 0.22 & 0.04 & 0.06 & 0.05 & 0.07 & 0.12 & 0.05 & 0.08 & 0.06 & 0.09 & 0.15 \\
\hline 190 & 590 & 0.00 & 0.05 & 0.08 & 0.07 & 0.09 & 0.16 & 0.07 & 0.10 & 0.08 & 0.11 & 0.19 \\
\hline 191 & 591 & 0.00 & 0.06 & 0.10 & 0.08 & 0.11 & 0.19 & 0.08 & 0.12 & 0.10 & 0.14 & 0.23 \\
\hline 192 & 592 & 0.18 & 0.17 & 0.21 & 0.19 & 0.17 & 0.40 & 0.20 & 0.24 & 0.22 & 0.19 & 0.49 \\
\hline 193 & 593 & 0.18 & 0.28 & 0.33 & 0.31 & 0.28 & 0.65 & 0.33 & 0.39 & 0.36 & 0.31 & 0.80 \\
\hline 194 & 594 & 0.29 & 0.40 & 0.48 & 0.45 & 0.40 & 0.93 & 0.47 & 0.56 & 0.51 & 0.45 & 1.14 \\
\hline 195 & 595 & 0.00 & 0.53 & 0.63 & 0.59 & 0.53 & 1.22 & 0.61 & 0.74 & 0.67 & 0.59 & 1.49 \\
\hline 196 & 596 & 0.04 & 0.38 & 0.40 & 0.40 & 0.39 & 0.42 & 0.41 & 0.43 & 0.42 & 0.41 & 0.50 \\
\hline
\end{tabular}




\begin{tabular}{|l|l|l|l|l|l|l|l|l|l|l|l|l|}
\hline \multirow{2}{*}{$\begin{array}{l}\text { Wave } \\
\text { No. }\end{array}$} & Wave & & & \multicolumn{3}{|c|}{ Inbound Ship speed (kt) } & \multicolumn{3}{c|}{ Outbound Ship speed (kt) } \\
\cline { 5 - 11 } & ID & Days/yr & 8 & 10 & 12 & 14 & 16 & 8 & 10 & 12 & 14 & 16 \\
\hline 197 & 597 & 0.04 & 0.62 & 0.65 & 0.65 & 0.63 & 0.69 & 0.66 & 0.70 & 0.69 & 0.66 & 0.81 \\
\hline 198 & 598 & 0.04 & 0.88 & 0.92 & 0.92 & 0.89 & 0.98 & 0.94 & 1.00 & 0.98 & 0.94 & 1.15 \\
\hline 199 & 599 & 0.07 & 1.16 & 1.22 & 1.21 & 1.17 & 1.28 & 1.24 & 1.31 & 1.29 & 1.23 & 1.51 \\
\hline 200 & 600 & 0.00 & 1.38 & 1.45 & 1.44 & 1.40 & 1.53 & 1.48 & 1.57 & 1.53 & 1.47 & 1.80 \\
\hline 201 & 601 & 0.00 & 0.87 & 0.86 & 0.86 & 0.85 & 0.83 & 0.90 & 0.89 & 0.89 & 0.87 & 0.86 \\
\hline 202 & 602 & 0.04 & 1.41 & 1.39 & 1.39 & 1.38 & 1.35 & 1.46 & 1.44 & 1.44 & 1.42 & 1.39 \\
\hline 203 & 603 & 0.00 & 2.02 & 1.98 & 1.99 & 1.97 & 1.93 & 2.08 & 2.05 & 2.05 & 2.02 & 1.98 \\
\hline 204 & 604 & 0.00 & 2.65 & 2.61 & 2.61 & 2.58 & 2.53 & 2.73 & 2.69 & 2.69 & 2.65 & 2.60 \\
\hline 205 & 605 & 0.00 & 3.16 & 3.11 & 3.12 & 3.08 & 3.02 & 3.26 & 3.22 & 3.21 & 3.17 & 3.11 \\
\hline 206 & 606 & 0.00 & 3.95 & 3.88 & 3.89 & 3.84 & 3.77 & 4.07 & 4.01 & 4.01 & 3.95 & 3.88 \\
\hline 207 & 607 & 0.04 & 1.84 & 1.75 & 1.69 & 1.69 & 1.65 & 1.90 & 1.81 & 1.75 & 1.76 & 1.71 \\
\hline 208 & 608 & 0.04 & 2.99 & 2.83 & 2.74 & 2.75 & 2.67 & 3.08 & 2.93 & 2.84 & 2.85 & 2.76 \\
\hline 209 & 609 & 0.00 & 4.26 & 4.04 & 3.91 & 3.92 & 3.81 & 4.39 & 4.18 & 4.05 & 4.07 & 3.94 \\
\hline 210 & 610 & 0.00 & 5.60 & 5.31 & 5.14 & 5.15 & 5.00 & 5.77 & 5.49 & 5.32 & 5.34 & 5.18 \\
\hline 211 & 611 & 0.00 & 8.97 & 8.51 & 8.24 & 8.25 & 8.01 & 9.25 & 8.80 & 8.53 & 8.56 & 8.30 \\
\hline
\end{tabular}




\section{Appendix E: Net UKC for Phase 1, Reach 1 Channel $(h=53 \mathrm{ft})$ and Reach 2 Mound ( $h=55 \mathrm{ft}$ ), Fully loaded ( $T=47.5 \mathrm{ft}$ ) Susan Maersk}

Table E1. Net UKC (ft), Phase 1, Channel Reach 1, $h=53 \mathrm{ft}$, fully loaded Susan Maersk, inbound and outbound transits.

\begin{tabular}{|c|c|c|c|c|c|c|c|c|c|c|c|c|}
\hline \multirow{2}{*}{$\begin{array}{l}\text { Wave } \\
\text { No. }\end{array}$} & \multirow{2}{*}{$\begin{array}{l}\text { Wave } \\
\text { ID }\end{array}$} & \multirow[b]{2}{*}{ Days/yr } & \multicolumn{5}{|c|}{ Inbound Ship speed (kt) } & \multicolumn{5}{|c|}{ Outbound Ship speed (kt) } \\
\hline & & & 8 & 10 & 12 & 14 & 16 & 8 & 10 & 12 & 14 & 16 \\
\hline 1 & 101 & 6.10 & 4.42 & 3.79 & 3.02 & 2.04 & 0.77 & 4.43 & 3.83 & 3.05 & 2.08 & 0.82 \\
\hline 2 & 102 & 2.74 & 4.40 & 3.76 & 3.00 & 2.01 & 0.72 & 4.43 & 3.82 & 3.04 & 2.07 & 0.80 \\
\hline 3 & 103 & 0.26 & 4.39 & 3.73 & 2.97 & 1.97 & 0.66 & 4.42 & 3.81 & 3.03 & 2.05 & 0.78 \\
\hline 4 & 104 & 0.04 & 4.37 & 3.70 & 2.95 & 1.93 & 0.60 & 4.42 & 3.80 & 3.02 & 2.04 & 0.75 \\
\hline 5 & 105 & 0.00 & 4.36 & 3.66 & 2.92 & 1.89 & 0.54 & 4.41 & 3.79 & 3.00 & 2.02 & 0.73 \\
\hline 6 & 106 & 0.00 & 4.25 & 3.54 & 2.76 & 1.81 & 0.32 & 4.35 & 3.72 & 2.93 & 1.97 & 0.64 \\
\hline 7 & 107 & 0.07 & 4.13 & 3.35 & 2.57 & 1.62 & -0.03 & 4.29 & 3.64 & 2.84 & 1.88 & 0.50 \\
\hline 8 & 108 & 0.07 & 4.00 & 3.15 & 2.37 & 1.42 & -0.40 & 4.23 & 3.56 & 2.75 & 1.79 & 0.35 \\
\hline 9 & 109 & 0.00 & 3.88 & 2.96 & 2.18 & 1.24 & -0.74 & 4.17 & 3.49 & 2.67 & 1.70 & 0.21 \\
\hline 10 & 110 & 0.00 & 3.74 & 2.74 & 1.96 & 1.01 & -1.15 & 4.10 & 3.39 & 2.57 & 1.60 & 0.04 \\
\hline 11 & 111 & 0.04 & 4.10 & 3.41 & 2.63 & 1.70 & 0.27 & 4.23 & 3.60 & 2.81 & 1.86 & 0.59 \\
\hline 12 & 112 & 0.00 & 3.87 & 3.13 & 2.35 & 1.44 & -0.11 & 4.08 & 3.45 & 2.65 & 1.69 & 0.42 \\
\hline 13 & 113 & 0.04 & 3.64 & 2.83 & 2.06 & 1.17 & -0.52 & 3.94 & 3.29 & 2.48 & 1.53 & 0.24 \\
\hline 14 & 114 & 0.04 & 3.43 & 2.57 & 1.80 & 0.92 & -0.89 & 3.80 & 3.14 & 2.33 & 1.37 & 0.07 \\
\hline 15 & 115 & 0.00 & 3.72 & 3.10 & 2.34 & 1.42 & 0.03 & 3.90 & 3.30 & 2.51 & 1.56 & 0.32 \\
\hline 16 & 116 & 0.00 & 3.24 & 2.61 & 1.87 & 0.98 & -0.51 & 3.54 & 2.95 & 2.15 & 1.21 & -0.04 \\
\hline 17 & 117 & 0.00 & 2.75 & 2.10 & 1.37 & 0.51 & -1.08 & 3.16 & 2.58 & 1.77 & 0.83 & -0.41 \\
\hline 18 & 118 & 0.00 & 2.30 & 1.64 & 0.92 & 0.09 & -1.60 & 2.82 & 2.24 & 1.43 & 0.50 & -0.75 \\
\hline 19 & 119 & 0.00 & 1.75 & 1.08 & 0.37 & -0.43 & -2.23 & 2.41 & 1.83 & 1.02 & 0.09 & -1.17 \\
\hline 20 & 120 & 0.00 & 1.43 & 0.75 & 0.05 & -0.73 & -2.60 & 2.17 & 1.59 & 0.77 & -0.15 & -1.41 \\
\hline 21 & 121 & 0.04 & 2.59 & 2.09 & 1.35 & 0.50 & -1.03 & 3.05 & 2.55 & 1.79 & 0.89 & -0.30 \\
\hline 22 & 122 & 0.00 & 1.38 & 0.94 & 0.23 & -0.54 & -2.27 & 2.13 & 1.71 & 0.96 & 0.09 & -1.07 \\
\hline 23 & 123 & 0.00 & 0.11 & -0.27 & -0.95 & -1.65 & -3.57 & 1.17 & 0.81 & 0.08 & -0.74 & -1.87 \\
\hline 24 & 124 & 0.00 & -1.04 & -1.36 & -2.01 & -2.64 & -4.75 & 0.31 & 0.01 & -0.71 & -1.50 & -2.60 \\
\hline
\end{tabular}




\begin{tabular}{|c|c|c|c|c|c|c|c|c|c|c|c|c|}
\hline \multirow{2}{*}{$\begin{array}{l}\text { Wave } \\
\text { No. }\end{array}$} & \multirow{2}{*}{$\begin{array}{l}\text { Wave } \\
\text { ID }\end{array}$} & \multirow[b]{2}{*}{ Days/yr } & \multicolumn{5}{|c|}{ Inbound Ship speed (kt) } & \multicolumn{5}{|c|}{ Outbound Ship speed (kt) } \\
\hline & & & 8 & 10 & 12 & 14 & 16 & 8 & 10 & 12 & 14 & 16 \\
\hline 25 & 125 & 0.00 & -3.27 & -3.47 & -4.08 & -4.57 & -7.03 & -1.38 & -1.54 & -2.24 & -2.96 & -4.00 \\
\hline 26 & 126 & 0.00 & -5.38 & -5.47 & -6.02 & -6.39 & -9.18 & -2.96 & -3.01 & -3.68 & -4.34 & -5.33 \\
\hline 27 & 127 & 0.00 & -5.89 & -5.95 & -6.49 & -6.83 & -9.70 & -3.35 & -3.37 & -4.03 & -4.68 & -5.65 \\
\hline 28 & 128 & 11.24 & 4.39 & 3.74 & 2.98 & 1.99 & 0.68 & 4.43 & 3.83 & 3.04 & 2.08 & 0.82 \\
\hline 29 & 129 & 3.80 & 4.36 & 3.68 & 2.93 & 1.92 & 0.57 & 4.42 & 3.82 & 3.03 & 2.06 & 0.80 \\
\hline 30 & 130 & 0.66 & 4.33 & 3.61 & 2.87 & 1.84 & 0.44 & 4.42 & 3.81 & 3.02 & 2.05 & 0.77 \\
\hline 31 & 131 & 0.04 & 4.30 & 3.54 & 2.81 & 1.77 & 0.32 & 4.41 & 3.80 & 3.01 & 2.04 & 0.74 \\
\hline 32 & 132 & 1.13 & 4.22 & 3.50 & 2.72 & 1.77 & 0.25 & 4.36 & 3.75 & 2.96 & 2.00 & 0.72 \\
\hline 33 & 133 & 0.18 & 4.08 & 3.28 & 2.50 & 1.56 & -0.14 & 4.32 & 3.70 & 2.90 & 1.94 & 0.64 \\
\hline 34 & 134 & 0.66 & 3.93 & 3.04 & 2.27 & 1.33 & -0.56 & 4.26 & 3.64 & 2.84 & 1.87 & 0.54 \\
\hline 35 & 135 & 0.15 & 3.78 & 2.81 & 2.04 & 1.11 & -0.98 & 4.21 & 3.58 & 2.77 & 1.80 & 0.45 \\
\hline 36 & 136 & 0.00 & 3.63 & 2.57 & 1.81 & 0.88 & -1.40 & 4.16 & 3.52 & 2.70 & 1.74 & 0.35 \\
\hline 37 & 137 & 1.20 & 4.04 & 3.35 & 2.58 & 1.66 & 0.20 & 4.24 & 3.63 & 2.85 & 1.88 & 0.64 \\
\hline 38 & 138 & 0.22 & 3.78 & 3.03 & 2.27 & 1.37 & -0.24 & 4.11 & 3.50 & 2.71 & 1.74 & 0.50 \\
\hline 39 & 139 & 0.07 & 3.51 & 2.69 & 1.94 & 1.06 & -0.70 & 3.97 & 3.36 & 2.56 & 1.59 & 0.35 \\
\hline 40 & 140 & 0.22 & 3.23 & 2.36 & 1.61 & 0.75 & -1.15 & 3.83 & 3.22 & 2.41 & 1.44 & 0.20 \\
\hline 41 & 141 & 0.15 & 2.96 & 2.02 & 1.28 & 0.45 & -1.61 & 3.69 & 3.07 & 2.26 & 1.29 & 0.04 \\
\hline 42 & 142 & 0.04 & 2.67 & 1.66 & 0.93 & 0.12 & -2.09 & 3.55 & 2.92 & 2.11 & 1.14 & -0.11 \\
\hline 43 & 143 & 0.88 & 3.68 & 3.06 & 2.31 & 1.41 & -0.06 & 3.95 & 3.37 & 2.58 & 1.63 & 0.39 \\
\hline 44 & 144 & 0.11 & 3.18 & 2.54 & 1.82 & 0.95 & -0.67 & 3.63 & 3.06 & 2.27 & 1.32 & 0.08 \\
\hline 45 & 145 & 0.04 & 2.65 & 2.00 & 1.31 & 0.48 & -1.30 & 3.30 & 2.73 & 1.94 & 0.99 & -0.25 \\
\hline 46 & 146 & 0.07 & 2.12 & 1.46 & 0.79 & 0.00 & -1.94 & 2.96 & 2.40 & 1.60 & 0.66 & -0.58 \\
\hline 47 & 147 & 0.04 & 1.60 & 0.92 & 0.28 & -0.48 & -2.58 & 2.62 & 2.08 & 1.27 & 0.34 & -0.90 \\
\hline 48 & 148 & 0.04 & 1.04 & 0.36 & -0.27 & -0.98 & -3.25 & 2.27 & 1.74 & 0.93 & -0.01 & -1.25 \\
\hline 49 & 149 & 0.04 & 0.52 & -0.19 & -0.78 & -1.46 & -3.89 & 1.93 & 1.41 & 0.59 & -0.33 & -1.57 \\
\hline 50 & 150 & 0.00 & -0.22 & -0.94 & -1.50 & -2.13 & -4.78 & 1.46 & 0.95 & 0.13 & -0.79 & -2.03 \\
\hline 51 & 151 & 0.18 & 2.98 & 2.45 & 1.74 & 0.89 & -1.12 & 3.52 & 3.01 & 2.26 & 1.33 & 0.13 \\
\hline 52 & 152 & 0.15 & 2.02 & 1.53 & 0.88 & 0.10 & -2.42 & 2.92 & 2.46 & 1.73 & 0.83 & -0.35 \\
\hline 53 & 153 & 0.11 & 1.01 & 0.57 & -0.03 & -0.73 & -3.78 & 2.29 & 1.88 & 1.17 & 0.30 & -0.85 \\
\hline 54 & 154 & 0.07 & -0.01 & -0.39 & -0.94 & -1.56 & -5.15 & 1.65 & 1.31 & 0.62 & -0.23 & -1.35 \\
\hline 55 & 155 & 0.04 & -1.02 & -1.35 & -1.85 & -2.40 & -6.52 & 1.02 & 0.73 & 0.06 & -0.75 & -1.85 \\
\hline 56 & 156 & 0.04 & -2.08 & -2.36 & -2.80 & -3.27 & -7.95 & 0.35 & 0.12 & -0.52 & -1.31 & -2.38 \\
\hline 57 & 157 & 0.00 & -3.09 & -3.32 & -3.71 & -4.10 & -9.32 & -0.28 & -0.45 & -1.07 & -1.84 & -2.88 \\
\hline
\end{tabular}




\begin{tabular}{|c|c|c|c|c|c|c|c|c|c|c|c|c|}
\hline \multirow{2}{*}{$\begin{array}{l}\text { Wave } \\
\text { No. }\end{array}$} & \multirow{2}{*}{$\begin{array}{l}\text { Wave } \\
\text { ID }\end{array}$} & \multirow[b]{2}{*}{ Days/yr } & \multicolumn{5}{|c|}{ Inbound Ship speed (kt) } & \multicolumn{5}{|c|}{ Outbound Ship speed (kt) } \\
\hline & & & 8 & 10 & 12 & 14 & 16 & 8 & 10 & 12 & 14 & 16 \\
\hline 58 & 158 & 0.00 & -4.50 & -4.67 & -4.98 & -5.27 & -11.23 & -1.17 & -1.26 & -1.85 & -2.58 & -3.59 \\
\hline 59 & 159 & 0.00 & -6.07 & -6.16 & -6.39 & -6.56 & -13.36 & -2.15 & -2.15 & -2.71 & -3.40 & -4.37 \\
\hline 60 & 160 & 0.00 & 2.46 & 1.95 & 1.29 & -0.11 & -2.89 & 2.87 & 2.36 & 1.66 & 0.75 & -0.37 \\
\hline 61 & 161 & 0.00 & 1.16 & 0.71 & 0.13 & -1.57 & -5.34 & 1.84 & 1.38 & 0.73 & -0.14 & -1.17 \\
\hline 62 & 162 & 0.00 & -5.75 & -5.87 & -6.03 & -9.29 & -18.41 & -3.63 & -3.79 & -4.17 & -4.86 & -5.44 \\
\hline 63 & 163 & 0.00 & -7.67 & -7.70 & -7.74 & -11.43 & -22.03 & -5.14 & -5.23 & -5.52 & -6.17 & -6.63 \\
\hline 64 & 164 & 0.00 & 1.38 & 0.89 & 0.32 & -2.33 & -6.78 & 1.39 & 0.93 & 0.35 & -0.50 & -1.45 \\
\hline 65 & 165 & 12.41 & 4.39 & 3.73 & 2.97 & 1.97 & 0.66 & 4.43 & 3.83 & 3.05 & 2.09 & 0.84 \\
\hline 66 & 166 & 3.14 & 4.35 & 3.65 & 2.90 & 1.88 & 0.51 & 4.43 & 3.82 & 3.04 & 2.08 & 0.82 \\
\hline 67 & 167 & 0.37 & 4.31 & 3.57 & 2.83 & 1.80 & 0.37 & 4.42 & 3.82 & 3.03 & 2.07 & 0.81 \\
\hline 68 & 168 & 0.00 & 4.23 & 3.41 & 2.70 & 1.62 & 0.09 & 4.41 & 3.81 & 3.02 & 2.05 & 0.77 \\
\hline 69 & 169 & 1.39 & 4.22 & 3.49 & 2.72 & 1.77 & 0.25 & 4.38 & 3.78 & 2.99 & 2.03 & 0.78 \\
\hline 70 & 170 & 0.37 & 4.06 & 3.25 & 2.48 & 1.54 & -0.19 & 4.33 & 3.73 & 2.94 & 1.98 & 0.73 \\
\hline 71 & 171 & 0.66 & 3.91 & 3.00 & 2.23 & 1.30 & -0.63 & 4.29 & 3.69 & 2.90 & 1.93 & 0.68 \\
\hline 72 & 172 & 0.07 & 3.76 & 2.77 & 2.00 & 1.08 & -1.05 & 4.25 & 3.64 & 2.85 & 1.88 & 0.63 \\
\hline 73 & 173 & 1.46 & 4.05 & 3.35 & 2.59 & 1.66 & 0.19 & 4.27 & 3.67 & 2.89 & 1.92 & 0.68 \\
\hline 74 & 174 & 0.26 & 3.77 & 3.00 & 2.25 & 1.34 & -0.28 & 4.15 & 3.55 & 2.76 & 1.80 & 0.55 \\
\hline 75 & 175 & 0.15 & 3.48 & 2.65 & 1.91 & 1.03 & -0.76 & 4.02 & 3.43 & 2.64 & 1.67 & 0.43 \\
\hline 76 & 176 & 0.18 & 3.22 & 2.32 & 1.59 & 0.73 & -1.21 & 3.91 & 3.31 & 2.52 & 1.55 & 0.30 \\
\hline 77 & 177 & 0.07 & 2.94 & 1.97 & 1.25 & 0.41 & -1.69 & 3.78 & 3.19 & 2.40 & 1.43 & 0.18 \\
\hline 78 & 178 & 0.00 & 2.65 & 1.62 & 0.91 & 0.09 & -2.16 & 3.66 & 3.07 & 2.27 & 1.30 & 0.05 \\
\hline 79 & 179 & 1.24 & 3.70 & 3.08 & 2.34 & 1.44 & -0.05 & 4.02 & 3.44 & 2.66 & 1.70 & 0.47 \\
\hline 80 & 180 & 0.26 & 3.18 & 2.54 & 1.83 & 0.98 & -0.71 & 3.72 & 3.15 & 2.37 & 1.42 & 0.18 \\
\hline 81 & 181 & 0.18 & 2.65 & 2.00 & 1.32 & 0.51 & -1.36 & 3.42 & 2.87 & 2.08 & 1.13 & -0.10 \\
\hline 82 & 182 & 0.04 & 2.15 & 1.48 & 0.83 & 0.06 & -1.98 & 3.13 & 2.59 & 1.80 & 0.86 & -0.37 \\
\hline 83 & 183 & 0.04 & 1.62 & 0.94 & 0.32 & -0.41 & -2.63 & 2.83 & 2.31 & 1.52 & 0.58 & -0.65 \\
\hline 84 & 184 & 0.04 & 1.09 & 0.39 & -0.19 & -0.88 & -3.29 & 2.53 & 2.02 & 1.23 & 0.30 & -0.93 \\
\hline 85 & 185 & 0.00 & 0.59 & -0.12 & -0.68 & -1.32 & -3.91 & 2.25 & 1.75 & 0.95 & 0.03 & -1.20 \\
\hline 86 & 186 & 0.91 & 3.06 & 2.54 & 1.87 & 0.90 & -1.39 & 3.67 & 3.16 & 2.43 & 1.51 & 0.31 \\
\hline 87 & 187 & 0.51 & 2.07 & 1.61 & 1.02 & 0.04 & -3.00 & 3.12 & 2.67 & 1.98 & 1.08 & -0.08 \\
\hline 88 & 188 & 0.15 & 1.08 & 0.68 & 0.17 & -0.82 & -4.61 & 2.57 & 2.18 & 1.52 & 0.66 & -0.48 \\
\hline 89 & 189 & 0.07 & 0.14 & -0.21 & -0.63 & -1.63 & -6.14 & 2.05 & 1.72 & 1.09 & 0.26 & -0.85 \\
\hline 90 & 190 & 0.00 & -0.85 & -1.14 & -1.48 & -2.49 & -7.75 & 1.50 & 1.23 & 0.64 & -0.17 & -1.24 \\
\hline
\end{tabular}




\begin{tabular}{|c|c|c|c|c|c|c|c|c|c|c|c|c|}
\hline \multirow{2}{*}{$\begin{array}{l}\text { Wave } \\
\text { No. }\end{array}$} & \multirow{2}{*}{$\begin{array}{l}\text { Wave } \\
\text { ID }\end{array}$} & \multirow[b]{2}{*}{ Days/yr } & \multicolumn{5}{|c|}{ Inbound Ship speed (kt) } & \multicolumn{5}{|c|}{ Outbound Ship speed (kt) } \\
\hline & & & 8 & 10 & 12 & 14 & 16 & 8 & 10 & 12 & 14 & 16 \\
\hline 91 & 191 & 0.15 & 3.02 & 2.50 & 1.87 & -0.09 & -2.81 & 3.40 & 2.89 & 2.20 & 1.30 & 0.16 \\
\hline 92 & 192 & 0.07 & 2.00 & 1.54 & 1.02 & -1.66 & -5.44 & 2.66 & 2.21 & 1.59 & 0.72 & -0.35 \\
\hline 93 & 193 & 0.04 & 0.98 & 0.59 & 0.16 & -3.22 & -8.07 & 1.92 & 1.53 & 0.98 & 0.15 & -0.85 \\
\hline 94 & 194 & 0.00 & 0.01 & -0.32 & -0.65 & -4.71 & -10.56 & 1.22 & 0.89 & 0.40 & -0.39 & -1.33 \\
\hline 95 & 195 & 0.00 & 2.76 & 2.25 & 1.07 & -2.53 & -6.20 & 2.73 & 2.25 & 1.65 & 0.78 & -0.28 \\
\hline 96 & 196 & 0.00 & 1.56 & 1.11 & -0.35 & -5.84 & -11.25 & 1.50 & 1.12 & 0.65 & -0.16 & -1.10 \\
\hline 97 & 197 & 11.86 & 4.39 & 3.73 & 2.97 & 1.98 & 0.66 & 4.43 & 3.83 & 3.05 & 2.08 & 0.83 \\
\hline 98 & 198 & 3.07 & 4.35 & 3.65 & 2.90 & 1.89 & 0.52 & 4.43 & 3.82 & 3.04 & 2.07 & 0.81 \\
\hline 99 & 199 & 0.58 & 4.31 & 3.57 & 2.84 & 1.80 & 0.37 & 4.42 & 3.81 & 3.03 & 2.06 & 0.79 \\
\hline 100 & 200 & 0.04 & 4.27 & 3.49 & 2.77 & 1.71 & 0.24 & 4.41 & 3.81 & 3.02 & 2.05 & 0.77 \\
\hline 101 & 201 & 1.10 & 4.22 & 3.50 & 2.72 & 1.77 & 0.25 & 4.38 & 3.77 & 2.99 & 2.02 & 0.77 \\
\hline 102 & 202 & 0.29 & 4.07 & 3.25 & 2.48 & 1.54 & -0.18 & 4.33 & 3.72 & 2.93 & 1.97 & 0.71 \\
\hline 103 & 203 & 0.47 & 3.91 & 3.01 & 2.24 & 1.31 & -0.62 & 4.29 & 3.68 & 2.88 & 1.91 & 0.64 \\
\hline 104 & 204 & 0.07 & 3.76 & 2.78 & 2.01 & 1.09 & -1.03 & 4.24 & 3.63 & 2.83 & 1.86 & 0.58 \\
\hline 105 & 205 & 0.00 & 3.61 & 2.55 & 1.79 & 0.87 & -1.45 & 4.20 & 3.58 & 2.78 & 1.81 & 0.52 \\
\hline 106 & 206 & 0.88 & 4.05 & 3.36 & 2.59 & 1.66 & 0.20 & 4.26 & 3.66 & 2.88 & 1.92 & 0.67 \\
\hline 107 & 207 & 0.15 & 3.77 & 3.01 & 2.25 & 1.35 & -0.27 & 4.14 & 3.54 & 2.75 & 1.79 & 0.54 \\
\hline 108 & 208 & 0.11 & 3.49 & 2.66 & 1.91 & 1.03 & -0.75 & 4.01 & 3.41 & 2.62 & 1.65 & 0.41 \\
\hline 109 & 209 & 0.15 & 3.22 & 2.33 & 1.59 & 0.73 & -1.20 & 3.89 & 3.29 & 2.50 & 1.53 & 0.28 \\
\hline 110 & 210 & 0.07 & 2.96 & 2.00 & 1.27 & 0.43 & -1.65 & 3.77 & 3.17 & 2.38 & 1.41 & 0.16 \\
\hline 111 & 211 & 0.00 & 2.62 & 1.59 & 0.87 & 0.06 & -2.21 & 3.62 & 3.02 & 2.22 & 1.25 & 0.00 \\
\hline 112 & 212 & 0.62 & 3.70 & 3.08 & 2.34 & 1.44 & -0.05 & 4.01 & 3.43 & 2.64 & 1.69 & 0.45 \\
\hline 113 & 213 & 0.26 & 3.18 & 2.54 & 1.83 & 0.97 & -0.70 & 3.70 & 3.13 & 2.35 & 1.40 & 0.16 \\
\hline 114 & 214 & 0.15 & 2.65 & 2.00 & 1.32 & 0.50 & -1.35 & 3.39 & 2.84 & 2.05 & 1.10 & -0.13 \\
\hline 115 & 215 & 0.11 & 2.15 & 1.48 & 0.83 & 0.05 & -1.97 & 3.10 & 2.56 & 1.76 & 0.82 & -0.41 \\
\hline 116 & 216 & 0.00 & 1.65 & 0.97 & 0.34 & -0.40 & -2.59 & 2.80 & 2.28 & 1.48 & 0.54 & -0.69 \\
\hline 117 & 217 & 0.00 & 1.01 & 0.32 & -0.27 & -0.96 & -3.37 & 2.43 & 1.92 & 1.12 & 0.19 & -1.04 \\
\hline 118 & 218 & 0.73 & 3.06 & 2.54 & 1.86 & 0.92 & -1.30 & 3.65 & 3.13 & 2.40 & 1.48 & 0.28 \\
\hline 119 & 219 & 0.22 & 2.07 & 1.60 & 1.00 & 0.08 & -2.84 & 3.09 & 2.63 & 1.92 & 1.03 & -0.14 \\
\hline 120 & 220 & 0.11 & 1.08 & 0.67 & 0.14 & -0.77 & -4.38 & 2.52 & 2.13 & 1.45 & 0.58 & -0.56 \\
\hline 121 & 221 & 0.07 & 0.14 & -0.22 & -0.68 & -1.57 & -5.85 & 1.98 & 1.65 & 1.00 & 0.16 & -0.95 \\
\hline 122 & 222 & 0.04 & -0.80 & -1.10 & -1.49 & -2.37 & -7.31 & 1.45 & 1.17 & 0.55 & -0.26 & -1.35 \\
\hline 123 & 223 & 0.00 & -1.99 & -2.22 & -2.53 & -3.38 & -9.17 & 0.77 & 0.56 & -0.02 & -0.80 & -1.85 \\
\hline
\end{tabular}




\begin{tabular}{|c|c|c|c|c|c|c|c|c|c|c|c|c|}
\hline \multirow{2}{*}{$\begin{array}{l}\text { Wave } \\
\text { No. }\end{array}$} & \multirow{2}{*}{$\begin{array}{l}\text { Wave } \\
\text { ID }\end{array}$} & \multirow[b]{2}{*}{ Days/yr } & \multicolumn{5}{|c|}{ Inbound Ship speed (kt) } & \multicolumn{5}{|c|}{ Outbound Ship speed (kt) } \\
\hline & & & 8 & 10 & 12 & 14 & 16 & 8 & 10 & 12 & 14 & 16 \\
\hline 124 & 224 & 0.11 & 2.90 & 2.39 & 1.75 & -0.09 & -2.82 & 3.29 & 2.77 & 2.08 & 1.18 & 0.04 \\
\hline 125 & 225 & 0.04 & 1.80 & 1.35 & 0.80 & -1.66 & -5.46 & 2.46 & 2.01 & 1.39 & 0.52 & -0.55 \\
\hline 126 & 226 & 0.04 & 0.70 & 0.31 & -0.14 & -3.23 & -8.09 & 1.64 & 1.25 & 0.69 & -0.14 & -1.13 \\
\hline 127 & 227 & 0.00 & 2.44 & 1.93 & 1.00 & -2.47 & -6.36 & 2.41 & 1.94 & 1.35 & 0.48 & -0.55 \\
\hline 128 & 228 & 0.04 & 1.01 & 0.57 & -0.48 & -5.75 & -11.53 & 0.95 & 0.58 & 0.12 & -0.68 & -1.56 \\
\hline 129 & 229 & 0.04 & -0.42 & -0.80 & -1.95 & -9.02 & -16.69 & -0.50 & -0.78 & -1.11 & -1.83 & -2.57 \\
\hline 130 & 230 & 18.03 & 4.39 & 3.74 & 2.98 & 1.99 & 0.68 & 4.43 & 3.82 & 3.04 & 2.07 & 0.81 \\
\hline 131 & 231 & 3.80 & 4.36 & 3.67 & 2.92 & 1.91 & 0.54 & 4.42 & 3.81 & 3.02 & 2.05 & 0.77 \\
\hline 132 & 232 & 0.37 & 4.32 & 3.59 & 2.85 & 1.82 & 0.40 & 4.41 & 3.79 & 3.01 & 2.03 & 0.73 \\
\hline 133 & 233 & 0.00 & 4.25 & 3.44 & 2.73 & 1.65 & 0.13 & 4.39 & 3.76 & 2.97 & 1.99 & 0.66 \\
\hline 134 & 234 & 2.23 & 4.25 & 3.54 & 2.76 & 1.81 & 0.32 & 4.37 & 3.75 & 2.96 & 2.00 & 0.71 \\
\hline 135 & 235 & 0.58 & 4.11 & 3.32 & 2.54 & 1.59 & -0.09 & 4.32 & 3.69 & 2.89 & 1.93 & 0.60 \\
\hline 136 & 236 & 0.58 & 3.96 & 3.08 & 2.31 & 1.37 & -0.51 & 4.26 & 3.62 & 2.82 & 1.86 & 0.48 \\
\hline 137 & 237 & 0.07 & 3.82 & 2.86 & 2.09 & 1.15 & -0.91 & 4.21 & 3.56 & 2.75 & 1.79 & 0.37 \\
\hline 138 & 238 & 1.06 & 4.09 & 3.41 & 2.63 & 1.70 & 0.27 & 4.25 & 3.64 & 2.85 & 1.89 & 0.65 \\
\hline 139 & 239 & 0.29 & 3.83 & 3.08 & 2.32 & 1.41 & -0.18 & 4.12 & 3.50 & 2.70 & 1.74 & 0.50 \\
\hline 140 & 240 & 0.11 & 3.56 & 2.75 & 1.98 & 1.10 & -0.64 & 3.97 & 3.35 & 2.54 & 1.58 & 0.34 \\
\hline 141 & 241 & 0.26 & 3.31 & 2.42 & 1.67 & 0.80 & -1.08 & 3.83 & 3.20 & 2.39 & 1.43 & 0.18 \\
\hline 142 & 242 & 0.11 & 3.05 & 2.10 & 1.35 & 0.51 & -1.52 & 3.69 & 3.06 & 2.24 & 1.27 & 0.03 \\
\hline 143 & 243 & 0.00 & 2.76 & 1.75 & 1.00 & 0.18 & -2.01 & 3.54 & 2.90 & 2.07 & 1.11 & -0.14 \\
\hline 144 & 244 & 0.69 & 3.73 & 3.11 & 2.36 & 1.45 & 0.02 & 3.96 & 3.37 & 2.59 & 1.63 & 0.39 \\
\hline 145 & 245 & 0.29 & 3.21 & 2.58 & 1.85 & 0.97 & -0.61 & 3.61 & 3.03 & 2.23 & 1.28 & 0.04 \\
\hline 146 & 246 & 0.18 & 2.65 & 2.01 & 1.30 & 0.46 & -1.26 & 3.23 & 2.66 & 1.86 & 0.92 & -0.32 \\
\hline 147 & 247 & 0.04 & 2.13 & 1.47 & 0.79 & -0.02 & -1.89 & 2.88 & 2.32 & 1.51 & 0.57 & -0.67 \\
\hline 148 & 248 & 0.07 & 1.60 & 0.93 & 0.27 & -0.50 & -2.51 & 2.52 & 1.97 & 1.16 & 0.23 & -1.02 \\
\hline 149 & 249 & 0.04 & 1.02 & 0.34 & -0.30 & -1.03 & -3.20 & 2.13 & 1.59 & 0.77 & -0.16 & -1.40 \\
\hline 150 & 250 & 0.00 & 0.58 & -0.12 & -0.74 & -1.44 & -3.73 & 1.83 & 1.30 & 0.47 & -0.45 & -1.70 \\
\hline 151 & 251 & 0.62 & 2.94 & 2.41 & 1.69 & 0.84 & -1.00 & 3.43 & 2.92 & 2.17 & 1.25 & 0.04 \\
\hline 152 & 252 & 0.22 & 1.82 & 1.35 & 0.68 & -0.10 & -2.39 & 2.69 & 2.24 & 1.50 & 0.61 & -0.56 \\
\hline 153 & 253 & 0.11 & 0.65 & 0.24 & -0.39 & -1.08 & -3.84 & 1.90 & 1.52 & 0.80 & -0.05 & -1.20 \\
\hline 154 & 254 & 0.00 & -0.46 & -0.82 & -1.40 & -2.02 & -5.22 & 1.16 & 0.84 & 0.14 & -0.69 & -1.80 \\
\hline 155 & 255 & 0.00 & -2.80 & -3.04 & -3.53 & -3.99 & -8.13 & -0.41 & -0.60 & -1.25 & -2.02 & -3.07 \\
\hline 156 & 256 & 0.15 & 2.39 & 1.88 & 1.20 & 0.09 & -2.52 & 2.75 & 2.23 & 1.52 & 0.61 & -0.51 \\
\hline
\end{tabular}




\begin{tabular}{|c|c|c|c|c|c|c|c|c|c|c|c|c|}
\hline \multirow{2}{*}{$\begin{array}{l}\text { Wave } \\
\text { No. }\end{array}$} & \multirow{2}{*}{$\begin{array}{l}\text { Wave } \\
\text { ID }\end{array}$} & \multirow[b]{2}{*}{ Days/yr } & \multicolumn{5}{|c|}{ Inbound Ship speed (kt) } & \multicolumn{5}{|c|}{ Outbound Ship speed (kt) } \\
\hline & & & 8 & 10 & 12 & 14 & 16 & 8 & 10 & 12 & 14 & 16 \\
\hline 157 & 257 & 0.11 & 0.86 & 0.42 & -0.18 & -1.40 & -5.03 & 1.49 & 1.03 & 0.37 & -0.50 & -1.52 \\
\hline 158 & 258 & 0.04 & 1.08 & 0.60 & 0.02 & -1.81 & -6.07 & 1.04 & 0.57 & -0.05 & -0.90 & -1.82 \\
\hline 159 & 259 & 0.00 & -1.42 & -1.81 & -2.23 & -4.72 & -11.21 & -1.48 & -1.86 & -2.35 & -3.13 & -3.81 \\
\hline 160 & 260 & 27.08 & 4.39 & 3.74 & 2.98 & 1.99 & 0.67 & 4.42 & 3.80 & 3.02 & 2.05 & 0.77 \\
\hline 161 & 261 & 6.72 & 4.36 & 3.67 & 2.91 & 1.91 & 0.54 & 4.40 & 3.77 & 2.99 & 2.01 & 0.70 \\
\hline 162 & 262 & 0.40 & 4.32 & 3.60 & 2.86 & 1.83 & 0.41 & 4.39 & 3.74 & 2.96 & 1.98 & 0.64 \\
\hline 163 & 263 & 0.00 & 4.29 & 3.53 & 2.80 & 1.75 & 0.28 & 4.37 & 3.72 & 2.93 & 1.94 & 0.57 \\
\hline 164 & 264 & 4.60 & 4.27 & 3.57 & 2.79 & 1.83 & 0.37 & 4.34 & 3.71 & 2.92 & 1.95 & 0.62 \\
\hline 165 & 265 & 0.91 & 4.14 & 3.38 & 2.59 & 1.64 & 0.01 & 4.28 & 3.62 & 2.81 & 1.85 & 0.44 \\
\hline 166 & 266 & 1.24 & 4.02 & 3.19 & 2.41 & 1.46 & -0.32 & 4.21 & \begin{tabular}{|l|}
3.53 \\
\end{tabular} & 2.72 & 1.75 & 0.28 \\
\hline 167 & 267 & 0.11 & 3.90 & 3.00 & 2.22 & 1.26 & -0.68 & 4.14 & \begin{tabular}{|l|}
3.43 \\
\end{tabular} & 2.62 & 1.65 & 0.11 \\
\hline 168 & 268 & 1.46 & 4.10 & 3.43 & 2.65 & 1.72 & 0.31 & 4.21 & 3.58 & 2.79 & 1.84 & 0.57 \\
\hline 169 & 269 & 0.33 & 3.86 & 3.14 & 2.36 & 1.46 & -0.08 & 4.04 & 3.40 & 2.60 & 1.65 & 0.36 \\
\hline 170 & 270 & 0.22 & 3.64 & 2.86 & 2.08 & 1.20 & -0.46 & 3.88 & 3.22 & 2.41 & 1.47 & 0.16 \\
\hline 171 & 271 & 0.40 & 3.40 & 2.57 & 1.79 & 0.93 & -0.85 & 3.71 & \begin{tabular}{|l|l}
3.04 \\
\end{tabular} & 2.22 & 1.28 & -0.06 \\
\hline 172 & 272 & 0.07 & 3.16 & 2.27 & 1.49 & 0.66 & -1.24 & 3.55 & 2.86 & 2.03 & 1.09 & -0.27 \\
\hline 173 & 273 & 0.00 & 2.90 & 1.96 & 1.19 & 0.38 & -1.66 & 3.37 & 2.66 & 1.83 & 0.89 & -0.49 \\
\hline 174 & 274 & 0.69 & 3.72 & 3.11 & 2.34 & 1.42 & 0.07 & 3.86 & 3.27 & 2.48 & 1.53 & 0.28 \\
\hline 175 & 275 & 0.33 & 3.20 & 2.58 & 1.83 & 0.93 & -0.50 & 3.45 & 2.85 & 2.06 & 1.12 & -0.13 \\
\hline 176 & 276 & 0.07 & 2.71 & 2.08 & 1.34 & 0.46 & -1.04 & 3.05 & 2.46 & 1.66 & 0.72 & -0.53 \\
\hline 177 & 277 & 0.04 & 2.19 & 1.56 & 0.82 & -0.03 & -1.60 & 2.64 & 2.05 & \begin{tabular}{|l|}
1.24 \\
\end{tabular} & 0.31 & -0.94 \\
\hline 178 & 278 & 0.04 & 1.68 & 1.03 & 0.31 & -0.51 & -2.17 & 2.22 & 1.64 & 0.83 & -0.10 & -1.35 \\
\hline 179 & 279 & 0.04 & 1.14 & 0.48 & -0.23 & -1.03 & -2.77 & 1.79 & 1.21 & 0.39 & -0.53 & -1.79 \\
\hline 180 & 280 & 0.22 & 2.91 & 2.38 & 1.62 & 0.75 & -0.57 & 3.24 & 2.71 & 1.94 & 1.03 & -0.18 \\
\hline 181 & 281 & 0.18 & 1.82 & 1.34 & 0.60 & -0.22 & -1.59 & 2.37 & 1.91 & 1.14 & 0.26 & -0.92 \\
\hline 182 & 282 & 0.04 & 0.79 & 0.35 & -0.38 & -1.14 & -2.56 & 1.56 & 1.14 & 0.38 & -0.47 & -1.62 \\
\hline 183 & 283 & 0.00 & -0.30 & -0.70 & -1.41 & -2.11 & -3.59 & 0.69 & 0.34 & -0.42 & -1.23 & -2.37 \\
\hline 184 & 284 & 0.00 & -1.40 & -1.74 & -2.43 & -3.08 & -4.61 & -0.17 & -0.47 & $\mid-1.22$ & -2.00 & -3.11 \\
\hline 185 & 285 & 0.00 & -2.54 & -2.83 & -3.51 & -4.10 & $\mid-5.69$ & -1.07 & $\mid-1.31$ & -2.06 & -2.81 & -3.89 \\
\hline 186 & 286 & 0.00 & -3.69 & -3.93 & -4.59 & -5.11 & -6.76 & -1.98 & -2.16 & -2.89 & -3.61 & -4.67 \\
\hline 187 & 287 & 10.22 & 4.42 & 3.81 & 3.03 & 2.06 & 0.79 & 4.43 & 3.81 & 3.04 & 2.07 & 0.80 \\
\hline 188 & 288 & 2.81 & 4.41 & 3.78 & 3.01 & 2.03 & 0.75 & 4.42 & 3.80 & 3.02 & 2.04 & 0.77 \\
\hline 189 & 289 & 0.22 & 4.40 & 3.76 & 2.99 & 2.00 & 0.70 & 4.41 & 3.78 & 3.00 & 2.02 & 0.73 \\
\hline
\end{tabular}




\begin{tabular}{|c|c|c|c|c|c|c|c|c|c|c|c|c|}
\hline \multirow{2}{*}{$\begin{array}{l}\text { Wave } \\
\text { No. }\end{array}$} & \multirow{2}{*}{$\begin{array}{l}\text { Wave } \\
\text { ID }\end{array}$} & \multirow[b]{2}{*}{ Days/yr } & \multicolumn{5}{|c|}{ Inbound Ship speed (kt) } & \multicolumn{5}{|c|}{ Outbound Ship speed (kt) } \\
\hline & & & 8 & 10 & 12 & 14 & 16 & 8 & 10 & 12 & 14 & 16 \\
\hline 190 & 290 & 0.00 & 4.39 & 3.74 & 2.97 & 1.97 & 0.65 & 4.40 & 3.76 & 2.99 & 1.99 & 0.69 \\
\hline 191 & 291 & 0.00 & 4.38 & 3.71 & 2.95 & 1.95 & 0.61 & 4.39 & 3.74 & 2.97 & 1.97 & 0.65 \\
\hline 192 & 292 & 0.18 & 4.29 & 3.61 & 2.83 & 1.86 & 0.44 & 4.31 & 3.65 & 2.86 & 1.90 & 0.51 \\
\hline 193 & 293 & 0.18 & 4.19 & 3.47 & 2.68 & 1.72 & 0.18 & 4.23 & 3.53 & 2.74 & 1.77 & 0.29 \\
\hline 194 & 294 & 0.29 & 4.09 & 3.32 & 2.52 & 1.56 & -0.11 & 4.14 & 3.40 & 2.60 & 1.63 & 0.05 \\
\hline 195 & 295 & 0.00 & 3.98 & 3.15 & 2.35 & 1.39 & -0.41 & 4.05 & 3.27 & 2.45 & 1.49 & -0.21 \\
\hline 196 & 296 & 0.04 & 4.13 & 3.47 & 2.68 & 1.75 & 0.38 & 4.15 & 3.51 & 2.72 & 1.78 & 0.45 \\
\hline 197 & 297 & 0.04 & 3.93 & 3.24 & 2.45 & 1.54 & 0.09 & 3.98 & 3.31 & 2.51 & 1.58 & 0.20 \\
\hline 198 & 298 & 0.04 & 3.72 & 2.98 & 2.19 & 1.30 & -0.24 & 3.78 & 3.08 & 2.27 & 1.35 & -0.09 \\
\hline 199 & 299 & 0.07 & 3.49 & 2.72 & 1.92 & 1.04 & -0.59 & 3.57 & 2.84 & 2.03 & 1.12 & -0.38 \\
\hline 200 & 300 & 0.00 & 3.31 & 2.50 & 1.69 & 0.84 & -0.87 & 3.41 & 2.65 & 1.83 & 0.93 & -0.62 \\
\hline 201 & 301 & 0.00 & 3.73 & 3.12 & 2.34 & 1.41 & 0.16 & 3.76 & 3.16 & 2.38 & 1.43 & 0.19 \\
\hline 202 & 302 & 0.04 & 3.28 & 2.67 & 1.89 & 0.97 & -0.28 & 3.34 & 2.74 & 1.95 & 1.02 & -0.23 \\
\hline 203 & 303 & 0.00 & 2.79 & 2.18 & 1.40 & 0.49 & -0.76 & 2.88 & 2.27 & 1.48 & 0.56 & -0.69 \\
\hline 204 & 304 & 0.00 & 2.27 & 1.65 & 0.88 & -0.01 & -1.27 & 2.39 & 1.78 & 0.98 & 0.08 & -1.18 \\
\hline 205 & 305 & 0.00 & 1.85 & 1.23 & 0.46 & -0.42 & -1.69 & 1.99 & 1.38 & 0.58 & -0.31 & -1.58 \\
\hline 206 & 306 & 0.00 & 1.21 & 0.58 & -0.19 & -1.04 & -2.32 & 1.38 & 0.77 & -0.03 & -0.91 & -2.18 \\
\hline 207 & 307 & 0.04 & 2.75 & 2.24 & 1.47 & 0.59 & -0.61 & 2.85 & 2.34 & 1.56 & 0.67 & -0.53 \\
\hline 208 & 308 & 0.04 & 1.71 & 1.25 & 0.48 & -0.35 & -1.52 & 1.86 & 1.41 & 0.63 & -0.22 & -1.39 \\
\hline 209 & 309 & 0.00 & 0.54 & 0.14 & -0.62 & -1.40 & -2.53 & 0.76 & 0.37 & -0.40 & -1.20 & -2.34 \\
\hline 210 & 310 & 0.00 & -0.68 & -1.02 & -1.78 & -2.50 & -3.60 & -0.39 & -0.72 & -1.49 & -2.24 & -3.35 \\
\hline 211 & 311 & 0.00 & -3.77 & -3.94 & -4.69 & -5.27 & -6.29 & -3.30 & -3.47 & -4.23 & -4.85 & -5.88 \\
\hline
\end{tabular}


Table E2. Net UKC (ft), Phase 1, Mound Reach 2, $h=55 \mathrm{ft}$, fully loaded Susan Maersk, inbound and outbound transits.

\begin{tabular}{|c|c|c|c|c|c|c|c|c|c|c|c|c|}
\hline \multirow{2}{*}{$\begin{array}{l}\text { Wave } \\
\text { No. }\end{array}$} & \multirow{2}{*}{$\begin{array}{l}\text { Wave } \\
\text { ID }\end{array}$} & \multirow[b]{2}{*}{ Days/yr } & \multicolumn{5}{|c|}{ Inbound Ship speed (kt) } & \multicolumn{5}{|c|}{ Outbound Ship speed (kt) } \\
\hline & & & 8 & 10 & 12 & 14 & 16 & 8 & 10 & 12 & 14 & 16 \\
\hline 1 & 401 & 6.10 & 6.45 & 5.84 & 5.10 & 4.16 & 2.95 & 6.47 & 5.88 & 5.13 & 4.21 & 3.02 \\
\hline 2 & 402 & 2.74 & 6.44 & 5.81 & 5.08 & 4.12 & 2.89 & 6.47 & 5.87 & 5.12 & 4.20 & 3.00 \\
\hline 3 & 403 & 0.26 & 6.42 & 5.77 & 5.05 & 4.08 & 2.83 & 6.47 & 5.87 & 5.12 & 4.19 & 2.98 \\
\hline 4 & 404 & 0.04 & 6.40 & 5.74 & 5.03 & 4.04 & 2.77 & 6.46 & 5.86 & 5.11 & 4.18 & 2.97 \\
\hline 5 & 405 & 0.00 & 6.38 & 5.70 & 5.00 & 4.00 & 2.70 & 6.46 & 5.85 & 5.10 & 4.17 & 2.95 \\
\hline 6 & 406 & 0.00 & 6.25 & 5.57 & 4.84 & 3.93 & 2.44 & 6.40 & 5.79 & 5.03 & 4.12 & 2.89 \\
\hline 7 & 407 & 0.07 & 6.11 & 5.35 & 4.65 & 3.74 & 2.05 & 6.34 & 5.73 & 4.97 & 4.05 & 2.78 \\
\hline 8 & 408 & 0.07 & 5.95 & 5.13 & 4.45 & 3.54 & 1.64 & 6.28 & 5.66 & 4.89 & 3.98 & 2.68 \\
\hline 9 & 409 & 0.00 & 5.81 & 4.93 & 4.26 & 3.36 & 1.27 & 6.23 & 5.60 & 4.83 & 3.91 & 2.58 \\
\hline 10 & 410 & 0.00 & 5.64 & 4.69 & 4.04 & 3.14 & 0.81 & 6.17 & 5.52 & 4.75 & 3.83 & 2.47 \\
\hline 11 & 411 & 0.04 & 6.10 & 5.43 & 4.71 & 3.82 & 2.43 & 6.27 & 5.67 & 4.91 & 3.99 & 2.81 \\
\hline 12 & 412 & 0.00 & 5.85 & 5.13 & 4.42 & 3.56 & 2.03 & 6.13 & 5.53 & 4.77 & 3.84 & 2.67 \\
\hline 13 & 413 & 0.04 & 5.58 & 4.81 & 4.12 & 3.29 & 1.61 & 5.98 & 5.38 & 4.61 & 3.69 & 2.51 \\
\hline 14 & 414 & 0.04 & 5.34 & 4.52 & 3.85 & 3.04 & 1.23 & 5.85 & 5.24 & 4.47 & 3.55 & 2.37 \\
\hline 15 & 415 & 0.00 & 5.72 & 5.12 & 4.39 & 3.51 & 2.23 & 5.94 & 5.36 & 4.60 & 3.69 & 2.52 \\
\hline 16 & 416 & 0.00 & 5.22 & 4.61 & 3.90 & 3.04 & 1.69 & 5.58 & 5.02 & 4.25 & 3.34 & 2.17 \\
\hline 17 & 417 & 0.00 & 4.69 & 4.08 & 3.39 & 2.54 & 1.13 & 5.21 & 4.65 & 3.88 & 2.98 & 1.81 \\
\hline 18 & 418 & 0.00 & 4.22 & 3.60 & 2.92 & 2.10 & 0.62 & 4.87 & 4.33 & 3.55 & 2.65 & 1.49 \\
\hline 19 & 419 & 0.00 & 3.64 & 3.02 & 2.36 & 1.56 & 0.00 & 4.46 & 3.93 & 3.14 & 2.25 & 1.09 \\
\hline 20 & 420 & 0.00 & 3.30 & 2.67 & 2.02 & 1.23 & $\mid-0.36$ & 4.21 & 3.69 & 2.90 & 2.01 & 0.85 \\
\hline 21 & 421 & 0.04 & 4.80 & 4.31 & 3.59 & 2.75 & 1.19 & 5.25 & 4.77 & 4.06 & 3.18 & 2.05 \\
\hline 22 & 422 & 0.00 & 3.69 & 3.28 & 2.57 & 1.79 & -0.02 & 4.45 & 4.04 & 3.35 & 2.50 & 1.40 \\
\hline 23 & 423 & 0.00 & 2.53 & 2.19 & 1.50 & 0.78 & -1.30 & 3.60 & 3.27 & 2.60 & 1.78 & 0.71 \\
\hline 24 & 424 & 0.00 & 1.48 & 1.21 & 0.54 & -0.13 & -2.45 & 2.84 & 2.58 & 1.92 & 1.14 & 0.10 \\
\hline 25 & 425 & 0.00 & -0.55 & -0.70 & -1.34 & -1.90 & -4.68 & 1.36 & 1.23 & 0.62 & $\mid-0.11$ & -1.10 \\
\hline 26 & 426 & 0.00 & -2.47 & -2.50 & -3.10 & -3.57 & -6.78 & -0.04 & -0.04 & -0.62 & -1.30 & -2.23 \\
\hline 27 & 427 & 0.00 & -2.94 & -2.93 & -3.53 & -3.98 & -7.30 & -0.38 & -0.35 & -0.92 & -1.58 & -2.50 \\
\hline 28 & 428 & 11.24 & 6.43 & 5.79 & 5.06 & 4.11 & 2.86 & 6.47 & 5.88 & 5.13 & 4.21 & 3.02 \\
\hline 29 & 429 & 3.80 & 6.39 & 5.73 & 5.01 & 4.03 & 2.74 & 6.47 & 5.87 & 5.12 & 4.20 & 3.00 \\
\hline 30 & 430 & 0.66 & 6.35 & 5.66 & 4.96 & 3.96 & 2.62 & 6.46 & 5.87 & 5.11 & 4.19 & 2.98 \\
\hline 31 & 431 & 0.04 & 6.32 & 5.59 & 4.91 & 3.88 & 2.50 & 6.46 & 5.86 & 5.11 & 4.18 & 2.97 \\
\hline
\end{tabular}




\begin{tabular}{|c|c|c|c|c|c|c|c|c|c|c|c|c|}
\hline \multirow{2}{*}{$\begin{array}{l}\text { Wave } \\
\text { No. }\end{array}$} & \multirow{2}{*}{$\begin{array}{l}\text { Wave } \\
\text { ID }\end{array}$} & \multirow[b]{2}{*}{ Days/yr } & \multicolumn{5}{|c|}{ Inbound Ship speed (kt) } & \multicolumn{5}{|c|}{ Outbound Ship speed (kt) } \\
\hline & & & 8 & 10 & 12 & 14 & 16 & 8 & 10 & 12 & 14 & 16 \\
\hline 32 & 432 & 1.13 & 6.23 & 5.53 & 4.82 & 3.91 & 2.38 & 6.41 & 5.81 & 5.06 & 4.14 & 2.95 \\
\hline 33 & 433 & 0.18 & 6.07 & 5.30 & 4.60 & 3.70 & 1.95 & 6.36 & 5.76 & 5.01 & 4.08 & 2.90 \\
\hline 34 & 434 & 0.66 & 5.89 & 5.06 & 4.38 & 3.49 & 1.50 & 6.31 & 5.71 & 4.95 & 4.03 & 2.84 \\
\hline 35 & 435 & 0.15 & 5.72 & 4.81 & 4.16 & 3.27 & 1.05 & 6.26 & 5.66 & 4.89 & 3.97 & 2.78 \\
\hline 36 & 436 & 0.00 & 5.55 & 4.57 & 3.93 & 3.06 & 0.59 & 6.21 & 5.61 & 4.84 & 3.91 & 2.71 \\
\hline 37 & 437 & 1.20 & 6.05 & 5.38 & 4.67 & 3.79 & 2.38 & 6.27 & 5.69 & 4.93 & 4.01 & 2.83 \\
\hline 38 & 438 & 0.22 & 5.77 & 5.05 & 4.36 & 3.51 & 1.95 & 6.14 & 5.55 & 4.80 & 3.87 & 2.69 \\
\hline 39 & 439 & 0.07 & 5.47 & 4.70 & 4.04 & 3.21 & 1.49 & 6.00 & 5.41 & 4.65 & 3.73 & 2.55 \\
\hline 40 & 440 & 0.22 & 5.18 & 4.35 & 3.71 & 2.91 & 1.03 & 5.86 & 5.27 & 4.51 & 3.59 & 2.40 \\
\hline 41 & 441 & 0.15 & 4.88 & 4.01 & 3.39 & 2.62 & 0.58 & 5.71 & 5.13 & 4.37 & 3.44 & 2.26 \\
\hline 42 & 442 & 0.04 & 4.57 & 3.64 & 3.05 & 2.31 & 0.10 & 5.56 & 4.98 & 4.22 & 3.29 & 2.10 \\
\hline 43 & 443 & 0.88 & 5.69 & 5.09 & 4.38 & 3.50 & 2.17 & 5.98 & 5.41 & 4.66 & 3.75 & 2.57 \\
\hline 44 & 444 & 0.11 & 5.17 & 4.57 & 3.88 & 3.02 & 1.60 & 5.65 & 5.10 & 4.34 & 3.44 & 2.27 \\
\hline 45 & 445 & 0.04 & 4.63 & 4.02 & 3.35 & 2.52 & 1.01 & 5.31 & 4.77 & 4.01 & 3.11 & 1.95 \\
\hline 46 & 446 & 0.07 & 4.08 & 3.47 & 2.83 & 2.02 & 0.41 & 4.96 & 4.44 & 3.68 & 2.78 & 1.63 \\
\hline 47 & 447 & 0.04 & 3.54 & 2.93 & 2.30 & 1.52 & -0.19 & 4.61 & 4.11 & 3.35 & 2.46 & 1.31 \\
\hline 48 & 448 & 0.04 & 2.96 & 2.35 & 1.75 & 1.00 & -0.82 & 4.25 & 3.77 & 3.00 & 2.11 & 0.97 \\
\hline 49 & 449 & 0.04 & 2.42 & 1.80 & 1.23 & 0.50 & -1.42 & 3.90 & 3.44 & 2.67 & 1.79 & 0.65 \\
\hline 50 & 450 & 0.00 & 1.65 & 1.03 & 0.49 & -0.20 & -2.26 & 3.42 & 2.97 & 2.20 & 1.33 & 0.20 \\
\hline 51 & 451 & 0.18 & 5.18 & 4.68 & 3.99 & 3.15 & 1.25 & 5.66 & 5.16 & 4.45 & 3.57 & 2.43 \\
\hline 52 & 452 & 0.15 & 4.32 & 3.88 & 3.23 & 2.45 & 0.08 & 5.12 & 4.68 & 4.00 & 3.15 & 2.03 \\
\hline 53 & 453 & 0.11 & 3.42 & 3.04 & 2.44 & 1.72 & -1.15 & 4.55 & 4.17 & 3.53 & 2.70 & 1.61 \\
\hline 54 & 454 & 0.07 & 2.52 & 2.20 & 1.65 & 0.98 & -2.39 & 3.98 & 3.66 & 3.05 & 2.25 & 1.19 \\
\hline 55 & 455 & 0.04 & 1.62 & 1.37 & 0.85 & 0.24 & -3.62 & 3.41 & 3.16 & 2.58 & 1.80 & 0.77 \\
\hline 56 & 456 & 0.04 & 0.67 & 0.49 & 0.02 & -0.53 & -4.92 & 2.81 & 2.63 & 2.08 & 1.33 & 0.33 \\
\hline 57 & 457 & 0.00 & -0.23 & -0.35 & -0.78 & -1.27 & -6.15 & 2.25 & 2.12 & 1.61 & 0.88 & -0.09 \\
\hline 58 & 458 & 0.00 & -1.49 & -1.52 & -1.89 & -2.30 & -7.88 & 1.45 & 1.41 & 0.94 & 0.26 & -0.68 \\
\hline 59 & 459 & 0.00 & -2.89 & -2.82 & -3.12 & -3.44 & -9.79 & 0.57 & 0.63 & 0.21 & -0.44 & -1.33 \\
\hline 60 & 460 & 0.00 & 4.97 & 4.49 & 3.83 & 2.30 & -0.18 & 5.23 & 4.73 & 4.08 & 3.21 & 2.13 \\
\hline 61 & 461 & 0.00 & 3.97 & 3.56 & 2.98 & 1.04 & -2.30 & 4.42 & 3.97 & 3.38 & 2.55 & 1.53 \\
\hline 62 & 462 & 0.00 & -1.31 & -1.33 & -1.57 & -5.67 & -13.54 & 0.07 & -0.06 & -0.34 & -0.97 & -1.65 \\
\hline 63 & 463 & 0.00 & -2.77 & -2.69 & -2.83 & -7.53 & -16.66 & -1.14 & -1.18 & -1.37 & -1.95 & -2.53 \\
\hline 64 & 464 & 0.00 & 4.57 & 4.07 & 3.25 & 0.32 & -3.24 & 4.31 & 3.84 & 3.27 & 2.45 & 1.46 \\
\hline
\end{tabular}




\begin{tabular}{|c|c|c|c|c|c|c|c|c|c|c|c|c|}
\hline \multirow{2}{*}{$\begin{array}{l}\text { Wave } \\
\text { No. }\end{array}$} & \multirow{2}{*}{$\begin{array}{l}\text { Wave } \\
\text { ID }\end{array}$} & \multirow[b]{2}{*}{ Days/yr } & \multicolumn{5}{|c|}{ Inbound Ship speed (kt) } & \multicolumn{5}{|c|}{ Outbound Ship speed (kt) } \\
\hline & & & 8 & 10 & 12 & 14 & 16 & 8 & 10 & 12 & 14 & 16 \\
\hline 65 & 465 & 12.41 & 6.42 & 5.78 & 5.06 & 4.10 & 2.84 & 6.47 & 5.88 & 5.13 & 4.21 & 3.02 \\
\hline 66 & 466 & 3.14 & 6.38 & 5.70 & 4.99 & 4.01 & 2.70 & 6.47 & 5.87 & 5.12 & 4.20 & 3.00 \\
\hline 67 & 467 & 0.37 & 6.33 & 5.63 & 4.93 & 3.92 & 2.56 & 6.46 & 5.87 & 5.11 & 4.19 & 2.99 \\
\hline 68 & 468 & 0.00 & 6.25 & 5.47 & 4.82 & 3.75 & 2.29 & 6.45 & 5.85 & 5.10 & 4.18 & 2.96 \\
\hline 69 & 469 & 1.39 & 6.24 & 5.54 & 4.83 & 3.92 & 2.40 & 6.41 & 5.82 & 5.07 & 4.14 & 2.96 \\
\hline 70 & 470 & 0.37 & 6.06 & 5.30 & 4.60 & 3.70 & 1.94 & 6.36 & 5.77 & 5.01 & 4.09 & 2.91 \\
\hline 71 & 471 & 0.66 & 5.89 & 5.05 & 4.37 & 3.49 & 1.48 & 6.32 & 5.72 & 4.96 & 4.04 & 2.86 \\
\hline 72 & 472 & 0.07 & 5.72 & 4.81 & 4.16 & 3.28 & 1.05 & 6.27 & 5.67 & 4.91 & 3.99 & 2.81 \\
\hline 73 & 473 & 1.46 & 6.06 & 5.40 & 4.68 & 3.80 & 2.40 & 6.29 & 5.70 & 4.95 & 4.03 & 2.84 \\
\hline 74 & 474 & 0.26 & 5.77 & 5.05 & 4.36 & 3.51 & 1.94 & 6.15 & 5.56 & 4.81 & 3.89 & 2.70 \\
\hline 75 & 475 & 0.15 & 5.47 & 4.70 & 4.03 & 3.21 & 1.48 & 6.01 & 5.43 & 4.67 & 3.75 & 2.57 \\
\hline 76 & 476 & 0.18 & 5.19 & 4.36 & 3.72 & 2.93 & 1.04 & 5.88 & 5.30 & 4.54 & 3.62 & 2.43 \\
\hline 77 & 477 & 0.07 & 4.89 & 4.01 & 3.40 & 2.63 & 0.58 & 5.74 & 5.16 & 4.40 & 3.48 & 2.29 \\
\hline 78 & 478 & 0.00 & 4.59 & 3.66 & 3.07 & 2.33 & 0.13 & 5.60 & 5.03 & 4.26 & 3.34 & 2.15 \\
\hline 79 & 479 & 1.24 & 5.72 & 5.12 & 4.41 & 3.53 & 2.20 & 6.01 & 5.44 & 4.69 & 3.78 & 2.61 \\
\hline 80 & 480 & 0.26 & 5.17 & 4.57 & 3.88 & 3.03 & 1.60 & 5.67 & 5.12 & 4.37 & 3.46 & 2.29 \\
\hline 81 & 481 & 0.18 & 4.63 & 4.03 & 3.36 & 2.53 & 1.00 & 5.33 & 4.80 & 4.05 & 3.14 & 1.98 \\
\hline 82 & 482 & 0.04 & 4.11 & 3.50 & 2.86 & 2.06 & 0.43 & 5.01 & 4.50 & 3.74 & 2.84 & 1.69 \\
\hline 83 & 483 & 0.04 & 3.57 & 2.96 & 2.34 & 1.56 & -0.17 & 4.68 & 4.18 & 3.42 & 2.53 & 1.38 \\
\hline 84 & 484 & 0.04 & 3.02 & 2.41 & 1.82 & 1.06 & -0.77 & 4.34 & 3.86 & 3.09 & 2.21 & 1.07 \\
\hline 85 & 485 & 0.00 & 2.50 & 1.89 & 1.32 & 0.59 & -1.34 & 4.02 & 3.55 & 2.79 & 1.91 & 0.77 \\
\hline 86 & 486 & 0.91 & 5.12 & 4.64 & 3.96 & 3.12 & 1.09 & 5.63 & 5.14 & 4.44 & 3.56 & 2.43 \\
\hline 87 & 487 & 0.51 & 4.15 & 3.75 & 3.12 & 2.32 & -0.31 & 5.02 & 4.60 & 3.94 & 3.09 & 1.99 \\
\hline 88 & 488 & 0.15 & 3.18 & 2.86 & 2.27 & 1.53 & -1.70 & 4.41 & 4.06 & 3.44 & 2.63 & 1.56 \\
\hline 89 & 489 & 0.07 & 2.26 & 2.01 & 1.47 & 0.78 & -3.03 & 3.83 & 3.54 & 2.96 & 2.18 & 1.14 \\
\hline 90 & 490 & 0.00 & 1.29 & 1.12 & 0.63 & -0.01 & -4.43 & 3.21 & 3.00 & 2.46 & 1.71 & 0.71 \\
\hline 91 & 491 & 0.15 & 5.13 & 4.64 & 4.00 & 2.37 & -0.06 & 5.39 & 4.88 & 4.23 & 3.36 & 2.27 \\
\hline 92 & 492 & 0.07 & 4.16 & 3.75 & 3.18 & 1.06 & -2.28 & 4.60 & 4.16 & 3.57 & 2.75 & 1.72 \\
\hline 93 & 493 & 0.04 & 3.19 & 2.86 & 2.37 & -0.26 & -4.51 & 3.82 & 3.45 & 2.92 & 2.13 & 1.18 \\
\hline 94 & 494 & 0.00 & 2.27 & 2.02 & 1.59 & -1.52 & -6.62 & 3.08 & 2.76 & 2.30 & 1.55 & 0.66 \\
\hline 95 & 495 & 0.00 & 4.91 & 4.41 & 3.39 & 0.43 & -2.92 & 4.68 & 4.22 & 3.63 & 2.80 & 1.79 \\
\hline 96 & 496 & 0.00 & 3.80 & 3.36 & 2.13 & -2.29 & -7.17 & 3.40 & 3.02 & 2.55 & 1.79 & 0.90 \\
\hline 97 & 497 & 11.86 & 6.42 & 5.79 & 5.06 & 4.10 & 2.85 & 6.47 & 5.87 & 5.12 & 4.20 & 3.00 \\
\hline
\end{tabular}




\begin{tabular}{|c|c|c|c|c|c|c|c|c|c|c|c|c|}
\hline \multirow{2}{*}{$\begin{array}{l}\text { Wave } \\
\text { No. }\end{array}$} & \multirow{2}{*}{$\begin{array}{l}\text { Wave } \\
\text { ID }\end{array}$} & \multirow[b]{2}{*}{ Days/yr } & \multicolumn{5}{|c|}{ Inbound Ship speed (kt) } & \multicolumn{5}{|c|}{ Outbound Ship speed (kt) } \\
\hline & & & 8 & 10 & 12 & 14 & 16 & 8 & 10 & 12 & 14 & 16 \\
\hline 98 & 498 & 3.07 & 6.38 & 5.71 & 5.00 & 4.02 & 2.72 & 6.46 & 5.86 & 5.11 & 4.18 & 2.97 \\
\hline 99 & 499 & 0.58 & 6.34 & 5.64 & 4.94 & 3.94 & 2.58 & 6.45 & 5.85 & 5.10 & 4.17 & 2.94 \\
\hline 100 & 500 & 0.04 & 6.30 & 5.57 & 4.89 & 3.86 & 2.46 & 6.44 & 5.84 & 5.08 & 4.15 & 2.91 \\
\hline 101 & 501 & 1.10 & 6.25 & 5.56 & 4.84 & 3.93 & 2.43 & 6.40 & 5.80 & 5.04 & 4.12 & 2.91 \\
\hline 102 & 502 & 0.29 & 6.08 & 5.33 & 4.62 & 3.72 & 2.00 & 6.34 & 5.74 & 4.98 & 4.05 & 2.82 \\
\hline 103 & 503 & 0.47 & 5.91 & 5.09 & 4.41 & 3.51 & 1.56 & 6.29 & 5.67 & 4.91 & 3.99 & 2.73 \\
\hline 104 & 504 & 0.07 & 5.75 & 4.87 & 4.20 & 3.31 & 1.15 & 6.23 & 5.61 & 4.84 & 3.92 & 2.65 \\
\hline 105 & 505 & 0.00 & 5.60 & 4.64 & 4.00 & 3.11 & 0.73 & 6.18 & 5.55 & 4.78 & 3.85 & 2.56 \\
\hline 106 & 506 & 0.88 & 6.07 & 5.41 & 4.69 & 3.81 & 2.42 & 6.26 & 5.67 & 4.91 & 3.99 & 2.81 \\
\hline 107 & 507 & 0.15 & 5.78 & 5.07 & 4.37 & 3.52 & 1.98 & 6.11 & 5.51 & 4.75 & 3.83 & 2.65 \\
\hline 108 & 508 & 0.11 & 5.49 & 4.73 & 4.05 & 3.23 & 1.54 & 5.95 & 5.36 & 4.59 & 3.67 & 2.48 \\
\hline 109 & 509 & 0.15 & 5.21 & 4.41 & 3.75 & 2.96 & 1.12 & 5.80 & 5.21 & 4.44 & 3.51 & 2.33 \\
\hline 110 & 510 & 0.07 & 4.94 & 4.08 & 3.45 & 2.68 & 0.70 & 5.66 & 5.06 & 4.28 & 3.36 & 2.17 \\
\hline 111 & 511 & 0.00 & 4.59 & 3.67 & 3.06 & 2.33 & 0.17 & 5.47 & 4.87 & 4.09 & 3.16 & 1.98 \\
\hline 112 & 512 & 0.62 & 5.71 & 5.12 & 4.40 & 3.51 & 2.22 & 5.96 & 5.38 & 4.63 & 3.71 & 2.54 \\
\hline 113 & 513 & 0.26 & 5.17 & 4.57 & 3.86 & 3.00 & 1.63 & 5.58 & 5.02 & 4.26 & 3.35 & 2.18 \\
\hline 114 & 514 & 0.15 & 4.62 & 4.02 & 3.33 & 2.49 & 1.05 & 5.20 & 4.66 & 3.89 & 2.99 & 1.83 \\
\hline 115 & 515 & 0.11 & 4.10 & 3.49 & 2.83 & 2.01 & 0.49 & 4.85 & 4.32 & 3.55 & 2.65 & 1.49 \\
\hline 116 & 516 & 0.00 & 3.58 & 2.97 & 2.32 & 1.52 & -0.07 & 4.49 & 3.98 & 3.20 & 2.30 & 1.15 \\
\hline 117 & 517 & 0.00 & 2.92 & 2.31 & 1.68 & 0.91 & -0.77 & 4.04 & 3.54 & 2.76 & 1.87 & 0.72 \\
\hline 118 & 518 & 0.73 & 4.95 & 4.46 & 3.75 & 2.91 & 1.21 & 5.42 & 4.93 & 4.22 & 3.34 & 2.20 \\
\hline 119 & 519 & 0.22 & 3.86 & 3.44 & 2.76 & 1.98 & -0.10 & 4.66 & 4.24 & 3.56 & 2.71 & 1.60 \\
\hline 120 & 520 & 0.11 & 2.77 & 2.42 & 1.76 & 1.05 & -1.41 & 3.89 & 3.55 & 2.89 & 2.08 & 1.00 \\
\hline 121 & 521 & 0.07 & 1.73 & 1.45 & 0.82 & 0.16 & -2.65 & 3.17 & 2.90 & 2.27 & 1.48 & 0.43 \\
\hline 122 & 522 & 0.04 & 0.69 & 0.49 & -0.12 & -0.73 & -3.90 & 2.45 & 2.24 & 1.64 & 0.88 & -0.14 \\
\hline 123 & 523 & 0.00 & -0.62 & -0.74 & -1.32 & -1.85 & -5.47 & 1.54 & 1.42 & 0.85 & 0.12 & -0.86 \\
\hline 124 & 524 & 0.11 & 4.66 & 4.17 & 3.50 & 2.37 & -0.02 & 4.93 & 4.42 & 3.74 & 2.87 & 1.80 \\
\hline 125 & 525 & 0.04 & 3.36 & 2.95 & 2.33 & 1.05 & -2.21 & 3.82 & 3.37 & 2.75 & 1.91 & 0.92 \\
\hline 126 & 526 & 0.04 & 2.06 & 1.72 & 1.16 & -0.27 & -4.39 & 2.72 & 2.32 & 1.75 & 0.95 & 0.04 \\
\hline 127 & 527 & 0.00 & 3.79 & 3.31 & 2.72 & 0.65 & -3.09 & 3.54 & 3.04 & 2.47 & 1.64 & 0.70 \\
\hline 128 & 528 & 0.04 & 1.88 & 1.46 & 0.99 & -1.90 & -7.48 & 1.44 & 1.01 & 0.56 & -0.20 & -0.97 \\
\hline 129 & 529 & 0.04 & -0.05 & -0.39 & -0.74 & -4.45 & -11.86 & -0.67 & -1.02 & -1.35 & -2.04 & -2.64 \\
\hline 130 & 530 & 18.03 & 6.43 & 5.80 & 5.07 & 4.12 & 2.88 & 6.46 & 5.86 & 5.11 & 4.18 & 2.97 \\
\hline
\end{tabular}




\begin{tabular}{|c|c|c|c|c|c|c|c|c|c|c|c|c|}
\hline \multirow{2}{*}{$\begin{array}{l}\text { Wave } \\
\text { No. }\end{array}$} & \multirow{2}{*}{$\begin{array}{l}\text { Wave } \\
\text { ID }\end{array}$} & \multirow[b]{2}{*}{ Days/yr } & \multicolumn{5}{|c|}{ Inbound Ship speed (kt) } & \multicolumn{5}{|c|}{ Outbound Ship speed (kt) } \\
\hline & & & 8 & 10 & 12 & 14 & 16 & 8 & 10 & 12 & 14 & 16 \\
\hline 131 & 531 & 3.80 & 6.40 & 5.74 & 5.02 & 4.05 & 2.76 & 6.45 & 5.84 & 5.09 & 4.16 & 2.93 \\
\hline 132 & 532 & 0.37 & 6.36 & 5.67 & 4.97 & 3.97 & 2.63 & 6.44 & 5.82 & 5.07 & 4.13 & 2.88 \\
\hline 133 & 533 & 0.00 & 6.29 & 5.54 & 4.86 & 3.82 & 2.39 & 6.41 & 5.78 & 5.03 & 4.07 & 2.78 \\
\hline 134 & 534 & 2.23 & 6.28 & 5.61 & 4.88 & 3.97 & 2.53 & 6.39 & 5.77 & 5.02 & 4.10 & 2.84 \\
\hline 135 & 535 & 0.58 & 6.14 & 5.41 & 4.69 & 3.78 & 2.15 & 6.32 & 5.69 & 4.93 & 4.02 & 2.69 \\
\hline 136 & 536 & 0.58 & 5.99 & 5.19 & 4.49 & 3.58 & 1.75 & 6.25 & 5.60 & 4.83 & 3.92 & 2.54 \\
\hline 137 & 537 & 0.07 & 5.84 & 4.99 & 4.30 & 3.40 & 1.37 & 6.18 & 5.51 & 4.74 & 3.84 & 2.39 \\
\hline 138 & 538 & 1.06 & 6.12 & 5.47 & 4.74 & 3.86 & 2.50 & 6.24 & 5.64 & 4.88 & 3.96 & 2.79 \\
\hline 139 & 539 & 0.29 & 5.86 & 5.16 & 4.44 & 3.59 & 2.11 & 6.07 & 5.46 & 4.69 & 3.77 & 2.60 \\
\hline 140 & 540 & 0.11 & 5.58 & 4.83 & 4.13 & 3.30 & 1.69 & 5.89 & 5.26 & 4.49 & 3.57 & 2.40 \\
\hline 141 & 541 & 0.26 & 5.31 & 4.52 & 3.84 & 3.03 & 1.29 & 5.71 & 5.08 & 4.30 & 3.38 & 2.21 \\
\hline 142 & 542 & 0.11 & 5.05 & 4.21 & 3.54 & 2.76 & 0.90 & 5.54 & 4.89 & 4.11 & 3.19 & 2.02 \\
\hline 143 & 543 & 0.00 & 4.76 & 3.87 & 3.21 & 2.46 & 0.46 & 5.35 & 4.69 & 3.90 & 2.99 & 1.82 \\
\hline 144 & 544 & 0.69 & 5.74 & 5.15 & 4.41 & 3.51 & 2.30 & 5.89 & 5.32 & 4.55 & 3.64 & 2.47 \\
\hline 145 & 545 & 0.29 & 5.19 & 4.60 & 3.87 & 2.99 & 1.76 & 5.46 & 4.89 & 4.12 & 3.21 & 2.04 \\
\hline 146 & 546 & 0.18 & 4.61 & 4.02 & 3.30 & 2.44 & 1.18 & 5.00 & 4.44 & 3.66 & 2.76 & 1.60 \\
\hline 147 & 547 & 0.04 & 4.06 & 3.47 & 2.76 & 1.92 & 0.64 & 4.57 & 4.02 & 3.23 & 2.33 & 1.17 \\
\hline 148 & 548 & 0.07 & 3.51 & 2.92 & 2.22 & 1.39 & 0.09 & 4.13 & 3.59 & 2.80 & 1.90 & 0.75 \\
\hline 149 & 549 & 0.04 & 2.91 & 2.31 & 1.62 & 0.82 & -0.51 & 3.65 & 3.12 & 2.32 & 1.43 & 0.28 \\
\hline 150 & 550 & 0.00 & 2.44 & 1.85 & 1.16 & 0.37 & -0.98 & 3.28 & 2.76 & 1.95 & 1.07 & -0.08 \\
\hline 151 & 551 & 0.62 & 4.81 & 4.32 & 3.57 & 2.72 & 1.52 & 5.15 & 4.67 & 3.93 & 3.06 & 1.92 \\
\hline 152 & 552 & 0.22 & 3.57 & 3.15 & 2.41 & 1.62 & 0.38 & 4.17 & 3.76 & 3.04 & 2.20 & 1.09 \\
\hline 153 & 553 & 0.11 & 2.27 & 1.92 & 1.19 & 0.45 & -0.80 & 3.13 & 2.81 & 2.10 & 1.29 & 0.22 \\
\hline 154 & 554 & 0.00 & 1.03 & 0.75 & 0.02 & -0.66 & -1.93 & 2.15 & 1.90 & 1.20 & 0.43 & -0.60 \\
\hline 155 & 555 & 0.00 & -1.57 & -1.70 & -2.42 & -2.99 & -4.31 & 0.08 & -0.01 & -0.68 & -1.38 & -2.34 \\
\hline 156 & 556 & 0.15 & 4.15 & 3.67 & 2.96 & 2.12 & 0.46 & 4.31 & 3.81 & 3.12 & 2.24 & 1.17 \\
\hline 157 & 557 & 0.11 & 2.41 & 2.02 & 1.35 & 0.56 & -1.45 & 2.71 & 2.26 & 1.62 & 0.76 & -0.21 \\
\hline 158 & 558 & 0.04 & 2.61 & 2.16 & 1.59 & 0.75 & -1.93 & 2.02 & 1.52 & 0.89 & 0.06 & -0.80 \\
\hline 159 & 559 & 0.00 & -0.26 & -0.60 & -1.05 & -1.82 & -5.61 & -1.29 & -1.72 & -2.26 & -3.02 & -3.65 \\
\hline 160 & 560 & 27.08 & 6.43 & 5.81 & 5.07 & 4.12 & 2.88 & 6.45 & 5.84 & 5.09 & 4.16 & 2.93 \\
\hline 161 & 561 & 6.72 & 6.40 & 5.75 & 5.02 & 4.06 & 2.77 & 6.43 & 5.80 & 5.06 & 4.11 & 2.85 \\
\hline 162 & 562 & 0.40 & 6.37 & 5.69 & 4.98 & 3.99 & 2.66 & 6.41 & 5.76 & 5.03 & 4.07 & 2.77 \\
\hline 163 & 563 & 0.00 & 6.34 & 5.64 & 4.93 & 3.92 & 2.54 & 6.38 & 5.72 & 4.99 & 4.02 & 2.69 \\
\hline
\end{tabular}




\begin{tabular}{|c|c|c|c|c|c|c|c|c|c|c|c|c|}
\hline \multirow{2}{*}{$\begin{array}{l}\text { Wave } \\
\text { No. }\end{array}$} & \multirow{2}{*}{$\begin{array}{l}\text { Wave } \\
\text { ID }\end{array}$} & \multirow[b]{2}{*}{ Days/yr } & \multicolumn{5}{|c|}{ Inbound Ship speed (kt) } & \multicolumn{5}{|c|}{ Outbound Ship speed (kt) } \\
\hline & & & 8 & 10 & 12 & 14 & 16 & 8 & 10 & 12 & 14 & 16 \\
\hline 164 & 564 & 4.60 & 6.31 & 5.65 & .91 & 3.99 & 2.60 & 6.35 & 5.72 & 4.97 & 4.05 & 2.74 \\
\hline 165 & 565 & 0.91 & 6.18 & 5.48 & 4.75 & 3.83 & 2.28 & 6.26 & 5.60 & 4.85 & 3.93 & 2.52 \\
\hline 166 & 566 & 1.24 & 6.07 & 5.31 & 4.59 & 3.68 & 1.98 & 6.18 & 5.48 & 4.73 & 3.82 & 2.31 \\
\hline 167 & 567 & 0.11 & 5.94 & 5.14 & 4.43 & 3.52 & 1.67 & 6.08 & 5.36 & 4.61 & 3.70 & 2.09 \\
\hline 168 & 568 & 1.46 & 6.14 & 5.50 & 4.76 & 3.86 & 2.56 & 6.19 & 5.57 & 4.82 & 3.91 & 2.69 \\
\hline 169 & 569 & 0.33 & 5.90 & 5.22 & 4.48 & 3.60 & 2.22 & 5.99 & 5.35 & 4.59 & 3.68 & 2.44 \\
\hline 170 & 570 & 0.22 & 5.66 & 4.96 & 4.22 & 3.36 & 1.90 & 5.79 & 5.13 & 4.37 & 3.47 & 2.21 \\
\hline 171 & 571 & 0.40 & 5.42 & 4.68 & 3.95 & 3.10 & 1.56 & 5.58 & 4.91 & 4.14 & 3.25 & 1.96 \\
\hline 172 & 572 & 0.07 & 5.18 & 4.40 & 3.68 & 2.85 & 1.22 & 5.38 & 4.68 & 3.91 & 3.02 & 1.71 \\
\hline 173 & 573 & 0.00 & 4.92 & 4.11 & 3.39 & 2.58 & 0.86 & 5.16 & 4.44 & 3.67 & 2.79 & 1.44 \\
\hline 174 & 574 & 0.69 & 5.73 & 5.14 & 4.39 & 3.49 & 2.31 & 5.79 & 5.21 & 4.45 & 3.54 & 2.36 \\
\hline 175 & 575 & 0.33 & 5.19 & 4.60 & 3.85 & 2.96 & 1.79 & 5.30 & 4.73 & 3.95 & 3.05 & 1.88 \\
\hline 176 & 576 & 0.07 & 4.68 & 4.09 & 3.34 & 2.46 & 1.30 & 4.83 & 4.26 & 3.49 & 2.59 & 1.42 \\
\hline 177 & 577 & 0.04 & 4.14 & 3.56 & 2.80 & 1.94 & 0.78 & 4.34 & 3.78 & 2.99 & 2.10 & 0.94 \\
\hline 178 & 578 & 0.04 & 3.60 & 3.02 & 2.27 & 1.41 & 0.26 & 3.85 & 3.29 & 2.50 & 1.61 & 0.46 \\
\hline 179 & 579 & 0.04 & 3.04 & 2.46 & 1.70 & 0.86 & -0.28 & 3.33 & 2.78 & 1.98 & 1.10 & -0.05 \\
\hline 180 & 580 & 0.22 & 4.87 & 4.36 & 3.60 & 2.74 & 1.60 & 5.01 & 4.51 & 3.76 & 2.89 & 1.75 \\
\hline 181 & 581 & $0.1 \varepsilon$ & 1 & 3.27 & 2.50 & 1.67 & 0.58 & 97 & 3.53 & 77 & 1.93 & 0.82 \\
\hline 182 & 582 & 0.04 & 2.61 & 2.23 & 1.45 & 0.66 & -0.40 & 2.97 & 2.60 & 1.83 & 1.03 & -0.05 \\
\hline 183 & 583 & 0.00 & 1.46 & 1.13 & 0.34 & -0.40 & -1.42 & 1.92 & 1.61 & 0.84 & 0.07 & -0.98 \\
\hline 184 & 584 & 0.00 & 0.30 & 0.04 & -0.76 & -1.46 & -2.45 & 0.87 & 0.63 & -0.14 & -0.88 & -1.90 \\
\hline 185 & 585 & 0.00 & -0.91 & -1.11 & -1.92 & -2.58 & -3.53 & -0.23 & -0.40 & -1.18 & -1.88 & -2.87 \\
\hline 186 & 586 & 0.00 & -2.12 & -2.26 & -3.07 & -3.69 & -4.61 & $\mid-1.33$ & -1.44 & -2.22 & -2.89 & -3.84 \\
\hline 187 & 587 & 10.22 & 6.47 & 5.86 & 5.12 & 4.19 & 2.98 & 6.46 & 5.86 & 5.11 & 4.18 & 2.97 \\
\hline 188 & 588 & 2.81 & 6.46 & 5.85 & 5.10 & 4.17 & 2.95 & 6.45 & 5.84 & 5.10 & 4.15 & 2.93 \\
\hline 189 & 589 & 0.22 & 6.45 & 5.83 & 5.09 & 4.14 & 2.91 & 6.44 & 5.81 & 5.08 & 4.12 & 2.89 \\
\hline 190 & 590 & 0.00 & 6.44 & 5.81 & 5.07 & 4.12 & 2.87 & 6.43 & 5.79 & 5.06 & 4.09 & 2.84 \\
\hline 191 & 591 & 0.00 & 6.43 & 5.79 & 5.06 & 4.10 & 2.84 & 6.41 & 5.77 & 5.04 & 4.07 & 2.80 \\
\hline 192 & 592 & 0.18 & 6.34 & 5.70 & 4.95 & 4.03 & 2.69 & 6.31 & 5.66 & 4.92 & 4.00 & 2.62 \\
\hline 193 & 593 & 0.18 & 6.25 & 5.58 & 4.83 & 3.91 & 2.47 & 6.21 & 5.52 & 4.78 & 3.87 & 2.35 \\
\hline 194 & 594 & 0.29 & 6.15 & 5.44 & 4.69 & 3.78 & 2.23 & 6.09 & 5.36 & 4.62 & 3.71 & 2.06 \\
\hline 195 & 595 & 0.00 & 6.04 & 5.30 & 4.55 & 3.65 & 1.97 & 5.97 & 5.19 & 4.46 & 3.56 & 1.76 \\
\hline 196 & 596 & 0.04 & 6.17 & 5.54 & 4.79 & 3.88 & 2.65 & 6.14 & 5.50 & 4.76 & 3.86 & 2.58 \\
\hline
\end{tabular}




\begin{tabular}{|c|c|c|c|c|c|c|c|c|c|c|c|c|}
\hline \multirow{2}{*}{$\begin{array}{l}\text { Wave } \\
\text { No. }\end{array}$} & \multirow{2}{*}{$\begin{array}{l}\text { Wave } \\
\text { ID }\end{array}$} & \multirow[b]{2}{*}{ Days/yr } & \multicolumn{5}{|c|}{ Inbound Ship speed (kt) } & \multicolumn{5}{|c|}{ Outbound Ship speed (kt) } \\
\hline & & & 8 & 10 & 12 & 14 & 16 & 8 & 10 & 12 & 14 & 16 \\
\hline 197 & 597 & 0.04 & 5.97 & 5.33 & 4.57 & 3.67 & 2.40 & 5.93 & 5.26 & 4.52 & 3.63 & 2.29 \\
\hline 198 & 598 & 0.04 & 5.76 & 5.09 & 4.33 & 3.44 & 2.13 & 5.69 & 5.00 & 4.26 & 3.38 & 1.97 \\
\hline 199 & 599 & 0.07 & 5.53 & 4.83 & 4.08 & 3.19 & 1.84 & 5.45 & 4.72 & 3.98 & 3.12 & 1.64 \\
\hline 200 & 600 & 0.00 & 5.35 & 4.63 & 3.87 & 2.99 & 1.61 & 5.25 & 4.49 & 3.76 & 2.91 & 1.37 \\
\hline 201 & 601 & 0.00 & 5.75 & 5.16 & 4.40 & 3.49 & 2.32 & 5.71 & 5.13 & 4.37 & 3.47 & 2.29 \\
\hline 202 & 602 & 0.04 & 5.29 & 4.71 & 3.94 & 3.04 & 1.87 & 5.24 & 4.65 & 3.89 & 3.00 & 1.83 \\
\hline 203 & 603 & 0.00 & 4.78 & 4.21 & 3.43 & 2.54 & 1.38 & 4.71 & 4.12 & 3.36 & 2.48 & 1.32 \\
\hline 204 & 604 & 0.00 & 4.25 & 3.68 & 2.90 & 2.01 & 0.85 & 4.15 & 3.57 & 2.80 & 1.93 & 0.78 \\
\hline 205 & 605 & 0.00 & 3.82 & 3.26 & 2.47 & 1.59 & 0.43 & 3.70 & 3.12 & 2.35 & 1.49 & 0.34 \\
\hline 206 & 606 & 0.00 & 3.16 & 2.60 & 1.80 & 0.94 & -0.21 & 3.01 & 2.44 & 1.66 & 0.81 & -0.33 \\
\hline 207 & 607 & 0.04 & 4.81 & 4.32 & 3.56 & 2.70 & 1.57 & 4.73 & 4.24 & 3.48 & 2.62 & 1.49 \\
\hline 208 & 608 & 0.04 & 3.77 & 3.35 & 2.58 & 1.76 & 0.66 & 3.64 & 3.21 & 2.44 & 1.62 & 0.53 \\
\hline 209 & 609 & 0.00 & 2.62 & 2.26 & 1.49 & 0.71 & -0.36 & 2.43 & 2.07 & 1.29 & 0.52 & -0.54 \\
\hline 210 & 610 & 0.00 & 1.41 & 1.13 & 0.35 & -0.40 & -1.42 & 1.16 & 0.87 & 0.08 & -0.65 & -1.66 \\
\hline 211 & 611 & 0.00 & -1.65 & -1.75 & -2.53 & -3.18 & -4.12 & -2.04 & -2.15 & -2.96 & -3.58 & -4.49 \\
\hline
\end{tabular}


Table E3. Net UKC (ft), Phase 1, Channel Reach 1, $h=58 \mathrm{ft}$, fully loaded Susan Maersk, inbound and outbound transits.

\begin{tabular}{|c|c|c|c|c|c|c|c|c|c|c|c|c|}
\hline \multirow{2}{*}{$\begin{array}{l}\text { Wave } \\
\text { No. }\end{array}$} & \multirow{2}{*}{$\begin{array}{l}\text { Wave } \\
\text { ID }\end{array}$} & \multirow[b]{2}{*}{ Days/yr } & \multicolumn{5}{|c|}{ Inbound Ship speed (kt) } & \multicolumn{5}{|c|}{ Outbound Ship speed (kt) } \\
\hline & & & 8 & 10 & 12 & 14 & 16 & 8 & 10 & 12 & 14 & 16 \\
\hline 1 & 101 & 6.10 & 9.48 & 8.91 & 8.20 & 7.31 & 6.18 & 9.50 & 8.93 & 8.23 & 7.35 & 6.24 \\
\hline 2 & 102 & 2.74 & 9.46 & 8.88 & 8.18 & 7.28 & 6.13 & 9.49 & 8.93 & 8.22 & 7.34 & 6.21 \\
\hline 3 & 103 & 0.26 & 9.44 & 8.84 & 8.16 & 7.24 & 6.07 & 9.49 & 8.91 & 8.21 & 7.32 & 6.19 \\
\hline 4 & 104 & 0.04 & 9.43 & 8.82 & 8.13 & 7.20 & 6.02 & 9.48 & 8.91 & 8.20 & 7.31 & 6.17 \\
\hline 5 & 105 & 0.00 & 9.40 & 8.78 & 8.11 & 7.16 & 5.95 & 9.47 & 8.89 & 8.19 & 7.30 & 6.14 \\
\hline 6 & 106 & 0.00 & 9.27 & 8.65 & 7.97 & 7.11 & 5.66 & 9.39 & 8.81 & 8.10 & 7.24 & 6.05 \\
\hline 7 & 107 & 0.07 & 9.11 & 8.45 & 7.79 & 6.95 & 5.26 & 9.32 & 8.72 & 8.01 & 7.15 & 5.90 \\
\hline 8 & 108 & 0.07 & 8.95 & 8.24 & 7.60 & 6.77 & 4.83 & 9.24 & 8.63 & 7.91 & 7.06 & 5.75 \\
\hline 9 & 109 & 0.00 & 8.80 & 8.05 & 7.43 & 6.61 & 4.45 & \begin{tabular}{|l|}
9.17 \\
\end{tabular} & 8.55 & \begin{tabular}{|l}
7.83 \\
\end{tabular} & 6.98 & 5.61 \\
\hline 10 & 110 & 0.00 & 8.61 & 7.82 & 7.23 & 6.41 & 3.99 & 9.08 & 8.44 & $\begin{array}{l}7.72 \\
\end{array}$ & 6.88 & 5.45 \\
\hline 11 & 111 & 0.04 & 9.10 & 8.49 & 7.81 & 6.97 & 5.67 & 9.23 & 8.66 & 7.94 & 7.08 & 5.98 \\
\hline 12 & 112 & 0.00 & 8.83 & 8.19 & 7.52 & 6.71 & 5.27 & 9.04 & 8.47 & 7.75 & 6.88 & 5.79 \\
\hline 13 & 113 & 0.04 & 8.54 & 7.87 & 7.22 & 6.44 & 4.85 & 8.85 & 8.26 & 7.54 & 6.68 & 5.59 \\
\hline 14 & 114 & 0.04 & 8.29 & 7.59 & 6.95 & 6.19 & 4.48 & 8.68 & 8.08 & 7.36 & 6.50 & 5.41 \\
\hline 15 & 115 & 0.00 & 8.67 & 8.12 & 7.42 & 6.57 & 5.49 & 8.82 & 8.27 & 7.56 & 6.70 & 5.61 \\
\hline 16 & 116 & 0.00 & 8.13 & 7.57 & 6.88 & 6.05 & 4.98 & 8.36 & 7.83 & 7.11 & 6.25 & 5.17 \\
\hline 17 & 117 & 0.00 & 7.55 & 7.00 & 6.32 & 5.50 & 4.44 & 7.88 & 7.36 & 6.64 & 5.79 & 4.71 \\
\hline 18 & 118 & 0.00 & 7.03 & 6.48 & 5.81 & 5.00 & 3.95 & 7.45 & 6.94 & 6.22 & 5.37 & 4.30 \\
\hline 19 & 119 & 0.00 & 6.39 & 5.85 & 5.19 & 4.39 & 3.36 & 6.93 & 6.42 & 5.70 & 4.85 & 3.79 \\
\hline 20 & 120 & 0.00 & \begin{tabular}{|l}
6.02 \\
\end{tabular} & 5.47 & 4.82 & 4.03 & 3.01 & 6.62 & 6.12 & 5.40 & 4.55 & 3.49 \\
\hline 21 & 121 & 0.04 & 7.58 & 7.12 & 6.48 & 5.62 & 4.59 & 7.87 & 7.43 & 6.79 & 5.93 & 4.88 \\
\hline 22 & 122 & 0.00 & 6.31 & 5.92 & 5.33 & 4.47 & 3.49 & 6.80 & 6.43 & 5.83 & 4.99 & 3.97 \\
\hline 23 & 123 & 0.00 & 4.98 & 4.66 & 4.12 & 3.26 & 2.33 & 5.67 & 5.38 & 4.83 & 4.00 & 3.01 \\
\hline 24 & 124 & 0.00 & 3.78 & 3.52 & 3.03 & 2.17 & 1.29 & 4.65 & 4.43 & 3.93 & 3.10 & 2.14 \\
\hline 25 & 125 & 0.00 & 1.44 & 1.31 & 0.91 & 0.05 & -0.74 & 2.67 & 2.59 & 2.17 & 1.37 & 0.46 \\
\hline 26 & 126 & 0.00 & -0.76 & -0.77 & -1.09 & -1.95 & -2.66 & 0.80 & 0.85 & 0.51 & -0.27 & -1.13 \\
\hline 27 & 127 & 0.00 & -1.29 & -1.27 & -1.58 & -2.44 & $\mid-3.12$ & 0.35 & 0.43 & 0.11 & -0.67 & -1.51 \\
\hline 28 & 128 & 11.24 & 9.45 & 8.86 & 8.17 & 7.26 & 6.10 & 9.50 & 8.93 & 8.22 & 7.35 & 6.23 \\
\hline 29 & 129 & 3.80 & 9.41 & 8.80 & 8.12 & 7.19 & 5.98 & 9.49 & 8.92 & 8.21 & 7.34 & 6.21 \\
\hline 30 & 130 & 0.66 & 9.37 & 8.73 & 8.07 & 7.11 & 5.86 & 9.48 & 8.91 & 8.20 & 7.33 & 6.19 \\
\hline 31 & 131 & 0.04 & 9.33 & 8.67 & 8.01 & \begin{tabular}{|l|l}
7.04 \\
\end{tabular} & 5.74 & 9.48 & 8.90 & 8.19 & 7.31 & 6.16 \\
\hline
\end{tabular}




\begin{tabular}{|c|c|c|c|c|c|c|c|c|c|c|c|c|}
\hline \multirow{2}{*}{$\begin{array}{l}\text { Wave } \\
\text { No. }\end{array}$} & \multirow{2}{*}{$\begin{array}{l}\text { Wave } \\
\text { ID }\end{array}$} & \multirow[b]{2}{*}{ Days/yr } & \multicolumn{5}{|c|}{ Inbound Ship speed (kt) } & \multicolumn{5}{|c|}{ Outbound Ship speed (kt) } \\
\hline & & & 8 & 10 & 12 & 14 & 16 & 8 & 10 & 12 & 14 & 16 \\
\hline 32 & 132 & 1.13 & 9.23 & 8.60 & 7.93 & 7.08 & 5.55 & 9.41 & 8.85 & 8.13 & 7.26 & 6.14 \\
\hline 33 & 133 & 0.18 & 9.05 & 8.38 & 7.73 & 6.90 & 5.08 & 9.35 & 8.78 & 8.06 & 7.19 & 6.05 \\
\hline 34 & 134 & 0.66 & 8.86 & 8.14 & 7.52 & 6.70 & 4.58 & 9.28 & 8.70 & 7.98 & 7.12 & 5.96 \\
\hline 35 & 135 & 0.15 & 8.67 & 7.90 & 7.31 & 6.50 & 4.08 & 9.22 & 8.63 & 7.91 & 7.04 & 5.87 \\
\hline 36 & 136 & 0.00 & 8.48 & 7.66 & 7.10 & 6.31 & 3.59 & 9.15 & 8.56 & 7.83 & 6.97 & 5.78 \\
\hline 37 & 137 & 1.20 & 9.04 & 8.44 & 7.76 & 6.94 & 5.58 & 9.24 & 8.68 & 7.97 & 7.10 & 6.00 \\
\hline 38 & 138 & 0.22 & 8.73 & 8.10 & 7.45 & 6.66 & 5.14 & 9.07 & 8.50 & 7.79 & 6.92 & 5.82 \\
\hline 39 & 139 & 0.07 & 8.41 & 7.75 & 7.12 & 6.36 & 4.66 & 8.88 & 8.32 & 7.60 & 6.73 & 5.63 \\
\hline 40 & 140 & 0.22 & 8.09 & 7.39 & 6.80 & 6.06 & 4.19 & 8.69 & 8.13 & 7.41 & 6.54 & 5.44 \\
\hline 41 & 141 & 0.15 & 7.76 & 7.04 & 6.47 & 5.76 & 3.72 & 8.51 & 7.95 & 7.22 & 6.36 & 5.26 \\
\hline 42 & 142 & 0.04 & 7.42 & 6.67 & 6.12 & 5.45 & 3.22 & 8.31 & 7.75 & 7.02 & 6.16 & 5.06 \\
\hline 43 & 143 & 0.88 & 8.65 & 8.10 & 7.41 & 6.57 & 5.44 & 8.88 & 8.34 & 7.63 & 6.77 & 5.68 \\
\hline 44 & 144 & 0.11 & 8.09 & 7.54 & 6.87 & 6.04 & 4.89 & 8.46 & 7.94 & 7.23 & 6.37 & 5.29 \\
\hline 45 & 145 & 0.04 & 7.50 & 6.95 & 6.30 & 5.49 & 4.31 & 8.02 & 7.52 & 6.81 & 5.96 & 4.88 \\
\hline 46 & 146 & 0.07 & 6.91 & 6.37 & 5.73 & 4.94 & 3.74 & 7.58 & 7.09 & 6.39 & 5.54 & 4.47 \\
\hline 47 & 147 & 0.04 & 6.32 & 5.78 & 5.16 & 4.38 & 3.16 & 7.14 & 6.67 & 5.97 & 5.13 & 4.06 \\
\hline 48 & 148 & 0.04 & 5.69 & 5.16 & 4.56 & 3.80 & 2.56 & 6.68 & 6.23 & 5.53 & 4.69 & 3.64 \\
\hline 49 & 149 & 0.04 & 5.10 & 4.57 & 3.99 & 3.25 & 1.98 & 6.25 & 5.80 & 5.11 & 4.27 & 3.23 \\
\hline 50 & 150 & 0.00 & 4.27 & 3.75 & 3.19 & 2.48 & 1.17 & 5.63 & 5.21 & 4.52 & 3.69 & 2.66 \\
\hline 51 & 151 & 0.18 & 8.03 & 7.55 & 6.91 & 6.07 & 4.72 & 8.38 & 7.91 & 7.27 & 6.43 & 5.36 \\
\hline 52 & 152 & 0.15 & 7.06 & 6.64 & 6.04 & 5.22 & 3.70 & 7.63 & 7.23 & 6.63 & 5.81 & 4.77 \\
\hline 53 & 153 & 0.11 & 6.04 & 5.68 & 5.13 & 4.32 & 2.63 & 6.85 & 6.52 & 5.96 & 5.16 & 4.15 \\
\hline 54 & 154 & 0.07 & 5.02 & 4.71 & 4.21 & 3.43 & 1.55 & 6.07 & 5.80 & 5.28 & 4.51 & 3.52 \\
\hline 55 & 155 & 0.04 & 4.00 & 3.75 & 3.30 & 2.53 & 0.48 & 5.28 & 5.08 & 4.61 & 3.85 & 2.89 \\
\hline 56 & 156 & 0.04 & 2.93 & 2.74 & 2.33 & 1.59 & -0.64 & 4.46 & 4.33 & 3.91 & 3.17 & 2.24 \\
\hline 57 & 157 & 0.00 & 1.90 & 1.77 & 1.42 & 0.69 & -1.71 & 3.68 & 3.61 & 3.23 & 2.52 & 1.61 \\
\hline 58 & 158 & 0.00 & 0.47 & 0.42 & 0.14 & -0.56 & -3.22 & 2.58 & 2.61 & 2.29 & 1.61 & 0.74 \\
\hline 59 & 159 & 0.00 & -1.11 & -1.07 & -1.28 & -1.95 & -4.88 & 1.37 & 1.50 & 1.25 & 0.60 & -0.23 \\
\hline 60 & 160 & 0.00 & 7.69 & 7.23 & 6.61 & 5.74 & 3.67 & 7.83 & 7.36 & 6.74 & 5.91 & 4.88 \\
\hline 61 & 161 & 0.00 & 6.50 & 6.10 & 5.54 & 4.66 & 1.96 & 6.73 & 6.31 & 5.75 & 4.96 & 3.96 \\
\hline 62 & 162 & 0.00 & 0.15 & 0.08 & -0.15 & -1.03 & -7.10 & 0.87 & 0.75 & 0.50 & -0.12 & -0.89 \\
\hline 63 & 163 & 0.00 & -1.61 & -1.58 & -1.72 & -2.61 & -9.62 & -0.76 & -0.79 & -0.95 & -1.52 & -2.24 \\
\hline 64 & 164 & 0.00 & 6.94 & 6.48 & 5.91 & 4.44 & 1.31 & 6.45 & 5.97 & 5.41 & 4.62 & 3.65 \\
\hline
\end{tabular}




\begin{tabular}{|c|c|c|c|c|c|c|c|c|c|c|c|c|}
\hline \multirow{2}{*}{$\begin{array}{l}\text { Wave } \\
\text { No. }\end{array}$} & \multirow{2}{*}{$\begin{array}{l}\text { Wave } \\
\text { ID }\end{array}$} & \multirow[b]{2}{*}{ Days/yr } & \multicolumn{5}{|c|}{ Inbound Ship speed (kt) } & \multicolumn{5}{|c|}{ Outbound Ship speed (kt) } \\
\hline & & & 8 & 10 & 12 & 14 & 16 & 8 & 10 & 12 & 14 & 16 \\
\hline 65 & 165 & 12.41 & 9.44 & 8.84 & 8.15 & 7.25 & 6.07 & 9.50 & 8.94 & 8.23 & 7.36 & 6.25 \\
\hline 66 & 166 & 3.14 & 9.39 & 8.77 & 8.09 & 7.16 & 5.93 & 9.49 & 8.93 & 8.22 & 7.35 & 6.24 \\
\hline 67 & 167 & 0.37 & 9.34 & 8.69 & 8.03 & 7.07 & 5.79 & 9.49 & 8.92 & 8.21 & 7.34 & 6.22 \\
\hline 68 & 168 & 0.00 & 9.24 & 8.54 & 7.91 & 6.90 & 5.51 & 9.48 & 8.91 & 8.20 & 7.33 & 6.20 \\
\hline 69 & 169 & 1.39 & 9.23 & 8.60 & 7.93 & 7.09 & 5.54 & 9.43 & 8.87 & 8.16 & 7.29 & 6.19 \\
\hline 70 & 170 & 0.37 & 9.03 & 8.35 & 7.71 & 6.88 & 5.01 & 9.37 & 8.81 & 8.10 & 7.23 & 6.13 \\
\hline 71 & 171 & 0.66 & 8.83 & 8.10 & 7.49 & 6.68 & 4.49 & 9.32 & 8.75 & 8.04 & 7.16 & 6.06 \\
\hline 72 & 172 & 0.07 & 8.64 & 7.86 & 7.28 & 6.49 & 3.99 & 9.26 & 8.70 & 7.98 & 7.11 & 6.01 \\
\hline 73 & 173 & 1.46 & 9.04 & 8.44 & 7.78 & 6.96 & 5.58 & 9.28 & 8.72 & 8.01 & 7.14 & 6.04 \\
\hline 74 & 174 & 0.26 & 8.71 & 8.08 & 7.45 & 6.66 & 5.09 & 9.11 & 8.56 & 7.85 & 6.98 & 5.88 \\
\hline 75 & 175 & 0.15 & 8.38 & 7.72 & 7.12 & 6.36 & 4.60 & 8.95 & 8.40 & 7.69 & 6.82 & 5.72 \\
\hline 76 & 176 & 0.18 & 8.06 & 7.38 & 6.80 & 6.08 & 4.13 & 8.79 & 8.24 & 7.53 & 6.66 & 5.56 \\
\hline 77 & 177 & 0.07 & 7.72 & 7.02 & 6.47 & 5.79 & 3.64 & 8.62 & 8.08 & 7.37 & 6.50 & 5.40 \\
\hline 78 & 178 & 0.00 & 7.39 & 6.66 & 6.14 & 5.49 & 3.14 & 8.46 & 7.92 & 7.20 & 6.34 & 5.24 \\
\hline 79 & 179 & 1.24 & 8.70 & 8.14 & 7.46 & 6.62 & 5.45 & 8.95 & 8.42 & 7.72 & 6.86 & 5.77 \\
\hline 80 & 180 & 0.26 & 8.11 & 7.56 & 6.91 & 6.08 & 4.86 & 8.56 & 8.04 & 7.34 & 6.49 & 5.41 \\
\hline 81 & 181 & 0.18 & 7.53 & 6.98 & 6.35 & 5.55 & 4.27 & 8.16 & 7.66 & 6.97 & 6.12 & 5.05 \\
\hline 82 & 182 & 0.04 & 6.98 & 6.43 & 5.82 & 5.04 & 3.72 & 7.78 & 7.30 & 6.62 & 5.77 & 4.70 \\
\hline 83 & 183 & 0.04 & 6.40 & 5.86 & 5.26 & 4.50 & 3.13 & 7.38 & 6.93 & 6.24 & 5.40 & 4.34 \\
\hline 84 & 184 & 0.04 & 5.81 & 5.28 & 4.71 & 3.97 & 2.54 & 6.99 & 6.55 & 5.87 & 5.04 & 3.98 \\
\hline 85 & 185 & 0.00 & 5.26 & 4.73 & 4.18 & 3.46 & 1.98 & 6.61 & 6.19 & 5.51 & 4.69 & 3.64 \\
\hline 86 & 186 & 0.91 & 8.17 & 7.71 & 7.08 & 6.26 & 4.58 & 8.53 & 8.07 & 7.44 & 6.61 & 5.56 \\
\hline 87 & 187 & 0.51 & 7.21 & 6.82 & 6.24 & 5.47 & 3.36 & 7.82 & 7.44 & 6.86 & 6.07 & 5.05 \\
\hline 88 & 188 & 0.15 & 6.26 & 5.93 & 5.41 & 4.67 & 2.15 & 7.12 & 6.81 & 6.29 & 5.53 & 4.54 \\
\hline 89 & 189 & 0.07 & 5.35 & 5.09 & 4.62 & 3.92 & 1.00 & 6.45 & 6.21 & 5.75 & 5.02 & 4.06 \\
\hline 90 & 190 & 0.00 & 4.39 & 4.20 & 3.79 & 3.13 & -0.21 & 5.75 & 5.59 & 5.17 & 4.48 & 3.55 \\
\hline 91 & 191 & 0.15 & 8.21 & 7.75 & 7.12 & 5.85 & 3.70 & 8.31 & 7.85 & 7.23 & 6.42 & 5.39 \\
\hline 92 & 192 & 0.07 & 7.28 & 6.89 & 6.33 & 4.77 & 1.87 & 7.46 & 7.06 & 6.51 & 5.75 & 4.76 \\
\hline 93 & 193 & 0.04 & 6.35 & 6.02 & 5.53 & 3.68 & 0.03 & 6.60 & 6.27 & 5.79 & 5.07 & 4.13 \\
\hline 94 & 194 & 0.00 & 5.46 & 5.21 & 4.77 & 2.65 & -1.71 & 5.79 & 5.52 & 5.11 & 4.43 & 3.53 \\
\hline 95 & 195 & 0.00 & 7.99 & 7.51 & 6.74 & 4.44 & 1.44 & 7.59 & 7.15 & 6.59 & 5.82 & 4.83 \\
\hline 96 & 196 & 0.00 & 6.91 & 6.49 & 5.67 & 2.34 & -2.02 & 6.22 & 5.87 & 5.42 & 4.72 & 3.79 \\
\hline 97 & 197 & 11.86 & 9.44 & 8.84 & 8.16 & 7.25 & 6.07 & 9.50 & 8.94 & 8.23 & 7.36 & 6.25 \\
\hline
\end{tabular}




\begin{tabular}{|c|c|c|c|c|c|c|c|c|c|c|c|c|}
\hline \multirow{2}{*}{$\begin{array}{l}\text { Wave } \\
\text { No. }\end{array}$} & \multirow{2}{*}{$\begin{array}{l}\text { Wave } \\
\text { ID }\end{array}$} & \multirow[b]{2}{*}{ Days/yr } & \multicolumn{5}{|c|}{ Inbound Ship speed (kt) } & \multicolumn{5}{|c|}{ Outbound Ship speed (kt) } \\
\hline & & & 8 & 10 & 12 & 14 & 16 & 8 & 10 & 12 & 14 & 16 \\
\hline 98 & 198 & 3.07 & 9.39 & 8.77 & 8.09 & 7.16 & 5.93 & 9.49 & 8.93 & 8.22 & 7.35 & 6.23 \\
\hline 99 & 199 & 0.58 & 9.34 & 8.69 & 8.03 & 7.07 & 5.79 & 9.49 & 8.92 & 8.21 & 7.34 & 6.21 \\
\hline 100 & 200 & 0.04 & 9.30 & 8.62 & 7.98 & 6.99 & 5.66 & 9.48 & 8.91 & 8.20 & 7.33 & 6.19 \\
\hline 101 & 201 & 1.10 & 9.23 & 8.60 & 7.93 & 7.09 & 5.54 & 9.43 & 8.86 & 8.15 & 7.28 & 6.18 \\
\hline 102 & 202 & 0.29 & 9.03 & 8.35 & 7.72 & 6.89 & 5.02 & 9.37 & 8.80 & 8.09 & 7.22 & 6.12 \\
\hline 103 & 203 & 0.47 & 8.84 & 8.11 & 7.50 & 6.68 & 4.51 & 9.31 & 8.74 & 8.03 & 7.15 & 6.06 \\
\hline 104 & 204 & 0.07 & 8.65 & 7.87 & 7.29 & 6.49 & 4.01 & 9.25 & 8.69 & 7.97 & 7.09 & 6.00 \\
\hline 105 & 205 & 0.00 & 8.46 & 7.64 & 7.08 & 6.30 & 3.52 & 9.20 & 8.63 & 7.91 & 7.03 & 5.94 \\
\hline 106 & 206 & 0.88 & 9.05 & 8.45 & 7.78 & 6.96 & 5.59 & 9.27 & 8.72 & 8.00 & 7.14 & 6.03 \\
\hline 107 & 207 & 0.15 & 8.71 & 8.09 & 7.45 & 6.66 & 5.10 & 9.10 & 8.55 & 7.84 & 6.97 & 5.87 \\
\hline 108 & 208 & 0.11 & 8.38 & 7.73 & 7.12 & 6.36 & 4.61 & 8.93 & 8.38 & 7.67 & 6.80 & 5.70 \\
\hline 109 & 209 & 0.15 & 8.07 & 7.38 & 6.80 & 6.08 & 4.14 & 8.77 & 8.22 & 7.51 & 6.64 & 5.54 \\
\hline 110 & 210 & 0.07 & 7.75 & 7.04 & 6.49 & 5.80 & 3.68 & 8.61 & 8.06 & 7.35 & 6.48 & 5.38 \\
\hline 111 & 211 & 0.00 & 7.35 & 6.61 & 6.09 & 5.44 & 3.09 & 8.40 & 7.86 & 7.14 & 6.28 & 5.18 \\
\hline 112 & 212 & 0.62 & 8.69 & 8.14 & 7.46 & 6.62 & 5.45 & 8.94 & 8.41 & 7.70 & 6.84 & 5.75 \\
\hline 113 & 213 & 0.26 & 8.11 & 7.56 & 6.90 & 6.08 & 4.86 & 8.54 & 8.02 & 7.32 & 6.46 & 5.38 \\
\hline 114 & 214 & 0.15 & 7.52 & 6.98 & 6.34 & 5.54 & 4.28 & 8.13 & 7.63 & 6.93 & 6.08 & 5.01 \\
\hline 115 & 215 & 0.11 & 6.97 & 6.43 & 5.81 & 5.02 & 3.72 & 7.74 & 7.26 & 6.57 & 5.73 & 4.66 \\
\hline 116 & 216 & 0.00 & 6.41 & 5.87 & 5.27 & 4.51 & 3.16 & 7.36 & 6.89 & 6.20 & 5.37 & 4.31 \\
\hline 117 & 217 & 0.00 & 5.71 & 5.18 & 4.60 & 3.86 & 2.46 & 6.87 & 6.43 & 5.74 & 4.91 & 3.86 \\
\hline 118 & 218 & 0.73 & 8.16 & 7.69 & 7.05 & 6.23 & 4.63 & 8.51 & 8.05 & 7.41 & 6.58 & 5.52 \\
\hline 119 & 219 & 0.22 & 7.19 & 6.79 & 6.21 & 5.42 & 3.46 & 7.79 & 7.40 & 6.82 & 6.02 & 4.99 \\
\hline 120 & 220 & 0.11 & 6.22 & 5.89 & 5.36 & 4.60 & 2.28 & 7.08 & 6.76 & 6.23 & 5.46 & 4.46 \\
\hline 121 & 221 & 0.07 & 5.30 & 5.03 & 4.55 & 3.83 & 1.17 & 6.40 & 6.15 & 5.66 & 4.92 & 3.95 \\
\hline 122 & 222 & 0.04 & 4.39 & 4.17 & 3.75 & 3.05 & 0.05 & 5.72 & 5.53 & 5.10 & 4.39 & 3.44 \\
\hline 123 & 223 & 0.00 & 3.23 & 3.09 & 2.73 & 2.08 & -1.36 & 4.86 & 4.76 & 4.39 & 3.71 & 2.80 \\
\hline 124 & 224 & 0.11 & 8.10 & 7.64 & 7.02 & 5.83 & 3.70 & 8.21 & 7.74 & 7.12 & 6.31 & 5.28 \\
\hline 125 & 225 & 0.04 & 7.10 & 6.70 & 6.14 & 4.73 & 1.87 & 7.28 & 6.88 & 6.33 & 5.56 & 4.56 \\
\hline 126 & 226 & 0.04 & 6.09 & 5.76 & 5.26 & 3.63 & 0.03 & 6.35 & 6.01 & 5.53 & 4.80 & 3.85 \\
\hline 127 & 227 & 0.00 & 7.76 & 7.28 & 6.68 & 4.45 & 1.40 & 7.32 & 6.87 & 6.31 & 5.53 & 4.55 \\
\hline 128 & 228 & 0.04 & 6.50 & 6.08 & 5.56 & 2.36 & -2.08 & 5.75 & 5.38 & 4.93 & 4.22 & 3.31 \\
\hline 129 & 229 & 0.04 & 5.25 & 4.89 & 4.44 & 0.26 & -5.56 & 4.18 & 3.89 & 3.55 & 2.91 & 2.08 \\
\hline 130 & 230 & 18.03 & 9.45 & 8.86 & 8.16 & 7.26 & 6.09 & 9.50 & 8.93 & 8.22 & 7.35 & 6.22 \\
\hline
\end{tabular}




\begin{tabular}{|c|c|c|c|c|c|c|c|c|c|c|c|c|}
\hline \multirow{2}{*}{$\begin{array}{l}\text { Wave } \\
\text { No. }\end{array}$} & \multirow{2}{*}{$\begin{array}{l}\text { Wave } \\
\text { ID }\end{array}$} & \multirow[b]{2}{*}{ Days/yr } & \multicolumn{5}{|c|}{ Inbound Ship speed (kt) } & \multicolumn{5}{|c|}{ Outbound Ship speed (kt) } \\
\hline & & & 8 & 10 & 12 & 14 & 16 & 8 & 10 & 12 & 14 & 16 \\
\hline 131 & 231 & 3.80 & 9.40 & 8.79 & 8.11 & 7.18 & 5.96 & 9.48 & 8.91 & 8.20 & 7.33 & 6.19 \\
\hline 132 & 232 & 0.37 & 9.36 & 8.71 & 8.05 & 7.09 & 5.82 & 9.47 & 8.90 & 8.19 & 7.31 & 6.15 \\
\hline 133 & 233 & 0.00 & 9.26 & 8.57 & 7.93 & 6.93 & 5.56 & 9.45 & 8.87 & 8.15 & 7.27 & 6.09 \\
\hline 134 & 234 & 2.23 & 9.27 & 8.65 & 7.97 & 7.12 & 5.65 & 9.42 & 8.85 & 8.13 & 7.27 & 6.13 \\
\hline 135 & 235 & 0.58 & 9.09 & 8.42 & 7.77 & 6.93 & 5.18 & 9.35 & 8.77 & 8.06 & 7.19 & 6.02 \\
\hline 136 & 236 & 0.58 & 8.90 & 8.18 & 7.56 & 6.73 & 4.70 & 9.28 & 8.69 & 7.97 & 7.11 & 5.91 \\
\hline 137 & 237 & 0.07 & 8.72 & 7.96 & 7.36 & 6.54 & 4.24 & 9.22 & 8.62 & 7.89 & 7.03 & 5.80 \\
\hline 138 & 238 & 1.06 & 9.09 & 8.49 & 7.81 & 6.98 & 5.66 & 9.26 & 8.70 & 7.98 & 7.12 & 6.02 \\
\hline 139 & 239 & 0.29 & 8.79 & 8.15 & 7.50 & 6.70 & 5.20 & 9.08 & 8.51 & 7.79 & 6.93 & 5.83 \\
\hline 140 & 240 & 0.11 & 8.46 & 7.79 & 7.17 & 6.39 & 4.72 & 8.88 & 8.32 & 7.59 & 6.73 & 5.63 \\
\hline 141 & 241 & 0.26 & 8.15 & 7.46 & 6.85 & 6.11 & 4.27 & 8.70 & 8.13 & 7.40 & 6.54 & 5.44 \\
\hline 142 & 242 & 0.11 & 7.85 & 7.12 & 6.53 & 5.82 & 3.81 & 8.52 & 7.94 & 7.21 & 6.35 & 5.25 \\
\hline 143 & 243 & 0.00 & 7.51 & 6.74 & 6.18 & 5.50 & 3.31 & 8.31 & 7.74 & 7.00 & 6.14 & 5.04 \\
\hline 144 & 244 & 0.69 & 8.71 & 8.15 & 7.46 & 6.61 & 5.51 & 8.89 & 8.35 & 7.64 & 6.78 & 5.69 \\
\hline 145 & 245 & 0.29 & 8.11 & 7.56 & 6.88 & 6.05 & 4.94 & 8.43 & 7.91 & 7.20 & 6.34 & 5.26 \\
\hline 146 & 246 & 0.18 & 7.48 & 6.94 & 6.28 & 5.46 & 4.35 & 7.95 & 7.44 & 6.73 & 5.88 & 4.80 \\
\hline 147 & 247 & 0.04 & 6.89 & 6.35 & 5.70 & 4.90 & 3.78 & 7.49 & 7.00 & 6.29 & 5.44 & 4.37 \\
\hline 148 & 248 & 0.07 & 6.29 & 5.76 & 5.12 & 4.34 & 3.21 & 7.03 & 6.55 & 5.84 & 5.00 & 3.94 \\
\hline 149 & 249 & 0.04 & 5.64 & 5.10 & 4.49 & 3.72 & 2.59 & 6.53 & 6.06 & 5.35 & 4.52 & 3.46 \\
\hline 150 & 250 & 0.00 & 5.13 & 4.60 & 4.00 & 3.25 & 2.11 & 6.14 & 5.69 & 4.98 & 4.14 & 3.09 \\
\hline 151 & 251 & 0.62 & 7.97 & 7.50 & 6.85 & 6.00 & 4.79 & 8.29 & 7.83 & 7.18 & 6.33 & 5.27 \\
\hline 152 & 252 & 0.22 & 6.83 & 6.42 & 5.83 & 4.99 & 3.69 & 7.38 & 6.99 & 6.39 & 5.56 & 4.53 \\
\hline 153 & 253 & 0.11 & 5.64 & 5.29 & 4.75 & 3.92 & 2.54 & 6.43 & 6.12 & 5.56 & 4.76 & 3.75 \\
\hline 154 & 254 & 0.00 & 4.50 & 4.22 & 3.72 & 2.90 & 1.44 & 5.53 & 5.28 & 4.78 & 3.99 & 3.01 \\
\hline 155 & 255 & 0.00 & 2.11 & 1.96 & 1.56 & 0.77 & -0.86 & 3.63 & 3.53 & 3.12 & 2.37 & 1.45 \\
\hline 156 & 256 & 0.15 & 7.62 & 7.15 & 6.53 & 5.68 & 3.92 & 7.77 & 7.29 & 6.65 & 5.82 & 4.78 \\
\hline 157 & 257 & 0.11 & 6.21 & 5.81 & 5.26 & 4.43 & 2.17 & 6.47 & 6.05 & 5.48 & 4.68 & 3.68 \\
\hline 158 & 258 & 0.04 & 6.73 & 6.26 & 5.70 & 4.71 & 1.83 & 6.28 & 5.79 & 5.19 & 4.40 & 3.43 \\
\hline 159 & 259 & 0.00 & 4.67 & 4.27 & 3.82 & 2.73 & -1.46 & 3.89 & 3.45 & 2.93 & 2.19 & 1.32 \\
\hline 160 & 260 & 27.08 & 9.45 & 8.86 & 8.16 & 7.26 & 6.09 & 9.48 & 8.91 & 8.20 & 7.32 & 6.18 \\
\hline 161 & 261 & 6.72 & 9.40 & 8.79 & 8.11 & 7.18 & 5.96 & 9.46 & 8.88 & 8.17 & 7.29 & 6.12 \\
\hline 162 & 262 & 0.40 & 9.36 & 8.72 & 8.05 & 7.11 & 5.83 & 9.44 & 8.85 & 8.15 & 7.25 & 6.06 \\
\hline 163 & 263 & 0.00 & 9.32 & 8.66 & 8.00 & 7.03 & 5.70 & 9.42 & 8.82 & 8.12 & 7.22 & 6.00 \\
\hline
\end{tabular}




\begin{tabular}{|c|c|c|c|c|c|c|c|c|c|c|c|c|}
\hline \multirow{2}{*}{$\begin{array}{l}\text { Wave } \\
\text { No. }\end{array}$} & \multirow{2}{*}{$\begin{array}{l}\text { Wave } \\
\text { ID }\end{array}$} & \multirow[b]{2}{*}{ Days/yr } & \multicolumn{5}{|c|}{ Inbound Ship speed (kt) } & \multicolumn{5}{|c|}{ Outbound Ship speed (kt) } \\
\hline & & & 8 & 10 & 12 & 14 & 16 & 8 & 10 & 12 & 14 & 16 \\
\hline 164 & 264 & 4.60 & 9.29 & 8.67 & 7.99 & 7.13 & 5.71 & 9.39 & 8.80 & 8.09 & 7.23 & 6.02 \\
\hline 165 & 265 & 0.91 & 9.13 & 8.47 & 7.81 & 6.96 & 5.31 & 9.30 & 8.70 & 7.99 & 7.13 & 5.84 \\
\hline 166 & 266 & 1.24 & 8.98 & 8.28 & 7.64 & 6.80 & 4.93 & 9.22 & 8.60 & 7.89 & 7.04 & 5.67 \\
\hline 167 & 267 & 0.11 & 8.82 & 8.09 & 7.46 & 6.63 & 4.53 & 9.13 & 8.49 & 7.78 & 6.94 & 5.49 \\
\hline 168 & 268 & 1.46 & 9.10 & 8.50 & 7.81 & 6.97 & 5.71 & 9.21 & 8.63 & 7.92 & 7.05 & 5.96 \\
\hline 169 & 269 & 0.33 & 8.81 & 8.18 & 7.51 & 6.69 & 5.30 & 8.99 & 8.41 & 7.69 & 6.83 & 5.73 \\
\hline 170 & 270 & 0.22 & 8.53 & 7.88 & 7.22 & 6.42 & 4.92 & 8.78 & 8.19 & 7.47 & 6.61 & 5.52 \\
\hline 171 & 271 & 0.40 & 8.24 & 7.56 & 6.91 & 6.13 & 4.52 & 8.57 & 7.96 & 7.24 & 6.38 & 5.30 \\
\hline 172 & 272 & 0.07 & 7.95 & 7.24 & 6.61 & 5.85 & 4.11 & 8.35 & 7.74 & 7.01 & 6.16 & 5.07 \\
\hline 173 & 273 & 0.00 & 7.65 & 6.90 & 6.29 & 5.55 & 3.69 & 8.12 & 7.50 & 6.77 & 5.92 & 4.84 \\
\hline 174 & 274 & 0.69 & 8.66 & 8.11 & 7.41 & 6.56 & 5.47 & 8.78 & 8.23 & 7.52 & 6.66 & 5.57 \\
\hline 175 & 275 & 0.33 & 8.06 & 7.51 & 6.82 & 5.98 & 4.91 & 8.25 & 7.72 & 7.00 & 6.14 & 5.06 \\
\hline 176 & 276 & 0.07 & 7.49 & 6.94 & 6.25 & 5.42 & 4.36 & 7.76 & 7.23 & 6.51 & 5.66 & 4.58 \\
\hline 177 & 277 & 0.04 & 6.88 & 6.34 & 5.66 & 4.84 & 3.80 & 7.23 & 6.72 & 6.00 & 5.15 & 4.08 \\
\hline 178 & 278 & 0.04 & 6.28 & 5.74 & 5.07 & 4.26 & 3.23 & 6.71 & 6.21 & 5.48 & 4.64 & 3.58 \\
\hline 179 & 279 & 0.04 & 5.64 & 5.11 & 4.44 & 3.65 & 2.63 & 6.16 & 5.67 & 4.94 & 4.10 & 3.05 \\
\hline 180 & 280 & 0.22 & 7.87 & 7.38 & 6.72 & 5.85 & 4.81 & 8.09 & 7.62 & 6.96 & 6.09 & 5.03 \\
\hline 181 & 281 & 0.18 & 6.69 & 6.26 & 5.63 & 4.76 & 3.76 & 7.07 & 6.67 & 6.04 & 5.18 & 4.14 \\
\hline 182 & 282 & 0.04 & 5.58 & 5.20 & 4.60 & 3.73 & 2.76 & 6.11 & 5.76 & 5.16 & 4.31 & 3.30 \\
\hline 183 & 283 & 0.00 & 4.40 & 4.08 & 3.51 & 2.65 & 1.71 & 5.09 & 4.81 & 4.24 & 3.40 & 2.41 \\
\hline 184 & 284 & 0.00 & 3.23 & 2.96 & 2.43 & 1.56 & 0.67 & 4.08 & 3.86 & 3.33 & 2.49 & 1.53 \\
\hline 185 & 285 & 0.00 & 2.00 & 1.78 & 1.29 & 0.42 & -0.43 & 3.01 & 2.86 & 2.36 & 1.53 & 0.60 \\
\hline 186 & 286 & 0.00 & 0.76 & 0.60 & 0.15 & -0.72 & -1.53 & 1.95 & 1.86 & 1.40 & 0.57 & -0.33 \\
\hline 187 & 287 & 10.22 & 9.49 & 8.92 & 8.21 & 7.33 & 6.20 & 9.49 & 8.92 & 8.22 & 7.34 & 6.21 \\
\hline 188 & 288 & 2.81 & 9.48 & 8.90 & 8.20 & 7.30 & 6.16 & 9.48 & 8.91 & 8.20 & 7.31 & 6.18 \\
\hline 189 & 289 & 0.22 & 9.46 & 8.87 & 8.18 & 7.27 & 6.12 & 9.47 & 8.89 & 8.19 & 7.29 & 6.14 \\
\hline 190 & 290 & 0.00 & 9.45 & 8.85 & 8.16 & 7.24 & 6.07 & 9.46 & 8.87 & 8.17 & 7.27 & 6.10 \\
\hline 191 & 291 & 0.00 & 9.43 & 8.83 & 8.14 & 7.22 & 6.03 & 9.45 & 8.85 & 8.16 & 7.25 & 6.07 \\
\hline 192 & 292 & 0.18 & 9.32 & 8.71 & 8.02 & 7.16 & 5.81 & 9.34 & 8.75 & 8.05 & 7.19 & 5.89 \\
\hline 193 & 293 & 0.18 & 9.20 & 8.56 & 7.88 & 7.03 & 5.52 & 9.24 & 8.62 & 7.93 & 7.08 & 5.66 \\
\hline 194 & 294 & 0.29 & 9.07 & 8.40 & 7.73 & 6.89 & 5.20 & 9.13 & 8.48 & 7.79 & 6.96 & 5.39 \\
\hline 195 & 295 & 0.00 & 8.93 & 8.23 & 7.57 & 6.74 & 4.87 & 9.01 & 8.34 & 7.65 & 6.83 & 5.12 \\
\hline 196 & 296 & 0.04 & 9.12 & 8.53 & 7.83 & 6.98 & 5.78 & 9.15 & 8.56 & 7.85 & 7.00 & 5.86 \\
\hline
\end{tabular}




\begin{tabular}{|l|l|l|l|l|l|l|l|l|l|l|l|l|}
\hline \multirow{2}{*}{$\begin{array}{l}\text { Wave } \\
\text { No. }\end{array}$} & \multirow{2}{*}{$\begin{array}{l}\text { Wave } \\
\text { ID }\end{array}$} & \multirow{3}{*}{ Days/yr } & 8 & 10 & 12 & 14 & 16 & 8 & 10 & 12 & 14 & 16 \\
\hline 197 & 297 & 0.04 & 8.88 & 8.27 & 7.57 & 6.73 & 5.48 & 8.92 & 8.32 & 7.61 & 6.76 & 5.60 \\
\hline 198 & 298 & 0.04 & 8.61 & 7.98 & 7.28 & 6.46 & 5.15 & 8.67 & 8.06 & 7.35 & 6.51 & 5.31 \\
\hline 199 & 299 & 0.07 & 8.33 & 7.67 & 6.98 & 6.17 & 4.79 & 8.41 & 7.78 & 7.07 & 6.23 & 5.01 \\
\hline 200 & 300 & 0.00 & 8.10 & 7.42 & 6.74 & 5.94 & 4.51 & 8.20 & 7.55 & 6.84 & 6.02 & 4.77 \\
\hline 201 & 301 & 0.00 & 8.65 & 8.10 & 7.39 & 6.53 & 5.44 & 8.68 & 8.13 & 7.42 & 6.55 & 5.47 \\
\hline 202 & 302 & 0.04 & 8.11 & 7.57 & 6.86 & 6.01 & 4.93 & 8.16 & 7.62 & 6.90 & 6.05 & 4.97 \\
\hline 203 & 303 & 0.00 & 7.52 & 6.98 & 6.27 & 5.42 & 4.36 & 7.59 & 7.05 & 6.33 & 5.48 & 4.41 \\
\hline 204 & 304 & 0.00 & 6.89 & 6.36 & 5.65 & 4.81 & 3.76 & 6.98 & 6.46 & 5.74 & 4.89 & 3.83 \\
\hline 205 & 305 & 0.00 & 6.39 & 5.86 & 5.15 & 4.32 & 3.27 & 6.49 & 5.98 & 5.25 & 4.41 & 3.36 \\
\hline 206 & 306 & 0.00 & 5.61 & 5.10 & 4.38 & 3.56 & 2.53 & 5.75 & 5.24 & 4.51 & 3.68 & 2.64 \\
\hline 207 & 307 & 0.04 & 7.64 & 7.18 & 6.52 & 5.64 & 4.60 & 7.71 & 7.25 & 6.59 & 5.72 & 4.66 \\
\hline 208 & 308 & 0.04 & 6.48 & 6.08 & 5.45 & 4.57 & 3.56 & 6.59 & 6.19 & 5.56 & 4.69 & 3.67 \\
\hline 209 & 309 & 0.00 & 5.19 & 4.85 & 4.26 & 3.38 & 2.40 & 5.34 & 5.01 & 4.42 & 3.54 & 2.56 \\
\hline 210 & 310 & 0.00 & 3.84 & 3.57 & 3.02 & 2.12 & 1.19 & 4.04 & 3.78 & 3.23 & 2.35 & 1.40 \\
\hline 211 & 311 & 0.00 & 0.42 & 0.32 & -0.13 & -1.03 & -1.87 & 0.74 & 0.66 & 0.20 & -0.68 & -1.54 \\
\hline
\end{tabular}


Table E4. Net UKC (ft), Phase 1, Mound Reach 2, $h=60 \mathrm{ft}$, fully loaded Susan Maersk, inbound and outbound transits.

\begin{tabular}{|c|c|c|c|c|c|c|c|c|c|c|c|c|}
\hline \multirow{2}{*}{$\begin{array}{l}\text { Wave } \\
\text { No. }\end{array}$} & \multirow{2}{*}{$\begin{array}{l}\text { Wave } \\
\text { ID }\end{array}$} & \multirow[b]{2}{*}{ Days/yr } & \multicolumn{5}{|c|}{ Inbound Ship speed (kt) } & \multicolumn{5}{|c|}{ Outbound Ship speed (kt) } \\
\hline & & & 8 & 10 & 12 & 14 & 16 & 8 & 10 & 12 & 14 & 16 \\
\hline 1 & 401 & 6.10 & 11.51 & 10.95 & 10.26 & 9.40 & 8.32 & 11.53 & 10.99 & 10.29 & 9.44 & 8.39 \\
\hline 2 & 402 & 2.74 & 11.49 & 10.92 & 10.24 & 9.36 & 8.26 & 11.53 & 10.98 & 10.28 & 9.43 & 8.37 \\
\hline 3 & 403 & 0.26 & 11.46 & 10.89 & 10.21 & 9.32 & 8.20 & 11.52 & 10.98 & 10.28 & 9.42 & 8.36 \\
\hline 4 & 404 & 0.04 & 11.44 & 10.85 & 10.19 & 9.29 & 8.14 & 11.52 & 10.97 & 10.27 & 9.41 & 8.34 \\
\hline 5 & 405 & 0.00 & 11.42 & 10.82 & 10.16 & 9.25 & 8.07 & 11.51 & 10.96 & 10.26 & 9.41 & 8.32 \\
\hline 6 & 406 & 0.00 & 11.27 & 10.67 & 10.01 & 9.20 & 7.69 & 11.44 & 10.89 & 10.18 & 9.34 & 8.25 \\
\hline 7 & 407 & 0.07 & 11.09 & 10.45 & 9.82 & 9.03 & 7.22 & 11.37 & 10.81 & \begin{tabular}{|l|}
10.11 \\
\end{tabular} & 9.26 & 8.15 \\
\hline 8 & 408 & 0.07 & 10.90 & 10.22 & 9.62 & 8.86 & 6.72 & 11.30 & 10.74 & 10.03 & 9.19 & 8.04 \\
\hline 9 & 409 & 0.00 & 10.74 & 10.02 & 9.44 & 8.70 & 6.28 & 11.24 & 10.67 & 9.96 & 9.12 & 7.94 \\
\hline 10 & 410 & 0.00 & 10.53 & 9.76 & 9.22 & 8.51 & 5.73 & 11.16 & 10.58 & 9.87 & 9.03 & 7.82 \\
\hline 11 & 411 & 0.04 & 11.09 & 10.52 & 9.86 & 9.04 & 7.74 & 11.27 & 10.73 & 10.03 & 9.18 & 8.14 \\
\hline 12 & 412 & 0.00 & 10.79 & 10.20 & 9.56 & 8.78 & 7.30 & 11.10 & 10.55 & 9.85 & 9.00 & 7.96 \\
\hline 13 & 413 & 0.04 & 10.48 & 9.87 & 9.26 & 8.50 & 6.84 & 10.91 & 10.37 & 9.66 & 8.82 & 7.78 \\
\hline 14 & 414 & 0.04 & 10.19 & 9.57 & 8.98 & 8.25 & 6.42 & 10.74 & 10.20 & 9.49 & 8.65 & 7.61 \\
\hline 15 & 415 & 0.00 & 10.69 & 10.16 & 9.48 & 8.65 & 7.61 & 10.87 & 10.35 & 9.65 & 8.81 & 7.78 \\
\hline 16 & 416 & 0.00 & 10.13 & 9.60 & 8.93 & 8.12 & 7.09 & 10.43 & 9.93 & 9.23 & 8.39 & 7.37 \\
\hline 17 & 417 & 0.00 & 9.54 & 9.02 & 8.37 & 7.57 & 6.54 & 9.97 & 9.48 & 8.78 & 7.95 & 6.94 \\
\hline 18 & 418 & 0.00 & 9.02 & 8.49 & 7.85 & 7.07 & 6.04 & 9.55 & 9.07 & 8.38 & 7.56 & 6.55 \\
\hline 19 & 419 & 0.00 & 8.37 & 7.85 & 7.23 & 6.47 & 5.43 & 9.04 & 8.58 & 7.89 & 7.07 & 6.08 \\
\hline 20 & 420 & 0.00 & 7.99 & 7.47 & 6.86 & 6.11 & 5.08 & 8.74 & 8.29 & 7.60 & 6.79 & 5.80 \\
\hline 21 & 421 & 0.04 & 9.83 & 9.39 & 8.76 & 7.92 & 6.86 & 10.11 & 9.68 & 9.06 & 8.24 & 7.24 \\
\hline 22 & 422 & 0.00 & 8.71 & 8.33 & 7.75 & 6.92 & 5.84 & 9.18 & 8.82 & 8.24 & 7.44 & 6.47 \\
\hline 23 & 423 & 0.00 & 7.53 & 7.21 & 6.68 & 5.87 & 4.77 & 8.19 & 7.90 & 7.38 & 6.60 & 5.66 \\
\hline 24 & 424 & 0.00 & 6.47 & 6.21 & 5.72 & 4.92 & 3.80 & 7.30 & 7.08 & 6.61 & 5.85 & 4.93 \\
\hline 25 & 425 & 0.00 & 4.41 & 4.26 & 3.86 & 3.08 & 1.93 & 5.58 & 5.49 & 5.10 & 4.38 & 3.51 \\
\hline 26 & 426 & 0.00 & 2.47 & 2.42 & 2.10 & 1.34 & 0.16 & 3.95 & 3.99 & 3.68 & 3.00 & 2.18 \\
\hline 27 & 427 & 0.00 & 1.99 & 1.98 & 1.68 & 0.92 & -0.27 & 3.56 & 3.62 & 3.34 & 2.66 & 1.86 \\
\hline 28 & 428 & 11.24 & 11.47 & 10.90 & 10.23 & 9.35 & 8.23 & 11.53 & 10.99 & 10.29 & 9.44 & 8.39 \\
\hline 29 & 429 & 3.80 & 11.43 & 10.84 & 10.18 & 9.28 & 8.12 & 11.53 & 10.98 & 10.28 & 9.43 & 8.37 \\
\hline 30 & 430 & 0.66 & 11.39 & 10.77 & 10.12 & 9.21 & 8.00 & 11.52 & 10.97 & 10.27 & 9.42 & 8.36 \\
\hline 31 & 431 & 0.04 & 11.34 & 10.71 & 10.07 & 9.14 & 7.87 & 11.51 & 10.97 & $\mid 10.26$ & 9.42 & 8.35 \\
\hline
\end{tabular}




\begin{tabular}{|c|c|c|c|c|c|c|c|c|c|c|c|c|}
\hline \multirow{2}{*}{$\begin{array}{l}\text { Wave } \\
\text { No. }\end{array}$} & \multirow{2}{*}{$\begin{array}{l}\text { Wave } \\
\text { ID }\end{array}$} & \multirow[b]{2}{*}{ Days/yr } & \multicolumn{5}{|c|}{ Inbound Ship speed (kt) } & \multicolumn{5}{|c|}{ Outbound Ship speed (kt) } \\
\hline & & & 8 & 10 & 12 & 14 & 16 & 8 & 10 & 12 & 14 & 16 \\
\hline 32 & 432 & 1.13 & 11.24 & 10.64 & 9.99 & 9.18 & 7.59 & 11.45 & 10.91 & 10.21 & 9.36 & 8.32 \\
\hline 33 & 433 & 0.18 & 11.04 & 10.40 & 9.78 & 9.00 & 7.06 & 11.39 & 10.85 & 10.14 & 9.29 & 8.25 \\
\hline 34 & 434 & 0.66 & 10.83 & 10.15 & 9.56 & 8.82 & 6.50 & 11.33 & 10.78 & 10.08 & 9.23 & 8.19 \\
\hline 35 & 435 & 0.15 & 10.63 & 9.89 & 9.34 & 8.63 & 5.93 & 11.27 & 10.72 & 10.01 & 9.16 & 8.12 \\
\hline 36 & 436 & 0.00 & 10.42 & 9.64 & 9.13 & 8.45 & 5.37 & 11.20 & 10.66 & 9.95 & 9.10 & 8.06 \\
\hline 37 & 437 & 1.20 & 11.04 & 10.47 & 9.82 & 9.02 & 7.68 & 11.27 & 10.74 & 10.04 & 9.19 & 8.15 \\
\hline 38 & 438 & 0.22 & 10.71 & 10.13 & 9.51 & 8.73 & 7.21 & 11.10 & 10.57 & 9.87 & 9.02 & 7.98 \\
\hline 39 & 439 & 0.07 & 10.36 & 9.76 & 9.18 & 8.43 & 6.71 & 10.92 & 10.39 & 9.69 & 8.85 & 7.81 \\
\hline 40 & 440 & 0.22 & 10.02 & 9.40 & 8.85 & 8.13 & 6.21 & 10.74 & 10.21 & 9.51 & 8.67 & 7.63 \\
\hline 41 & 441 & 0.15 & 9.67 & 9.04 & 8.52 & 7.83 & 5.71 & 10.55 & 10.04 & 9.33 & 8.49 & 7.45 \\
\hline 42 & 442 & 0.04 & 9.31 & 8.66 & 8.17 & 7.52 & 5.18 & 10.36 & 9.85 & 9.15 & 8.31 & 7.26 \\
\hline 43 & 443 & 0.88 & 10.68 & 10.14 & 9.47 & 8.65 & 7.57 & 10.91 & 10.40 & 9.71 & 8.87 & 7.84 \\
\hline 44 & 444 & 0.11 & 10.11 & 9.58 & 8.93 & 8.12 & 7.02 & 10.50 & 10.01 & 9.32 & 8.49 & 7.47 \\
\hline 45 & 445 & 0.04 & 9.51 & 8.99 & 8.36 & 7.57 & 6.45 & 10.07 & 9.59 & 8.92 & 8.09 & 7.08 \\
\hline 46 & 446 & 0.07 & 8.92 & 8.40 & 7.78 & 7.02 & 5.87 & 9.63 & 9.18 & 8.51 & 7.69 & 6.69 \\
\hline 47 & 447 & 0.04 & 8.32 & 7.81 & 7.21 & 6.46 & 5.29 & 9.20 & 8.77 & 8.10 & 7.29 & 6.30 \\
\hline 48 & 448 & 0.04 & 7.69 & 7.19 & 6.61 & 5.88 & 4.68 & 8.74 & 8.33 & 7.67 & 6.87 & 5.89 \\
\hline 49 & 449 & 0.04 & 7.10 & 6.60 & 6.04 & 5.33 & 4.11 & 8.31 & 7.92 & 7.27 & 6.47 & 5.50 \\
\hline 50 & 450 & 0.00 & 6.26 & 5.78 & 5.24 & 4.56 & 3.30 & 7.70 & 7.34 & 6.70 & 5.91 & 4.96 \\
\hline 51 & 451 & 0.18 & 10.26 & 9.80 & 9.17 & 8.36 & 6.94 & 10.54 & 10.09 & 9.47 & 8.66 & 7.66 \\
\hline 52 & 452 & 0.15 & 9.42 & 9.01 & 8.42 & 7.64 & 5.98 & 9.88 & 9.50 & 8.92 & 8.14 & 7.17 \\
\hline 53 & 453 & 0.11 & 8.53 & 8.18 & 7.64 & 6.89 & 4.97 & 9.19 & 8.88 & 8.35 & 7.60 & 6.65 \\
\hline 54 & 454 & 0.07 & 7.65 & 7.35 & 6.86 & 6.14 & 3.96 & 8.50 & 8.25 & 7.77 & 7.05 & 6.13 \\
\hline 55 & 455 & 0.04 & 6.76 & 6.52 & 6.07 & 5.39 & 2.95 & 7.81 & 7.62 & 7.20 & 6.50 & 5.61 \\
\hline 56 & 456 & 0.04 & 5.84 & 5.65 & 5.25 & 4.60 & 1.89 & 7.08 & 6.97 & 6.59 & 5.93 & 5.06 \\
\hline 57 & 457 & 0.00 & 4.95 & 4.82 & 4.47 & 3.84 & 0.87 & 6.39 & 6.34 & 6.02 & 5.38 & 4.54 \\
\hline 58 & 458 & 0.00 & 3.71 & 3.66 & 3.37 & 2.79 & -0.54 & 5.42 & 5.47 & 5.21 & 4.62 & 3.82 \\
\hline 59 & 459 & 0.00 & 2.34 & 2.37 & 2.16 & 1.62 & -2.11 & 4.35 & 4.50 & 4.32 & 3.77 & 3.01 \\
\hline 60 & 460 & 0.00 & 10.12 & 9.67 & 9.05 & 8.02 & 5.96 & 10.14 & 9.70 & 9.10 & 8.31 & 7.33 \\
\hline 61 & 461 & 0.00 & 9.18 & 8.79 & 8.23 & 7.07 & 4.36 & 9.23 & 8.85 & 8.31 & 7.56 & 6.62 \\
\hline 62 & 462 & 0.00 & 4.21 & 4.15 & 3.86 & 2.07 & -4.18 & 4.36 & 4.32 & 4.11 & 3.59 & 2.85 \\
\hline 63 & 463 & 0.00 & 2.83 & 2.86 & 2.65 & 0.68 & -6.55 & 3.01 & 3.07 & 2.95 & 2.49 & 1.80 \\
\hline 64 & 464 & 0.00 & 9.74 & 9.28 & 8.68 & 6.82 & 3.73 & 9.20 & 8.77 & 8.22 & 7.47 & 6.53 \\
\hline
\end{tabular}




\begin{tabular}{|c|c|c|c|c|c|c|c|c|c|c|c|c|}
\hline \multirow{2}{*}{$\begin{array}{l}\text { Wave } \\
\text { No. }\end{array}$} & \multirow{2}{*}{$\begin{array}{l}\text { Wave } \\
\text { ID }\end{array}$} & \multirow[b]{2}{*}{ Days/yr } & \multicolumn{5}{|c|}{ Inbound Ship speed (kt) } & \multicolumn{5}{|c|}{ Outbound Ship speed (kt) } \\
\hline & & & 8 & 10 & 12 & 14 & 16 & 8 & 10 & 12 & 14 & 16 \\
\hline 65 & 465 & 12.41 & 11.47 & 10.89 & 10.22 & 9.34 & 8.21 & 11.53 & 10.99 & 10.29 & 9.44 & 8.39 \\
\hline 66 & 466 & 3.14 & 11.42 & 10.82 & 10.16 & 9.26 & 8.07 & 11.52 & 10.98 & 10.28 & 9.43 & 8.38 \\
\hline 67 & 467 & 0.37 & 11.36 & 10.74 & 10.10 & 9.18 & 7.93 & 11.52 & 10.97 & 10.27 & 9.42 & 8.36 \\
\hline 68 & 468 & 0.00 & 11.26 & 10.59 & 9.98 & 9.03 & 7.66 & 11.50 & 10.96 & 10.26 & 9.41 & 8.34 \\
\hline 69 & 469 & 1.39 & 11.25 & 10.65 & 9.99 & 9.19 & 7.61 & 11.46 & 10.92 & 10.21 & 9.36 & 8.32 \\
\hline 70 & 470 & 0.37 & 11.04 & 10.39 & 9.77 & 9.00 & 7.04 & 11.40 & 10.85 & 10.15 & 9.30 & 8.26 \\
\hline 71 & 471 & 0.66 & 10.83 & 10.14 & 9.56 & 8.82 & 6.47 & 11.34 & 10.79 & 10.09 & 9.24 & 8.20 \\
\hline 72 & 472 & 0.07 & 10.63 & 9.90 & 9.35 & 8.64 & 5.93 & 11.28 & 10.74 & 10.03 & 9.18 & 8.14 \\
\hline 73 & 473 & 1.46 & 11.05 & 10.49 & 9.84 & 9.03 & 7.70 & 11.29 & 10.76 & 10.06 & 9.21 & 8.17 \\
\hline 74 & 474 & 0.26 & 10.71 & 10.12 & 9.51 & 8.73 & 7.20 & 11.11 & 10.58 & 9.88 & 9.04 & 8.00 \\
\hline 75 & 475 & 0.15 & 10.36 & 9.76 & 9.18 & 8.43 & 6.70 & 10.93 & 10.41 & 9.71 & 8.87 & 7.83 \\
\hline 76 & 476 & 0.18 & 10.03 & 9.41 & 8.86 & 8.15 & 6.22 & 10.76 & 10.25 & 9.55 & 8.70 & 7.66 \\
\hline 77 & 477 & 0.07 & 9.68 & 9.04 & 8.53 & 7.85 & 5.71 & 10.58 & 10.07 & 9.37 & 8.53 & 7.49 \\
\hline 78 & 478 & 0.00 & 9.33 & 8.68 & 8.20 & 7.55 & 5.21 & 10.41 & 9.90 & 9.20 & 8.36 & 7.32 \\
\hline 79 & 479 & 1.24 & 10.71 & 10.18 & 9.51 & 8.68 & 7.60 & 10.95 & 10.44 & 9.75 & 8.91 & 7.88 \\
\hline 80 & 480 & 0.26 & 10.12 & 9.59 & 8.94 & 8.13 & 7.02 & 10.52 & 10.03 & 9.35 & 8.52 & 7.50 \\
\hline 81 & 481 & 0.18 & 9.52 & 9.00 & 8.37 & 7.58 & 6.44 & 10.10 & 9.63 & 8.95 & 8.13 & 7.12 \\
\hline 82 & 482 & 0.04 & 8.96 & 8.44 & 7.83 & 7.06 & 5.89 & 9.69 & 9.24 & 8.58 & 7.76 & 6.76 \\
\hline 83 & 483 & 0.04 & 8.37 & 7.86 & 7.26 & 6.51 & 5.32 & 9.27 & 8.84 & 8.18 & 7.37 & 6.38 \\
\hline 84 & 484 & 0.04 & 7.77 & 7.27 & 6.69 & 5.97 & 4.74 & 8.85 & 8.44 & 7.78 & 6.98 & 6.00 \\
\hline 85 & 485 & 0.00 & 7.21 & 6.71 & 6.15 & 5.44 & 4.19 & 8.44 & 8.05 & 7.41 & 6.61 & 5.64 \\
\hline 86 & 486 & 0.91 & 10.23 & 9.78 & 9.15 & 8.35 & 6.84 & 10.50 & 10.06 & 9.44 & 8.64 & 7.65 \\
\hline 87 & 487 & 0.51 & 9.29 & 8.90 & 8.32 & 7.56 & 5.72 & 9.75 & 9.39 & 8.83 & 8.07 & 7.10 \\
\hline 88 & 488 & 0.15 & 8.35 & 8.03 & 7.50 & 6.77 & 4.60 & 9.00 & 8.72 & 8.22 & 7.49 & 6.56 \\
\hline 89 & 489 & 0.07 & 7.45 & 7.20 & 6.71 & 6.02 & 3.53 & 8.30 & 8.08 & 7.64 & 6.95 & 6.04 \\
\hline 90 & 490 & 0.00 & 6.51 & 6.33 & 5.89 & 5.23 & 2.41 & 7.55 & 7.41 & 7.03 & 6.37 & 5.50 \\
\hline 91 & 491 & 0.15 & 10.27 & 9.82 & 9.20 & 8.09 & 6.04 & 10.29 & 9.85 & 9.24 & 8.46 & 7.48 \\
\hline 92 & 492 & 0.07 & 9.36 & 8.98 & 8.40 & 7.12 & 4.35 & 9.39 & 9.02 & 8.49 & 7.75 & 6.81 \\
\hline 93 & 493 & 0.04 & 8.45 & 8.13 & 7.61 & 6.15 & 2.65 & 8.50 & 8.20 & 7.73 & 7.04 & 6.14 \\
\hline 94 & 494 & 0.00 & 7.59 & 7.33 & 6.86 & 5.23 & 1.05 & 7.65 & 7.42 & 7.01 & 6.37 & 5.51 \\
\hline 95 & 495 & 0.00 & 10.02 & 9.56 & 8.92 & 6.91 & 3.88 & 9.54 & 9.12 & 8.56 & 7.82 & 6.87 \\
\hline 96 & 496 & 0.00 & 8.94 & 8.53 & 7.94 & 5.09 & 0.65 & 8.10 & 7.78 & 7.32 & 6.65 & 5.77 \\
\hline 97 & 497 & 11.86 & 11.47 & 10.90 & 10.22 & 9.34 & 8.22 & 11.53 & 10.98 & 10.28 & 9.43 & 8.37 \\
\hline
\end{tabular}




\begin{tabular}{|c|c|c|c|c|c|c|c|c|c|c|c|c|}
\hline \multirow{2}{*}{$\begin{array}{l}\text { Wave } \\
\text { No. }\end{array}$} & \multirow{2}{*}{$\begin{array}{l}\text { Wave } \\
\text { ID }\end{array}$} & \multirow[b]{2}{*}{ Days/yr } & \multicolumn{5}{|c|}{ Inbound Ship speed (kt) } & \multicolumn{5}{|c|}{ Outbound Ship speed (kt) } \\
\hline & & & 8 & 10 & 12 & 14 & 16 & 8 & 10 & 12 & 14 & 16 \\
\hline 98 & 498 & 3.07 & 11.42 & 10.83 & 10.16 & 9.27 & 8.09 & 11.52 & 10.97 & 10.27 & 9.42 & 8.35 \\
\hline 99 & 499 & 0.58 & 11.37 & 10.76 & 10.11 & 9.19 & 7.96 & 11.51 & 10.96 & 10.25 & 9.40 & 8.32 \\
\hline 100 & 500 & 0.04 & 11.33 & 10.69 & 10.05 & 9.12 & 7.83 & 11.50 & 10.94 & 10.24 & 9.39 & 8.29 \\
\hline 101 & 501 & 1.10 & 11.26 & 10.66 & 10.01 & 9.20 & 7.66 & 11.44 & 10.90 & 10.19 & 9.34 & 8.28 \\
\hline 102 & 502 & 0.29 & 11.06 & 10.42 & 9.79 & 9.02 & 7.12 & 11.37 & 10.82 & 10.12 & 9.27 & 8.19 \\
\hline 103 & 503 & 0.47 & 10.86 & 10.18 & 9.58 & 8.83 & 6.58 & 11.30 & 10.75 & 10.04 & 9.19 & 8.09 \\
\hline 104 & 504 & 0.07 & 10.67 & 9.95 & 9.38 & 8.66 & 6.07 & 11.23 & 10.67 & 9.97 & 9.12 & 8.01 \\
\hline 105 & 505 & 0.00 & 10.48 & 9.72 & 9.18 & 8.49 & 5.55 & 11.17 & 10.60 & 9.89 & 9.05 & 7.92 \\
\hline 106 & 506 & 0.88 & 11.07 & 10.50 & 9.84 & 9.03 & 7.73 & 11.26 & 10.72 & 10.02 & 9.17 & 8.13 \\
\hline 107 & 507 & 0.15 & 10.73 & 10.15 & 9.51 & 8.73 & 7.25 & 11.06 & 10.53 & 9.82 & 8.98 & 7.94 \\
\hline 108 & 508 & 0.11 & 10.39 & 9.79 & 9.18 & 8.42 & 6.76 & 10.86 & 10.33 & 9.62 & 8.78 & 7.74 \\
\hline 109 & 509 & 0.15 & 10.07 & 9.45 & 8.87 & 8.14 & 6.30 & 10.68 & 10.14 & 9.43 & 8.59 & 7.55 \\
\hline 110 & 510 & 0.07 & 9.75 & 9.11 & 8.55 & 7.85 & 5.84 & 10.49 & 9.95 & 9.25 & 8.40 & 7.36 \\
\hline 111 & 511 & 0.00 & 9.34 & 8.68 & 8.16 & 7.49 & 5.26 & 10.25 & 9.72 & 9.01 & 8.17 & 7.13 \\
\hline 112 & 512 & 0.62 & 10.69 & 10.16 & 9.48 & 8.66 & 7.62 & 10.89 & 10.37 & 9.68 & 8.84 & 7.81 \\
\hline 113 & 513 & 0.26 & 10.09 & 9.56 & 8.90 & 8.09 & 7.05 & 10.42 & 9.92 & 9.23 & 8.40 & 7.38 \\
\hline 114 & 514 & 0.15 & 9.48 & 8.96 & 8.31 & 7.52 & 6.48 & 9.96 & 9.48 & 8.79 & 7.96 & 6.95 \\
\hline 115 & 515 & 0.11 & 8.90 & 8.39 & 7.76 & 6.98 & 5.94 & 9.51 & 9.05 & 8.37 & 7.55 & 6.55 \\
\hline 116 & 516 & 0.00 & 8.33 & 7.82 & 7.20 & 6.44 & 5.40 & 9.07 & 8.62 & 7.94 & 7.13 & 6.14 \\
\hline 117 & 517 & 0.00 & 7.60 & 7.10 & 6.50 & 5.76 & 4.72 & 8.51 & 8.09 & 7.41 & 6.61 & 5.63 \\
\hline 118 & 518 & 0.73 & 10.01 & 9.56 & 8.93 & 8.10 & 6.89 & 10.28 & 9.85 & 9.22 & 8.41 & 7.41 \\
\hline 119 & 519 & 0.22 & 8.91 & 8.53 & 7.94 & 7.14 & 5.81 & 9.39 & 9.02 & 8.45 & 7.66 & 6.69 \\
\hline 120 & 520 & 0.11 & 7.82 & 7.49 & 6.96 & 6.17 & 4.73 & 8.49 & 8.20 & 7.68 & 6.91 & 5.97 \\
\hline 121 & 521 & 0.07 & 6.78 & 6.51 & 6.03 & 5.25 & 3.70 & 7.64 & 7.42 & 6.94 & 6.20 & 5.29 \\
\hline 122 & 522 & 0.04 & 5.74 & 5.53 & 5.09 & 4.34 & 2.67 & 6.78 & 6.63 & 6.21 & 5.49 & 4.61 \\
\hline 123 & 523 & 0.00 & 4.43 & 4.30 & 3.92 & 3.18 & 1.36 & 5.71 & 5.64 & 5.29 & 4.60 & 3.74 \\
\hline 124 & 524 & 0.11 & 9.82 & 9.37 & 8.75 & 7.93 & 6.11 & 9.88 & 9.43 & 8.81 & 8.01 & 7.02 \\
\hline 125 & 525 & 0.04 & 8.59 & 8.20 & 7.65 & 6.85 & 4.47 & 8.69 & 8.30 & 7.75 & 6.98 & 6.03 \\
\hline 126 & 526 & 0.04 & 7.36 & 7.03 & 6.54 & 5.76 & 2.83 & 7.51 & 7.17 & 6.68 & 5.95 & 5.04 \\
\hline 127 & 527 & 0.00 & 9.13 & 8.67 & 8.11 & 6.96 & 4.09 & 8.56 & 8.09 & 7.52 & 6.75 & 5.81 \\
\hline 128 & 528 & 0.04 & 7.40 & 7.01 & 6.54 & 5.18 & 1.00 & 6.43 & 6.02 & 5.54 & 4.83 & 3.95 \\
\hline 129 & 529 & 0.04 & 5.68 & 5.35 & 4.97 & 3.40 & -2.10 & 4.30 & 3.94 & 3.56 & 2.90 & 2.09 \\
\hline 130 & 530 & 18.03 & 11.48 & 10.91 & 10.23 & 9.36 & 8.25 & 11.52 & 10.97 & 10.27 & 9.42 & 8.35 \\
\hline
\end{tabular}




\begin{tabular}{|c|c|c|c|c|c|c|c|c|c|c|c|c|}
\hline \multirow{2}{*}{$\begin{array}{l}\text { Wave } \\
\text { No. }\end{array}$} & \multirow{2}{*}{$\begin{array}{l}\text { Wave } \\
\text { ID }\end{array}$} & \multirow[b]{2}{*}{ Days/yr } & \multicolumn{5}{|c|}{ Inbound Ship speed (kt) } & \multicolumn{5}{|c|}{ Outbound Ship speed (kt) } \\
\hline & & & 8 & 10 & 12 & 14 & 16 & 8 & 10 & 12 & 14 & 16 \\
\hline 131 & 531 & 3.80 & 11.44 & 10.85 & 10.18 & 9.29 & 8.13 & 11.50 & 10.95 & 10.25 & 9.39 & 8.30 \\
\hline 132 & 532 & 0.37 & 11.39 & 10.78 & 10.13 & 9.22 & 8.01 & 11.49 & 10.92 & 10.23 & 9.37 & 8.25 \\
\hline 133 & 533 & 0.00 & 11.31 & 10.66 & 10.03 & 9.09 & 7.77 & 11.46 & 10.88 & 10.19 & 9.32 & 8.16 \\
\hline 134 & 534 & 2.23 & 11.31 & 10.71 & 10.05 & 9.23 & 7.80 & 11.43 & 10.87 & 10.17 & 9.33 & 8.20 \\
\hline 135 & 535 & 0.58 & 11.13 & 10.50 & 9.86 & 9.07 & 7.35 & 11.34 & 10.77 & 10.07 & 9.23 & 8.04 \\
\hline 136 & 536 & 0.58 & 10.95 & 10.28 & 9.67 & 8.89 & 6.87 & 11.26 & 10.67 & 9.97 & 9.14 & 7.87 \\
\hline 137 & 537 & 0.07 & 10.78 & 10.07 & 9.48 & 8.73 & 6.42 & 11.17 & 10.58 & 9.88 & 9.05 & 7.71 \\
\hline 138 & 538 & 1.06 & 11.12 & 10.55 & 9.88 & 9.06 & 7.82 & 11.24 & 10.70 & 9.99 & 9.15 & 8.11 \\
\hline 139 & 539 & 0.29 & 10.82 & 10.22 & 9.56 & 8.77 & 7.39 & 11.03 & 10.47 & 9.77 & 8.92 & 7.89 \\
\hline 140 & 540 & 0.11 & 10.49 & 9.87 & 9.24 & 8.46 & 6.94 & 10.80 & 10.24 & 9.53 & 8.69 & 7.65 \\
\hline 141 & 541 & 0.26 & 10.18 & 9.54 & 8.92 & 8.17 & 6.50 & 10.58 & 10.02 & 9.30 & 8.47 & 7.43 \\
\hline 142 & 542 & 0.11 & 9.87 & 9.21 & 8.61 & 7.88 & 6.07 & 10.36 & 9.79 & 9.08 & 8.24 & 7.21 \\
\hline 143 & 543 & 0.00 & 9.53 & 8.84 & 8.27 & 7.56 & 5.59 & 10.12 & 9.55 & 8.83 & 8.00 & 6.96 \\
\hline 144 & 544 & 0.69 & 10.70 & 10.17 & 9.48 & 8.65 & 7.63 & 10.82 & 10.30 & 9.60 & 8.76 & 7.73 \\
\hline 145 & 545 & 0.29 & 10.08 & 9.55 & 8.87 & 8.05 & 7.05 & 10.29 & 9.79 & 9.09 & 8.25 & 7.23 \\
\hline 146 & 546 & 0.18 & 9.42 & 8.91 & 8.23 & 7.43 & 6.44 & 9.74 & 9.24 & 8.54 & 7.71 & 6.71 \\
\hline 147 & 547 & 0.04 & 8.80 & 8.29 & 7.63 & 6.83 & 5.86 & 9.20 & 8.73 & 8.02 & 7.20 & 6.20 \\
\hline 148 & 548 & 0.07 & 8.18 & 7.67 & 7.02 & 6.24 & 5.27 & 8.67 & 8.21 & 7.51 & 6.69 & 5.70 \\
\hline 149 & 549 & 0.04 & 7.49 & 7.00 & 6.35 & 5.59 & 4.63 & 8.09 & 7.64 & 6.94 & 6.13 & 5.15 \\
\hline 150 & 550 & 0.00 & 6.96 & 6.47 & 5.83 & 5.08 & 4.14 & 7.64 & 7.20 & 6.50 & 5.69 & 4.72 \\
\hline 151 & 551 & 0.62 & 9.81 & 9.35 & 8.72 & 7.87 & 6.89 & 10.03 & 9.59 & 8.95 & 8.12 & 7.12 \\
\hline 152 & 552 & 0.22 & 8.52 & 8.13 & 7.54 & 6.69 & 5.76 & 8.91 & 8.54 & 7.95 & 7.13 & 6.16 \\
\hline 153 & 553 & 0.11 & 7.17 & 6.85 & 6.31 & 5.46 & 4.58 & 7.73 & 7.44 & 6.90 & 6.09 & 5.15 \\
\hline 154 & 554 & 0.00 & 5.88 & 5.63 & 5.13 & 4.29 & 3.45 & 6.60 & 6.39 & 5.90 & 5.10 & 4.19 \\
\hline 155 & 555 & 0.00 & 3.18 & 3.06 & 2.66 & 1.82 & 1.08 & 4.25 & 4.19 & 3.80 & 3.03 & 2.18 \\
\hline 156 & 556 & 0.15 & 9.31 & 8.87 & 8.26 & 7.42 & 6.44 & 9.43 & 8.98 & 8.34 & 7.51 & 6.53 \\
\hline 157 & 557 & 0.11 & 7.66 & 7.29 & 6.74 & 5.91 & 4.98 & 7.87 & 7.47 & 6.88 & 6.07 & 5.14 \\
\hline 158 & 558 & 0.04 & 8.22 & 7.79 & 7.23 & 6.43 & 5.02 & 7.59 & 7.12 & 6.49 & 5.69 & 4.79 \\
\hline 159 & 559 & 0.00 & 5.76 & 5.40 & 4.96 & 4.19 & 2.50 & 4.67 & 4.23 & 3.66 & 2.89 & 2.10 \\
\hline 160 & 560 & 27.08 & 11.48 & 10.92 & 10.23 & 9.36 & 8.25 & 11.50 & 10.95 & 10.25 & 9.39 & 8.30 \\
\hline 161 & 561 & 6.72 & 11.44 & 10.86 & 10.18 & 9.30 & 8.14 & 11.48 & 10.91 & 10.22 & 9.35 & 8.22 \\
\hline 162 & 562 & 0.40 & 11.41 & 10.81 & 10.14 & 9.24 & 8.03 & 11.45 & 10.87 & 10.19 & 9.31 & 8.15 \\
\hline 163 & 563 & 0.00 & 11.37 & 10.75 & 10.09 & 9.18 & 7.92 & 11.42 & 10.83 & 10.15 & 9.27 & 8.07 \\
\hline
\end{tabular}




\begin{tabular}{|c|c|c|c|c|c|c|c|c|c|c|c|c|}
\hline \multirow{2}{*}{$\begin{array}{l}\text { Wave } \\
\text { No. }\end{array}$} & \multirow{2}{*}{$\begin{array}{l}\text { Wave } \\
\text { ID }\end{array}$} & \multirow[b]{2}{*}{ Days/yr } & \multicolumn{5}{|c|}{ Inbound Ship speed (kt) } & \multicolumn{5}{|c|}{ Outbound Ship speed (kt) } \\
\hline & & & 8 & 10 & 12 & 14 & 16 & 8 & 10 & 12 & 14 & 16 \\
\hline 164 & 564 & 4.60 & 11.33 & 10.75 & 10.07 & 9.25 & 7.89 & 11.39 & 10.82 & 10.13 & 9.29 & 8.07 \\
\hline 165 & 565 & 0.91 & 11.18 & 10.57 & 9.91 & 9.11 & 7.52 & 11.28 & 10.69 & 10.00 & 9.18 & 7.82 \\
\hline 166 & 566 & 1.24 & 11.04 & 10.40 & 9.76 & 8.97 & 7.17 & 11.17 & 10.57 & 9.89 & 9.07 & 7.59 \\
\hline 167 & 567 & 0.11 & 10.89 & 10.22 & 9.59 & 8.83 & 6.80 & 11.06 & 10.44 & 9.76 & 8.96 & 7.34 \\
\hline 168 & 568 & 1.46 & 11.13 & 10.57 & 9.88 & 9.05 & 7.90 & 11.19 & 10.63 & 9.93 & 9.09 & 8.04 \\
\hline 169 & 569 & 0.33 & 10.84 & 10.26 & 9.58 & 8.77 & 7.53 & 10.93 & 10.37 & 9.67 & 8.83 & 7.77 \\
\hline 170 & 570 & 0.22 & 10.57 & 9.97 & 9.30 & 8.50 & 7.18 & 10.69 & 10.12 & 9.42 & 8.59 & 7.52 \\
\hline 171 & 571 & 0.40 & 10.28 & 9.66 & 9.00 & 8.21 & 6.81 & 10.44 & 9.85 & 9.15 & 8.33 & 7.25 \\
\hline 172 & 572 & 0.07 & 9.99 & 9.35 & 8.70 & 7.92 & 6.44 & 10.19 & 9.59 & 8.89 & 8.07 & 6.99 \\
\hline 173 & 573 & 0.00 & 9.68 & 9.03 & 8.38 & 7.63 & 6.05 & 9.92 & 9.31 & 8.61 & 7.80 & 6.71 \\
\hline 174 & 574 & 0.69 & 10.67 & 10.14 & 9.44 & 8.60 & 7.58 & 10.72 & 10.19 & 9.49 & 8.65 & 7.62 \\
\hline 175 & 575 & 0.33 & 10.04 & 9.52 & 8.82 & 8.00 & 6.99 & 10.13 & 9.61 & 8.91 & 8.08 & 7.06 \\
\hline 176 & 576 & 0.07 & 9.45 & 8.93 & 8.24 & 7.42 & 6.42 & 9.57 & 9.07 & 8.36 & 7.53 & 6.53 \\
\hline 177 & 577 & 0.04 & 8.82 & 8.31 & 7.62 & 6.81 & 5.83 & 8.98 & 8.49 & 7.78 & 6.96 & 5.96 \\
\hline 178 & 578 & 0.04 & 8.19 & 7.70 & 7.01 & 6.21 & 5.23 & 8.39 & 7.91 & 7.20 & 6.39 & 5.40 \\
\hline 179 & 579 & 0.04 & 7.54 & 7.05 & 6.36 & 5.57 & 4.61 & 7.77 & 7.30 & 6.59 & 5.78 & 4.81 \\
\hline 180 & 580 & 0.22 & 9.80 & 9.33 & 8.68 & 7.83 & 6.84 & 9.90 & 9.45 & 8.79 & 7.95 & 6.95 \\
\hline 181 & 581 & 0.18 & 8.55 & 8.14 & 7.52 & 6.67 & 5.71 & 8.73 & 8.33 & 7.72 & 6.87 & 5.90 \\
\hline 182 & 582 & 0.04 & 7.36 & 7.01 & 6.42 & 5.56 & 4.64 & 7.61 & 7.28 & 6.69 & 5.85 & 4.91 \\
\hline 183 & 583 & 0.00 & 6.11 & 5.82 & 5.26 & 4.40 & 3.52 & 6.44 & 6.17 & 5.62 & 4.77 & 3.86 \\
\hline 184 & 584 & 0.00 & 4.87 & 4.63 & 4.11 & 3.24 & 2.39 & 5.26 & 5.06 & 4.54 & 3.70 & 2.81 \\
\hline 185 & 585 & 0.00 & 3.56 & 3.38 & 2.89 & 2.02 & 1.21 & 4.03 & 3.89 & 3.41 & 2.57 & 1.71 \\
\hline 186 & 586 & 0.00 & 2.25 & 2.13 & 1.67 & 0.80 & 0.03 & 2.80 & 2.72 & 2.28 & 1.44 & 0.62 \\
\hline 187 & 587 & 10.22 & 11.52 & 10.97 & 10.28 & 9.42 & 8.36 & 11.52 & 10.97 & 10.27 & 9.41 & 8.35 \\
\hline 188 & 588 & 2.81 & 11.51 & 10.96 & 10.26 & 9.40 & 8.32 & 11.50 & 10.95 & 10.26 & 9.39 & 8.31 \\
\hline 189 & 589 & 0.22 & 11.50 & 10.94 & 10.25 & 9.38 & 8.29 & 11.49 & 10.92 & 10.24 & 9.36 & 8.26 \\
\hline 190 & 590 & 0.00 & 11.49 & 10.92 & 10.23 & 9.36 & 8.25 & 11.47 & 10.90 & 10.22 & 9.34 & 8.22 \\
\hline 191 & 591 & 0.00 & 11.48 & 10.90 & 10.22 & 9.34 & 8.22 & 11.46 & 10.88 & 10.20 & 9.31 & 8.18 \\
\hline 192 & 592 & 0.18 & 11.37 & 10.79 & 10.11 & 9.28 & 8.01 & 11.34 & 10.76 & 10.08 & 9.26 & 7.92 \\
\hline 193 & 593 & 0.18 & 11.26 & 10.67 & 9.99 & 9.17 & 7.76 & 11.21 & 10.61 & 9.94 & 9.14 & 7.61 \\
\hline 194 & 594 & 0.29 & 11.14 & 10.52 & 9.85 & 9.05 & 7.48 & 11.07 & 10.44 & 9.79 & 9.00 & 7.27 \\
\hline 195 & 595 & 0.00 & 11.01 & 10.37 & 9.71 & 8.92 & 7.19 & 10.93 & 10.26 & 9.63 & 8.86 & 6.92 \\
\hline 196 & 596 & 0.04 & 11.16 & 10.60 & 9.90 & 9.06 & 7.99 & 11.13 & 10.57 & 9.88 & 9.04 & 7.91 \\
\hline
\end{tabular}




\begin{tabular}{|l|l|l|l|l|l|l|l|l|l|l|l|l|}
\hline \multirow{2}{*}{$\begin{array}{l}\text { Wave } \\
\text { No. }\end{array}$} & \multirow{2}{*}{$\begin{array}{l}\text { Wave } \\
\text { ID }\end{array}$} & \multirow{3}{*}{ Days/yr } & $\mathbf{8}$ & 10 & 12 & 14 & 16 & 8 & 10 & 12 & 14 & 16 \\
\hline 197 & 597 & 0.04 & 10.92 & 10.35 & 9.65 & 8.82 & 7.72 & 10.88 & 10.30 & 9.61 & 8.79 & 7.60 \\
\hline 198 & 598 & 0.04 & 10.66 & 10.08 & 9.38 & 8.56 & 7.43 & 10.60 & 10.00 & 9.32 & 8.51 & 7.26 \\
\hline 199 & 599 & 0.07 & 10.38 & 9.78 & 9.09 & 8.28 & 7.13 & 10.30 & 9.69 & 9.01 & 8.22 & 6.90 \\
\hline 200 & 600 & 0.00 & 10.16 & 9.55 & 8.86 & 8.05 & 6.88 & 10.06 & 9.43 & 8.77 & 7.98 & 6.61 \\
\hline 201 & 601 & 0.00 & 10.67 & 10.14 & 9.44 & 8.60 & 7.58 & 10.64 & 10.11 & 9.41 & 8.58 & 7.55 \\
\hline 202 & 602 & 0.04 & 10.13 & 9.61 & 8.91 & 8.07 & 7.06 & 10.08 & 9.56 & 8.86 & 8.03 & 7.02 \\
\hline 203 & 603 & 0.00 & 9.52 & 9.02 & 8.31 & 7.48 & 6.48 & 9.46 & 8.95 & 8.25 & 7.43 & 6.43 \\
\hline 204 & 604 & 0.00 & 8.89 & 8.39 & 7.69 & 6.87 & 5.88 & 8.81 & 8.31 & 7.61 & 6.80 & 5.81 \\
\hline 205 & 605 & 0.00 & 8.38 & 7.89 & 7.18 & 6.37 & 5.39 & 8.28 & 7.78 & 7.09 & 6.28 & 5.30 \\
\hline 206 & 606 & 0.00 & 7.59 & 7.12 & 6.41 & 5.61 & 4.64 & 7.47 & 6.99 & 6.29 & 5.50 & 4.53 \\
\hline 207 & 607 & 0.04 & 9.70 & 9.25 & 8.61 & 7.76 & 6.76 & 9.64 & 9.19 & 8.55 & 7.69 & 6.70 \\
\hline 208 & 608 & 0.04 & 8.55 & 8.17 & 7.56 & 6.70 & 5.74 & 8.46 & 8.07 & 7.46 & 6.60 & 5.65 \\
\hline 209 & 609 & 0.00 & 7.28 & 6.96 & 6.39 & 5.53 & 4.60 & 7.15 & 6.82 & 6.25 & 5.38 & 4.47 \\
\hline 210 & 610 & 0.00 & 5.94 & 5.69 & 5.16 & 4.30 & 3.41 & 5.77 & 5.51 & 4.98 & 4.11 & 3.23 \\
\hline 211 & 611 & 0.00 & 2.57 & 2.49 & 2.06 & 1.20 & 0.40 & 2.29 & 2.20 & 1.77 & 0.89 & 0.11 \\
\hline
\end{tabular}




\section{Appendix F: Wave-induced Vertical Motion Allowances (ft) for Phase 2, Reach 1 Channel ( $h=53 \mathrm{ft}$ ) and Reach 2 Mound $(h=55 \mathrm{ft}$ ), Lightly $(T=46.0 \mathrm{ft})$ and Fully loaded ( $T=47.5 \mathrm{ft}$ ) Susan Maersk}

Table F1. Wave-induced vertical motion allowances (ft), Phase 2, Channel Reach 1, $h=53 \mathrm{ft}$, light-loaded Susan Maersk, inbound and outbound transits.

\begin{tabular}{|c|c|c|c|c|c|c|c|c|c|c|c|c|}
\hline \multirow{2}{*}{$\begin{array}{l}\text { Wave } \\
\text { No. }\end{array}$} & \multirow{2}{*}{$\begin{array}{l}\text { Wave } \\
\text { ID }\end{array}$} & \multirow[b]{2}{*}{ Days/yr } & \multicolumn{5}{|c|}{ Inbound Ship speed (kt) } & \multicolumn{5}{|c|}{ Outbound Ship speed (kt) } \\
\hline & & & 8 & 10 & 12 & 14 & 16 & 8 & 10 & 12 & 14 & 16 \\
\hline 19 & 119 & 0.01 & 2.49 & 2.57 & 2.68 & 3.37 & 5.55 & 1.97 & 1.99 & 1.97 & 2.04 & 2.61 \\
\hline 22 & 122 & 0.02 & 2.68 & 2.55 & 2.49 & 3.29 & 5.33 & 2.13 & 2.04 & 1.93 & 1.85 & 1.78 \\
\hline 46 & 146 & 0.06 & 2.17 & 2.23 & 2.36 & 3.05 & 5.28 & 1.49 & 1.49 & 1.46 & 1.44 & 1.57 \\
\hline 52 & 152 & 0.15 & 2.18 & 2.05 & 2.27 & 3.45 & 5.94 & 1.50 & 1.41 & 1.30 & 1.24 & 1.19 \\
\hline 61 & 161 & 0.01 & 2.87 & 2.71 & 3.23 & 4.80 & 8.23 & 2.51 & 2.36 & 2.21 & 2.13 & 1.97 \\
\hline 64 & 164 & 0.01 & 2.56 & 2.61 & 3.34 & 4.53 & 7.57 & 2.88 & 2.71 & 2.53 & 2.44 & 2.22 \\
\hline 82 & 182 & 0.04 & 2.21 & 2.27 & 2.38 & 3.14 & 5.61 & 1.37 & 1.35 & 1.31 & 1.30 & 1.29 \\
\hline 87 & 187 & 0.52 & 2.19 & 2.01 & 2.37 & 4.18 & 7.39 & 1.38 & 1.26 & 1.13 & 1.06 & 0.99 \\
\hline 92 & 192 & 0.07 & 2.25 & 2.18 & 2.92 & 5.19 & 8.97 & 1.87 & 1.70 & 1.53 & 1.44 & 1.30 \\
\hline 95 & 195 & 0.01 & 1.58 & 1.86 & 3.06 & 4.75 & 7.65 & 1.83 & 1.68 & 1.50 & 1.41 & 1.27 \\
\hline 115 & 215 & 0.10 & 2.16 & 2.22 & 2.34 & 3.07 & 5.44 & 1.37 & 1.36 & 1.32 & 1.30 & 1.30 \\
\hline 119 & 219 & 0.21 & 2.20 & 2.03 & 2.38 & 4.02 & 7.06 & 1.41 & 1.30 & 1.18 & 1.11 & 1.04 \\
\hline 125 & 225 & 0.05 & 2.39 & 2.34 & 3.00 & 5.08 & 8.78 & 2.02 & 1.86 & 1.70 & 1.61 & 1.46 \\
\hline 127 & 227 & 0.01 & 1.81 & 2.02 & 3.07 & 4.61 & 7.54 & 2.09 & 1.93 & 1.75 & 1.65 & 1.49 \\
\hline 147 & 247 & 0.04 & 1.94 & 1.99 & 2.10 & 2.69 & 4.58 & 1.39 & 1.40 & 1.37 & 1.36 & 1.58 \\
\hline 152 & 252 & 0.21 & 2.04 & 1.92 & 2.04 & 2.97 & 5.02 & 1.47 & 1.40 & 1.30 & 1.25 & 1.19 \\
\hline 157 & 257 & 0.12 & 2.48 & 2.31 & 2.64 & 3.66 & 6.19 & 2.24 & 2.12 & 2.01 & 1.94 & 1.80 \\
\hline 158 & 258 & 0.04 & 2.20 & 2.18 & 2.62 & 3.34 & 5.54 & 2.51 & 2.36 & 2.25 & 2.17 & 1.98 \\
\hline 177 & 277 & 0.03 & 2.12 & 2.17 & 2.24 & 2.78 & 4.49 & 1.76 & 1.79 & 1.77 & 1.87 & 2.46 \\
\hline 181 & 281 & 0.17 & 2.31 & 2.23 & 2.18 & 2.67 & 4.17 & 1.90 & 1.83 & 1.76 & 1.69 & 1.64 \\
\hline 205 & 305 & 0.01 & 2.02 & 2.08 & 2.06 & 2.48 & 3.74 & 1.94 & 1.98 & 1.95 & 2.24 & 3.22 \\
\hline 206 & 306 & 0.00 & 2.51 & 2.58 & 2.56 & 3.07 & 4.64 & 2.40 & 2.46 & 2.42 & 2.78 & 3.99 \\
\hline 208 & 308 & 0.03 & 1.91 & 1.84 & 1.80 & 1.78 & 2.49 & 1.82 & 1.76 & 1.71 & 1.64 & 1.93 \\
\hline 209 & 309 & 0.01 & 2.75 & 2.65 & 2.59 & 2.56 & 3.58 & 2.62 & 2.53 & 2.46 & 2.36 & 2.78 \\
\hline
\end{tabular}


Table F2. Wave-induced vertical motion allowances (ft), Phase 2, Mound Reach 2, $h=55,56$, and $57 \mathrm{ft}$, light-loaded Susan Maersk, inbound and outbound transits.

\begin{tabular}{|c|c|c|c|c|c|c|c|c|c|c|c|c|}
\hline \multirow{2}{*}{$\begin{array}{l}\text { Wave } \\
\text { No. }\end{array}$} & \multirow{2}{*}{$\begin{array}{l}\text { Wave } \\
\text { ID }\end{array}$} & \multirow[b]{2}{*}{ Days/yr } & \multicolumn{5}{|c|}{ Inbound Ship speed (kt) } & \multicolumn{5}{|c|}{ Outbound Ship speed (kt) } \\
\hline & & & 8 & 10 & 12 & 14 & 16 & 8 & 10 & 12 & 14 & 16 \\
\hline \multicolumn{13}{|c|}{$h=55 \mathrm{ft}$} \\
\hline 19 & 419 & 0.01 & 2.74 & 2.83 & 2.80 & 3.34 & 5.84 & 2.07 & 2.07 & 2.03 & 2.01 & 2.11 \\
\hline 22 & 422 & 0.02 & 2.55 & 2.42 & 2.49 & 2.95 & 5.83 & 1.98 & 1.88 & 1.75 & 1.68 & 1.61 \\
\hline 46 & 446 & 0.06 & 2.34 & 2.40 & 2.38 & 2.89 & 5.29 & 1.60 & 1.58 & 1.53 & 1.50 & 1.49 \\
\hline 52 & 452 & 0.15 & 2.02 & 1.90 & 2.15 & 2.71 & 6.05 & 1.41 & 1.31 & 1.18 & 1.11 & 1.06 \\
\hline 61 & 461 & 0.01 & 2.31 & 2.22 & 2.80 & 3.82 & 8.51 & 2.10 & 1.96 & 1.80 & 1.70 & 1.57 \\
\hline 64 & 464 & 0.01 & 1.79 & 1.92 & 2.83 & 3.94 & 8.16 & 2.20 & 2.08 & 1.91 & 1.81 & 1.66 \\
\hline 82 & 482 & 0.04 & 2.58 & 2.65 & 2.61 & 3.17 & 5.88 & 1.73 & 1.70 & 1.64 & 1.61 & 1.59 \\
\hline 87 & 487 & 0.52 & 2.54 & 2.35 & 2.70 & 3.47 & 8.07 & 1.79 & 1.64 & 1.47 & 1.37 & 1.29 \\
\hline 92 & 492 & 0.07 & 2.55 & 2.43 & 3.17 & 4.46 & 10.19 & 2.30 & 2.12 & 1.92 & 1.80 & 1.65 \\
\hline 95 & 495 & 0.01 & 1.80 & 2.00 & 3.20 & 4.55 & 9.54 & 2.24 & 2.08 & 1.89 & 1.77 & 1.62 \\
\hline 115 & 515 & 0.10 & 2.54 & 2.60 & 2.59 & 3.10 & 5.50 & 1.85 & 1.84 & 1.80 & 1.78 & 1.76 \\
\hline 119 & 519 & 0.21 & 2.81 & 2.65 & 2.84 & 3.44 & 7.13 & 2.12 & 2.00 & 1.84 & 1.75 & 1.68 \\
\hline 125 & 525 & 0.05 & 3.35 & 3.17 & 3.66 & 4.65 & 9.54 & 3.08 & 2.94 & 2.75 & 2.65 & 2.49 \\
\hline 127 & 527 & 0.01 & 2.94 & 2.95 & 3.72 & 4.78 & 9.35 & 3.50 & 3.37 & 3.18 & 3.07 & 2.85 \\
\hline 147 & 547 & 0.04 & 2.12 & 2.18 & 2.12 & 2.48 & 4.15 & 1.75 & 1.77 & 1.74 & 1.73 & 2.02 \\
\hline 152 & 552 & 0.21 & 2.38 & 2.28 & 2.24 & 2.48 & 4.37 & 1.97 & 1.90 & 1.80 & 1.73 & 1.67 \\
\hline 157 & 557 & 0.12 & 3.05 & 2.93 & 2.92 & 3.32 & 5.67 & 2.95 & 2.85 & 2.73 & 2.68 & 2.59 \\
\hline 158 & 558 & 0.04 & 2.71 & 2.62 & 2.86 & 3.19 & 5.30 & 3.34 & 3.23 & 3.14 & 3.07 & 2.93 \\
\hline 177 & 577 & 0.03 & 2.11 & 2.16 & 2.11 & 2.32 & 3.59 & 1.96 & 2.00 & 1.97 & 1.96 & 2.70 \\
\hline 181 & 581 & 0.17 & 2.26 & 2.19 & 2.16 & 2.08 & 3.02 & 2.08 & 2.02 & 1.96 & 1.90 & 1.89 \\
\hline 205 & 605 & 0.01 & 2.25 & 2.30 & 2.26 & 2.31 & 3.28 & 2.33 & 2.40 & 2.34 & 2.51 & 3.78 \\
\hline 206 & 606 & 0.00 & 2.63 & 2.69 & 2.64 & 2.69 & 3.83 & 2.72 & 2.79 & 2.74 & 2.93 & 4.42 \\
\hline 208 & 608 & 0.03 & 2.04 & 1.98 & 1.92 & 1.86 & 2.02 & 2.12 & 2.06 & 2.02 & 1.94 & 2.56 \\
\hline 209 & 609 & 0.01 & 2.76 & 2.68 & 2.60 & 2.51 & 2.74 & 2.87 & 2.78 & 2.73 & 2.63 & 3.46 \\
\hline \multicolumn{13}{|c|}{$h=56 \mathrm{ft}$} \\
\hline 19 & 419 & 0.01 & 2.81 & 2.88 & 2.78 & 3.28 & 5.65 & 2.16 & 2.17 & 2.12 & 2.09 & 2.09 \\
\hline 22 & 422 & 0.02 & 2.56 & 2.43 & 2.46 & 2.90 & 5.69 & 2.05 & 1.95 & 1.81 & 1.74 & 1.67 \\
\hline 46 & 446 & 0.06 & 2.39 & 2.44 & 2.36 & 2.83 & 5.11 & 1.68 & 1.65 & 1.60 & 1.57 & 1.55 \\
\hline 52 & 452 & 0.15 & 2.02 & 1.89 & 2.12 & 2.65 & 5.89 & 1.47 & 1.36 & 1.24 & 1.16 & 1.10 \\
\hline 61 & 461 & 0.01 & 2.28 & 2.17 & 2.71 & 3.66 & 8.55 & 2.15 & 2.01 & 1.85 & 1.75 & 1.62 \\
\hline
\end{tabular}




\begin{tabular}{|c|c|c|c|c|c|c|c|c|c|c|c|c|}
\hline \multirow{2}{*}{$\begin{array}{l}\text { Wave } \\
\text { No. }\end{array}$} & \multirow{2}{*}{$\begin{array}{l}\text { Wave } \\
\text { ID }\end{array}$} & \multirow[b]{2}{*}{ Days/yr } & \multicolumn{5}{|c|}{ Inbound Ship speed (kt) } & \multicolumn{5}{|c|}{ Outbound Ship speed (kt) } \\
\hline & & & 8 & 10 & 12 & 14 & 16 & 8 & 10 & 12 & 14 & 16 \\
\hline 64 & 464 & 0.01 & 1.77 & 1.85 & 2.71 & 3.70 & 8.58 & 2.23 & 2.11 & 1.95 & 1.85 & 1.72 \\
\hline 82 & 482 & 0.04 & 2.64 & 2.69 & 2.58 & 3.12 & 5.68 & 1.82 & 1.78 & 1.72 & 1.69 & 1.66 \\
\hline 87 & 487 & 0.52 & 2.53 & 2.35 & 2.66 & 3.39 & 7.86 & 1.87 & 1.71 & 1.54 & 1.44 & 1.35 \\
\hline 92 & 492 & 0.07 & 2.52 & 2.37 & 3.08 & 4.26 & 10.26 & 2.36 & 2.18 & 1.98 & 1.86 & 1.72 \\
\hline 95 & 495 & 0.01 & 1.79 & 1.92 & 3.05 & 4.25 & 10.10 & 2.28 & 2.13 & 1.94 & 1.82 & 1.68 \\
\hline 115 & 515 & 0.10 & 2.60 & 2.65 & 2.57 & 3.04 & 5.32 & 1.94 & 1.93 & 1.88 & 1.85 & 1.83 \\
\hline 119 & 519 & 0.21 & 2.82 & 2.66 & 2.81 & 3.38 & 6.96 & 2.19 & 2.07 & 1.91 & 1.82 & 1.74 \\
\hline 125 & 525 & 0.05 & 3.31 & 3.14 & 3.57 & 4.48 & 9.54 & 3.11 & 2.99 & 2.79 & 2.69 & 2.54 \\
\hline 127 & 527 & 0.01 & 2.88 & 2.85 & 3.58 & 4.55 & 9.65 & 3.49 & 3.39 & 3.21 & 3.10 & 2.91 \\
\hline 147 & 547 & 0.04 & 2.18 & 2.23 & 2.17 & 2.45 & 4.03 & 1.83 & 1.85 & 1.81 & 1.79 & 1.99 \\
\hline 152 & 552 & 0.21 & 2.40 & 2.30 & 2.27 & 2.45 & 4.28 & 2.03 & 1.95 & 1.85 & 1.78 & 1.72 \\
\hline 157 & 557 & 0.12 & 3.02 & 2.90 & 2.86 & 3.24 & 5.63 & 2.92 & 2.83 & 2.72 & 2.66 & 2.58 \\
\hline 158 & 558 & 0.04 & 2.62 & 2.54 & 2.75 & 3.07 & 5.32 & 3.25 & 3.16 & 3.08 & 3.02 & 2.89 \\
\hline 177 & 577 & 0.03 & 2.18 & 2.23 & 2.18 & 2.29 & 3.50 & 2.04 & 2.07 & 2.04 & 2.02 & 2.64 \\
\hline 181 & 581 & 0.17 & 2.30 & 2.23 & 2.20 & 2.12 & 2.98 & 2.14 & 2.08 & 2.01 & 1.95 & 1.89 \\
\hline 205 & 605 & 0.01 & 2.34 & 2.39 & 2.35 & 2.32 & 3.21 & 2.42 & 2.47 & 2.43 & 2.48 & 3.69 \\
\hline 206 & 606 & 0.00 & 2.73 & 2.78 & 2.74 & 2.71 & 3.74 & 2.82 & 2.89 & 2.83 & 2.90 & 4.31 \\
\hline 208 & 608 & 0.03 & 2.08 & 2.02 & 1.97 & 1.90 & 2.01 & 2.16 & 2.10 & 2.06 & 1.98 & 2.53 \\
\hline 209 & 609 & 0.01 & 2.82 & 2.74 & 2.67 & 2.58 & 2.72 & 2.92 & 2.84 & 2.78 & 2.69 & 3.42 \\
\hline \multicolumn{13}{|c|}{$h=57 \mathrm{ft}$} \\
\hline 19 & 419 & 0.01 & 2.88 & 2.95 & 2.84 & 3.25 & 5.09 & 2.26 & 2.25 & 2.20 & 2.17 & 2.14 \\
\hline 22 & 422 & 0.02 & 2.57 & 2.45 & 2.44 & 2.85 & 4.51 & 2.11 & 2.01 & 1.87 & 1.79 & 1.73 \\
\hline 46 & 446 & 0.06 & 2.44 & 2.49 & 2.38 & 2.80 & 4.57 & 1.76 & 1.73 & 1.67 & 1.63 & 1.61 \\
\hline 52 & 452 & 0.15 & 2.01 & 1.90 & 2.09 & 2.59 & 4.64 & 1.53 & 1.42 & 1.29 & 1.21 & 1.15 \\
\hline 61 & 461 & 0.01 & 2.26 & 2.13 & 2.63 & 3.51 & 7.72 & 2.19 & 2.05 & 1.89 & 1.79 & 1.71 \\
\hline 64 & 464 & 0.01 & 1.75 & 1.78 & 2.57 & 3.47 & 8.88 & 2.26 & 2.15 & 1.99 & 1.89 & 1.82 \\
\hline 82 & 482 & 0.04 & 2.69 & 2.74 & 2.62 & 3.07 & 5.07 & 1.90 & 1.86 & 1.80 & 1.76 & 1.72 \\
\hline 87 & 487 & 0.52 & 2.52 & 2.35 & 2.61 & 3.31 & 6.12 & 1.94 & 1.78 & 1.60 & 1.49 & 1.42 \\
\hline 92 & 492 & 0.07 & 2.50 & 2.33 & 2.98 & 4.08 & 9.30 & 2.42 & 2.24 & 2.04 & 1.91 & 1.81 \\
\hline 95 & 495 & 0.01 & 1.79 & 1.85 & 2.88 & 3.96 & 10.52 & 2.34 & 2.18 & 2.00 & 1.88 & 1.79 \\
\hline 115 & 515 & 0.10 & 2.65 & 2.71 & 2.60 & 3.01 & 4.78 & 2.02 & 2.01 & 1.95 & 1.92 & 1.89 \\
\hline 119 & 519 & 0.21 & 2.82 & 2.68 & 2.77 & 3.31 & 5.48 & 2.27 & 2.14 & 1.97 & 1.88 & 1.81 \\
\hline 125 & 525 & 0.05 & 3.28 & 3.12 & 3.48 & 4.34 & 8.54 & 3.15 & 3.03 & 2.84 & 2.74 & 2.66 \\
\hline
\end{tabular}




\begin{tabular}{|l|l|l|l|l|l|l|l|l|l|l|l|l|}
\hline \multirow{2}{*}{$\begin{array}{l}\text { Wave } \\
\text { No. }\end{array}$} & \multirow{2}{*}{$\begin{array}{l}\text { Wave } \\
\text { ID }\end{array}$} & Days/yr & $\mathbf{8}$ & $\mathbf{4}$ Inbound Ship speed (kt) & \multicolumn{4}{c|}{ Outbound Ship speed (kt) } \\
\hline & & & & 12 & 14 & 16 & 8 & 10 & 12 & 14 & 16 \\
\hline 127 & 527 & 0.01 & 2.83 & 2.76 & 3.43 & 4.34 & 9.80 & 3.49 & 3.40 & 3.23 & 3.13 & 3.06 \\
\hline 147 & 547 & 0.04 & 2.24 & 2.29 & 2.23 & 2.42 & 3.64 & 1.90 & 1.92 & 1.88 & 1.85 & 1.89 \\
\hline 152 & 552 & 0.21 & 2.42 & 2.33 & 2.29 & 2.42 & 3.46 & 2.09 & 2.01 & 1.90 & 1.83 & 1.78 \\
\hline 157 & 557 & 0.12 & 3.00 & 2.89 & 2.83 & 3.16 & 5.05 & 2.90 & 2.81 & 2.70 & 2.65 & 2.61 \\
\hline 158 & 558 & 0.04 & 2.56 & 2.47 & 2.66 & 2.97 & 5.27 & 3.16 & 3.08 & 3.01 & 2.96 & 2.91 \\
\hline 177 & 577 & 0.03 & 2.25 & 2.30 & 2.25 & 2.27 & 3.20 & 2.11 & 2.15 & 2.11 & 2.08 & 2.46 \\
\hline 181 & 581 & 0.17 & 2.33 & 2.27 & 2.24 & 2.16 & 2.55 & 2.18 & 2.13 & 2.06 & 2.00 & 1.94 \\
\hline 205 & 605 & 0.01 & 2.42 & 2.47 & 2.43 & 2.39 & 2.97 & 2.50 & 2.55 & 2.50 & 2.47 & 3.39 \\
\hline 206 & 606 & 0.00 & 2.83 & 2.88 & 2.83 & 2.79 & 3.47 & 2.92 & 2.98 & 2.92 & 2.88 & 3.95 \\
\hline 208 & 608 & 0.03 & 2.13 & 2.07 & 2.01 & 1.95 & 1.89 & 2.19 & 2.13 & 2.09 & 2.02 & 2.19 \\
\hline 209 & 609 & 0.01 & 2.88 & 2.80 & 2.72 & 2.63 & 2.56 & 2.97 & 2.89 & 2.83 & 2.74 & 2.97 \\
\hline
\end{tabular}


Table F3. Wave-induced vertical motion allowances (ft), Phase 2, Channel Reach 1, $h=53 \mathrm{ft}$, fully loaded Susan Maersk, inbound and outbound transits.

\begin{tabular}{|c|c|c|c|c|c|c|c|c|c|c|c|c|}
\hline \multirow{2}{*}{$\begin{array}{l}\text { Wave } \\
\text { No. }\end{array}$} & \multirow{2}{*}{$\begin{array}{l}\text { Wave } \\
\text { ID }\end{array}$} & \multirow[b]{2}{*}{ Days/yr } & \multicolumn{5}{|c|}{ Inbound Ship speed (kt) } & \multicolumn{5}{|c|}{ Outbound Ship speed (kt) } \\
\hline & & & 8 & 10 & 12 & 14 & 16 & 8 & 10 & 12 & 14 & 16 \\
\hline 19 & 119 & 0.01 & 2.41 & 2.47 & 2.41 & 2.26 & 2.77 & 1.81 & 1.79 & 1.83 & 1.80 & 1.81 \\
\hline 22 & 122 & 0.02 & 2.65 & 2.51 & 2.45 & 2.29 & 2.71 & 2.00 & 1.85 & 1.82 & 1.74 & 1.67 \\
\hline 46 & 146 & 0.06 & 2.13 & 2.19 & 2.09 & 1.93 & 2.59 & 1.36 & 1.32 & 1.34 & 1.32 & 1.32 \\
\hline 52 & 152 & 0.15 & 2.20 & 2.09 & 1.98 & 1.81 & 2.98 & 1.38 & 1.25 & 1.21 & 1.15 & 1.09 \\
\hline 61 & 161 & 0.01 & 2.99 & 2.85 & 2.66 & 3.34 & 5.65 & 2.36 & 2.24 & 2.12 & 2.04 & 1.85 \\
\hline 64 & 164 & 0.01 & 2.74 & 2.64 & 2.45 & 3.96 & 6.83 & 2.73 & 2.61 & 2.43 & 2.33 & 2.07 \\
\hline 82 & 182 & 0.04 & 2.18 & 2.25 & 2.12 & 1.94 & 2.72 & 1.24 & 1.19 & 1.19 & 1.18 & 1.17 \\
\hline 87 & 187 & 0.52 & 2.26 & 2.12 & 1.94 & 1.96 & 3.67 & 1.25 & 1.11 & 1.03 & 0.97 & 0.90 \\
\hline 92 & 192 & 0.07 & 2.37 & 2.23 & 1.99 & 3.65 & 6.13 & 1.73 & 1.58 & 1.43 & 1.34 & 1.18 \\
\hline 95 & 195 & 0.01 & 1.68 & 1.59 & 1.98 & 4.62 & 7.05 & 1.71 & 1.58 & 1.41 & 1.32 & 1.14 \\
\hline 115 & 215 & 0.10 & 2.13 & 2.20 & 2.08 & 1.91 & 2.64 & 1.25 & 1.19 & 1.20 & 1.19 & 1.18 \\
\hline 119 & 219 & 0.21 & 2.25 & 2.13 & 1.96 & 1.92 & 3.52 & 1.29 & 1.15 & 1.08 & 1.02 & 0.95 \\
\hline 125 & 225 & 0.05 & 2.51 & 2.37 & 2.15 & 3.58 & 6.01 & 1.88 & 1.74 & 1.59 & 1.51 & 1.34 \\
\hline 127 & 227 & 0.01 & 1.92 & 1.84 & 1.98 & 4.40 & 6.95 & 1.95 & 1.83 & 1.65 & 1.56 & 1.36 \\
\hline 147 & 247 & 0.04 & 1.89 & 1.94 & 1.86 & 1.73 & 2.26 & 1.28 & 1.24 & 1.27 & 1.25 & 1.25 \\
\hline 152 & 252 & 0.21 & 2.04 & 1.94 & 1.86 & 1.72 & 2.53 & 1.37 & 1.25 & 1.21 & 1.16 & 1.11 \\
\hline 157 & 257 & 0.12 & 2.57 & 2.45 & 2.33 & 2.52 & 4.23 & 2.12 & 2.02 & 1.93 & 1.87 & 1.71 \\
\hline 158 & 258 & 0.04 & 2.36 & 2.28 & 2.13 & 2.75 & 4.86 & 2.39 & 2.30 & 2.18 & 2.11 & 1.88 \\
\hline 177 & 277 & 0.03 & 2.04 & 2.07 & 2.03 & 1.93 & 2.24 & 1.63 & 1.62 & 1.65 & 1.62 & 1.63 \\
\hline 181 & 281 & 0.17 & 2.27 & 2.17 & 2.13 & 2.01 & 2.13 & 1.79 & 1.67 & 1.66 & 1.59 & 1.54 \\
\hline 205 & 305 & 0.01 & 1.92 & 1.94 & 1.93 & 1.87 & 1.90 & 1.82 & 1.82 & 1.84 & 1.79 & 1.81 \\
\hline 206 & 306 & 0.00 & 2.38 & 2.40 & 2.40 & 2.32 & 2.35 & 2.26 & 2.26 & 2.28 & 2.22 & 2.24 \\
\hline 208 & 308 & 0.03 & 1.84 & 1.75 & 1.74 & 1.65 & 1.60 & 1.74 & 1.64 & 1.64 & 1.56 & 1.51 \\
\hline 209 & 309 & 0.01 & 2.65 & 2.51 & 2.50 & 2.38 & 2.31 & 2.50 & 2.36 & 2.35 & 2.24 & 2.18 \\
\hline
\end{tabular}


Table F4. Wave-induced vertical motion allowances (ft), Phase 2, Mound Reach 2, $h=55,56$, and $57 \mathrm{ft}$, fully loaded Susan Maersk, inbound and outbound transits.

\begin{tabular}{|c|c|c|c|c|c|c|c|c|c|c|c|c|}
\hline \multirow{2}{*}{$\begin{array}{l}\text { Wave } \\
\text { No. }\end{array}$} & \multirow{2}{*}{$\begin{array}{l}\text { Wave } \\
\text { ID }\end{array}$} & \multirow[b]{2}{*}{ Days/yr } & \multicolumn{5}{|c|}{ Inbound Ship speed (kt) } & \multicolumn{5}{|c|}{ Outbound Ship speed (kt) } \\
\hline & & & 8 & 10 & 12 & 14 & 16 & 8 & 10 & 12 & 14 & 16 \\
\hline \multicolumn{13}{|c|}{$h=55 \mathrm{ft}$} \\
\hline 19 & 419 & 0.01 & 2.69 & 2.72 & 2.64 & 2.53 & 2.87 & 1.92 & 1.86 & 1.89 & 1.87 & 1.85 \\
\hline 22 & 422 & 0.02 & 2.56 & 2.40 & 2.36 & 2.23 & 2.81 & 1.87 & 1.70 & 1.65 & 1.58 & 1.51 \\
\hline 46 & 446 & 0.06 & 2.33 & 2.34 & 2.24 & 2.13 & 2.55 & 1.47 & 1.41 & 1.42 & 1.39 & 1.37 \\
\hline 52 & 452 & 0.15 & 2.08 & 1.93 & 1.83 & 1.70 & 2.84 & 1.31 & 1.17 & 1.09 & 1.03 & 0.97 \\
\hline 61 & 461 & 0.01 & 2.41 & 2.23 & 2.08 & 3.06 & 5.13 & 1.98 & 1.84 & 1.69 & 1.60 & 1.45 \\
\hline 64 & 464 & 0.01 & 1.84 & 1.75 & 1.82 & 3.76 & 6.07 & 2.10 & 1.98 & 1.81 & 1.71 & 1.52 \\
\hline 82 & 482 & 0.04 & 2.57 & 2.59 & 2.47 & 2.34 & 2.82 & 1.59 & 1.51 & 1.52 & 1.49 & 1.47 \\
\hline 87 & 487 & 0.52 & 2.63 & 2.41 & 2.28 & 2.14 & 3.78 & 1.65 & 1.46 & 1.35 & 1.27 & 1.18 \\
\hline 92 & 492 & 0.07 & 2.67 & 2.45 & 2.25 & 3.63 & 6.11 & 2.16 & 1.98 & 1.80 & 1.69 & 1.51 \\
\hline 95 & 495 & 0.01 & 1.85 & 1.74 & 2.07 & 4.47 & 7.02 & 2.12 & 1.98 & 1.78 & 1.67 & 1.47 \\
\hline 115 & 515 & 0.10 & 2.50 & 2.52 & 2.43 & 2.32 & 2.68 & 1.71 & 1.65 & 1.67 & 1.65 & 1.63 \\
\hline 119 & 519 & 0.21 & 2.85 & 2.66 & 2.59 & 2.43 & 3.41 & 1.98 & 1.79 & 1.72 & 1.64 & 1.56 \\
\hline 125 & 525 & 0.05 & 3.45 & 3.26 & 3.11 & 3.51 & 5.80 & 2.94 & 2.78 & 2.65 & 2.56 & 2.35 \\
\hline 127 & 527 & 0.01 & 3.07 & 2.96 & 2.77 & 4.08 & 7.01 & 3.36 & 3.25 & 3.06 & 2.95 & 2.67 \\
\hline 147 & 547 & 0.04 & 2.07 & 2.07 & 2.04 & 1.97 & 2.05 & 1.64 & 1.60 & 1.63 & 1.62 & 1.60 \\
\hline 152 & 552 & 0.21 & 2.36 & 2.22 & 2.21 & 2.11 & 2.15 & 1.87 & 1.73 & 1.70 & 1.64 & 1.58 \\
\hline 157 & 557 & 0.12 & 3.12 & 2.97 & 2.91 & 2.81 & 3.44 & 2.89 & 2.78 & 2.70 & 2.65 & 2.49 \\
\hline 158 & 558 & 0.04 & 2.87 & 2.76 & 2.63 & 2.57 & 3.68 & 3.31 & 3.24 & 3.15 & 3.08 & 2.85 \\
\hline 177 & 577 & 0.03 & 2.02 & 2.02 & 2.02 & 1.98 & 1.95 & 1.85 & 1.83 & 1.86 & 1.83 & 1.82 \\
\hline 181 & 581 & 0.17 & 2.20 & 2.08 & 2.10 & 2.02 & 1.95 & 2.00 & 1.87 & 1.88 & 1.82 & 1.76 \\
\hline 205 & 605 & 0.01 & 2.14 & 2.12 & 2.15 & 2.11 & 2.09 & 2.23 & 2.22 & 2.24 & 2.19 & 2.17 \\
\hline 206 & 606 & 0.00 & 2.49 & 2.47 & 2.51 & 2.47 & 2.44 & 2.61 & 2.59 & 2.61 & 2.56 & 2.53 \\
\hline 208 & 608 & 0.03 & 1.96 & 1.84 & 1.85 & 1.79 & 1.73 & 2.06 & 1.94 & 1.96 & 1.88 & 1.82 \\
\hline 209 & 609 & 0.01 & 2.66 & 2.50 & 2.51 & 2.42 & 2.34 & 2.79 & 2.63 & 2.65 & 2.55 & 2.46 \\
\hline \multicolumn{13}{|c|}{$h=56 \mathrm{ft}$} \\
\hline 19 & 419 & 0.01 & 2.76 & 2.77 & 2.68 & 2.60 & 2.82 & 2.02 & 1.95 & 1.97 & 1.96 & 1.93 \\
\hline 22 & 422 & 0.02 & 2.57 & 2.41 & 2.30 & 2.26 & 2.71 & 1.94 & 1.76 & 1.68 & 1.64 & 1.57 \\
\hline 46 & 446 & 0.06 & 2.37 & 2.37 & 2.27 & 2.19 & 2.49 & 1.56 & 1.48 & 1.48 & 1.46 & 1.43 \\
\hline 52 & 452 & 0.15 & 2.06 & 1.92 & 1.79 & 1.71 & 2.72 & 1.37 & 1.22 & 1.14 & 1.08 & 1.01 \\
\hline 61 & 461 & 0.01 & 2.36 & 2.19 & 2.03 & 2.85 & 4.77 & 2.03 & 1.88 & 1.74 & 1.65 & 1.50 \\
\hline
\end{tabular}




\begin{tabular}{|c|c|c|c|c|c|c|c|c|c|c|c|c|}
\hline \multirow{2}{*}{$\begin{array}{l}\text { Wave } \\
\text { No. }\end{array}$} & \multirow{2}{*}{$\begin{array}{l}\text { Wave } \\
\text { ID }\end{array}$} & \multirow[b]{2}{*}{ Days/yr } & \multicolumn{5}{|c|}{ Inbound Ship speed (kt) } & \multicolumn{5}{|c|}{ Outbound Ship speed (kt) } \\
\hline & & & 8 & 10 & 12 & 14 & 16 & 8 & 10 & 12 & 14 & 16 \\
\hline 64 & 464 & 0.01 & 1.80 & 1.71 & 1.72 & 3.44 & 5.59 & 2.13 & 2.01 & 1.85 & 1.75 & 1.58 \\
\hline 82 & 482 & 0.04 & 2.62 & 2.62 & 2.49 & 2.40 & 2.76 & 1.68 & 1.60 & 1.59 & 1.57 & 1.54 \\
\hline 87 & 487 & 0.52 & 2.60 & 2.40 & 2.23 & 2.12 & 3.60 & 1.73 & 1.53 & 1.41 & 1.33 & 1.24 \\
\hline 92 & 492 & 0.07 & 2.62 & 2.41 & 2.21 & 3.38 & 5.69 & 2.22 & 2.04 & 1.86 & 1.74 & 1.57 \\
\hline 95 & 495 & 0.01 & 1.81 & 1.71 & 1.95 & 4.08 & 6.48 & 2.16 & 2.02 & 1.83 & 1.72 & 1.53 \\
\hline 115 & 515 & 0.10 & 2.56 & 2.56 & 2.46 & 2.39 & 2.62 & 1.80 & 1.74 & 1.74 & 1.73 & 1.70 \\
\hline 119 & 519 & 0.21 & 2.85 & 2.66 & 2.53 & 2.46 & 3.27 & 2.06 & 1.86 & 1.77 & 1.71 & 1.63 \\
\hline 125 & 525 & 0.05 & 3.39 & 3.20 & 3.02 & 3.30 & 5.40 & 2.97 & 2.81 & 2.66 & 2.57 & 2.39 \\
\hline 127 & 527 & 0.01 & 2.97 & 2.86 & 2.68 & 3.76 & 6.41 & 3.36 & 3.26 & 3.07 & 2.98 & 2.73 \\
\hline 147 & 547 & 0.04 & 2.13 & 2.12 & 2.08 & 2.03 & 2.01 & 1.72 & 1.68 & 1.69 & 1.69 & 1.66 \\
\hline 152 & 552 & 0.21 & 2.38 & 2.25 & 2.16 & 2.15 & 2.09 & 1.94 & 1.78 & 1.72 & 1.70 & 1.63 \\
\hline 157 & 557 & 0.12 & 3.07 & 2.93 & 2.81 & 2.78 & 3.22 & 2.88 & 2.77 & 2.69 & 2.65 & 2.50 \\
\hline 158 & 558 & 0.04 & 2.75 & 2.65 & 2.52 & 2.47 & 3.36 & 3.24 & 3.18 & 3.10 & 3.04 & 2.83 \\
\hline 177 & 577 & 0.03 & 2.10 & 2.08 & 2.07 & 2.05 & 2.02 & 1.93 & 1.90 & 1.92 & 1.91 & 1.88 \\
\hline 181 & 581 & 0.17 & 2.24 & 2.12 & 2.07 & 2.07 & 2.00 & 2.05 & 1.93 & 1.88 & 1.87 & 1.81 \\
\hline 205 & 605 & 0.01 & 2.23 & 2.20 & 2.21 & 2.20 & 2.17 & 2.32 & 2.30 & 2.30 & 2.28 & 2.24 \\
\hline 206 & 606 & 0.00 & 2.60 & 2.56 & 2.58 & 2.57 & 2.53 & 2.71 & 2.68 & 2.68 & 2.66 & 2.62 \\
\hline 208 & 608 & 0.03 & 2.01 & 1.89 & 1.84 & 1.84 & 1.78 & 2.10 & 1.98 & 1.93 & 1.93 & 1.87 \\
\hline 209 & 609 & 0.01 & 2.72 & 2.56 & 2.49 & 2.49 & 2.41 & 2.84 & 2.69 & 2.62 & 2.61 & 2.53 \\
\hline \multicolumn{13}{|c|}{$h=57 \mathrm{ft}$} \\
\hline 19 & 419 & 0.01 & 2.82 & 2.83 & 2.74 & 2.65 & 2.79 & 2.11 & 2.05 & 2.06 & 2.04 & 2.01 \\
\hline 22 & 422 & 0.02 & 2.58 & 2.43 & 2.32 & 2.28 & 2.60 & 2.00 & 1.84 & 1.74 & 1.70 & 1.63 \\
\hline 46 & 446 & 0.06 & 2.42 & 2.41 & 2.31 & 2.22 & 2.46 & 1.63 & 1.56 & 1.55 & 1.53 & 1.50 \\
\hline 52 & 452 & 0.15 & 2.06 & 1.92 & 1.80 & 1.72 & 2.59 & 1.43 & 1.29 & 1.19 & 1.13 & 1.06 \\
\hline 61 & 461 & 0.01 & 2.33 & 2.17 & 2.01 & 2.67 & 4.46 & 2.07 & 1.93 & 1.78 & 1.69 & 1.55 \\
\hline 64 & 464 & 0.01 & 1.77 & 1.69 & 1.64 & 3.16 & 5.18 & 2.16 & 2.05 & 1.89 & 1.79 & 1.62 \\
\hline 82 & 482 & 0.04 & 2.66 & 2.66 & 2.54 & 2.44 & 2.72 & 1.77 & 1.68 & 1.67 & 1.64 & 1.61 \\
\hline 87 & 487 & 0.52 & 2.58 & 2.39 & 2.23 & 2.12 & 3.42 & 1.81 & 1.62 & 1.48 & 1.39 & 1.30 \\
\hline 92 & 492 & 0.07 & 2.58 & 2.38 & 2.19 & 3.16 & 5.32 & 2.28 & 2.10 & 1.91 & 1.80 & 1.63 \\
\hline 95 & 495 & 0.01 & 1.79 & 1.70 & 1.86 & 3.75 & 6.04 & 2.21 & 2.07 & 1.89 & 1.77 & 1.59 \\
\hline 115 & 515 & 0.10 & 2.61 & 2.60 & 2.52 & 2.44 & 2.58 & 1.89 & 1.82 & 1.82 & 1.80 & 1.78 \\
\hline 119 & 519 & 0.21 & 2.85 & 2.67 & 2.54 & 2.48 & 3.14 & 2.14 & 1.95 & 1.83 & 1.77 & 1.69 \\
\hline 125 & 525 & 0.05 & 3.35 & 3.16 & 2.99 & 3.13 & 5.05 & 3.01 & 2.86 & 2.70 & 2.61 & 2.44 \\
\hline
\end{tabular}




\begin{tabular}{|l|l|l|l|l|l|l|l|l|l|l|l|l|}
\hline \multirow{2}{*}{$\begin{array}{l}\text { Wave } \\
\text { No. }\end{array}$} & \multirow{2}{*}{$\begin{array}{l}\text { Wave } \\
\text { ID }\end{array}$} & \multirow{4}{*}{ Days/yr } & $\mathbf{8}$ & $\mathbf{8}$ Inbound Ship speed (kt) & \multicolumn{4}{c|}{ Outbound Ship speed (kt) } \\
\hline 127 & 527 & 0.01 & 2.89 & 2.78 & 2.61 & 3.47 & 5.90 & 3.37 & 3.27 & 3.10 & 3.00 & 2.78 \\
\hline 147 & 547 & 0.04 & 2.18 & 2.17 & 2.13 & 2.08 & 2.05 & 1.79 & 1.75 & 1.76 & 1.75 & 1.73 \\
\hline 152 & 552 & 0.21 & 2.40 & 2.27 & 2.19 & 2.18 & 2.08 & 1.99 & 1.85 & 1.77 & 1.75 & 1.69 \\
\hline 157 & 557 & 0.12 & 3.04 & 2.90 & 2.78 & 2.76 & 3.03 & 2.86 & 2.75 & 2.68 & 2.63 & 2.50 \\
\hline 158 & 558 & 0.04 & 2.65 & 2.56 & 2.44 & 2.39 & 3.09 & 3.16 & 3.11 & 3.03 & 2.98 & 2.79 \\
\hline 177 & 577 & 0.03 & 2.16 & 2.15 & 2.14 & 2.11 & 2.08 & 2.01 & 1.98 & 1.99 & 1.98 & 1.95 \\
\hline 181 & 581 & 0.17 & 2.28 & 2.17 & 2.11 & 2.11 & 2.04 & 2.10 & 1.98 & 1.93 & 1.92 & 1.87 \\
\hline 205 & 605 & 0.01 & 2.31 & 2.28 & 2.29 & 2.27 & 2.24 & 2.40 & 2.38 & 2.37 & 2.35 & 2.32 \\
\hline 206 & 606 & 0.00 & 2.69 & 2.66 & 2.67 & 2.65 & 2.62 & 2.80 & 2.77 & 2.77 & 2.74 & 2.70 \\
\hline 208 & 608 & 0.03 & 2.06 & 1.94 & 1.88 & 1.88 & 1.82 & 2.14 & 2.03 & 1.97 & 1.97 & 1.91 \\
\hline 209 & 609 & 0.01 & 2.78 & 2.63 & 2.55 & 2.55 & 2.47 & 2.89 & 2.74 & 2.67 & 2.67 & 2.58 \\
\hline
\end{tabular}




\section{Appendix G: Net UKC for Phase 2, Reach 1 Channel $(h=53 \mathrm{ft})$ and Reach 2 Mound ( $h=55 \mathrm{ft}$ ), Lightly ( $T=46.0 \mathrm{ft}$ ) and Fully loaded ( $T=47.5 \mathrm{ft}$ ) Susan Maersk}

Table G1. Net UKC (ft), Phase 2, Channel Reach 1, $h=53 \mathrm{ft}$, light-loaded Susan Maersk, inbound and outbound transits.

\begin{tabular}{|c|c|c|c|c|c|c|c|c|c|c|c|c|}
\hline \multirow{2}{*}{$\begin{array}{l}\text { Wave } \\
\text { No. }\end{array}$} & \multirow{2}{*}{$\begin{array}{l}\text { Wave } \\
\text { ID }\end{array}$} & \multirow[b]{2}{*}{ Days/yr } & \multicolumn{5}{|c|}{ Inbound Ship speed (kt) } & \multicolumn{5}{|c|}{ Outbound Ship speed (kt) } \\
\hline & & & 8 & 10 & 12 & 14 & 16 & 8 & 10 & 12 & 14 & 16 \\
\hline 19 & 119 & 0.01 & 3.48 & 2.80 & 1.94 & 0.31 & -3.08 & 4.00 & 3.38 & 2.65 & 1.64 & -0.14 \\
\hline 22 & 122 & 0.02 & 3.29 & 2.82 & 2.13 & 0.39 & -2.86 & 3.84 & 3.33 & 2.69 & 1.83 & 0.69 \\
\hline 46 & 146 & 0.06 & 3.80 & 3.14 & 2.26 & 0.63 & -2.81 & 4.48 & 3.88 & 3.16 & 2.24 & 0.90 \\
\hline 52 & 152 & 0.15 & 3.79 & 3.32 & 2.35 & 0.23 & -3.47 & 4.47 & 3.96 & 3.32 & 2.44 & 1.28 \\
\hline 61 & 161 & 0.01 & 3.10 & 2.66 & 1.39 & -1.12 & -5.76 & 3.46 & 3.01 & 2.41 & 1.55 & 0.50 \\
\hline 64 & 164 & 0.01 & 3.41 & 2.76 & 1.28 & -0.85 & -5.10 & 3.09 & 2.66 & 2.09 & 1.24 & 0.25 \\
\hline 82 & 182 & 0.04 & 3.76 & 3.10 & 2.24 & 0.54 & -3.14 & 4.60 & 4.02 & 3.31 & 2.38 & 1.18 \\
\hline 87 & 187 & 0.52 & 3.78 & 3.36 & 2.25 & -0.50 & -4.92 & 4.59 & 4.11 & 3.49 & 2.62 & 1.48 \\
\hline 92 & 192 & 0.07 & 3.72 & 3.19 & 1.70 & -1.51 & -6.50 & 4.10 & 3.67 & 3.09 & 2.24 & 1.17 \\
\hline 95 & 195 & 0.01 & 4.39 & 3.51 & 1.56 & $\mid-1.07$ & -5.18 & 4.14 & 3.69 & 3.12 & 2.27 & 1.20 \\
\hline 115 & 215 & 0.10 & 3.81 & 3.15 & 2.28 & 0.61 & -2.97 & 4.60 & 4.01 & 3.30 & 2.38 & 1.17 \\
\hline 119 & 219 & 0.21 & 3.77 & 3.34 & 2.24 & -0.34 & -4.59 & 4.56 & 4.07 & 3.44 & 2.57 & 1.43 \\
\hline 125 & 225 & 0.05 & 3.58 & 3.03 & 1.62 & -1.40 & -6.31 & 3.95 & 3.51 & 2.92 & 2.07 & 1.01 \\
\hline 127 & 227 & 0.01 & 4.16 & 3.35 & 1.55 & -0.93 & -5.07 & 3.88 & 3.44 & 2.87 & 2.03 & 0.98 \\
\hline 147 & 247 & 0.04 & 4.03 & 3.38 & 2.52 & 0.99 & -2.11 & 4.58 & 3.97 & 3.25 & 2.32 & 0.89 \\
\hline 152 & 252 & 0.21 & 3.93 & 3.45 & 2.58 & 0.71 & -2.55 & 4.50 & 3.97 & 3.32 & 2.43 & 1.28 \\
\hline 157 & 257 & 0.12 & 3.49 & 3.06 & 1.98 & 0.02 & -3.72 & 3.73 & 3.25 & 2.61 & 1.74 & 0.67 \\
\hline 158 & 258 & 0.04 & 3.77 & 3.19 & 2.00 & 0.34 & -3.07 & 3.46 & 3.01 & 2.37 & 1.51 & 0.49 \\
\hline 177 & 277 & 0.03 & 3.85 & 3.20 & 2.38 & 0.90 & -2.02 & 4.21 & 3.58 & 2.85 & 1.81 & 0.01 \\
\hline 181 & 281 & 0.17 & 3.66 & 3.14 & 2.44 & 1.01 & -1.70 & 4.07 & 3.54 & 2.86 & 1.99 & 0.83 \\
\hline 205 & 305 & 0.01 & 3.95 & 3.29 & 2.56 & 1.20 & -1.27 & 4.03 & 3.39 & 2.67 & 1.44 & -0.75 \\
\hline 206 & 306 & 0.00 & 3.46 & 2.79 & 2.06 & 0.61 & -2.17 & 3.57 & 2.91 & 2.20 & 0.90 & -1.52 \\
\hline 208 & 308 & 0.03 & 4.06 & 3.53 & 2.82 & 1.90 & -0.02 & 4.15 & 3.61 & 2.91 & 2.04 & 0.54 \\
\hline 209 & 309 & 0.01 & 3.22 & 2.72 & 2.03 & 1.12 & -1.11 & 3.35 & 2.84 & 2.16 & 1.32 & -0.31 \\
\hline
\end{tabular}


Table G2. Net UKC (ft), Phase 2, Mound Reach 2, $h=55,56$, and $57 \mathrm{ft}$, light-loaded Susan Maersk, inbound and outbound transits.

\begin{tabular}{|c|c|c|c|c|c|c|c|c|c|c|c|c|}
\hline \multirow{2}{*}{$\begin{array}{l}\text { Wave } \\
\text { No. }\end{array}$} & \multirow{2}{*}{$\begin{array}{l}\text { Wave } \\
\text { ID }\end{array}$} & \multirow[b]{2}{*}{ Days/yr } & \multicolumn{5}{|c|}{ Inbound Ship speed (kt) } & \multicolumn{5}{|c|}{ Outbound Ship speed (kt) } \\
\hline & & & 8 & 10 & 12 & 14 & 16 & 8 & 10 & 12 & 14 & 16 \\
\hline \multicolumn{13}{|c|}{$h=55 \mathrm{ft}$} \\
\hline 19 & 419 & 0.01 & 5.26 & 4.59 & 3.89 & 2.45 & -1.20 & 5.93 & 5.35 & 4.66 & 3.78 & 2.53 \\
\hline 22 & 422 & 0.02 & 5.45 & 5.00 & 4.20 & 2.84 & -1.19 & 6.02 & 5.54 & 4.94 & 4.11 & 3.03 \\
\hline 46 & 446 & 0.06 & 5.66 & 5.02 & 4.31 & 2.90 & -0.65 & 6.40 & 5.84 & 5.16 & 4.29 & 3.15 \\
\hline 52 & 452 & 0.15 & 5.98 & 5.52 & 4.54 & 3.08 & -1.41 & 6.59 & 6.11 & 5.51 & 4.68 & 3.58 \\
\hline 61 & 461 & 0.01 & 5.69 & 5.20 & 3.89 & 1.97 & -3.87 & 5.90 & 5.46 & 4.89 & 4.09 & 3.07 \\
\hline 64 & 464 & 0.01 & 6.21 & 5.50 & 3.86 & 1.85 & -3.52 & 5.80 & 5.34 & 4.78 & 3.98 & 2.98 \\
\hline 82 & 482 & 0.04 & 5.42 & 4.77 & 4.08 & 2.62 & -1.24 & 6.27 & 5.72 & 5.05 & 4.18 & 3.05 \\
\hline 87 & 487 & 0.52 & 5.46 & 5.07 & 3.99 & 2.32 & -3.43 & 6.21 & 5.78 & 5.22 & 4.42 & 3.35 \\
\hline 92 & 492 & 0.07 & 5.45 & 4.99 & 3.52 & 1.33 & -5.55 & 5.70 & 5.30 & 4.77 & 3.99 & 2.99 \\
\hline 95 & 495 & 0.01 & 6.20 & 5.42 & 3.49 & 1.24 & -4.90 & 5.76 & 5.34 & 4.80 & 4.02 & 3.02 \\
\hline 115 & 515 & 0.10 & 5.46 & 4.82 & 4.10 & 2.69 & -0.86 & 6.15 & 5.58 & 4.89 & 4.01 & 2.88 \\
\hline 119 & 519 & 0.21 & 5.19 & 4.77 & 3.85 & 2.35 & -2.49 & 5.88 & 5.42 & 4.85 & 4.04 & 2.96 \\
\hline 125 & 525 & 0.05 & 4.65 & 4.25 & 3.03 & 1.14 & -4.90 & 4.92 & 4.48 & 3.94 & 3.14 & 2.15 \\
\hline 127 & 527 & 0.01 & 5.06 & 4.47 & 2.97 & \begin{tabular}{|l}
1.01 \\
\end{tabular} & -4.71 & 4.50 & 4.05 & 3.51 & 2.72 & 1.79 \\
\hline 147 & 547 & 0.04 & 5.88 & 5.24 & 4.57 & 3.31 & 0.49 & 6.25 & 5.65 & 4.95 & 4.06 & 2.62 \\
\hline 152 & 552 & 0.21 & 5.62 & 5.14 & 4.45 & 3.31 & 0.27 & 6.03 & 5.52 & 4.89 & 4.06 & 2.97 \\
\hline 157 & 557 & 0.12 & 4.95 & 4.49 & 3.77 & 2.47 & -1.03 & 5.05 & 4.57 & 3.96 & 3.11 & 2.05 \\
\hline 158 & 558 & 0.04 & 5.29 & 4.80 & 3.83 & 2.60 & -0.66 & 4.66 & 4.19 & 3.55 & 2.72 & 1.71 \\
\hline 177 & 577 & 0.03 & 5.89 & 5.26 & 4.58 & 3.47 & 1.05 & 6.04 & 5.42 & 4.72 & 3.83 & 1.94 \\
\hline 181 & 581 & 0.17 & 5.74 & 5.23 & 4.53 & 3.71 & 1.62 & 5.92 & 5.40 & 4.73 & 3.89 & 2.75 \\
\hline 205 & 605 & 0.01 & 5.75 & 5.12 & 4.43 & 3.48 & 1.36 & 5.67 & 5.02 & 4.35 & 3.28 & 0.86 \\
\hline 206 & 606 & 0.00 & 5.37 & 4.73 & 4.05 & 3.10 & 0.81 & 5.28 & 4.63 & 3.95 & 2.86 & 0.22 \\
\hline 208 & 608 & 0.03 & 5.96 & 5.44 & 4.77 & 3.93 & 2.62 & 5.88 & 5.36 & 4.67 & 3.85 & 2.08 \\
\hline 209 & 609 & 0.01 & 5.24 & 4.74 & 4.09 & 3.28 & 1.90 & 5.13 & 4.64 & 3.96 & 3.16 & 1.18 \\
\hline \multicolumn{13}{|c|}{$h=56 \mathrm{ft}$} \\
\hline 19 & 419 & 0.01 & 6.20 & 5.56 & 4.95 & 3.56 & 0.07 & 6.85 & 6.27 & 5.61 & 4.75 & 3.63 \\
\hline 22 & 422 & 0.02 & 6.45 & 6.01 & 5.27 & 3.94 & 0.03 & 6.96 & 6.49 & 5.92 & 5.10 & 4.05 \\
\hline 46 & 446 & 0.06 & 6.62 & 6.00 & 5.37 & 4.01 & 0.61 & 7.33 & 6.79 & 6.13 & 5.27 & 4.17 \\
\hline 52 & 452 & 0.15 & 6.99 & 6.55 & 5.61 & 4.19 & -0.17 & 7.54 & 7.08 & 6.49 & 5.68 & 4.62 \\
\hline 61 & 461 & 0.01 & 6.73 & 6.27 & 5.02 & 3.18 & -2.83 & 6.86 & 6.43 & 5.88 & 5.09 & 4.10 \\
\hline
\end{tabular}




\begin{tabular}{|c|c|c|c|c|c|c|c|c|c|c|c|c|}
\hline \multirow{2}{*}{$\begin{array}{l}\text { Wave } \\
\text { No. }\end{array}$} & \multirow{2}{*}{$\begin{array}{l}\text { Wave } \\
\text { ID }\end{array}$} & \multirow[b]{2}{*}{ Days/yr } & \multicolumn{5}{|c|}{ Inbound Ship speed (kt) } & \multicolumn{5}{|c|}{ Outbound Ship speed (kt) } \\
\hline & & & 8 & 10 & 12 & 14 & 16 & 8 & 10 & 12 & 14 & 16 \\
\hline 64 & 464 & 0.01 & 7.24 & 6.59 & 5.02 & 3.14 & -2.86 & 6.78 & 6.33 & 5.78 & 4.99 & 4.00 \\
\hline 82 & 482 & 0.04 & 6.37 & 5.75 & 5.15 & 3.72 & 0.04 & 7.19 & 6.66 & 6.01 & 5.15 & 4.06 \\
\hline 87 & 487 & 0.52 & 6.48 & 6.09 & 5.07 & 3.45 & -2.14 & 7.14 & 6.73 & 6.19 & 5.40 & 4.37 \\
\hline 92 & 492 & 0.07 & 6.49 & 6.07 & 4.65 & 2.58 & -4.54 & 6.65 & 6.26 & 5.75 & 4.98 & 4.00 \\
\hline 95 & 495 & 0.01 & 7.22 & 6.52 & 4.68 & 2.59 & -4.38 & 6.73 & 6.31 & 5.79 & 5.02 & 4.04 \\
\hline 115 & 515 & 0.10 & 6.41 & 5.79 & 5.16 & 3.80 & 0.40 & 7.07 & 6.51 & 5.85 & 4.99 & 3.89 \\
\hline 119 & 519 & 0.21 & 6.19 & 5.78 & 4.92 & 3.46 & -1.24 & 6.82 & 6.37 & 5.82 & 5.02 & 3.98 \\
\hline 125 & 525 & 0.05 & 5.70 & 5.30 & 4.16 & 2.36 & -3.82 & 5.90 & 5.45 & 4.94 & 4.15 & 3.18 \\
\hline 127 & 527 & 0.01 & 6.13 & 5.59 & 4.15 & 2.29 & -3.93 & 5.52 & 5.05 & 4.52 & 3.74 & 2.81 \\
\hline 147 & 547 & 0.04 & 6.83 & 6.21 & 5.56 & 4.39 & 1.69 & 7.18 & 6.59 & 5.92 & 5.05 & 3.73 \\
\hline 152 & 552 & 0.21 & 6.61 & 6.14 & 5.46 & 4.39 & 1.44 & 6.98 & 6.49 & 5.88 & 5.06 & 4.00 \\
\hline 157 & 557 & 0.12 & 5.99 & 5.54 & 4.87 & 3.60 & 0.09 & 6.09 & 5.61 & 5.01 & 4.18 & 3.14 \\
\hline 158 & 558 & 0.04 & 6.39 & 5.90 & 4.98 & 3.77 & 0.40 & 5.76 & 5.28 & 4.65 & 3.82 & 2.83 \\
\hline 177 & 577 & 0.03 & 6.83 & 6.21 & 5.55 & 4.55 & 2.22 & 6.97 & 6.37 & 5.69 & 4.82 & 3.08 \\
\hline 181 & 581 & 0.17 & 6.71 & 6.21 & 5.53 & 4.72 & 2.74 & 6.87 & 6.36 & 5.72 & 4.89 & 3.83 \\
\hline 205 & 605 & 0.01 & 6.67 & 6.05 & 5.38 & 4.52 & 2.51 & 6.59 & 5.97 & 5.30 & 4.36 & 2.03 \\
\hline 206 & 606 & 0.00 & 6.28 & 5.66 & 4.99 & 4.13 & 1.98 & 6.19 & 5.55 & 4.90 & 3.94 & 1.41 \\
\hline 208 & 608 & 0.03 & 6.93 & 6.42 & 5.76 & 4.94 & 3.71 & 6.85 & 6.34 & 5.67 & 4.86 & 3.19 \\
\hline 209 & 609 & 0.01 & 6.19 & 5.70 & 5.06 & 4.26 & 3.00 & 6.09 & 5.60 & 4.95 & 4.15 & 2.30 \\
\hline \multicolumn{13}{|c|}{$h=57 \mathrm{ft}$} \\
\hline 19 & 419 & 0.01 & 7.14 & 6.51 & 5.92 & 4.64 & 1.70 & 7.76 & 7.21 & 6.56 & 5.72 & 4.65 \\
\hline 22 & 422 & 0.02 & 7.45 & 7.01 & 6.32 & 5.04 & 2.28 & 7.91 & 7.45 & 6.89 & 6.10 & 5.06 \\
\hline 46 & 446 & 0.06 & 7.58 & 6.97 & 6.38 & 5.09 & 2.22 & 8.26 & 7.73 & 7.09 & 6.26 & 5.18 \\
\hline 52 & 452 & 0.15 & 8.01 & 7.56 & 6.67 & 5.30 & 2.15 & 8.49 & 8.04 & 7.47 & 6.68 & 5.64 \\
\hline 61 & 461 & 0.01 & 7.76 & 7.33 & 6.13 & 4.38 & -0.93 & 7.83 & 7.41 & 6.87 & 6.10 & 5.08 \\
\hline 64 & 464 & 0.01 & 8.27 & 7.68 & 6.19 & 4.42 & -2.09 & 7.76 & 7.31 & 6.77 & 6.00 & 4.97 \\
\hline 82 & 482 & 0.04 & 7.33 & 6.72 & 6.14 & 4.82 & 1.72 & 8.12 & 7.60 & 6.96 & 6.13 & 5.07 \\
\hline 87 & 487 & 0.52 & 7.50 & 7.11 & 6.15 & 4.58 & 0.67 & 8.08 & 7.68 & 7.16 & 6.40 & 5.37 \\
\hline 92 & 492 & 0.07 & 7.52 & 7.13 & 5.78 & 3.81 & -2.51 & 7.60 & 7.22 & 6.72 & 5.98 & 4.98 \\
\hline 95 & 495 & 0.01 & 8.23 & 7.61 & 5.88 & 3.93 & -3.73 & 7.68 & 7.28 & 6.76 & 6.01 & 5.00 \\
\hline 115 & 515 & 0.10 & 7.37 & 6.75 & 6.16 & 4.88 & 2.01 & 8.00 & 7.45 & 6.81 & 5.97 & 4.90 \\
\hline 119 & 519 & 0.21 & 7.20 & 6.78 & 5.99 & 4.58 & 1.31 & 7.75 & 7.32 & 6.79 & 6.01 & 4.98 \\
\hline 125 & 525 & 0.05 & 6.74 & 6.34 & 5.28 & 3.55 & -1.75 & 6.87 & 6.43 & 5.92 & 5.15 & 4.13 \\
\hline
\end{tabular}




\begin{tabular}{|c|c|c|c|c|c|c|c|c|c|c|c|c|}
\hline \multirow{2}{*}{$\begin{array}{l}\text { Wave } \\
\text { No. }\end{array}$} & \multirow{2}{*}{$\begin{array}{l}\text { Wave } \\
\text { ID }\end{array}$} & \multirow[b]{2}{*}{ Days/yr } & \multicolumn{5}{|c|}{ Inbound Ship speed (kt) } & \multicolumn{5}{|c|}{ Outbound Ship speed (kt) } \\
\hline & & & 8 & 10 & 12 & 14 & 16 & 8 & 10 & 12 & 14 & 16 \\
\hline 127 & 527 & 0.01 & 7.19 & 6.70 & 5.33 & 3.55 & -3.01 & 6.53 & 6.06 & 5.53 & 4.76 & 3.73 \\
\hline 147 & 547 & 0.04 & 7.78 & 7.17 & 6.53 & 5.47 & 3.15 & 8.12 & 7.54 & 6.88 & 6.04 & 4.90 \\
\hline 152 & 552 & 0.21 & 7.60 & 7.13 & 6.47 & 5.47 & 3.33 & 7.93 & 7.45 & 6.86 & 6.06 & 5.01 \\
\hline 157 & 557 & 0.12 & 7.02 & 6.57 & 5.93 & 4.73 & 1.74 & 7.12 & 6.65 & 6.06 & 5.24 & 4.18 \\
\hline 158 & 558 & 0.04 & 7.46 & 6.99 & 6.10 & 4.92 & 1.52 & 6.86 & 6.38 & 5.75 & 4.93 & 3.88 \\
\hline 177 & 577 & 0.03 & 7.77 & 7.16 & 6.51 & 5.62 & 3.59 & 7.91 & 7.31 & 6.65 & 5.81 & 4.33 \\
\hline 181 & 581 & 0.17 & 7.69 & 7.19 & 6.52 & 5.73 & 4.24 & 7.84 & 7.33 & 6.70 & 5.89 & 4.85 \\
\hline 205 & 605 & 0.01 & 7.60 & 6.99 & 6.33 & 5.50 & 3.82 & 7.52 & 6.91 & 6.26 & 5.42 & 3.40 \\
\hline 206 & 606 & 0.00 & 7.19 & 6.58 & 5.93 & 5.10 & 3.32 & 7.10 & 6.48 & 5.84 & 5.01 & 2.84 \\
\hline 208 & 608 & 0.03 & 7.89 & 7.39 & 6.75 & 5.94 & 4.90 & 7.83 & 7.33 & 6.67 & 5.87 & 4.60 \\
\hline 209 & 609 & 0.01 & 7.14 & 6.66 & 6.04 & 5.26 & 4.23 & 7.05 & 6.57 & 5.93 & 5.15 & 3.82 \\
\hline
\end{tabular}


Table G3. Net UKC (ft), Phase 2, Channel Reach 1, $h=53 \mathrm{ft}$, fully loaded Susan Maersk, inbound and outbound transits.

\begin{tabular}{|c|c|c|c|c|c|c|c|c|c|c|c|c|}
\hline \multirow{2}{*}{$\begin{array}{l}\text { Wave } \\
\text { No. }\end{array}$} & \multirow{2}{*}{$\begin{array}{l}\text { Wave } \\
\text { ID }\end{array}$} & \multirow[b]{2}{*}{ Days/yr } & \multicolumn{5}{|c|}{ Inbound Ship speed (kt) } & \multicolumn{5}{|c|}{ Outbound Ship speed (kt) } \\
\hline & & & 8 & 10 & 12 & 14 & 16 & 8 & 10 & 12 & 14 & 16 \\
\hline 19 & 119 & 0.01 & 2.03 & 1.37 & 0.65 & -0.16 & -1.91 & 2.63 & 2.05 & 1.23 & 0.30 & -0.95 \\
\hline 22 & 122 & 0.02 & 1.79 & 1.33 & 0.61 & -0.19 & -1.85 & 2.44 & 1.99 & 1.24 & 0.36 & -0.81 \\
\hline 46 & 146 & 0.06 & 2.31 & 1.65 & 0.97 & 0.17 & -1.73 & 3.08 & 2.52 & 1.72 & 0.78 & -0.46 \\
\hline 52 & 152 & 0.15 & 2.24 & 1.75 & 1.08 & 0.29 & -2.12 & 3.06 & 2.59 & 1.85 & 0.95 & -0.23 \\
\hline 61 & 161 & 0.01 & 1.45 & 0.99 & 0.40 & -1.24 & -4.79 & 2.08 & 1.60 & 0.94 & 0.06 & -0.99 \\
\hline 64 & 164 & 0.01 & 1.70 & 1.20 & 0.61 & -1.86 & -5.97 & 1.71 & 1.23 & 0.63 & -0.23 & -1.21 \\
\hline 82 & 182 & 0.04 & 2.26 & 1.59 & 0.94 & 0.16 & -1.86 & 3.20 & 2.65 & 1.87 & 0.92 & -0.31 \\
\hline 87 & 187 & 0.52 & 2.18 & 1.72 & 1.12 & 0.14 & -2.81 & 3.19 & 2.73 & 2.03 & 1.13 & -0.04 \\
\hline 92 & 192 & 0.07 & 2.07 & 1.61 & 1.07 & -1.55 & -5.27 & 2.71 & 2.26 & \begin{tabular}{|l}
1.63 \\
\end{tabular} & 0.76 & -0.32 \\
\hline 95 & 195 & 0.01 & 2.76 & 2.25 & 1.08 & -2.52 & -6.19 & 2.73 & 2.26 & 1.65 & 0.78 & -0.28 \\
\hline 115 & 215 & 0.10 & 2.31 & 1.64 & 0.98 & 0.19 & -1.78 & 3.19 & 2.65 & 1.86 & 0.91 & -0.32 \\
\hline 119 & 219 & 0.21 & 2.19 & 1.71 & 1.10 & 0.18 & -2.66 & 3.15 & 2.69 & 1.98 & 1.08 & -0.09 \\
\hline 125 & 225 & 0.05 & 1.93 & 1.47 & 0.91 & -1.48 & -5.15 & 2.56 & 2.10 & \begin{tabular}{|l|l}
1.47 \\
\end{tabular} & 0.59 & -0.48 \\
\hline 127 & 227 & 0.01 & 2.52 & 2.00 & 1.08 & -2.30 & -6.09 & 2.49 & 2.01 & 1.41 & 0.54 & -0.50 \\
\hline 147 & 247 & 0.04 & 2.55 & 1.90 & 1.20 & 0.37 & -1.40 & 3.16 & 2.60 & \begin{tabular}{|l}
1.79 \\
\end{tabular} & 0.85 & -0.39 \\
\hline 152 & 252 & 0.21 & 2.40 & 1.90 & 1.20 & 0.38 & -1.67 & 3.07 & 2.59 & 1.85 & 0.94 & -0.25 \\
\hline 157 & 257 & 0.12 & 1.87 & 1.39 & 0.73 & -0.42 & -3.37 & 2.32 & 1.82 & 1.13 & 0.23 & -0.85 \\
\hline 158 & 258 & 0.04 & 2.08 & 1.56 & 0.93 & -0.65 & -4.00 & 2.05 & 1.54 & 0.88 & -0.01 & $\mid-1.02$ \\
\hline 177 & 277 & 0.03 & 2.40 & 1.77 & 1.03 & 0.17 & -1.38 & 2.81 & 2.22 & 1.41 & 0.48 & -0.77 \\
\hline 181 & 281 & 0.17 & 2.17 & 1.67 & 0.93 & 0.09 & -1.27 & 2.65 & 2.17 & 1.40 & 0.51 & -0.68 \\
\hline 205 & 305 & 0.01 & 2.52 & 1.90 & 1.13 & 0.23 & $\mid-1.04$ & 2.62 & 2.02 & \begin{tabular}{|l|l}
1.22 \\
\end{tabular} & 0.31 & -0.95 \\
\hline 206 & 306 & 0.00 & 2.06 & 1.44 & 0.66 & -0.22 & -1.49 & 2.18 & 1.58 & 0.78 & -0.12 & -1.38 \\
\hline 208 & 308 & 0.03 & 2.60 & 2.09 & 1.32 & 0.45 & -0.74 & 2.70 & 2.20 & $\mid 1.42$ & 0.54 & -0.65 \\
\hline 209 & 309 & 0.01 & 1.79 & 1.33 & 0.56 & -0.28 & -1.45 & 1.94 & 1.48 & 0.71 & -0.14 & -1.32 \\
\hline
\end{tabular}


Table G4. Net UKC (ft), Phase 2, Mound Reach 2, $h=55,56$, and $57 \mathrm{ft}$, fully loaded Susan Maersk, inbound and outbound transits.

\begin{tabular}{|c|c|c|c|c|c|c|c|c|c|c|c|c|}
\hline \multirow{2}{*}{$\begin{array}{l}\text { Wave } \\
\text { No. }\end{array}$} & \multirow{2}{*}{$\begin{array}{l}\text { Wave } \\
\text { ID }\end{array}$} & \multirow[b]{2}{*}{ Days/yr } & \multicolumn{5}{|c|}{ Inbound Ship speed (kt) } & \multicolumn{5}{|c|}{ Outbound Ship speed (kt) } \\
\hline & & & 8 & 10 & 12 & 14 & 16 & 8 & 10 & 12 & 14 & 16 \\
\hline \multicolumn{13}{|c|}{$h=55 \mathrm{ft}$} \\
\hline 19 & 419 & 0.01 & 3.79 & 3.17 & 2.50 & 1.69 & 0.17 & 4.56 & 4.03 & 3.25 & 2.35 & 1.19 \\
\hline 22 & 422 & 0.02 & 3.92 & 3.49 & 2.78 & 1.99 & 0.23 & 4.61 & 4.19 & 3.49 & 2.64 & 1.53 \\
\hline 46 & 446 & 0.06 & 4.15 & 3.55 & 2.90 & 2.09 & 0.49 & 5.01 & 4.48 & 3.72 & 2.83 & 1.67 \\
\hline 52 & 452 & 0.15 & 4.40 & 3.96 & 3.31 & 2.52 & 0.20 & 5.17 & 4.72 & 4.05 & 3.19 & 2.07 \\
\hline 61 & 461 & 0.01 & 4.07 & 3.66 & 3.06 & 1.16 & -2.09 & 4.50 & 4.05 & 3.45 & 2.62 & 1.59 \\
\hline 64 & 464 & 0.01 & 4.64 & 4.14 & 3.32 & 0.46 & -3.03 & 4.38 & 3.91 & 3.33 & 2.51 & 1.52 \\
\hline 82 & 482 & 0.04 & 3.91 & 3.30 & 2.67 & 1.88 & 0.22 & 4.89 & 4.38 & 3.62 & 2.73 & 1.57 \\
\hline 87 & 487 & 0.52 & 3.85 & 3.48 & 2.86 & 2.08 & -0.74 & 4.83 & 4.43 & 3.79 & 2.95 & 1.86 \\
\hline 92 & 492 & 0.07 & 3.81 & 3.44 & 2.89 & 0.59 & -3.07 & 4.32 & 3.91 & 3.34 & 2.53 & 1.53 \\
\hline 95 & 495 & 0.01 & 4.63 & 4.15 & 3.07 & -0.25 & -3.98 & 4.36 & 3.91 & 3.36 & 2.55 & 1.57 \\
\hline 115 & 515 & 0.10 & 3.98 & 3.37 & 2.71 & 1.90 & 0.36 & 4.77 & 4.24 & 3.47 & 2.57 & 1.41 \\
\hline 119 & 519 & 0.21 & 3.63 & 3.23 & 2.55 & 1.79 & -0.37 & 4.50 & 4.10 & 3.42 & 2.58 & 1.48 \\
\hline 125 & 525 & 0.05 & 3.03 & 2.63 & 2.03 & 0.71 & -2.76 & 3.54 & 3.11 & 2.49 & 1.66 & 0.69 \\
\hline 127 & 527 & 0.01 & 3.41 & 2.93 & 2.37 & 0.14 & -3.97 & 3.12 & 2.64 & 2.08 & 1.27 & 0.37 \\
\hline 147 & 547 & 0.04 & 4.41 & 3.82 & 3.10 & 2.25 & 0.99 & 4.84 & 4.29 & 3.51 & 2.60 & 1.44 \\
\hline 152 & 552 & 0.21 & 4.12 & 3.67 & 2.93 & 2.11 & 0.89 & 4.61 & 4.16 & 3.44 & 2.58 & 1.46 \\
\hline 157 & 557 & 0.12 & 3.36 & 2.92 & 2.23 & 1.41 & -0.40 & 3.59 & 3.11 & 2.44 & 1.57 & 0.55 \\
\hline 158 & 558 & 0.04 & 3.61 & 3.13 & 2.51 & 1.65 & -0.64 & 3.17 & 2.65 & 1.99 & 1.14 & 0.19 \\
\hline 177 & 577 & 0.03 & 4.46 & 3.87 & 3.12 & 2.24 & 1.09 & 4.63 & 4.06 & 3.28 & 2.39 & 1.22 \\
\hline 181 & 581 & 0.17 & 4.28 & 3.81 & 3.04 & 2.20 & 1.09 & 4.48 & 4.02 & 3.26 & 2.40 & 1.28 \\
\hline 205 & 605 & 0.01 & 4.34 & 3.77 & 2.99 & 2.11 & 0.95 & 4.25 & 3.67 & 2.90 & 2.03 & 0.87 \\
\hline 206 & 606 & 0.00 & 3.99 & 3.42 & 2.63 & 1.75 & 0.60 & 3.87 & 3.30 & 2.53 & 1.66 & 0.51 \\
\hline 208 & 608 & 0.03 & 4.52 & 4.05 & 3.29 & 2.43 & 1.31 & 4.42 & 3.95 & 3.18 & 2.34 & 1.22 \\
\hline 209 & 609 & 0.01 & 3.82 & 3.39 & 2.63 & 1.80 & 0.70 & 3.69 & 3.26 & 2.49 & 1.67 & 0.58 \\
\hline \multicolumn{13}{|c|}{$h=56 \mathrm{ft}$} \\
\hline 19 & 419 & 0.01 & 4.73 & 4.13 & 3.49 & 2.67 & 1.30 & 5.47 & 4.95 & 4.20 & 3.31 & 2.19 \\
\hline 22 & 422 & 0.02 & 4.92 & 4.49 & 3.87 & 3.01 & 1.41 & 5.55 & 5.14 & 4.49 & 3.63 & 2.55 \\
\hline 46 & 446 & 0.06 & 5.12 & 4.53 & 3.90 & 3.08 & 1.63 & 5.93 & 5.42 & 4.69 & 3.81 & 2.69 \\
\hline 52 & 452 & 0.15 & 5.43 & 4.98 & 4.38 & 3.56 & 1.40 & 6.12 & 5.68 & 5.03 & 4.19 & 3.11 \\
\hline 61 & 461 & 0.01 & 5.13 & 4.71 & 4.14 & 2.42 & -0.65 & 5.46 & 5.02 & 4.43 & 3.62 & 2.62 \\
\hline
\end{tabular}




\begin{tabular}{|c|c|c|c|c|c|c|c|c|c|c|c|c|}
\hline \multirow{2}{*}{$\begin{array}{l}\text { Wave } \\
\text { No. }\end{array}$} & \multirow{2}{*}{$\begin{array}{l}\text { Wave } \\
\text { ID }\end{array}$} & \multirow[b]{2}{*}{ Days/yr } & \multicolumn{5}{|c|}{ Inbound Ship speed (kt) } & \multicolumn{5}{|c|}{ Outbound Ship speed (kt) } \\
\hline & & & 8 & 10 & 12 & 14 & 16 & 8 & 10 & 12 & 14 & 16 \\
\hline 64 & 464 & 0.01 & 5.69 & 5.19 & 4.45 & 1.83 & -1.47 & 5.36 & 4.89 & 4.32 & 3.52 & 2.54 \\
\hline 82 & 482 & 0.04 & 4.87 & 4.28 & 3.68 & 2.87 & 1.36 & 5.81 & 5.30 & 4.58 & 3.70 & 2.58 \\
\hline 87 & 487 & 0.52 & 4.89 & 4.50 & 3.94 & 3.15 & 0.52 & 5.76 & 5.37 & 4.76 & 3.94 & 2.88 \\
\hline 92 & 492 & 0.07 & 4.87 & 4.49 & 3.96 & 1.89 & -1.57 & 5.27 & 4.86 & 4.31 & 3.53 & 2.55 \\
\hline 95 & 495 & 0.01 & 5.68 & 5.19 & 4.22 & 1.19 & -2.36 & 5.33 & 4.88 & 4.34 & 3.55 & 2.59 \\
\hline 115 & 515 & 0.10 & 4.93 & 4.34 & 3.71 & 2.88 & 1.50 & 5.69 & 5.16 & 4.43 & 3.54 & 2.42 \\
\hline 119 & 519 & 0.21 & 4.64 & 4.24 & 3.64 & 2.81 & 0.85 & 5.43 & 5.04 & 4.40 & 3.56 & 2.49 \\
\hline 125 & 525 & 0.05 & 4.10 & 3.70 & 3.15 & 1.97 & -1.28 & 4.52 & 4.09 & 3.51 & 2.70 & 1.73 \\
\hline 127 & 527 & 0.01 & 4.52 & 4.04 & 3.49 & 1.51 & -2.29 & 4.13 & 3.64 & 3.10 & 2.29 & 1.39 \\
\hline 147 & 547 & 0.04 & 5.36 & 4.78 & 4.09 & 3.24 & 2.11 & 5.77 & 5.22 & 4.48 & 3.58 & 2.46 \\
\hline 152 & 552 & 0.21 & 5.11 & 4.65 & 4.01 & 3.12 & 2.03 & 5.55 & 5.12 & 4.45 & 3.57 & 2.49 \\
\hline 157 & 557 & 0.12 & 4.42 & 3.97 & 3.36 & 2.49 & 0.90 & 4.61 & 4.13 & 3.48 & 2.62 & 1.62 \\
\hline 158 & 558 & 0.04 & 4.74 & 4.25 & 3.65 & 2.80 & 0.76 & 4.25 & 3.72 & 3.07 & 2.23 & 1.29 \\
\hline 177 & 577 & 0.03 & 5.39 & 4.82 & 4.10 & 3.22 & 2.10 & 5.56 & 5.00 & 4.25 & 3.36 & 2.24 \\
\hline 181 & 581 & 0.17 & 5.25 & 4.78 & 4.10 & 3.20 & 2.12 & 5.44 & 4.97 & 4.29 & 3.40 & 2.31 \\
\hline 205 & 605 & 0.01 & 5.26 & 4.70 & 3.96 & 3.07 & 1.95 & 5.17 & 4.60 & 3.87 & 2.99 & 1.88 \\
\hline 206 & 606 & 0.00 & 4.89 & 4.34 & 3.59 & 2.70 & 1.59 & 4.78 & 4.22 & 3.49 & 2.61 & 1.50 \\
\hline 208 & 608 & 0.03 & 5.48 & 5.01 & 4.33 & 3.43 & 2.34 & 5.39 & 4.92 & 4.24 & 3.34 & 2.25 \\
\hline 209 & 609 & 0.01 & 4.77 & 4.34 & 3.68 & 2.78 & 1.71 & 4.65 & 4.21 & 3.55 & 2.66 & 1.59 \\
\hline \multicolumn{13}{|c|}{$h=57 \mathrm{ft}$} \\
\hline 19 & 419 & 0.01 & 5.68 & 5.10 & 4.47 & 3.67 & 2.40 & 6.39 & 5.88 & 5.15 & 4.28 & 3.18 \\
\hline 22 & 422 & 0.02 & 5.92 & 5.50 & 4.89 & 4.04 & 2.59 & 6.50 & 6.09 & 5.47 & 4.62 & 3.56 \\
\hline 46 & 446 & 0.06 & 6.08 & 5.52 & 4.90 & 4.10 & 2.73 & 6.87 & 6.37 & 5.66 & 4.79 & 3.69 \\
\hline 52 & 452 & 0.15 & 6.44 & 6.01 & 5.41 & 4.60 & 2.60 & 7.07 & 6.64 & 6.02 & 5.19 & 4.13 \\
\hline 61 & 461 & 0.01 & 6.17 & 5.76 & 5.20 & 3.65 & 0.73 & 6.43 & 6.00 & 5.43 & 4.63 & 3.64 \\
\hline 64 & 464 & 0.01 & 6.73 & 6.24 & 5.57 & 3.16 & 0.01 & 6.34 & 5.88 & 5.32 & 4.53 & 3.57 \\
\hline 82 & 482 & 0.04 & 5.84 & 5.27 & 4.67 & 3.88 & 2.47 & 6.73 & 6.25 & 5.54 & 4.68 & 3.58 \\
\hline 87 & 487 & 0.52 & 5.92 & 5.54 & 4.98 & 4.20 & 1.77 & 6.69 & 6.31 & 5.73 & 4.93 & 3.89 \\
\hline 92 & 492 & 0.07 & 5.92 & 5.55 & 5.02 & 3.16 & -0.13 & 6.22 & 5.83 & 5.30 & 4.52 & 3.56 \\
\hline 95 & 495 & 0.01 & 6.71 & 6.23 & 5.35 & 2.57 & -0.85 & 6.29 & 5.86 & 5.32 & 4.55 & 3.60 \\
\hline 115 & 515 & 0.10 & 5.89 & 5.33 & 4.69 & 3.88 & 2.61 & 6.61 & 6.11 & 5.39 & 4.52 & 3.41 \\
\hline 119 & 519 & 0.21 & 5.65 & 5.26 & 4.67 & 3.84 & 2.05 & 6.36 & 5.98 & 5.38 & 4.55 & 3.50 \\
\hline 125 & 525 & 0.05 & 5.15 & 4.77 & 4.22 & 3.19 & 0.14 & 5.49 & 5.07 & 4.51 & 3.71 & 2.75 \\
\hline
\end{tabular}




\begin{tabular}{|l|l|l|l|l|l|l|l|l|l|l|l|l|}
\hline \multirow{2}{*}{$\begin{array}{l}\text { Wave } \\
\text { No. }\end{array}$} & \multirow{2}{*}{$\begin{array}{l}\text { Wave } \\
\text { ID }\end{array}$} & Days/yr & $\mathbf{8}$ & $\mathbf{4}$ Inbound Ship speed (kt) & $\mathbf{1 2}$ & $\mathbf{1 4}$ & $\mathbf{1 6}$ & $\mathbf{8}$ & 10 & 12 & 14 & 16 \\
\hline 127 & 527 & 0.01 & 5.61 & 5.15 & 4.60 & 2.85 & -0.71 & 5.13 & 4.66 & 4.11 & 3.32 & 2.41 \\
\hline 147 & 547 & 0.04 & 6.32 & 5.76 & 5.08 & 4.24 & 3.14 & 6.71 & 6.18 & 5.45 & 4.57 & 3.46 \\
\hline 152 & 552 & 0.21 & 6.10 & 5.66 & 5.02 & 4.14 & 3.11 & 6.51 & 6.08 & 5.44 & 4.57 & 3.50 \\
\hline 157 & 557 & 0.12 & 5.46 & 5.03 & 4.43 & 3.56 & 2.16 & 5.64 & 5.18 & 4.53 & 3.69 & 2.69 \\
\hline 158 & 558 & 0.04 & 5.85 & 5.37 & 4.77 & 3.93 & 2.10 & 5.34 & 4.82 & 4.18 & 3.34 & 2.40 \\
\hline 177 & 577 & 0.03 & 6.34 & 5.78 & 5.07 & 4.21 & 3.11 & 6.49 & 5.95 & 5.22 & 4.34 & 3.24 \\
\hline 181 & 581 & 0.17 & 6.22 & 5.76 & 5.10 & 4.21 & 3.15 & 6.40 & 5.95 & 5.28 & 4.40 & 3.32 \\
\hline 205 & 605 & 0.01 & 6.19 & 5.65 & 4.92 & 4.05 & 2.95 & 6.10 & 5.55 & 4.84 & 3.97 & 2.87 \\
\hline 206 & 606 & 0.00 & 5.81 & 5.27 & 4.54 & 3.67 & 2.57 & 5.70 & 5.16 & 4.44 & 3.58 & 2.49 \\
\hline 208 & 608 & 0.03 & 6.44 & 5.99 & 5.33 & 4.44 & 3.37 & 6.36 & 5.90 & 5.24 & 4.35 & 3.28 \\
\hline 209 & 609 & 0.01 & 5.72 & 5.30 & 4.66 & 3.77 & 2.72 & 5.61 & 5.19 & 4.54 & 3.65 & 2.61 \\
\hline
\end{tabular}




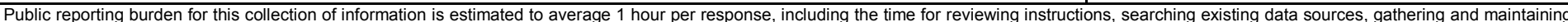

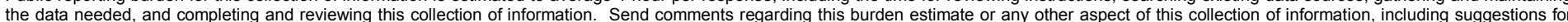

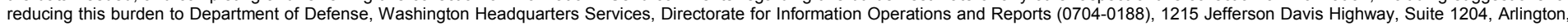

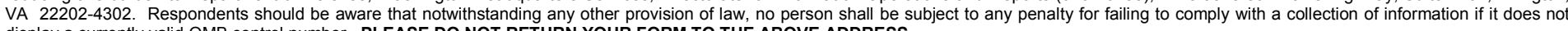
display a currently valid OMB control number. PLEASE DO NOT RETURN YOUR FORM TO THE ABOVE ADDRESS
1. REPORT DATE (DD-MM-YYYY)
May 2014

4. TITLE AND SUBTITLE

Vertical Ship Motion Study for Ambrose Entrance Chanel, New York
3. DATES COVERED (From - To)

5a. CONTRACT NUMBER

5b. GRANT NUMBER

5c. PROGRAM ELEMENT NUMBER

\section{AUTHOR(S)}

Michael J. Briggs, Zeki Demirbilek, and Lihwa Lin

\begin{tabular}{|c|c|}
\hline Michael J. Briggs, Zek1 Demirbilek, and Lihwa Lin & 5e. TASK NUMBER \\
\hline & 5f. WORK UNIT NUMBER \\
\hline $\begin{array}{l}\text { 7. PERFORMING ORGANIZATION NAME(S) AND ADDRESS(ES) } \\
\text { Coastal and Hydraulics Laboratory } \\
\text { US Army Engineer Research and Development Center } \\
\text { 3909 Halls Ferry Road } \\
\text { Vicksburg, MS 39180-6199 }\end{array}$ & $\begin{array}{l}\text { 8. PERFORMING ORGANIZATION REPORT } \\
\text { NUMBER } \\
\text { ERDC/CHL TR-14-3 }\end{array}$ \\
\hline $\begin{array}{l}\text { 9. SPONSORING / MONITORING AGENCY NAME(S) AND ADDRESS(ES) } \\
\text { Commander, US Army Engineer District, New York } \\
\text { (CENAN-EN-H) }\end{array}$ & $\begin{array}{l}\text { 11. SPONSOR/MONITOR'S REPORT } \\
\text { NUMBER(S) }\end{array}$ \\
\hline
\end{tabular}

\section{DISTRIBUTION / AVAILABILITY STATEMENT}

Approved for public release; distribution is unlimited.

\section{SUPPLEMENTARY NOTES}

\section{ABSTRACT}

New York Harbor Pilots have expressed a concern to the New York District (NAN) about a mound that is approximately 1.5 miles seaward of the new limit of the Ambrose Channel. This mound is probably construction rubble that was placed there when the original Light Tower isolated and protected it somewhat from the main channel. The mound's diameter and depth are similar to the width and depth of the Ambrose Channel offshore reach. Now that the Light Tower is no longer marking this mound, the Pilots are concerned about whether a ship might experience larger or more dramatic ship motions due to possible amplification across the mound relative to similar transits in the offshore reach. The US Army Engineer Research and Development Center (ERDC), Coastal and Hydraulics Laboratory (CHL), used the numerical models STWAVE and CMS-Wave to evaluate possible amplification effects of a range of wave conditions. The Channel Analysis and Design Evaluation Tool (CADET) was used to predict vertical ship motions due to wave-induced heave, pitch, and roll. Ship squat estimates calculated with the PIANC and Ankudinov empirical formulas were compared with the Beck, Newman, Tuck (BNT) squat predictions used in CADET. The net underkeel clearance based on these vertical ship motion components was used in a risk-based method of evaluating transits over the mound compared to similar transits in the main channel. These results were used to select a minimum dredge depth over the mound to insure that inadvertent transits over the mound would not incur any significant differences in ship response and potential grounding relative to similar transits in the offshore reach of the Ambrose Channel.

\section{SUBJECT TERMS} Container ship, underkeel, Ambrose

Ambrose Channel, CADET, PIANC, Vertical Mound

Ship Motion, ship squat, 16. SECURITY CLASSIFICATION OF:

\begin{tabular}{|l|c|c|}
\hline \multicolumn{2}{|l|}{} \\
\hline a. REPORT & b. ABSTRACT & c. THIS PAGE \\
Unclassified & Unclassified & Unclassified \\
\hline
\end{tabular}

17. LIMITATION18. NUMBER OF DF ABSTRACT PAGES 19a. NAME OF RESPONSIBLE PERSON

19b. TELEPHONE NUMBER (include area

213 code) 